



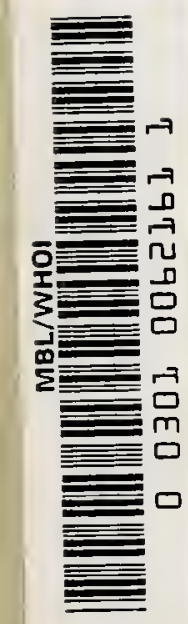





\section{DER ORGANISMUS}

DER

\section{N FUS I O N S T II I ER E.}





\section{DER ORGANISMUS}

DER

\section{INFUSIONSTHIERE}

NACH EIGENEN FORSCHUYGEN

IN SYSTEMATISCHER REIHENFOLGE BEARBEITET

VON

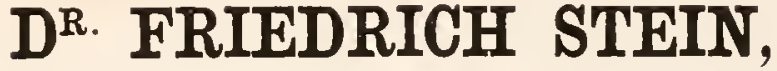

O. Ö. PROFEssoR DER ZOOLOGIE AN DER K. K. UNIVERSITÄT 7U PRAG.

\section{AB'IHEILUNG.}

ALLGEMEINER THEIL UND NATURGESCIICITE DER HPOTRICHEN INFLSIONSTHIERE.

LEIPZIG, VERLAG VON WILHELM ENGELMANX. 
Das Recht der englischen und französischen Uebersetzung behält sich der Verleger vor. 


\title{
SEINEN FREUNDEN
}

\author{
HERRN
}

\section{R. ERNST BRÜCKE,}

O. O. PROFESSOR DET PHÝSIOLOGIE AX DER K. K. UXIYEISITIT ZE WIEX, RITTER DES KAIS. OSTERREICHISCHE. IRA.Z JOSEPII-ORDLIS ETC. ETC.

\section{HERRN}

\section{D ${ }^{\mathrm{R} .}$ AUGUST EM. REUSS,}

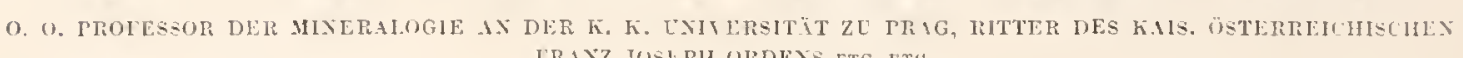
IRINZ JUSLPH-OLDENS ETC, ETE

WIDNEL DIESE SCHRIFL

HOCHACHTLYGSTOLL

IER YEREASSER. 



\section{V o l' W o l t.}

W ie vielfich anch die in nenester Zeit mit so regem Eifer der Infusorienwelt zugewendeten Forschungen noch von cinander abweichen mögen, darin stimmen sie olne Ansnahme mit cinander überein, dass das von Lihrenberg anfgefühnte und zu seiner Zeit mit Recht allgemein bewunderte wissensehaftliche Gebiinde der Infusorienkunde an so erheblichen Mïngeln leide und zum 'Theil anf' so unhaltbaren Grundligen beruhe, dass cine wesentliehe Umgestaltung desselben zu cincm dringenden wissenschaftlichen Bedürfnisse geworden sei. Die Lösung dieser Aufgabe ist jedoch überaus schwierign, und es wird noch cincr geramen Zeit und der voreinten angestrengten Krätte vicler tüchtiger Forseher bedürfen, bevor wir uns eines einigermaissen vollendeten, den gegenwärtigen Anforderungen der Wissenschaft entsprechenden Infusoriensystems werlen erfrenen können. Ekhenbery hat viele Jalne mit eisernen Fleisse gearbeitet, um das ungeheure Material zusammen zu bringen und zu bewältigen, welehes er in seinem allbekannten grossen Infusorienwerke niedergelegt hat. Wenn wir nun gleich nach dem heutigen Standpuncte unseres Wissens eine sche bedeutende Anzahl der von ihm unter dem Namen der Infusionsthicre zusammengefassten mikroskopischen Lebensormen als den eigentlichen Infusorien durchan fremdartige Organismen von vornherein ansscheiden können, so bleibt doch immer noch ein unfangreicher Kreis von Formen übrig, die sümmtlich von Nenen geprüft und viel eingehender untersucht werden müssen, als dies ron Ehrenbery geschehen ist, wenn ihre wahre Katur und ihre gegenseitigen Beziehungen zu eininder definitiv festgestellt werden sollen. Schon das blosse Auffinden nur der wichtigsten dieser Formen erfordert cinen grossen Anfwand von Zeit und Mühe, und setzt cine jahlrelange Beschäftigung mit der Infusorienwelt vorans, und wie oft muss jede einzelne Form untersucht werden, bevor man sich sagen kann, wenigstens die wichtigsten Eigenthünlichkeiten ihres Baues völlig richtig aufgefasst zu haben.

Ich halue seit zehn Jahren meine Thaitigkeit fast manusgesetzt anf das Studium der Infusionsthicre verwendet. Durch die von mir zunäehst über die Fortpflanzung und Entwickelung dieser Thiere angestellten Untersuchungen gelangte ich frühzeitig zn der festen Ueberzengung, dahs sie keineswegs so hoch organisirte Geschöpfe scien, als wofür sic likrenbery ansgegeben hat, dass ihre innere Organisation von diesem Forscher durchans imig gedeutct worden sei und dass auch die Kenntnisse, welehe wir demselben über ihre äusscre Gestaltung verdinken, noch vieler Beridhtignngen und Ergänzungen bedürften. Die Resultate meiner Forschungen, welche sich am ansü̈hrlichsten in der ron mir in Jihre 1854 heransgegebenen Schrift: ,Wie Infusionsthicre 


\section{VIII}

auf ihre Entwickehngsgeschichte mntersucht" veröffentlicht finden, haben nicht wenig dazu beigetragen, diss cin allgemeiner Unschwumg in den Anschten über den Organismus der Infusorien eintrit, und diss fortan das eifrige Bestreben erwachte, die Naturgeschichte derselben nach nenen Principien zu bentbeiten. Ich selbst stellte bercits in der Forrecle zu der eben genmuten Schrift cine solche Bearbeitung in Anssicht. Seitclem bin ich rastlos bemüht gewesen, immer tiefer in die feineren Organisationsverhailtnisse und in die Entwickehungsgeschichte der Infusorien cinzudringen, un dadurch die nothwendigen Grundlagen zu einem naturgemïssern srsteme derselben zu gewinnen. Ich fund jedoch bald, dass eine planlose Untersuchung der heterogensten Formen, wie sie der Zufall dem Beobachter in die IÏ̈nde spielt, nicht zu einem erwünschten Ziele führen werde, da ich nur zu oft die Erfahrung machte, dass ich bei einer für sich allein betrachteten Forn gar manche feinere Structurverhältnisse und sclbst sehr wichtige Charactere übersilh, auf die ich erst aufmerksam wurde, wenn der Blick zuror durch cinen Tergleich vieler nahe verwandter Formen geschärft worden war. Ich entsehied mich daher mehr und mehr für eine vorwiegend gruppenweise monographische Bearbeitung der Infu- orienwelt. Da ich bei meinen früheren Untersuchungen ganz besonders dic vorticellenartigen Infusorien berïcksichtigt hatte, so wählte ich mumehr cine andere natürliche Gruppe, die mir am meisten eine gründliche Revision zu erfordern schien, zum vorzugsweisen Gegrenstand meiner Forschungen. Diese Gruppe wird ron den drei Elwenbergschen Familien der Oxytrichinen, Euploten und A-pidiscinen gebildet, denen ich noch cine vierte, erst ron mir begründete Familie, die Chlamydodonten, zugesellt habe. In dicsen vier Familien erkannte ich eine eigene Orchnng, welcher ich den Namen der hypotrichen Infusorien ertheilte. Die gesammten übrigen Infusorienformen vertheilen sich mir in vier gleichwerthige Ordnumgen, in die der peritrichen, heterotrichen, holotrichen und geisseltragenden Infusorien; simmolliche Ordnungen beruhen auf der Form und Anordnung der ïnssern Körperwimpern. Neben dem umfarsendsten Studium der hypotrichen Infusionsthice, dic ihren Platz zwischen den peritrichen und heterotrichen Infusorien einnehnen, versïunte ich keine Gelegenheit, mich anch nit den zu den übrigen Ordnungen gchörigen Infusorienformen, in so weit sie mir nicht schon durch frühere Untersuchungen bekannt waren, möglichst vertraut zu machen; am wenigsten befasste ich mich mit den geisseltragenden Infusorien, die ich cinstweilen un so eher glaubte mehr bei Seite liegen lassen zu kümnen, als sie sich am weitesten ron den übrigen Ordnungen entfernen.

Die Früchte meiner bisherigen Forschungen sind zum 'Theil in der vorliegenden Schrift nichergelegt, wolche die erste Abtheilung eines grö̈seren Werkes bilden soll, in welchem ich nach und nach die Naturgeschichte aller von mir anfgefundenen und hinlïnglich genau untersucliten Infusionsthicre in zusimmenhüngenden Monographien zu bearbeiten gedenke. Diese crste Abtheilnng, welche, wie dies anch bei jeder folgenden der Fall sein wird, ein in sich abgerchloscues Ganzes dinstellt, besteht ans einem einleitenden allgemeinen und einem specicllen Theile. Der allgeneine behandelt in einem ersten Abschnitt die rerschiedenen Phasen, welche die Infusorienkunde bisher durchlanfen hat; ich habe darin gezeigt, wie die irrigen Vorstellungen entstanden, welche so lange über die Natur der Infusorien verbreitet waren, und wie diese allnüihlig richtigeren Ansichten Platz nachten; ich habe ferner die eigentlichen Infusions. thicre ans der grossen Mase der mit ihnen seit alter Zeit zusammengeworfenen frendartigen Organimen aususcheiden gesucht und sie schliesslich als eine selbstständige Thierlinsse be- 
stimmt, welehe ich durch scharfe Charactere zu begrïnzen bemüht walr. Dieser Abschnitt ist vornehmlieh dirauf berechnet, den minder eingeweihten Leser sehnell mit allen nambaften Leistungen auf dem Gebicte der Infusorienkunde bekannt zu machen und ihn so anf den Standpunct zu rersetzen, den die Wissenschaft in den letzten Jihren eingenommen hat und ron dem ans meine Untersuchungen unternommen wurden. - In zweiten Abschnitt des allgencinen Theiles habe ich hauptsiichlich nach den Ergebnissen meiner eigenen Beobachtungen cine zusimnenfarsende, vergleichende Darstellung von dem allgemeinen Bau der Infusorien, ron den versehiedenen Formen und Verrichtungen ihrer einzelnen Organe und ron ihrer Entwickelung geliefert, wobei ich Gelegenheit fand, vielerlei neue Thatsachen zur Sprache zu bringen. Ein besonderes Interesse dürften in diesem Abschnitt unter Anderem die Resultate in Anspruch nehmen, zu denen ich hinsichtlich der geschlechthichen Fortpflauzung und des Befruchtungsactes der Infusorien gelangt bin. Die ron mir in meinen früheren Arbeiten entwickelten Ansichten über die Acinetinen habe ich trot\% der Angriffe, welehen sie ansgesetzt waren, noch immer nicht aufgeben könncn, sie erfuhren jedoch eine wesentliche Modification.

Der specielle Theil unfusst die Naturgeschichte der hypotrichen Infusionsthiere in strenger systematischer Reihenfolge. Ich war so glïcklich, die meisten der ron Ekrenberg beschriebenen, hierher gehörigen Infusorienformen wieder anfzufinden und ilıre gesummten Organisationsrerhältnisse weit vollständiger und genaner zu ergründen, als sie ron diesem Forscher dirgestellt worden sind. Ausserdem lernte ich noch eine nicht unbedentende Anzahl neuer oder doch von früheren Beobachtern nur schr ungenügend erforschter Arten kennen, die zum Theil zur Aufstellung von neven Gattungen Vermlissung gaben. Die von Eilenberg aufgestellten Gattungen bewïhrten sich meistens als wohlbegründet, nur mussten sie zuweilen enger begrïnzt und durchweg durch neue schärfere Chanactere bestimmt werden. Das Letztere gilt auch ron seinen Arten. Bei der Auscinandersetzung der Arten bin ich, soweit dies möglich war, bis anf O. F. Müller, den ersten Begründer der wissenschaftlichen Infusorienkunde, zurückgegangen. In Ganzen wurden von mir 42 Arten hypotricher Infusionsthiere unterschieden, die sich in 20 Gattungen rerthcilen. Simmtliche Arten, mit Ausnahme ciner einzigen, sind abgebildet worden; die Abbildungen wurden durehweg naeh cin und derselben 300maligen Lincarrergrösserung cntworfen. Von jeder Art habe ich mehrere Ansichten gegeben oder rerschiedene Entwickelungsstufen derselben dargestellt. Namentlich wurden die nïheren Vorginge bei der Theilung bei vielen Arten sorgfültig ermittelt; sie erwiesen sich oft sehr complicirt und erfolgten nach eigenthümlichen, bisher unbekmnt gebliebenen Gesetzen. Zu den werthollsten Renultaten meiner Forschungen dürften die ron mir bei zwei Gattungen entdeckten reichhaltigen 'Thatsachen gehören, welche sich auf die embryonale Fortpflanzung derselben bezichen. - Das Material zu meincu Untersuchungen lieferten die nächsten Ungebungen ron Prag, Tharand in Sachsen und meiner Vaterstadt Niemegk, welehe in der preussischen Provinz Brandenburg, 5 Stunden nördlieh ron Wittenberg gelegen ist. Ausserdem habe ich mir auch Kenntniss ron den in Meere lebenden Infusorienformen zu rerschaffen gesucht; ich besuchte zu dem Ende zwei Mal, jedoch leider nur anf kuze Zeit, die norddentschen Küsten und liess mir öfters Sendungen ron Seewisser kommen.

Die zu dem rorliegenden Werke gehörigen Kupfertafeln waren bereits simmtlich gestochen, und ich hatte anch schon einen betrïchtlichen 'Theil des 'Textes rom allgeneinen Theil ansgearbeitet, als mir die rortreffliche, auf selı genanen und unsichtigen Beobachtungen 
beruhende und an neuen Entdeekungen so reiche Schrift vou Claparède und Lachmann: „Etudes sur les Infusoires et les Rhizopodes. Livraison I. Genève 15.58" zuging, welche sich ebenfalls die Aufgabe gestellt hat, die Nilturgeschichte der Infusionsthiere anf neuen Grundlagen zu errichten. Es war nun nicht mehr möglich, an der Anlage und der beabsichtigten Durchführung meiner Arbeit noch irgend eine wesentliche Verïnderming rorzunehmen; ich führte daher zurörderst den allgemeinen Theil meines Buches zu Ende und ging erst rom specicllen Theil an auf die Schrift ron Claparede und lachmom cin, die ich olmehin nicht mehr Musse find, ihrem ganzen Umfimge nach gründlich zu studiren. Die eben genamnten Forseher haben eine grosse Anzahl der hypotrichen Infusorienformen beobachtet, wekhe von mir in dem rorliegenden Werke abgehandelt sind; ron denselben wird jedoch lediglich die Organisation, nicht die Entwickclungsgeschichte berïcksichtigt. In Allgemeinen zeigt sich zwischen den Resultaten unserer ron einander gilnz mabhängig geführten Untersuchungen cine grosse und sehr erfrenliche Uebereinstimnung; die rorhandenen Differenzen habe ich überall speciell hervorgchoben, sie werden sich bei einer nochmaligen Controle der betreffenden Arten ohne Zweifel leicht ansgleichen lassen. An weitesten gehen unsere Ansichten in systematischer Beziehung auseinander.

Möge mein Werk, an dem ich seit Jahren mit angestrengten Fleisse gearbeitet hilbe, sich eincr beifilligen Aufnahme zu erfreuen haben, und mögen dic Mïngel und Irrthümer dessclben eine nachsichtige Beurtheilung finden. Ich werde alsdann nicht verfehlen, baldmöglichst mit dor zweiten Abtheilung hervor zu treten, welche die monographische Bearbeitung der heterotriehen und holotrichen Infusorienformen umfassen soll. Reiche Materialien liegen mir dazu bereits ror.

Prag Ende Seprember 1839.

F. Stein. 


\section{Inlaltsver'zeichniss.}

Allgemeiner Theil.

Prster A bsebnill. Ceber die Ilnuptresultate der bisherigen Infusorienforsedungen. . . . . I

Schluss. Begrillsbestimmung ter Infusionsthiere. . . . . . . . . . . . . . . . . . . 8 ?

Zweiter Absehniu. Ueber die Organisation Jer Infusionsthiere in Mlgeneinen. . . . . . . . . .j.;

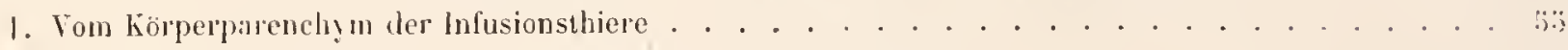

9. Von den stabförmigen Körperchen in Parenchym der lnfusorien . . . . . . . . . . . . . . . 60

3. Von den Pigunenten, Fetten und anderen körnigen Ablagerungen in Parenchym . . . . . . . . tí

4. Yon den Bewegrungsorganen und der darauf zu gründenden Eintheilung der Infusionsthiere . . . . bis

¿. Von dem Emälurungsorganismus der Infusionsthiere . . . . . . . . . . . . . . . . . . . . iö

6. Von den contractiten Behältern und dem Wasserkanalsystem der Infusionsthiere. . . . . . . . . . 86j

\%. Von der Fortphanzung und Entwickelung der Infusionsthiere. . . . . . . . . . . . . . . @1

Specieller Theil.

Ersles Buch. Die Ordnung der hypotrichen Infusionsthiere . . . . . . . . . . . . . 107

Erste Familie. Chlamydolonta . . . . . . . . . . . . . . . . . . 10!

1. Gatlung. Phascolodon. . . . . . . . . . . . . . . . . . 109

Phascolodon vorticella . . . . . . . . . . . . . . . . . 110

9." "Chilodon ........................ . . 1111

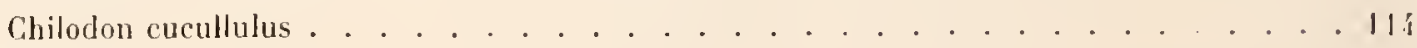

3. " Opisthodon . . . . . . . . . . . . . . . . . . . . I1:

Opisthodon Niemecensis . . . . . . . . . . . . . . . . . . . . . . . 11:3

4. " "Chlamydodon . . . . . . . . . . . . . . . . . . . . 11"

Chlamylodon Mnemosyne. . . . . . . . . . . . . . . . . . . . . . . . 116

5." " Scaphidiodon ....................... . 116

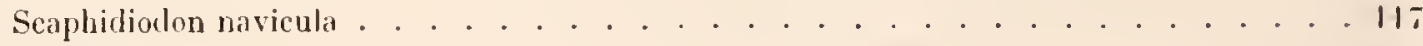

6. " $"$ Trochilia . . . . . . . . . . . . . . . . . . . . . 117

1. Trochilia palustris . . . . . . . . . . . . . . $1 / 8$

๑." " sigmoides. . . . . . . . . . . . . . . . . 118

7. " $"$ Ervilia. . . . . . . . . . . . . . . . . . . . . 11!

1. Ervilia monosţla . . . . . . . . . . . . . . . . . . . . 119

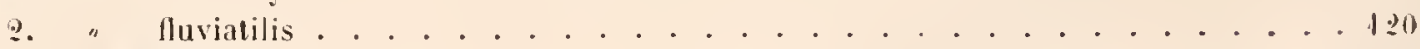

Zwe ite Familie. Aspilliscinal. . . . . . . . . . . . . . . . . . 120

Gatlung Aspidisca. . . . . . . . . . . . . . . . . . . . . . . . 191

1. Aspidisca lỵncaster . . . . . . . . . . . . . . . . . . . . . . . . . 122

จ. lynceus. . . . . . . . . . . . . . . 123

3. "turrita . . . . . . . . . . . . . . . . . 19i

4. , costata . . . . . . . . . . . . . . . . 12:

". polystyla . . . . . . . . . . . . . . . . . . . . . . . . 


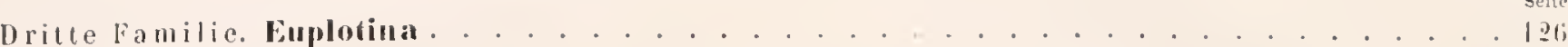

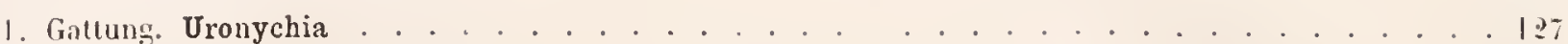

Uronjchia transluga . . . . . . . . . . . . . . . . . . . . . . . . . . 12!

2. "Styloplotes . . . . . . . . . . . . . . . . . . . . . . . . 130

Styloplotes appendiculatus . . . . . . . . . . . . . . . . . 13?

3. " Euplotes. . . . . . . . . . . . . . . . . . . . . . . . . . 133

1. Euptotes patella . . . . . . . . . . . . . . . . . . . . . . . . 13:3

?. "

3. "charoll. . . . . . . . . . . . . . . . . . 137

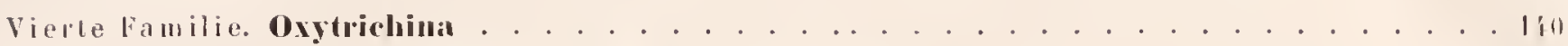

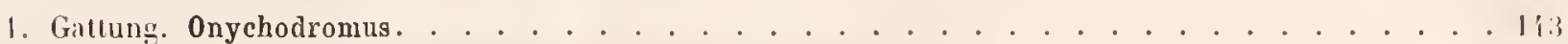

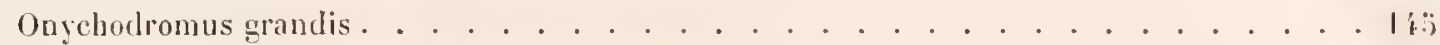

2. " "Stylonychia. . . . . . . . . . . . . . . . . . . . . . . . . . . 1 亿

1. Stylonychia mytilus . . . . . . . . . . . . . . . . . . . . . . . . 19

Fortpllanzung und Entwickelung . . . . . . . . . . . . . . . . . | il

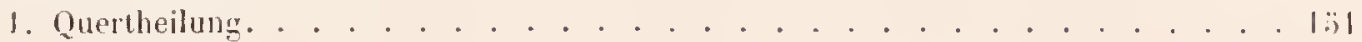

L. Längtheilung . . . . . . . . . . . . . . . . . . . . . . . 1:3

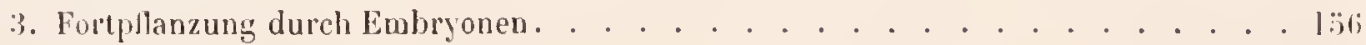

․ Stylonychia pustulata . . . . . . . . . . . . . . . . . . . . 161

3. " " . . . . . . . . . . . . . . . . . . . . . . 1606

3. "Pleurotricha . . . . . . . . . . . . . . . . . . . . . lliS

1. Pleurotricha grandis. . . . . . . . . . . . . . . . . . . . . . . . 16!

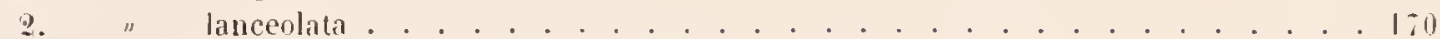

i. "Kerona. . . . . . . . . . . . . . . . . . . . . . . . . . 17

Kerona polyporum. . . . . . . . . . . . . . . . . . . . . . . . 173

5. "Stichotricha . . . . . . . . . . . . . . . . . . . . . . . 17t

Stichotricha secunda . . . . . . . . . . . . . . . . . . . . 17:

6. Uroleptus. . . . . . . . . . . . . . . . . . . . . . . . 171

1. Uroleptus musculus. . . . . . . . . . . . . . . . . . . . . . . . 177

2. " piscis. . . . . . . . . . . . . . . . . . . . . . . . 178

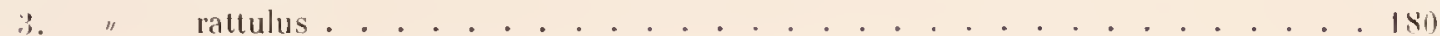

i. " violaceus . . . . . . . . . . . . . . . . . . . . . 180

7. "

Psilotricha acuminata . . . . . . . . . . . . . . . . . . . . . . . 1S1

\&. " " Oxytricha . . . . . . . . . . . . . . . . . . . . . . . 1s?

1. Oxytricha gibba . . . . . . . . . . . . . . . . . . . . . 181

๑. pellionella. . . . . . . . . . . . . . . . . . . . . . . 183

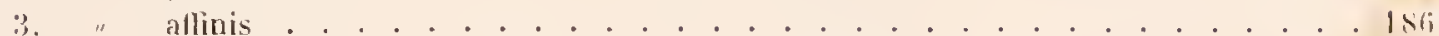

4. ferruginea. . . . . . . . . . . . . . . . . . . . . 187

3. mystacen . . . . . . . . . . . . . . . . . . . 18s

(i. " fallax. . . . . . . . . . . . . . . . . . . I\$9

7. "platistoma . . . . . . . . . . . . . . . . . . . 190

9." " Urostyla . . . . . . . . . . . . . . . . . . . . . . . . . 1!1

1. Urostyla Weissei . . . . . . . . . . . . . . . . . . . . . . . . 192

2. " grandis . . . . . . . . . . . . . . . . . . . . 193

Leher die Fortpllanzung und Entwieketung von Crosty grandis. . . . . . . . . . 1!

3. Urostyla viridis . . . . . . . . . . . . . . . . . . . . . . . 206 


\section{Erster Abschnitt.}

\section{Ueber die IFauptresultate der bisherigen Infusorienforschungen.}

In Jahre 16703 wurden von dem hollandischen Naturforscher Anton v. Leenuenhoek in einem Gefdisse mit stehendem Regenwasser die ersten Infusionsthiere enthlecht; es verging jedoch fast noch ein volles Jahrhundert, während dessen bereits viele Infusorienformen theils noch durch Leemeenhoch sellust, theils durch Joblot, Balier, Will, Nectham, Trembley, Schacffer, Degeer und namentlich Roesel hehannt wurten, bevor in den zooIogischen Schriften von Infusionsthieren die Rede war. Dieser Name tancht zum ersten Male im Jahre I763 bei den bekamten Verfasser der mikroscopischen Gemütls- und Angenergötzungen, Ledemüller, anf, mul zwei Jahre später wurde durch die von der Göttinger Societăt der Wissenschaften gekrönte Schrift von Wrisbery: „OHservationum de animaleulis infusoriis satura. Goettingae $176 \%$. die lateinische Benennung in den wissensehaftlichen Verkehr gebracht. Die Urheber dieser Namen wollten damit nur jene ülıeraus kleinen, dem blossen Auge unsichtbaren und allein mit Hülfe von Vergrössernngsgläsern leutlich unterschejdbaren Thierformen bezeichnen, welche massenhaft in allen fauligen Flissigheiten auftreten. Diese gehcimnissvollen, ller Forschung so schwer zugäuglichen Wesen erregten damals die allgeneinste Aufuerksankeit und Theihahne, und zwal vornehmlich deshalb, weil es den Ansclıein hatte, als liönne man sie durch blosses Uebergiessen thicrischer oder vegetabilischer Substanzen mit Wasser nach Belieben ins Dasein rufen.

Der ron Ledermüller und Irisberg in einem so beschasinkten Sime gebrauchte Name wiirde wohl kamm Beachtıng gefunden haben, ouler doch nie zur allgemeinen wissenschaftlichen Geltumg gelangt sein, hätte ihn nicht der grosse dänische Zoolog Otto Frietrich Mïller, der cinen bedeulenden Theil seines arbejtsreichen Lchens auf ein specielles und unfussendes Studium der Infusorienwelt verwendete, seit dem Jahre 1773 adoptirt und ilmm eine viel weiter greifende Bedeutung beigeleģ. Mäller vereinigte nämlich unter den Namen Infusorien alle rückenmarklosen, nicht mit geglieilerten Bewegungsorganen versehenen Thierformen, welehe lediglich mittelst des Mikroscopes hestimmbar sind und ansschliesslich in Flïssigheiten leben, mögren dies nun faulige Infusionen, oder die natiorliclien stehenden und diessenden Gewasser, oder der normale Inhalt der innern Organe lebendiger Organismen sem. Die bei weitem grössere Anzahl von Thieren, welche unter diese Begriffshestimnung fallen, waren Entdeckumgen von Müller, und indem er diese, wie die hereits bei friblieren Autoren vorkommenden Infusorienformen, welche er sellsst hatte untersuchen liönnen, nicht blos sorgfälig beschrieb, sondern auch nach den P'rincipien Limés zum crsten Male in cin System brachte, worin Gattungen und Arten unterschieden, wisscnschaftich benannt und durch pracise Diagnosen characterisirt wurlen, lieferte er den thatsichlichen Bewcis, dass die Infusorienwelt nicht ein chaotisches Reich von regellos wechsehnden und in einander ibergelıenden Formen sei, wie noch Limé selbst wenige lahre zuvor behauptet latte, sondern dass in ilı dasselbe Gesctz der Formbestancligheit walte. wie in der ibrigen Thierwelt. 
Die Resultate von Müller's Forschungen sind in zwoi klassischen Arbeiten niedergelegt, namlich in der Vermium terrestrimm et fluviatilium listoriı. Havniae et Lipsiae 1773 Vol. I Pars I, worin jedoch nur die Süsswasserbewohner abgehandelt wurden, und in dem erst nach Müller's frithzeitigem 1783̈ erfolgtem Tode von Otto Fabricius herausgegebenen, auch durch bildliche Darstellungen fast aller beschriebenen Formen erläuterten Werke: "Animalcula infusoria lluviatilia et marina, quae detexil, systematice descripsit et ad vivum delineari curavit $O$. $F$. Mïller. Opus posthumum cura O. Fabricii. Havniae 1786." Der Inhalt der frïheren Arbeit ist zum grössten Theil wörtlich in diese letzlere übergegangen, laher jene entbehrlich ist, wälrend diese die ganze Summe des Wissens umfasst, das sieh Müller nach etwa zwanzigjährigen mühsamen Forschungen von der Infusorienwelt erworben batte. Durch heide Werke fand der Name Infusorien allgemeinen Eingang in die Wissenschaft, und er hat sich seitdem so fest eingebirgert, dass es vergebliches Bemühen sein würde, ihn durch einen anderen, wenn auch viel zwechmässiger gewihlten, verdrangen zu wollen. Müller stellte die Infusionsthiere in die sechste Limuésche Thierklasse, die der Wümer, und bildete aus ihnen eine besondere Ordnung, die Anfangs aus 13, zuletzt aus 17 meist sehr artenreichen Gattungen bestand, welche nach folgendem Schema angeordnet waren: A. Infusorien ohne äussere Organe: a) dickliche: Monas, Proteus, Volvox, Enchelys, Vibrio; b) häutige: Cyclidium, Paramaecium, Kolpoda, Gonium, Bursaria. B. Infusorien mit áusseren Organen: a) nackte: Cercaria, Trichoda, Kerona, Himantopus, Leucophra. Vorticella; b) mit einer Schale bedeckte: Brachionus. Diese Gatlıngsnamen sind fast sammtlich noch hente im Gebrauch, nur werden sie in einem andern, viel engeren Sinne genommen, als ihr Begriunder damit verliniipfte.

Wenm man erwagt, auf wic wenige brauchbare Vorarbeiten sich Mïller stiilzen konnte. und wie unvollkommen die Instrumente waren, nit denen er beohachtete, so mussen wir seine Leistungen selır hoch anschlagen. Mäller war jedenfalls der erste epoehemachende Schriftsteller auf dem Gebiete der Infusorienkunde, ilm verdanken wir die Fundamente, auf welchen das ganze neuere Gebäule dieser zoologischen Disciplin beruht. Eine Einsicht in die wahre Natur der Infusionsthiere konnte natürlich mit den damaligen optischen Hülfsmilteln nicht erreich werden; daher sind alle Anschaumgen Müller's iber die eigentliche Organisation, die Ernährung, Forlpflanzung und Entwiclielung dieser Thiere höchst ungenïgend und grossentheils irrig.

Müller hatte bei einer nicht unbedeutenden Anzahl seiner Infusorien deutliche innere Organe erkannt, ja bei den grössten und vollkommensten (den spiileren Räderthieren) unterschied er sogar einen Darnkanal oder doch Theile desselben, namentlich den Schlundkopf mit seinen beiden Kiefern, den er musculus deglutorius nannte; dessenungeachtet behauptete er, dass die Infusorien nichı im Stande seien, fremde Köıper aus der Aussenwelt aufzunehmen und zu verdauen ${ }^{1}$ ). Bei den Vorticellen, Trichoden und Keronen würden wohl häuligg durch den von ihren Wimpern erregten Strudel Weine Thiere und andere Körperchen in cine Oeffnung des Körpers oder in einen Schlund hineingetrieben, sie wirden aber nur einige Augenblicke im Innern schnell umbergewalzt und dann aul demselben Wege und in Folge desselben Wimperspieles wieder ausgeworfen, ohne getödtel worden zu sein oder eine Veranderung ertilten zu haben. Nach Müller's Ansicht war zur Emaihlung der Infusorien das blosse umgebende Wasser volliommen ausreichend; wie dasselbe aufgenomnen werde, daruber hat er sich nicht klar ausgesprochen, er setzte aber wohl uberall einen Mund voraus. In Betrefl der Fortpllanzung hatte er beobachtet, dass sich viele lifusorien durch I:ings - oder Quertheilung, oder auf bejele Weisen vermebrten, und er warnte nachdrücklich davor, die in der Theilung begritlenen Thiere nicht für besondere Arten oder für zwei in der Begattung begriflene Individuen anzusehen, wie es häufg von früheren Beobachtern geschehen war. In andern Fälen nahn er aber ${ }^{2}$ )

1) O. F. Niiller Animalcula infusoria p. XlI. m omnibus meis observationibus per plures annos instilutis, ne minimum animalculum vel moleculam unquam dcvorari, contra quolquot vortice Vorticellarum, vel vibratione pilorum Trichodarum Keronarumque in voraginem seu aperturam earum agebantur. eadem vi cilis vel pilis irretita, vehementergue momentis paucis circumacta absque utlius vi-• lae jactura ejici semper vidi."

2) Ebendaselbst p. VI. 
sellost wieder eine Begattung au. Bei eingen des höchsten Formen, namentlich bej der Gattung Brachionus wurde von Mïller bereits ausser dem Darm noch ein Eierstock, wenu auch nicht ganz klar, unterschjeden; auch beobachtete er. wie die grossen Eier aus tem Körper trateu, ăusserlich an ihm hingen blicben und wie aus denselhen die Jungen hervorschliuften. Gleichwohl sprielıt er sich schliesslich zu Gunsten der Ansicht aus, dass alle Infusorien auch olne Elter'u, durch dic sogenamnte generatio aequivoca aus blossen sich zerselzenden organischen Substanzen enIstehen köınten. Lelztere sollten zuerst in blasige İütcheı ubergeheu, welelıe aus nelzförmig an cinander gereihten Kïgelehen bestanden. Weiterhin sollten sich die Kügelchen von ejuander trennen, lebendig werten und ibberaus einfache und lileine die Flisssigkeit massenhaft erfillende Infusionsthierchen bilden, die hinsichtlich ihrer Sulsstanz umd Organisation ganz und gå von den übrigen Infusorieu versehieden und als die Keime zu allen Thier - und Pl]anzengestalten iuzusehen seien ${ }^{\mathbf{1}}$.

Schliesslich sei noch erwähnt, dass Mäller bereits der spaitern Eintheilung der Infusionslhjere in zwei Ḱlassen oder Orduungen auf des Spur war. In der noch von ilın selbst greschriebenen Vorrede zu seiuem nachgelassenen Werke werden nämlieh sämmnliche Infusorien in zwei Abtheilungen gebracht, in die Infusorien im engern Sinue und in die Bullaria ${ }^{2}$. Unter letzteren Namen sollten alle tliejenigen Infusorienformen zusammengefasst werden, welche sich schou äusserlich durch einen compliciıtern Körperbau und bedentendere Grösse auszeichnen, im Innern deutliche, oft blasig erscheinende Eingeweide erkennen lassen mu sich durch Eier oder lebendige Junge fortpflanzen. Zu den lnfusorien im engerı Sinne sollten dagegen alle kleineru, gallertartigeu, lomogenen Formen gerechnet werden, bei denen gar keine Organe unterschieden werden könuten und deren Fortpflanzung unklar sei. Dass die Bullarien vorzugsweise die Räderthiere der spitereu Autoren umfassen sollten, geht schon aus ilırer Begriffshestimmung hervor, noch deutlicher aber ans dem Zusatz zu der Gattung Brachionus ${ }^{3}$ ), dass in ihr die vollkommensten Bullarienformen euthalten seien. Hătte Müller die Herausgabe seines letzten grossen Werkes noch selbst besoryen lönnen, so würde uns dieses jedenfalls in ejner ganz anderen und wesentlich vollkommeneren Form vorliegen, als die ist, welche ihm 0 . Fabricius gegeben hat und auch uur geben konnte.

Gleichzeitig mil Müller, oder doclı bald nach ihm haben noch Bomnel, Saussure, Goeze, v. Gleichen-Russtiotm, Eichhorn, ILrmunn, Corli, Colombo, Guamali und in besonders hervorragender Weise Spallanzani und Franz v. Panla Schrank, dann später in unserem Jahılundert Treviramus, Olien, Grmilhuisen, Dutrochet, Nitzsch und namentlich Bory de St. Vincent nach versehiedenen Richtusggen hin fördernd auf die Infusorjenkunde eingewirkt, ejnen wesentlich umgestaltenden Einfluss auf dieselbe vermochten sie jedoch nicht auszuiben, da ihnen sämmılich nur dieselben unvollkommenen oder doch nicht viel bessere Mikroscope zu Gebote standen, wie Mïller, und da sie zum grossen Theil weniger eigene umfissente Untersuchungen anstellten, als darauf bedacht waren, tom von Mäller zusammengebrachten Material eine andere, zeitgemässere systematische Form zu geben. Seine Arbeiten blieben daher noch wilurend der drei ersten Decennien unseres Jahrlunderts die Hauplquelle für die Erkenntniss der Infusiousthiere. Nur in Betrefl ihrer Eintheilung wurde in diesen Zeitraume cin wesentlicher Schritt in der bereits von Miller angedeuteten Richtung vorwairts gyethaus.

Dutrochet wies uämlich im Jahre I 812 in den Aunales du Museum Tome XIX p. 335 nach, dass unter den Müller'schen Infusorjen zwei sehr verschiedene Organisationstypen mit einander zusammengeworfen seien. Bei den einen, welche die grosse Nehrzahl bilden, konuten keine gesonderten Eingeweide ermittelt werden; sie zeigten auch äusscrlich die einfachsten Körpergestalten. Bei den anderen, wozu Müller's Gattung lBrachionus und eine Anzalsl remwandler Formen gehören, die in den Gallungen Vorticella, Trichoda und Cercarja zerstreut stelıen, Jiessen sich insere Organe, namentlich ein scharfbegräuzter Darmkanal, zum Theil auch ein deutlicher Eierstock unterscheideu. IJs Körper bestand ferner meist aus drei gesonderteı Abschnitteı, einem vorderen. aus- und ein-

1) Ebendaselbst p. XXIY.

2) Ebendaselbst p. VII.

3) Ebendaselbst p. 333 . 
stiilpbaren, scheibenförmigen, gelappten Wirluelorgane, aus dem eigentlichen. die Eingeweide enthaltenden Leib und aus einem scharf abgeselzten. sehr bewegglichen, quergeringelten, wie ein Fernrobr aus - und einschiebbaren und am Ende meist in zangenartige Fortsitze auslaufenden Schwanz. Wenn das Wirbelorgan in Thătigheit war, so machte es auf den Beobachter tauschend ten Eindruck, als ob ein Kammrarl sehuell um seine Axe getrieben wïrde. Dutrochet nannte deshalh diese Infusorienformen Rotifères, und da er beobachtet zu haben glaubte, dass bei ihnen der Mund und After dicht nelıen einander im Grunde des Wirbel- oder Räderorgans ligen, so erkannte er hieriu, wie anch in deu Rủlerorgin, welches schon von Schranli als Respirationsorgan gedentet worden war'1), eine Verwandischaft mit den Ascilien; er schlug deshalb vor, die Rotiferen ganz von den iblrigen Infusorien zu entfernen und sie mit den Mollusken Cuvier's zu vereinigen. Dic Systematiker nalımen nun sänmtlich, Lamarck und Curier an der Spitze, die Gruppe der Rotiferen an, in Deutschland vertauschte man aber diesen Namen mit der Bezeichnung Rotatoria (Rïlerthiere), weil bereits früher eine Gattung ılen Namen Rotifer erbalten hatte. Lamarck stelte die Raderthiere zu den Polypen, aus den ïbrigen Infusionsthicren bildete el' zuerst eine eigene Klasse des Thierreiclies und zwar die erste oder unterste. Cuvier dagegen liess die gesammten Müller'sehen Infusorien in einer Klasse vereinigt, er stelle diese an das Ende seines vierten und letzten Organisationsplanes, der Zoophyten oder Strahlthiere, und theilte sie in zwei Ordnungen, in die Räderthiere und in die homogenen Infusionsthiere.

Dies war der Standpunct unserer Wissenschaft, welchen Christim Gottfried Ehrenberg vorfand, dem der Rulım beschierlen war, eine neue glänzende Aera der Infusorienkunde zu begriunden. Nachdem Eheuberg sich bereits Jahre lang erfolgreich nit dem Studium der niederen thierischen und vegetabilisehen Organismen beschäftigt und sich in einem Grade, wie kein anderer gleichzeitiger Forscher, mit feineren miliroscopischen Untersuchungen vertıaut gemacht hatte, giug er mit den neusten, ausserordentlich verbesserten, achromatischen Mihroscopen, wie sie ilm zuerst Chevalier in Paris und spater noch vorzigglicher Pistor und Schich in Berlin lieferten, an die sehwierige Aufgabe, den gesammten Organisationsgehalt der Infusionsthiere definitiv festzustellen und namentlich zu einer festen Ausicht über die bisher so unklar gebliebenen imeren Structurverbälunisse derselben zu gelaugen. Sebon nach wenigen Jahren war Eluenberg in der glicklichen Lage, der Berliner Academie der Wissenschaften Resultate rorlegen zu können, die die herkömmlichen Ausichten vou den Infusionsthieren zum grossen Theil völlig umstiessen, iiber ilure Naturgeschichte gauz neuc. auf offenbar sehr sorgfätige und scharfe Bcobachtungen gestutzte Anschanungen verbreiteten, unt daher überall, wo sie bekanut wurden, ein ausserordentliches Aufsehen erregten. Denu nun erschienen auch diejenigen Infusionsthiere, welche noch Cuvier als lomogene bezeichnet batte und welche fur liaum mehr, als blos äusserlich geformte, helebte Schleimmassen gehalten worken waren, mil einer reichen äusseren und inneren Organisation ausgestattet, die sie auf eine gleiche Slufe mit den gesammten iibrigen Thieren crhob.

Die erste epochemachende Arbeit von Ehrenbery waren „lie "Beiträge zur Kenuniss der Organisation der Infusorien und ihrer geographischen Verbreitung. besonders in Siljirien « Abhandlungen der Berliner Academie aus dem Jahre 1930 S. 1-88; sic wurlen in Verhindung mit einen kleinen altern Aufsatz über die geographische Verbreitung der Infusionsthiere in Norlafrica und Westasien anch als besondere Schrift berausgegeljen, unter dem Titel: "Organisation. Systematik und geographisehes Verbailtniss der Infusionsthierchen. Mit 8 Kupfertafeln. Berlin 1830." Diese Schrift zăhlte später als erster Beitrag zur Erliemuniss der Organisation in der Richtung des kleinsten Rammes. Die zweile wichlige Arbeit ron Ehrenberg findet sich in den Abbandlungen der Berliner Academie aus dem Jahre 1831 S. I - 15\% inter der Ueberschrift: "Ueber die Entwickelmng und Lebensdaner der Infusionsthiere nebst fermern Beiträgen zu einer Vergleichung ihrer organisehen Systeme." As besondere Schrift fiilut sie den Titel: "Zur Erkenutniss der Organisation in der hichtung des kleinsten Rummes. Zweiter

1) Schrank Fauna Boica Band III. Ahth. 2. S. 147 
Beitrag. Entwickelung, Lebensdauer und Structur der Magenthicre und Raderthiere orler sogenamuten Infusorien, nelsst einer physiologischen Characteristik beiler Klassen und 4.12 Arten dersclben. Mit 4. Kupfertafeln. Berlin 1832." Die dritte noelı bedeutendere Arbeil erschien in den Abhandlungen der Berliner Aeademie aus dem Jahre 1833 S. 145-336 unter der Ueberschrift: "Dritter Beitrag zur Erkenntniss grosser Organisation in der Richtung des hileinsten Raumes" mit 11 Kupfertafehn, und als besondere Sehrift unter gleichem Titel Berlin 1834. Hierzu wurden die ebenfalls wichligen: „Zusälze zur Erkenntniss grosser organischer Ausbildung in den kleinsten thierischen Organismen“ veröfrentlicht (Abhandl. der Berl. Academie aus dem Jahre 1835 S. 151-180), die auch besonders unter dem Titel erschienen: „Zusätze zur Erkenntniss grosser Organisation im kleinen Raume. Mit 1 Kúpfertafel. Berlin 1836."

Zuletzl gelangten Elrenberg's vieljahirige Forsehungen uber die lebenden Infusionsthiere in dem allhekannten grossen Prachtwerke: „Die Infusionsthierchen als vollkommene Organismen. Ein Blick in das tiefere Leben der Natur. Nebst einem Atlas von 64. Kupfertafehn. Leipzig 1838 “ zum Abschluss, worin sich die Resultate aller fruheren Arbeiten nebst einer ungemein reichen Fiille newer Thatsachı'n zu einem wohlgegliederten systematischen Ganzen verarbeitet und durch zahlreiche, alle bis dahin bekanut gewordenen bildlichen Darstellungen weit hinter sich lassende Abbildungen erlautert finden. Dieses grossartige Werk wirt noch lange Zeit den Ausgangspunct fur alle ferneren Infusorienforsehungen bilden, und zu allen Zeiten als eins der herrlichslen Denkmale mensehlichen Fleisses und Scharfsinnes hewundert werden.

Ehenberg crwies sich zundichst als ein trener Nachfolger Müller's; er nahm ganz und gar die Begränzung an, die Mïller den Infusorien gegeben hatte, und hielt dieselbe durch alle seine Arbeiten hindurch als wohlbegrijndet und naturgemäss fest. Selbst in dem grossen Infusorienwerke findel sich keine andere Bestimmung des Begriffs Infusionsthier, als die folgende, an die Spitze der Vorrede gestellte: "In den reinsten Gewassern und auch in Irüben. stark sauren und salzigen Flüssigkeiten der verschiedenen Erdzonen, in Quellen, Flissen, Seen und Meeren, oft auch in den innern Fenchligkeiten der lebenden Pflanzen und Thierkörper, selbst zahlreich im Körper des lebenden Menschen, ja auch periodisch getragen in Wasserdinsten und Stanl, der ganzen Atmosphare unserer Erde, giebt es eine den gewöhnlichen Sinnen des Menschen unbemerkbare Wclt sehr heiner lebender eigenthümliches Wesen, die man seit nun chwa 70 Jahren Infusorien nennt." Man sieht hieraus, dass Ehrenberg noch im Jahre 1838 die Infusorien so begrinzt, wie Müller 1773. Uass er also wohl nicht im Stande war, morphologische, allen Infusorien gemeinsame und sie scharf von den gesammten übrigen Thieren unterscheidende Charactere anfzustellen. Ehromberg hat auch allen von Müller beschriebencn Infusorienformen einen mehr oder weniger genau bestimnten Platz in seinem eigenen Infusoriensysleme angewiesen; nur sehr wenige sehloss er als fremdartige Organismen ans. Es waren dies gewisse Arten der Galtungen Vibrio und Cerearia, dic zu den Eingeweidewiumern wanderten, und einige Arten der Gattung Leucophora, in welchen theils blosse Kiemenfragmente von Muschelthieren, theils junge Aleyonellen erkannt wurden.

Ausserdem erfuhren die Mr̈ller'schen Infusorien noch insofern eine bedeutende Reduction, als nicht wenige Formen zusammengezogen werden mussten, die auf unwesenfliche iussere Gestaltverschiedenheiten hin von einander specifisch und selbst generisch getrennt worden waren; andere ergaben sich nur als verschiedene Lebensstadien einer und derselben Art, so namenllich viele Arten der Gatlıng Vorticella, und noch andere wurden als blosse Fragmente oder verstümmelte Indiviluen dieser oder jener Art erkamn, was namentlich von Mitgliedern der Galtungen Kerona und Trichoda gilt. Für die ans dem Kreise der Mäller'schen lnfusorien ausseheidenden Formen, so wie fur diejenigen, welche nicht wieder aufgefunden werden komnten und daher zweifelhaft oder ganz unbestimmbar blieben, gewahle Ehremberg reichliehen Ersatz durch das grosse Heer nener Formen, welehe erst von ihm in die Wissenschaft eingefuhrt wurten. Diese lassen sich, jedoch shmmılich, wie grosses lnteresse sie anch lür sich darbieten, auf die Grundformen zuruclifuhren. die bereits Mhiller als Infusorien bestimmte.

Wemn nun gleich Ehrenberg, wie Curier, streng an dem Mäller'schen hufusorienbegriff festhielı, so war ej 
doch darin mit Dutrochet und den auf ihn folgenden Systematikern von Anfang an vollkommen einverstanden. dass die katulerlhicre von den übrigen Infusionshieren abzusondern, ja ihnen scharf gegenuber zu stellen seien; nur dazu konnte er sich nicht entschliessen, jede Verbindung zwisehen beiden Thiergruppen zu lösen, vielmehr schienen ihn die Räderthiere bei aller Verschiedenheit von den Infusionsthicren in engern Sinne democh mit denselben weit imniger verwandt zu sein, als mit irgend einer andern naturlichen Abtheilung les Thierreiches. Um diese Beziehungen systematisch auszudricken, erhob Ehrenberg sowohl dic Räderthiere, welche er zuerst ganz scharf und naturgemass begrainzte, wie auch die Infusorien im engern Sinne, welche fortan M agenthiere (Polygastrica) genannt wurden, zu selbstslindigen Thierklassen und schloss beide wieder unter der allgemeinen Bezeichmung Infusionshliere zu einer höheren sýstematischen Einheil, zu einem für sich bestelıenden Organisationsplane zusanmen.

Dass fiir Ehrenberg von vornherein die innere Identitat von Räder- und Magenthieren feststand, dass bei beiden Gruppen eine gleiche Anlage der Organisation vorausgesetzt wurde, hat auf den Gang seiner Untersuchungen den grössten Einfluss ansgeiibt und ist für dieselben zum Theil verhängnissvoll gevorden. Waren die Rảderthiere die volliommensten Infusionsthiere, so mussten in ilnen auch die Eigenthïmlichkeiten der Infusorienorganisation am deullichsten ansgejrägt sein, und ihre Untersuchung, die olnehin nit weit geringeren Schwierigkeiten verlinüpft war, musste den Schlissel für das Verständniss der einfachern Infusorien, der Magenthiere, an die Hand geben. Ehrenberg befolgte daher bei allen seinen Forschungen das Verfahren, dass er stets Räder- und Magenthiere wie zwei untrenuhare Gruppen gleichmissig und gleichzeilig bearbeitete, sie forlgeselzt mil einander verglich, und die reichen Resıltate, welche die Beobachtung der Räderthiese ergab, dazu benulzte, sich in den unklaren und für sich allein unverständlich bleibenden Organisationsverhälnissen der Magenthiere zurecht zu funden.

In den ersten der oben citirten viej academischen Ablandlungen nimmt die meisterhafte und fast erschöpfende Darstellung der gesammten Organisation eines der grössten Rảderthiere, der Iydatina senta (Vorlicella senta Müller) die hervorragendste Stelle ein $\left.{ }^{2}\right)$. Sie, sowie die Erlauterung des Baues von noch vier andern Raiderthiergattungen gewährten die erste klare Einsicht in die Organisation der Räderthiere und lehrten, wie zusammengesetzt dicselbe sei. Ehrenberg wies unmittelbar unter der structurlosen, durchsichtigen IIaut scharflegrämzte, Jandförmige Muskeln von bestimmter Zahıl und Lage und eine dculliche, hinter dem Raderorgan im Nacken gelegene Gehirnganglienmasse und davon ausgehende Nervenstränge nach. Er zeigle ferner, dass der Mund am Grunde des Räderorgans naher der Bauchseite, eine zweite Oeffnung, die der Kloake, dagegen kurz vor dem hintern Körperende oder am Grunde des Schwanzes liege, und dass der Darmkanal aus einem kugligen, muskulösen, im Innern mit zwei sehr complicirten gezthinten kiefern bewaffneten Schlundkopfe, ciner kurzen engen Speiseröhre, einem weiten, darmartigen, an Anfange mit zwei pancreasartigen Driisen besctzlen Magen und emem kurzen, engen, in die Kloake ausmündenden Mastdarm bestelı. Quere, in gleichen Abständen auf einander folgende, ringförmige, schmale Reifen wurden als Gefasse gedeutet, die durch ein medianes Rijckengefiss mil cinander in Verbindung stehen sollten; es komnte jedoch an ilmen weder ein Pulsiren, noch eine imnere Fliissigkeitssı̈̈mung beobachtet werden. Von Geschlechıtsorganen wurde ein ansehnlicher sack-oder lıerzörmiger, dem Darmkanal anliegender, wenige grosse Eier entwickelnder Eierstock nachgewiesen, der mil eincun kurzen Eiergange in die Kloake ausmindet. Der Austritt der Eier durch dic Kloaliöllunng, die Entwickelunğ von dem Mlutlerthiere völlig gleichen Jungen und ihr Ausschliipfen aus den Liern wurden direct beobachtet. Als Samen bereitende Organe betrachtete Ehrenberg zwei, bej allen Individuen vorlandene, lange, geschlangelte, strangförmige Organe, die im rordern Ende neben dem Schlundkopfe l,eginnen, sich zu beiden Seiten der Leibeshöhle herabziehen und in cinc geräımige, von Zeit zu Zejt sich plötzlich zusammenziehende Blase übergehen, die mil einer halsfömigen Verengerung in dic Kloake ausmindel. Durch die Contractionen dieser Blase sollte der in ilı sich ansammelnde Samen in den benachbarten Eierstock hinübergeschnellt werden und hier die Befruchtung der Eier bewirken.

I) Ablarudl, der Berliner Academie vom Jahre 1830 S. 27--33. 
Diese in hohem Grade anerkennenswerthe Entdeckung des so sehr zusammengesetzten Baues der Rảderthicre ging aller Wahrscheinlichkeit nach ganz oder theilweise den von Ehrenberg in dersethen Abhandlung uber die Magenthiere veröflentlichten Beobachıtungen voraus, und sie erweckle wohl erst in ilım den Gedanken, dass auch die Organisation dieser Thiere eine weit zusammengeselztere sein werde, als bis dahin geahnt worden war. Die Systematiker, von Dutrochet an his auf Cuvier, hatten dic Raderthiere vornehmlich wegen des bei ihmen zu unterscheidenden Darmkanals von den übrigen Infusionsthieren abgesondert, musste nun nicht aber bei den letzteren ebenfalls ein wenn atch einfacher gestalteter Darmkanal vermuthet werden, der sich nu den bisherigen Beobachtungen entzogen haben mochte, weil man nicht die rechte Untersuchungsmelhorle befolgte? Um iber diesen Punct zu einer festen Ansicht zu gelangen, nahm Ehrenberg zu einem ganz in Vergesseuhcit gerathenen Experinente seine Zulucht, welches bereits im vorigen Jahthunderte von einem sorgfthligen und verdienstvollen Mikrographen, den Freihern v. Gleichen genannt Russworm, in :Hhlicher Absicht und nicht ohne Erfoly angewemlet worden war.

Die Thatsache, dass die Knochen der Thiere, welche mit Krappwurzeln gefuttert werden, nach hurzer Zeit roth gefäht essebeinen, brachte Gleichen auf den Gedunken, ob man nicht auch den Infusionsthieren neiu ihe Eingeweide farbendes Futter" geben hönne). "lch färbte also, fahturt er fort, netwas Wasser mit Karmin und vermischte es mit einer Infusion von Weizen, in welcher eine grosse Menge der grössten Pandeloquen- und kleinen Ovalthierchen (Paramaecium colpoda und Glaucona scintillans von Ehrenberg) schon einige Monate lebte. Gleich des andern Tages sah ich meine Erwartungen von dieser Anstalt erfült und mich nicht nur durch die imnere Röthe der meisten dieser Thierchen von einer wirklich geschehenden Einschluchung der Speise tberzeugh, sondern ich lernte auch zugleich iłı Imneres noch besser kennen "Gleichen unterschied nabulich im Inneren rothe Kugeln, die "mit hellen Ringen wie Froscheier " umgeben waren, und er sah dergleichen auch öfters an linleren Ende der Thiere ausgeschieden werden. Anstatt nun aber in ihnen die nur in Blasenràunen eingeschlossenen kugelförmig zusammengeballten Karminheilehen wieder zu erkennen, sah er sie seltsamer Weise für die Eier oder die Embryouen der gefulterten Infusionsthiere an; er verfolgte deshalb die wieder ausgeworfenen Karminballen mit der grössten Aufmerksamkeit, in der Hoffnung, sie lebendig werden und sich in junge Thiere unwandeln zu selıen. Da jedoch weder das Eine noch das Andere zu beolsachten war, so wurde er m seiner Annalıme wieder schwankend, und er erhlarte schliesslich, dass die ausgeworfenen Ballen viellcicht nichts weiter als die Excremente der gefütterten Thiere sein möchten. So hatten deun gleich die ersten Füterungsversuche der Infusorien das eigene Schicksal, dass sie eher zu irrigen Vorstellungen über die Organisation derselben Veranlassung gaben, statt diese genauer aufzuschliessen; mit den spater vou Ehrenbery wieder aufgenommenen sollte dies in einem nicht minderen Grade der Fall sein.

Ehrenberg luatte sich bereits in der friihesten Periode seiner Forschungen bemiilit, das Gleichen'sche Fütterungsexperiment zu wiededholen ${ }^{2}$ ), es war jedoch stets misslungen, weil er dazu nur mineralische Farbstoffe oder doclı mit solehen versetzte, wie sie in den gewöhnlichen Tuschkästen enthalten sind, angewendet halte. Diese zertheilen sich aber in Wasser nicht fein genug und fallen schnell zu Boden. Erst als el sich 10 Jahre später organisclıer Farbstoffe, des reinen Karmins, Indigos und Saftgriuns, bediente, die sich in Wasser in äusserst feine und in ilm suspendirt bleibende Molecule auflösen, glicklen die Versuche vollkommen, und sie wurlen nun soggleich über eine grosse Anzahl der versehieulenartigsten lufusorienformen ausgedehnt. Ehrenberg ging hierbei im Allgemeinen so zu Werke, dass er erst zu dem bereils auf dem Ohjectglase in einem flach ausgebreiteten Wassertropfen isoliten Infusionsthicre eine kleine Quantitit Fabstoff hinzusetzte, und num mit des unermüdlichsten Ausdauer das Thier so

1) F.v. Gleichen, genanut Russworm, Abhandlung über die Samen- und lnfusionsthierehen. Nürnberg 1778 . S.140 und Taf. XXIII. b. und S. 151. Tir. XXVIII. Fig. 19. - Man vergleiche auch desselben Verfassers Auserlesene mikroseopische Entdeckungen bei den Pflanzen, Blumen, Blïtben, lısecten und anderu Merkwürdigkeiten. Nürnberg 1781. S. 48 und Taf. XXIl. Fig. 8. Die letzlere Abbildung, welehe ein mil Karmiti gefïltertes Glaucoma scintillans darstellt, ist die gelungenste, und für die damalige Zeit vorziiglich.

2) A. a. O. S. 22 . 
lange unter dem Mikroscope verfolgte, bis er ermittelt hatte, wie und wo die Farbpartikelchen in das Innere des Körpers eindrangen, welche Bahn sie hier durchliefen und an wclcher Stelle sie endlich wieder nach aussen gefördert wurlen. Bei den meisten Infusorien liess sich leicht beobachien, wie theils in Folge der Tolalform ihres Körpers, theils in Folge der Stellung und Bewegung ihrer Wimpern die Farbtheilchen in dichter Strömung vorzugsweise nach einem lestimmten Puncte hin dirigit und dann nach der entgegengeselzten Richtung wieder fortgeschlendert wurden. In der Nähe dieses Punctes wurde dann auch bei genauerer Beobachtung eine deutliche Mundöffnung erkannt und geschen, wie durch dieselbe Theile des äussern Farbstromes in das Innere des Körpers eindrangen, hier sich eine Streclie weit in einer bestimmten Bahn beweglen, dann aber plötzlich verschwanden, während gleich darauf bald hier, balıl dort cin vorher nicht sichtbar gewesener runder Blasenraum auftanchte, der dicht mit zusammengedrängten Farbtheilchen erfült war. Auf diese Weise füllte sich das Innere des Körpers nach und nach mit zahlreichen farbstoffhaltigen Blasen an, und je mehr dies der Fall war, un so häufiger war an ciner bestimmten, meist in der Nähe des hinteru Körperendes gelegenen Stelle die Ausscheidung von hleinern oder grössern Farbstoliballen zu heobarhten, daher diese Stelle als After bezeichnet wurde.

Dies ist in wenigen Worten das reine Resultat der Ehrenberg'schen Fitterungsversuche, deren Werth darin besteht, dass durch sie nicht blos die bei den ältern Forschern') so verbreitete Ansicht von einer Aufnahme der Nahrungsstolle durch die gesammte Körperoherfliche fïr die meisten Infusionsthicre eine griindliche Widerlegung fand, sondern dass auch zum ersten Male und gleich bei sehr vielen Infusorien Mund und After unterschieden und genau ihrer Lage nach lestimmt wurden. Damil wurde ein ganz neues und oflenbar sehr wescntliches Element zur schärfern Characteristik der einzelnen Infusorienformen und zu ihrer naturgemässern Classification in die Wissenschaft eingefibrt, von dem anch Ehrenberg sofort den glicklichsten und ausgedehntesten Gcbrauch machte. Allein er blieb hierbei nicht stehen, sondern ging noch einen Schritt weiter und iiber die unmittelbare Beobachlung hinaus.

Die mit Farbstoffen erfiillteu Blasenräume, welche Gleichen für Eier oder Embryonen halten wollte, wurden ron Ehrenberg fiur von cigenen häutigen Wandungen hegräinzte Magenblasen erliărt, wclche wie die Beeren an einer Weintaube miltelst enger Sticle an einem zwischen ihnen sich hindurchziehenden und Mund und After verbindenden robıenförmigen Darmkanale festsitzen sollıen. Magen, nichı Blinddärme, seien diese Anhänge des Darms deshalb zu nennen, weil sie nicht zum Verdaunngsprozess vorbercitete Stoffe aufnähmen, sondern mit ganz rohen

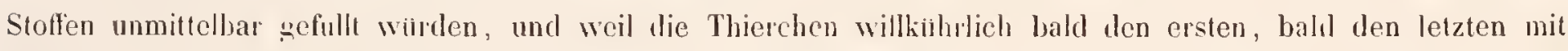
Uebergehen der andern füllten ${ }^{2}$. "Unangefull, " erklär Ehrenberg weiter ${ }^{3}$ ), "sind diese Blindsäcke wegen farbloser Durchsichligheit, wegen fadenformig zusammengezogener Form und lileinen Durchmessers nicht zu unterscheiden, jeloch kann sie das Thier auch mit Wasser füllen, und dann crscheinen sie als die farblosen Blasen, welche wohl die Meisten bisher fur Eier oder verschluckte Monaden hielten. Jhre Veränderlichkeit in Zihl und Form ist nun wohl zu begreifon. Angeliult mit festen Nahrungsstoffen erscheinen diese Jagensäclie wie abgeschlosscne Kugchn, indem der Verbindungskanal, welcher zum Darm geht. sich zuschnürt und durchsichtig wird. Auch sind die Magensäcke einer willibibrichen Ausclehung fähig und füllen sich bei Raubthieren daher zuweilen mit ganz unverhältnissmässig grossen Stäbchenthieren und dergheichen. Wird ciner stälker ausgefillt, so rerbindert seine Eırweiterung, dass die benachbarten gefüllı werden, daher sicht man immer mehr Magen, wo dieselben kleiner und gleichförmiger erscheinen, weniger. Wo einzelne grössel sind. "Man brauchte indessen nur zu erwägen, dass sich bei den Fitterungsversuchen nicmals weder der vorausgesetzte Darmkanal, noch die zahlreichen Acste, welche von ihm abgehen sollen, mit Farbstoflen injicirten, und dass bei Thieren, welche weder flussige noch leste Nahrungsstoffe

\footnotetext{
1) Man vergleiche z. B. Schrank Fauna Boica III. Band 2. Abth. S. 14.

2) A. a. O. S. 34 . Anmerhung.

3) Ebendaselbst S. 20:
} 
aufgenommen hatten, keine Spur von Magenblasen жu entdecken war, um von vornherein gegen diesen den Infusorien zugeschriebenen Eruährungsorganismus mit dem grössten Misstrauen erfillt zu werden.

Die wirkliche Existenz des von Ehrenberg angenomnenen Enahıungsapparates musste ilın natürlich selır willkommen sein; denn damit ergal, sich für die bisher nur negativ bestimmten Infusionsthiere im engern Sinne ein positiver Character, und dieser hatte die ausgezeichnete Eigenschaft, dass er eben so scharf den Unterschied, wie die nahe Verwandtschaft zwischen den Räderthieren und den Infusorien im engern Sinne bezeichnete. Letztere wurden nun fortan unter dem Namen der Polygastrica oder Magenthiere als eine scharf hestimmte Thierklasse behandelt, obgleieh die Fütterungsversuche bei einer nieht unbedeutenden Anzahl derselhen völlig vergeblich geblieben waren. Die Bacillarien, Vilırionien, Closterinen und alle gleichförmig griun gefübten Infusorienformen hatten sich nie zur Aufuahme farbiger Substanzen bringen lassen, sie konnten demnach auch gar keinen Anspruch auf den Nanen Magenthiere machen; Ehrenberg liess sie aber dennoch mit den Farlsstoffe aufnchmenden Fornen heisammen, weil sie sich denselben durch ihre gesanmte iilsrige Organisation zu innig anzuschliessen schienen. Bei einem Theil der Formen, welche sich mit Farbstoffen anfüllen liessen, war nur ein Mund, aber keine besondere Auswurfsstelle zu heohachten. "Von ihrer Struetur, sagt Ehrenberg'), machte ieh mir die Idee, als wảre bei ihnen Mundund Auswurfsölfnung ein und dasselbe, oder als hinge die sichtbare Mehrzahl bleiner Magen mit dem Munde radienartig zusammen. Dies var also nur eine Illee, nicht wirkliche Beobachlung; gleichwohl wurden jene Formen als Anentera (darmlose) bezeichnet und aus ihnen die erste Hauptahtheilung der Magenthiere gebildet, der auch alle diejenigen Infusorien zuertheilt wurden, welehe gar keine Farbstoffe aufnahmen. Die ibrigen nit Mund und After versehenen Magenthiere erhielten den Namen Enterodela (darmfulurende) und bildeten die zweite Hauptabtheilung. Die relative Stellung von Mund und After gab bei len Enterodelen zur Aufstellung von vier Gruppen Veranlassung. In der Gruppe der Anopisthia liegen Mund und After neben einander in dersellsen Grube, in der der Enantiotreta eiuander gegenüber am vordern und hintern Körperende. In der Gruppe der Allotreta befindel sich nur der Nund oder der After am Ende, in der der Katotreta liegt weder Mund, noch After an Ende.

Nachdem den Magenthieren ein so complicirter Emahrungsorganismus zuerkannt worden war, bäte man wohl erwarten sollen, dass sich bei ihnen auch für die übrigen thierischen Functionen scharf ausgeprảgte innere Organe herausgestellt hälten. Allein Ehrenberg sah in dieser Beziehung nicht mehr, als seine Vorgănger; nur bei einigen grünen Arten der Müller'schen Gattung Cercaria, die zu der neuen Gallung Euglena erhoben wurden, benerkte er in der Năhe des vordern Körperendes einen schon von Nitssch im Jahre 1817 hei einer dieser Arten beobachteten²) rothen Pigmentfleck, der als Auge gedeutet und woraus auf das Vorhandensein von Nerven geschlossen wurde ${ }^{3}$. Ferner hatte Ehrenbery hei Kolpoda cucullus fadenförmige, netzartig verstrickte Fasern, welche aus sehr kleinen an einander gereibten liörnehen bestanden, in Absäzen aus der Analöffnung answerfen sehen; er deutete diese Fasern als Eierstock, die Körnchen als Eier und liess den Eierstock periodiseh ausgesehieden werden ${ }^{4}$. Ebenso wurde das plölzliche Zerlliessen der Magenthiere in einen feinkörnigen Schleim für einen Geburtsact von Eiern erklärt, wofür dieser. Vorgang auch sehon von den ältern Forschern, z. B. von Gleichen, gehalten worden war ${ }^{5}$.

Dies waren die Anschanungen, welche Ehrenbery in seiner ersten Abhandlung über die Organisation der Infusorien im engern Sinne entwickelte. Wie Vieles an denselben hypothelisch ist und einer genauern Begründung bedurt hatte, ist zum Theil angedeutet worden, zum Theil leuchtet es nach dem Mitgetheilten von selbst ein. An die Darstellung der Organisation der Räder- und Magenthiere schloss Ehrenberg seinen ersten Entwurf zu einer neuen

1) A. a. O. S. 35 .

2) Nitzsch Beilrag zur Infusorienkunde oder Naturbesehreibung der Cercarien und Bacillarien. Halle 1817. S. 10.

3) A. a. 0. S. 33 .

4) A. a. O. S. 24. 26.77 und Taf, III. 1. und 14. a.

5) Ausertesene mikroscopische Enldeckungen S. 101 und Taf. XLIX. Fig. 19

stein, Organisnus der Infustonsthiere. 
systematischen Eintheilung der gesammten Infusionsthiere, der bereits die llauptgruppen so hinstellt, wie sie in dem endguiltig angenommenen System erscheinen, und in dem sich die bis dahin gebräuchlichen, viel zu weit und unbestimun gefassten Gattungen durch eine grosse Anzahl kleinerer, meist scharf und natiirlich begräinzter ersetzt finden. Da die neue Eintheilung in Ehrenberg's erster Abhandlung weniger ausgeführt und nicht so übersichtlich dargestellt ist, als in der zweiten, so wollen wir sie erst nach dieser in Betracht ziehen.

Die zweite Abhandhung bringl iiber den inneren Bau der Räder- und Nagenthiere keine wesentlich neuen Aufschlisse, sie ist aber sehr reich an interessanten Detailangaben ïber die verschiedenen Formen der Schlundkiefer, des Darmkanals und der mit dem Darmkanal in Verbindung stehenden Drüsen bei den Räderthieren ${ }^{1}$ ). Sie stellt ferner für die äussern Körperabschnitte oder Körperregionen und für die verschiedenen Arten der Körperbedeckung und der von derselben ausgehenden Fortsitze, welche bei Raider- und Magenthieren zu unterscheiden sind, eine bestimmte Nomenclatur fest ${ }^{2}$ ), wobei wieder mancherlei interessante Einzelheiten zur Sprache kommen, auf die ich, so weit sie die eigentlichen Infusionsthiere betreffen, in den speciellen Abschnitten meiner Arbeit zurïckkommen werde. Die frühern Angaben über den Ernähırungsapparat der Magenthiere werden mit noch grösserer Bestimmtheit und Zuversich wiederholt, ohne dass neve, uberzeugendere Thatsachen beigebracht würden ${ }^{3}$ ). An die Stelle der Idee, welche sich Ehrenberg Anfangs von dem polygastrischen Ernährungsapparat der Anentera gebildet hatte, tritt nun die Abbildung einer illeal vergrösserten Monade mit weitem, ringsum bewimpertem Munde, von dem zahlreiche gestielte Magenblasen in das Innere des Leibes hinabhangen. Ebenso bestimmt werden die Darmformen, welche sich bei den Enterodelen finden sollen, abgelildet und letztere hiernach in drei Gruppen gesondert, in die Cyclocoela, Orthocoela und Campylocoela. Bei den Cyclocölen fält Mund und After zusammen, und der Darmkanal beschreiht einen Kreis; sie entsprechen genau der früher anfgestellten Abtheilung Anopisthia. Bei den Orthocölen ist der Darmkanal ein grader Schlauch in der Längsaxe des Körpers, bei den Campylocölen verläuft er ausserhalb der Längsaxe, jedoch in der Längsrichtung des Thieres gekrümmt oder gewunlen. Die Enantiotreta sollen ibberwiegend graddarmig, die Allotreta und Katotreta meist krummdarmig sein.

Zu den wenigen, bisher auf die Gattung Euglena beschrankten Fällen von dem Vorkommen eines angenähnlichen, rothen Pigmentfleckes bei den Magenthieven fügte Ehrenberg ferner eine Anzahl neuer hinzu, die zur Aufstellung der Galtungen Amblyophis, Ophryoglena, Eudorina, Microglena und Lagenula Veranlassung gaben; auch wurden jetzt zwei winzige schwarze Pünctchen, die schon früher bei einer ältern Gattung Distigma in der Năhe des vordern Körperendes unterschieden worilen waren, ebenfalls für Augen erklart ${ }^{4}$. Für die Angennatur dieser. Pigmentflecke konnte jedoch kein anderer Grund geltend gemacht werden, als dass sich bei den Raderthieren sehr allgemein in der Nackengegend ähnliche, nur weit schäfer umschriebene rothe Pigmentflecke finden. dic in einem nachweisbaren Zusammenhang mit dem Gehirnganglion stehen und offenbar als Sehorgane fungiren.

Ausserdem wurden noch einige Versuche ïber dje Vermehrung von Räder- und Magenthieren mitgetheilt, die einzeln in enge, mit reinem Brunnenwasser gefullte, eine vollkommene Uebersicht mit der Loupe gestattende Glasröhren gebracht worden waren. In ejner derselben hatte ein Individuum von Paramaecium aurelia nach 24 Stunden durch Quertheilung 8 Individuen geliefert, und in einer andern waren in derselben Zeit aus 3 lndividuen 12 hervorgegangen. Ehrenberg schliesst hieraus, dass ein einziges Magenthier durch Theilung schon am siebenten Tage eine Million Individuen liefern hönne, und dass man mithin zur Erklärung zahlloser Hengen von lnfusorien in höchst lurzer Zeit keiner Generatio primitiva mehr bediurfe ${ }^{5}$ ).

Ihrr vorzüglichstes Interesse erhielt die zweite Abhandlung Ehrenberg's aber dadurch, dass er in derselhen

1) Abhandlungen der Berliner Academic rom Jahre 1831 S. 44-54.

2) S. $19-40$.

3) S. $40-44$. und Taf. ItI ligg. $1-4$.

4) S. $12-19$ und Taf. I-II.

5) S. $9-12$. 
schljesstich sein System vollstandig entwickelte und alle von ihm sellst beobachteten Răder- mond Magenthierarten characterisite. Alles was sich auf die Raderthiere bezieht, muss hier unbericksichtigt bleihen, da die vorliegende Schrift nur die eigentlichen Infusionsthiere zum Gegenstande luat, diese aber allein in der Ehrenberg'sohen Klasse der Magenthiere enthatten sind. Der sehr ausführliche Clsaracter, welcher den Magenthieren beigelegt wird ${ }^{3}$ ), beruht wesentlich auf der innern Organisation derselben, die num posiliv so angegeben wurde, wie sie sich Elurenberg vorstellte. Besonders auffallend ist hierbei noch die Aufführung eines iiber die ganze Körperoberflache verbreiteten. zarten Gefasssystemes, von dem fruher gar nicht die Rele war, welches dalser olıne alle nähere Begrindung dasteht. Ohne Zweifel wurden die paraflelen, dicht neben einander stehenden eingedrücliten Längslinien, welche sich an der äussern Oherfliche fast aller dicht mit Wimpern besetzten Infusionsthiere fnten, fur Gefässe gehalten. was gewiss nicht geschehen wäre, wenn nicht unausgesetzt die Riderthiere als untrügliches Vorbih der llagenthiere festgehalten worlen wären. Dies geht anch sonst aus der ganzen Fassung Jes Characters der Magenthiere hervor, der also lautel:

"Skelet-, wirbel- und fusslose, zuweilen geschwänzte, nackte oder gepanzerte, sehr kleine, dom blossen Auge wenig sichtbare, aber zahllos durch alle Gewasser verbreitete Thiere, welche schwimmen und mejstens mil Wimpern Strudel- oder Radhewegungen im Wasser machen. Ein Netz von wasserhellen, sehr feinen, selten deutlichen Linien überzieht lie ganze Oberfläche des Körpers und erseheint als ein zartes Gefüsssystem ohne Herzerweiterung und Pulsation. Scharfer Tastsinn und oft durch schönothes Pigment ausgezeichnete Augenspuren deuten, nicht selten vereint, auf ein gesondertes Nervensystem hin. Die meisten, auch die lileinsten, laben einen gewimperten Nund, der entweder olıne Darm unnittelbar zu einer Mehrzahl von Speisebehältern oder Magen fuihrt (wie bei den darmlosen), oder in einen ausgebildeten mil vielen Magentaschen traubenartig versehenen Darm übergeht (wie bei den darmführenden). Der unbewaffnete Schlund ist ohne Auszeichnung. Keine Kiemen. Gebiren einer netzförmigen und gekörnten Masse. Männliche Geschlechtsorgane noch unerkannt. Eierlegen oder Lebendiggebären neben dreifacher Selbsttheilung, nämlich Quertheilung, Längstheilung und Bildung sich ahßösender, frei werdender Kinospen. Grösste Vermelırungsfähigkeit unter allen beliannten organischen Wesen. Keine Verwandlung. (Ob man die inneren zahllosen Körnchen innere Knospen oder Eier nennen diurfe, kann nur spåtere Beobaclutung entscheiden)."

Das Infusoriensystem Ehremberg's ist nach den Grundsizizen der natirlichen Systematik gebildet, es weicht jedoch in seiner urspriuglichen Anlage dadurch wesentlich von der herkömmlichen Form natiurlicher Systeme ab, dass die Familien, welche in demselben unterschieden werden, nicht in cine, sondern in zwei anfsteigende Reihen geordnet sind, die als Ordnungen bezeichnet werden und deren Glieder einander parallel sein sollen, in der Weise, dass sich zu einem Gliede rler einen Reihe ein oder zwei analoge Glieder in der andern finden. Die erste Ordnung unfasst alle nach ten Formen (Nuta), d. h. diejenigen, deren Körper olıne besondere schiizende Itiulle, oder, wie Ehrenberg sagt, nohne Körperbedeckung« ist; die zweite enthäl die g e panz ert en Formen (Loricata), deren Körper mit einer schützenden IJille versehen ist, mag dies nun die zu einer starren Schale erhärtete äusserste Körperschicht. oter ein ılen Körper umschliessendes, aber von ihm abstehendes Gehäuse oder ein dem Körper innig anliegender gallertartiger Mantel sein. Die Magenthiere werden zunäclıst in zwei Kreise gesondert, die Anentera und Enterodela, deren Charactere oben angegehen worden sind; jeder Kreis besteht aus den beiden Ordnungen der Nacliten und Gepanzerten. Die Anentera werden dam weiter nach dem Vorhandensein äusseres Organe in drei Abtheilungen gebracht, in die Anhanglosen (Gymnica), deren Körper unbehart und olme veranderliche Fortsatze ist, in die B eharten (Epitricha), deren Körper durch Borsten oder Wimpern behaart ist, und in die Wecluselfussigen (Pseudopodia), deren Körper mit fussähulichen ver'underlichen Fortsätzen verselıen ist, die aber nur bei einigen wenigen Formen wirklich beobachtet, bei den ubrigen blos vorausgesetzt wurden. Die

1) A. a. 0. S. 55 . 
Enterodelen zerfillen nach der relativen Lage von Mund und After in die schon oben characterisirten Abtheilungen der Anopisthia orler Eimmindigen. Enantiotreta oder Gegenmindigen, der Allotreta oder Wechselmindigen, und del Katotreta oder Bauchmindigen. Nun erst folgen die Fanilien, deren im Gamzen 20 unterschieden werden, die 78 Gatlungen mit 291 Arteı unfassen. Zur besseren Uebersicht dieser Eintheilung lasse ich hier den Rahmen des Systems bis auf die Familien herab folgen, wobei zu beachten ist, dass die in den beiden Ordnungen einander entsprechenden Familien gegenizberstehen.

\section{Erster Kreis. Anentera.}

Erste 0rdumg, Nackte. Zweite 0rdung. Gepanzerte. Erste $A$ bilueilung. Gymnina.

1. Fam. Honadina. 1. Fam. Cryptomonadina.

2. Fam. Vibrionia. 2. Fam. Closterina.

3. Fam. Astasiaea.

Zweite Abtleilung. Epitricha.

4. Fam. Cyclidina. 3. Fam. Peridinaea.

Dritte Abtheilung. Pseudopodia.

5. Fam. Amoebaea. 4. Fam. Bacillaria.

3. Fam. Arcellina.
Zweiter Kreis. Enterodela.

Erste Abtheilung. Anopistlia.

6. Fam. Vorticellina. 6. Fam. Ophryulina.

Zweite Abtheilung. Enantiotrela.

7. Fam. Enchelia. 7. Fam. Colepina.

Ditte Abtheilung. Allotrela.

8. Fam. Trachelina. 8. Fam. Aspidiscina.

9. Fam. Ophryocercina.

Vierte Abtheilung. Katotreta.

10. Fam. Kolpodea.

11. Fam. Oxytrichina. 9. Fam. Euplota.

Icls bin weit davon entfernt, die ausserordentlichen Verdienste Elrenberg's um die Ausbildung des Infusoriensystems zu usterschäzeı, iclı kanı diese jedoch nicht iı den Hauptabıheilıngen seines Klassification erkennen. Dass zum obersten Eiulheilungsprincipe Organisationsverhältnisse gewăhlt wurden, die sich nicht auf eine für Jedermann iiberzeugende Weise begriinden liessen, kanı unmöglicls gutgeheissen werten. Wollten wir aber auch ganz von dem angenommenen innern Unterschied zwischen Anentera und Enterorlela alsselıen und diese bejden Abtheilungen lediglich nach der An- oder Ahwesenheit eines Afters untersclueiden, so hätten doch zu den Anenteris nichı die Gruppen gebracht werden dürfen, deren Mitglieder die Aufnahme fester Nalurmngsstoffe beharrlich verweigerten und keine Spur von Jundöffung erkennen liessen, wie die Vibrionia, Bacillaria und Closterina, vielmehr lıătle aus ihnen nocls eine dritle Abtheilnng, die der Astoma, gebildet werden müssen. Allein auch mit dieser Abanderung wüde das System in der Praxis noch immer ausserordentliche Schwierigkeiten dargeboten umd häulig zu irrigen Bestinmungen Veranlassung gegeben haben. Wie schwer bäh es bei den sehr kleinen Formen, darüber Gewissheit zu erlangen, ob sie mit einem Munde verseben sind oder nicht, ob sie also der Abthellung der Astoma oder der Anentera angehörus. Nicht nindere Schwierigheiten verursacht in der Abtheilung der Enterodela die Bestimmung des Afters, weil er nicht, wie der llund, eine vosgebildete, zu jeder Zeit wahrnehmbare Oeffnnng ist, sondern sich nur in dem Momente zu erkennen giebt, in welchem Excremente nach aussen entleert werden. Man kann nun aber oft Stunden lang ein Thier verfolgen und ist doch nicht so gluchlich, die Ausscheidung von Exerementen zu beobachten; gelingt dies endlich wirlikich einmal, so bleibt man oft wieder ungewiss, ob die Excremente genau am Ende des Thieres und nicht elwa dicht vor demselhen hervortreten. Auf diesen geringfügigen Unstand kommt es aber an, ob ein enterodeles Infisionsthier in die Abtheilung der Allotreta oder in die der Katotreta oder der Enantiotreta gehört.

Eiue andere schwache Seite des Systems liegt in der so consequent durchgeführten Sonderung von nackten und gepanzerten Formen, die nur dadurch möglich wurde, dass unter dem Namen Panzer dic heterogensten Gebilde zusammengefasst wuden. Wollte man auch hieran keinen Anstoss nchmen, so wirl man doch häufig beim Bestimmen einer Infusorienform in die Lage kommen, nicht zu wissen, ob dieselbe in die Ordnung der nackten oder der gepanzerten Infusorien zu stellen sei; lenn zwischen beiden Ordnungen bestelıen durchaus lieine scharfen 
Gränzen, sondern sie gehen ganz allmahlig in oinander uber. Wir werden auf diesen Punct weiter unten zuriickkommen; hier genüge es beispiclsweise nur auf einen soleden Fall hinzuweisen. Wer mit Ehrenberg in Cryptomonas, Cryptoglena, Perilinium und Glenorhinim gepanzerte Formen erkennt, der wird sicheslich geneigt sein, Chlorogonium, Phacelomonas, Microglena und lolygloura ehenfalls als gepanzerte zu bestinmen; diese Gattungen stehen aber in Ehrenberg's Systen in tler Ordnung ter nackten Infusorien.

Gegen die Zweckmassiglieit von Ehrenberg's Eintheilungsprincipien spricht endlich auch das Resultat, zu welchem dieselben fïhren. Es ergeben sich Verhindungen von Gattungen, die nach ihrer gesammten tibrigen Organisation völlig von einander verschieden sind, und andercrseits werden Gruppen, die in der innigsten Verwandtschaft mit einander stehen, widermatiolich aus einander gerissen. In ersterer Beziehung verghteiche man z. B. uur die Gattungen, welche die Familien der Trachelina. Colpodea und Enchelia zusammensetzen, und man wird mir gewiss beislimnen, wenn ich in diesen Familien unnatioliche Combinationen von Formen erblicke, die oft gar nichts weiter mit einander gemein halsen, als the relative Lage ron Mund und After. In letzterer Beziehung hieten die Aspidiscina eins der schligendsten Beispiele dar; sie erscheincu in System mit den von ihnen funtamental verschiedenen Trachelinen und Ophryocercinen verbunden, während sie sich doch ihrem gesammten Baue nach so innig an die Euplota anschliessen, dass sie von diesen katm als gesonderte Familien getrennt zu werden verdienen. Aus allen diesen Grüden werden wir Ehrenberg's System nicht beibehalten liönnen.

Ehenberg's dritte und vierte Ablandlung, welche eben so innig mil einander zusanmenhängen, wie die erste unt zweite, erweiterten die Kenntniss der inneren Organisation der Magenthiere auf eine luöchst iiberraschende Weise und brachten dieselbe im Wesentlichen bis zu der Stufe der Ausbildung, von der aus Ehenberg in seinem grossen Infusorienwerke die Naturgeschichte der Magenthiere hearbeitete und iber die er bis auf den gegenwätigen Augenblick nicht weiter hinausgegangen ist. Auch die innere Organisation der Ridlerthiere erhielt in der dritten Ablandlung noch eine wichtige Bereicherung. Ehrenberg entdeckte nämlich hoj versehiedenen Gattungen auf beiden Seiten der Leibeshöhle mehrere eigenthümliche, kleine, gesticlte, zilterntle Organe ${ }^{1}$ ), welche dic Form von Notenzeichen hatten, mit ihren Sticlehen den beiden als lloden betrachteten, strangfürmigen Organen aufsassen und nit ihrem erweiterten, zitternden Ende frei in der Leibeshölıle flottirten. Diese Organe wurden für Kiemen erklärt und mit ilınen ein schon frïher vielfach beobachtetes, äusseres, röhrenförmiges Organ im Nacken der Räderthiere in Zusammenhang gehracht, welches zuerst fur ein Begattungsorgan gehalten worden war, nun aher als Respirationsröhre gedeutet wurde. Durch dieselbe sollte Wasser zur Untcrhaltung des Respirationsprozesses in die Körperhöhle cin- und ausgefiihrt werden. Ausserdem wurden in der dritten Abhandhung zahlreiche neue Räder- und Magenthierformen greschildert, von denen die interessantesten durch Abbildungen erläulert wurden, in denen ein grosser Fortschritt zu erliennen ist. Zu den Magrenthieren allein kamen 27 neue Gattungen hinzu; auch nussten in der Ahtheilung der Anentera noch zwei neuc Fanilien, die Dinobryina und die Volvocina, errichtet werlen ${ }^{2}$. Die Hauptrepräsentanten der letzteren Familic waren zwar lingst bekannt, sie hatten aber bis dahin für einfache Thiere gegolten und waren deshalb von Ehrenberg in seinen heiden ersten Abhandlungen mit den Peridinäen vereinigt worden; jetzt lieferte er den iberraschenden Beweis, dass sie aus vielen Individuen zusammengesetzte Monadenstöcke seien.

Was nun die neuen Aufschlisse iber die innere Organisation der Magenthiere anbetrilft, so bezichen sich

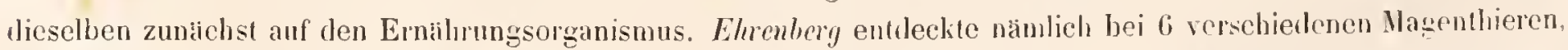
welche zur Aufstellung der drei newen Gattungen Chilodon (Anfangs Euodon genanut), Nassula und Prorodon Veranlassung gaben, einen sich scharf absetzenden, graden und staren, rohrenförmigen Schlund, der an seiner innern Oberflache nach Art einer Fisehreuse von dicht nehen einander stehenten borstenfömigen Zähneu ausgehleidet

1) Abbandlungen der Berliner Academie aus dem Jilire 1833 S. $188-89$.

2) S. $279-82$. 
war. welche sich nach rom zu hraftiger, hirter und sehitfer begränzt zeigten und mit diesen Enten gegen einanter geneigh und weiter von einander enternt werden honnten. Ehrenberg erblichte hierin eine nene Verwandtschaft zwischen Magen- und Riderthicen und verglich den Schlund jener Gattungen mit dem Schlunthopfe der Raderthice, und die horstenförmigen Zilme der ersteren mit den beiden Kiefer'n der Jeztern; natiolich musste nun das fribere Kennzeichen der Magenthiere: uler unbewallinete Schlund olne Auszeichnungu aufgegeben werden ${ }^{\text {) }}$.

Bei zwei Arten der Galtung Nassula (N. elegans und N. ornata) wurlen ferner meist zahlruiche, schön violett gefarbte. bei Buraria vernalis mehr veremzelte und röthliche blasenartige Kugeln im lonern les hörpers beobachtet, die den Thieren das Ansehen gaben, als wären sie mit violetten orler röblichen Substanzen gefuttert worden. Ehrenberg deutete diese farbigen Kugehn als cimen eigenthimlichen, von den Thieren erzeugten unt die Vertaung heförlernden Saft, der sich in ten Darm erogiesse, die Excremente farbe und mit ibnen vereint ausgeschieden werle; er sollte dem farbhosen Absonderungsproducte der panereatischen Drisen der Raderthiere analog sein. Da in vordern hörperende von Nissula elegans, lem Zahnçlinder gegenuber, meistentheils ein grösserer, aus dicht nebon einander liegenden violetten kïgelehen zusammengesetzter Fleck vorhanden war, so wurte dieser fur den Bihlungsheerd des violetten l)anmsaftes erhlarl; ein leller, in der Mittellinie der Rickseite verlaufender perlschnurfömiger Kanal sollte ihn von dort aus nach dem hintern Drittel des Körpers fullren und ihn hier in die Magenblasen ergiessen. Diese Anmahme stützte sich darauf, dass im hintern körperende gewöhnlich die grössten violetten Kugeln lagen, und dass hier häulig ein Zusammenfliessen hleinerer beobachtet wurde $\left.{ }^{2}\right)$. Wir werden weiter unten sehen, dass sich diese Erscheinungen auf eine viel einfachere und ungezwungenere Weise erklaren lassen.

Das lei weilem wichtigste unt am meisten msere Aufmerlssmheit verdienende Moment in Ehrenberg's dritter Abhandlung war aber dies, dass in ihr zun ersten Nale wieder innere Organisationsverhiiluisse der Magenthiere zur Sprache gebracht und gleich sehı unfassend erörtent wurden, von denen bereits die älıern Mikrogmaphen einige Kenntniss hatten, dlie aber später głanzlich unleachtet gebliejsen waren. Der wackere Roesel, der in rorigen Jahmunderte die hesten Abbildugen vorticellenartiger Infusorien lieferte, unterschied schon im dahre 17330 an allen Individuen seines mispelformigen Afterpolypen (ich erkemne darin Epistylis flavicans Ehbg.) im lonern des körpers einen hellen, geschlangelten, strangförmigen Körper und cine kleine, helle Blase, und erklärte sie für wesentliche Organe dieses Thieres ${ }^{3}$ ) Femer beobachtele er im Innern aller Individuen seines berbersbeerförmigen Afterpolypen (Opercularia berberina Stein) ein scharf begranztes helles ovales Organ ${ }^{4}$ ).

Spallanami entleckte sodann 1776 hei Paramacium aurelia zwei sternförmige contractile Organe, von denen er vermuthet, dass sie zur Respiration ljestimmt sejen ${ }^{5}$. "Die beiden Sterne, "sagt er, "liegen fast in den Brenıpuncten dieser elliptischen Thiere und haben in ilırer Mltte eine sehr kleine Kugel. Sie sind stets in Bewegung, mögen die Thiere stillstchen oder sich bewegen, und ilıe Bewegung ist eine regelmassig alternirende. Alle 3-4. Secunden schwellen die beiden kleinen centralen kiugeln zu 3-4. mal grösscren Schliuchen an, dann nimmt ihr Umfang wieder ab; Zu- und Abmahme ales Umfungs erfolgt sehu langsam. Derselbe Rhythnus ist an den Sirahlen жu beobachten, nur mit dem Unterschierte, dass, wenn die likinen Kugeh anschwellen (s'enflent), die Ausdehnung der Strahlen abnimmt (les rayous se désenflent), und dass, weun diese anschwellen, der Unfang der kleinen Kungeln abnimmt." Etwa in der Jlite zwischen ten beiden sterufömigen Organen unterschied Spallanzani noch ein sehr lileines, länglich elliptisches Gebilele (Figr. XVIII. R.), an welchem unaufhörlich eine continuirliche Bewegung zu beobachten war. Es war dies der Mund des Thieres, der jedoch noch nicht als solcher erkanıt wurde.

1) S. $168-72$ und Tisl. I แ1, II

2) S. $179-82$.

3) Roesel v. Liasenhof Monallich heransgegehene Insectenbelustigungen Band III S. 615 und Taf. C. Fig. 5. 6. 0. P.

4) Ebendaselbst s. Gik und Taf. XCl. Hig. 3-9.

3) Spallanzani Opuscules de fligsigue animale el vegetale. Traduits par Senebier. Genive 1777. Tom. I. p. 248 und PI. II Iig. IIII. A. A. 
Unabhängig ron Spallamzani beobachtcte auch Gleichen 1778 die contractilen Blasen von Paramaecium aurelia, doch unterschied er nur die vordere und ibhersah auch die strahlenförnigen Fortsutze derselben. Zuerst war ihm nur an der einen Seite des Thieres neine Erhöhung wie ein Blaschen aufgefallen, tas seine Stelle nicht veränlere." Als sich aber das Thier bein Verdunsten des Wassers alpplatlete, sah er zu seiner Ueberraschung, dass das Bläschen mohol als zehnmal mach einander bahd hineingezogen, bald wieder heraus und in die Höle getrieben wurde, " und er warf deshalb die Frage auf, ob nicht das Bhaschen das Ilerz des fhieres sein möge ${ }^{1}$ ). - Endlich hat auch O.F. Mäller bei mehreren ächten Infusionsthieren innere drisenálumblie Organe (z. B. bei seiner Kolporla meleagris und Vorticella polymorplai) mul cinzehe constante wasscrluelle Blasen ( . B. bei seiner Enchelys relrograda und pupula, Trichoula aurantia, ignita und vermicularis angegeben; am schufsten simd beide fohilde bei seinem Paranaecium marginatum, worin ich Prorolon niveus Ehbq. erkenne, hervorgchoben. Dic grosse wasserhelle Blase liegt hier an hintern Ende und vor ihr in der Axe les Köppers ein gewundener weisser Strang. den Müller als "luor intestini spiralis " bezeichnet $\left.{ }^{2}\right)$.

Ehenberg's Anfmerlisamkeil wurle erst spat auf diese beilen Organe hingelenkl, bachden er bei rlem von ihm schnı unzihlige Nale beobachueten Paramaecium aurelia eines Tages die beitlen sternförmigen confractilen Blasen Spallanzani's zufillig wieder aufgefunden halle. Wurden eine grosse Anzahl von Thicren auf einmal durch ein aufgelegtes Dechglischen chwas glattgedriickt, so sah el nalsbald ron jenen zwei Blasen aus bis 8 stralılenförmig nach allen Köpergegenden hinlaufende Kanäle, welche sich laugsam erweiterten, wenn dic Blascn sich zusammenzogen und fast verschwanden, und die sich langsam verenglen und zuletzt verschwanden, wenn die Blasen sich erweiterten; die strahlenförmigen Kantle waren in ihrer Austehnung dicht hei den Blasen zwiebelfömig erweitert." Sofort untersuchte Ehrenberg nun andere Magenthiere auf contractile Blasen, und er traf dieselben unch bei 24. Arten an. Bei den meisten waren sie ohne strahlenförmige Ausliufer und nur in einfacher Anzahl vorhanden. Ausserdem wurle moch hei Chilodon cucullulus, welches allein mil 3 contrachilen Blasen versehen war, und hei drei Arten der Gattung Yassula, etwas später auch hei l'aramaecium aurelia, cin " pundliches, weniger durchsichtiges Organ " neben den contractilen Basen beobachtet, oflenbal also Analoga der von Roesel und Müller heobachleten weissen driisenarligen Organe.

Die letzlem Gebilde boten gar keinen Anhaltspunet für ihre Deutung dar. in den contractilen Blasen aber komte Ehrenberg wegen ihrer zu langsamen Bewegung weder ein Ilerz, noch wegen der zu geringen Entwickelung cines Gefässsystemes, das er jedoch in schwachen spuren als seh feine netzförmige Kantle bei Paramaecium heobachtet haben wollte, ein Respirationsorgan erkennen. So wurde denn wieder zu dem bedenklichen Auskunftsmittel gegriffen, dic Raiderthiere ïber die fraglichen Organe der Nagenthiere Aulschluss geben zu lassen. Es lag matiulich sehr nahe, die contractile Blase der Iagentliere dem als Samenblase gedeutelen contractilen Organe dler Riblerthiere gleich zu setzen. Da mit dem letzteren noch drüsenartige Organe, die sogenannten Hoden oder Samendrisen in Verbindung standen, so mussten auch bei den Hagenthieren analoge Gebilde vorhanden sein. Die einzigen Organe, welche hier noch der Deutung harten, waren die bei Chiloulon, Nassula und Paramaecium beobachteten opakern, rundlichen Organe; sie wurlen daher von Ehrenberg fur Samen bereitcule Driisen, und die contractilen Blasen fï Samenhlasen erklirt. Auf diese Weise hatten die Nagenthiere nun auch ein mämnliches Geschlechtssystem erluatten, und sie galten fortan als Zwillerthiere ${ }^{3}$.

Der neuen Lehre von dem doppelten Geschlcehte der Magenthiere eine breitere Basis zu geben, war die Hauptaufgabe von Ehrenbery's vierter Abhandlung, die aussertem noch lä neue Gattungen ron Magenthieren auffuhrte ${ }^{4}$ und einge Zusätze zum Gefisssystem der Räderthiere brachte, darunter die Berichtigung, dass das angeb-

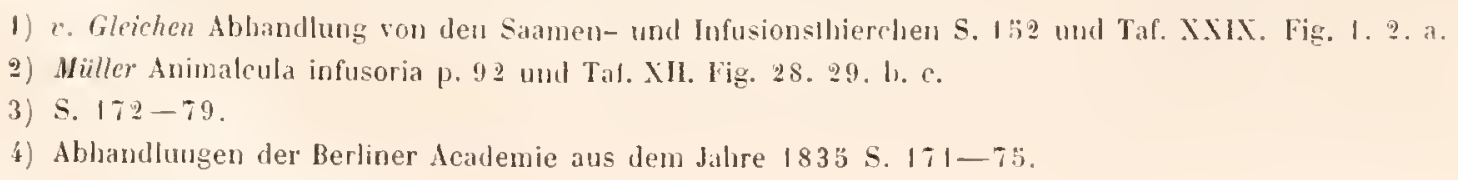


liche Riichengefiss sich neucrlich als ein Lingsmushel herausgestellt habe). In Betreff (les weiblichen Geschlechtsorganismus der Magenthicre wird angegeben, dass derselhe aus kugel-oder eifömigen, periorlisch den ganzen Körper des Thieres erfüllenden, zu anderen Zeiten aber fehlenden, in netzförmig anastomosirenden Rühren liegenden Kürnern bestehe, die haufig lehhaft grius, auch gelb, blat, soth und braun gefarbt seien. Nimentlich bei Thieren mit grinen Eiern, wie z. B. bej Stentor polymorphus, könne man sich leicht von der periodischen Ausscheidung der Eier uberzengen, da ihr Körper balı lebhaft grün gefurbt, bald ganz wasserhell und farblos erscheine. Beobachte man sie auf einer Glasplatte mit wenig Wasser, so zerreisse zıletzt der Körper an einer Stelle und es würde dann ein Theil der grüıen Eier kiunstlich geboren, das Thier aber lebe weiter fort, wenn man nur nenes Wasser hinzu setze. Der natiirliche Geburtsact der Eier durch die After- und Geschlechtsöffnung sei schwer zu beobachten, aber bei Colpoda cucullus wirkich geschen. Bei einigen Formen, namentlich bei Nlonas vivipara, wirden die Eikörnchen sehon im Innem des Mutterthieres lebendig, aber der wirkliche Aet des Ausliriechens der Jungen aus solehen Eihörnchen oder leere zuriicligelassene Eischalen hätten sich noch bei keinem Magenthiere beobachten lassen ${ }^{2}$ ). Dic Einatur der Körner war also doch weder aus ihrer Entwickelung, noch aus ihrer Structur dargethan, auch war durchaus nicht näher naclıgewiesen, dass sie wirklich in netzörmig anastomosirenden Röhren enthalten sind. Das periodische Versclıwinden von Körnern in einem lebendigen Organismus berechtigte ferner noch nicht zu dem Selılusse, dass sie wirklich aus dem Körper ausğeschieden werden; es ist eben so gut möglich, dass sie nur resorbirt werden. Genug, Ehrenberg's Gründe fur einen weiblichen Geschlechtsapparat der Magenthiere hatten durchaus keine zwingende Beweiskraft.

Zu Gunsten der männlichen Geschlechtsorgane der Magenthieje konnten auch jetzt heine andern Grinde gettend gemacht werden, als die von der Analogie mit den Raderthieren hergenommenen. Dafü aber licferte Ehrenberg den sehr dankenswerthen Nachweis, dass die sogenannte Samendrüse ein bei den Magenthieren sehr allgemein rerbreitetes Organ sei, welches bei den versehielenen Arten unter verschiedenen Fornen auftrete, am häufigsten in der Kugel- und Eiform, nicht selten aber auch in Nieren-, Band- und Perlschnurform. In nicht minder allgemeiner Verbreitung wurden ferner auclı die contractilen Blasen nachgewiesen, eine Communication derselhen mit den Samendrüsen konnte jedoch nicht beobachtel werden. Trotzdem lässt Ehrenberg abfulırende Gefässe von der Samendrise nach der contractilen Blase hingehen und letztere nu das erweiterte Ende dieser Samenleiter sein. Ferner nimmt er an, dass die contractile Blase entweder', unmittelbar dureh eine oder nelırere Oefinungen, oder mittelbar dureh strahlenförmige Ausliufer mit dem balıl einfachen, bald mehrfachen, aber cbenfalls noch nicht darstellbar gewesenen Eileiter in Yerbindung stehe ${ }^{3}$. Man muss zugeben, dass dies Alles recht wohl so scin hounte, nu fehtte es an jeden Beweise für die gemachten Annahmen. Das Uebelste war, dass nicht einmal bei den Räderthieren in den als Samendrüsen bezeichneten Organen die Entstehung von Spermatozoen hatte beobachtel werden liönnen, und dass sich eben so wenig in ihren contractilen Blasen entwickelte Spermatozoen erkennen liessen.

Die Beobachtung der sogenannten Samendruisen der Magenthiere lietel bei vielen Arten durelaus beine Schwieriglieiten dar, es muss daher gewiss auffalten, dass ein so genauer Forseher, wie Ehrenberq, diesellien so lange ibbersehen komte, während er doch bereits in seinen heiden ersten Abhandlungen bei gewissen Formen den Verlauf des Darmkinales mit einer Bestimmtheit darstellte, wie haum später bei irgend einer andern Form. Sollte dieser Unstand nicht daraul hinweisen, dass vielleicht bei jenen Formen nur strang- und schnurfömige Samendrisen, welche sich zwischen den verschlucliten Nahrungsstoffen hinschlangelten, gesehen und für den Darmkanal, nach welchen Ehrubery so eifrig snchte, gehalten wurden? Ich fur meine Person bin üherzengt, dass in len meisten Fillen eine solche Verwechselung stattgefunden hat. Ganz sicher gilt dies von der Gattung Stentor, der Ehrenbery in der zweiten Ahluandlung S. 4.3 einen durch viele Anschwellungen rosenkranzförmigen Darmkanal
1) S. 169 .
2) S. $155-36$.
3) S. $158-67$. 
zuschueibl, welcher auch auf Taf. III. Fig. 3 fur sich alıgebildet isı. Genau von derselhen Gestalt und Grösse isl die Samendriase von Stentor polymorphus. Dass diese in den beiden crsten Ablandlungen als Darmlianal aufgefasst wurle, wird noch evidenter dadurch heriesen, dass Ehrenberg in der ersten Aluhandlungr S. 26 bemerlit: "Bei der Gatung Stentor (Vorticella polymorpha, stentorea) sah schon Müller den Verlauf des Darmkanals, erkannte ihn aber nicht," und dass er in der dritten Abhandlung S. 326 das in Müller"s Abbildungen dargestellte sehnurförmige Organ wieder als Samendriise cilirt.

Ehrenberg hat fermer in der essten Abhandlung auf Taf. V. Fig. B. J. 3. Aler Vorticella citrina einen Darmlianal zuertheilt, der genau die Form und Lage zeigt, welche der Samendrise dieses Thicres zuliommen. - Enchelys pupa besitzl meinen Untersuchungen zufolge eine lange, fast ganz grade. strangförmige Samentlriise, welche die Längsaxe des Körpers einnimmt; diese wurde offenbar auch von Ehrenberg gesehen und fuir einen vorn mit dem Jund, hinten mit dem After zusammenhängenden Darmkanal gehalten, der dann weiter durch seitliche Aeste mit den die Nahrungsstofle unschliessenden Blasentüumen in Verbindung gesetzl wurde. So cntstand der polygastrische Ermahungsapparat, der anf Taf. II. Fig. I. 13̈. algebildet ist. Auch bei Lencophrys patula gicht Ehrenbery mil grosser Bestimmlheil den Verlauf des Darmkanales an (vergl. Tal. Il. Fig. II. 1. und 6). Leider isl dic in aler ersten Abtheilung gelieferte Darstellung dieses Thieres von der späler im grossen Infusorienwerk gegebenen so lotal verschieden, dass es zweifelhaft bleilst, was fur ein Thier eigentlich unter den Namen Leucoplurys patula gemeint wurde. Ich vermuthe, dass in beiden Fällen Bursaria truncatella Müll. heobachlet wurde, ron welchem Thicre Ehrenberg auch nur eine ungenaue und fehlerhafte Darstellung geliefert hat; hinsichllich tlen Leucophrys patula der ersten Abhandlung ist mir dies fast gewiss. Denn ich habe of Exemplare von Bursuria Iruncatella gesehen, welelıe äusserlich den von Ehrenberg abgebildeten Individuen der Leucophrys patula täusehend ähnlich waren. Ihıc sehı lange. strangförmige Samendriise zeigte sich nicht selten eben so weilläuftig spiralfömig gewunden, wie Ehrenbery den Verlauf des Darmkanales bei Leucophrys patula darstellı. So düfte sich denu aucls der Darmkanal dieses Thicres auf eine nicht scharf genug beobachtete Samendruise reduciren.

Das grosse Infusorienwerk von Ehrenberg ist ganz und gal auf die Anschauungen von der innern Organisation der Rüder- und Magenthicse basirt, welche die im Vorstehenden analysirten vier acadernisthen Abhandlungen zu begrijnden versuchten; es setzt dieselhen als in allen wescullichen Puncten bewiesen roraus. Schon der prägnante Tilel dieses Werkes: "Dic Infusionshlierchen als vollkommenc Organismen "asst daran nicht zweifeln. Was Ehrenberg damit sagen wollte, geht am deutlichsten aus den Worten hervor, mit denen er den allgemeinen Theil seiner dritten academischen Abhandlung (S. 196) schliesst: "Somil wären denn bei den Infusorien, als den keinsten Körjern, welche der menschliche Gesichtssion ibberhaupt zu erreichen vormag, alle die Systeme der Organisation, welche den Organismus des Menschen begrünlen, nicht rudimenlarisch, sondern lheils augenseheinlich, theils mil der grössten Wahrscheinlichkeit elsen so in sich vollendel, nur in anderer Form gestaltel, aufgefunden und die thierische Organisalion auf eine beim Menschen um dem Ritherthiese, ja der polygastrischen IIonade gleiche Summe, einen einzigen durchgreifenden Typus gewiesen." Dicser Ausspruch könnle auch dann noch nicht gerechtfertigh erscheinen, wenn Ehrmberg's Auffassung der Infusorienorganisation in jeder Beziehung begrindet witre. Denn wie uncullich complicirter und darum vollkommenes sind doch alle einzelnen organiseheu Systeme selbst noch bei den niedrigsten Wirbehhieren, geschweige denn bein Vensehen, im Vergleich zu denen der höchsten Infusionsthiere, dic Răderthiere mit inbegriffen! Der Lnterschied in der Organisation der Infusionsthiere und des Mensehen ist doch wahrlich mehr als ein blos formeller. Das Prädicat „rollkommene Organismen " lür die Infusionsthiere würde also nur den Sinn haben liönnen, dass bei ihnen für die Grundausserungen des thierischen Lebens, fur Emplindung, Bewegung, Ernährug und Fortpllanzung, eben so gut bestimmle Organsysteme vorhanden sind, wic beim Menschen.

Den Magenthieren waren durch Ehrenberg's bisherige Arbeiten ein polygastrischer Darmhanal, Spuren eines netzförmig verzweigten Blutgefaisssystemes. ein complicirter hermaphroditischer Geschlechtsapprat und Augen 
vindicirt worden, auch waren bei ihnen von Bewegungsorganen lheils sehr versehiedene Arten wirbehder Fortsätze, theils verinderliche, ans- und einstijphare Scheinfusse oder Psendopodien nachgewiesen. Es fehılte also den Magenthieren immer noch ansserordentlich viel, um sie auch nur ganz entfernt mit den Wirbelthieren vergleichen zu können. Das Gefisssystem wurde iberdies im grossen Infusorienwerke (S. ****) wieder zurijckgenommen, der Glaube an dasselbe aber keineswegs aufgegeben. "Ein Gefässsystem ist noch bei keiner Form denllich geworden, das bei Piramaecium aurelia ungegebene war cine Irrung durch die Eierketren. Es scheint zu fein fir die bisherige Beobachtung." Dagegen wurden nun den Magenthieren in bestimmterer Weise, als friher, auch Huskeln und Nerven zuertheilt. Schon in der zweiten Abhaullung S. 30 hatte Ehrenberg bemerkl, dass bei denjenigen Magenlhieren, deren ganzer Körper mit Wimpen bedeckt sei, die Wimpern immer in deullichen Reihen ständen und dass diese Anordung der Wimpern auf Lings- und Quermuslieln hinzudenten scheine, welche dic Wimpern reihenweis in Bewcgung setzten. Im grossen Infusorienwerke sprichl er sich über die Huskeln der Magenthiere (S. ***) also aus: "Man kann aber anch Muskeln sehen. Diese bilden bei Stentor deullich, wie bei Megalotrocha der Rảlerthiere, den Boden, worauf die Wimpern steben, als trube Längsstreifen oder Spiraten. Im Stiele des Schnell-Vorlicellen und im Leibe der Opercularia sind sie noch klarer." Bei der letztern Gatlung hielt Ehrenberg den holslen Stiel des Wirbelorgans fiur einen Längsmuskel. Diss der dunkle Streif im Stiel der Vorticellen und die Iriibern Längsstreifen der Stentoren wirkiche Muskehn seien, bleibt gegeniber der grossen Meluzahl der iibrigen Magenthiere, bei welchen sich nichts Aehnliches findet, mindestens sehr zweifehaft. Auf das Vorhandensein von Nerven wird im Wesentlichen noch immer aus dem Vorkommen ron rothen Augenflecken, die in Ganzen bei 48 Arten nachgewiesen wurden, geschlossen (S. ***** und 491), nur bei den Galtungen Amblyoplus und Euglena wurden angeblich wirkliche "Nervenmark-Ganglien als Unterlage der Augen " beobachtet. Ich habe diese anscheinende Unterlage des rothen Augrenflecks bei beiden Galtungen oft untersuchl, aber nur die Ueberzeugmugr gewinnen können, dass sie nicht von einem soliden Kinoten, sondern von einen schr langsam veränderlichen, wasserhellen Blasenraum gebildet wird, der offenbar in die Kintegorie der contractilen Blasen gehört.

Für die Klasse der Migenthiere wirl $\left(S .^{*}\right)$ folgender, sehr vereinfachter Character aufgestellı: "Ilagenlliere sind rickenmarklose und pulslose Thiere mit in zahlieiche blasenartige Magen zertheiltem Speisekanale, mit (wegen Kuospenbildung oder Selbstheilung) mabgeschlossener Körperform, mit doppelten veremten Geschlecht, bewegt durch (of wirbehol() Scheinfüsse und ohne wahre Gelenkfuisse. Der Character der Raiderlhierklasse wird dagegen auf S. 384 also bestimmt: "Räderthiere sind rückenmarklose und pulslose Thicre mit einfach schlauchförmigem Ernahrungshanal, den Insecten und Riickenmarksthiejen gleich alggeschlossener Form, mil doppeltem vereinten Geschlecht und Räderorganen, ohne wahre Gelenkfusse und meist mit einem einzelnen Scheinfusse. Waren dicse Charactere der getreve Ausdruck unmiltelbarer Beobachtung, ständen sie unantasıbar fest, so würde Nicmanıl die innige Verwandtschaft zwischen Magen- und Räderthieren zu läugnen wagen, und der Vereinigung beider Thierklassen zu ciner höhcren Einheil unter dem Namen der Infusionshiere könnte kein Bedenken entgęrenstehen. Nehmen wir aber in den Character der Magenthiere nur die sehr allgemein und direct beobachtelen Organisalionsverhätnisse mil Ausschluss jeder nicht volliommen sicher zu begrimdenden Deulung auf, so erhalten wir zwar einen Character, der elsen so scharf ist, wie der von Ehrenberg aufgestelle, es verschwindet dann aber jede Aehnlichkeit mit den Raterthicren. Dieser Character würde etwa so lauten: Die Magenthiere sind nerven-, muskel- und gefisslose Thiere, deren stets ungegliederte Locomotionsorgane in Wimpern oder Pseudopodien bestehen. welche ferner die Nahrungsstoffe in innere Blasenräune der Körpersubstanz aufnehnen, mit cinem eigenthimlichen, innern drusenartigen Organe und einer odes mehreren contractilen Blasen versehen sind und sich am gewöhnlichsten durch freiwillige Theilung, seltener durch Knospenbildung fortpflanzen ${ }^{2}$ ).

1) Warum Thiere, Welche sich durch Theilung oder Knospenbildung vermelıren, eine unabgesclılossene Körperform besilzen sollen, vermag iclı nicht einzuselien. 
Es darf jedoch nicht ibersehen werden, dass dieser Character immer nur für einen Theil der Magenthiere Guiltigkeit hätte, keineswegs aber für alle jene Organismen, die von Ehrenberg unter diesem Namen aufgefübrt werden. Die Magenthiere unfassen in dem grossen Infusorienwerke 553 Arten in 123 Gattungen und 22 Familien. Die Eintheilung berulıt ganz auf denselhen Principien, wie in den beiden ersten Abhandlungen, in der Form weicht sie aber darin ab, dass nicht mehr die nackten und gepanzerten Magenthiere als zwei selbststandige Ordnungen mit parallelen Familien einander gegeniibergesteltt werden, sondern sămmtliche Familien sind in eine einzige aufsteigende Reihe geordnet, in der die einander entsprechenden Familien von nacklen und gepanzerten Formen unmiltelbar auf einander folgen. Die nackten Formen werden jetzt "panzerlose "genamut. Ich lasse clas Sehema dieser Eintheilung, auf die ich in den speciellen Abschnitten meiner Arbeit immer wieder werle zuriickgehen miissen, hier folgen und füge zu jeder Familie auch die sammtlichen Gattungen hinzu, die Ehrenberg innerhalb derseblben unterschied. Nur die zahlreichen Gattungen der Bacillarienfamilie habe ich unberücksichligt gelassen, da sie meiner Ausicht nach nur pflanzliche Organismen sind.

\section{Anentera.}

A. Anhanglose (Fusslose). Gymnica

1) Körperform bestindig

i) vollkommene Selbstllieilung

(e) panzerlose

I. Fam. Monadina.

(Monas. Uvella. Polytoma. Microglena. Phacelomonas.

Glenomorum. Doxococcus. Chilomonas. Borlo.)

$\beta$ ) gepanzerle

2. Fam. Cryptomonadina.

(Cryptomonas. Ophidlomonas. Prorocentrum. Lagenella. Cryploglena. Traclielomonas.)

b) unvollkommene Sellsttheilung (Nonadenslockbildung)

r) allseitige Selbstheilung mil Panzer (Kugelbildung)

$\beta)$ einseitige Selbstheilung (Fadenbildung.) a) panzerlose

3. Fam. Volvocina.

(Gyges. Pandorina. Gonium. Syncrypla. Synura. Uroglena. Eudorina. Chlamidomonas. Sphaerosira. Volvox.)

\section{Fam. Vibrionia.}

(Baclerium. Vibrio. Spirochaeta. Spirillum. Spirodiscus.)

bb) gepanzerte

ร. Fam. Closterina.

(Closterium.)

2) Körperform wechselnd

a) panzerlose

6. Fam. Astasiaea.

(Astasia. Amblyophis. Euglena. Chlorogonium. Colacium. Distigma.)

b) gepanzerte

7. Fam. Dinobryina.

Epipyxis. Dinobryon.)

B. Wechselfiissige. Pseudopoda

1) panzerlose

8. Fam. A mo ebaea.

(A moeba.) 
2) gepanzerte

a) vietheiliger Fuss aus einzelner Oeffnung

b) einfacher Fuss aus einzelner oder jeder einzelnen Oeflinung

C. Behaarte. Epitricha

1) panzerlose

2) gepanzerte
9. Fall. Arcellina.

(Difflugia. Arcella. Cyphiclium.)

10. Fam. Bacillaria.

(Hierher die Gruppen Desmidiacea, Naviculacea, Echinellea, Lacernata und anhangsweise die Gatlung Acineta.)

11. Fant. Cyclidina.

(Cycliclium. Pantotrichum. Chaetomonas.)

12. Fant. Perilinaea.

(Chaetotyphla. Chaetoglena. Peridinium. Glenodinium.

\section{Enterodela.}

A. Einmündige. Anopistlia

1) panzellose

2) gepanzerte

B. Gegenmiindige. Enantiotreta

1) panzerlose

2) gepanzerte

C. Wechselmindige. Allotreta

1) panzerlose

a) mit von einem Riissel uluerragtem Munde ohwe Schwanz

b) mit vorderem Munde und schwanzarligem Bauchende

\section{2) gepanzerte}

D. Bauchmindige. Catotrela

1) panzerlose
a) nur nit Wimprern bewegt

13. Fam. Vorticellina.

(Stentor. Trichodiua. Urocentrum. Vorlicella. Carchesium. Epistylis. Opercularia. Zoothamnium.

14. Fam. Ophrydina.

(Ophrydium. Tintinnus. Vaginicola. Cothuruia.)

15. Fam. Enchelia.

Enchelys. Disoma. Actinophrys. Trichodiscus. Podophrya. Trichoda. Lacrymaria, Leucophrys. Itolophrya. Prorodon.)

16. Fam. Colepina.

(Coleps.

17. Fam. Trachelina.

(Trichelius. Loxodes. Bursaria, Spirostomum. Phialina. Glaucoma. Chilodon. Nassula.)

18. Faus. Oplugncerciua.

T'rachelocerci.

19. Faun. Aspidiscina.

Aspidisca.)

20. Farm. Colpodea.

Colpoda. Paranaecium. Amplileptus. Urolepus. Ophryoglena.) 
b mit mehrfachen Bewegungsorganen

2) gepanzerte
21. Fam. Oxylrichina.

(Oxylricha. Ceralidium. Kerona. Urosiyla. Stylonychia.)

(Discocephalus. Himantophorus. Chlamydodon. Euplotes.)

Ich habe bereits oben (S. 12) die Gründe entwickelı, welche sich ter Annahme von Ehrenberg's Eintheilungsprincipien entgegenstellen; hier will ich nur noch in Allgemeinen bemerken, dass ich anch in der Mehrzahl seiner Fanilien keine naturlichen Gruppen zu erkennen vermag. Sie werden theils wesenlich anders begranzt, theils głanzlich aufgelöst werden müssen. Aus der Gatlung Acineta und einer erst wảhrend des Druckes des grossen Infusorienwerkes entdeckten neuen Gattung, Dentrosoma, bildete Ehrenberg nachtriglich S. 316 cine eigene, zwvischen Bacillarien und Vorticellinen einzureihende Familie, die Acinetina, zu der er auch die Gattungen Podophrya und Trichodiscus aus der Familie der Enchelien zu stellen geneigt ist. Die Zahl der Magenllierfamilien im grossen Infusorienwerk belrigt demnach 23, nicht 22, wie gewöhnlich angegeben wird.

Nach dem Alsschluss des grossen Infusorienwerkes war Ehrenberg's Thätigkeil fast ausschliesslich auf die Erforschung der fossilen, so wie der im almosphïrischen Staube, in besonderen Staubmeteoren, in Fluss- und Meeresabsätzen und in der Dammerde enthaltenen miliroscopischen Organismen und organischen Beimengungen gerichtel, woriber die Monatsherichte und Denkschriften der Berliner Acadenic bis auf dic neueste Zeit zahlreiche Abhandlungen enthalten. Friichte dieser sehr umfangreichen und mühseligen Forschungen waren die schrift: "Passatslaub und Blutregen, ein grosses organisches unsichıbares Wirken und Leben. Mit 6 Kpftafl. Leipzig 1849 " und ein zweites grosses Prachtwerk: nMikrogeologie; das Erden und Felsen schaffende Wirken des unsichtbar kleinen selbststandigen Lebens auf der Erde. Mit 41 Kupfertafeln. Leipzig 1834."Fur uns haben jedoch nur diejenigen neuern Arbeiten Ehrenberg's, welche sich auf die lebenden Infusionsthiere, nach Ausschluss der Bacillarien und anderer fremdartigen Formen beziehen, Interesse, und deren Zahl ist sehr gering.

Im Jahre 1839 entdeckte Ehrenberg in der Nordsee bei Kuxharen eine neue Galtung, Dinophysis, die anfangs zur Familie der Ophrydinen, später zu der der Peridinaen gestellt wurde ${ }^{\mathbf{1}}$. In J. IS40 wurden einige 30 wahre Hagenthiere, die grösstentheils in der Nord- und Ostsee eutdecht wurden und sämmtlich bekannten Gattungen angehören, mit zahlreichen neuen Bacillarienformen und einigen neuen Raderthieren characterisirt 2 ). Im folgenden Jahre legte Ehrenberg der Academie zur Besläligung aller seiner Anschaumgen über die Infusorienorganisation die als selı genan gerihmten Abbildungen der von Dr. Werneck bei Salzburg beobachtelen Infusionsthiere vor. bei welcher Gelegenheit füf nene, von Werneck unterschiedene Magenthiergattungen (Callia, Eretes, Ancyrium, Stephanoma und Dicella) characterisirt wurden ${ }^{3}$ ). Im J. 184.8 wurde eine nene Familie, Hydromorina, anfgestell, welche sich einerseils an die Monadinen, andrerseits an die Volvocinen anschliesst Mit den letzteren hat sie anfangs die unvollkommene Selbsthbeilmog gemein, zuletzt aber zerfallt der Honadenstock in einzelne monadenähnliche Individuen. Die neue Familie wird ron der friiher zu den Monadinen gestellten Gattung Polytoma und der neuen. in Berliner Feuerkibeln entdechten Gattung Spondylomorum gebildet. Die Ilagenthiere unfassen demuach nun 24. Familien. Für die ausseheidende Galtung Polytoma erhielt die Familie der Mlonatinen eine nene, in rler Gesellschaft von Spondylomorum aufgefundene Galtung Chloraster ${ }^{4}$ ). Auch die Familie der Yolvocinen wurde noch durch die neue Gattung Trochogonimm bereichert 5 ).

1) Monatsberichte der Berliner Academie von $1839 \mathrm{~S} .157$, und Abhandlungen der Berliner Academie aus den Jahre 1839 S. 124. Ich beobachtete die Gattung Dinophysis bei Wismar in der Ostsee und fand, dass sie meiner Gattung Spirochona am uichsteı verwandt ist.

2) Monatsberichte von 1840 S. $198-219$.

3) Monatsberichle von 184 S. $102-10$ und S. 373-77. Die Galtungscharactere finden sich S. 377.

4) Monatsberichte von 1848 S. $233-37$.

5) Ilaude- und Spener'sche Zeitung rom 28. April 18 \&6 (vergl. auch die Zeitschift lür wissenschaft. Zoologıe Band IY. S. 8;. 
Von Interesse sind ferner Ehrenberg's Nitheilungen iber die durch Luftströmungen aus den Gewissern gehobenen, und auf den verschiedensten Gegenstanden, auf Dicherı, Mauern, Felsen, Bäumen und namentlich in Baummoosen mit Sand und Staub wieder abgesetzten mikroscopischen Organismen, die sehr schnell wieder zu voller Lebensenergie erwachten, wenn die erdigen oder staubigen Massen, worin sie sich fanden, mit Wasser itbergossen wurlen, welches zuvor abgekocht worden war, um jede Spur von Leben in ilın zu tödten. Unter den in Baummoosen lebendig bleibenden achten Infusionsthieren fanden sich einige neue Arlen: Bursaria arborum, B. triquetra, Cyclidium arjorum und Trachelius dendropluilus ${ }^{1}$ ). - Mit grossem Eifer verfolgte Ehrenberg gleichzeitig das seit alter Zeit beriihnte und vom Aberglauben in entsetzlicher Weise ausgebeutete blutige Plıänornen auf Brod und auf anderen Speisen, als dessen Urheber ein sehr kleines monadenartiges Thier, die Purpurmonade (Monas prodigiosa) erkannt wurde ${ }^{2}$. - Endlich wurden 1853 noch einige neue Infusorienarten, darunter dic oben erwahnten, in Baummoosen lebenden, characterisirt und die Familie der Trachelinen um eine neue Gattung, Liosiphon, bereichert $\left.{ }^{3}\right)$.

In vielen der seit 1838 veröffentlichten Abhandlungen Ehrenberg's finden sich gelegentliche Bemerkungen cingewebt, aus denen zu ersehen ist, dass an allen in den frühern Arbeiten entwickelten Ansichten über die Infusorienorganisation mit unerschütterlicher Consequenz festgehalten und auch nicht die leiseste Modification derselben gestattet wirl. Nene Thatsachen zur bessern Begriindung dieser Ansichten werden jedoch nirgends vorgebracht. Die zihlreichen, von den verschiedensten Seiten her erhobenen und auf die zuverbissigsten Thatsachen gegründeten Einwiirfe gegen Ehrenberg's Lehren finden keine eingehende Wiirdigung, sondern es wird darauf oft nur mit herben Urtheilen geantwortet und schliesslich immer wieder auf das grosse Infusorienwerk von 1838 zurïckverwiesen, als ob darin die gesammten Organisationsverhältnisse der Infusorien für alle Zciten endgiiltig festgestellt seien. Dies gill namentlich von der durch und durch polemischen Abhandlung: „Ueber die nenesten die Formbeståndigkeit und den Entwickelungskreis der Fornen betreffenden Bewegungen in den organischen Naturwissenschaften " $\left.{ }^{4}\right)$.

Ehrenbery's Lehren finden hereits seit dem Jahre 1835 in Frankreich an Felix Dujardin einen entschiedenen Gegner. Dieser Forscher hatte die sehr wichtige Entdeckung gemacht, dass die lieinen, im Sande der Meereskïsten so verbreiteten, vichammerigen Kalkschalen, welche von den allern Zoologen mil den Nautilaceen rereinigt und Polyllatamien genamt, von l'Orbigmy aber unter dem Namen der Foraminiferen als eine besondere Ahtheilung der cephaloporlen Mollusken betachtet wurden, keineswegs von einem Cephalopoden herrührten, sondern das Product von viel einfacher organisirten Thieren seien, aus denen eine eigene, den Infusorien am nächsten stehende Thierklasse guhildet werden misse ${ }^{5}$. Die ron Dujardin in Nittelmeer lebend beobachteten Polythalamien (Hiliolen, Vorticialen, Rolalinen, Truncatulinen, Helonien und Cristellarien) zeigten einen ganz innerlichen, die Kanmern der Schale ausfüllenden, sehr weichen und homogenen, feinkörnigen, thierischen Korper, aus so vielen, durch Commissuren mit einander zusammenhingenden Segmenten oder Lappen bestehend, als die Schate Kammern besitz. Von gesonderten innern, der Emahrung und Forfpllanzung vorstehenden Organen, von Muskeln unt Nerven war keine Spur aufzufinden, die gesammte homogene Körpersubstauz erwies sich aber ausserortentlich empfindlich und contractil. Sie besitzt die Fahigkeit, sich in ausserst feine, fadenförmige, als Bewegungsorgane

1) Monatsberichle von 1 \$4 S. $325-45$ und S. $370-81$ und Monatsberichte von 1849 S. $91-98$.

2) Monalsherichte von 1848 S. 349 -62. Monalsb. von 1849 S. 101 -16 und Monatsb. von 1850 S. 5 und S. 215.

3) Monatsbericiste von $18: 33$ S. $183-94$.

4) Monatsherichle yon $18: 3$ S. 761 . Diese Abhandlung erschien auch für sich unter dem Titel: Ueber die Formbeständigheit und den Enwickelungshreis der organischen Formen. Rerlin 1832.

5) Ammles des sciences naturelles 1830. 11. Série jome Ill p. $108-9$ und p. $312-14$ und Tome IV p. $343-52$. Recherehes sur les organismes inférieurs. 
dienende Fortsatze auszudehnen, welche durch eine Muıdung in der vordersten Kammer oder durch zahlreiche Poren in den Wandungen der Schale naclı aussen hervortreten, sich nach allen Richtungen hin lastend ausbreiten und vielfach wiederholt dichotomisch verästeln. So lange sich die Faden verlängern, strönt unaufhörlich körnige Substanzmasse aus dem Körper nach den Spizen der Fäden, die wieder zurüchfliesst, weun sieh die Fảden zu verküurzen anfangen. Stossen benachıarte Fäden mit ihren Aesten aul einander, so können dieselben streckenweis vollständig mil einander verfliessen. Ilittelst dieser wurzelähnlichen Fortsitze, die wieder spurlos in die allgemeine Körpersubstanz zurückgezogen werden können, heften sich die Thiere an fremden Gegensländen fest, und indem sie ahwechselnd die einen fixiren, die andern weiter vorwarts schiehen, bewegen sie sich sehr langsam hriechend weiter.

Gleichzeitig mit den genannten Polythalamien hatte Dujardin im Mittelmeer eine Thierform entdeckt (er nannte sie Gromia oviformis), welche rücksichtlich ihrer Körperbeschaffenheit und ibrer wurzelarligen Bewegungsorgane ganz usd gar mit den Polythalamien ubereinstimmte, allein sie wurde nur von einem einfachen, ovalen, pergamentartigen Gehåuse umschlossen, welches am vordern, halsartig verengerten und grad abgestulzten Ende mil einer weiten Mundung zum Austritt seh. ästiger Pseudopodien versehen war. Da diese einlianmerige For'm unmöglich von den viclkammerigen getrennt werden konnte, der Name Polythalanje aher auf sie eben so wenig anwendbar war, als die Bezeichnung Foraminifere, so nannte Dujardin fortan den Verein dieser Formen nach den so characteristischen Bewegungsorganen Rhizopoden ${ }^{1}$ ). So innig sich die Gattung Gromia an die Polythalamien anschliessı, in ebenso unverkenbbar naher Verwandtschaft steht sie zu den beiden Ehrenberg'schen Magenthierfamilien der Amöbäen und Arcellinen. Dujadim mahm daher auch keinen Anstand, diese ebenfalls den Rhizopoden zuzugesellen. Ein genaneres Studium verschiedener Amöbaarten 2 ), mil welchen aber irriger Weise auch ein gregarinenartiger Parasit des Regenwurms ${ }^{3}$ ) zusammengeworfen wurde, führte ihn zu der Ueberzeugung, dass der Körper dieser Thiere aus derselben homogenen, structur- und organlosen Substanz bestehe und auf dieselbe Weise Pseudopodien bilde, wie bei den Gromien und Polythalamien, und dass mithin die Amöbaien nichts weiter, als schalenlose Rhizopoden sejen.

Nachdem Dujardin diesen gliicklichen Griff in die Magenthiere hinein gethan batte, liess er sich leider verleiten, auch den ührigen Magenthieren, ohne sie genügend untersucht zu haben, eine ebenso einfache Organisation zuzuschreiben, wie sie sich ihm für die Rhizopoden ergeben hatte. Er sjurach den Magenthieren nicht blos den ihnen ron Ehrenberg beigelegten polygastrischen Ernährungsapparat, sondern auch allen ohne Ausmahme den Mlund und eine Auswurfsöffnung $a b^{4}$ ). Was man als Mund bezeichnet habe, sei eine blosse Vertiefung, aus der langere Wimpern hervorgestreckt würden ${ }^{5}$; das Auswerfen von Excrementen durch einen After beruhe auf einer Tauschung, die dadurch veranlasst würde, dass die von den Wimpern zu beiden Seiten des Thieres in dem Wasser erregten Strömungen am hintern Ende zusamment’åfen, wo sich dann leicht fremde, der Strömung entzogene und durch Schlein vereinigte Körperchen vorfinden hönnten, die den Schcin von Excrementen hervorbrächten ${ }^{6}$ ). Das von Ehrenberg bei Chilodon, Nassula und Prorodon entdecte fischreusenförmige Zahngestell stehe nicht mit einem Munde in Verbindung, sondern entspreche den bei Polypen und Quallèn in der Körpersubslanz eingebettelen Horngebilden (offenhar meinte Dujardin hiermit die Nesselkapseln ${ }^{7}$. Die Bacillarien und Navieulen, welche man häufig im Innern

1) A. a. O. Tome III p. 314 .

2) A. a. O. Tome IV p. $352-64$.

3) Dujardin wollse in demselben den Proteus lenax ron O. F. Müller (Animal. infus. Taf. II Fig. 13-18) erkennen, lelzlerer lebt aber frei im Wasser und isl eine wahre Amoeba. Das von Dujardin a. a. O. Taf. 10 Fig. A. B. C. als Proteus tenax abgebildete Thier isl Monocystis agilis Stein (verg]. meine Abhandlung über die Nalur der Gregarineen in Mäller's Archiv 1848 P. $182-223$ und Taf. IX Fig. 1-3).

4) A. a. O. Tome IV P. $364 \cdot-76$.

5) p. 367 . Anmerkung.

6) p. 374

7) p. 373 . 
der Infusorien treffe, seien zufïlig, in Folge ihrer eigenen Bewegung, in die sehr weiche, nachgiebige Körpeısuhstanz eingedrungen ${ }^{1}$ ).

Die Aufnalıme von Farbstoffen in innere blasenförmige Riume der Magenthiere sucht Dujardin aus der eigenthümlichen Beschaffenheit ihrer Körpersubstanz zu erklären. Lir nennt dieselhe Sarcode ${ }^{2}$. Sie soll bei allen niederen Thieren sehr verbreitet sein und sich hier zwischen den ührigen Gewebselementen eingeschohen finden, bei den Infusorien aber die wichtigste Rolle spielen. Die Sarcode wird als durchsichtige, glutiuöse, im Wassel unlösliche Substanz characterisirt, welche sich in kugelige Massen zusammenziehe, sich an die Secirnadeln hefte und wie Schleim ausziehien lasse. Im Wasser zersetze sie sich allmählig unler Verringerung ihres Volumens, bis zuletzt nur ein geringes lörniges Residuum ührig bleibe. Als die auffallendste Eigenschaft der Sarcorle wird herrorgehoben, dass sich in ihrer Masse von selbst kleine, von der umgebenden Fliissigkeit erfüllte, rundliche Ilöhlungen (Vacuolen) hildeten, welche sich allmählig vergrösserten, und die Zersetzung der Kügelchen dlieser Substanz beschleunigten, von denen bald nur nocl eine Art Gitterwerk und zuletzt ein geringes Residuum zur'ickbleibe. Wenn man lnfusorien mit kreuzweiser Streifung der Oberfläche, welche also eine netzförmig durchbrochene Körperbedeckung lıätten, z, B. Paramaecium aurelia, Kolpoda cucullus, mit einem Deckglase fixire oder Ammoniakdiunsten aussetze, so trete bei ihrem almähligen Absterben die Sarcode in Form von Kugeln über die Körperaberfläche hervor, welche sich oft ğanzlich abtremnten und lisweilen mut Vacuolen erfüllten. Infusorien mit glatter Oberfläche, wie die Keronen (Stylonychia Ehbg.), rundeten sich dagegen bei derselben Behandlung ab und umgtiben sich mit einer mehr oder weniger unregelmässigen, weithin sich ausbreitenden Sarcodehülle, in der ebenfalls früher odler später Vacuolen erschienen ${ }^{3}$.

In (len Magenblasen Ehrenberg's erkennt nun Drjarlin nichts weiter als blosse mit Wasser erfüllte Vacuolen in der sarcodigen Korpersubstanz, deren scluarfe Contouren dalıer rührten, dass die Sarcode in der unnittelbaren Ungebung der Vacuolen stärker zusammengeschoben sei. Wirkliche, von eigenen Membranen begränzte Blasen könnten sich nicht so bedeutend und fast plötzlich zusammenzichen, ohne dass man die Dicke und Falıngen der Membran und den Kanal, durch welchen ihnen Flüssigkeit zugeführt werden solle, sähe; auch wärden sie nicht abwechsehnd und auf eine so variabele Weise mit Flüssigkeit erfült werden, wenn sie diese von einem verảstelten Darmkanal erhielten. Am entschiedensten werde aber die Annahme, dass die Magenblasen von eigenen Wandungen begranzt seien, datureh widerlegt, dass man benachbarte Magenblasen, die bei der Ausdelınung auf einander stiessen, allmählig vollständig in eine verschmelzen săhe. Die Aufnahme von Farbstoffen in den Infusorienkörper lindet nach Dujardin lediglich durch die Maschen der Körperbedeckung und die sich unmiltelbar unter der Oberfläche bildenden Vacuolen statt; das umgebende Wasser mit den in ilm suspendirten Farljpartikelchen dringe ummittelbar in den so entstehenden leeren Raum, worauf sich die Vacuole zusammenziehe, das Wasser austreibe und die Farbpartikelchen zurichlıalte. Je öfter sich die Vacuole abwechselnd ausdehne und zusammenziehe, um so grösser werde der Farbstoffballen. Die contractilen Samenblasen Ehrenberg's wirft Dujardin mit den Magenblasen zusammen ${ }^{4}$, und auf die Samendruse geht er gar nicht ein.

Diese abenteuerliche Darstellung der Infusorienorganisation bildete den bereits von Elhenberg vorliegenden klaren und unzweideuligen Beobachtungen gegenüber einen offenbaren liückschritt in die Zeilen $\boldsymbol{O}$. F. Mr̈ller's, und sie musste nothwendig Misstrauen gegen das Beobachtungstalent ihres Urhehers erregren. Dies fühlte Dujardin auch selbst. und deshalh trat er schon im folgenden Jahre mit einer Reihe von Beobachtungen ibber die geisselartigen Bewegungsorgane einiger der einfachsten und lileinsten Infusorienformen hervor ${ }^{5}$ ), um zu zeigen, dass er mit seinen

1) p. 375

2) p. $367-68$.

3) 1).369-70. Diese Ausscheidung der Sarcode wird speciell an Leucophra nodulata Pl. 11. Fig. I. 1-6 erläulerı.

4) P. 372 .

5) Aunal. des, scienc. Iulur. II Sér. $18: 36$. Tome V. p. 193-205 und Pl. 9. Recherches sur les organismes inférieurs. No. JV. 
Mikroscopen sehr feine Organisationsverhälnisse zu ermitteh im slande gewesen sei, die Ehreuberg in seinen ersten Arbeiten, in denen grade der polygastrische Ernahirungsapparat am bestimmtesten angegeben sei, gar nicht oder doeh nicht richlig dargestelt habe. Er will daraus folgern, dass es nieht an ihm und seinem Mikroscope liege, wenn er bei den Magenthieren keinen polygastrischen Ernäırungsapparat anfzufinden vermöge. Uebrigens rabumt Dujurtin jetzl schon ein, bei Colpoda und Nassula einen Mund und das Verschluclien von Nahırungsstoffen gesehen zu haben. Es werden sodann die geisselartigen Bewegungsorgane von Euglena longicauda und einer andern zu der nenen Galtung Crumenula emobenen Euglena und von verschiedenen Monaden dargestellı und zwar als sehr lange und iiberaus feine Fäden, und es wird mit Recht bemerkl, dass Ehrenberg diese Organe, wo er sie angab, zu kurz und zu dick darstelle. Auch wird die Ehrenberg'sehe Bezeichnung derselben als Russel getadelt. Dujardin macht ferner auf die grosse Verwandtschaft zwischen den geisselartigen Bew egungsorganen und den sclu zarten Pseudoporlien seiner neuen Rhizopodengattung Trinema (Difflugia enchelys Ehbq.) aulmerlisan, so wie anch anf das Vorkonmen mehrerer langen geisselihnlichen Fortsätze bei einem bewimperten Infusionsthier, aus dem er die neue Gatlung Pleuronema bildet (es war Paramaecium chrysalis Ehbg.)

In Jahre 1837 euthlectste Dujardin die zwei ersten monadenartigen Infusorien mit doppelten Geisseln ${ }^{\text {}}$, auch beschrieb er eine neue Gromia des süssen Wassers (Gr. fluviatilis), die genau dieselben Charactere zeigh, wie die friber entdeelte Meeresform. Gleichzeitig erlauterte er den Bau einer wenen Difflugia des süssen Wassers (D. globosa) $)^{2}$. Die von diesen beiden Formen gegebenen Daistellungen setzten es vollends ansser Zweifel, dass Ehrewberg's Amöbäen und Arcellinen den Rhizopoden zuzuzahlen seien. Ehremberg hat dies freilich nie zugeben wollen; er erklatle im grossen Infusorienwerk S. 133-36, dass, wenn die Polythalamien wirklich den ihnen von IMjardin zugesehriebenen Bau hätten, so wïrden sie zu den Magenthieren zu bringen und vielleicht in besondern Familien den Amöbăen und Arcellinen anzureihen sein, deren plyysiologisehen Claracter (d. h. den polygastrischen Ermahıungsorganismus) Dujardin nicht erkannt habe, weil er offenbar seine Untersuehungen nicht vorurtheilslrei und mit einem nicht mehr zeitgemassen Mikroscope angestelth habe. Uebrigens findet Ehreuberg einen starken Gegengrund gegren Dijardin's Ansicht darin, dass die Polythalamien cine Kulhschale besizen, welehe noch bei keinem Infusionshiere ljeobachtet sei, wohl aber bei den Bryozoen, welchen Ehrenberg die Polythalamien zugesellı wissen will. Da nun aber bei ganz nahe verwandten Bryozoengattungen die Zellen bald kalkig, bahl hornig sind, so ist gal nicht einzuselıen, warum nicht auch in der Abtheihung der Rhizopoden neben kalkschaligen Gattungen zugleich solehe mit horniģen Sclıalen sollten stehen können.

Im Jahre 1840 war Ehrenberg endlich so gliicklich, im Meereswasser von Cuxhaven, welches er scit mehreren Monaten in Berlin aufhewahrte, lebende, in voller Thatigkeit begriffene Polyhakmien aufzulinden umd anhaltend beobachten zu könnem. Es waren dies zwei neue Formen, die als Geoponus stella borealis und als Nonioniua gremanica rerzeichnet wurden ${ }^{3}$. Wer die schönen Abbildungen, welche Ehrenberg von diesen Thieren geliefert hat ${ }^{4}$, unbefangen betrachtel, der wird sich uberzeugen, dass sie in Wesentlichen den Organismus der Polythalamien eben so darstellen, wie ihn Dujardin zuerst erkannt hat, nur treten bei der angewandten viel stärkerı Vergrösserung alle Einzehnheiten, namentlich die Schalenstructur viel klarer hervor, auch sind die gefäbbten Parthieen der Körpersubstanz und in ihr beobachtete Nahrungsstofle angegeben. Vergebens wird man sich aber in den Abbildungen von Nonionina nach den von Ehreuberg angenommenen einfachen, in den Körpersegmenten bis zum Umfang derselben angeschwollenen und in der einfachen Commissur zwischen je zwei Segmenten sehr verengerten, also gegliederten Darmhanal unsehen; man wird ferner nicht begreifen, warum die in den einzelnen Segmenten gelegenen gelben Massen Eierstöcke sein sollen, und noch weniger eiuselıen, weshalb Geoponus, der sich von Nonionina nur durch die mehrfachen Commissuren zwischen den einzelnen Segmenten unterscheidet, einen aus parallel

1) Annal. d. sc. nat. 1837. Tome VIII p. 305-9. - 2) Ebendaselbst 1. 310-12. — 3) Monatsberichte der Berliner Academie von 1840. S. 18-23. - 4) Abhandlungen der Berliıer Academie rom Jahre 1839. Berlin 18:1. S.81-174. "Ueher noch jetzl zahlreich lebende Thieranlen der lireidebildung und den Organismus der Polythalanien." Tal. I und II.

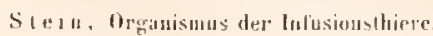


neben cinander liegenden Individuen zusammengesetzten Thicrstock darstellen soll. Wie unhahtbar E/renberg's Ansichten von dem imneren Ban der Polythalamien waren, und wie richtig Dujardin in der Ilauptsache die Rhizopodenorganisation aufgefasst hatte, das lehrten erst 14 Jahre später die an sehr verschiedenen lebenden Rhizopoden des Miltelmeers angestellten höchst sorgfiltigen Untersuchungen von Max Schullze, die in der sehönen Monographic: "Ueber den Organismus der Polythalamien (Foraminferen) nebst Bemerkungen ibber dic Rhizopoden im Allgemeinen. Mit 7 Kupftafln. Leipzig I 854 " niedergelegt sint.

Die groben Fehler, welche Dujardin in seiner ersten Darstellnng der Infusorienorganisation hegangen hatte. suchte er im Jahre 1838, nachdem ilım inzwischen Ehrewberg's grosses Infusorienwerk bekannt geworden war, in einer weillaufigen Abhandlung') zu rerbessern, in der er sich anch mit Schärfe gegen due ilım von Ehrenberg gemachten Vorwürfe vertheidggl. Zunachst wirh die Grundanschannng festgehalten, dass der Körper der Infusorien (von denen die Räderthiere als viel höhere Thierformen, die Bacillarien und Closterinen als vegelabilische Organismen ausgeschlossen werden) aus einer homogenen, glutinösen Substanz olme sichtbare Organe, der Sarcode, bestehe, die an der äussern Oberfliche zu einem Panzer oder zu einem netzförmigen lulegumente erstarren und sich in Wimpern oder fadenförmigge Verlängerungen fortsetzen, im Innern aber verschiedene Arten von Körnern, conıpacte ovale Massen und mit Wasser oder fremden Stoffen erfullte Blasenraiume enthaten lönne. lm Uebrigen wird die Sarcode wie früher geschildert $\left.{ }^{2}\right)$. Sodann wirl die grosse Uebereinstimmung in den Bewegungsorganen der Infusorien betont; von den Pscudopodien der Rhizopoden finde ein ganz allmähliger Uebergang durch die geisselarligen Fiden der monadenarligen Infusorien zu den gewöhulichen Wimpern, Borsten, Grilleln und Krallen der hölıern Infusorienformen statt; alle diese Organe sejen völlig homogene Fortsălze der Körpersubstanz und autonom. nie durch Muskeln bewegt ${ }^{3}$ ).

Den meisten bewimperten Infusorien gesteht Dujardin jetzt einen wirklichen, bisweilen von stabförmigen Zähnen umgebenen Mund zu, bestreitet denselben aher bei allen nackten Infusorjen (Monadinen, Vibrionien, Eugleninen, Amöbäen ete.). Ein eigentlicher After scheint ihm nirgends vorhanden zu sein, sondern die Auslecrung von Excrementen soll nur durch eine zuftilige Oeffinung erfolgen, welche sich mehrmals nach einander in lerselben Gegend, doch nicht genau an demselhen Puncte des Körpers bilden könme ${ }^{4}$. Die Ansicht. dass Ehrenberg's Magenblasen nur Vacuolen in der Körpermasse seien, wird aufrecht erhalten und ihre Bildung folgendermaassen erkiär'. Der durch das Wimperspicl in den Ilund getriebene Flissigkeitsstrom stosse unaufhörlich gegen die den Grund des Mundes cinnehmende, nachgiebige innere Körpersubstanz und lıöhle diese ersl zu einem Sack, dann zu cinem immer länger werdenden, blind endigenden Kanal aus. Die nur von der innem nachgieligen Körpersubstanz gebildeten Wandungen dieses Kanales strebten unaulhörlich, sicl wieder mit einander zu vereinigen, sie näherten sich allmählig in der Nitte des Kanals und zuletzt werde der ganze hintere Abschnitt desselben abgeselunür, der nun dic Form einer mit Flussigkeit und fremden Körpern erfülten Blase annehme. Die sichıliche Fortbewegung ejner solchen blasenartigen Vacuole durch den Körper beweise rollends, dass von enem Zusammenhange derselhen mit einem Darmkanale nicht die Rede scin könne ${ }^{5}$. Bei den mundlosen hıfusorien mit weichem Körper, z. B. bei den Monaden und auch bei den Amöbizen làsst Dujardiu feste und flüssige Nahırungsstolle ron der ganzen Oberfliche auf die fruher son ihm für alle Infusorien angenommene Weise aufgenommen werden, während die staren mundlosen Formen, wie die Cryptomonadinen und Volvocinen, so wie auch die Euglenen nur gelöste Stoffe durch die Haut aufsaugen sollen 6 .

Schliesslich unterwirf Dujurlim Ehrenberg's Answchten von dem doppelten Geschlechte der Infusorjen eines cingehenden hirik ${ }^{7}$ ) und liommt zu dem Resultate, dass dieselben durch und durch mhalthar sejen. Er habe zwar anch bei einer grossen Anzahl von lnfusorien die sogenannten Samendrisen beobachtet, aber er wisse weder ilnen, noch den verschieclenen von Ehrmberg für Eier gehaltenen Körnern eine bestimmte Function heizulegen.

1) Mémoire sur l'organisation des Infusoires. Annal. des sc. nal. II. Sér. 1838. Tome X p. $230-315$ und Til. 14 und 13. 9) P. $247-60 .-$ 3) p. $260-67$ - 4) P. $267-72 .-$ 3) p. $286-87 .-6)$ p. $283-84 .-7)$ p. 289-308. 
Sicher sei nur, dass sieh die meisten Infusorien dureh Theilung, einge auch durch Kunospenbildung vermehrten. Die contracliten Blasen hatt Dujardin für nahe unter der Olierflache gelegene, mit Wasser erfiille Vacuolen, welche abwechselnd Wasser aus der Aussenwelt aufnehmen und es dann wieder ausstossen, sie seien demnach wohl nach (lem Vorgange von Spallunzami als Respinationsorgane zu betrachten ${ }^{1}$ ). Dass den lufusorien endlieh Augen, Nerven und Iblutgefasse abgesprochen werden, ist sellsstverstindlich.

Von dem Standpuncte aus, den die eben analysirte Abhandhung einnimmt, hearbeitete Dujardin sein belianntes, einen Theil der Suites de Bulfon bildendes Handbuch der lnfusorienkunde: "Histoire nalurelle des Zoopliyles. Infusoires, comprenant la pliysiologie el la classification de ces animaux. Ouvage accompagné de 22 planches. Paris 1841." Die in demselhen auf p. 26-114. gegebene allgemeine Schiklerung der Infusorienorganisation ist ein wörtlicher Abdruck der Abhandlung in den Annales des se. nal. Tome X von 1\%.24.7-312. Der speeielle Theil fusst aberall auf Ehemberg und O.F. Müller; er enthall zwar anch viele eigene Beobachlungen, diese hleiben aber un Selıärfe und Genaugheit meist weit hinter denen von Ehrenborg zurïck. Es werden manehe nene Formen geschildert und verschiedene Gallungen nalurgemasser begränzt oder ueu begrundel, nicht selten aber auch bereits klar auseinandergesetzle Formen wieder verwirt. In positiver Richlung wird weder dic Organisation, noeh die Entwiekelungsgesehichte der Infusionsthiere un einen wesentliehen Schrill vorwảıts ggebracht.

Wahrend Dujardin in seinen ersten Abhandlungen die Rhizoporlen als eine besonlere Klasse des Thierreiehes betraehtet, führt er dieselben in seinem Itandbuche nur als eine für sich bestehende Ordnung der Infusionsthiere anf. Zu den letztern rechnet er ausserden alle Ehenbug'sehen Magenthiere mil Ausnahme der Bacillarien und Closterinen. und seltsimer Weise auch noch die zwei von Ehrenberg mit den Räderlhieren vereinigten Gattungen Chactonotus und Jehthydium. Diese entfernen sich allevlings, wie neuerlieh $\boldsymbol{M}$. Schultze näher nachgewiesen hat $\left.{ }^{2}\right)$, sehr erheblich von den übrigen Raderthieren, aber mit den Infusionsthieren liönnen sie sehon wegen des abgeschlossenen Darmlianals und der entwichelten Geschlechtsorgane unmöglieh verbunden werden; wahrscheinlich gehören sie zu den Turbellarien. Noeh wunderlicher aber ist es, dass Dujurdin aus jenen beiden Gattungen und der Ehrenberg'schen Magenthiergatung Coleps. so wie aus einer ganz untlaren, Planariola genannten Form, die nur ein Fragment von einem höheren Thiere zn sein scheint, eine eigene Iauplabtheilung seines lnfusoriensystemes bildet, die er nsymmetrische Infusorien nennt, während er alle übrigen Infusorien als munsymmetrische» liezeiehnet und zu einer zweiten Hauptahuheilung vereinigl. Soll Coleps ein symmetrisehes Infusionsthier sein, dann muss man auch alle andern Infusorien, welche den Mund am vordern Ende in der Längsaxe zu liegen haben, z. B. Prorodon, Holophrya, Lacrymaria, Enehelys etc. für symmetrische erklären

Im Uebrigen hat Dujardin's System ${ }^{3}$ ) das Verdienstliche, zuerst die Bewegungsorgane, also itussere, unzweideutige und im Allgemeinen leicht zu beobachtende Körpertheile, die auch die meisten und auflillendsten Verschiedenheiten darbieten, znm Haupteintheihngsprincip der Infusorien erhoben zu baben. Leider kannte Dujardin diese Versehiedenheiten im Einzelnen nur zu wenig genau, um eine griichliche Anwendung von scinem Eintheilungsprineipe machen zu können. Er sondert die asymmetrisehen Infusorien in fünf Ordnungen, die jedoch keine besonderen Namen erhalıen haben. Die Mitglietler der ersten Ordnung, welehe nur die Familie der Vibrioniden unfasst, besitzen keine sichtbaren Bewegungsorgane. Die zweite Ordnung begreift die dureh ihre veränderlichen Körperfortsălze (Pseudopodien) ausgezeichneten Rhizopoden, mit denen jetzl auch die Aeinetinen Elrenberg's vereinigl werden. Sie sind in drei sebr ungleiche Familien: Amibiens, Rhizopodes (Polylhalamien und Arcellinen) und Actinophryens (Actinophrys, Triehodiscus, Podophrya, Acineta und Dendrosoma) gesondert. Die dritte Ordnung unfasst alle Infusorien mit greisselartigen Bewegungsorganen; sie bestcht aus den sechs Familien: Monadiens, Volvociens, Dinobryens, Theeamonadiens, Eugléniens und Peridiniens. Die Thecamonadiens entsprechen den Cryptomonadinen, die Eugléniens den Aslasiłen Ehrenbery's, eine Aenderung der Familiennamen war daher unnöthig; die übrigen

1) P. 305. - 2) „Ueber Chaelonotus und Ichthydium und eine neue verwandte Gatlung Turbanella in Mïllcr's Archiv 1853. S. $241-34 .-3)$ A. a. 0. p. $126-27$. 
Familien sind ehenfalls ganz ăbulich begranzt, wie die gleichnamigen Familien Ehrenberg's. In Dujardin's vierter und füfter Ordnung endlich sind alle bewimperten Infusorien enthalten, und zwar soll die vierte Ordnung die Formen ohne contractile Körperbedeckung. oller, was für gleichbedeutend gehalten wird, die Formen ohne regelmissig reihige Anordnung der Wimpern hegreifen. Sie wird aus den fünf Familien: Enchélyens, Trielıdiens, Keroniens. Ploesconiens und Erviliens zusammengesetzt; von diesen entsprechen die Keroniens den 0xytrichinen. die Ploesconiens den Euploten und Aspidiscinen Ehrenberg's. Die kleine Familie der Erriliens schliesst sich innig an die Euploten an, ihre bekannteste Form ist bei Ehemberg nur eine Species der Gatlung Euplotes. Die Enchélyens dagegen enthatten ganz andere Thiere. als die gleichnamige Familie Ehrenberg's, und zwar nur selır ungenügend beobach1ete, grösstentheils sich nahe an Cyelidinn glancoma Ehbg. anschliessende Formen. Die Fanilie der Trichodiens ist hauptsảchlich aus einigen Ehrenberg'schen Trachelien und Amplilepten (A. anser und margaritifer) und aus Loxodes rostrum Ehbg. gebildet.

Die fünfte Ordnung unfasst die bewimperten Infusorien mit lockerer, netzförmiger, contractiler Körperbedeckung, welche stets an der regelmassig reihigen Stellıng der Wimpern oder deren Anordnung im Quincunx, so wie an Granulationen und Iöckerchen der Oberfläche zu erkennen scin soll. Sie bestcht ebenfalls aus fünf Familien: den Leucophryens, Paraméciens, Bursariens, Urceolariens und Vorticelliens. Die Familie der Leucophryens ist auf Infusorien gegrindet, die grösstentheils zu der von Purkinje und Valentin ') im Jahre 1830 unterschiedenen Gattung Opalina gehören. Die Familie Paraméciens ist hauptsichlich aus Mlitgliedern der Ehrenberg'schen Enchelien (Lacrymaria, Holophrya, Prorodon), Trachelinen (Glaucoma, Chilodon, Nassula) unıl Kolpodeen (Kolpoda. Paramaecium und Amphileptus) zusammengesetzt. Die Bursariens begreifen die meisten Arten der Gattung Bursaria, die Gattungen Ophryoglena und Spirostomum und einige verwandte Formen. Die Familie Urceolariens besteht aus den Ehrenberg'schen Gattungen Stentor, Trichodina, Ophrydium und Lrocentrum. Die Vorticelliens endlich umfassen die Ehrenberg'schen Galtungen Vorticella, Carchesium, Zoothannium, Epistỵlis, Opercularia, Vaginicola und Cothurnia. Hierauf folgen sclıliesslich in einer zweiten Hauptabtheilung, und gewissermaassen eine sechste Ordnung des Systems bildend, die symmetrischen Infusorien mit ihren vier Gallungen Coleps, Planariola, Chactonotus und Ichthydium. Anhangsweise hat Dujardin auch eine gedrangte Uebersicht der Naturgeschichte der Riderthiere geliefert. die er mit dem ganz ungerechtfertigten und unü̈thigen Namen der Systoliden bezeichnet.

Ein Hauptverdienst der Dujardin'schen Klassilication liegt in der scharfen Sonderung der geisseltragenden von den bewinperten Infusionsthieren; auch werden wir in seinen beiden ersten Ordnungen, abgesehen von der Vereingung stimutlicher Acinetinen mit den Rhizopoden, durchaus natiurliche Gruppen anerkennen müssen. Ob aher liese mit den geisseltragenden und bewimperten Infusorien in derselben Klasse vereinigt werden duirfen, das ist eine Frage, die eine nähere Prufung verlangt hätte. Die beiden Ordnungen, in welche Dujardiu die bewimperten Infusorien zerlegte, sind röllig unnafiirlich und berulıen auf ganz unzurerlassigen Characteren. Es genigg, darauf hin zu weisen, dass die Enchélyens und Trichodiens der vierten Ordnung eben so gut in regelmảssige Reihen geordnete Wimpern besitzen, wie die Nitglieder der funften Ordnung. denen sie sich auch in ihrem Gesanmthabilus anschliessen, und dass der Körper vieler Mitglieder der vierten Ordnung, z. B. von Oxytricha, Urostyla und Trachelius, weit contractiler ist, als der von manchen Mitgliedern der funften Ordnung, z. B. ron Paramaeciun unil Ophryoglena. Eben so wengg können wir in den zehn Familien, in welche Dujardin die bewimperten Infusorien theilt, einen Fortschrit im Vergleich zu Ehrenberg's Eintheilung seiner enterodeten Magenthiere erl,icken, die fast genau den bewimperten Inlusorien entsprechen.

Eben so früh, wie Dujarlin in Frankieich, und ganz unabluangig von ihm, trat in Deutschland W. Foclie gegen den polygastrischen Ernthrungsorganismus der Infusorien auf und zwar zuerst $183 \ddot{3}$ auf der Naturforscherversamnlung in Bonn? ${ }^{2}$, unl dann 18 4.2 auf (ler in Mainz ${ }^{3}$. Dieser Forscher machte die Entdeckung, dass bei

1) Purlinje el Valentin de phenomeno generali el fundamentali molus vibratorii. Vratislaviae 1835. p. 43.59. - 2) Isis von 1836. $\therefore$. 85 87. - 3) Antlicher Berichl über die 20. Versammlung deulscher Nalurforscher und Aerzle in Manz 1842 . p. 227. 
Loxodes bursaria Ehbg., welches Thier er richtiger als Paramaecium bursaria beslimmte, und bei einer Vaginicoli (ohne Zweifel war es V. crystallina) die angeblichen grinen Eihörnchen Ehrenberg's zwischen dem Rande und dem Centrum des Körpers in einer beständig rotirenden Strömung begriffen seien, sie stiegen auf der einen Seite herab und auf der andern wieder hinauf. Die Vaginicola nahm leicht Indigo auf, und nun beschrieben die sich bilkenden blauen Kugeln genau dieselbe Bahı, wie die grinen Körner. Die Rolation der Farbstoffkugeln wurde später auch bei Paramaecium bursaria, aurelia und andern Magenthieren beobachtet und Focke schloss daraus mit Recht, dass diese Erscheinung mit der Annahme eines polygastrischen Damkanales unvertagglich sei. Ehreuberg honnte die Thatsache nicht lăugnen und suchte nun seine Lehre durch Berufungr auf die grosse Contractilität des selır weichen gallertartigen Körpers vieler Infusorien zu vertheidigen ${ }^{1}$ ), die beständige Verschiebungen der innern Theile in ilırer Lage gegen einander bewirke, mithin auch ein Auf- und Abwogen der mit dem Darmkanal zusammenhängenden Ilagenblasen veranlassen könne. "Es ist ein Irrtlum im Uıtheil über das Gesehene grarle in der Art, wie im Scheeren- und Zangenspiel der Kinder, wo die auf netzartig verbundene Scheerenarme gestellten Băunchen oder Thiere beim Bewegen der Scheerenarme ihren Ort selır zu ver:indern scheinen, ohne irgend aus ihrer walıren und festen Stellung weg zu kommen. Dieser Vergleich passt jedoch ganz und gar nicht. denn die Farbstoffballen wogen nicht bald aufwarts, bald abwärts und regellos durch einander, sondern jeder bewegte Ballen durchlăuft von dem Puncte aus, an dem er sich grade befindet, immer erst den ganzen Unfang des Körpers, bevor er wiecler auf denselben Punct zurückliehrt. Auch wird die Rotation der Ballen nicht entfernt durch die Contractilität des Körpers bedingt; denn diese ist grade bei Param. aurelia und bursaria ausscrordentlich gering, und eine genaue Beobachtung der Rotation ist ja ublerhaupt nur hei völlig stillstehenden Thieren möglich.

Derselbe von der Rotation der Nahrungsstoffe bei Param. aurelia gegen die Polygasterie entlehnte Einwurf wurde von Rymer Jones $183 \mathrm{~s}$ in der Versammlung ter britischen Naturforscher in Newcastle, an der Ehrenberg Theil nahm, wieder crhoben ${ }^{2}$. Letzterer entgegnete hieraul', dass grade P. aurelia eine fur Beobachtungen iber den Darmkanal weniger günstige Form sei. Allein sie gehört doch zu den wenigen, beı welchen der ganze Verlauf' des Darmhanals mit den an ilım hinggenden Mlagenblasen abgebildet wurle. Schliesslich stellte Ehrenberg, von der Gewalı der ihm entgegenstehenden Thatsichen gedrängt, die neue Hypothese auf, dass sich zuweilen der Darmkanal der Infusorien auf Kosten der anhängenden Magensilcke so weit ausdehne, dass er die ganze Körperhöhle ausfülle und danı schienen die verschluckten Stofle, welche Magensàcken sehr ähnlich săhen, im ganzen Körper zu circuliren. Die verschluchten Stoffe circuliren aher bei P. aurelia und bursaria unaufhörlich in derselben Richlung. was durch die neue Hypothese auch nicht entfernt erkhart wirl. Rymer Jones bestritt daher auch fernerhin die Polygasterie der Infusorien mit denselben Grinden ${ }^{3}$ ), und sein Landsmann Edw. Forbes trat grleichfalls dagegen auf 4 .

In Deutschland fanden Dujardiu's Anschauungen von der Organisation ler Infusorien bereits IS39 an dem bekannten Pflanzenphysiologen J. Meyeu einen entsehiedenen Vertreter ${ }^{5}$. Er erkärte die Infusorien für blasenartige Thiere, deren Höhle mit einer schleimigen, etwas sulzigen Substanz erfüllt sei. Von der Mundöllnung aus erstrecke sich schrảg in die innere Körpersubstanz hinein ein cylindrischer, hinten oflener Spcisekanal, dessen unterer Theil mit Wimpern ausgekleilet sei und sich bei eingenommener Nahrung allmăhlig his zur Grösse der hugeln ausdehne, welche das Innere derselben Infusorien erfullten. Meyen nennt diesen hintern Abschnitı des Speiselianals Magen; die Wimpern lesselben sollen die eingedrungenen Stolle schnell im Kreise umhertreiben, bis sie zu einer regehmässigen Kugel zusanumengeballt sind. Diese Kugel werde zuletzl durch den fort und fort von den ämssern Wimpern in den Speisekanal getriebenen Nahrungsstron aus dem Ilagen in die Körpersulstanz hineingeschoben,

1) Ehrenberg die Lufusionslliere 5. 262. - 2) Annals of natural history 1838. Vol. Il p. 121 und eiu Auszug in .Mïller's Arehis 1839. S. 80-81. - 3) Annals of n. 1. 1839. Fol. III p. 74 und Rymer Jones a general outline of the animal kingdom 1841. p. $58 .-$ 4) Annals of nalural hislory 1840. Vol. Y P. 364. - a) Meyen Einige Bemerkungen über den Verdauungsapparal der Infusorien it Miiller's Arehiv 1839. S. $74-79$.

sitein, Organisnus der lufusionshicre. 
"Worauf sich sofort in Magen eine neue Kugel bilde; letztere schiebe, wenn sie aus dem Magen trete, die ältere Kugel und den zwischen bejden gelegenen Schleim vor sich her und so wirden nach und nach die ältern Kugeln ron den nachfolgenden immer wejter riockwirts und zuletzt anf der entgegengesetzten Seite nach vorwărts bewegt. Man sicht, dass diese Erkizirung ron der Entstehung der Ehreuberg'schen Magenblasen nur cine unbedeutende Modification der Lehre Dujardin's ist, und dass Meyen bej seiner Schilderung nur Paramäcien und Vorticellen in Auge hatte. Die contractilen Blasen fasst Meyen genan wie Mujartin auf.

Wahrend so die Hauptsäule des Ehrmberg'schen Infusoriengebaudes zusammenbrach, drohte demselben von Seite der Botaniker eine neue Gefaln. Es wurden namlich an den Sporen verschiedener Algen und an den in den Antheridien vieler höheres Cryptogamen entwickelten Spermatozoen, die man anfangs fü Entophyten hich, so tauschend waren ihre Bewegungen den thierischen ähnlich, Wimpern und geisselartige Bewegungsorgane entdeckt. die bisher als ausschliessliches Eigenthum der Thierwelt und als hesonders für die Infusorien characteristische Organe gegolten hatten. Zuerst erhannte G. Thuret 184.0 an den langen geschlangelten, wurmförmigen Spermatozoen der Charen zwei lange dicht himler dem vordern Ende cingefïgłte schwingende Geisseln, die in allen Stiicken genau mit den Geisschn oder Rüsseln der monadenartigen Infusorion ïbereinstimmten ${ }^{1}$ ). Alsdann machte $F r$. Unger 1843 die schöne Entdeckung, dass sich in den angeschwollenen Eudschläuchen der bekannten Sirsswasseralge Vaucheria clavata der gesammte Inhalt zu ejuer grossen, ovalen, grinen spore entwickelte, deren farblose durchsichtige Membran auf der ganzen Oberflache dicht mit zarten, lehhaft schwingenden Wimpern beselzt war. Dje Spore durchbricht zuletzt das Ende des Schlauches, schwämt lebhaft, anscheinend williwhrlich, im Wasser unher und glejcht in diesem Zustande tauschend gewissen auf der ganzen Oberfliche wimpernden Infusorien, z. B. einer grimen Holophrya. Nach efwa zwei Stunden verliert sie aber ibr Wimperlileid. fallt zu Boden und fängt an zu liejmen *). Noch in demsellen Jahre bestatigte Thuret die Beobachtungen Luger's und schilderte zugleich die Schwärmsporen verselichener Conferven $\left.{ }^{3}\right)$. Einige derselben, die von Prolifera rivularis und Candollii, sind oval, griun und am rordern Ende mit einem farblosen warzenförnigen Vorsprung versehen, der cinen Kranz ron zarten langen Wimpern trägt; andere sind läuglich eiförmig, griun und nach vorn in einen farblosen schnabelförmigen Fortsatz ausgezogen, der zwei oder vier Geisselı trägt; ersteres ist bei Conferva rivularis und glomerata, letzteres bei Chaetophora elegans des Fall. Die lokteren Formen der Schwämsporen sehen manchen grimen monadenarligen Infusorjen, z. B. den Galtungen Chlamydomonas, Mticroglena, Phacelomonas, zum Verwechseln ahnlich, ja die Sehwärmsporen von Chactophora elegans besitzen sogar, wie einige Jahre spater Fresenims ${ }^{5}$ nachwies, einen eben solchen roben Augenfleck, wie vicle grime monadenatige Infusorien. Thuret entdechic fernes 1845 im Vercine mil Decuisue die speruatozoen der Fucaceen, die sich cbenfalls mittelst zweier langer Geisseln hewegen und im Innern des Köorpers ein rothes, ancentibnliches Grantum enthatten 4 .

Die vielen, in den folgenden Jahren in derselhen Riehtumg von den Botanilsern genachten Beobachtungren aufzuzihılen, gehört nicht hierher. Die angefuhrten Thatsachen reichten allein schon hin, die Naturforscher auf den Gedanken zu fulıren, dass viele von Ehweuberg suguen geisseltragenden Infusorien, namentlieh dic ganz starten Formon, nichts weiter scin möchten, als Schwämsporen von Agen. Wollte nan sie als Thiere festhalten, so war man in Verlegenheit, woduch sic ron den beweglichen Agenkeimen unterschieden werden solten, denn es war an ihnen m der That of nicht melır Organisationsdetail uachgeviesen, als an den letzteren. Jedenfalls war nun eine scharfe Begrämzung der Infusorienwelt ausserordentlich schwierig und unsicher geworden, und die Versuchung lag nahe, jede Gränze zwischen den niedersten Regionen des Thier- und Pflanzenreiches zu läugnen. Es lebrte denn anch Kützing bereits I8 í dic Lmwandlung von wahren Infusorien uamentlich von Chlamydomonas pulvisculus! in

1) Annales des se. natur. Botanique. 1840. II Sér. Tom. XIV p. 67 und Pl. †. - 2) Fr. Inger Die Ṕllanze im Momente der ThierWerdung. Wien 1843. - 3) Recherches sur les organes locomoleurs des spores des Algues. Annales d. sc. nal. Botanique 1843. II Sir. Tome XIX P. 266 und P. 10 und 11. - 4j G. Fresenius Zur Coutroverse über die Verwandlung von Infusorien in Algen. Frank-

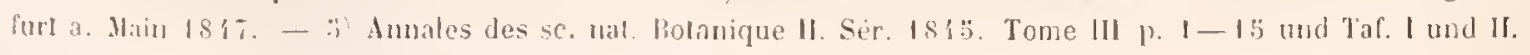


Algen ", und auch $и$. Flotow hlieb in seiner Abhandlung über Hacmatococcus pluvialis") uber (lie Grinzen zwischen lufusorien und Algen zweifelhaft.

Von grossem Einlluss anf die weitere Entwickelung der Infusorienkunde war es, (lass sich in Jahre is4.:) ciner der crsten deutschen Zoologen, C. Th. v. Siebold, mit der grössten Eutschiedeuheit den neuem, segren Ehrenberg's Darstellung der Infusorienwelt gerichteten Bewegungen anschloss. Er resümirte in seinem "Lehrbuch der vergleichenden Anatomie der wirbellosen Thiere « S. 7-25 nicht blos den damaligen Standpunct der Forschungen in höchst Harer und pröiciser Weise, sondern er theilte auch mchreve werthrolle neue Thatsachen mit. die von einem eingehenden Studium der Infusionsthiere und der mit ihnen zusammengeworfenen Organismen zeugten. v. Siebold erklärte sich in alten wesentlichen Puncten fur Dujardin's Auffassung der Ernahumgsweise der Infusorien, er hob alıer bestimmter das Vorkommen einer wirklichen speiserölnc und die sehr allgemeine Verbreitung eines Afters bei den mil einem Mund versehenen Formen hervor. In der contrachilen Blase und den ofters mit ihr in Verbindung stehenden strahlenfömigen Ausliufern erkennt er die erste Anlage eines Circulationssystemes; während der Diastole des contractilen Hohhaumes werde derselhe mit einer aus dem umgebenden Parenchym hervorquellenden Ernährungsllïssigkeit gefitll, welche bei der Systole wieller in das Parenchym zuriicktrete. Nerven, Muskeln und Sinnesorgane werden den Infusorien eben so entschieden, wie von Dujardin, abgesprochen; nur allein der dunkle Streifen im Stjel gewisser Vorticellinen wirl für einen Längsmuskel erklät.

Der höchst schwachen, nur auf der Analogie mit den Raiderthieren beruhenden Lehre von dem doppelten Geschlechte der Infusionsthiere cntzogr $r$. Siebold anch noch die einzige Stiuze, auf der sie beruhte, iudem er ulen wichtigen Nachweis führte ${ }^{3}$ ), dass auch das angebliche mämnliche Geschlechtssystem der Rärlerthicre eine samz andere Function, als die ron mänulichen Geschlechısorganen crfille. v. Sicbold erliannte namlich, dass sich in den beiden mit der contractilen Blase im Zusammenhang stehenden strangfürmigen Organen, den vemeintlichen Samendrisen Ehrenberg's, ein gefissartiger starrer lianal entlang winde, der durch die kurzen, ein schwingendes Wimperläpjehon enthaltenden Seitenaste, welehe Ehrenberg für selbststandige, len Hoden blos äusserlich angreheftele Kiemen gohalten hatte, frei in the Leiheshöhle ausminde. Hiernach lionoten tie fraghichen Organe nur die Bodeutung cines Wassergefisssystemes haben, welches durch die kurzen seitenäste Wasser aus der Leibeshöhle in die beiden Längstumme und aus diescu in die contractile Blase fiilurt, durch deren Contractionen es dann nach ausseu gepunpt wird. Den Wassergefässsystem legte $\iota$. Sicbold eine respiratorische Function bei, indem er mil Ehrenherg annahm, dass durch die Nackenröhre der Ratuerthiere das zur Respiration dienende Wasser in die Leibeshohle gelange. Wie

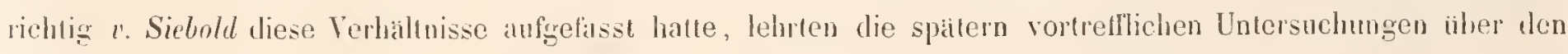

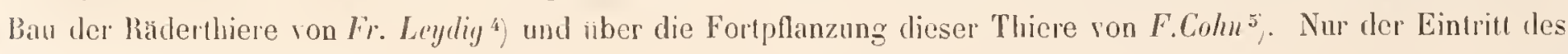
Wassers dureh die Nackenröhre bestatigte sich nicht, da diese als völlig geschlossen erkanut wurde und als ein fïhlerartiges Organ aufgefasst werden musste. Hiermil wurde auch die respiratorische Funclion des Wassergefisssystems wieder zweifelhaft und viel wahrscheinhicher, dass dasselhe nur die Bedeulung eines Secretionsorganes hahe, welches das aus dem Darmlianal in die Leibeshöhle iubertretente und fur die Emährung iiberllissige Wasser und vielleicht auch andere aus dem Organismus auszuscheidende gelöste Stoffe nach aussen hefördere. Dàs das Wassergefisssystem auch nicht cutfernt zu der männlichen Geschlechtsfunction in Beziehung stehen kömme, das wurde auf das Evidenteste rlurch die epochemachende Entdeckung der männlichen Räderthiere durch Brighturell und Dalrymple in den Jahren IS s.8 und 49 dargethan ${ }^{6}$, welche Leydig und Cohn in den eben erwahinten Abhandlungen bestätigten und erweiterten.

Vachden sich die angeblichen maiınlichen Geschlechtsorgane der Räderthiere als cin Wassergefässsystem

1) Lützing Leber die Verwandlung der Infusorien in niedere Algenformen. Nordhausen 18.44. - 9) Nova acta Acad. Cae. Leop. Car. Vol. XI. P. If. p. IS. - 3) A. a. O. S. 181. - 1) Zeitschrift für wissenseluaftliche Zoologie 18:3a. Band VI. S. 1 - 120. 5) Ebendaselbst 1856. Band VII. S. 431-86. - 6) Annals of nat. hist. 1848 . Vol. Il p. 153 und 1849 bol. III p.518 und besonders Philosoph. Transact. 1849. II, p 331. 
ergeben hatten, lionnte fortan gar nicht mehr davon die Rede sein, dic contractile Blase und die sogenannte Samen(lrise der Magenthiere, zwischen welchen nie ein Zusammenhang nachgewiesen worden war, als ein mainuliches Geschlechlssystem zu bezeichnen. Welche Function $v$. Siebold der contractilen Blase beilegle. ist bereits erwähnt worden; die Bedleutung del Samendrise liess er unbestimmt, vermutlıete aber, dass sie zur Fortpflanzung der Infusorien in Bezielıung stehe, nu sei sie kein Samen bercilendes Organ, eigentliche Geschlechtsorgane fehlten iberhaupt den Infusorien gånzlich. Was Ehrenberg für Eier gehalten habe, seien nichs weiter ads Parenchyn- oder Pigmentliörner oder zerfallene Nahrungsstoffe gewesen. Die Samendrüse musste natiolich nun eine andere unbestimmlerc Bezeichnung erhatten, $v$. Siebold wahlte den Namen Ker n (Nucleus), der bis auf die Gegenwart fast allgemein im Gebrauch geblieben ist. Dieser Name wirde sehwerlich Anstoss erregt haben, hätte nicht $v$. Siebold den Nucleus der Infusorien mit einem Zellenkern, dem er freilich oft täuschend ähnlich sieht, und den Infusorienkörper mit einer Zelle verghichen und behauptet, dass die Infusorien sowohl, als auch die Rhizopoden in ihres Zusammensetzung einer einfachen Zelle gleichkämen und mithin als einzellige Thiere zu lızeichnen seien.

Von rlen Infusorien werden nicht blos die Bacillarien und Closterinen als vegetahilische Organismen ausgreschlossen, sondern auch die ganze Gruppe der Volvocinen wird dem Pflanzenreiche überwiesen, und auch unter den ibrigen Amenteren Ehrenberg's sollen noch viele, nicht năher bezeichnete pflanzliche Formen enthalten sein. r. Siebold verlangt selbst von den cinfachsten thierischen Organismen, dass sie dic Fihigheit besitzen, ihre äussern Umrisse durch willkührliche Contraction und Expansion des Körperparenchyms zu verindern. Weil dies die Volvocinen nicht vermögen, uud weil sic anch in ihrer ganzen ibrigen Organisation gewissen Schwärmsporen der Algen zum Verwechseln ähulich sind, werden sie eben für vegetabilische Organismen erklärt ${ }^{1}$ ). Aus den Amöbäen, Arcellinen und Polythalanien bildet v. Sicbold mit Recht wieder eine selbstständige Thierklasse, die der Rlizopoden, welche mit der K’lasse der Infusorien zu einem eigenen Organisationsplane des Thierreiches, dem der Prolozoen, vereinigt wirl. Die Protozoen bilden den untersten Kreis des Thierreiches, sie werden als "Thiere characterisirt, in welchen die verschiedenen Systeme der Organe nicht scharf ausgesehieden sind, und deren unregelmissige Form und einfache Organisation sich auf eine Zelle reduciren lassen." Die beiden Klassen der Protozoen werden lediglich nach den Bewegungsorganen moterschieden, bei den lnfusorien "bestehen sie hauptsichlich aus Flimmerorganen ", bei den Rhizopoden naus verästetten, stets veränderlichen und gänzlich zurtickziehbaren Fortsätzen." Die Infusorien theilt v. Siebold nicht glücklich in zwei Ordnungen, in die Mundlosen (Astoma), wohin tie geisseltragenden Formen und die auf der ganzen Oberfliche wimpernden Opalinen gerechnet werden, und in dic mit einer Mundöllinung und Speiseröhre versehenen Formen (Stomatoda), die alle übrigen bewimperten lnfusorien unfassen.

Gegen v. Sicbold's Darstellung der Infusorien- und Riderthierorganisation traten zwar sofort zwei effrige Schüler Elrenberg's, O. Schmidl ${ }^{2}$ ) und C. Echhard ${ }^{3}$ in die Sehranken, allein da sie fast nur Ehrenberg's Angaben wiederholten, olne irgend erhebliche umb unzweideutig für denselben sjrechende nene Thatsachon anzufuhren, so blieb ihre Vertheidigung völlig erfolglos und unbeachtet. Vom Werth war in Eckhurl's Aufsatz die Mlitlıeilung einiger. wenn auch muvollstandiger Beobachtungen iber das Auftreten von grossen Keimkingeln im Leibe von Stentor coerulens und polymorphus, deren Entwickelung zu lobendigen, dem Mutterthier unähnlichen Jungen verfolst wurle 4 ).

Die verschiedenen, durch Ehrenberg's grosses Infusorienwerk angeregten mu überhaupt erst möglich gुewordenen Beabeitungen localer Infusorienlaunen liessen die Controverse über die Organisation dicser Thiere meist

1) In einer spätern ausführlichen Abhandhug: "Ueber einzellige Planzen und Thiere" in der Zeilschrift für wissenseh. Zoologie 1849. Band I. S. 270-9i lut v. Siebold, anknüpfend an die Schrift von Vaegeli, "Gallungen einzelliger Algen. Zürich 1849 a seine Ansichten über die Stellung der Bacillirien, Closterinen und Votvocinen zu den Algen weiter zu begrüuden versucht. - 2 ) „Versuch einer Darstellung der Organisation der Itiderlhiere mil Bezug auf die neuesten gegen die Emenberg"schen Ansichten gerichleten Angrifle." IIieg-

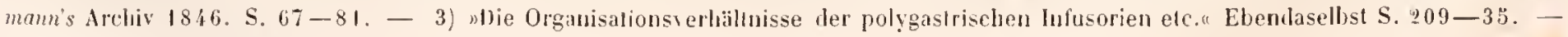
4) A. is $0.5,227-29$. 
ganz unberulut und folgten in allen Stuchen unbedingt Ehrenberg; sie behandelten deshall) auch inmer gleichzeitig die Rhizopoden. Bacillarien, Closterinen unı Raderthice. Von Ritss' ${ }^{1}$ ) und Schmarda ${ }^{2}$ ) wurde die Wiener Iníusorienfuma bearbeitet, letzterer heriuchsichtigte zuşleich auch die nördlichen Küisten des adriatischen Meeres und stellte cinige neue Formen au ${ }^{3}$ ). Eichwuld behandelte die Infusorienfauna Russlands ${ }^{4}$; nach seinen Mblilungen zu urtheilen, können jedoch seine Bestimmungen als nicht sehr zuverlässig̣ gọclten. Weit gründlicher und manche neue Thatsachen enthaltend sind die seit 1 \$ 4 von $F$. Weisse iilıer die St. Petershurger Infusorien verüflentlichten Arbeiten ${ }^{\tilde{5}}$. Von besonderem Interesse ist die von ihm entleckte Fortpflanzungsweise des Chlorogonium euchlorum, die darin besteht, dass der gesammte Leibesinhalt des Thicres durch fortgeselzte, jedoch ziemlich unregelmässig erfolgende Theilung in einen taubigen llaufen von beweglichen Keimkörnern zerfillt, die dann plötzliclı nach aussen hervorbrechen; vom lutterthier bleibt nichts weiter als die leere, abgestorhene körperhuille zuriick ${ }^{6}$ ).

Ungekehrt schloss sich der sorgfälig beobachtende Focke seit 1847 wieder innigr an Elhronberg an, obgheich er noch elsen so entschieden, wie fribler, die Darmmagentheorie verwarf ${ }^{7}$ ). Er erliärte Ehenberg's Begrảnzung und Eintheilung der Magenthiere für wohlbegrundet und naturgemäs, wenn sie auch in einzelnen Puncien der Berichtigung bedurftig sei. Die einfachsten Formen, deren thierische Natur mau in Zweifel grezogen habe, eigrneten sich nicht zu physiologischen Studien, sondern man könne sie nur durch dic grösseren und vollkommneren verstehen Jernen. Die natürliche Verwandtschaft der meisten Familien sei su einleuchtend, dass es genüge, nur bei wenigen Arten die Organisation mit Sicherheit erhannt zu halıen. Focke hat sich bisher mit den ersten 10 Familien der Ehrenberg'sehen Anentera beschaftigt, die monographischen Darstellungen, welehe er von den Closterinen umd den Bacillarinen (Enastrum und Tavicula) gelicfert hat, enthalten jedoch meiner Ansicht nach kein emziges Moment, aus dem auch nur mit Wahrscheinlichleit auf die thierische Natur dieser Organismen geschlossen werden liönnte. Das von Ehrenberg behauptete schneckenfussartige Berwegmogsorgin konnte nicht aufyefunden werden, uml die Wimpern, welche Focke an der innern Oberfliche der Closterinen geselıen lablen wollte, sind von Niemand bestäligt worden. Was uber die unzweifelhaft thierischen Anentera milgetheilt wird, ist Alles mit Juijardin's und ". Sirbold's Ansichten von der Organisation der Infusorien wohl vereinbar, fur welche sich 1849 noch $v$. Frant:ius, auf Untersuchungen von Ophrydium versatile und Paramaecium aurelia gestiitzt, mit voller Enlschiedenheit aussprachs;

Dagegen wurden ron 0 . Schmilt einige schr beachtenswerthe feinere Structurverhälnisse ler Infusorien zur Sprache gebracht, die offenbar gegen die Deutung der hnfusorien als cinzellige Organismen sprachen und auf eine nähere Verwandtschaft derselben mit den Turbellarien hinwiesen \%. Schmilt zeigte nämlich, dass bei Paramaecium aurelia und der nahe verwandten Bursaria lencas Ehbg. genau eben solche stabförmige Körjerchen in der äusseren Körperbedeckungr enthalten seien, wie in der Hautschichı der Turbellarien, die äussere Körperschicht cler Iufusorien künne daher unmöglich mit ciner Zellenmembran verostichen werden. Forner enteckle Schmidt. dass die contractile Blase von Bursaria leucas mit einer constanten Oefluung nach aussen munde, und er schloss daraus, dass durch diese Wasser zur Unterhaltung des Respirationsprozesses ein- und ausgepumpt werale, und dass die conıractile Blase mit ilıren strahılenfürmigen Ausliuferu durchaus dem Wassergefässsysteme der Tuhliellarien entspreche. Endlich bestätigrle Schmidt die Beobachtung Echhard's hinsichtlich der Entwickelung Iebendiger Jungen bei Sientor coeruleus.

1) F. Riess Beitrigge zur Fauna der Infusorsen mit dem beigefügten Ekrenberg'schen Sysleme. Wien 1840. - 2) L. Schmarda Klein Beiträge zur Nilturgeschichte der Infusorien. Mit 2 Tilfeln Alılildungen. Wien 1846. - 3) Vergl. auch dessen Ablandlung über neue Infusorienformen in den Denkschr. der Wiener Acad. I. 18:30. p. 9. - 4) Eicheald Beitrag zur lufusorienkunde Russlands. Bullelin des

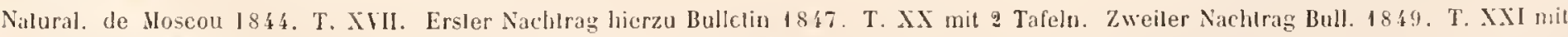
1 Tafel. Driller Nachlıag Bull. $18: 5$ ? wit 2 Tafelı. Diese Abhtandlungen erschienen auch als besondere Schriften. - 5) Bullelin de l'Acild. de St. Petersbourg Tome III. No. 2. 20. 21. 22. Tone IV. No. 8. 9. Tome V. No.3.15. Tome VI, No. 7. 20. 23. Tome VII. 20. Tome Vill.

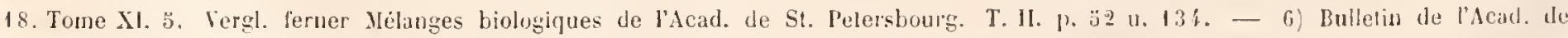
St. Pelersbourg. Tome. II No. 20 und IViegmamis Archir 18:8. I. S. 6:3-i1. - 7) WV. Fuclie Physiologische Studien. Ersles Hef1.

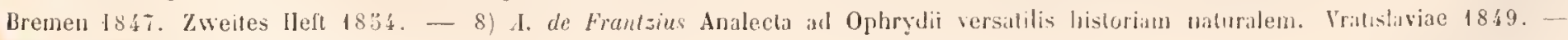
9) Frorirp's Nolizen für Natur- und lleilkunde. Dritte lirihe. Band IX. 1849. S. 3-6.

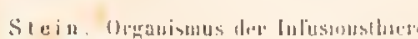




\section{4}

In manchen Beziehungen linter tler Zeit zuriick blieb eine spätere umfangreiche Schırift von M. I'erty: "\%ur Kenntniss kleinster Lebensformen, nach Bau, Functionen, Systematik, mit Specialverzeichniss der in der Schweiz beobachteten. Mit 17 Tafelu. Bern $1832 . "$ Sie stelu ganz auf dem Standpuncte des Dujardin'scheu Itandbuches, ja die Darstellung mancher Formen rersetzt uns in die Zeiten 0 . Müller's zurizck. Perty lat offenbar der Infusorienwelı viel Fleiss zugewendet und sehr viele Formen, darunter gar manche neue, beobachtet, aber die meisten sind nicht intensiv genug untersucht, und bei sehr vielen sind niclst einmal die nothwendigsten Bestimmungselemente, ermiltelt. Nucleus, contractile Stelle, Schlund und Lage des Afters werden fast nie erwälnt, ja Perly spricht gerarlezu den meisten Infusorien den Nucleus ab ${ }^{\mathbf{1}}$. Ebenso unzureichend sind die Angaben uber die Art der Bewimperung und über dic Besclıallenhcit des Mundes, dessen Lage nicht selten sogar bei ganz grossen Formen unbestiumt gelassen wird. Bei einer so oberflachlichen Betractstung der mikroscopischen Lebensformen ist es hegreiflich, dass Perty die spontane Erzeugung derselben wieder vertheidigt, dass er ferner die verschiedenartigsten rundlichen Gebilde im Innern des Körpers, z. B. Feltkörner, Oeltropfen und die kugligen Zersetzungsproducte der aufgenommenen Nalırungsstoffe, fur sporenartige Keime, welche Blastien genannt werden², erklïrt, mol dass er jede scharfe Grinzluestimmung zwischen den niedrigsten thierischen und vegetahilisehen Organisnen laugnet. Perly setzt aus den bewimperten und geisseltragenden Infusorien Dujardin's und ans den Vibrionien und Acinetinen Ehrenberg's scine Klasse der Infusorien zusanmen, vereinight damit aber wunderlicher Weise anch sämmtliche Schwarmsporen der Algen, ungeachtet er weiss, dass diese sich zu Algen entwickeln. Er gesteht selbst. dass die so begränzte Klasse allerdings eigenlliumlicher Art sei un sich nichı mit einer andern Klasse des Thier- oder Pflanzenreichs parallelisiren lasse, sie werde aber doch durch einige gemeinschaftliche Merlimale (口alle bestehen aus zarter protoplasmatischer Substanz, ermangeln dilferenzirter organischer Systeme, liönnen sich durch Theilung fortpllanzen und allen ist Spiralbervegung eigen a) gereelufertigt; wolle man diese Klasse nielıt annehmen, so bleibe nichts weiter iibrig, als alle geisseltragende Formen dem Pflanzenrciche zu iilserweisen ${ }^{3}$ ).

Perty theilt seine Infusorienklasse in zwei Ordnungen, in die Ciliata, deren Körper an allen oder eimigen Stellen mit "Bewegungswimpern " bekleidet ist und die meist einen Mund besizen, und in die Phytozoidia, welehe mundlos und nie bewimpert sind, aber sehr läufig schwingende Faden tragen und von denen viele in ihrem Lebenseyclus bald dem Thier- bald dem Pflanzenreiche angehören und zwischen beiden oscilliren ${ }^{4}$. Aus den Ciliaten werden zwei Sectionen gebildet; die erste umfasst die Formen mil schwingenden Wimpern, also sämmtliche bewimperte Infusorien Inujahin's; die zweite besteht allein aus den Acinctinen Ehremberg's, leren Tentakeln fălschlich als nicht schwingende, wenig coutractile Winpern bezeielnet werden. Die Phytozoiden zerfallen in drei Seclionen, in die Filigera, welche den geisseltragenden Infusorien Dujardin's entsprechen, in die Sporozoidia, welche meist durch Fäden, selten dureh Wimpern sich bewegend in entschiedene Algenbildungen auswachsen, also doch nichts veiter als Schwärmsporen von Algen simd; und iu die Lampozoidia oder Vibrioniden, welehe keine Spuren ausserer oder inuerer Organe erkemen lassen. Die lufusionsthiere und Rhizopoden zusammen bezeichnet Perty mit dem Nimen Archezoa, der jedenfills dler ältern Benennung Protozoen weichen muss. Die von Perty aufgestellten neuen Gattungen und Arten sind zwar zum Theil wohlberechtigl, und machen das Ilauplrerdienst seiner Selurilt aus, die aussertem auch noch die Kenntniss der geographischen Verbreitung der Infusorien fördert, sie bediurfen jedoch last sämmblieh einer weit sorgfältigern Begründung und müssen viel schäıfere Charactere erhalıen.

Fassen wir die neuen bis zum Jabre 1849 reichenden lnfusorienforschungen zusanmen, so mussen wi ihnen das Verdienst zugestelıen, den polygastrischen Ernährungsapparat und das doppelte Geschlechısşsıcm, welches Elerenberg seinen Magenthicren zuschrieh. Ginzlich beseiligl zu haben. Auch wurle die Kilasse der hufu- 
sionshiere von vielen fremdarligen Organismen gereinigt und in immer naturgemässere Guänzen cingeschlossen, nur nach dem Pflanzenreiche lin blich ihre Bugränzung noch mehrfach unhlar, namentlich hot die Stellung der Volvocinen forlgesetzt erhebliche Schwierigkeiten dar. Dic Bedcutung des Nucleus dagegen. dessen sehr allgeneine Verbreitung bei den Infusorien bereits sicher constatirt war, hatte sich auch nicht entfernt ergriunden lassen, und hinsichtich der contractilen Blase blieb man zweifelhaft, ob dieselbe zu den Circulations- oder zu den Respirationsorganen zu rechnen sci. In tiefes Dunkel gehült blieb der erste Ursprung der Infusionsthiere; man wusste nur mit Sicherheit, dass sich die meisten sehr leicht durch Theilung, eine beschramkte Anzahl auch durch Knospenbildung vermehrten, und vermochte also woll zu begreifen, wie eine Flissigkeit in kurzer Zeit von einer Unzahl von Individuen bevölkert werden komnte, wenn nur ein einziges Inlividum zu derselben Zugang gefunden hatte, woher aber dieses stanmte, und wie Infusorien in abgekochten Flüssiglieiten und in der ersten besten durch atmosphärische Niederschläge gebildeten Lache erscheinen konnten, das war noch immer höchst rätlıscllıafı.

Zur lösung dieser P'robleme haben in den nächstfolgenden Jahren die Arbeiten von $F$. Colm und meine eigenen Forschungen unstreilig am meisten beigetragen, und wir dïrfen, ohne unbescheiden zu sein, wohl das Verdiensi für uns in Anspruch nehmen, nene Bahnen gebrochen und die ausserordentlich erfolgreiche Thitigkeit, welche gegenwärlig auf dem Gebiete der Infusorienkunde herrscht, vorzugsweise angeregt zu haben. Cohlu verfolgte als Botaniker mit besonderer Vorliebe die zwischen dem Thier- und I'llanzenreich streitigen mikroscopischen Lebensformen, insbesondere die Naturgeschichte der Volrocinen. Zucrst nahm er die Untersuchungen r. Flotou's ijber den Chlamydococcus pluvialis A. Braun (Hlaematococcus pl. Flotow, Protococcus pl. Kützing), wieder auf und lieferte $185 ̋ 0$ darüber einc umfasscnde Monographie'). Cohn zeigte, dass dieses Geschöpl” zu den Volvocinen gehöre und der Gallung Chlamydomonas Ehbg. so nahe verwandt sei, dass es kaum von derselben generisch getrennt werden könne.

Der Chlamydococcus bestcht aus einer farblosen, durchsichtigen, dunuhautigen kugligen Hülle, welche zundichst cine wasserige Flissigkeit und im Centrum einen rundlichen bald grün, bald scharlachroh gefarbten Körper umschliesst, der sich nach vorn in eine farblose Spitze auszieht, die zwei lange, die Huille durchbohrende geisselförmige Wimpern trigt. Mittelst der beiden Geisseln bewvegt sich der Chlanydococcus genau in derselben Weise wie die Schwirmsporen der Mgen, aber auch cbenso wie unzweifelhafte geisseltragende Infusionsthiere. Cohu vermoclıte zwischen den Bewegungen der letzteren und denen der Schwärmsporen bei der sorgfäligsten vergleichenden Beobachtung auch nicht den leisesten Unterschied wahıunehmen, eben so wenig zwischen den Geisseln einer Euglena, die er wegen der hohen Energie ihrer Contractilität durchaus als Thiere anerkennt, und denen der Schwärmsporen. Der Clılamydococcus lıat ein bewegliches und cin ruhendes Lebensstadium, in beiden vermag er sich durch Theilung zu vermehren, In dem beweglichon Stadium zerfällt der in der Hälle eingeschlossene Körper gewöhnlich zuerst in zwei, dann in vier Portionen, eine jede bekommt später an dem einen zugespitzten Ende zwei neue Geisseln, sie durchbricht nun die IJutterhülle und sondert, nachdem sie frei greworden ist, eine neue, erst innigr anliegende, dann durch Wasseraufnahme aufschwellende llïlle ab. Die neue Generation verhält sich nun wic tlie frühere. Zu gevvissen Zciten aber zicht sich der Chlamydococcushörper in seiner Hülle kuglig zusammen und umgriebt sich innerhalb derselben allmählich mit einer neuen, weit derbern geschlossenen Hülle, die ihn auch bei gänzlichem Wassermangel ror dem Absterben schützt; die ursprüugliche Hülle lost sich allmählich auf. Dies ist der ruhende Zustand; während desselben kann die Chlanydlococcuskugel durch fortgesetzte Theilnng in 2 , i oder 8 Segmentc zerfallen und diese vermögen ehenfalls, wenn die giinstigen Lebensbedingungen vorhanden sịnd, die derbe Hülle zu sprengen und sich wieder zu der beweglichen Form zu cntwickeln, indem sie zwei Geisseln entwickeln und um sich eine neue Hülle ausscheiden. Bisweilen erfolgt dic Theilung des rubenden Chlanydococenskörpers in einer höhern Potenz von 2, so dass 16-64 Segmente entstehen. Die aus densclben hervorgehenden beweglichen Formen sind elenfalls mil zwei Geisseln versehen, scheiden aber nie cine Iülle aus; sie wurden von

1) Cohn „Nachträge zur Naturgeschichte des Protococeus pluviatis Kï̈lzing. "Nova Acta Acad. Caes. Lcop. Carol. Nal. Cur. 1850. Vot. XXII. P. If. p. $607-764$. 
Cohn später als Microgonidien bezeichnet, während die eine Hülle absondernden Formen Macrogonidien genannt wurden.

Dies sind die Grundzige aus der Naturgeschichte des Chlanydococcus, wie sie Colm ermiltelte; er machıte ausserdem die interessante Entleckung, dass die Jille des Chlamydococcus nach der Einwirkung rou Jod und Schwefelsiture blau geftirbt wurde, mithin aus Jolzfaser oder Cellulose bestelien musste. Vorziiglich dieser Lmstand, und dann die Erwägung, dass alle Eigenschaften, welche der Chlamgdococcus mit wahren geisseltagenden Infusionsthieren, z. B. den Euglenen, gemein hat, sich auch bei den Schwärmsporen der Algen finden, bestimmie Colm, in dem Chlamydococcus einen entschiedenen vegetabilischen Organismus und zwar eine einzellige Alge zu erkennen. Die Analogie mit der vegetabilischen Zelle lag um so năher, als erst unlängst bei den I'llanzenplı!siologen die Lehre in Anfnahme gekommen war, dass die innere, stickstoffhaltige Auskleidung der Zelle, der sogenannte Primordialschlauch, den urspringlichen und wesentlichsten Theil derselben, die aus Cellulose gebildete Mlembrun aber nur cin Absonderungsproduct des Primordialschlauches darstelle. Demgemäss bezeichnete Cohn die Hijle des Chlamydococcus als Hiillzelle, den eingeschlossenen Körper als Primordialzelle, und er sals in dem ruhenden Zusland dis eigentliche vegetative, in dem beweglichen das den Schwärmsporen der Algen analoge Lehensstiıdium.

Die Entıleckung einer neuen Volvocinenform, der Stephanosplutera pluvialis, gab Colm 1832 zu einer zweiten interessinten Monographie Veranlassung 1 ), in der nun sämmtliche Volvocinen mit voller Entschiedenheit zu Algen degradirt werden. Die Steplanosplaera schliesst sich ebenso innig an Chlamydococcus, wie an Pandorina, Gonium und Volvox an; sie bestelıt aus einer kugligen, ebenfalls von Cellulose gebildeten und eine wasserige Flüssigheil mmschliessenden Ilülle, an deren innerer Oberfläche in einem grössten Kreise acht einzelne grüne Individnen (die Primordialzellen Colm's) sitzen, deren jedes zwei, die gemeinsame Hülle durchbohrende, lebhaft schwingende Geisseln aussendet. Durch eine sich dreimal wiederholende Theilung liann jedes der acht lndividuen, naclulem sie sich zuror ansehnlich vergrössert haben, in acht neue Individuen zerfallen, die ihre besondern Geisseln cntwiclieln und eine besondere sje gemeinsam umschliessende Hiille absondern. Die mitterliche Kugel enthailt alsdann acht lebhaft in ilı sich umhertummelnde und zuletzt nach aussen hervorbrechende Töchterliugeln, deren jecle wierler aus achı Individuen besteht. Bisweilen zerfallen die acht ludividuen einer liugel durch sich oftmals nach einander wiederholende Theilungsacte in eine grosse Anzabl lileiner spindelfürmiger Körperchen, die keine Hiille ausscheiden, sondern sich gäuzlich von einander trennen, an dem einen Ende vier fieisseln hekommen und nun in der Hutlerluille nach allen Richtungen hin durch einander wogen. Zuletzt brechen sje ans derselben vor und zerstrenen sicls im Wassur; ihr weiteres Schicksal blieb unerforscht. Cohn sieht in diesen beiden Entwickelungsweiscn ganz analoge Verhăltnisse wie bei ächten Algen, z. B. lei Hydrodyction, und lsezejchnet deshalb dic zulełzt erwäihnten spindelförmigen Körperclıen als Microgonidien, die in einer Mutterkugel entwichelten Tochterlugeln aber als Macrogonidien. Wie ihm früher Chlamydococcus und Chlamytomonas als einzellige Algen im strengsten Sinne des Worts erselienen waren, so stellen sich ilm nun Stephanosphaera und die iibrigen Volvocinen als Zellenfamilien dar.

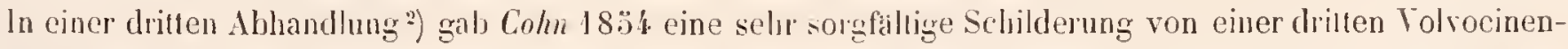
form, dem Gonium pectorale. Er zeigte, dass auch hier wesentlich derselbe Bau vorhanden sei und eine eben solehe Macrogonidienbildung stat finde, wie bei Stephanospliaera. Die einzelnen hudividuen, welche bei Gonium pectorale in einer lafelförmigen Hüle steckeu, zeighten aber ein hochst auftallendes schon ron Ehrubery gelianntes Organisationsrerhältniss, welches gerechtes Misstranen gegen die Deutung der Volvocinen als Mgen herrorrufen musste. Im vordern Ende wahe linter dem Ursprung der beiden Geisseln fanden sich nämlich constant loei jedem Individuum (Primordialzelle) zwei bis drei wasserluelle Vacuolen, die in liurzen Intervallen abwecliselnd verschwanden und dann wieder erschienen, die ganz den Eindruck eines Hohlaums machien, der sich mit Wasser fült und es nach einiger

1) "Leber cine nete Gatlung aus der Familie der Volvocinen. "Zeitschrift für wisscuschaflliche Zoologie Band IV. S. $77-1$ I 6.

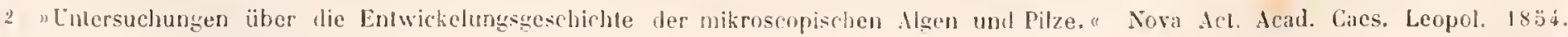
bul. IXIll Pars I. P. 163-20! 
Zeit wieder anstreibt und die in allen Beziehungen mit den contractiten Hohbannen der tichten hufusionsthiere vollkommen übereinstimmten ${ }^{1}$ ). Dieselben contractilen Hohträume halle Ehrenberg auch bei Volvox erkannt, und Cohn beobachlete sie ferner noch bei Chlanydomonas. Das plötzliche Verschwinden der Hohtrame setzl offenbar ein sehr energisches Contractionsvermogen in der die Hohluame umgebenden Substanz roraus, ein solches konnte man aber doch unmöglich dem Inhalte ciner blossen Pflanzenzelle zuschreiben. An keiner wirlichen Schwărmspore liess sich etwas Achnliches beohachten. Cohn fihlte zwar das ungeheure Gewicht dieser Thatsache, dennoch beharrte er schliessich bei der Ansicht, dass die Volvocinen Algen seien.

Cohn's fortgesctzte Studien ibler die Volvocinen fülırten endlich I 856 zu der wichtigen Entdeckung einer geschlechllichen Fortplanzung hei dem am längsten behamnten Repu'tiscutanten del ganzen Familie, den Volvox globator ${ }^{2}$. Yon mir war bereits 1834 . nachgewiesen worden ${ }^{3}$, was Cohm aber ganz mil Stillschweigen ubergeht, lass hei V. glohator ausser der gewijhulichen, schon von Ehrenberg im Wesendichen lichtig dargestellten Vermehrungsweise durch acht im Innern des Mutterstoches entstehende Töchterstöcke (Vacrogonilien Cohn's) noch cine andere Entwickelungsweise auftrete, die darin besteht, dass von den vielen Individuen, welehe einen Stock zusammensetzen, einige 30 - 50 in ganzen Umfange der Kugel zerstreut liegende sicl zu gewissen Zeiten zu vergrössern anfangen und nach und nach zu ziemlich umfänglichen, ganz glcicharlig bleibenden grimen Kugeh auswachsen. Ich zeigle fermer, dass die Kugeln, wenn sie ilre defnilive Grösse erreicht laben, in ilırem ganzen Unfange eine sie umhiblende Gallertschicht ausscheiden, die sich imner mehr verlicki und zulelzt die Form einer zierlichen, ganz starren, sternförmigen Kapset anmimml. Volvoxstöche mit solchen stemförmigen Kapseln waren von Ehrenberg für eine eigrene Art (Volvox stellatus) gehalten worden, während er die Zwischenslufe mit blos vergrösserten, noch nicht ron einer sternförmigen Hiłle umschlossenen Individuen als Sphaerosira volvox beschrieb.

Das Verlienst ron Colm besteht nun darin, dass von ihm entleckt wurde, dass keineswegs alle jene 30-30 Individucn, welche sich zu Zeiten in einem Volvoxstocke zu vergrössern anfangen, die eben geschilderte Entwickehng durchmachen, sondern eine kleinere oder srossere Anzalil derselben zerfallt nach und nach durch fortgesetzle Theilung in eine unbestimmle Anzahl von Segmenten. die in einer Ebene tafelformig an einander gereiht liegen. Dic aus der letzten Theihung hervorgyegangenen segmente bilden sich in gellıe spindelförmige Stăbchen um, welche nach vorm in einen zarten, farblosen, gekrimmten Schmabel von der Länge des Slabchens anslanfen. Der Schnabel trägt an seiner Basis zwei lange, lebhaft schwingende Wimpern und zeichnet sich durch ein ausserordentliches Coutraclionsvermögen aus; erkann sich verlängern und verkurzen, drehen und zusammenwinden. Diese höchst beweglichen Stabchen sind die Spermatuzoen und die Individuen, aus denen sie hervorgingen, die Mamchen des Volvoxslockes. Die übrigen Individuen des Stockes, welche sich vergrösserten, ohne sich zn theilen, müssen als Weibchen gedeutet werden. Sic haben z.n der Zeit, wenn die Spermatozoen vollstindig entwickelt simd mol sich nun in tem inneru mit Wasser erfülten Raume der Volvoshible zerstrenen, ihre delinilive Grösse erreicht und erseheinen als liurzgestiette, an der innern Oberfliche der Volvoxhülle aufgehängte Kugeln. In diese Kugehu dringen die Spermatozoen cin und bewirken die Befruchtung, deren nächstes Resultat iṣt, dass nun erst die Bildung der oben erwähnten sternfömigen Hulle erfolgt. Wenn diese vollendel ist, slirbt der Volvoxstock ab, und die sternförmigen Kapseln, die Cohn als Sporen bezeichnel, fallen auf den Boden der Gewisser. Was weiter aus ihnen wird, ist noch unbeliannt.

Ohne Zweifel is die geschlechlliche Fortplanzung des Volvox globalor den in neuester Zeil bei verschie-

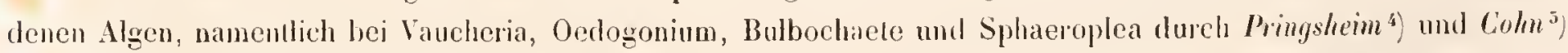
entdeckien geschlechllichen Fortprlanzungsweisen in viclen Lezichungen analog, allein es bleibl aloch immer noch ein lıöchst wesentlicher. Unterschied zwischen Volrocinen und Algen iibrig, den bereits Thuret nachıchiucklich betont

1) A. a. O. S. 193.200. 201. - 2) Annales (les sc. Matur. 1856. Botanique 1Y. Sér. Tom. V. p. 323-32. - 3) Stein nDie Infu-

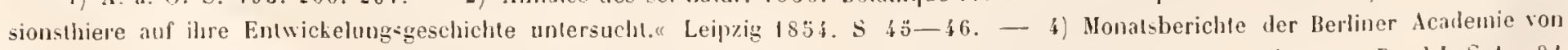

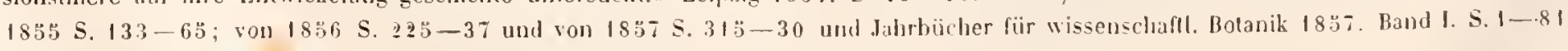
und S. $28\{-306$. - 5) Ebendaselhst 185. p. 335 - 1 1.

Sicin, Orginisnu: der Infusionsiliere 


\section{8}

hat ${ }^{1}$. Die hefruchete Agenspore keint und wachst wiedor zu einem rein regetirenden Organisnus, zu einer einoder mehrzelligen Algge aus. welche crst in einem spattern Lebenssladium bewegrliche Keime hervorbringt. Dic Yolvocinen dagegen sind ihr ganzes L.cben himburch sich bewegende Organismen, die nur vorübergehenl in cinen rulıcnden Zustand übergehen, wie dies lie wahren Infusionsthiere auch Lhun; aus dem ruhenden Zustuncle tritt. sofont wieder dic sich bewegende Form hervor. Die Vermehrung durch Theilung im rulıenden Zuslande kann lieine Vegretationserscheinung sein. denn sie findet sich bei den ruhenden Zustanden der Infusionsthicre cbenfills, wie wir weiter unten schen werden. Die beweglichen Algenkcime gchen nach kurzer Zcit zur Vegetation iulser und sind nicht im Slande, sich während der Bewegung durch Theilung zu vermehren, die Volvocinen dagegen pllanzen sich währent ihrer Bewegung fortgesetzt durch Theilung fort. Muss uns schon ein Organismus, der sich sein ganzes Lehen hindurch rastlos bewegt und sich zugleich fortpflanzt, aber nie vegetirt, als ein seftsames Mitglied der Pflanzenwelt erscheinen, so werten wir an seiner vegetabilischen Natur vollends irre werden, wenn sich zeigh, dass alessen Parenchym mit einem energischen Contractionsvermögen hegabt ist. Dass ein solches vorhanden sein muss, beweisen aher die bei len meisten Volvocinen nachgowiesenen contractilen Hohlramo. Auch der ausserordentlich contractile unl expansible Schmahel an den spermatozoen des Volvox globator spricht doch wohl dafiir, dass dieselben Producte eimes thierischen Organismus sind. Aus diesen Gründen und wegen der unläugbarcn innigen Verwandtschaft, die zwischen Volvocinen, Cryptomonadinen und Euglenen statt findet, nebme ich keinen Anstand, den Volvocinen wieder ihren Plat\% unter den geisseluagenden Infusionsthieren anzuweisen. Dass llie IJille ron Chlamydococcus und Stephanosphacra ans Cellulose besteht, kann uns nicht mehr beunruhigen, seitrem wir wissen, dass auch der Mantel der Ascidien von Cellulose gebiludet wirl.

Die geschlechltiche Fortpflanzung von Volvox globalor steht ibrigens nicht mehr isolirt da; sie findet sich, wie wir hald sehen werden, auch bei den höheren Infusorienformen. Aus den ganz vor Kurzem von einem sorgyfältigen und eifrigen Forscher, II. J. Carler, verötfentlichten Beobachlungen geht ferner hervor, dass auch noch bei anderen geisseltragenden Infusorien, nambich bej Eudorina elegans und Cryptoglena lenticularis, eine geschlechtliche Forlpflanzung vorkommt *. Die Spermatozoen werden hier chenfalls dadurch gebildet, dass bei gewissen Individuen das gesammte Körperparenchym durch fortgesetzte Theilung in einen Hanfen spindelformiger oder rundlicher Körperchen zerfillt, die sirh mittelst zweier endstindiger Geissehn lebhaft bewegen. Der Befruchtungsact selbst und scine Wirkung ist noch nicht hinlänglich klar erkamnt.

Von Cohn wurde noch eine zweite Ehrenberg'sche Infusorienfamilie dem Pflanzenreiche uberwiesen, deren thierische Natur bisher noch von Niemand in Frage gestcllt worden war, nambich dic Vibrionia. Von diesen Organismen wissen wir in der That njehts weiter, als dass sie anscheincnd williülurlich bewegte, hald grade, bald geschlängelte, bald spiralig ģewundene, melı oder wenigger deullich ggegliederte Füden sind, die lieine Spur von wejlerer Organisation erkennen lassen. Cohn zeigte num ${ }^{3}$, (lass sich die anscheinend williuhrlichen Bewegungen tler Vibrionien ginz genau auf die Bewegungserscheinungen zuruchfühen lassen, welehe unzweifelhaften Algen, den Oscillarieen, cigen sind Dic Vibrioniengathung Spirochacla stimmt in ihren Bewegungen und auch in ihren Formen so vollkommen mit der Oscillarieengallung Spirutina uberein, dass sie gralezu als einc blosse Art der letzlem Gattung angesehen werden muss. Bei beiden Organismen besteht das Hamptmoment der Bewegung in einem Drehen des Fadens um seine Laingsaxe, in Folge dessen sich der Faden sehr rasch bald rorwảts, bahd rickwärts schrabu.

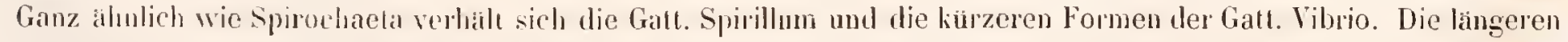
sich langsam bewegenden Formen lagegen reihen sich ohne Zwang an die lumblosen Oscilluricen an, welche die Galtung Beggiatoa bildeu. In fauligen Infusionen finden sich nehen zahllosen frei umherschwirmenden Indiviluen von Vibrio lincola Ehbg. (Bacteriun termo Dujurl.) gewöhnlich anch liuglige, lappige orler hautarlige, dicke Gallertmassen, in denen zahilose, unbewegte Strichelchen, welche Vibrio lineola sehr ähnlich selren, eingebetted liegen. Cohn

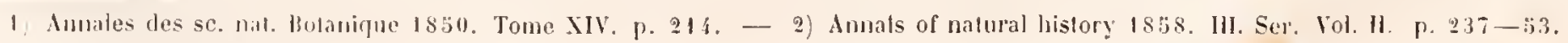
3) "Teler die mikioscopinchen Algen und libe. "Novi aclat Ariul. L. Leop. Car. Vol. XXIll. Pars 1. P. I16-32. 


\section{9}

glaubı, dass jene Strichelehen aus der Gallertmasse ausschwámen und dann den Viluro lineola liefern; er erkennt daher in den Gallertmassen einen morphologisch mit Palmella und Tetraspora zunächst verwandten, zu den Wasserpilzen zu rechnenden regetabilischen Organismus, aus dem er dic Gallung Zoogloea loildet. Vibrio lineola wiurde hiernach nur die Schwarmform eines Wasserpilzes sein. Wenn man auch diesen Punct noch nicht für ausgemacht ansieht, so thum doch Cohm's Untersuchnngen überzeugend dar, dass die Bewegungen der Vibrionien keine willkiihrlichen sein kömnen. Damil fällt alser atuch der einzige Grund weg, der bisher die Stelluug der Vilırionien bei den lufusionsthieren zu rechtfertigen schien.

Einige andere Arbeiten von Colm schliessen sich so innig an meine eigenen an, dass wir sie am fiighichsten im Zusammenhange mit denselben belrachlen. Der Entwickelungsgang meiner Infusorienforschungen ist am harsten aus meiner letzten zusammenfassenden Arbeit: "Die Infusionsthiere, auf ihre Entwickelungsgeschichle untersuchl. Leipzig 1834 " zu ersehen; daher ich hier hauptsichlich dieser folge. Mrine crsten Beobachtungen wurlen in Wiegmami's Archiv fü Naturgeschichte 1849 S.92-14.8 und in der Zeilschrift für wissenschaflliche Zoologie 1832 band III S. 475-509 veröffentlicht. Zum Studium der Infusorienwelt wa ich zunächst durch meine Lnter-

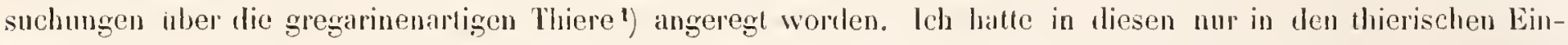
geweiden, namentlich im Darmkanal der Insecten und Würmer scharenweis vorkommenden Geschöpfen cine eigene, den einfichsten Rhizopoden und Infusionshicren nahe verwandte, aber von beiden doch wesentlich verschiedene Abtheilun der Protozoen erkannt. Ueber ihre Organisalion konnte hei der bedeutenden Grösse, die viele Gregarinenformen erreichen, nicht der mindeste Zweifel äbrig bleiben; sie ist höchst einfach. Der Körper stellt eineu meist länglichen, ringsum geschlossenen Schlauch dar, der von einer derben, elastischen, hyalinen und völigr structurlosen Ilembran begranzt wird unl ein sehr weiches, hreiariges, von vielen Fethörnchen getruhtes Parenchym umschliesst. Innerhalb desselben liegt ein heller, rundlicher, scharf begrảnzter Nucleus mit einem oder mehreren Nucleolis. Andere inncre Organe fehlen durchans, ehenso jede Spur eines Mundes. Gewöhnlich setzt sich das vortere Köpperende durch eine Einschniirung und cine dieser entsprechende senkrcehte Scheidewand wie eine Art Kopf ab, und dieser ist hiulig in einen hohlen ritsselartigen Fortsalz oder eine Haftscheibe ausgezogen; auch findel. sich bei einigen Formen noch eine zweite Scheilewand in der Milte des Körpers. Die meist sehr lràgen und langsamen Bewegungen gleichen denen der Eingeweidewirmer; sie werden durch die Contractionen und Expansionen des gesammten Körperparenchyms vollfühıt. Die Nahrung der Gregarinen besteht in den thierischen Fliissigheilen, welehe in ihrer Ungebung vorkommen; diese werden von der gesammten Körperoberllache aufgesogen. Die Fortpflanzung wird durch die Conjugation zweier hodividuen eingeleitet, die sich kugelförmig zusammenziehen und sich so innig an einamler schmiegen, dass sie zwei mit ihren Grundflachen zusammengefügte IIalhkugelı darstellen. Um diese bildet sich eine von den beiden Individnen abgesonderte kuglige Iliille, die nach und nach die Form einer

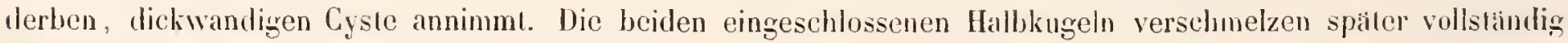
mit einander zu einem einzigen Ballen, und dieser zerfillt zuletzt in eine Anzahl eigenthünlich geformter Sporen, aus denen sich wieder den Mutterthier áhnliche Junge entwịckeln ${ }^{2}$ ),

Nachdem ielı durch genane Untersuchung einer grossen duzahl von Gregarinenformen dic unerschütlerliche Ueberzengung gewonnen hatte, dass whilich zahlreiche entwickichte Thiere existirten, welche sich ohne Muskehn hewegen, olıe Nerven emplinden, ohne Darmkanal verdauen mul ohne Geschlechısorgane dureh einen höehst eiı-

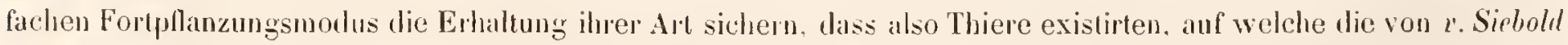
aufgestellte Begriffsbestimmung der Protozon volkommen anwendbar war, wurte es mir immer einleuchtender.

1) Stein "Leber die Nalur der Gregarinen. Jüller's Arehiv 1848. S. 182_223. - 2) Dies gill wenigslens von den in Inseclen lebenden Gregarinen. Bei den in den Regenwiirmenı vorkommenden gehl nach neuern Lnlersuehungen ron N. Lieberkizhn (aleuoires des

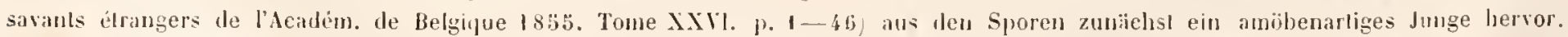
das sich dann wieder in eine Gregarine umwandelt. Dass die Conjugation zweier ludividuen bei den Gregarinen der Jnsecten Regel ist. davon habe ieh mich durch sehr umfassende Untersuehungen bestimml ïberzeugl. Unumgänglieh nolluwendig isl jedoch diese Conjugalion nichl, sondern es ham auch ein vereinzelles eneystirtes Thier Sporen liefern, wie Lieberkiihn richlig herrorgehoben hal. 
dass auch die grgen Ehrenberg's Auffassung der Infusorienorganisation gerichtete Opposition wenigstens in den wesentlichsten Puncten im Rechte sein werde. Schon um ein selbststundiges Urtheil iuber den Organisationsgehalt der Infusorien zu gewinnen, fibhte ich mich lebhaft zu einem Studiun derselben hingezogen, noch mehr aher trich mich dazu der Gedanke an, bei ihnen vielleicht dieselhe Fortptlanzung nachweisen zu kömnen, wie bei ılen gregarimenartigen Thicren, von denen manche Formen, namentlich Nonocystis agilis (Proteus tenax Dujard.) auffallend an die Astasiảen unter den Infusorien erinnerten.

Im Herbst 184.7 beganuen meine lnfusorienforschungren. Natürlich war von Anfang an mein vorzuiglichstes Augenmerk darauf gerichtet, einen Encystirungsprozess bei den Infusorien aufzufinden, wozu um so mehr Iloffnumg rorhanden war, als bereits ". Siebnld bemerkt hatte, dass sich die Euglena viridis zu Zeiten kugelförmig zusammenziehe und mit einer Art Kapsel otler Cyste ungebe 1). Sehr bald beobachtete ich diese Erscheinmg bei demselben Thiere; allein die neu gebildeten, noch ganz weichen Cysten umschlossen immer nur ein einziges hndividuum, die älteren, härteren dagegen enthielten håufg zwei oder vier kleinere, die nur durch eine einmalige oder doppelte Theilung aus einem urspriinglich einlachen Thier hervorgegangen sein homnten. Gleichzeitig wurden auch die ersten Cysten von zuei bewimperten Infusorien (Prorodon niveus und Itolophrya discolor) aufgefunden; sie waren selır weich und gallertartig und enthielten nur ein einziges kugelförmig contrabirtes Thier, das sich leicht aus den Cysten hervorpressen liess.

Im folgenden Winter untersuchte ich anhaltend die wegen ihres häufigen, masseuhaften Auftretens in Heuinfusionen so bekanut gewordene Colpoda cucullus $\left.{ }^{2}\right)$. Die Organisation dieses Thieres zeigte sich wesentlich anders und einfacher, als sie Ehrenberg dargestellt hat, und die von ilum behauptete perjodische Ausscheidung eines aus netzförmig verbundenen, schuuförmigen Eierröhren zusammengesetzten Eierstockes reducirte sich auf ein zufalliges, lediglich durch Wassermangel bedingtes Zerfliessen einzelner Individuen, in Folge dessen die imnern grobliörnigen Bestandtheile aus dem Körper hervortraten und ein ganz unregelmassiges Haufwerk bildeten. Eine Entwickelung der einzelnen Körner zu jungen Colpoden liess sich in keiner Weise constatiren. Jiermit war das Hauptargument, auf welchem Ehrenberg's Lehre von dem weiblichen Geschlechtsorganismus der Infusionsthiere beruht, widerlegt. Es wurde aber auch der wahre Hergang bei der Fortpflanzung der Colpoden ermittelt. Diese Thiere vermehren sich nicht. wie andere Jnfusorien, wăhrend sie ilıre gewöhnliche Lebensthätigheit fortsetzen, durch Theilung, sondern sie thun dies nur, nachdem sie sich liugelförmig zusammengezogen haben und in einen ruhenden Znstand ubergegangen sind. Alsdann bildet sich um deu contrahirten Körper, der sich unaufhörlich auf demselhen Flecke langsanı im Kreise hermmwälzt und sich häufig schon zu Hıeilen anfingt, eine dichwandige Cyste, in welcher der Körper durch fortgeselzte Theilung in zwei otler vier, seltener in acht Segmente zerfillt, die die Organisation des Mutterthieres zeigen, sich eine Zeit lang lebhaft in der Cyste umbertummeln, damn aber zur Ruhe kommen und sich oft wieder mit Specialcysten umgeben. Das häuge Vorkommen ron leeren gesprengten grossen und kleinen Cysten liess keinen Zweifel darüber, dass die in ihnen eingeschlossen gewesenen Theilungssprösslinge aus den Cysten spater wieder zu nener Lebenshbitigheil herausgetreten sein mussten. Oflenhar ist ulieser ganze Torgang genau derselbe wie bei den ruhenden Zustanden des Chlanydococcus phvialis und daraus folgt, dass die Vermehrung des Chlamydococcus während seines ruhenden Lebensstadiums nicht entfernt einen Beweis fur dessen regetabilische Natur abgeben liann.

Die von mir endeckte Forlpllanzungsweise der Colpoden, die unlangst durch Weisse durehaus bestätigt worden ist ${ }^{3}$ ). erklarte nun mit einem Nale auf die einfachste und naturlichste Weise von der Welt das schnelle und zahlreiche Erscheinen dieser Thiere in Heuanfgissen, die nit dem reinsten, destilliten oder frisch abgekochten Wasser bereitef worden waren, eime Thatsache, die so olt zur Begrindung tler materialistischen Lehre ron einer

1) v. Siebold"Leturbuch der vergteichenden Anatomie « S. 25. - 2) Stem "Die Infusionshiere" S. 15-25. - 3/ J. F. Heise Einige Worte über segetabilische Aufüisse und über die Vernehrungsart ron Colpoula cucullus." Nélanges biologigues de l'Acad. de si Pelersbour's 18:38. Tone III. $\beta .29-37$ 
elternlosen Zeugung organischer liörper missbraucht worden war. Am lleu sitzen die winzig kleinen, den Sporen vergleichbaren Cysten von Colpoden und deren Theilungssprösslingen, und es bedarf unr der Darreichung der unentbehrlichsten Lebenshedingung der Infusorien, des Wassers, um dic in den Cysten eingeschlossenen und wohlverwahrten Keime der Colpoden wieder zu neuer Lebensenergie zu erwechen. In den durch die Maceration des Heues frei werdenden organischen Substanzen finden daun die aus den Cysten geschlipften jungen Colpoden eine reichliche Nahıug. An den aufgeweichten Heustengeh lassen sich auch leicht die an ilmen bängenden Cysten nachweisen. Der natürliche Aufenthalt der Colpoden scheinen nasse Wiesen zu sein; Irocknen die uassen Stellen aus, so bleiben die ençstirten Colpoden an den Grasstengeh kleben. Es mögen aber auch die Colpodencysten oft von ihrer urspringlichen Bildungsstätte durch die Winde fortgefüht und nur zufällig auf Ileu abgesetzt werden.

Hiermit war der Schliissel zur Erlibung des Auftretens von Infusorien in beliebigen, durch almosphärische Niederschlige chen erst gebildeten Wasserlachen, so wie in hünstlichen, mit ren verschieleuartigsten Körpern hereiteten Infusionen gefunden; es kan nun darauf an, den Encystirungsprozess weiter verbreitet bei den Infusorien nachzuweisen, namentlich für solche Formen, die sich in künstlichen Infusionen und in der ersten besten Wasseransammlung einzustellen pllegen. Eine der gemeinsten Erscheinungen in fauligen Infusionen ist die Vorticella microstoma; sie bildete den uachstfolgenden Gegenstand (ler Untersuchung ${ }^{1}$. Auch von diesem Thiere wurden sehr bald ruhende, encystivte Formen aufgefunden, und zwar zuerst grosse isolitte kugelformige Cysten, in welehen noch ganz deutlich der kngelförnig contrahirte Vorticellenkörper zu unterscheiden war, dann aber anch Cysten, die sich um jungere, noch auf ihren Stielen silzende Vorticellenkörper gebildet hatten. Da sich nun fermer ergab, dass die Vermehrung der Vorticellen durch Theilung und Knospenbildung keineswegs auf den ausgewachsenen Zustand des Thieres beschrankt war, sondern schon auf sehr frühen Entwichelungsstufen eintrat, so kam ich auf die Vernuthung, es möge bei den Vorticellen ein Generationswechsel stattfuden, der darin bestehe, dass auf eine Reihe von durch Theilung und Knospung entstaudenen Generationen zuletzt cine Generation folge, die miltelst einer andern, der geschlechtlichen Zeugung der iblrigen Thiere äquivalenten Fortpflanzungsweise die ersten Keime neuer Vorticellen hervorbringe. Die freien kugelförmigen Cystenzustande der Vorticellen schienen mir eine Einleitung zu dieser letztern Fortpflanzungsweise zu sein; allein die Bemühungen, an denselben weitere Veränderungen zu beobachten, blicben einstweilen ohne Erfolg.

Bald nachher wurden meine Forschungen durch das Studium der Vaginicola crystallina ${ }^{2}$ ) in eine ganz andere Bahn gedrängt. Dieses vorticellen:ihnliche Thier ist im Grunde einer den grössern Theil des Köpers umsehliessendem und von ilm alygesonderten, biegsamen, hyalinen, becherfömigen llälse befestigt, mit der es auf Conferven und Wassedinsenwurzeh aufsitzt. In Gesellschaft dieses Thieres Iraf ich ungemein häufg und auf demselheis Pllanzentheile dicht nehen einander sitzend ein Geschöpf, in dem ich balıl die von Ehrenberg neht sehr Whar dargrestellte dcineta mystacina erlaunte. Fü ein selbstständiges Infusionsthier schien mir seine gresammte Organisation gar zu abweichend ron der aller andern, wohl aber bot es auffallende Analogien mit der Vag. crystallina dar. Die Acin. mystacina besass eine ganz ähnliche Huilse, wie die Vaginicola, nur war dieselbe nach hinten oft stielartig verengert und ihre Jlundung durch eine dachförmige Zusammenneigung des vordern Theils der Seitenwandungen in der Art verschlossen, dass nur sechs, von der Mitte strahlenartig nach aussen verlaufende, schmale Spalten frei l, liebeu. Unmittelbar unter dem dachförmigen Verschluss war durch ein gallertartiges Bindemittel ein völlig geschlossener rundlicher Köper aufgehängt, von dem nach rom zahlreiche, durch die spalten der Hulsenmundumg liervortretende, fadenförmige und in einem Kuöpfehen endende Tentaheln ausstrahıten, welche sich langsin rerkiurzten und verlangerten, auch hoben und senkten. Der Körper besass weder einen Innı, noch liessen sich in seinem ganz homogenen Innern verschluckle frenule Körper nachweisen; nur en contractiler Iohlraum und ein runder Nucleus war vorlanden. Da sich auch Acineten fanden, deren Körper noch keine Spur von Tentakeln zeigte, und da ich ferner

1) A. a. 0. S. $25-3 \ddot{3}$. - 2) Ebendaselbst S. $35-42$.

L teill, Organismus der lufusionslliere. 
melıfach heobachtete, dass bei Vagr. crystallina der sich von seiner Hülse ablösende Körper die Hiilse nichı, wie es sonst Regel ist, verliess, sondern in der Mijndung derselben schweben blieb und eine Gallertschicht anszuscheiden anfing. so zweifelte jch nicht länger daran, dass die Acinela mystacina nur einen aus der Metamorphose der Vagin. crystallina hervorgegangenen ruhenden Zustand der letzteren darstelle, ja in einem Fulle glaubte ich die Jetamolphose direct verfolgy zu haben.

Es ham nun weiter daranf an, den Zweck einer solchen Mctamorphose zu ermitteln. Bei Acin. myslacina hatte ich oft das Volumen des eigentlichen Körpers ausserordentlich verringert gefunden, ich schloss daraus, dlass anf Kosten der Körpersubstanz irgend eine Art von Keimen entwickelt und nach anssen ausgeschieden worden sei. Dieser Schluss erwies sich auch als vollkommen richtig. Icl fand namlich demnächst auf Cyclops quadricornis sehr hảufig eine andere, fast immer gleicluzeilig mit rorticellenartigen Infusorien, namentlich mit Epistylis cligitalis rorkommende Acinetenform ${ }^{1}$, und an dieser machte ich zuerst die folgenreiche Entdeckung, dass sich im Innern des Acinctenkörpers ein dem Iutterthier völlig ungleiches, äusserst bewegliclıes Junge entwickelte, welelıes den Acinetenkörper am vordern Encle durchbrach unt höchst lebhaft und stiimisch im Wasscr mmherschwärmte. Ich nanute dieses Junge wegen seiner Analogie mit den Schwämsporen der Algen Schwärmsprössling. Der länglich ovale Körper desselhen zeigte sich sehr contractil und biegsam und vor der Mitte mit einem dichten Wimpernkranze umgeben, sonst war er nackt und ringsum geschlossen; in der ganz lomogenen Lcibessubstanz war nur ein contractiler Hohlram und ein rundlicher Nucleus zu unterscheiden.

Bei einer dritten Acinetenforn ${ }^{2}$ ), welche ich sehr hänfg auf Wasserlinsenwurzeln in Gesellschaft ron Vorticella nebulifera und Epistylis mulans antraf, beobachtele ich die alhuahliche Entwichelung des hier ganz ähnlich gestalteten Schwärmsprösslings aus einem dem Nucleus der Acinete volliommen gleichenden und demsellsen of innig anliegenden rundichen liörper. Hierdurch ham iclı zuerst auf die Vermuthung; dass sich der Schwärmsprössling aus dem Nuclens der Acinete entwickeln werde. Die beiden zuletzt erwälnten Acinetenirten unterschieden sich wesentlich ron der Acin. mystacina, ihr Körper wird nämlich von keiner Hijlse umschlossen, sondern sitzt frei am Ende eines steifen Stieles, der diesclbe Beschaffenheit hat, wie der Stiel der Vorticellinengattung Epistylis. Da für mich feststand, dass sich die Vağinicola erystallina in die Acineta myssacina umbilde, so war zu erwarten, dass auch noch andere vorticellenartige Infusorien in einen Acinetenzustand iblergelıen würden. Die Uebereinstinmmng in der Stielbildung bei unsern beiden Acincten mit der der Gatung Epistylis, das so häufige gleichzeitige Vorhommen von Acineten und Epistylisarten auf ein und demselben Körper und die unverkennbare Aehulichkeit zwisehen den Schwärmsprösslingen der Acineten und den Knospensprösslingen der Vorticellinen überhalupt hestimmten mich laher zu der Annahme, dass die steifstieligen Acineten in den Entwickelungslireis der Galtung Epistylis grehörten und dass sie das letzte Glied desselben darstellten. Welehes nur die Bestimmung hahe, die Keime zu nenen Episł̨̣lisstöcken zu produciren. Die Schwärmsprösslinge unserer Acineten mussten dieser Annahme zufolge wieler zu einem jungen Epistylisthjer werden. Es gelang jedoch niemals, diesen Uebergang dircet zu verfolgen, sondern ich verlor sie wegen jhrer ungestiumen Bewegungen immer kurze \%eit nach ilırem Auslritt aus dem Acinetenkörper aus dem Auge 3 ).

Bei einem wierlerholten Studium der Vorticella microstoma heohachtete ich wieder in grosser Anzahl die bereits erwihnten kugelförmigen Cysten. Bei vielen derselben war der eingeschlossene Körper in cine röllig geschlossene kugel umgewandelt. Es fanden sich aber auch seh. häufg ganz ahhnliche Cysten mit quergerjppten

1) Ebendaselbst S. 48- \$8. Die von mir enteckten Acinetinen blieben in meiner Schrift olme systematische Nanten, weil ich sie für blosse Entwickelungsslufen vorlicellenarliger Infusorien ansah. Ich suchte sie sogleich auf beslinmte forlicellinen zu reduciren, und las war jedenfalls ein verfrühtes linternehmen. Da diese Reductionen, wie wir gleich sehen werden, zweifelhaft geworden siud, so wird es zwechmässiger sein, jene Acinelinen einstweilen durch hesondere Namen zu fixiren, bis ihre Nalur lefinitiv festgestell sein wird. Die auf den Cyclopen lebende Acinele (Tal. 11I. Fig. 38-41 meiner Schrift) mag Acinela Cychopum heissen. - 2) Ebendaselbst S. 59-64 und Taf. III. Fig. 32-33. Diese Acinete mag Acin. Lemnarum heissen. - 3) Die Acineta Lemnarum wurde anfangs ron mir als eine Entwichelungsstufe der Epistylis nutaus betrachtet, später $20 g$ ich es vor, sie von Vorticella nebulifera abzuleilen. 
Wandungen, die nach hinten in einen kurzen hohlen Stiel ausgezogen waren. Bei noch anderen, etwas langer grestielten gingen von dem Scheiteltheile des cingeschlossenen Körpers die für llie Acincten so characteristischen gelnopften Tentakeln aus ${ }^{\dagger}$ ). Die letzteren Formen stellen unverkennbar die Podophry fixa Ehbq. dar. Hiernach schien es keinem Zweifel unterliegen zu können, dass ule Podoplurya fixa die Acinetenform der Vort. uicrostona darstelle, welche aus ciner einfachen Vetamorphose tler Vorticellencysten hervorgehe, indem der ejngeschlossene

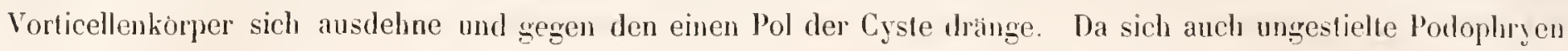
fanden, von tleren Körper nach allen Richtungen hin Tentakelı ausstrahtten ich bestimmte sie irrthümlich als Actinophrys sol Ehbg.), so nahm ich an, dass diese aus den Vorticellencysten in Folge einer allseiligen gleichfömignen Ausdehnung des eingeschlossenen Körpers entstanden seien. In diesen Ansichten wurde ich noch mehr dadurch bestarkt, dass bereits vor mir Pinean in Frankreich 184.5 einen genetischen Zusammenhang zwischen Podophrya fixa und Torticella microstoma nachzureisen gesucht hatte; nach ihm sollte sich die Podophrya lixa aher in Vorlicella microstoma unwandehn ${ }^{2}$ ) und aus ten Vorticellencysten sollte sich eine Oxytricha entwickeln ${ }^{3}$ ).

Mit den iber die Entwichelung der vorticellenartigen Infusorien gewomnenen Resultaten trat ich im Herbsl 1849 vor die Oeffentlichleit ${ }^{4}$. Es waren zwar schon zuvor einige vereinzelte Beobachtungen uber die Entwichelung und Geburt von innern Sprösslingen bej Infusorien gemacht worden, die Mittheilungen dariber waren jedoch so unvolstäulig, dass sie last ganz unbeachtet blieben; auch ging aus denselhen heineswegs hervor, dass die Sprösslinge eine von dem Mutterthier ganz und gar verschiedene Generation biluteten. $v$. Sicbold erwähnte 183.) ganz beiläulig in seiner beruhmten Abhandlung iber Monostomum mutabile ${ }^{5}$, dass er hei einer der im Darmianal der Frösche lebenden Infusorienformen (ohne Zweifel war es eine Bursaria. keine Opalina) nim Schwanzende eine durchsichtige Höhle (Uterus) beobachtet habe, in welcher sich vicle Junge äusserst lebhaft bewegten, von denen mehrere ilıren Aufenthahtsort verliessen und gleich ihren Itittern in Wasser geschicht unherschwammen." Auffallend ist, dass $v$. Siebold dieser Beobachtung in seiner vergleichenden Auatomie gar nich gedacht hat. Ferner hatte Focke I84.4 auf der Naturforscherversammlung in Bremen die wichlige Mitheilung gemacht ${ }^{6}$, dass er im Herlsst und Winter bei grossen und sehr blassgrinen Exemplaren von Loxodes bursaria die Eulwickelung von ein bis drei lebendigen Jungen innerhall der Samendruse Ehrenberg's. die deshalb als Uterus zu bezeichnen sei, beobachtet labe. Der Austritt der Jungen wurde ebenfalls verfolgt, von diesen aber nur angeyeben, dass sic dieselhe Farbe und dieselbe Anordnung der contractilen Blasen und der Samendruise besässen, wiu

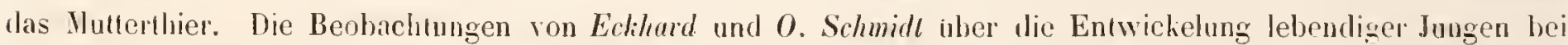
sientor coeruleus und polymorphus sind bereits oben (S. 32 und 33) erwahnt worden.

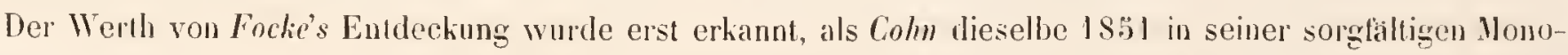
graphie von Loxodes bursaria hestatigte, erweiterte und zum Theil berichtigte ${ }^{7}$ ). Cohn zeigte, dass die innern Sprösshinge dieses Thieres, die er Embryonen nenut, keineswegs in tlem Nucleus, sondern in einer besondern Ilöhle liegen, welche durch einen die Körpersubstanz durchsetzenden Gang mit der Aussemwelt communicirt. Durch diesen Gang treten die Embryonen, deren Ursprung dumliel blieb, nach aussen. Sie waren stets farblos. ohne: Mund, auf der ganzen Oberfläche bewimpert und schr häufig mit kurzen, au Ende ggeknopften. fadtuförmigen Fortsätzen versehen, und im Innern enthielten sie zwei contactile Blasen. Cohn hebt mit besouderm Nachulruck hervor, dass die Embryonen von dem Mutterthiere Lotal verschieden seien, dass mithin bei Loxodes bursaria eine Metamorphose, wenn nicht gar cin Generationswechsel statufuden misse. Wichlig war in Cohn's Albeit ferner der Nachweis, dlass die grünen Köruer im Leibe von Loxodes bursaria Chlorophyllhörner scien und dass der Nucleus.

1) A.a.O. S.139-146 u. Taf.IV. Fig. 21.30.31. - 2) Anuales des se. nal. 1843. III. Sér. Tome III p. $182-89$ u. Tome IN. p. 103 -4.

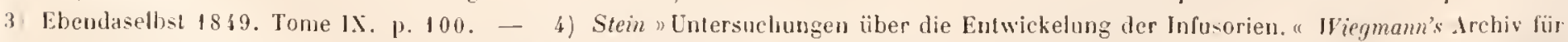
Naturgesch. 1849. S. 92-148. - 3) 1Viegmann's Archiv 1835. 1. S. 73-74. - 6) Amtlicher Berichl über die 22. Yersamml. deutsch. Nalurf. und Aerzte in Bremen 1845. Abth. II. S. 110. - 7) Coln "Beitrige zur Entwickelungsgeschichte tler Infusorien. Zeitschrift fïr wissenschaftl. Zoologie 1851. Band III. S. 257-79. 
wie zuerst $v$. Siebold angegeben hatte'j, aus zwei ganz verschiedenen Bestandheilen, dem eigentlichen bohnenförmigen Nucleus und einem demselben anliegenden kleinen weizenkoruähnlichen Nucleolus bestehe und dass beide von eigenen Membranen begranzl seien. Sehliesslich führt Cohn noch an, dass er auch bei Urostyla grandis häufig das Innere von einer grossen Anzahl dunkler Kugehn erfüllt gefunden hahe, die den Loxodeskeimen sehr ähnlieh sahen. Als sie dureh Quetsehen des Thieres frei wurden, fingen sie sich lebhaft an zu bewegen, sie zeigten sieh nun auf der ganzen Oberfliehe bewimpert und enthielten einen verwaschenen Kerı und zwei contractile Blasen.

Colm zog spăter auch den Encystirungsprozess der Infusorien in den Kreis seiner Untersuchungen ${ }^{2}$. Er beobachtete dic Cystenbildung bei Vorticellen und Euglenen, bei Prorodon teres, Holophrya ovum, Trachelius ovum, Trachelocerea olor und Amphileptus fasciola, auch gedenlit er einer bei Chilodon uncinatus (?) ron Anerbach beobaehteten Cystenbildung, welcher Forscher später selbst noch den Cystenzustand von Oxytricha pellionella beschrieb ${ }^{3}$. Cohn folgerte bereits aus den bisherigen Untersuchungen, dass das Encystiren ein in der Klasse der Infusorien verbreiteter, bei sehr verschiedenen Familien stattindender Prozess sei, der theils zum Schutz gegen äussere schädliehe Einflüsse, theils als Vorhercitung zu einer Fortpflanzung eintrete. Cohu machte ferner auf die Verwandtsehaft zwischen Cystenbildung und den verschiedenen Formen von Gehause- und Pauzerbildung bei lnfusorien aufmerksam, und er bezeichnete mit Rechı nur diejenigen Infusorien als gepanzert, die von einer spröderen, starren. niemals contractilen (?) Haut begtanzt seien. In einem besondern Aufsatze ${ }^{4}$ ) ging er specieller auf die äussere Körperluedeckung der Infusorien ein; er zeiģte, dass Loxodes bursaria und Paramaecium aurelia von einer zarten strueturlosen Membran begräuzt seien, dic er" "Cuticula " nennt.

Inzwischen waren meine eigenen Forschungen fortgeselzt darauf gerichtet gewesen. neue Thatsaehen zur weitern Begründung des genetischen Zusammenhanges zwisehen den vorticellenartigen lıfusorien usd den Acinetinen aufzulinden. Wenn bei meinen hisherigen Beobachtungen und Schliissen nicht Irrthimer mit untergelaufen waren. so mussten sich nach und nach für alle vorlicellenartigen Infusorien die zu ilinen gehörigen Acinelenformen nachweisen lassen. Ich bemuilıte mich daher, mir so viele Vorlicollinen als nur möglich zu verschaffen. Da diese Thiere rorzugsweise auf Wasserlinsenwurzeln. Wasserhifern, Phrygandenlarven, Crustaceen und Wassersehneckengehäusen festsitzen, so durchsuchte ich diese Körper mit der grössten Ausdauer auf Vorticellinen. Mleine Benuhungen wurden von dem günsligsten Erfolge gekrön. Ich lernte nicht blos die meisten bercits bekunnten Vorticellinen kennen. sondern ich entdeckte auch eine uicht unbedeutende Anzahl neuer Formen. Unter diesen waren bej weitem die interessanlesten die neuen Gatlungen Lagenophrys und Spirochona und die merkwürdige Acinetenform Dendrocometes paradoxus. Ueber diese Formen und iber neuere die Entwichelung der Vorticella microstoma betreffende Beobachtungen beriehtete ich bereits 1852 in einer besondern Abhandlung 5 \%. Die ubrigen neuen Formen gehörten den Gallungen Epistylis, Opercularia, Zoothamnium und Cohhurnia an. Das anhaltende Studiun der von mir aufgefundesen Vorticellinen führte zu einer sehärferen Begranzung der einzelnen Galtungen, auch wurden viele neue Thatsachen üher ihre feinere Organisalion und namentlich tiber ihre Fortpflanzung durch Theilung und Knospenbildung. ublser die Entwichelung der Fanilienstöcke und ïber die Gehäusebildung der Vaginicolen und Cothurnien ermultelt.

Sehr verbreitel wurde von mir bei den Torlicellinen die Cystenbildung nachgeviesen und gezeigt, dass diese ebenso wie die Fortptlanzung durch Theilung und Knospenbildung auf allen Altersstufen eintreten könne. An den grössem freien kugelförmigen Cysten der Vorticella microstoma entdechte ich noclı eine neue eigenthümliche Entwichelungsweise ${ }^{6}$. Der encystirte und in eine einfache liuglige Blase umgewandelte Vorticellenkörper bekam ıänlich häuligg eine unebene blasig-höckrige Oberflache; einer oder melırere von den Höckern wuchsen nach und

1) Lehrbuch der vergleichenden Anatomie S. 24. - 2) Zeitschrift für wissenschaftl. Zoologie 1853. Band IV. S. 253 und 1854. Band Y. S. 434-35. - 3) Ebendaselbst Band V. S. 430-33. - 4) Ebendaselbst Band Y. S. 420-29. - 3) Stein "Neue Beiträge zur Kenutuiss der Enlwickelungsgeschichte und des feineren Baues ler lufusionshliere. Zeitschrilh für wissensch. Zoologie 1852. Band III. S. 475-509. - t) Stein "Die Iufusionslluiere. "S. 194-96. 
nach in zapfenförmige Fortsätze aus, die die Cystenwandung durchbohrten. Zulelzt öflnete sich das frei in die Aussenvelt hervorragende Ente des Zapfens, und es quoll nun plötzlich eine weiche, zusammenlıaltende, tribe Gallertmasse hervor, dic an der Mündung des Zapfens h'ingen hlieb und sich bald darauf zu einem hellen kugelförmigen Tropfen erweiterte, in dem zalılreiche, sehr kleine, opake, monadenähnliche Keime sich lebhaft durch einander bewegten. Nach wenigen Minuten floss der Gallertropfen in Folge von immer stälierer Wasseraufnahme aus einander, und die Keime zerstrenten sich sehr behende nach allen lichtungen; ilır Bewegnngsorgan liess sich nichı deutlich erkennen. Da ich im Nucleus sowohl der freien, als der encystirten Vorticellen häufig eine kleinere oder grössere Anzahl scharfbegränzter, scheibenförniger Kerne auftreten sah, so vermulhete ich, dass dies der Anfang zu einer Art innerer Brubildung sei, die zu Zeiten bei gewissen encystirten Vorticellen eintrete und zuletzt mit dem eben geschilderten Gebursacte endige.

Den bei weitem höchsten Werth aber hatte fiir mich die Constatirung der Thatsache, dass sich in Gesellschaft der vorticellenartigen Infusorien sehr hiufig auch Acinetinen fanden. Die meisten derselben waren bis dahin ganz unbehannt geblieben. Es wäre sicherlich durchaus ungerechtfertigt gewesen, aus dem blossen Nebeneinandervorkommen von Vorticellinen und Acinetinen auf einen entwickelungsgeschichtlichen Zusammenhang dieser beiden Inlusoriengruppen zu schliessen. Der Umsland, dass in Infusionen neben den Cystenzustanden von Vorticella microstoma von unir in sehr vielen Fällen die Podophrya fixa beobachtel wurde, konnte ein rein zufälliger sein, da ja in Infusionen auch noch mancherlei andere Infusorienformen sehr häufig rorkommen; ebenso zufällig lionute das von mir of beobachtete massenhafte Vorkommen der A. Lemnarum und der Vorticella nebulifera auf ein und terselhen Wasserlinsenwurzel sein. Wenn sich dagegen in den allerverschiclensten Localităten auf ein und demselben Naturhörper immer nur eine bestimmte Vorticellinenform und ein und dieselbe Acinetenform und sonst liein anderes Infusionsthier vorfanden, so konnte ich darin tein blosses Spiel des Zufalles mehr erkennen, sondern ich hielt mich für berechtigt, einen innern nothwendigen Zusammenhang zwischen beiden anzunelımen.

Nun traf ich aber auf Dytiscus marginalis nie ein anderes Infusionsthier, als die Opercularia articulata, und zwar meist in zahlreichen dicht bei einander sitzenten Familienstöchen; in tlen meisten Fällen fanden sich daun auch zahllose Individuen ciner Acinctenform mit birnförmigem, an ganzen freien Rande mit Tentakeln besetztem Körper, deren Stiel genau dieselben Structurverhältnisse zcigte, wie das Slielgerust der Opercularien $\left.{ }^{1}\right)$. Die Acineten sassen in der Regel unmittelbar unter und zwischen den Opercularienstöchen oder doch in ihrer nächsten Umgebung. Ferner beobachtete ich vielfach an ganz verschiellenen Orten reichasige Familienstöcke von Epistylis plicatilis, die dicht and stets mit ein und derselben Acinetenform ${ }^{2}$ ) besetzt waren. Wierler eine andere Acinetenform liam auf den Stöcken von Epistylis branchiophila vor ${ }^{3}$ ). Auf dem Flusskrebse fand ich zwar verschiedene Vorticellinen, besonders häufig aher Epistylis crassicollis und in ilurer Gesellschaft unzahlige Male eine sonst nirgents beobachtete Acinetenform, die wieder genau die Stielbildung von Epistylis crassicollis zeigte ${ }^{4}$. Ein ganz seltsames acinetenartiges Geschöpf, der Dendrocometes paradoxus, wurde von mir ebenfalls in den verschiedensten Localitảten auf den Ǩiemenblättern von Gammarus pulex fast constant in Gesellschaft eines ebenso seltsamen vorticellenartigen Thieres, der Sprochona genmipara, beobachtet. Diese Acinetine ist stets ungestielt und stimmt in ihrer starren, panzerartigen Körperbedeckung auf's vollkommenste mit der Spirochona überein; dagegen unter'scheidet sie sich von allen bekannten Acinetinen sehr auffallend duch den Besitz von dicken, starren, mehr oder weniger verästelten, armartigen Fortsätzen, die die Stelle der gewöhnlichen retractilen Tentake!n vertreten.

Diese Fälle von Nebeneinandervorkommen von Vorlicellinen und Acinetinen, die sich anch neuerlich hier bei Prag immer wieder bestätigten, so wie gewisse Analogieen im Bau und Wachsthum beider Thierformen waren für mich ein Haupthestimmungsgrund, die Acineten in den Entwickelungskreis derjenigen Vorticellinen zu ziehen,

1) A. a. O. S.117-122 und Taf. Il. Fig. 2-6. Sie heisse A. Operculariae. - 2) S. 12-14 und S. 9 ă und Taf. I. Fig. 1. D E. Sie heisse A. quadriloba. - 3) S. 124 und Taf. 1. Fig. 10. Sie heisse A. Phryganidarum. - 4) S. 23 i und Taf. VI. Fig. $27-$ \&1. Sic lieisse A. Aslaci.

slein, Organismus der lufusioushiere 
in deren Gesellschaft sie so constant vorkamen. Ausserdem beobachtete ieh noch eine Anzalıl anterer Acinetinen. die entweder isolirt oder doch nicht immer in Gesellschaft derselben Vorticellinenform vorkamen; uber ibren Zusammenbang mit einer bestimmten Vorticclinenform konnten daher auch nur Vermuthungen ausgesprochen werden. Hieher gehört ausser der schon erwihnten Acineta Lemnarum und A. Cyclopum die sehr eigenthümliche grosse Acinete mit dem zungenföımigen Fortsatz' ${ }^{1}$, fermer die diademartige Acinete, der der Name A. cothurmata gebiilırt, unter den sie schon vor mir von Weisse beschriehen wurde ${ }^{2}$ ), sodann dic A. tuberosa Ehbg. und endlich die von mir auf Hyphydrus ovatus entdeckte Acinete ${ }^{3}$ ). Ueber die Ahstamnung der merkwiirligen, auf den Kiemenblattern (ler Wasserasseln lebenden, gefingerten Acinete ${ }^{4}$, die sich am nächsten an Dendrocometes anschliesst, konnte uicht einmal eine Vermulhung geăussert werden. Ob die von mir auf den Gallertkugeln des Ophrydium versatile beobachteten, der gefingerten Acinete :ihulichen Gebilde ${ }^{5}$ ) wahre Acineten waren, ist nur neucrlich deshalb zweifelhaft geworden, weil sie grime und braune Chloroplıyllkörner enthielten.

Die Acinetinen waren vor mir sehr gewöhnlich als die nächsten Verwandten der Rhizopoden angesehen worden, ja Dujardin hatle sie gradezu mit den Rhizopoden vereinigt und in scine Familie der Actinopluyen gebracht. Ich wies dagegen nach, indem ich die bercits von Kölliker ${ }^{6}$ sorgfaltig studirte Actinophrys Eichhomii und die von mir in der Ostsee aufgefundene Actinoph. oculata analysirte, diss die Actinophryen und die Acinetinen trotz aller áusseren Aehnichkeit fundamental von einander verschieden seien. Die Achnophryen sind wahre Rhizopoden, die an jeder beliebigen Stelle der Körperoberfliche die versehiedenartigsten thierischen und vegetabilisehen Körper als Nahrung aus der Aussenwelt aufnebmen können und zwar auf eine Weise, die neuerlieh Cluparede nảher gescliildert hat ${ }^{7}$ ); die unverdaulichen Nahrungsreste werden ebenfalls wieder an den rerschiedensten Puncten (ler Körperoherfläche nach aussen geschieden. Die Acinetinen dagegen besitzen weder einen Mund noch einen After, ihr Körper enthält niemals fremde, thierisehe oder vegetabilisehe Jiörper, sondern sie vermögen nur nittelst, ihrer Tentakeln gelöste organische Substanzen aufzunehmen. Diese ganz cigenthumbiehe Ernährungsweise, auf die ich weiter unten zurückliommen werde, schien gleiclıfalls dafür zu sprechen, dass die Acinetinen keine selbststandigen Thicrformen seien.

Ats das wichtigste Resultat meiner Untersuchungen iber die Acinetinen stellte sich beraus, dass sieh im Innern derselben ganz allgemein Schwärmsprösslinge entwickelten. Iclı sah immer nur einen Schwärmsprössling in einer Acinete entstehen, und dic Anlage zu demselben lieferte stets der Nucleus. In allen Fällen vergiössert sich zuerst der Nucleus, indem er entweder an dem einen Ende anschwillt (Acinela ligulata). oder einen zapfenfömmigen Fortsatz entwickelt (Acineta Lemnarum) oder sich mehr oder weniger veröstelt (Acin. Operculariac). Zuletzl sclıniil sich die vergrösserte Portion oder ein Zweig des veristelten Nucleus ab, und dieses Scgment bildet sich dann unmittelbar zu einem Sprössling aus, der stets in einer besondern Aushöhlung der Leibessubstanz dicht nehen dem persistirenden Theile des Nucleus liegt. Die reifen Schwirmsprösslinge sind bald nur partiell (Acinet. Lemnarum, Cyclopum, Astaci, Dendrocometes paradoxus), bald auf der ganzen Oherlliche bewimpert (Acineta ligulata, cothurnata, Operculariac), und enthalten stets einen Nueleus und cinen oder mehrere contractile Hohlräume. Sie durchbrechen meist an dem vordern Ende den Acinetenkörper, der sich batd nach ihrer Geburt wieder schliesst, sich dann wieder wie ein unversehrler Körper verhält, nach und nach seinen frühern Umfang erhảlt und später einen neucn Sprössling entwickelt.

Die Schwämsprösslinge gleichen in allen Bezielungen gewöhnlichen bewimperten Infusionsthieren, nur besitzen sie heinen Ilund; sie heweisen schlagend, dass die Acinetmen zu den wahren Infusionshlieren gehören und nichts mit den Aetinophryen zu thun haben. Nicmals waren mil unter den Tausenden von Acinetinen, welche

1) S. 103. und Taf. 11. Fig. I1-22. Ich nenne sie jetzl A. ligulala. - 2) Bultetin de l'Acad. de Sı. Petersbourg. Tom. V. No. 3. 3) S. 226 und Taf. Y. Fig. 32-36. Sie mag A. Hyphydri heissen. - 4) S. 228 und Taf. V. Fig. 19-22.. Sie mag einslweilen A. digitala heissen, obwohl sie von den ibrigen Acinelen generisch verschieden is!. — 8) S. 247 und Taf. IV. Fig. 4. 5. - 6) Zeilschrif für wissenschafliche Zoologie 1849. Band 1. S. 198-217. - T) "Ueber Achinophrys Eichlornii." Müller's Archiv 1854. S. 398. 
ich zn beobachten Gelegenheit hatte, Individnen in der Theilung vorgeliommen; diesen Umstand deutete ich ebenfalls zn Gunsten meiner Ansicht, dass die Acinetinen lieine selbststandigen Infusorienformen seien. Nicht mindes schien dafür die Thatsache zu sprechen, dass. während die Entwickelung von Schwärmsprösslingen bej den Acinetinen eine der allergewöhnlichsten Erscheinungen war, eine analoge Fortpllanzungsweise bisher nur höchst selten luei einigen wenigen bewimperten Infusionsthieren beobichtet worken war. Das weitere Schichsal der von den Acinetinen geborenen Sprösslinge hatte ich aller Mühe ungeachtet nicht ergründen können; sie entzogen sich früher oder spåter meinen Nachforschungen, ohne cine Verwandlung eingegangen zu sein. Dagegen sah ich nicht selten in solchen Acinetinen bereits einen reifen Schwämsprössling, die noch gar nicht ihre definitive Form erreicht hatten. \%. B. in völlig armlosen Dendrocometen. Konnte ich wohl in solchen einfachen, regungslosen, kugligen Kapseln ein selbststandiges Infusionsthier crblicken, und war es nicht natülicher, sie ron den so analogen Knospensprösslingen der stets gleichzeitig rorkommenden Spirochona gemmipara abzuleiten? Die mit steiftistigen Vorticellinen zusammen vorkommenden Acinetinen leitete ich von gewöhnlichen Individuen ler ersteren ab, indem ich annahm, llass die sich von ihren Stielen ablösenden Thiere sich in der nächsten Ümgebung wieder festsetzten, einen neuen Stiel ausschieden und ihren contrahirt bleibenden Körper mit einer dünnen Cystenhülle umgäben; der Körper sollte sich damn in eine geselılossene Blase verwandeln und nach aussen Tentakeln hervortreihen. Die zu contractilstieligen Vorticellinen gezogenen Acinetenformen leitete ich auf die schon für Yorticella microstoma angegebene Weise aus den Cystenzustinden lerselben ab.

Die Bedeutung des Nucleus der Infusionsthiere war bisher völlig dunkel geblieben, meine Untersuchungen uber die Entstehung der Schwärmsprösslinge bei den Acinetinen lieferten den ersten Beweis, dass der Nuclens das eigentliche Fortpflanzungsorgan der Infusorien sein müsse. Ich zeigte ferner, dass der Nucleus der Infusionsthiere stets aus einer umgränzenden structurlosen Hembran und aus einem homogenen feinkörnigen Inlualt bestelse. Ausser den Beobachtungen über die Vorticellinen und Acinetinen enthielt meine Schrift moch mancherlei neue Thatsachen über verschiedene andere Infusorien, namentlich bereicherte sie die Naturgeschichte der Gattungen Volvox, Chilodon, Trichodina, Opalina, Phacelomonas und des Losodes bursaria, der sich in jeder Bezielıung als ein wahres Paramaecium erwies und daher fortan Param. hursaria genannt wurde. Cohn's Beolachtungen uber die Organisation dieses Thieres und seine Fortpflanzung durch lebendige Junge, so wie Weisse's Entdeckung der Brutbildung bei Chlorogoniun euchlorum wurden bestatigt und zum Theil erweitert. Ausser in den bereits oben angefiuhrten Fällen wurde die Cystenbildung noch bei Folvox globator und dem erst ron mir unterschiedenen Volvox uninor, ferner bei Chilodon cucullulus, Stylonychia pustulata, Glaucoma scintillans und bei einer neuen Nassula (N. ambigua) nachgewiesen. Sowohl bei Acinetinen, als auch bei Actinophryen beobachtete ich einen Conjugationsact, in diesem honnte ich jedoch lieine Bezichung zur Fortpflanzung erkennen, da ich bei Actinophrys oculata nicht selten drei, vier und mehrere Individuen mil einander conjugirt antral. In Betreff der Organisation der Infusionsthiere führten alle meine Untersuchungen, wie auch die von Cohn, zu dem Resultate, diss Dujardin's und $v$. Siebold's Ansichten von der Infusorienorganisation im Wesentlichen die richtigen grewesen waren.

Die ron mir aufgestellte Lehre, dass die Acinetinen in den Entwickelungshreis der Yorticellinen gehören - man hat sie als die Acinetentheorje bezeichnet - war ohne Zweifel diejenige Seite in meinen Arbeiten, welche eine nur sehr unvollkommene Begrindung erhalten hatte; sie wurde dalser auch sehr lualı von den verschiedensten Seiten her heftig angegriffen. Die ersten gewichtigen Einwürfe gegen die Acinetentheorie rühren von Cienkousli her. Durch meine Arbeiten angeregt, hatte dieser Forscher sich die Aufgahe gestellt, den Encystirungsprozess bei möglichst vielen Infusorienformen nachzuweisen $\left.{ }^{1}\right)$. Es gelang ilın dies auch für eine ziemliche Anzahl dadurch. lass er Objectgläser, auf welchen bestimmte Infusorienlormen in einem Wassertropfen isolirt waren, auf kilöze in eine nur an Boden mit Wasser erfülte Untertasse stellte, die dann mit einer Glastafel bedeckt wurle. Iuf dies"

1) „Ueber Cystenbildung bei Infusorien.، Zeitschrift für wissenschaftl. Zoologie 183̈. Band I'I. S. $301-6$. 
Weise wurde dic Verlunslung des Wassers auf den Objectgläsern verhindert und ein und dasselbe lnfusionsthier konnte melurerc Tage lang in seinem kleinen Wasserraume verfolgt werden. Nach 2 -7 Tagen gingen viele der zu den Versuchen rerwendeten Infusorien in den ruhenden Zustand iber. An den Cystenzuständen einer Nassula, die Cienkowski zuerst als N. viridis Duj. lucstimmte, in der er aber späler meine N. ambigua erkannte, wurde eine ganz ähnliche Entwickelung und Geburt von lebendiger Brut beobachtet, wie ich an den Cysten der Vorticella microstomä nachgewiesen habe. In Innern des encystirten Nassulakörpers bilden sich nảmlich rundliche Blasen, diese verlangern sich in einen die Cystenwand durchbohrenden Schlauch, letzterer platzt an der Spitze und es quilt cin kugliger Haufen von monadenartiger Brut hervor, die Cienkow'ski als Schwämsporen bezeichnet. Aehnliche Schläuche, nur in geringerer Anzahl, hatte auch ich oft in den Vorticellencysten auftreten und Brut liefern sehen.

Cienkowsli hatte auch die ron mir als die Acinetenform der Vorticella microstoma betrachtete Podophrya fixa auf die vorhin angegehene Weise isolirt, und er machte nun die wichtige Beobachtung, dass sie sich chenfalls encystirte und jene kurzgestielten quergerippten Cysten lieferte, die mir so hảufig zwischen den Cysten der Vorticella microstoma begegnet und ron mir für directe Uebergangsstufen der Vorticelleneysten in Podophryen angesehen worden waren. In einem zwciten, speciell gegen die Acinetentheorie gerichteten Aufsatze giebt Cienkonski die näheren Details an ${ }^{1}$ ). Diese Angaben sind vollkommen richtig, wie ich mich selbst seit I 8355 durch eigene Beohachtung vielfach überzengt habe. Es folgt jedoch hieraus weiter nichts, als dass die Podophryen nicht aus Vorticellencysten hervorgehen und dass sie deshalb nicht länger zum Entwichelungshireis der Vort. microstoma gerechnet werden duirfen. Mit den Podophryen habe ich ubrigens irriger Weise eine ganz verschielene Acinetenforın zusammengeworfen, die nicht. wie die Podophryen, im ganzen Umfange des Körpers gleiclıfömig mit Tentakeln besetzt ist, sondern nur zwei bis vier Tentakelbischel triggt (vergl. meine Schrift Taf. IV. Fig. 33-30̈. 38. 39. 41. 45-48 und Fig. 29). Sie ist der gewöhnliclıste Begleiter der Vort. mierostoma und in fauligen Infusionen uberaus häufig, weshalb sie einstweilen den Namen Acineta infusionum führen mag; sie producirt auch alicin die den Knospensprösslingen der Vorticellen so ähnlichen, nackten, mit einem Wimperkranze verselıenen Schwärmsprösslinge (Fig. 36. 37), nicht aber thut dies die Podophrya fixa ${ }^{2}$ ). Es bleibt daher immer noch eine auf Vort. microstoma beziehbare Acinetenform, die A. infusionum, übrig.

Bei Podophrya fixa beobachtete Cienkoursti nur cine Vermehrung durch Theilung, die jedoch von der sonst bei den Infusorien vorkommenden Theilung wesentlich verschieden ist. Nachdem sich nåmlich der kugelförmige. uberall dicht mit Tentakelı besetzte Körper im Lequator ringförnig eingeschnürt hat, nimmt das vordere Segment allmåhlig eine länglich ovale Gestalt an, die an demselben vorlıandenen Tentakeln werden eingezogen und seine ganze Obcrlache nicht blos das vordere Ende, wie Cienkouski angiebt) bedeckt sich mit cinem sehr dichten und zarten Wimpcrkleide. Nun schnïr sich der vordere Theilungssprössling von dem hintern ab; während letzterer unverandert die Podophryenform beibehält, gleicht ersterer vollkommen einem ringsum hewimperten Schwirmsprössling, er bewegt sich eben so gewandt, schwirmt eine langere oder kürzere Zeit umher, dann aber werden seine Bewegungen langsamer, unt el bleibt bald gauz still liegen. Der Körper niumt wieder die Kugelform an, dic Wimpern verschwinden, und auf der ganzen Oberflache treten die gewöhnlichen Tentakeln hervor. So erhalten wir zunächst cine ungestielte Podophrya, die spïter durch Alsonderung eines Stieles die gewöhnliche Form annimmt. Ich selhst habe diese Vorgänge in neuerer Zeit unzählige Male verfolgh, niemals aber beobachtete ich im Innern einer Podophrya einen Schwirmsprössling; ich schliesse daraus, dass der von einer Podophrya durch Quertheilung sich ahschnurende bewegliche Sprössling dem Schwärmsprössling anderer Acineton entspricht.

Cientiouslii hat endlich auch die Schwàrmsprösslinge der so eben von mir als Acin. infusionum bezeichneten Acinetenform beohachtet, und es gelang ihm, diesclben so lange zu verfolgen, bis sie wieder zur Ruhe kamen. Sie verwandelten sich jelnch licineswegs in eine Vorticelle, soudern lieferten wieder eine Acinete. Diese

1) "Bemerkungen über Stein's Acineten-Lehre. Mélanges biologiques lirés du Bullet. de l'Acad. de St. Pelersbourg 185 ä. Tome II. P. 263-72. - 2) Die auf Taf. IY. Fig. 32 meiner Sclırift abgebildele Podophrya fixa enthält irrthümlicher Weise einen Schwärmsprösslirig. 
Thatsache, so wie die ibrigen von Cienkowshi emittelten Verhältnisse waren natirlich der Acinetentheorie åusserst ungiinstig und schienen sie völig zu beseitigen. Cienliousti selbst folgerte jedoch daraus uur, duss die Acinetenlehre lediglich für Vorticella microstoma als hypothetisch und nicht auf Thatsachen begrindet anzusehen sei. Auch Carter liess sich dadurch noch nicht bestimmen, den Gedanlien, dass dennoch die Acinetinen in den Entwickelungskreis der Vorticellinen gehören könnten, aufügeben, da er in den ostindischen Gewåssern bei Bombay auf Epistylisstöclien ebenfalls wiederholt Acineten angetroflen hatte ${ }^{1}$ ).

Mit der grössten Entschiedenheit trat dagegen 1856 J. Lachmamn gegen die Acinetentheorie auf. In einer ron gründlichen eigenen Forschungen zeugenden Abhandlung ${ }^{2}$ ) iiber die Organisation der lufusorien im Allgemeinen und die der Vorticellen insbesondere, auf die ich im folgenden Abschnitt specieller eingehen werde, wies Lachmam zuyörderst nach, dass die Acinctinen diejenigen Infusionsthiere, wetche sie mit ihren Tentakeln ergriffen haben, mittelst derselben wahhaft aussaugen. Während sich nämlich gewisse Tentakeln verkiirzten und verdicklen, erweitere sich ihr knopfförmiges Ende zu einer tellerformigen Sangscheibe und durch diese dringe der Chymus des gefangenen Thieres in die Axe des Tentakets und ströme durch diese in den Acinetenkörper; jeder Tentakel sei mithin ein wirklicher Saugrussel. Dies isı, wie ich jetzt aus eigener Erfahrung weiss, fur dic Acinetinen mit retractilen Tentakeln durchaus richtig, allein bei Dendrocometes paradoxus und Acineta digitata muss dennoch eine andere Nahrungsaufnahme stattfnden. Denn die dicken fugerförmigen Tentakeln der $\mathbf{A}$. digitata sind zugespitzt und liaum an der Spitze ein wenig biegsam, geschweige denn in einen Saugnajf ausdehnhar; dasselbe gilt von den zugespitzten Endisten der ganz starren, regungslosen Arme von Dendrocomeles. Auf letzteres Geschöpf, das doch iiberall so leicht zur Untersuchung zu haben ist und der Acinetentheorie besonders zur Stiitze gedient hat, ist Lachmam iberhaupt gar nicht eingegangen.

Dic Gründe, welche von Lachmann gegen die Acinetenlehre vorgebracht werten, sind im Wesentlichen dieselben, wie die von Cienliowski. Lachmam hebt zunachst hervor, dass die directe Umwandlung der Vaginicola crystallina in Acineta mystaciná durch die von mir mitgetheilten Beobachıtungen noch keineswegs uberzeugend bewiesen wërde, und dass sie iberhaupt höchst unwahrscheinlich sei, worin ich ihn Recht gebe. Wenn Vorticellen isolirt wurden, so wurden zwar haufig genug die Cystenzustande, aber keine Fortentwickelung derselben zu Acineten beobachtet. Bei zwei Acinetenformen verfolgte endlich Lachmam den ausschwärmenden Sprössling, den er als Embryo bezeichnet und den er sich innerhall, einer ahgeschnürten Portion des Nucleus entwickehn lässt, bis zur Verwandlung, und es ergab sich, dass der Schwärmsprossling wieder zu einer Acinete wurde.

Einen grossen Theil seiner Untersuchungen hat Lachmam gemeinschaftlich mit $\boldsymbol{E}$. Claparède angestellt. Beide hahen eine bedleutende Anzahl wichtiger Entdeckungen, namentliclı wahrend eines langeren Aufenthaltes an den norwegrischen Kiisten gemacht, wortiber sich bereits in Lachmamm's Ahhandlungen reiche Andeutungen finden. Die Resultate ihrer Forschungen wurden in einer gemeinsamen Arbeit niedergelegt, wclche 1838 mit der einen Hălfte des Preises gekrönt wurde, welchen die Pariser Academie der Wissenschaften fur die genauere Erforschung der Fortpllanzungs - und Entwickelungsverhaltnisse der Infusionsthiere ausgesetzt halle; die andere Hälfte des Preises wurde der ausserdem nu noch concurrirenden Arbeit von $\Lambda$. Lieberliühn zuerkannt. Beide Preisschriften liegen leider noch nicht gedrucht vor, jedoch haben Claparide und Lachmam einen Auszug aus ilırer Arbeit veröffentlicht ${ }^{3}$, der das Hauptergebniss ihrer entwickelungsgeschichtlichen Forschungen zusammenfasst. Von Lieberkïhn kenne ich nur \%wei frühere Aufsätze. Der eine: "Beitrige zur Anatomie der Infusorien " ${ }^{4}$ ), bezielıt sich hauptsächlich auf die Organisation der Ophryoglena flavicans und Bursaria flava, bei denen Lieberkühu ein eigenthimliches, räthselhaft gebliebenes, uhrglasförmiges Organ in der Umgebung der Mundspalte entdeckte; ausserdem werden neue Thatsachen über die contractilen Behälter und deren gefassartige Fortsetzungen bei verschiedenen Infusorien mitgetheilt und daraus gefolgert, dass dieses System der Circulation der Säfte vorstehe. In dem zweiten

1) Annals of natural history. Vol. 20. p. 21-41. - 2) Mäller's Archiv 18:36. S. 340-98. - 3) "Note sur la reproduction des Infusoires."Anuales des scien. nat. 1857. IV. Sẻr. Tome VIII. P. 221-41. - 4) Wiiller's Archiv 1836. S. 20-36.

Ste in, Organismus der lufusionsltierce 


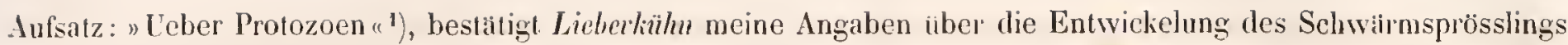
ron Acincla infusionum (Taf. IV. Fig. 47 meiner Schrift) für eine Acinete der Fischkiemen, was der Behauptung Lachmamis gegenuber, dass der Schwälmsprössling sich in einem abgeschnürten Nucleusstücke entwickele, von Wichtigkeit ist. Ferner bestitigte Lieberkïhu die von mir beobachtete Conjugation mehrerer Indiviluen von Actinophrys; später salı er die conjugirten Individuen sich wierler von eiuander tremnen. Irgend welche Folgen dieses Vorganges liessen sich durchaus nicht nachweisen.

Was nun die Arbeit von Claparede und Lachmann betriff, so geht dieselbe abermals von meiner Schrift aus, der das Verdienst zugestanden wird, eine ganz neue Epoche in der Entwickelungsgeschichte der Infusionsthicre begründet zu haben. Dies hindert natirlich nicht, dic Acinetentheorie auf"s Aeusserste zu bekimpfen. Die Verfasser beobachteten dic Schrä̉msprösslinge von 11 verschiedenen Acinetenformen; für den Namen Acineta führen sie olne triftigen Grund ${ }^{2}$ ) die Benennung Podophrya ein, die Schwămnsprösslinge hezeichnen sie als Embryonen. Die Grinde gegen die Acinetentheorie sind, bis auf einen, die alten, sie werden diesmal von sehr umfassenden Untersuchungen der Epistylis plicatilis hergenommen, die zu merkwiirdigen Resultaten fuihrten. Auf dem Stocke dieser Epistylisart wurde dieselbe Acinetenform angetrofien, die ich so bäufig auf ilır beobachtete und als cine Entwickelungsstufe der E. plicatilis betrachtete; die Verfasser bezeichnen sie als Podophrya quadripartita ${ }^{3}$ ). Sie sahen den aus ihr hervortretenden, durch den Besitz eines Wimperkranzes characterisirten Schwämsprössling nach kurzer Zeit des Herumschweifens sich wieder auf dem Epistylisstocke niederlassen und in eine Acinete umwandeln; zuerst verschwand der Wimperkranz, daun traten an zwei Puncten der Oberfläche Tentakeln hervor und etwas später begann die Ausscheidung eines Stieles. Hiusichtlich der von mir beschriebenen, kurzgestielten Epistyliscysten, welche oft so zahlreich auf der Unterlage des Epistylisstocks rorkommen, wurde beobachtet, dass das cingeschlossene Thier später die Cyste wieder durchbrichı, aus derselben auf einem neu gebildeten Stiele hervorwachst und so die Grundlage eines neuen Epistylisstockes wird, dessen Basis von dem napfö̈migen Reste der Cyste umfasst wird.

Ausserdem wurde aber noch eine ganz andere Art von Cysten aufgefunden, welche auf den Epistylisstocke selbst und zwar an den Enden der Zweige sassen. Sie enthielten entweder einen lebhaft rotirenden, auf der ganzen Olserlliche wimperulen und mit viclen contractilen llohlräumen versehenen Körper, der sich beim Ausschlüpfen aus der Cyste als ein Amphileptus zu erkennen gab; oder es steckte in der Cyste der noch mit seinem Stiele in Verbinlung stehende Epistyliskörper, und iiber diesen war der sich bald nach links, bald nach rechts bewegende Amphileptuskörper so herüher gestiilpt, wie der IIandschuh iber einen Finger. Zuletzt drehte der Amphileptus den Epistyliskörper von seinem Stiele ab, der contrahirte Epistyliskörper lag nun ganz im Innern des $\Lambda$ mplileptus, und letzlerer begam sofort seine unaufhörlichen kreisenden Bewegungen in der Cyste. Claparéde und Lachmam deuten diese seltsamen Erscheimungen so und wollen dies anch einmal direct beobachtet haben, dass ein gewöhnlicher Amphileptus ein Epistylisthier von vorn her mil seinem weiten llunde ergreife und sich dergestalt uber dasselbe hinuberwürge, bis der Epistyliskorper ganz m Innern des Anphileptuskörpers liege; alsdann ziehe sich der Amphileptus huglig zusammen und sondere eine Cyste ab. Wenn nichts weiter vorläge, als dass Epistylisthierchen ren Amphilepten gefresscn wirden, so würde sich doch wohl schwerlich constant um den Amphileptus und seine Beute eine Cyste bilklen. Mir will es scheinen, als hätten wir es hier mit noch lange nicht genügend erforsclıten Verhältnissen zu thun. Ich sellsst habe schon hei meinen allerersten Beohachtungen der Epistyl. plicatilis im Jahre I $84: 7$ die in Rede stelicnten Cysten kenuen lernen; sie kamen nir jedoch nur selır vereinzelt vor und enthielten stets blos einen auf der ganzen Oberlliche wimpernden, lebhaft rotirenden Körper, den ich nichı ausschlüpfen sah.

1) Zeitschrift fïr wisseuschaftiche Zoologie 1856. Band VIII. S. 307-10. - 2) Der Podophrya fixa Ehby. am nächsten verwandt isl dic Acinela mysliteina Khby.; letztere hiblte also höehslens Podoph. Inyslacina genannt werden können. - 3) Da die Einschnitte am vorlern Ende des Acinctenkörpers nur sehr seicht sind und nur bis zur Nille reichen, so zog ich oben die Bezeichnung quadriloba für liese Arinetenforn vor. 
Die Cyste war eben so innig mit dem Ende der Stockasste verwachsen, wie dies sonst bei Epistyliscysten der Fall ist. Da ich nicht wusste, was ich mit diesen Cysten anfangen sollte, so habe ich sie in meiner Schrift ganz mit Stillschweigen übergangen. Claparède und Lachmam beobachtelen auch auf Carchesium die angeblich parasitischen Amphileptuscysten. Auf Epistylis plicatilis entdeckten sie noch ein sehr merkwürdiges Geschöpf, welches sie Urnula Epistylidis nennen und worin sie einen parasitischen Rhizopoden erkennen wollen; ich komme darauf später zu sprechen.

Nach diesen Erfahrungen musste auch die auf Epist. plicatilis so vielfach angetroffene Acinetenform mehr und mehr als ein hlosser Parasit erscheinen. Den entschiedensten Beweis, dass sie nicht in den Entwickelungskreis der Ep. plicatilis gehören könne, finden aber Claparède und Lachmamn darin, dass sie im Innern des letztern Thieres sich auf dieselbe. Weise Embryonen entwickeln sahen, wie bei den Acinetinen, und damit falle jeder Grund weg, weshalb sich ein Epistylisthier in cine Acinete verwandeln solle. Betrachten wir zunachst die Thatsache selbst. Wenn Epistylisthjerchen Embryonen erzeugen, so thun dies gewöhnlich alle oder doch die meisten Individuen eines Stockes und man erkennt die fruchtharen sogleich daran, dass sie an der Seite des Körpers einen an der Spitze durchbohrten Höcker, eine Art os uteri, besitzen, durch welchen die Embryonen nach aussen hervortreten. Letztere entwickehn sich ebenfalls vom Nucleus aus, indem sich von diesem ein Stück abschnürt, welches entweder selbst zum Embryo wird oder beträchtich aufschwillt und dann in seinem Innern eine Anzahl rundlicher oder ovaler Körperchen entwickelt. Jedes dieser Körperchen wird ein Embryo, der mit einer contractilen Blase und einem Wimperkranze versehen ist und mittelst desselben sich nach und nach von seiner Bildungsstatte durch die Leibessubstanz hindurch bis zur Basis des nach aussen geöflneten Höckers bewegt. So wie der Embryo gehoren war, bewegte er sich so sturmisch durch das Wasser, dass sein weiteres Schicksal nicht erforscht werden konnte.

Claparède und Lachmam nelımen ohne Weiteres an, dass sich der Embryo früher oder später direct in ein Epistylisthier verwandeln werde. Grade dieser Punct hätte aber auf das Zuvellassigste bewiesen werden muissen, wenn die Acinetentheorie wirklich widerlegt sein sollte. Der Epistylisembryo gleicht offenbar ganz und gar dem Schrvåmsprössling der Acineta quadriloba, er muss also doch jedenfalls einmal dieselbe Metamorphose durehmachen, die ich für den letztern voraussetzte und die meinen Gegnern so unwahrscheinlich erschien. Wenn sich nun aber herausstellen sollte, was für mich kaum noch zweifelhaft ist, dass die Epistylisembryonen in Folge einer geschlechtlichen Zeugung entstehen, ist es dann wohl nothwendig, oder auch nur sehr wahrscheinlich, dass die Epistylisembryonen, die so viel kleiner sind, als die gewöhnlichen Epistylisthiere und eine wesentlich andere Organisation hesitzen, sofort wieder ein Epistylisthier liefern werden? Kann nicht vielmehr ein Generationswechsel eintreten und der Epistylisembryo auf dieselhe Weise, wie der ihm gleiche Schwärmsprössling der Acinete, sich in eine Acinete umbilden, die eine Zeit lang auf ungeschlechtlichem Wege nur ihres Gleichen producirt, um zuletzı mit einer Sclıwirmsprösslingsgeneration zu endigen, die wieder die Form des Epistylisthicres annimmt? Es ist das freilich einstweilen nur eine Hypothese, sie erljärt aber ganz einfach das immer wieder constatirte Zusammenvorkommen von Vorticellinen und Acinetinen, und sie ist nicht im Widerspruch mit den in anderen Thierklassen nachgewiesenen Entwickelungsgesetzen.

Vor einer Umwandlung encystirter Vorticellinen in Acinetinen kann natiorlich fernerhin nicht mehr die Rede sein; diese Seite der Acinetentheorie ist hinlänglich von ihren Gegnern widerlegt und von mir selbst schon 1830 auf der Naturforscherversammlung in Wien als irrig bezeichnet worden. Kieineswegs ist aber iiher allen Zwveifel festgestellt, dass die Acinetinen wirlich selbststandige Infusionsthiere sind, im Gegentheil, es existiren Thatsachen, die mir mit dieser Ansicht unvereinbar erscheinen. Von diesen Thatsachen, die Claparede und Lachmann ganzlich ignoriren, bin ich bereits anf der Naturforscherversammlung in Wien ausgegangen, um der Acinetentheorie eine neue Basis zu geben ${ }^{1}$ ). Die Embryonen selır verschiedenartiger Infusionsthiere (z. B. von Paramaecium,

1) Tageblatt der 32. Versammlung deutscher Naturforscher und Aerzle in Wien im Jahre 1856. No. 3. S. 53. 
Stylonychia und Urostyla) tragen nämlich alle Charactere der Acinetinen an sich, sie besitzen bei gleich eiufacher innerer Organisation genau dieselben aus- und einzielıbaren, am Ende gehnopften Tentakeln. wie die Acinetinen. sie können sich miltelst derselben an anderen Infusionsthieren festsaugen und ilıen Körpersäfte entziehen, und sie verwandeln sich, so weit meine Erfahrungen reichen, nie direct in das Mutterthier, sondern naelsdem sie die Form einer ungestielten Podophrya angenommen lıaben, vermehren sie sich genau auf dieselbe Weise, wie Podophrya, durch Quertheilung. Die näheren Angaben hierüber sind in den folgendeu Abschnitten enthalten. Wenn nun die Uebereinstimmung zwischen dem Embryo z. B. von Paramaecium bursaria und dem Theilungssprössling von Podophrya fixa so vollkommen ist, dass sich auch niclıt der leiseste Unterschied zwischen beiden anffinden lässt, wenn ferner jener Embryo bis zur Umwandlung in eine ungestielte Podophrya verfolgt und an dieser die Theilung in dersellsen Weise beobachtet wurde, wie an grösern ungestielten und gestielten Podophryen, so ist gewiss der Schluss erlaulı, dass die Podophryen keine selbststandigen Infusionsthiere sind, sondern mur eine acinetenartige Entwickelungsphase der Paramäcien darstellen. Dies sind die Grüde, die mich bestimmen, die Acinetentheoric auch jetzt noch aufrecht zu erhalten, jedoch in einer wesentlich modificirten Gestalt; ich nehme nämlich an, dass selır verschiedene höhere Infusionsthiere während ibrer Entwickelung ein acinetenartiges Stadium durchlaufen und dass dieses unmittelbar aus der Embryonalform hervorgeht.

Ich habe bereits ron Embryonen der Infusionsthiere gesprochen; dieser Ausdruck setzt voraus, dass wır es mil einer Nachkommenschaft zu thun haben, die auf dem Wege einer geschlechtlichen Zeugung entstanden ist. Die Entdeckung derselben gehı̈rt zu den betleutendsten Errungenschaften der neuesten Zeit. Zuerst wurde, wie wir bereits oben sahen, bei geisseltragenden Infusionsthieren eine geschlechtliche Fortpflanzung nachgewiesen. Die ersten auf die geschlechtliche Zeugung der bewimperten Infusionsthiere beziiglichen Thatsaclıen wurden von J. Müller, Lieberkïhn, Claparède und Lachmam entdeckt ${ }^{1}$ ), doch wagten diese Forscher noch nicht, iJuren Beobachtungen eine entschiedene Deutung zu geben; nur Claparede und Lachmamn sprachen sich in einem Nachtrage zu dem Auszuge aus ihrer Preisschrift ${ }^{2}$ ) bereits zu Gunsten einer geschlechtlichen Fortpllanzung bei den Infusionsthieren aus. Aber erst E. G. Balbiani wies 1838 mit überzeugenden Gründen dieselbe bej Paramaecium bursaria nach $\left.{ }^{3}\right)$, indem er zeigte, dass unter gewissen Umständen der Nucleus dieser Thiere als Geschlechtsorgan fungire und zwar der eigentliche Nucleus als weibliches, der Nucleolus als männliches Organ. Ich ziehe es vor, diese neuesten, noch in der ersten Entwickelung begriffenen Entdeckungen im folgenden Abschnitt in Zusammenhange mit meinen eigenen gleichzeitigen Beobachtungen äber die gesehlechtliche Fortpflanzung der Infusorien zu besprechen.

\section{Schluss.}

\section{Begriffsbestimmung der Infusionsthiere.}

Fassen wir alle neueren Infusorienforsclumgen zusammen, so ergiebt sich das erfreuliche Resultat, dass uiber den Organisationsgehalt der Infusiousthiere kaum noch erhebliche Jleiungsifferenzen herrschen. Vollkommen einig ist man darüber, dass die Infusionsthiere nieht jene complicirte innere Organisation besitzen, die ihnen der Begrinder der neueren Infusorienkunde vindicirte und dass seine Organdeulungen in den Hauptpuncten durchaus verfeht waren. Es haben sich bei den Infusorien weder Muskeln, noch Nerven und eigentliche Sinnesorgane nachweisen lassen; nur bei den contractilstieligen Vorticellinen pllegt man noch fast allgemein den dunklen Streifen in der Axe

1) Joh. Mäller "Einige Beobachlungen an Infusorien." Monatsherichte der Berliner Academie. Juli 1856. S.390-92. - 2) A.a. O. S. 243-44. - 3) Note relative a l'exislence dune génération sexuelle chez les Infusoires par L. G. Balbiani. Journal de la Physiologic publ. par E. Brown-Séquard. Paris 1858. p. 347-52 
des Stiels als Muskel zu bezeichnen. Da jedoch hei den übrigen Infusorien. auch wenn sie der energischsten ConIractionen fähig sind, keine gesonderten contractilen Fasen aufgefunden werden können; da ferner Muskeln Nerven roraussetzen, die doch nicht vorhanden sind, so liann ieh in dem sogenannten Mluskel jener Vorticellinen uur eine strangförmige Fortsetzung des contraetilen Körperparencluyns crblicken. Auch eine Zusammenselzung aus Zellen oder zellenahnhichen Elementen hat sich bei keinem lnfusionsthiere erkennen lassen; stets bestelı der Körper aus einer homogenen, ungeformten, mehr oder minder contractilen Substanz. Vit den uberzengendsten Griunden ist ferner dargethan und allseitig anerkannt worden, dass die Infusionsthiere keine polygastrischenThiere sind, und dass sie iberhaupt kein gesondertes Verdaumgsorgan besizen; die Nahrungsstoffe gelangen oft dureh einen mehr oder weniger entwickelten Schlund in das Innere des Körpers, lier aber werden sie stets von Jer umgebenden Körpersubstanz verdaut. Der Nucleus hat sich umbestreitbar als das wahre und einzige vortpllanzungsorgan der Infusorien herausgestellt; eine geschlechtliche Fortpllanzung existirt zwar, aber in einer ganz anderen Weise, als Ehrenberg annahm. Ueber die Bedeutung der contractilen Behälter sind die Meinungen noch getheilt, jedoch darin vollkommen einig, dass sie in keiner Beziehung zu geschlechtlichen Functionen stehen. Von den meisten neueren Forschern werden sic als die herzartigen Mittelpuncte eines sehr unvollkommen entwickehen Blutkreislaufsystems angesehen; ich theile diese Ansicht nich, sondern ich werde zu zeigen suchen, dass die contractilen Behälter und ihre gefässartigen Fortsetzungen dem Wassergefässystem der Rälerlhiere, Turbellarien und vieler Wümer entsprechen.

Auch uber die Begrauzung der Infusionsthiere hat man sich immer melı ein und demselben Ziele gentihert. Dass die Rảderthiere ganz aus dem Verbande mit den Infusionsthieren zu lösen sind, ist laingst und allgemein anerkannt; nur dariber bestehen noch Differenzen, ob sie dem Kreise der W ïrmer, oder dem der Arthropoden einzureihen sind. Ich entscheide mich fiur die erstere Ansieht und betrachte die Raderthiere als die unterste Kkasse im Kreise der Wiirmer, die sich durch die Ichhydinen an nächsten an die Turbellarien anschliesst; auf leztere lasse ich die Entozoen und dann die Anmulaten folgen. Allgemeine Zustimmung hat fermer die Aufstellung der Rhizopodenklasse gefunden, und dieser missen natülich die so lange zu den Infusionslhieren gerechneten Amöbäen, Arcellinen und Actinophryen cinverleibt werden. An den Closterinen und Bacillarien Ehrenberg's, die vielfach Gegenstand neuerer umfassender Untersuchungen gewesen sind, bat kein unzweifelhaft thierischer Cluracter machgewiesen werden können; das von Ehrenberg angenommene Beweģungsorgan hat Niemand luestätigt, und anch die nur bei einigen Navienten und unter ungewöhnlichen Verhailuissen beobachtele Aufnalme von Indigo- und Carminpartiketehen hat alle Beweistraft fiir die Hierische Natur dieser Organismen verloren, seitdem Th. Marlig entdeckl hat, dass auch der Kern der Pllanzenzellen lndigotheilchen aufzunehnen vermag. Wir werden daher die Closterinen und Baeillarien dem Pllanzenrejche überweisen missen. Dassellse gilt anch von den Vilsrionien, wie bereits oben (S. 38; niher dargethan wurde. Dagegen missen die Volvocinen, die hereits eine Zeit lang als Pflanzen behandelt wurden, aus den S. 37 angefulnten Grinden wieder ihren Platz unter den Infusionsthieren einnehmen. Auch Claparide und Lachmann vertreten diese Ansicht.

Von den 24. Familieu der polygastrischen Infusorien Ehrenberg's bleiben also nur die folgenden 19 als Bestand der eigentlichen Infusionsthiere übrig: 1) Honalina, 2) Cryptomonadina, 3) Volvocina (nach Ausschluss der Gathmg Gyges und nach Beschrinkung der Gattung Gonium aul G. pectorale), 4.) Hydromorina, :3) Astasiaea, 6) Dinobryina. 7) Cyelidina, 8) Perilinaca, 9 Vorlicellina, 10) Ophrydina, 11) Enchelia (nach Ausschluss von Actinopluys und Trichodiscus , 12 Colepina, 13) Trachelina, 14, Ophryocerciua, 15) Aspidiscina, 16) Colpodea, 17) Oxytrichina, is Euplota. Ihierzo kommen 19) die Acinetina (Acincta, Jodophrya, Dendrosoma), ron denen sich noch nich mit Sicherheit sagen laisst, ob sie selhststandige hufusionsthiere oder ob sie nur Entwickelungsstulen anderer Infusorienformen sind. An diesen Kreis von Formen schiliessen sich alle spateren Entdechungen leicht und ungezwungen an.

Ein gemeinsaner Plan der Organisation zieht sich durch alle diese Formen hindurch und schliesst sie zu einer durchaus natiolichen Klasse des Thierreichs zusammen. Sie hesizen nämlich simmolich äussere Wimpern, 
wenn anch hisweilen (die Acinetinen) nicht für die ganzo Lebenszeil, und ihre innere Organisation ist so einfach, dass man sie hiernach als Protozoen be\%eichnen muss. Folgender Character diufte die Infusionsthiere geniigend sowohl von allen andern Thieren, wie auch von den ihnen ähnlichen vegetabilischen Organismen unterscheiden.

"Die Infusionsthicre sind mit aussern Wimpern ansgeriistete Thiere, deren homogenes. durchsichtiges, " "nie aus Zellen odler Zellenderivaten zusammengesetztes Körpergewehe wenigstens an gewissen Stellen willkiihr- " "licher Contractionen und Expansionen lahig ist. Ein abgeschlossener Darmkanal und ein besonderes Verdaungs-" "organ fehlen ihnen gänzlich; desgleichen auch Muslieln und Nerven. Alle hesitzen ein scharf umschrichenes " „ inneres drüsenartiges Organ ohne Ausfihrungsgänge. den Nucleus. welcher wenigstens hei den höheren Formen " »entschieden als Fortphlanzungsorgan fungirt. Die meisten, vielleicht alle, sind mit inneren contractilen Behaltern " "versehen, welche sich abwechselnd a!s der umgebenden Leibessubstanz, oft durch besondere zufiihrende Kanäle, " "mit einer wässerigen Flissigkeit füllen und dieselbe dann wieder austreiben (wahrscheinlich direct oder mittelbar " "nach aussen). Ihre gewöhnlichste Fortpflanzung besteht in der freiwilligen Theilung, die jedoch noch nicht bei " "allen nachgewiesen ist. Wahrscheinlich gehen alle zeitweis durch Encystirnng in einen ruhenden Zustand iiber, " "welcher auch die Erhaltung der Art sichert, wenn derselben die gewöhnlichen Lebenshedingungen mangeln. "

Die Infusionsthiere grehören in den Kreis der Protozoen. Innerhalb desselben hilden sie eine eigene und zwar die am höchsten stehende Klasse. 


\section{Zweiter Abschnitt.}

\section{Ueber die Organisation der Infusionsthiere im Allgemeinen.}

\section{Vom Körperparenchynn der Infusionsthiere.}

Die Grundmasse, aus welcher der Infusorienkörper geformt ist, nennen wir das Körperparenchym. Dieses besteht aus einer ganz gfeichartigen, klaren, durchsichtigen, von sehr feinen Molecularkürperchen mehr oder weniger getrübten Substanz, welche auch mit den allerslärksten Vergrösserungen und bei Anwendung der verschiedenartigsten Reagentien keine Spur vou Zusanmensetzung aus bestimmt gelornien und gruppirten Elementen erkennen lasst, also in Wahrheit amorph ist. Wăhrend sich der Kärper aller andern, nicht in den Kreis der Protozoen gehörigen Thierformen aus Zellen aufbaut, die in verschiedenartige Gewebe von bestimmter physiologischer Wirkamkeit umgewandelt werden, zeigt das Parenchym der Infusorien und der Protozoen überhaupt nienals eine zellige oder auf Zelten zurückfuhrbare Structur; ihr Körper ist zu keiner Zeit ilıres Lebens ein Complex von Zellen. Hieraus folgt jedoch ganz und gar nicht, dass die Protozoen einzellige Organismen seien, wofür sie $v$. Siebold, kölliker und nach ihnen verschiedene jügere Forscher ausgegeben hahen. Dazu sind die morphologischen Differenzirumgren, die im Körjerparenchym namentlich der höheren Infusionsthierc auftreten, viel zu eigentıümlich; auch erreichen sie eimen Grad ron Complication, bis zu welchen eine blosse Zelle niemals fortschreitet.

Das Parenchym der Infusionsthiere ist zwar eine völlig structurlose, aber darum doch keineswegs unterschiedslose Substanz. Nicht un bei den verschiedenen Infusorienformen zeigh das Parenchym cin sehr verschiedenes Verbalten hinsichtlich seiner Consistenz, sondern aucl bei einer und derselben Art sind in der Richung von aussen nach innen mehr oder weniger betrichtliche Unterschiede in der Dichtigkeit des Parenchyms wahrzunehmen. Stets besizt wenigstens das Parenchym an seiner ăussersten Grảnze einen vieł höheren Grad von Cohăsion und Resistenz, als weiter nach immen zu. Je weicher und nachgiebiger das gesammte Parenchym eines Infusionsthieses ist, und je weniger die äussern Schichten in der Dichligkeit von den innern differiren, un so mehr kann der Körper seine Totalform verandern, sich lang ausrecken und bis zur Kugrelform zusammenziehen, sich nach den verschiedensten Richtumgen biegen. krünmen und winden. Wir wollen dergleichen Infusionsthiere im Allgemeinen als netabolische bezeichnen.

Unter den melabolischen Infusionsthieren zeichnen sich vicle noch dadurch aus, dass iłı Körper plötzlich aus dem Zustande seiner grossten Ausdelınung in den seiner grössien Verkürzung übergehen kann; diese unterscheiden wir als schnellende Infusionsthiere, z. B. Vorticellinen, Ophrydinen, Stentor, Spirostomum ambigum, Lacrymasia, Trachelocerca. Das Schnellvermögen muss bei der Aufsteftung von Gattungen herïcksichtigt werden, und es kömnen schnellende und nichı schnellende Formen nicht wohl in eines Gattung vereinigt bleiben. Dies lehrt recht augenfällig die Gattung Spirostommu; denn das nicht schnellende Spirost. virens unterscheidel sich auch durch andere Charactere, namentlich durch einen sehr entwichelıeı, im Innern wimperuden Schlund sehr wesentlich von dem schnellenden, schlundlosen Spirost. aunbiguum. Aus del erstern Art bilde iclı daher eine neue Gatung ClinacostommIII.

Den metabolischen Infusionsthieren stehen die formbestandigen gegeniber; ihr Parenchym hat bis zu einer melı oder weniger betrichtlichen Tiefe eine viel grössere Consistenz und zahere Beschaffenheit, als das weiter nach immen zu gelegene Parenchym. Sie vermögen daher die Totalform des Körpers entweder gar nicht, oder doch nur in einem geringen Grade zu verändern; niemals kann sich der Körper lang ansstrecken und kugel- 
förmig zusammenziehen, noch können gegenuberliegende Ränder der Körperperipherıe einander bis zur Beriuhrung genähert werden. Nur in seiner Totalitat vermag sich der Körper elwas zu krümmen und zu winden. auch wohl ein wenig zu strecken und zu verkïrzen. Als Beispiele formbestandiger Infusorien nenne ich: Paranaecium, Ophryoglena. Nassula, Pleuronema, Urocentrum, Chlanydodon, Prorodon, Holophrya, Bursaria.

Eine besondere Unterabtheilung der formbeständigen Infusorien bilden die gepanzerten Infusorien. Unter diesem Namen begreife ich nur dicjenigen formbeständigen Infusorjen, bei welchen eine mässig dicke Schicht des aussersten Parenchyms fast ganz starr und glasartig durchsichtig geworden ist und ihr selbstständiges Contractionsvermögen eingebisst hat. Diese Schicht, der Panzer, kann nicht wohl ein Absonderungsproduct des gesammten Körpers sein, wie Cohm annimm("); denı zwischen dem Panzer und dem innern contractil bleibenden Parenchym giebt es keine sichtbare Gränze, berde gehen ganz allmblig in einander ibluer, und sie hänen so imnig zusammen, dass sie weder durch mechanische Manipulationen, noch durch chemische Einwirkungen von einander gesonder werden hömmen. Bei Anwendung von Essigsäure, die sich sonst so wilksan zeigt, wenn es sich un die Trennung innig verbundener Theile handelt, schrumpft der Körper der gepanzerten Infusorien unter den verschiedenartigsten Aufblähungen, Kriummungen und Verwerfungen des gesammten Parenchyms zusammen, niemals aber heht sich der Panzer als ein für sich hestehendes Gebilde ab. Gepanzerte Infusorien sind z. B. Stỵlonỵchia, Euplotes. Aspidisca, Spirochona, Coleps, Peridinium. Prorocentrum und Cryptomonas.

Zwischen den vier, nach der Beschallenheit des Körperparenchyms von mir unterschiedenen Gruppen von Infusionsthieren gicht es keine scharfen Gränzen, sondern sie gehen durch zahlıeiche Zwischeuformen in einander über. und das Urtheil bleibt oft schrankend, ob man eine gegehene Form in die eine oder andere Gruppe bringen soll. Es lässt sich daher die Beschaffenheit des Körperparenchyms nicht zu einem Haupteintheilungsgrunde der Infusionsthiere benutzen, wie ron Elrenberg und nenerlich wieder von Perly geschehen ist, sondern man wird daron höchstens bej Aufstellung der Gattungscharactere Gebrauch machen kömnen. Ehrenberg unterschied nur zwei Kategorien ron Infusionsljieren, die gepanzerten und die panzerlosen. Zu den gepauzerten rechnete er auch allo diejenigen Inlusorien, welche entwerter ein Gehäse bewohnen, wie die Gallungen Vaginicola, Cothurnia, TracheIomonas, Claetoglena, Dinobryon und Lagewella. oder auf einer von dem Körper abgesonderten Gallerte aufsitzen, wie Ophrydium. oder von einer solchen unsehlossen werden, wie die Volrocinen. Diese Gebilde hönnen aber doch unmöglich mit dem Panzer identilicirt werden, ler stets einen integrirenden Bestandtheil des Kööper's, und nieht ein todtes Absonderungsproduct desselben darstellt. Als panzerlose Infusorien wurden alle ibrigen metabolischen und die meisten formbeslänligen Infusorien im engeren Sinne zusammengefassı. Alygeselıen von diesen logischen Hängeln. leidet die Eintheilung der Infusionsthiere in gepanzerte und panzerlose anch noch daran. dass sich beide Gruppen noch immer uich scharf gemug von eimander unterscheiden. sondern ganz ummerlich in einander ibergrehen. So sehe ich z. B. nicht ein, warun die Gallung Stylonychia von Ehremberg zu den panzerlosen Infusorien gestellt wird. da doch namentlich stylongch. mytilus eben so entschierten grepanzert ist, als Euplotes charon. Bringt man aber Stylonychia zu den gepanzerten Infusorien, so muss man auch die nahe rerwandte, wenu auch mit einem eqwas bjegsamen Körpej versehene Gattung Kejona folgen lassen; diese schliesst sich wieder ganz unmerlilich an die Gallung Uroleptus an, und durch letzlere werden wir ebenso allmahlig in die entschiolen panzerlose Gallung Oxytricha hinubergefuhr. Elrenberg rechet ferner die Gattung Chlamydodon zu den gepanzerten Infusorien. ih. Parenrlịm ist aber nicht im mindesten von dem der Galtungen l’aramaecium. Ophryoglena und Nassula verschieden, die als panzerlos hestimmt werden.

Perly $\left.{ }^{2}\right)$ theilte die Infusionsthiere nach der Beschaffenheit des lö̈rperparenchyms in drei Gruppen. nämlieh in schneltende oder zuckende (Spastica), in beharrende Monima) und in formwechselnde (Mletabolica). Zu den erstern werden die Vorticellinen und Ophrydinen Ehrenberg's gerechnet; darunter befinden sich auch die nie schnellenden Lrocentum Lurbo, Trichodina vorax unl grandinella. Die zwejte Gruppe umfasst nicht blos die wirklich formbestaudigen, sondern auch sehr entschieden metabolische Infusorien, wie z. B. Trachelius, Amphileptus, OxyIricha. Stichotricha, Urostyla. In die dritte Gruppe endlich sind nut die Gattungen Trachelocerca und Lacrymaria gebracht, die sich doeh durehans nicht himreichend von den schnellenden Infusorien unterscheiden. Wie wenig die verschiedenen Moditicationen des Parenchyms geeignet sind, zur Basis der Classffeation der Inlusionsthiere zu die. nen, das lohrt das von Perly aufgestellte System. Nahe verwandte formen, wie die Oxyluchinen und Euplotinen.

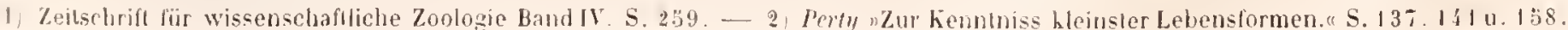


ferner die Trachelinen und Ophryocercinen Perly's, werden weit von einamler getrennt, und die beterogensten, wie Aspidisea und Coleps, Paranaecium und Blepharisua foggen unmillelbar auf einander.

An tem Parenchym mancher Infusionsthiere lassen sich namentlich durch künstliche Behandlung drei verschicdene Schichten muterscheiden, die aber ohne scharfe Gränzen in einander ibergehen. Am leichtesten sind dieselben bei Vorticellinen, namentlich bei len Gattungen Epistylis und Opercularia, ferner Lej Paramaecium, Ophryoglena und verwandten Formen nachzuweisen. Behandelt man z. B. Opercularia nutans oder O. Inicrostoma mit Essigsäure, so helıt sich im ganzen Umfange des contrahirten Kürpers eine hrystallhelle, völlig strnelurlose, elastische, membranarlige Schicht ab, welche eine weit abstehende, bahl ganz glatte, bald falige Huille um das ïbrige, die Form des contrahirten Körpers beibehaltende Parenchy̧m bildet und mil demsellıen nur am vordern und lintern Ende im Zusammenhang bleibt. Diese Schicht bezeichne ich ilwer Struchurlosigkeit wegen nach dem Vorgange von Cohn') als Cuticula. An dem innern contralirten Parenchyum unterscheidet man furner cine lichtere, beine köınigen Ablagerungen entlaltende, consistentere Aussenschicht, die eine ziemliche llachtigkeit besitzt und eine schwache, der Oberfache parallele Streifung zeigt. Diese Schicht ist das Rin denparenchym; ilıre Streifung riihrt wahrscheinlich daher, lass sie selbst wieder aus mehreren concentrischen, von aussen nach innen zu an Dichtigkeit abnehmenden Lagen zusimmengesetzt ist. Den ganzen ibrigen, rom Rinlenparenchym umschlossenen Raum fült continuirlich dis breiartige Inneuparenclıym aus; es ist von körnigen Ablagerungen mehr oder weniger getrüht und schliesst die verschluchten Nahrungsmittel und deren Zersetzungsproducte ein. Schon an lehenden Thieren fillt das lnnenparenchym durch seine grosse Nachgiebigkeit und Verschichharkeit anf; wir sehen Nahrungsstoffe in dasselbe eintreten und darin eine langere oder liürzere Strecke weit vermöge des ihnen durch das Spiel der aussern Wimpern ertheilten Impulses fortbewegt werden.

Bei den Paramäien verhalten sich die drei Schichten des Parencluyms folgendermaassen, wvie man am leichtesten bei Paramaecium bursaria sehen kann. Die ebenfalls nur durch Anwendung von Essigsäure fur sich darstellbare Cuticula ist eine uncbene, mehr ciner aufgequollenen Gallerte, als einer scharf begränzten Membran gleichende, brystallhelle Schicht, welche die Wimpern trägt und an der ganzen Oberlläche ein sehr regelmässiges, fein chagrinirtes Ansehen zeigt. Das Rindenparenchym ist dadurch sehr markin, dass es von zahllosen, dicht neben einander und auf der Cuticula nahebei senkrecht stehenden, starren, stabförmigen Körperchen durchselzt wird, und dass in ihm dichı unter der Stabchenschicht zahlreiche Chlorophylliörner eingebettet liegen, welche rlie lebhaft grüne Farbe des Körpers verursachen. Die Spilzen der slabförmigen Körperchen lassen in der Culicula feine punctrörmige Findrucke zurük, und lediglich davon rubrt das lein chagrinirte Ansehen derselben her, heineswegs aber von zwei; nach entgegengesetzten Richtungen spiralig um den körper herumlanfenden und sich lireuzenden Liniensystemen, wie Colm glaubte ${ }^{2}$ ) und ich selbst friher anmahm ${ }^{3}$. Mit Unrechit bestritt Colm (lie stabförmigen Körperchen im Rindenparenchym; sie lassen sich durch Quetschen des Thieres ohne Schwierigkeit isolirt darstelien, und sind auch an lebeuden Individuen, wenn man erst mit ilnen vertraut geworden ist, so leicht zu beobachten, dass man sich nur darublser wundern kann, wie wir sie bei unseren frülıeren Untersuchungen überselıen konnten.

Das Innenparenchym von Param. bursaria hat dadurch ein ungewöhnliches, alser wie mir jetzt scheint, unverdientes Interesse erregt, dass dasselbe in einer unaufhurlichen Rotationsström ung begritlen ist, die zuerst von Foclie ${ }^{4}$ bemerht wurle und die man seiltem noch nicht genügend zu erklären vermocht hat. Bei dieser Erscheinung ist besonders beachtenswerth, einmal, dass die äussersten, an das Rindenparenchym gränzenden Bestandtheile des Innenparenchyms eine viel starkere Rotation erfalıren, als die inneren, welche nur wenig und regellos unter einander geschoben werden, aber keineswegs ein ganz ruhendes Mittelfeld bilden, und sodann, dass die Rotation unabänderlich in derselben Richtung erfolgt. Die rotirende llasse bewegt sich nämlich, wie zuerst von mir nachgewiesen wurde, auf der linken, lägeren und gekrimmteren seite des Körpers auliwärts, biegt dann inı vordern Ende nach rechts um, steigt auf der rechten, libzeren und graderen Seite nach abwärts, und wendet sich dann im hintern Ende wieder nach links. Erwägt man nun, dass in der hintern Körperlälfte und zwar auf der rechten Seite der kurze trichterförmige Schlund liegt, dass dessen linteres Ende nach links gekrimm ist, umd dass durch ihn unausgesetzt, auch wenn das Thier völlig still steht, ein kraftiger Nahrungsstrom in das Inncnjareuchym getrieben wird, der nur von den in der Nähe des Mundes stehenden Körperwimpern erregt zu werden brauchıt, so muss man in diesem Nahrungsstrome die Ursache der Rotation des Innenparenchyms erkennen; denn er erklärt

1) Zeitschrift für wissenschaftliche Zoologie Band Y. S. $420-28$. - 2) Futuendaselbst S. 424. - 3) Stein Die Infusionsthiere. S. 239. - 4 Isis 1836. S. 786 .

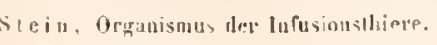


durchaus hefriedigend die beiden Ilauphomente dieses Plänomens. Weil der Nalurungsstrom im hintern Enule des Körpers und zwar ron der rechten Srite her in sehiefer Richtung in das Inuenparenclıym tritt, so muss dieses heständig anf der limken Seite in die Höhe getrieben werden, und weil der Nahrungsstrom gemass der Lage des Schlundes dicht unter dem lindenpatenchym nur auf die ansserste Schicht des Innenparenchyms einwirkt, so miissen die aussersten Bestandtheile desselben in eine stärere Rotation versetzt werden, als die inneren.

\% Gunsten der eben vorgetragenen Erhlärungsweise des Rotationsphinomens sprechen noch zwei andere Thatsachen. Bei Paramaecium aurelia rotirt namlich ebenfalls das lmnenparenchyn, jedoch minder energisch und continuirlich, als hei P. bursaria. Dies rührt offenbar daher, dass P. aurelia bei sonst ganz gleichem Körperbau beträchtlich länger und schmaler ist, als P. bursaria; der bei P. aurelia in hintern Drittel tes Körpers eindringende Nahrungsstrom hat milhin den Widerstand einer weit langeren Strecke rom Innenparenchym zu überwinden, als hei P. bursaria, seine Wirliung muss daher eine schwächere sein. Die zweite Thatsache ist die, dass, soball sich im Innern der Paramaecien ulie voluminösen Keimkugeh ent wickelt haben, aus welehen die Jungen hervorgehen, die Rotation des Innenparenchỵms nicht mehr stattfindet; der Fortbewegung desselben dureh den Nahrungsstrom stellen sich jetzt die Keimkugeln entgegen.

D) breiarlige Besclualfenheit des Innenparenchyms und seme grosse Verschiehbarkeit hat neuerlich Lachmann zu der Ansicht geführ' '), dass dasselbe nicht einen Theil des Körperparenchyms bilde, sondern dass es als Chymus zu betrachten sei, der den Inlaalt einer grossen Verdaumgshölle oder eines llagens ausmache. Als Körperparenchym sieht Lachmam nur unser Rindenparenchym an, welches allein contractil sein soll, die Cuticula hezeichnei er, was gleichgiiliger ist, als lie eigentliche Oberluat der Infusorien; dafur gilt sie auch uns, es wurde aber der Name Cuticula vorgezogen, weil wir mit ihm die Vorstellung von einer structurlosen Hant verbinden. Lachmam's Anschaungsweise ist bereits von Frey fiir eine sonderbare erklärt und mit melıren triftigen Grümlen beläimpft worden $\left.{ }^{2}\right)$; auch ich muss nich gegen dieselhe auf das Entschierlenste aussprechen.

Es ist bereits darauf hingewiesen worden, wie unmöglich es sei, selbst hei denjenigen lnfusorien, an welchen wil durch kiunstliche llülsmittel drei verschiedene Schichten des Parenchyms zu unterseheirlen vermögen, ganz bestimmte, scharfe Gränzen zwischen denselben anzugeben. Bei der grossen Melızalıl von lnfusionsthiejen können aber ibberhaupt solche Schichten in liciner Weise mehr nachgewiesen werden. Schon bei den gepanzerten Infusorien bleiben wir zweifelhaft, ob wir den fir sich nicht tarstellbaren Panzer als eine verdickte, star gewordene Cuticula, oder nicht vielmehr als ein Verschmelzungsproduct von Cuticula und Rindenparenchym aufzufassen haben. da ein besonderes Rindenparenchym absolut nicht zu unterscheiden ist. Bei den meisten metabolischen Infusorien, wie z. B. bei Stentor, Spirostomum, Urostyla, Amphileptus, Trachelius, und vielen formbeständigen, z. B. Bursaria, Prorodon, Chilodon, Chlamydodon, ist nicht eimmal eine besondere Cuticula darzustellen, die wir doch hier, wie bei allen Infusorien, annelmen müssen, da die ausserste Granzschicht des Körpers stets augenfillig resistenter ist, als das ubrige Körperparenchym. Letzteres bildet bei den eben genannten Gattungen eine unterschiedslose Masse, die nur von aussen nach innen zu ganz allmählig an Dichtigkeit ahzunehmen scheint. Die Nahrungsmittel werden nach allen Richtungen hin durch dieselbe geschohen, und sie streichen sehr haulig ganz nahe unter der äusseren Oberlläche hin.

Wie kann man nun von einer leibeshöhle tler Infusionsthiere sprechen, wenn deren Gränzen bei den meisten absolut unbestimmbar sind, und wenu selbst in den wenigen Fällen, wo scheinhar eine Leibeshöhle vorlanden ist, dicse nie fur sich, sonden immer nur als ein continurlich mit organischer Substanz erfuilter Raum beobachtet werden kann? Lachmam will die Zusammensetzung des Infusorienkörpers auf die des Polypenkörpers zuruickfihhen; allein die Organisation des einfachsten Polypen (llydra) ist denn doch noch sehr wesentlich von der der Paramäcien und Vorticellen verschieden. Bei den Polypen unterscheiden wir stets eine wahre, nach innen zu ganz scharf umschrichene und durelı einen eigenen Epithelialuberzug vom übrigen Korperparenchyn abgegränzle Leiheshöhle, die bald völlig leer ist, bald melı oder weniger verdaute Nahrungsstofte enthält, aber niemals in der Art mit org̣atnischer Sulıstanz erfullt ist, dass ihre Grínzen dadurch undeutlich oder gar völliğ unangelıbar wiirden.

Ware hei len Infusionsthieren cine mit Chymus erfullte Leibeshölle vorhanden, so misste bei allen hinlainglich tief verletzten Individuen der Chynus herausfliessen und zuletzt die leere Leibeshöhle jhrem ginzen Umfunge nach übersehen werlen hönnen. Dies ist jedoch nie der Fall, wic man sich leicht uberzeugen kann, wenn

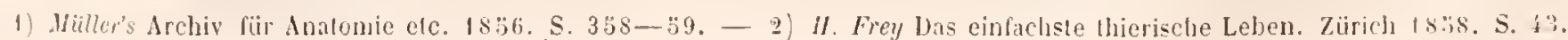


man z. B. eine grosse Stylonychia mylilus, was nichı schwer hält, quer durchschncidel, Die Schnitulache bleibt danu lange unvertindert, es legen sich die Ränder derselben nichıt etwa an einanter, und doch fliesst gar keine Masse aus dem Innem heraus. Ebensowenig ist dies an zuftillig rerstimmelten Exemplaren anderer Oxytrichinen zu beobachten, die zu den altriglichsten Erscheinungen unter den Mlikoseope gehören. Bei den meisten Iıfusorien, welche lehendige Junge geharen, z. B. bei Stylonyehia uyglilus, Urostyla gramblis, Paramaecium aurelia und P. humsalra bilden sich ansehnliche, das granze Parenchy̆m bis zun Körpercentrum durebsetzende und an der äussern Oberfliche mit weiter Oeffnung ausmündende kanalarlige Liicken, durch welche die im Innerı entwickelten Jungen ausschämen (vergl. unsere Taf. TII, VII und XIY). Auf diescm Wege misste auch der Chymus, wenn er existirle, herausfliessen; davon ist jedoch nic elwas zu beobacluten.

Lachmom fasste unser Inneuparenchym auch deshalb als blossen Chynus auf, weil er an isolirten Parthicen desselben heine Contractionserscheinungen wahrnehmen konnte; aber an blossen Fragmenten des Rindenparenchyms, in welches Lachmam allein den Silz des Contractionsvermögens verlegt, sind elenfalls lieine Contractionen und Expansionen zu beobachten, sondern immer nur an grösserm, noch ron der Culicula zusammengehaltenen Körperstiicken. Die Thatsache, auf welche sich Lachmam beruft, dass namlich pine Stylonychia, deren innerste Parenchymmasse von ciner Acinete ausgesogen worden war, sich noch bewegte und den begonnenen Theilungsprozess vollendete, beweist nicht entferut, dass das Centrum der Slylonychien aus blossem Chymus besteheı miisse. sondern sie lehıt nur, dass ler Körper auch nach Verlust eines betrichtichen Theils seiner innern Parenchymmasse sein Contractionsvermögen und seine Lebensfahigheit noch nicht eingebiisst hat.

Es giebt aber anch Thatsachen, welche unzweideutig lehren, dass das breiartige Imnenparenchym der lufusorien nit selbststündiger Contractılitit begabt sein misse. Die gepanzenten Infusionsthierc können iluren Körper nicht vou allen Puncten der Perjpheric her senkrecht zur Língsaxe zusammenzielıen, die verschluckten Nahrungsmittel müsten mithin z. B. bei den Euploten und Stylonjchien, denen ein besonderer Schlund aljgehı, in der Nảhe Jes Ilundes im Parenchym liegen heiben; sie rüicken aber nach und nach weiter, theils rorwärs, theils rijckwairts. Freilich werlen sie nicht selten von nachfolgenden Nahrungsmassen gedringt, aber auch olme dass dies geschieht. wandern alle verschluchten Stofle mit der Zest immer weiter nach hinten. Ganz isolint im Parenchym liegende Kärperchen sieht man bei völlig stillstehenden ludividuen plötzlich aus ihrem Ort verdıàngl werden, was sich nur durclı die AnnalıJe erklären lässt, dass dem Innenparenchym ein selbstständiges Contractionsvermögen zukommt. Ferner kann man hei den Vorlicellinen sich sehr leicht üherzengen, dass, während der körper vollkommen rulig ausgestrecki bleibt, unverlauliche Stoffe aus dem Ceutrum des Körpers sich nach vorn bewegen, ohne von nachfolgenden Nahıungsbalien geschohen zu werden, und so zuletzl nach der Stelle gelangen, an welcher sie nach aussen cntleert werden 1 .

Ich verkenne nicht, dass es auf den ersten Anblick etwas Paradoxes hat, einer äusserst verschiebbaren hreiartigen Substanz, deren Continuitat jeden Augenblick durch zwischen dieselbe tretende fremole Körper unterbrochen werden kann, ein gemeinsames Contractions- und Expansionsvermögen zuzuschreiben; allein blan ỉhersehe doch nicht, dass diese substanz nicht isolint im Centrum des Infusorienkörpers liegt, sondern dass sie mit den aussern dichtern Parenchym innig verwebt ist und in diesem, so zu sagen, ihre Wurzeln hat. Und simd rlenn elwa die völig sicher constatirten Erscheinungen an Parenchym der Rhizopoden anderer Ant und weniger w underbar? Nichıts ist hei diesen Thieren gew öhnlicher, als getrennte Theile des Körperparenchyns wieder zusanmenfliessen und als einheilliche Masse wirken zu sehen. Wollen gewisse Rhizopolen, z. B. Actinophrys, Nahrungr aufnelımen. so weicht an einer beliebigen stelle der Körperoherfliche das Parenchym aus einander, umfasst den zu verzehrenden Köper und schliesst sich lings um denselben wieder zusammen. Die getrennt ans dem Rhizopodenkiojper hervoruetenden umb sich vielfach verästelnden Pseudopodien verbindeu sich leicht unter einander in querer Richtung durch zahlreiche Substanzlnticken. Letztere delmen sich oft zu umfänglichen Platten aus, von denen wieder, wie aus dem eigentichen Körper, besondere Pseudopodien ilıren Üsprung nchmen. Um fremde Körper, dlie als Nalırung remwendet werden sollen, lliesst die Substanz der Pseudoporlien elenfalls plattenförmig aus cinander, bis cin solcher Körper ganz eingehiallt ist ${ }^{2}$ ). Wahılich nach solchen Erfalırungen muss auch das letzle Bedenken schwinden, welches gregen die Annahue, dass lie innerste Masse des Infusorienlörpers zum Parenchỵ gehöre und contractil sei, seltend gemacht werden könnte. Wir werden demnach dem Körperparenchyn des Infusionsiliere den fundamentalen

1) Vergl.: Stein Die Infusionsthiere Taf II. Fig. 10. A'. i. - g) Ver⿳⺈. Max' Schultze: Ueber den Organismus der Polythalamien S. 17 und Taf. I. Fig. I 
Character beizulegen haben, dass dasselbe den gesammten Raum des Körpers continuirlich erfullt, und dass es das Bestreben besitzl, die durch fremde Kürper unterbrochene Continutit wieder herzustellen. sobald diesellsen rerdraingt worden sind.

Auch das chemische Verhalten lehrt, dass das gesammte Körperparenchyu der Infusionsthiere nach Abzug der Culicula eine untrennbare, unterschiedslose Einheit bildet. Man kann sich davon am leichtesten bej den Vorticellinen uberzcugen ${ }^{1}$ ). Belındelt man den Körper z. B. von Vorlicella, Carchesium, Zoothamuinm, Epistylis, Opercularia mil Jodtinetur, so färbt sich das gesammte Parenchym ticf goldgelb, nur dic Cuticula bleibt farblos. Ganz ahulich ist die Wirkung von Salpetersäure, nur färbt sich das Parenchym weniger intensiv goldgelb. Trankt man den Körper nit einer concentrirten Zuckenlösmg, so schrumpft er ausserordentlich zusanmen, quillt aber beim Zusatz eines Tropfens Schwefelsáure noch uber seinen ursprijuglichen Umfang auf; das Parenchym farbt sich lief rosenrolh, die Cuticula aber bleibt ebenfulls firblos. Kalte Salpeter- und Salzsäure und kalte Kalilange greifen die Culicula nicht an; werden aber diese Flüssigkeiten in kochenden Zustande angewendet. so wird die Cutieula aufgelöst. In concentriter Schwefelstiure quillt die Cuticula sehr schnell auf und löst sich zuletzt vollstindig auf. Aus diesen Reactionen folgt, dass die Cuticula aus einem der Cellulose und dem Chitin nahe verwandten Stolle bestehen muss und dass das gesammte ïbrige Parenchym eine Proteïnverbindung ist.

Die aussere Oberląche des Körpers vieler Infusionsthiere ist mit seịchteren oder lieferen, gleich weit von einander enfernten und meist sehr dicht auf einander folgenden Furchen verselsen, die mit mehr oder weniger erhabenen Zwischentiumen abwechseln. Sie verlaufen entweder der Länge nach von einem Ende des Thieres zum anderı, z. B. bei Prorodon, oder ziehen sich in schräger Richtung zur Längsaxe rings um den Körper herum, indem sie mehr oder weniger genan weit ausgezogene Spirallinien un die Längsaxe des Thieres beschreiben, z. B. hei Loxodes jostrum. Nicht selten kommen zwei nach entgegengesetzten Richtungen verlanfende und sich daher kreuzende Systeme von spiralen Furchen vor. z. B. bei Spirostomum ambiguum und Trachelocerca. Manche Infusionsthicre zeigen zwvei ganz verschicdene und nicht in einander übergehente Systeme von Furchen. z. B. Stentor und Spirostomum virens; andere besitzen un auf einem Theil der Körperoberfliche, velche dann immer die untere ist, Furchen, z. B. Chilodon, Chlamydodon und Scaphidiodon. Da die erhabenen Zwischentaume zwischen den Furchen in der Regel dicht bewimpert sind, so scheinen die Wimpern reihenweis angeordnel zu sein. was jerloch streng genommen nicht der Fall ist. Bei manchen Vorticellinen, z. B. Epistylis digitalis. Opercularia berberina, ist der Körper auch in Zustande vollkommener Expansion häulig mit sehr dicht auf einander folgenten und zalten ringfërmigen Furchen versehen. Die Körpreroberfläche der gepanzerten lıfusorien ist meist ganz glatt, sie zeigt aber grosse Neigung zur Enwickelung scharfliantiger vorspringemder Leisten und nügelförmiger oder dornarliger Fortsitze; dergleichen linden sich z. B. bei Euplotes und Aspidisea. Bei cinigen Infusorien Ireten in Folge parlieller Verdickung

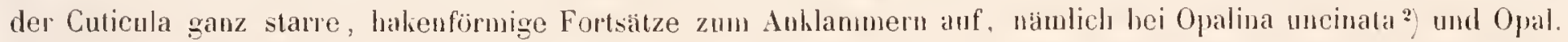
irmata ${ }^{3}$. Noch anffallender ist der Hiffapparat ron Trichodina pediculus und Tr. mitra ${ }^{4}$; er besteht aus einem starren. dis hintere abgestutzte Ende des Körpers einnchmenden, uhrridchenähnlichen Hornringe, ron dem eine ebenfalls hornarlige, aber sehr biegsime und feine quergestreifte ringförmige Membran a!sgeht, die die Form eines Saugnaples annchuen unct anch als solcher fungiren kann. Bei Opalina secuns, einer nenen, langen, ju Darmkanal verschiedener Naidinen lebenden Species, entwickelt die Cuticula eine schueidende. hornartige Längsleiste, welche sich von vordern Körperende mehr oder weniger weit natch riickwärts erstreckl.

\section{Von den stabö̈rmigen Kïrperchen im Parenchỵm der Infusorien.}

Unmittelbar unter der Cuticula finden sich bei einer mässigen Anzahl von Infusionshieren eigenthumliche starre, stabförmige Körperehen, welche in transversaler Richtung die áusseren Schichten des Parenchyns durchsetzen. Sie wurden von Ehrenbery im Jahre 1832 bei Bursaria vernalis enteleckt und sehr lienntich abgebilulet und beschrieben5). "Die Wimpern, sagt Ehemberg in der Erklärng der Abbildungen, "sind bei dieser Form sehr

1) Vergl. Stein Die Infusionshliere S. 81. - 2) M. Schultze Beitrige zur Naturgeschichte der Turbellarien. Greifswalde 185̆. S. 68. Taf V11. Fig. 8.9. - 3) Stcin Die Infusionslliere S. 185. Taf V. Fig. 24. - 4) Ebendaselbst S.174-75. Taf. V1. Fig. 34-57. $\because$ Abhandl. der Berliner Acad, von 1833, S. 236 und S. 32 4. Taf. III. Fig. 4. d. 
stark und dazwischen liegen kleine prismatische Stabchen in der horjersubstanz. wie die von mir neuerlich entdeckten Krystalle bei Fröschen und Fischen. "In Text heisst es: "Verdunstet der Wassertropfen, welcher das Thierchen auf dem Oljectritger des Hiliroscopes enthält, so bleibt dasselhe ruhig liegen, wird immer breiter und fangt, ohne im Wirbehn aufzuhören. an sich aufzulösen. Es berstet an irgend einer Stelle und man sieht danı, wahluend der hnhalt ausfliesst. die gallertıge Haut des Körpers mit den Wiupern wie mit lauter feinen Nadeln und Stabchen belegt." Im grossen Infusorienwerte wirl in der Beschreibung von Bursaria remalis \$. 329 nur ganz kur. erwahnt, dass ter Körper mil prismatischen kleinen Stabchen durchwirkt sei, mnd die ältern Abhildungen werden cinfach reproducirt.

Ehrenberg's Entrleclimg blieh ohne weitere Folggen, bis 0 . Schmidt im Jibre 1849 die stabförmigen Körperchen wieder zur Sprache brachte; er beobachtete sic bei Bursaria leucas. Paramaeciun aurelia und P. caudatum und verglich sie sehr treffend mit den stabfömigen Körperchen im Parenchym der Turlellarien J). Schmidt wird daher gewöhnlich für den Entdecker dieser Gebilde bei den lnfusionsthieren ausgegeben, aber mit Unrecht, wie die vorstehenden Stellen aus Ehenberg's Schriften beweisen. Im Jahre 18.j.) hestatigte Allmam das Vorkommen der stabförmigen Körperchen hei Bursaria leucas, dentele sic aber als Nesselorgane, weil er beobachtet haben wollte, dass bei Zusatz von Essigsäure ans der Spitze der stabförmigen Körperchen ein feiner Faden hervortıete ${ }^{2}$ ). In folgenden Jahre fügte Lachmam zu den bereits bekannten Fällen noch Parauaecium bursaria und die Gatlung Ophryoglena hinzu, anch lemerht dieser Forscher, dass er in Gemeinschaft mit chluarede bei einem acinetenartigen auf Campanularien schmarotzenden Thiere dichere, den Nesselorganen der Campanularien täuschend ähnliche Körperchen beobachtet habe ${ }^{3}$. Ich selbst habe die stabförmigen Körperchen bei Bursaria leucas und B. vernalis. Ophryoglena atra und 0 . acuminata, Paranaecium aurelia und P'. bursaria, Plenronema chrysalis Dujard., Nassula ornata, Cyclogramma rubens Perty, Urocentrum furbo. Trachelius ovmm, Ampliteptus anser, 1. meleagris und A. Iongicollis angetroflen und darüber im Jahre 1836 auf der Naturforscherversammlung in Wien einen Vortrag gehalten, in welchem ich die stabförmigen Körperchen als Tastkörperchen deutete ${ }^{4}$. Diesem Namen gebe ich auch jetzt noch vor andern Bezeichnungen den Vorzug, da ich mich noch immer nicht habe ibberzengen können, dass die in Rede stehenden Gebilde ten in andern Thierklassen vorkommenden Nesselorganen entsprechen, wohl aber glaube ich eine Beziehung derselben zum Tastsinn nachweisen zu können.

Die Tasthörperchen sind sehr scharf contourirte, gerade. starre Stabchen, die sich nach beiden Enden hin mehr oter weniger scharf zuspitzen, mithin sehr langgezogene spindelfömige Körperchen darstellen. Sie bestehen durch und durch aus eiuer ganz homogenen. farblosen, glasartigen Substanz, und es lässt sich an ihnen keine Spur von eines centralen Höhle crkennen. Ihre Länge beträgt bei Bursaria leucas und Nassula ornata, wo ich sie am entwickeltsten fand, $\tau_{1 ! 0}^{\prime}$ bis höchstens $\frac{1}{150}{ }^{\prime \prime}$. Isolirt man sic durch Zerquetschen des Thieres. so quellen sie bald nachher aul, besonders wenu viel Wasser hinzutrilt, sie werden immer blasser und undentlicher, fangen an zu zerAlessen und verschwinden zuletzt spurlos. Noch viel schneller lösen sie sich in Essigsäure auf. In allen diesen Eigenschaften stimmen sie ganz und gar mit den stabförmigen Köperchen der Turbedlarien iberein, die uns M. Schulle geschildert hat ${ }^{5}$, entfernen sich dagegen weit ron den hei Polypen, Quallen, Wümern und Mollusken zn beobachtenden Nesselorganen. Lelztere werden werler von Wasser noch Säuren aufgelöst und enthalten stets eine Hohle, die nit einer terninalen Oeffnung rersehen ist, durch welche der im lonern erzengte Nesselfaden bervortritt.

Mir ist es nie möglich gewesen, ungeachtet ich diesen Gegenstande meine angestrengtuste Iufmerksamkeit wirlmete, und obgleich mich seil langer Zeit eigene Untersuchungen mil allen Formen der Vesselorgane bei Hydroiden nnd Würmern volliommen vertraut gemacht liaben. an lebenden Infusionsthieren aus den Tastlörperchen Fäden lervortreten zu sehen. Eben so wenig vermochte ich an den unzihlige Vale von mir isolirten Tasiliörperchen irgend eine $S_{p}$ ur eines fadon- oder borstenartigen Fortsatzes zu beobachten. Ich hann daher Allmam nicht beistimmen. dass die Tastiörperchen Nesselorgane sein sollen. Leider kenne ich Allmunu's Arbeit über Bursaria leucas nur au. dem kurzen Referale von R. Leuckar ${ }^{6}$;, daraus scheint mir aber hervorzugetien, dass Allmam, wie auch Lenchart,

1 Froriep's Notizen von 1849. Band IX. p. 5 und 0 . Schmidt Itandbuch der vergleichenden Anatonie. Jena 1849. S. 75. 2) Report of British Association 1855. p. 105 und Quarlerly Journal of microscop. Sociely 1853. No. X1. p. 177. - 3) Müller's Archis 1856. S. 338. - 4) Tageblatl der 32. Versammlung deutscher Naturforscher und Aerzte in Wien 1856. No. 3.5 .55 . Das Referal ist sehr ungenau und theilweis unrichlig. - 5) Beiträge zur Naturgeschichle der Turbellarien S. 14. - 6) Wiegmann's Archiv für Nalurgeschichle 1836 . S. $433-34$.

stein, Ormanisnus der lufusingsthipre 
der sich fir Allman's Ansicht ausspricht, mur dieselbe Erscheinung beobachtet habe, anf alie ich schon in memer Beschreibung von Paramaccium bursaria ') aufmerksam machte. Behandelt man namlich Par. Jursaria, Ophryoglena atra unl acuminata und Bursaria leweas mit concentrirter Essigsäure, so treten im ganzen Umfange des Körpers lange borstenförmige, theils gekr'iuselte, theils geknickte und regellos durch einander gewirte Fäden hervor. Diese sind wahrscheinlich für die hervorgeschnellten Nesselfäden gehalten worden; allein es läst sich nicht heweisen, dass sie von den Tastkörperchen ausgehen, da letztere nach der Einwirkung von Essigsiure verschwunden sind. Wären die langen Borsten wirklich Nesselfüden, so müssten doch ausserdem anch noch die Körperwimpern zı unterscheiden sein, da dies aber nicht der Fall ist, so kann ich in ihnen nur die widernaturlich verlängerten Körperwimprern erkennen. Bringt man die genannten Jufusionsthiere durch Einwirkung sehr verdiunnter Essigsäure ganz allmählig zum Absterben, so behalten die Wimpern ihre normale Länge, und es treten zwischen ihnen durchaus lieine läugern Fidlen hervor, was doch gewiss geschehen würde, wenn die Tastkörperchen Nesselorgane wären.

Dass bei den Infusionsthieren auch wirkliche Nesselorgane vorkommen können, will ich nicht in Abrede stellen; schon die oben erwähnte Beobachtung von Lachmom und Claparede scheint dafiir zu sprechen, und es wirt mir dies auch wach einer eigenen Beobachtung sehr wahrscheinlich, die ich an einem in der Ostsee bei Wismar aufgefundenen Thiere anstellte, welches in seiner gesammten Organisation dhe grösste Uebereinstimmung mit Amphileptus meleagris des sissen Wassers zeigte. In dem Halstheile dieses Thieres und zwar in dem convexen Seitenrande lagen nłmblich nahe hiuter cinander, so wie auch zerstreut im ganzen übrigen Rande des Körpers, transversal gestellte, ten Tastkörperchen sehr ähuliche, aber etwas dickere, Jänglich ovale Stähchen, von welchen ich bei mehreren Individuen, die in voller Lebensthätigkeit waren, eine die Körperwimpern un das Doppelte iaberragende, gradausgestreckle Borste ausgehen sah. Mit noch grösserer Aufmerksamkeit untersuchte ich nun den Amphileptus meleagris der süssen Gewässer, aber ich fand hier immer nur die gewölulichen Tastliörperchen, und niemals konnte ich über die Wimpern hinausragende Borsten wahrnehmen.

Die Tastliörperchen durchsetzen von der Cuticula ans bald in senkrechter, bald in mehr oder weniger schräger. Richtung das Rindenparenchyn und liegen meist gleichweit entfernt und sehr dicht neben einander; sie bilden zusammen immer nur cine cimzige Schicht, nie stchen von aussen nach innen zu nehrere Tasthöpperchen hinter einander. Ganz gleichförmig im ganzen Umfunge des Körpers vertheilt und dicht gedrängt neben einander stehen die Tastlörperchen bei Paramaecium aurelia (wovon ich P. caudatum nicht als besondere Art zu trennen vermagh), Par. bursaria, Pleuronema chrysalis, Ophryoglena atra und O. acuminata, Cyclogramma rubens, Bursaria lencas, und Urocentrum turbo. Wird bei der Beohachtung eines dieser Thiere das Nikroseop so eingestellt. das nur der mittlere Theil der Körperoberfläche im Focus des Instrumentes liegt, so zeigb dieser ein fein chagrinirtes Ansehen, weil jetzt nur die Spitzen der Tastkörperehen gesehen werden. Bei ticferer Einstellung bleibt der Anblick in der Mitte im Wesentlichen derselbe, weil hier nur die Quersclunitte der Tastkörperchen zur Ansicht gelangen können, nach aussen zu aber treten die Tastiörperchen als ungleich lange, radiale oder centrifugale Strichelchen auf, die um so länger werden, je mehr man sich dem Ramble nahert. Gelangt man endlich bis zur mittern horizontalen Durchselnittsebene des Thieres, so iibersicht man die Tastkörperchen unverkürøt ihrer Länge nach; sie erscheinen nun als ein den ganzen Rand des Körpers säumendes, aus glejch langen queren Strichelehen zusammengesetztes Band.

Bei Nassuli ornata finden sich die sehr ansehnlichen Tashörperchen zwar auch in ganzen Unfange des Körpers, sic sind aber viel weiter aus cinander gericht und umegehnassiger vertheilt, indem sie theils in lileinen Gruppen beisammen liegen, theils ganz vereinzelt stehen. Sie wurlen bereits im Jahre I 832 von Ehreuberg ${ }^{2}$ ) unterschieden, aber irrhimlich für stähere, zwischen den gewöhnlichen Wimpern stehende Borsten schalten, obgleich bemerkt worden war, dass sie heim Zerfliessen des Thieres "wie kurze Nadelu " ersehrinen. Imphileptus anscr, womit A. margaritifer zu veremigen ist. besitzt feine borstenförmige, regellos und vereinzelt im ganzen Körper zerstreut liggende Tastiörperchen, ausserdem aber noch eine sehr scharf marlirte Zone dicht hinter einander liegender borstenformiger Tastkörperchen, welche sich an dem gewöhnlich convexen Seiten rande les langen, platıerliuckten, sehr beweglichen Ilalses von der Spitze desselben his zu dem an seiner Basis gelegenen Munde berabzieht. Bei der Flächenansicht des Halses erscheinen die Tastkörperchen als feine transversale Streifung des ganzen vor dem Ilunde gelegenen Seitenrandes; ist aber die Kante dieses Seitenrandes dem Beobachter zugeliehrt, so sicht man auf derselben einen schmalen, aus sehr feinen l’ünctehen zusammengesetzten Streifen von der spitze des llatses 
bis zum Nunde herablaufen. Eine ahnliche Zone von borstenförmigen Tastliöperchen săumt bei Trachelius ovum den ganzen convexen Seitenrand des Halses bis zum Mlunde, im ganzen ubrigen Kürper fehlen aber die Tastkörperchen. Bei Amphileptus tongicollis oder doch einer nahe verwandten Art sah ich nur in der gekrimmten Spitze des Halses eine geringe Anzahl dicht hinter einander liegender Tastliörperchen, ausserdem einzelne zerstreute im Halse und iubrigen Körper. Bei Ampliileptus meleagris endlich ist der gesammte Bauchrand und Hinterrand des plattgedruchten, blattartigen Köpers mit diclıt binter einander liegenden, transversalen borstenfürmigen Tasthörperchen rersehen, an Ruckenrande finden sie sich aher mur in den zahnförmigen Vorsprüngen und zwar in einem jeden zu cinem Biindel zusammengehiuft. Ausserdem kommen auch noch unter den beiden breiten Seitenflichen regellos zerstrute Tastliörperchen vor.

Die Arten der Gattungen Trachelius und Amphileptus benutzen ihren sehr ausdehnharen und biegsamen Ilals zum Betasten fremder Gegenstäude, und zwar wird dazu stets der die Tasthörperchen enthaltende Seitenrand des Ilalses verwendet, an dem auch vorzugsweise die Nahrungsstolle herab zum Munde troiben. Diese Wahrnelumung war es, welche mich zunächst auf den Gedanken fïhrte, in den stabfïrnigen Körperclıen der Intusorien Organe zur Verschäfung les im Uebrigen in der ganzen Oberflache des Parenchyms verbreiteten Tastsinnes anzunchmen. Die Tasthörperchen setzen dem Druck, wetehen fremde Körper auf die oberflìchlichsten Schichıten des Parenchỹms ausibben. einen Widerstand entgegen, und dadurch muss die Empfindung in diesen schichten eine intensivere werden. Dieselhe Bedeutung hat auch M. Schultse den stabförmigen Körplerchen ler Turbellarien beigelegh "). Sie bleibt die wahrscheinlichste, so lange uicht mit Evidenz dargethan werden ham, dass die Tasthörperchen der Infusorien zusammengesetztere Gebilde sind, als sie nach meinen bisherigen Untersuchungen erscheinen. Als blosse sheletbildente Theile des Parenchyms können sie noch weniger aufgefasst werden, denı dann missten sie in dem so beweglichen Halse von Trachelius und Amphileptus eher fehlen, statt hier vorzugsweise entwickelt zu sein.

Die Infusionsthiere, welchen Tastkörperchen zukommen, zeigen diesclben nicht zu allen Zeiten gleich deutlich. Icl traf niclıt selten Individuen von Paramaecium aurelia, Bursaria leucas und Urocentrum turbo, an denen heine Spur von diesen Gebilden aufzufinden war; bei andern Individuen unterschied ich sie zwar, sie waren aber viel wenger scharf hegranzt und besassen eine viel geringere Grösse, als bei den normalen Individuen. Es waren njcht etwa junge Thiere, bei denen die Taskörperchen fehlten oder unentwickelt erschienen, sondern diese Beobachtung habe jch nicht selten an den grössten Individuen ilırer Art gemacht. Wir müssen daher wohl anuehmen. dass sich die Tastkörperchen ron Zeit zu Zeit regeneriren. Hochten sie aber in einem Thiere auch noch so wenig entwickelt sein, stets sah ich sie sogleich in derselben Anordnung auftreten, wie in den Individum mit normal ausģebilıleten Tasthörperchen. Bei den Turbellarien entstehen die stabförmigen Körperelıen in gekeruten Zelleı. deren lmeres sich mit einer grösseren oder geringeren Anzahl von Stabchen erfullte; bei den Infusionsthicren sah ich uiemals bindelweis vereinigte und von einer gemeinsimen Membran umschlossene Tasthörperchen. Es wäre daher sehr verkehrt, weun man aus dem Vorkommen von stabförmigen Körperchen bei Infusorien und Tublliarien und aus der bei den letztern statfindenden Entwickelungsweise derselben den Schluss ziehen wollte. die Tástkörperchen der lufusorien müssten auf dieselbe Weise entstehen und ihr Parenchỵ nusse lemuach ans Zellen zusammengesetzt sein.

bie so scharf hervortretenden Tistkörperchen haben bisher bei der Systematik der Inlusionsthiere noch lieine Bertickichtigung gefunden, sie liefern aber recht brauchbare Gattumgsmerkmale. Infusorien mit und ohne Tasthörperchen liönnen meiner Ansicht nach nicht in terselben Gattung vereing bleiben. Bursaria leucas, womit 3. vernalis rereingt werden muss, unterscheidet sich nicht blos durch den Besitz von Tastlörperchen sehr auflallend ron allen übrigen Bursarien, sondern auch durch kurze stahchenförnige Zähne im Anfangshlheile des Schlundes, sowie durch eine ganz gleichförmige Bewimpermug. Ich bilde daher aus dieser Art eine newe Gattung Cyrtostomum ${ }^{2}$ ), die ihren natürlichsten l'latz nehen der Gatung Nassula findet. Yon der letzleren Gattung muss die Nassula ornata. die allein nit Tastköpperchen verselıen ist, abgosondert werden. Icl erlienne in ihr den Repräsenlanten einer nenen Gattung Acidophorus ${ }^{3}$ ), in welche anch das von Perly sehr ungenigend beschriebene Cyclogranma ruhens zu stellen ist. Die Charactere dieser Galtung sind die Tastkörperchen, ein lischreusenförmiger schlund und die gleichförmige Bewimperung. Aus Amphileptus anser und margaritifer hat bereits Jujardin die Cattung Dileptus, aus Amphileptus meleagris die Gattung Loxophyllum gebilulet; beide Gattungen nehme ich an. 
characterisire sie aher scharfer theils nach der oben angegebenen Anordnungsweise der Tastkörperchen, thens nach der Beschatlenheit des Mundes und Schlundes. Die Gattung Trachelius wird auf T. ovum zu beschrankien sein; die ibrigen Trachelien vereinige ich mit dem Reste von Ehrenberg's Amphilepten in der Gattung Amphileptus. Zur Gattung Paranaecium rechne ich nur Par. aurelia und Par. bursaria Focke (Loxodes Ehbg.).

\section{Vou den Pigmenten, Fetten und andern körnigen Ablagerungen im Parenchym.}

Das Parenchym der Infusionsthiere fiur sich allein ist inmer volligr forblos; dies beweisen nicht blos die vielen zeitlebens farblos bleibenden Arten, sondern es geht dies auch daraus hervor, dass die gewöhnlich gefärbt erscheinenden Formen nicht selten in ganz farblosen Individuen auftreten und dass die fruhesten Entwichelungsstufen wenigstens aller höheren Infusorienformen ungefàrbt sind. Wenn das Parenchỵm gefárbt erscheint, so rührt die Farbe stets von besondern Pigmenten her, die in kleinern oder grössem Massentheilchen und in grösserer oder geringerer Entfernung von einander im Parenchym vertheilt liegen. Die Pigmente werden entweder im Parenchym gebildet, oder sie stammen von den Nahrungsmitteln ab, durch deren Zersetzung sie frei wurden.

Das verbreitetste Pigment in der Infusorienwelt und wahrscheinlich das einzige, welches im f'arenchym seinen Ursprung nimmt, ist das Chlorophyll. Cohm wies zuerst nach'), dass die bei Infusorien vorkommenden grünen Farbstolle sich genau ebenso verhalten, wie das Clılophyll der Pflanzen, namentlich der Algen. Eine hinrejchend concentrirte Schwefelsäure lärbte nämlich den grïnen Farbstoff vou Stentor. Paramaecium bursaria und Euglena zuerst spangriun. dann inmer intensiver blauğrin und zuletzt unter Auflösung fast blau. Bei den höheren Infusorienformen tritt das Chlorophyll immer in Form isolirter, scharf hegranzter, runder Körner von lebhaft saftgruner oder gelbgrüner Farbe auf, die in den anssern Schichten des Parenchyms, in einiger Entfernung von der Cuticula, und wenn ein Rindenparenchym zu unterscheiden ist, in den inneren Lagen desselben eingebettet liegen. le dichter die Chlorophyllkörner auftreten, um so intensiver erscheint der ganze Körper grün gefarht. Die reichste Entwickelung von Chlorophyllkörnern treffen wir bei Paramaecium bursaria. Ophrydium versatile. Stcntor poly-

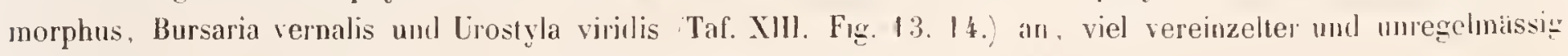
vertheilt erscheint das Chlorophyll bei Euplotes patella (Taf. IV. Fig. 9-11.

Besonders heachtenswerth ist es, dass die Entwickelung des liörnigen Chlorophylls bei einer und derselben Art ausserordentlichen Schwankungen unterworfen ist. Ich habe bereits in memer frihern Arbeit iber Paramaecium bursaria erwähnt, dass von dieser Art gar nicht selten Individuen vorkommen, welche keine Spur von Chlorophyll enthalten, und dass diejenigen Individnen, welche lebendige Junge gebähren, stets vicl ärmer an Chlorophyll sind² Stentor polymorphus tritt haufig sowohl in Individuen mit sehr sparsamen und kleinen Chlorophyllkömern, wie auch in ganz chlorophylllosen Indiviluen auf. Letztere wurden von Ehrenberg als Stentor Roeseli beschrielsen, welche Art also einzuzichen ist; ausserdem ist mit St. polymorphus auch noch der elonfalls firhlose St. Mulleri zu vereinigen, der sich nur umwesentlich durch die Forn des Nucleus unterscheidet, welcher bei den Stentoren sehr variahel ist. Lachmann mo Claparède hahen sich bereits für die Zusammenziehnng dieser drei Arten in eine ausgesprochen, und sie wollen auch noch St. cneruleus, ja sogar St. ig̣neus und niger in den Formenlireis von St. polymorphus zichen ${ }^{3}$. Hinsichtlich des St. coesuleus bin ich noch schwankend, gebe jedoch zu, dass er eine Varjetat von St. polymorphus sein könne, St. igneus und niger sind aber sicherlich von St. polymorphus verschieden, nur werden beide in eine Art zusammenzuziehen scin. Wie Stentor polymorphus sich zu St. Mülleri und Roeseli verhảlt, grade so verhält sich Bursaria vernalis zu B. leucas, Jeide sind daher ebenfalls zu einer Art zu vereinigen, die jch Cyrtostomum leucas neme. Spirostomum virens, welehes Ehrenberg in aler Regel mit Chlorophyll erfillt fand, habe ich lisher, obwohl sehr hafig, doch jmmer nur farblos beobachtet. Vaginicola crystallina und Euplotes patella werden last ebenso lıaulig larblos, wie mehr oder weniger mit Chlorophyll erfiillt angetroflen.

Hanche Infusionsthiere sind in der Regel farblos, entwickelı aber in gewissen Localitäten reichlich Chlorophyll. So sah ich z. B. Spirostomum ambiguum und Stichotricha secunda Perly in Torfgewtissern oft ebenso dicht mit Chlorophylliörnern erfült (vergl. Taf. X. Fig. 12) wie Ophrydium versatile. Auch von Euplotes charon. Coleps

1) Zeitschrift für wissenschafl. Zoologie 1851 . Band III. S. 264. - 2) Stein Die Infusionshhiere S. 240 und 244. - 3/ Miller Archis S. 358 und Annales des sciences naturelles 1857. IV. Sér. Tome VIII. p. 233. 
hirtus, Vorticella nebulifera, Epistylis plieatilis, Loxodes rostrum, Amphilephus longicollis und andenn gewöhnlich farblosen Arten sind nir chlorophyllialtige Formen rorgekommen. Ilan muss sich naturlich bei Beurtheilung des griinen Körperinhalts hiten, dass man nicht etwa oft massenhaft verschluckte, heine, grime monadenartige Infusorien mit Chlorophỵllkörnern verwechselt. Ehrenberg, der bei allen Infusionsthieren, in welchen er Chlorophyllkörner beobachtete, diese fur die Eier derselben ansah, ist darin sehr inconsequent verfahren, dass er die chlorophyllfuhrenden Individnen bala als besondere Arten ron den ihnen sonst in allen antern Beziehungen volliommen gleichenden farblosen tremnte (so Stentor polymorphus ron st. Mialleri und Roeseli, Bursaria vernalis von B. leucas), bald beide in einer Art vereinigt liess, wie Vaginicola crystallina und Spirostomum virens beweisen. Für uns ergiebt sich dagegen die Regel, dass, wenn sich zwei Infusorienformen nur dadurch von einanler unterscheiden, dass die eine chorophyllhattig ist, die andere nicht, wir beide stets als zu einer Art gebörig zu betrachten haben. IIicrnach iverden noch manche der von Ehrenberg aufgestellten Arten einzuziehen sein, so nanentlich: Vorticella chlorostigma, Lacrymaria rugosa, Coleps viridis, Amphileptus viridis und Trachelocerea viridis.

Bei den niederen, mit geisselförmigen Wimpern rersehenen Infusionsthieren tritt das Chlorophyll meist nicht in scharf begranzten körnern. sondern theils in kleineren oder grösseren verwaschenen Flecken, theils in einem so äusserst fuin vertheillen Zustande auf, dass das Parenchym seiner ganzen Ausilehnung nach gleichförmig grün gefarbt erscheint, so \%. B. bei Eugylena. Chlorogonimm, Cryjtomonas, Trachelomonas und den Volvocinen. Das Chlorophyll zeichmet sich bei diesen Thieren auch dadurch aus, dass es eine grosse Neigung besitzl, sich zu Zeiten in einen rothen Farbstofl umzuwandeln. Eine solche Unwandlung tritt regehaissig hei den befruchteten weihlichen Indiviluen von Volvox ghohator ein, nachden sie sich mit einer sternfömigen Cyste ungeben haben (vergl. S. 37); der grüne Farbstofl wird nach und nach goldgelb. orangefarbig und zuletzt lebhaft ziegelroth. Dasselhe gilt von dem analogen Lebensstadium des Volvox minor, welches von Ehrenberg als V. aureus beschrieben wurde J). Auch die rubenden Formen von Chlamydococeus pluvialis werden durehgingig mit der Zeit dunkelblutroth bis schmuzigbranmoth: zuerst tritt die Umwandlung der grünen Farbe im Centrum des encystirten Thieres auf, und von diesen centralen Fleck aus breitet sich die rothe Farbung immer weiter nach der Peripherie aus. Umgekehrt verwandelt sich die rollse Farbe wieder in die griune. wenn der Chlanydococeus aus dem ruhenden in den beweglichen Zustand iubergeht. Die bewegliche Form des Clılangdoenceus ist sehr gewöhnlich zweifarbig, und zwar vorherschend grin mit einem kleineren oder grösseren mittleren rothen Fleck, orler grim und roth gesprenlselt. Veben ganz grinen und zweifarbigen beweglichen Foruen finden sich seltener ganz rothe und hisweilen auch fast ocler ganz farblose ${ }^{2}$ ).

Auch bei den Euglenen kann man sich leicht von der Umwandlung des Chlorophylls in einen rothen Farbstofl uberzeugen. Ich sah luafig encystirte Individuen von Euglena virilis schmulzigholhbraun gesprenkelt oder statt des gewohulichen Augenflecks mit einem grossen verwaschenen schmuzigrothen Fleck versehen. Ferner kamn man zu gewissen Zeiten alle Uelsergänge von gewöhnlichen grinen Indiviluen der E. viridis zu ganz blutrolhen und zu völlig fablosen verfolgen ${ }^{3}$. Arten. die blos anf die Farbe gegrindel sind, wie Euglena sanguinea und E. hyalina von Ehrenberg, müsen hiernach als unhaltbar erscheinen. In dem mothen Augenfleck vieler grinen monadenartigen Infusorien werden wir ferner nichts weiter, als eine örliche. Iodification des gewöhnlichen Chorophylls erkennen können. Dass derselhe kein Sehorgan sein kann. beweisen schlagend die Schwarmsporen und Spermatozoen verschiedener Algen (vergl. S. 30), die mit einem eben solehen rothen Pigmentfeck verselien sind. Auf die An- orler Ibwesenheit des rothen Augenflecks hat Ehronberg verschiedene Gattungen gegrundel, die eben so wenig haltbar sind, wie die blos auf der verschiedenen Farbe des Chlorophylls beruhenden Species. So unterscheidet sich z. B. die Gattung Eudorina von der Gattung Pandorina nur dadurch, dass dle erstere cinen rolhen Pigmentlleck fuiht, letzere nichl. Ich habe alıer bei Prag unter gewöhnlichen Indivilnen alor Pandorina morum oftmals ihnen in allen ubrigen Bezichungen völlig sleiche gefunden, die mil einem sehr scharf ausgeprägten rolhen Augenfleck versehen waren. Ehrenberg hat diese oflenbare Varietit der Pand. morum als Endorina clegans beschrieben.

1) Stein Die Inlusionsthiere S. 47. -- 2) Man vergl. hieruber besonders die reichen Angaben von Cohn Nachtrige unr Nisurgeseh. Jes Prolococeus pluvialis Nova Acla Acad. Caes. Leop. Car. Vol. XXII. P. Il. p. 607-76f und von Perty Zur Kenuluiss hleiuster Lebensformen S. 87-100 ïber Chlamydococcus (IIsginum) pluvialis und nivalis. - 3) Focke Physiologisehe Sludien Ileft II. S. I3 und Taf. 11. Fig. 18. 19. Die Euglena chlorophoenicea Schmarda (Kleine Beilräge zur Nalurgesch. der Infusorien Taf. I. lig. III. 1--7) isl offenbar nur eise Uehergangslorm von der gewöhnhehen grünen Euglena viridis zu der blulrolhen Farielä. und die Aslasia margarilifera dieses Forschers (Ebendaselbst Taf. I. Fig. V.) nur eine farblose Eugleua. 
Bei manchen geisseltragenden Infusorien findet sich ein rostgelher oder gelbbranner Farbstoff. dor ebenfalls theils sehr fein und gleichförmig durch das Parenchym rertheilı isı. theils unregelmässige grössere und kleinere verwaschene Flecken und Streifen bildet. Es ist dies offenbar dieselbe Mlodification des Chlorophylls, die bei den Bacillarien so rerbreitet auftritt. Das gelbbraune Chlorophỵll findet sich z. B. bei vielen Arten von Peridiniun, bei Glenodinium cinctum, Dinobryon sertularia, Prorocentrum micans und Mallomonas Ploeslii; es liommt läufiger bei Meeresbewohnern, als bei den in sissen Gewassern lebenden Fomen vor, wie die vielen braunen Peridiniumarten les Meeres lehren. Zwischen grünem und brannem Chlorophyll giebt es vielfache Uebergainge, ja cin und dieselbe Art honınt in derselben Localitat bald grijn, bald gelbgrün, bald rostfarbig vor, z. B. Glenodinium tabulatun. Von dem rostfarbigen Peridinium tripos beobachtete ich in der Ostsee einmal ein intensiv grünes Individum. Anch bei Thieren mit braunem Chlorophyll finden sich sogenannte rothe Augenflecke, z. B. ein sehr grosser, hufeisenförmiger blutroher, aber auch haulig ganz unregelmassiger und verwaschener bei Glenodinium cinctum. Bei ruhenden Formen dieses Thieres sah jch mehrmals den braunen Farbstoff fleckenweis in einen schmutzig blutrothen umgewandelt.

Die nicht durch im Parenchym erzeugtes Chlorophyll bedingten Farben der höheren Infusionsthiere rühren zum grossen Theil ron den zersetzten Nahrungsstoffen her. Recht augenfällig ist dies bei denjenigen Infusorien der Fall, deren Nahrung vorzugsweise in Oscillarien besteht, wie namentlich hei allen Arten der Gattung Nassula in Sinne Ehrenberg's und hei Cyclogramma rubons Perly. Das Parenchym dieser Thiere zeigt meistens eine mehr oder weniger intensive, ganz gleichmassige rostgelbe oder haulichrothe Färbung und ausserdem finden sich gewöhnlich zalılreiche, lleinere und ğrössere rundliche Kugeln von schwarzblaver, violetter, indigoblauer, spangrüner, purpurrother, zicgelrother und gelber Farbung in den verschiedensten Niancen im Parenchym zerstreut, die den Thieren ein prachtrolles Aussehen verleihen, so namentlich der $N$. ornata, bei der die farbigen Kugelı von beträchtlichem Umfange sind. Bein Zerquetschen der Thiere sieht man, dass die farbigen Kugeln flüsige Tropfen sind, die leicht mit benacłbarten zu grösseren Tropfen zusammenlliessen. Gleichzeitig finden sich gewöhnlich im Innern des Körpers theils noch ganz unveränderte Oscillarienfäden, theils Haufen von kleinen Bruchstijchen derselben. Letztere sind von einem rundlichen Hofe rou wein other oder blaner Flissigheit ungeben, wie Ehrenbery berests ganz richtig bei Bursaria vernalis beobachtet hat ${ }^{3}$. Offenbar rulurt der farbige Hof von der Verdaung des Oscillarienfarlens her, desseu grüner Farbstoff sich theiheis in eine bläulichrothe Flussigkeit umwandelte, die in das umgebende Parenchym austrat. Dic ausqeschiedene Flissigkeit durchläuft nach und nach die verschiedensten Farbennäuncen und durchdringt zuJetzt in der rostgelben Modification gleichfömig das ganze Parenchym. Ein Theil der farbigen Kugeln, welche durch Zersetzung der Oscillarien frei werden, wird mit den unverdaulichen Nahrungsıesten durch den After ausgeworfen.

Auf die eben angegebene Weise hat unlangerst auch Cohn den Ursprung der furbigen Kugeln bei Nassula elegans erklărt ${ }^{2}$ ) und zu Gunsten dieser Erklärung noch besonder's hervorgehoben, dass der grüne Furbsıff der Oscillarien, das sogenannte Phytochrom, an den Oscillarien sellst alle jene Farbenniancen durchlaufe, welche die Kugeln im Innern der Nassulaarten zeigen; ferner Hass Wasser, in dem Oscillarien faulen, sich violett und blau färbe und dass das Papier, auf dem man diese Algen trockne, einen blauen Rancl erhafte. Hiemach muss die von Ehrewherg aufgestellte Ansicht (vergl. oben S. 14), dass die farbigen Kugelı im Innerı von Nassula elegans und ornata und von Bursaria vernalis eigenthunuliche, von den Thieren abgesonderte Verdaunngssäfte seien, als granz unbaltbar erscheinen. Vergehens wird man hei diesen Thieren nach dem besouderen Absonderungsorgan, welehes im vorderen Körperende liegen soll, suchen. Nassula elegans zeight zwar hier sehr hăufig eine Anhäufung von schwarzblauen Kugeln, aber sie sind von lieinem drüsenartigen Organe umschlossen. Zur Annahme eines von vorn nach rückwärts verlaufenden Ausführnngsganges des vermeintlichen Absondermngsorganes gaben ohne Zweifel die drei längs des Rückens hinter einander liegenden contlactilen Behälter Veranlassung, welche durch eine gefässarlige Verljindung mit einander zusammenhangen. Zur Zeit, als Ehrenberg die Lchre von einen besonderen Verdaungssaft aufstellte, waren ihm die contractilen Hohlräume der Infusorien noch nicht bekannt.

Eine gleichmássige Făblbung des Parenchyms fundet sich noch bei manchen anderen Infusionsthieren. So ist Chlamydodon Mnemosyne bald grünlich und rosenrolh, bald orangefarbig, Oxylricha ferruginea rostroth, Oxytrieha rubra ziegelroth (nach Ehrenberg), Loxodes rostrum in torfigen Gevässern dunkelkaffeebraun. Stentor coeruleus graublau bis fast spangriun, Stentor niger ziegelroth, violelt oder schmutzigbraun, Ophryoglena acuminata gelb-

1) Ehrenberg Die Infusionsthiere Taf XXXIV. Fig. 1H5. 3. 5. v. - 2! Zeilschrifl für wissenschaftliche Zoologic 1857. Band IX. S. $133-45$. 
Jraun, O. atra schwarzlich, Blepharisma persicinum Perty (Bursaria laterititia Ehbg.) pfirsichl)lithroth, Leucophrys sangunea blutroth (nach Ehreuberg). Eigentliche färbende Noleciile sind in dicsen Fällen entweder gar nicht zu unterscheiden, oder es sind doch nur ganz feine Pünctchen vorhanden, wie z. B. Lei Stentor coeruleus. Die uneisten der genannten Artcn kommen aucl ganz farblos vol, z. B. Oxytriclua lerruginea, Chamydodon Mnemosyne, Loxodes rostrum. Ophryogtena acuminala und Blepharisna persicinum; dic Parblosen Individuen der letzteren Alt luat Perty als Bleph. hyalinum ') beschricben. Höchst wahrscheinlich wipl die Färbung all dieser Infusorien nur durch Zersetzungsproducte ilurer Nalurungsmittel bedingt.

Im Parenchym aller Infusorien finden sich mehr oder weniger betrichtliche Ablagerungen von festen oder flüssigen Fetten, die leicht an ihrem starken Lichtbrechungsvermögen zu erkennen sind, in Folge dessen sie selır. lunkel contourirt erscheinen. Sie bilden stets abgerundete Massen und zwar sehr verschieden grosse, feste Körner oder llissige Tropfen, seltener compacte, breitc, stabartige Körper mit abgerundeten Kanten und Ecken. welche abgeriebenen Seifenstiicken ähnlich sehen. Letzteres ist bei verschiedenen Arten von Euglena (E. acus, lougicauda. spirogyra, deses, viridis) und namentlich bei Amblyophis viridis der Fall?2). Ehronberg deutete die Felltafeln dieser Thiere als Samendrusen; allein bei allen ist ausserdem noch ein besonderer Nuclens (die Samendriise Ehronberg's vorhanden, den auch Ehrenberg sclbst schon bei Amblyophis unterschied.

Nach reichlicher thicrischer Nahrung treten die stälisten Anhảulung̣en von Fettuassen im l'arenchụm der Infusorien auf, und die Farbe und Durchsichtigkeit desselben wird dadurch sehr wesentlich verandert. In cinem rechl auffallenden Grade ist dies bei Bursaria flava zu beobachten. dessen Nahrung hauptstichlieh in den Weichtheilen abgestorbener, funlender thierischer Körper besteht. Iat dieses Thier lăngere Zeil sefustet, so ist es völlị̆ farblos und selır durchsichtig, fand es dagegen reiche Nahrung: so ist das ganze Parenchym dicht unit grossen schmutziggelhen Fett-older Oelkugehn erfült, und diese sind die Ursache, dass das Thier bei auffallenden Lichte ganz undurchsichtig und lireide- oder rötlulichweiss, bei durchfallendem Lichte dagegen schmulzig ockergelb, braungelb oder leberbraun erschcint. Aehnliche grosse Oeliugeln finden sich sehr haufig auch bei Prorodon teres, sie eriheilen jedoch dem Thiere eine weniger dunkle Farbe. Dileptus anser Duj. sah ich oft von Oeltropten schnutzig graubraun. Bei Urostyla grandis und noch häufiger bei U. Weissei finden sich sehr' gewöhnliclı uberaus kleine, schwefelgelbe oder braungelbe Oelblasschen, die unmittelbar unter der äussern Oberlache theils zerstreut, theils dicht gedrängt hinter einander in Längsteihen liegen (Taf. XIII. Fig. I. 4. 6. 8.10 und Taf. XIV. Fig. 4). Sie ertheilen dem ganzen Thier eine schwefel- oder braungelhe Farbe. Die inneren Schichten des Parenchyms enthalten gewöhnliche, farblose Fetlkörner. Manche Infusionsthiere sind zeitweis so dichı mit ganz feinen, liir sich betrachtel farblosen Fethiörnchen erfillt, dass sie bei durchfallendem Licht fast ganz schwarz erscheinen. z. B. Trachelius ovum Opercularia artjeulata; bei auffullendem Lichte sinł sie kreideweiss.

Die Fetkörner finden sich nicht immer regellos im Parenchym vertheilt, sondern häufigr vorzugsweise in gewissen Körpergegenden abgelagert. Bei den Vorticellinen, namentlich bei Epristylis und Opercularii, zeigen sie sich besonders im hintern Körperende aufgespeichent ${ }^{3}$. Bei den Oxytrichinen bilden sie meist eine dichte, breite Zone längs des linken Seitenrandes (vergl. Taf. 11. Fig. 1. Taf. VII. Fig. 9-11. Taf. IX. Fig. 1. Taf. XIII. Fig. 2. 3). Bei Oxytricha pellionella kommt ausserdem noch constanter ein zientich scharf unschuebener rundlicher Haufen von sehr feinen Fettkömehen iu vorderen und binteren liörperende vor, in dessen Centrum fist imnier ein selır grosses, kugliges, von einem hellen Hof ungebenes Fettliorn cingeschlossen liegt Taf. XI. Fig. 13. f. 1". Fig. 14. 17. 18). Wären diese Körnehaufen nur in dem vorderen körperende vorhanden. so könute man versucht werden, an ein Auge zu denken und las centude Fettkorn als liystallinse zu denters. Bei Uroleptus violaceus findel sich im vorderen Körperende ein áhnlicher, ziemlich scharf ungränzter Körnerhaufen, jedoch ohne centrales Feltkorn. während im hinteren Körperende die Fettiörnchen regelloser zerstreut liegen (Taf. XI. Fig. 6. f.f' und Fig. 7. 8).

Auch der bei len Arten der Gatlungr Ophryog̣lena in vorderen Körperende vorkommende, schwärzliche O. atra und acuminata, oder rothbranne (O. llavicans) sogenamute Augentleck ist nichts weiter als eine locale, in Form und Unsang variirente Anhäufung von sehr kleinen, starli lichtbrechenden Körnchen, wie man sich leicht beinı

1) Da Blepharisma persicinum und hyalinum zusiunmenfalten, so ususs der Ehrenberg'sche Speciesname laterilia wieder eintrelen. — 2) Man vergl. die gute Darslellung von Focke Physiologische Studien Heft 2. Taf. IT. Fig. 21. 22. Die Arten der Gallung Euglena sind noch nicht befriedigend festgestellt; Focke geht aber in der Zusammenzichung der Lihrenbcrg'schen Arten offenbar zu weit. Nach ihm solt aucl Amblyophis viridis nur eine Entwickelungsform von Eugtena viridis sein. — 3) Vergl. Stcin wDie Infusionsthierea Taf. I. Fig. 1. g. Taf. Il. Jig. 1. i. Taf. V. Fig. 31, h 
Zerquetschen der Thiere uberzengt. Oh die Körnchen Fetthönchen sind, lasse ich dahin gestellt sein; en grösseres centrales Korn ist niemals zu beobachten. Zu demselben Ergebniss ist auch bereits Lieberkïhn gelangt ${ }^{1}$ ). Den von diesem Forscher hei Ophryoglena llavicans und Bursaria flava entdeckten ulırylasförmigen Organe $\left.{ }^{2}\right)$, welches ich bei dem letzteren Thicre ans vielfacher eigener Anschaung kenne, dirfte wohl haum eine tiefere Bedeutung zukommen. Anfollend ist allerdings sein constantes Vorkommen und seine in allen lndividuen sich sehr gleich bleibende Gestalt. Das uhrglasförmige Organ von Burs. Mava zeigte sich mir als ein sehr lileines, dunkel contourites, hyalines

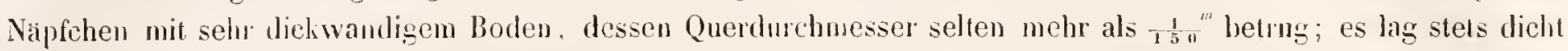
neben dem Munde, an der obern Wand des kurzen, weiten Schlundrohres und hehrte die offene, concave Seite nach oben und vorm. Der optische Eindruck des uhrglasförmigen Organs ist ganz und gar ter von gewönlichen Fetthörnern, wie sie in sciner unmittelharen Umgebung vorkommen, ja in gewissen Lagen ist es von solchen gar nicht zu unterscheiden. Während es im Profil gesehen einer planconvexen, von der planen Seite her seicht ausgehohlten Linse gleicht, erscheint es bei der Ansicht auf die letztere wie ein rundes, von doppelten Contourlinien engefasstes Fethorn. Bei Oxytricha pellionella ist das centrale, in dem vordern und hintern Körnchenhaufen gele. gene grosse Fettkorn, abgesehen von tem hellen Hofe, von dem es ungelsen ist, meist auch von doppelten Contourlinien begrânzt : vielleicht ist es auch von der einen Seite her etwas ausgehöhlt.

Nicht selten treten im Parenchym der Infusorien und zwar meist an Stellen, wo sich weniger dichte hönige Ablagerungen finden, isolirte, grosse und sehr dunkel contourirte Fetthugeln auf, welche von einem mehr oder weniger weit abstehenden hellen Hofe eingefasst sind. Am lıäuligsten sind dergleichen Feltkugeln, welche einigermaassen einem Gehörblischen mit einem Otolithen ähneln, im vordern und hintern Körperende ron stylonychia mytilus zu beobachten (vergl. Taf. V. Fig. I-3. f. f. und Taf. VIII. Fig. 3. 4. 6). Man kann hier aber auch leicht alle Uebergânge von gewöhnlichen Fethörnern zu solchen mit einem gadnz schmalen Hofe bis zu den grössten Kugeh mit weit ahstehenden llole verfolgen. Der helle llof rührt höchst wahrscheinlieh daher, dass die Fettkugel an der Peripherie in der Schmelzung begrillen isl; das aufgelöste Fett vermag sich nicht sofort mit dem wasserhaltigen Parenchyn zu mischen, es häuft sich einstweilen rings un die Fettugel an und wird lann nach und nach von dem benachharten Parenchym anfgenommen. Ganz ähnliche, von einem weit ibstehenden Hofe eingefasste. sehr dunkel contourirte Kugeln linden sich in grösserer oder geringerer Anzalil bei loxodes rostrum; sie licagen trien in einer heihe parallel den convexen Ritchenrande des Thieres und in vorlern Ende meist dicht hinter einander. Joh. Müller machte zuerst auf sie aufmerlisam ${ }^{3}$; er beschrieb sie als eigene hasenartige Organe mit centralen. runden Körpercheu, was sie sicherlich nicht sind.

IIn und wieder kommen endlich im Parenchym auch lleine. eckige, spröle, dunticlgerandele, durchsichlige Körperchen vor. die sehr unentwickelt geblielıenen Krystallen äbnlich sehen. Sie fehlen bei Paramaecium aurelia fast nie und liegen regellos im ganzen Köpper zerstreut; in vorlern und hintem hörjerende sind sie meist in grösserer Anzahl und in kleinen Guppen zusammengehäuft vorhanden. Bei Param. bursaria sah ich sie mit den Excrementen uach aussen entleert werden. Auch bei Euplotes charon und mamclien andern lnfusorien sind sie cine gewöhnliche Erscheinung; vielleicht stellen sie eine Art Hambörperchen dar. - Bei Polytoma uvella linden sich nach den Untersuchungen von A. Schneider ${ }^{4}$ bald nur im hintern Körperende angehänft, bahl durch das ganze Parenclyym inassenhaft vertheilt dunhelcontourite Kornchen, die bein Zusatz ron Chiorzinkjod etwas zerfliessen und sich schön blau firben. Diese amylonartigen Körper, welche nicht von aussen aufgenommen zu sein scheinen. verwandeh sich zuweilen in ein blaues, indigularbiges Pigment.

\section{Von den Bewegmigsoryanen und der daranf zu gründenden Eintheilung der hifusionsthiere.}

Dis allgemeinste und wesentlichste Locomolionsorgan der Infusorien. dureh welehes oft ganz allein die Ortsveränderungen sermittelt werden, sind die Wimpern. Unter diesem Namen begreifen wir sammtliche von der Cuticula und deren nach innen sich erstrechenden Fortselzungen entspringende. linear-conische Fortsatze,

1) Müller's Archiv 1856. S. 22-23. - 2) Ebendaselbst S. 22. - 3) Monitsberichte der Berliner Academe 1856. S. $389 .-$ '. I Schneider Beiträge zur Naturgesch. Ier Infusorien. Mäller's Aıchis 1854. S. 193. 
welche schnell himter einander in schwingende oder wibehde Bewegung verselzi Werden können. Die Wimprin

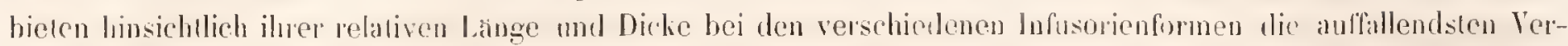
scliedenhuten dar; sie erscheinen bald als ganz feine Härchen, bald als lingere orler liurzere, starliere oder schwachere Borsten. bald als diche, gerade. geschlingelte oller lakenförmig gehrimmte Griflel, bald als lange Geisseh. Scharf begranzte drten von Wimpern lassen sich jedoch in liener Weise aublellen; die extremsten Formen gehen durch zahllose Zwischenglieder allmällig in einantler iiber. In Allgemeinen lisst sich nur sagen, dass die Wimpern um so zartere Härchen sind, je dichter sic zusanmengedrangt slehen; je zerstreuter sie auftreten, um so mehr nchmen sie die Form von Borsten und Gritlehn oder ron beisseln $\mathrm{n}$.

Die geisselartigen Wimpern sind allein anf die niederen, monalenähnlichen Infusorien beschränkt; lie horsten-, lakien- und griffelförmigen Wimpern kommen vorzighich bei den Familien der Oxytrichnen. Euplotinen und Aspidiscinen vor. Auch die lediglich auf cinzelne kianzformige oder spirale Zonen beschrankten Wimpern der Vor-

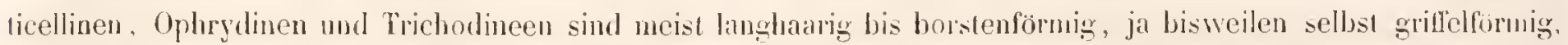
wie mamentlich bei manchen im Neere lebenden Arten der Gattung Halteria Wuj. Die ibrigen Infusionsthiere sind entweder nur nit sehr leinen und dichtstehenden Winpern versehen, oder sic besitzen ausser diesen noch eine Zone längerer horstenförmiger Wrimpern, welche stets am Ihunde endigt und demselben dic Nahrungsstuffe zutreibt. l.h werde die Wimpern dieser Zone als adorale Wiupern bezeichnen.

Die feineren Körperwimpern sind an leheuden Thieren oft seh" schwer direct zu beobuchten, lmingt man die Thiere aher sehr allmählig durch Zusatz von verdumnen Säuren, namentlich von schwacher Essigsäure oder von verdiunter Jodtinctur zum Absterben, so wird maı sich slets, wenı auch nicht grleich beim ersten Versuche, selbst die kibzesten und zartesten Wimpern zur Anschaung bringen. Wendet man zu starke Reageutien an, so schrumpfen die Wimpern cntweder his zur. Unkenntlichkeit zusammen, oder sie dehnen sich auch wohl uibermassig aus. Ohne genaue Kenntuss der Bewimperungsverhälnisse blesbt die Bestimmung vieler Infusorien, nameutlich soleher, die sonst heine auffallenden iussern Merkmale hesizen, durchaus unsicher, und noch weniger vermag man einem lnfusionsthier, dessen Bewimperung nicht genügent erforscht ist, einen beslimmten Platz in Systeme anzuweisen. Aus diesem Grunde ist mit den meisten Darstellungen. welche die ältern Forscher ron den von ihnen beobachtcten Infusorienformen gegehen haben. so wenig anzufangen, selhst Elrenberg's Abbildungen lassen in Bezug auf die Bewimperung der Infusorien noch sehr viel zu wünschen ubrig. Es sind nicht blos die tcineren Körperwimpern oft ibersehen worden, z. B. bei den Gattungen Enchelys, Trichodi, Lacrymaria. Trachelncerca, Phialina und sonst bei einzelnen Arten, sondern auch die Zahl umb Stellung der gröbern Wimpern ist meist sehr unvollständig oder geradezu falsch angegeben. wie wir namentlich bei den Oxylrichinen und Euploten sehen werden. Noch iel mangelhafter hat Perly die Bew imperung dargestellt.

Ehreubery wollte vier verschichene Arten von Bewegungsorwanen bei den Infusorien unterscheiden ${ }^{1}$ ), nåmlich Wimpern cilice, Borsten sctae; Griffel (styli) und Haken (uncini); die geisselartigen Winpern sah er für Rüssel an. Die Wimpern wurlen als wibehte, aul einer zwiebelartig verdichten Basis sitzende Ha:me lsestimm, welche enweder mit der Zwiobelbasis cin Continumu hilden orler in diesclbe eingelenkt sein sollten und daher von ihr ablallen kümten. Eine :-ering̣ schwankende Bewegung der Zwiebelbasis in ihrer Gelenkpfanne oder mm ihren Befestigungspuncl, welche Ehwhberg durch die Anmahme von je zwei nit der Basis in Verbindung stehenden Ilusheln erkikirbar fand. sulte dic Urache der Wirbelberegung sein und bewirken, dass die Spitze der Wimpern fortwährend selı schmell einen grösseren hreis heschreibe. Unter Borsten wurden des Wimpern ahnliche steife hewegliche Haare verstanden, die nicht zum Wirbeln, sondern nur zun Stuzen und Ḱlellern verwendet würdeu. Die Griffel definirt Ehenberg als nicht wirhehnde. gerade. diche Borsten ohne zwiebelartige Basis, welche wie die Schuanzferlem der Vögel an hintern Körperende auf der bauchseite sizen und ebenfalls zum Stiizen und Klettern dienen. Die IJaken endlich soltten nicht wibelnde, aber allseitig buwegliche, lakenartig gobogche, dickere und kitrzere, aul einer Zwiebelhasis sitzende Borsten sein. wolche auf der bauchseite die Stelle der Fisse sehr anschaulich vertrïten.

Zu der Amnahne von viererlei verschiedenen Bewegungsorganen haben die bei den Oxytrichnen und Euplotinen vorkommenden Wimperformen Yeranlassung gegeben, die Elrenberg nit liecht zur Unlerscheidung rou Gattungen benutzte; er hat dieselben jedoch bei heiner einzigen Form linhingrlich genau beobachlet, und deshalb sud seine Gattungsoliagnosen unhaltbar. Die Gattung Stylonychia soll nach Elwenberg alle vier Irten ron Berve-

1) Abhandlungen der Berliner Acad. vom Jahre 1831. S. $29-31$ und Ehrenberg Dic Infusionsthierchen S. 363. 
gungsorganen besitzen. Als Wimpern werden hier allein die sich an beiden Seiten des Köpiers herabziehenden Wiupern (Taf. V1. Fig. 1. r. r.) und die adoralen Wimpern (I. p.) angeselsen; die koineswegs gleichartigen. bald gerar ausgestreckten, bald hakenförmig geliümmten, srilfelfömigen Wimpern neben der Vittellinie der Banchseite (st. b. b.) bezeichnet Ehrenberg als Haken, die funf dahinter in einer Querreihe stehenden dicken, meist gerad ausgestreckten Winpern (a.) als Griffel, die drei langen terminalen Wimpern (s.) endlich als Borsten. Ein Blick auf meine Abbildungen muss schon die Veberzengung gewähen, dass diese verschiedenen Körperanhängsel nur Modificationen eines und desselben Organs, dass sie nur Wimpern sein liönnen, und dass es unmöglich ist, sie nach ihrer Form in scharf gesonderte Arten zu trennen. Sie können aher auch stimmtlich in wirbelnde Bewegung versetzl werlen, und ich muss Ehrenberg's Behauptung, dass Halien, Griffel und Borsten nicht wirbelten, entschieden entgegentreten. Die Griffel sind wảbreul des Schwimmens of in heftig vibrirender Thätigkeit und unterstiatzen alann die slets lebhaft wirbehden Bewegungen der Halienwinupern; in ihrem gewöhnlichen ausgestreckten Zustande wirken sie durch Drehumg nach links oder rechts zusammen als Steuertuder. Auch an ganz stillstehenden Thieren sieht man häufig alle oder einzehne Griffel sich plötzlich heftig nach vom umbiegen (Taf. Vlll. Fig. I und Taf. X. Fig. 4) und sie gleichen dann volliommen den vor ihnen stehenden Hakien. Von den drei terminalen Borsten beobachtete ich ebenfalls nicht setten die eine oder andere in der lebhaftesten Rotation um ihren Anheftungspunct, in der Art, dass die Borste cinen Kogelmantel beschrieb. Zum Klettern werden ibrigens nicht blos die Haken und Griffel, sonders oft auch die Randwimpern rerwendet.

Es ist ferner untiehtig, dass Wimpern, Ilaken und Borsten mit einer Zwiebelbasis versehen sein sollen, die Grilfel aber nicht. Eine Zwiebelbasis ist nirgends vorhanden und noch weniger Iluskeln, die dieselbe regieren; alle wimperartigen Bewegungsorgane, welches auch ihre Form sein magr, sind viehmehr stels unmiltelbare Auswiichse der Cuticula und als solche ganz homogene, solide, hyaline Gebilde, welche mit ihrer sich allmählig rerbreiternden Basis continuirlich und ohne jrgend eine bemerkbare Granze in die Cuticula übergelıen. Zu Ehrenberg's Vorstellung ron einer besondern, mit der Culicula gelenkig verbundenen zwiebelartigen Basis mag ein doppelter Umstand Veranlassung gegeben haben. Krünmt sich nämlich eine stärkere Wimper über ilıren Anlıeftungspunct nach vorwärts (man vergleiche z. B. die zwei Reihen hakenlörmiger Wimpern auf Taf. V. Fig. I und 2, ferner die linke Randwimperreihe auf Tilf. VI. Fig. I oder die eine der mitleren Wimperreilsen auf Taf. X. Fig. 14. und 15), so erscheint der ungeliumm bleibende Grundheil als ein besonderer rundlicher Abschnitt; dass ein soleher jedoch nicht existirt, Jehren alle gerad ausgestreckten, der Körperoberfache anliegenden Wimpern. am deutlichsten aber die lüuf sogenannten Griffel. Sodann zeigt sich nicht selten um die Basis der drei teminalen Borstenwiwpern von Stylonychia mylilus, so wie auch an den Wimpern des Hinterandes bei Euplotes charon, ein mehr oder weniger deutlicher ringförmiger Eindruck, der alleufalls für eine Gelenkpfanne gehalten werden kinn; er ruihrt jedoch leuliglich daher, dass die starre Wimper sich nur zufillig ein wenig in das nachgiebigere líörperparenchym an ihrer Basis eingesenkt liat.

Viel wesentlicher als die Form der Wimpern ist fur die Oxytrichinen, Euplotinen und Aspidiscinen die Gruppirung derselben, die für die einzelnen Gattungen vortreffliche Charactere darbietet. Bei allen fintel sich eine nach links gekrummte bogenförnige Zone von adoralen Wimpern (Taf. Ill. Fig. 4. o. Taf. 1Y. Fig. 7. I. p. Taf. Vul. Fig. 1. . p.). Zu beiden Seiten des Körpers zieht bei den Oxytrichinen eine dichte Reihe borstenförmiger Wiınpern herab (Taf. VI. Fig. 1. r. r.); (liese bezeichue ich als Randwimpern. Beide Randwimperteilsen grehen am Hinterrande entweder in einander uber (Taf. IX. Fig. 17. Taf. X. Fig. 5. 7), oder sie sind hier unterhrochen und dann zeigen sich in lem Zwischenraume drei längere bosstenfömige Wimpern (Taf. VI. Fiğ. I. 3), die Schwanzwimpern; es sind dies die Borsten Elmenberg's. Die Aspidiscinen besitzen keine Randwimperu, die Euplotinen meist einige wenigre, griffelförmige, weit ron einander enternt stehende (Taf. WV. Fig, 7. r. r". Sehr allgemein liomm in einiger Entfernung vom hiutern liörperende eine quere Reihe von 5-12 borslen- oder griflelförmičn Wimpern vor (Taf. IV. Fig. 7. a. Taf. VI. Fig. 1. a. Taf. Xlll. Fig. 2. 7 8. a.); diese bezeichne ich, da sich in ilnes Nailıe immer die Afterstelle findet. als $\Lambda$ fterwimpern, es sind die Griffel Ehremberg's. Die sonst noch vorkenunenden Winjern sind in gerade orler schüige laingsreihen geordnet, deren bald nur zwei und damn stels der Nittcllinie genálierte (Taf. VI. Fig. 1. st. b. b. Taf X. Fig, 14), bald mehrere vorhanden sind (Taf. X. Fig. 1. Fig. 5- 7. Tat. XIll. Fig. 2. und 5). Meistens unterscheiden sich die am vordern lí̈rperende rechts nehen dem Eingange zum Jlunde geleģuen Wimpern durch bedeutendere Grösse und andere Gruppirung von den abrigen Bauchwimperı; ich nenne sie in diesen Falle Stinu impern Taf. Vl. Fig. I. st. Taf. Xll, Figg. 2. st. Tal. XIT. Fig. ä. st.). 
Dic starkern Wimpern der Infusionsthiere zeigen eine grosse Neigung, durch eine theils an der Spitze, theils an den Seiten beginnende und bis zum Anheftungspunct fortschrcitende Zerspaltungr in eine kleinere oder grössere Anzahl ron gesonderten Fasern zu zerfallen. Diese Zerkluftung kann man zu jeder Zeil an den Stirn-, Bauch- und Afterwimpern und selhst an den Randwimpern der Stylonychia mytilus, so wie an den griffelförmigen Wimpern anderer Oxytrichinen und der Euplotinen beobachten, wenn sich die Thiere in einem sehr flach ausgebreitclen Wassertropfen belinden, in dem sic nicht mehr zu schwimmen vermögen. Sic \{ritt aber auch sofor bei reichlicher Anwesenheit von Wasser ein, wenn man demselben eine kleine Quantilat verdiunter Essigsäure zuselzt. Die dicksten Wimpern lösen sich dlann in ein aus vielen, of ungleich dicken Fasern zusanmengeselzles Büschel auf, während die dimneren Wimpern sich nur einfach gabeln oder in wenige Aeste zerfallen (Taf. VIII. Fig. 1. a. st. Fig. 3. Tal". IN. Fi⿳亠口冋. auf der einen Seite (Taf. Vull. Figg. 3. 4.), bahl auf bejden Seiten (Taf. VllI. Figg. 1. a.) kileinc zahuförmige Vorsprimge, die Einschnitte zwischen denselben werden dann immer tiefer und zuletzt entstelıt ein Buschel ungleich langer Fasern. Beginnt die Auflösung rorzugsweise an der Spitze der Wimporn, so entstehen ziemlich gleich lange Fasern. Bei Enphotes patella traf ich die Jeiden rechten Randwinpern am lintern Körperende (Taf. IV. Fig. 6-11. I') an der Spitze bestandig flerlerarlig verästelt. Lachmam machte znerst auf das Vorkommen von istigen Wimpern hei (liesem Thiere aufmerksam, er lisst aber nur eine Wimper verästell sein ${ }^{\mathbf{}}$ ).

Sehr beachtenswerth isı, dass, wenn eine diclie Winuper sich in ein Faserbischel auflöst. jurle Faser fiur sich noch eben so gut schwingende und wirbehde Bewegungen ausfullt, wie die unzerlheilte Wimper, ja selbst die vorhin crwähnten kleinen zahnförmigen Fortsäıze an der dicksten Afterwimper ron Styjlonychia mylilus zeig̣en schon cin selbstsländiges Bewegungsvermögen. indem sie sich hald an alen Wimperkörper anlegen, bald aufrichten. worbuch das Anselıen culsteht, als sei derselbe an den Seiten von einem undulirenden Saume eingefasst. Diese Thalsalchen heweisen, dass die Mimpern in und durch sich selbst beweglich sein missen: der Grund ilurer Bewesung kann unmöglich ausserhalb der Wimpern, etwa in Muskehn, die sich ihrer Basis inseriren, liegen, wie Ehrenbery glauble. Eine solche Annahme wird schon durch das Vorkommen von Wimpern bei vegetabilischen Organismen. wo doch von Muskeln nicht die liede sein liann, widerlegt. Aber anch von allen, durch das ganze Thierreich sonst noch so vorbreiteten Wimpern ist völlig sicher constatirt, dass sie keinen Zusammenhang nit Muskeln laben. sondern autonomisch beweglich sind. Ferner lehren besonders die langen geissellörmigen Wimpern gewisser Monadinen, z. B. von Heteromita Duj. (Bodo grandis Ehbg.), Peranema und Anisonema Duj.. dass nicht ein besonderer Bewegungsmechanismus an ihrer Basis angebracht sein kann; man sicht dieselben oft ganz gerade ausgestrecht. und nur der äusserste Spitzentheil ist in vibrirender, peitsehender Bewegung.

Die erste Entstehung der Wimpern und ihr allmähliges Hervorwachsen aus der Culicula lässt sich boi den Infusorien sehr genau wihrend ihrer Vermehrung durch Theilung beobachten, namentlich bei solchen Formen, die duch den Besiz släkerer, nur auf gewisse Regionen des Körpers angewiesener Wimpern ausgezeichnel sind. wie die Oxytrichinen und Euplotinen. Bei diesen Thieren wird während der Theilung eine grosse Anzahl der Wimpern fur bejde aus der Theilung hervorgehende Individuen von Neucm gebildet, woriber der specielle Theil meiner Schrift zu vergleichen ist. Hier sei nur benerlit, dass alle Wimpern, auch die diclisten, zucrst als iusserst fene und kurze, sogleich bewegliche Auswiichse der Cutiena anftreten, die in sehr kurzer Zeil ilıre definitive Gestalt erhaten, später aber nur in demselben Verhälnisse weiter wachsen, in den sich der Umfang des gesammuten Körpers vergrössert. So schuell neue Wimpern gebildet werden, eben so schnell können bereits vorhandene wieder verschwinden. Diese Erscheinung isl ebenfalls in grosser Ausdehnung bei der Theilung der OxyInchincn, Euplotinen und Aspiliscinen zu beohachten. Die ausscheidenden Wimpern scheinen jedoch nichı einfach alggeworfen, sondern resorbirt zu werden. Ein anderes hehanntes Beispiel hicten die Vorticellinen und Ophrydinen dar. Wenn diese Thiere sich von ihrem Stiel orler von der Hülse, in der sie sitzen, lösen, sind sie vor ihrem hinteren Enle mit einem Wimperkanze versehen, mittelst dessen sie längere oder kiirzere Zeil mmher sehwärmen. Sobald sie sielı wieder festsetzen und einen neuen Stiel oder eine neue Hülse auszuscheiden begimen, geht der hintere Wimperkinz wieder ein, die Wimpern werlen zuerst in iliren Bewegungen mattes, schrumpfen danı zusammen und rerschwinden bald darauf spurlos.

Yon hohem systematischen Werthe ist alie Vertheilung der Wimpern iiber den Infusorientiörper. Nach meiner.

1) Vüller's Archis $5.3: 38$ und $36 \%$ 
Kenntniss der Infusorienwelt ist kein Organisationsverhätniss geeigueter, zum obersten Eintheilungsprincipe der Infusionshicre zu dienen, als die Anordnung und Vertheilngg der íusseren Körperwimperm. die ja auch den unterscheidenden Character dieser Thiere vou den übrigen Protozoen ausmachen, und von denen augenscheinlich die gesammle Lebensweise der Infusorien sehr wesentlich abhingig ist. Dies ist theilweis anch bereits anerkannt worden, indem man scit Dujardin dic Jnfusorien ziemlich allgemein in die beiden Ordnungen der geisseltragenden /Fhagellifera) und bewimperten Infusorien (Ciliata) eintheilt. Allein die letztere Ordnung ist im Verlualtuiss zm ersten viel zu umfungreich und in sich zu heterngen; ich habe sie daher nach der Art der Bewimperung in rier, den Flagelliferen gleichwerthige Ordnungen aufgelöst, die ich als Holotricha. Heterotricha, Hypotricha und Perilricha bezeichne ${ }^{1}$ ). Sollten sich die Acinetinen doch noch als selbstständige Infusoricn herausstellen, so wiirden sie eine sechste, zwischen den geisseltragenden und holotrichen lufusoricn einzureiliende Ordnung bilden.

Die geisseltragenden Infusorien besitzen einen nackiten Körper, der nur an einem Puncte, meist an vorlem Körperende, seltener auf der cinen Seite (Perinlinium, Glenodinim) ein odler zwei, bisweilen mehrere höchstens zehn) sehr lange faden- oder peischenförmige Wimpern tright, die rlen Körper gewöhnlich hedeulend. oft um das Doppelte und Dreifache an Länge übertreffen, oder doch wenigstens nabebei seine hänge erreichen. Gleichzeitig finden sich zuweilen (hei den Peridin'jen) noch iusserst zarte, liurze, schwer wahrnehmbare Wimpern. die sich jedoch inumer nur auf gewisse Zonen heschanken, so dass der grösste Theil des Körpers nacht bleibt. IJicı her gehören Elurenberg's Monadina, Cryptomonalina, Volvocina, Hydromorina, Astasiaea, Dinobryina und Peridinaea. so wie sein Trachelius trichophorus und globulifer, woraus Dujudin die Gatlung Peranema gebildet hat. Eine cinzige Geissel fumet sich z. B. bei Monas, Uvelli, Mallomonas Perly, Prorocentrum. Trachelomonas, Lagenella, Euglena. Peranema und Peridinum. Doppelte Geisseln besizen die Volvocinen. Polyloma. Chlorogoniun. Meteromita. Anisonema und Zygoselmis. Bei den drei letzlen von Dujardin aufgestellen Galtungen ist eine der beiden Geisseln viel kïres und lebhafter beweglich als die andere; hei Heleromila wird die längere, gुewöhnlich star nach riichwarts ausgestreckte, einerseits zum Fixiren des Körpers, andererseits zum plötzlichen Fortschnellen verwendel. Vier lis füuf Geisseln kommen den Galt. Spondylomorum und Chloraster²) zu; Pluacelomonas besitzl 8-10 Geisseln.

Bei den holotrichen Infusorien ist der Körper auf der ganzen Oberläche dicht mit grleichartigen. feinharigen Wimpern besetzt, die stets sehr viel liurzer sind, als der Körper. Da letzterer in ler Regul ller Liinge nach gestretft ist, so scheinen die Wimpern in Längsreihen geordnet zu sein. In der Umgehung des Humdes linden sıch zuweilen etwas längere Wimperu, nienals aber hommt eine wahre adorale, aus längeren borstenförnigen Wimpers gebildete Zone vor. Hierher gehören von hekanuten Formen die Gallungen Opaliua, Gyclidium, Trichoda. Colpoda, Glaucoma, Coleps, llolophrya, Prorodon, Enchelys, Lacrymaria mit Phialinaj, Trachelucerea ${ }^{3}$ ). AmphiJeptus. Traclielius. Dileptus Duj., Loxophyllum Duj., Loxodes (mul L. rosirum). Nassula, Acidophorus St., Liosıphon 4, Cyrtostomum St., Paramaecium, Pleuronema Duj. unl Ophryoglena.

Die heterofriehen Infusorien stimmen mit den holotrichen in der gleichmässigen, dichten Bekleidung der gesanmten Körperoberflache mit kurzen. feinhaarigen Wimpern iiherein, die auch hier gewönlich in Folge ron Langsstreilung reihg geordnet erscheinen. Ausserdem ist aber stets noch eine deutlich euturchelte Zoue von borsten- oder grillelfömigen adoralen Wimpern vorhanden. Die belianntesten Reprasentanten dieser Ordnung sinul die Galtungen Bursaria ${ }^{5}$, Leucophrys ${ }^{6}$, Plagiotoma Duj. Blepharisma Perly, Lembadion Perly, Condylostona Du! Spirostomum, Climacostomum Si., Stentar und Tintinums.

Die hy pol richen lafusorien sind nur partiell bewimpert und zeichnen sich durch den scharfen Gegen-

1) Ich hahe diese Einheilung der lnfusionsthiere schon seit dem Jahre 1855 bei meinen zoologischen Vortrigen befolgt und sje auch 11 der Sitzung der K. Böhmischen Gesellschaft der Wissenschaften vom 19. Oct. 1857 entwichelt. - 2) Die von mir beschriebene Pha(:elomonas bodo (Slein Die Infusionshliere S. 191) ist jedenfalls mil Ehremberg's Spondylomorum quaternarium (Monalsber. der Berliner Acal. 1848. S. 236) identisch, laher der von mir gegehene Name zu unterchüchen ist. Die von mir a. a. O. erwähnten isulirten, m der kinospenbildung begrilienen Individuen von Phacelo. bodo " aren Ehrenberg's Chloraster gyrans (a. a. O. S. 237). - 3) Die Gallung Trachelocerca beschrähe ich auf Tracheloc. Saghta Ehbg. (Monalsher. der Berliner Acad. 1840. S. 202 ); die übrigen Trachelocercen vermag ich nichl von Lacrymaria zu \{remen. - 4) In diese Gattung gehört meine Nassula ambigua (Stein Die Infusionslh. S. 24\$-49), die diher Liosiphon ambiguus heissen muss. - 5) Die Gallung Bursuria wird auf B. Iruncatella zu beschränken sein, da Wesenllich auf diese Art O.F. Mäller die Gallung Bursaria gründete. B. vorticella Ehbg. isl vielleicht gar nicht von B. Iruncalella verschiedeu. - 6) In Ehrenberg's Leucophrys patula kinn ich nur Burs. Iruncatella erkennen. L. spabtula gelıört in die Gatt. Enchelys, L. Aundontae zu Plagio-

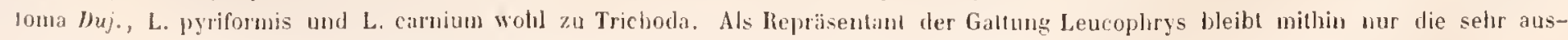
gezeichnete L. singuinea übrig; eine ihr nahe verwandte Art ist L. entozoon Burs. entozoon und intestinatis son Ehrenberg). 
satz yon Ricken- und Bauchseite aus. Die Ruckenseite ist stets ganz nacht und nur die Bauchseite allein trigt Winperm. Hierher gehören vier sehr natühiche Familien, nämlich die Oxỵtrichinen Ehrenberg's, denen auch seine Gathung Troleptus zuzngesellen ist, die Euplotinen, Aspidiscinen und die Familie der Chlanydodonten, welche ich aus Ehrenberg's Gatt. Chilodon und Chamydodon, ferner aus den Gatt. Frvilia und Trochilia ron Dnjudin uma aus den ueven Gatt. Phascolodon, Opisthodon und Scaphidiorlon zusammensetze. Nur die Chlamydodouten besitzen dicht gedangt stehende, gleichartige, feinharige Wimpern, welche hald die ganze Bauchseite, bald nur den mittlern Theil dersethen einnelımen. Die drei iibrigen Familien zeichnen sich dureh zerstreut stehende, borsten- oder griffelförmige Wimpern aus, deren Stellungsverhaltnisse S. 70 besprochen wurden.

Die peritrichen Infusorien besitzen eimen drelurunden, stets nur partiell bewimperten. anu dem grössten Theil der Oberfläche nachten Körper. Die meist langhaarigen, nicht selten borstenförmigen Wimpern bilılen theils einen ringförmigen, auf der Lingsaxe des Körpers senkrecht stehenden Gürtel, theils eine niedrige Sjuralzone um das vordere Kürperende; im letzteren Falle sind die Wimpern stets adorale. Zuwcilen kommen noch cinzchne zcrstreute Wimpern orler ein Wimperhiischel anf der sonst ganz nacken Körperoberfliche vor. Die belinntesten Reprisentanten dieser Ordnung sind lie Vorticellinen Vorticella, Scyphidia Duj. Lachm., Carchesium, Zoothamniun, Epistylis, Opercularia und dic Ophrydinen (Vaginieola, Cothurnia, Lagenophrys St., Ophrydium). Ilieran schliesst sich die neue Familic der Ophryoscolecinen Ophryoscolex St. und Entodinim St., deren Mitglieder parasitisch im Pansen der Wiederkäuer leben ${ }^{2}$ ), ferner die Spirochoninen Sprochona St. und Dinophlysis Ehby.), so wie die Gattungen Trichodiua, Urocentrum, IIalteria Duj. Trichodina voras und grandinella von Ehbg. nelsst mehreren im Neere lebenden Arten und die Gattung Didinium St. ${ }^{3}$ ) Einen sehr breiten, medianen Wimpergurtel freffen wir bei der Gattung Urocentrum, die ausserdem noch am hintern Körperende einen stielähnlichen excentrischen Wimperschopf besitzt. Die Gattung Didinim hat einen vordern umb hintern geschlossenen Wimperkranz, Trichodina dagegen eine vordere adorale Wimperspirale ${ }^{4}$ und einen hintern Wimperkranz. Bei den Torticellinen, Ophrydinen und Spirochoninen sind lediglich adorale Wimpern vorhanden 5 ), umd nur hei den Mitgliedern der beiden ersten familien entwickelt sich zeitweilig noch ein hinterer Wimperkanz, wenn sie sich ron ilırem Anheftungspuncte ablösen wollen.

Nächst den Wimpern kommen bei den Infusorien noch in ziemlicher Verbreitung zarte, glashelle, hautarlige Fortselzungen der Cuticula vor, welche nach Belieben zusanmengefaltet und ausgespreitzi oder in wellenförmige Bewegungen versetzt werden können. Ich nenue (liese Gebilde nach dem Vorgange $r$. Siebold's ${ }^{6}$ ) unduljremde Yemluranen. Am hăufigsten lindon sie sich in der nächsten Lmgehung des Mundes, und sie dienen dann zum Ergreifen der Nalırungsmittel. Die entwickeltste undulirende Membran hesitzt die Gatlungr Pleuronema Duj. (Pin:amaecium clırysalis Ehbg.); sie zieht sich hier vom vordern Köpperende in einer Furche des Bauchrandes bis zu dem weit wach hinten gelegenen Munde heral, ist im ausgespreitzten Zustande mehr als lalb so breit, als ller Körper und zeigh anch dann noch meh. oder wenger zahlreiche wellenförmige Falten. Sie wurle deshall, von Dujardin und Perty irrig als ein Biischel Janger beweglicher Fäden aufgefasst, umbl auch Ehrenbery j beschreibt sie als n sehr lange merkwurdige Mundwinpern, die einer wellenartig bewngten Menhran gleichen." Bei den Oxytrielinen und vieleu Bursaricen. z. B. Jei Lembadion, Condylostoma, Blepharisma, zeigh sich am Innenrande Jes weiten Peristomausschnittes, den adoralen Wimpern gesceniber, eine meist schmal bandförmige undulirende Memhan Taf. V. Fig. I. i. Taf. VI. Fig. 1. i. Taf. X. Fig. 1. i. und Taf. XII. Fig. 1 S. 19. i. i., welche gewohnlich durch schnige Falun!r imnigr an den Innenrand angelegt werden kimn; hei Lembadion biklet sie dann einen zipfelförmigen Vorsprungr über das rordere beim Schwimmen gewähnlich nach hinten gerichtete, Körperende. Wo dı bamdfömuge Ilembran schr lebhafter Undulationen fihlig ist, da zeigh sie während derselben an ilıem freien Rande slumpfere orler spitzere

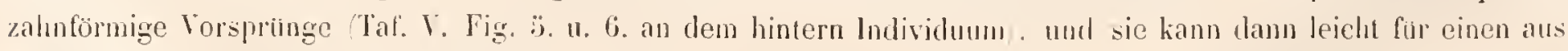
Wimpern zusammengesetzten saum gehalten werden.

In die Kategorie der undulirenden Membranen gehören auch der von mir bei der Gattung Opercularia

1) Vergl. Stein Chalacteristik neuer Infusorien-Gattungen in der Priger Lotos Januar 1859. S. 2-3. - 2) Priger Lotos März. 1859. S. $57-58 .-3)$ Lhendaselhst S. 5. - 4 Dass die vordern Wimperı uichl kreistörmig, sondern spiral angeorduel sind, wurde für Trichodina pediculus zuerst von $1 V$. Busch nachgewiesen (Mïller's Archiv 1853. S. 35i). - 5) Lachmann zeigte zuerst, dass die ant vordern Körperende der lorlirellinen vorkommenden Wimpern zusammen eine einzige alorale Wimperzone darstellen (Müller's Arehiv 1856.5. $346-300 .-6)$ v. Siebold neber undulirende Membranena, Zeilschrift lür Wissenschaftl. Zoologie 1850. Band II. S. 33̈6-64.

7) Ehrenberg nDie Infusionshlieve $\mathrm{S} .3 \%$.

siril, Grgonsmus der lufusionsthire.

19 
beobachtete, mil dem Wibelorgan aus dem Peristom hervortretende manscheltenarligu Fortsatz', ferner alie zitternde Klappe am Munde von Glancoma scintillans ${ }^{2}$ ) und endlich die an hintern Kürperende von dem uhardehenfürmigen Gerust der Trichodinen ansehende ringförmige Hembran ${ }^{3}$ ). Dagegen ist (ler von Ehrenberg bei seinem Stentor Mibleri, coeruleus und hoeselii beobachtete und zur Unterscheidung der Arten henutzle seitliche Wimperkamm “. Welcher nach den Abbildungen leicht für eine undulirende Membran gehalten werden hönnte, nichs: weiter, als der Anfang zu einer neuen adoralen Wimperzone für einen durch schjefe Theilung spaiter abzuschnürenten Theilungssprössling. Der scildiche Wimperliamm lindet sich daher auch keineswegs bei allen Individuen, somlern nur bei solchen, die im Begrill stehen, sich zu theilen, und hei diesen zeigt er sich wieder auf schr verschiedenen Enłwickelungsstufen, indem er bald aus ausserst liurzen und zarten, bald aus längem borsten-odur srillelförmigen Wimpern besteht. Wenn Ehrenberg bei cinen schon ziemlich weit in der Theilung vorgeschrittenen Stentor Roeselii ausser den beiden adoralen Wimperzonen noch einen seitlichen Wimpertianm hinter jeder dersellsen (arstell ${ }^{5}$ ), so ist dies ein offenharer Irthum. Clupurede und Lachmamn haben bereits auf die wahre Bedeutung des seitlichen Wimperkaumes der Stentoren aufmerksam gemachı ${ }^{6}$ ).

Manche Infusionsthiere besitzen wahre, nicht wirbelnde, aber biegsame B orsten, andere bewegliche oder unbewegliche Stacheln. Bei den Vorticellen ragt eine ticf im Rachen entspringende, lange, gebogene Borste aus dem Peristom hervor, welche erst von Lachmann entdechl wurde ${ }^{7}$; ich kann ilre Anwesenheit für viele Yorticellinen und Ophrydinen beslätigen. Bei llallomonas Perty ist der ganze Körper dicht mit langen, feinen, abstehenden Borsten besuzt, welche nur passiv beweglich zu sein scheinen. Ein beweglich eingefugter, starrer, griffelförmiger Stachel findet sich am hintern Körperende bei den Gattungen Ervilia und Trochilia Taf. II. Fig. 17. I 8. a. Fig. 28. a.); drei his fünf kurze, zahnfömige, bewegliche Stachehn kommen am hintern Körperende bei der Galtung Coleps ror. In einen langen, an der Basis nicht articulirten. aber biegsamen, stachelartigen Fortsalz liuft das lintere Körperende von Ophryoscolex Purkinjei St. aus; dicht vor dem Schwanzstachel sizen auf dem Ruicken und an den Seiteu des Thieres noch zahlreiche, in mehrere fast ringformige Gurtel geordnete, sehr ansehnliche. gekrimmte Stachelfortsátze. Aehnliche Stachelfortsatze finden sich auch bei zwei Arlen von Entodinium St, am hintern Körperende. Dichı neben einander stchende, feine, biegsame Borstenhanre sämen don ganzen freien kand tes spiraltrichterförmigen Peristons von Spirochonil Scheutenis $\%$

Eine sehr eigenthünliche Art beweghlicher Körperfor'sätze, welche den Psendopodien der Rhizopoden, namenlich rlenen der Actinophryen am nüchsten stehen, sind endlich die Tentakeln, sehr enge, röhrenförmige, an der Spitze in einen rundlichen Kü̈pfchen oder in einer scheibenförmigen Erweiterung endende Ausstulpungen des Körperparenchyms, welche gewöhnlich geral ausgestreckl sind und dann eine ganz glatte Oberfliche zeigen, wihrend ihr Inneres aus einer ausserst verschiebbaren, dem breiartigen Innenparenchym des Körpers gleichenden Substanz bestcht. Die Tentakeln können sich verlangern und verkiirzen, sie liönnen ganz in den Körper zurückgezogen, aber auch zu enormer Länge und Feiıheit ausgedehnt werden; Boides geschieht in tler Regel allmählig und langsam. Sie vermögen aber auch, wenn sie weit genugg ausgestreckt, sind. plötzlich cine andere Stellung anzunehnen, indem sie sich in weiten Bogen krimmen oder um ihren Fusspunet nach irgend einer Richtung drehen. Beim Verküren legen sie sich nicht selten in schraben- oder ziclizachförmige Windungen, oder sie schwellen unregelmässig auf. Die Tentakeln sind bısher nur bei den Embryonen der höheren lufusionsthiere (vergyl. Taf. VIll. Fig. I. 4. 6. e. e. und Taf. XIV. Fig. 3. a-e. umd bei den Acinetinen beohachtet worden; von letzleren besizen jedoch einige (Dendrocometes paradoxus und Acineta digitata stalt der Tenhaheln nur ganz starre, nicht retractile. einfache ocler astige Köperfortsaze. Die Tentakeh dienen als Greif- und Haftorgune; auch fundet durch sie, wie wir gleich näher sehen werden, die Aufnahme flissiger Nahrungsstoffe stall.

1) Steire Die Infusionshliere" Taf. I1. Fig. 1. c. 10. A. b. Taf. V. Fig. 31. b. - 2) Ebendaselbsı Taf V1. Fig. 46. a. - 3) Ebendaselbst Taf. 11. Fig. B4-57. 1. - 4) Ehrenberg Die Infusionsluiere Taf. X.JIl. Fig. I. 2. 3. und Taf, XXIV. lig. H. 1. - 5) A. a. O. Taf. XXIV. Fig. 11. 4. - 6) Annales des scienc, natur. 1857. W. Sér. Tome WII. p. 23\}. - 7) Miuller's Archir 1856. S. 348 und Taf. XIII. Fig. I 3. g. - 8j Ich habe dies Thier neucrlich lebend in der Ostsee beobachtel und mich üherzeugt, dass bei ihn dan Peristom wesentlich eben so gebaut ist, als bei Spiroch. gemmipara; die Borsten, welche ihm eigenthümlich sind, sitzen nicht, wie Scheuten angab (vergl. 'Stein Die Infusionslhiere S. 216 und Taf. V. Fig. 29), blos auf einer Seile dé Perislommandes, sondern rings herum un! dichter hinter einander. 


\section{Von dem Ernährungsorganismus der Infusionsthiere.}

Die Infusorien nehmen entweder nur hussige, oder sowohl feste als flissige Nahrungrsslofie auf. Im ersteren Fall können die Nahrungsstoffe von der ganzen Körperoberlliche absorbirt orler durch eigenthumliche tentahelartige Körperfortstitze aufgesogen werden; im letzleren Fall ist stels ein Mund und auch wohl immer eine constiunte Stelle vorhanden, an welcher die unverdaulichen stolle wieder ansogchichlen werden; sie wird After gemannt, obwohl nur selten eine eigentliche Afteröflumg zu beobachten ist. In allen Fällen gelangen die Nahrungsstofle, ohne zuvor irgend eine Veräderung erlitten zu haben, direct in das Körperparenclıym selbst; lier ersı crlolght ilıre Verdauung oder ihre Assimilation, und was nicht verdaut werden liann, wird durch dic Contractionen des Parenchlyms allmähligr ler Afterstelle zugedhingt. Ein lusonderes Verdaunngsorgan ist hei heinem Infusionsthiere nachzuweisen. Wenn ein Mund vorhanden ist, so ist die iussere Ungebung desselben oft eigenthimlich gestaltet oder durch eine besondere Stellung der Wimpern ausgezcichnel, wodurch eine reichlichere und sicherere Nahlurungszufuhr zum Mlunde hezweckt wirl. leh werde diese durch Form oder Bewimperung oder durel Beides zugleich aursgezeichnete Umgehung des Mundes im Aligeneinen als Peristom bezeichnen. Der Mund setzt sich häufig nach immen in cinen lingern oder librzern, von eigenen Wandungen begrinzten Schlauch fort, durch welchen die Nahrungsstolfe in das Jarenchym übergeführt werden. Er repräsentirt bahı nur den Schlund, bald Schlund und Speiseröhre der hölıeren Thiere zugleich; der Küre wegen werde ich ihn blos sichlund nennen. Bisweilen steht anch mil dem After, der dann stets eine jedcrzeit sichthare Oelfnung ist, ein kurzer ausfuhrender Kanal, eine Art Afterdarm in Verbindung; niemals aher spannt sich bei den Infusorien zwischen Hund und After ein continuirlicher Darmkanal aus.

Die Grinde, welche Ehrenbery lyestimmten, den Infusorien einen ganz rom Parenchym abgeschlossenen, polyzastrischen Darnkanal zuzuschreiben und densellsen zu ihrem wesentlichsten Character zu erheben, sind bereits im ersten Abschnitt umständlich erörtert und hinlänglich widerlegt worden. Nicht eine Vielheit von Mägen, die rom llumle oder einem Darm aus mit Nalurungsstoflen erfült werden, characlerisirt die lnfusionstluiere, sondern der gänzliche Hangel eines Hagens oder eines mittleren verdauenden Darmabschnittes. Hlierdureh unterscheiden sich auch die vollkommensten Infusorienformen sofort von sämmtlichen Räderthieren und Strudelwiirmern, die unter allen iber den Infusorien stehenden Thierlilassen doch noch die meisten Analogien mit denselben darbieten, und möslicher Weise mit ihmen verwechselt werken können; diesen beiden Thierklassen liommt jedoch stets ein für sieh bestehender allseitigr abgeschlossener Darmkanal zu. Die seltsamen Gestalten der Gattungen Ophryoscolex und Entodiniun wird man beim ersten Anblick viel elıer fur Ratlerthiere, als für Infusorien halten; die Nahrungsmiltel werden alser bei ihnen ius Parenchym abgeligert und darum sind sie unzweifelhaft Infusorien. Manche holotriche Infusorien, namentlich Cyrtostonum lencas und rerwande Formen nähem sich sowohl in ihrem Habitus, als anch in manchen Organisalionsverdaltnissen un vertienmbar (len rhabdocölen Strudelwirmern. Was $O$. Schmidt veranlasste I), die Infusionsthiere unmillelbar an die Strudelwuimer anzuschliessen, allein der stels abgeschlossenc, wenn anch meist innigg mil dem ungebenden Parenchỵm verwachsene Darmkianal des letztern scheidet sic fundamental unul leichıt hemntlich von an Infusorien.

Entschieden mund- und afterlos ist unter den entwickelten, bewimperten Infusionsthieren num die artenreiche holotriche Galtung Opalina. Sammtliche Opalinen teben sehaarenweis in Darmkanal oder in abgeschlossenen Leibeshöhlen z. B. Opal. hranchiarum St.) anderes Thiere. und sie erreichen eine so ansehnliche Grösse Opal. ranarum grehört zu den grössten beliannten Infusorienformen, dass ein Hund, wäre er auch selı klein, sich nicht den bisher so of und von so verschiedenen Seiten her auf dicse Thiere gerichteten Forschungen hatte entziehen können. Es sind anch noch bei keiner Opaline im Parenchyn die geringsten Spmen ron fremden festen Körperu. zwischen denen sich doch die den Dammanal bewohnenden Formen beständig umbertummeln, beobachtet worden. Die Nihrung der Opalinen kann daher nur in den in ihrer I'mgebung stels reichlich vorkommenden thierischen Flissigheiten bestehen, und liese müssen ron der gesamnten Körperoberlliche aufgesogen werden liömuen, ta leine stelle tlerselben eine antere, hicrzu geeignetere Beschaffenheit zeigh, als die iibrige Oberfliche.

1) O. Schmidt Lelıbuch der Zoologie. Wïn 18ał. S. 73-83̈. Mil den Infusorien Werden auch die Gregarinen und Rhizopoden

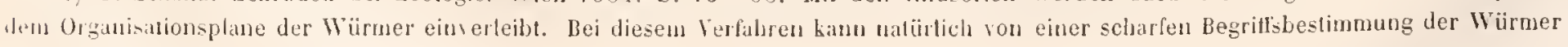
uicht die Rede sein. 
Anclı die Acinetinen und lie mir belianten Embryonen der böberen Infusoren luesilzen lieinen Mund und After. Sie nehmen niemals fremde feste Körper aus der Aussenwelt auf, und jeder Versuch, sie mit Kammin oder lıdigo zu fütern, bleibt erfolghlos. Diejenigen Acinetiuen und Embryonen. welche mit retractilen Tenlakeln verschen sind, leben ron den flissigen Bestandheilen und Fetten anderer Infusorien. welche sie denselben millelst der kmopfoümigen Enden ihrer Tentaheln entzichen. An deullichsten lionnte ich diesen Vorgang bei den grösseren Acimetimen. mamentich bei Acineta Operculariae und A. cothurmata beobachten, und ich moss durehwer die genave Schilderungr, welche zuerst Lachmam hierron gegeben lat', bestäligen. Schwimmt ein Infusionsthies in erreichbarer Nähe an den Acineten roriber, so fahren die zunächst gelegenen Tentahelu schnell gegen dasselbe zusanmen, wobei sie sich of betrichılich verlingern, bogenfürnig zusammenkrümmen. selı verschieden wiurlen und regrllos durch cinander wirren. Diejenigen Tentalieln, deren knopfö̀miges Ende in unmiltellsare Berihrung mit rler Oberfläche des umstrickten Thieres liommt, crweitern dasselhe scheibenartig und saugeu sich damit fest. Ist dies ersi mehreren gelungen, so rermag sich das gefangene Thier nicht melı loszureissen, scine Bewegungen werden immer

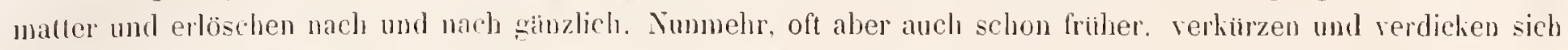
diejenigen Tentahehn, welche sich an festesten angesangt hatten, beträchtlich und ziehen, während andere wieder loskssen, die Bente naher an den liörper heran; wobei sie entweder gerad gestreckit bleiben oder sielı hakenförmig sciwaits oder sogar nach abwärs umbicgen. Plötzlich sieht man, sobahl die Haftscheibe die Culicula rles gefangenen Thieres durchbolut luat, von demselben aus einen continuirlichen, sehr rapiden, durch dic beigemengten üheraus feinen Feltkömchen bezcichneten Strom sich durch die Axe des Tentakels ergiessen und an seiner Basis in das henachbarte Korperparenchym ausströmen, was so lange währ, bis das gefangene Thier entweder zerfliesst, oder his ihm der grosste Theil seines halbllissigen Inneuparenchyms entzogen ist und es nun cine ganz zusammenyesehrumpfte, unkenulliche Masse bildet. Wrudurch die anfallend schnclle und continuirliehe Strömung im Inueru des Tentakels bedingt wirl. ist mir nicht geniggend erlibrlich: sie ist eben so rapid, wenn der Tentakel, an dem rlie Beute haftel. nach abwärts ģekrimmt. die innere Strömung also eine aufwirts steigende ist. Irgend welche von den Wandungen des Tentakels ausgefuhrte schluckende od 'p peristaltisehe Bewegungen liessen sich nicht beobachten, die Contonren des Tentakels blieben vieluselır ganz unverinderl, während ein ununterbrochener Körnchenstrom durch seine Axe floss. - Bei den mit starren, armartigen Körperfortsilzen versehenen Acinetinen (Dendrocometes und Acineta digitata kamm vou einem Fangen und Anssangen anderer Infusorien nicht die Rede sein; jedenfalls werden aber auch sie nur mit den wenger starren. zugespitzten Euden ihrer Arme flissige Nahrungsstoffe aufnehmen. Woher diese stammen und wie sic iluen zugefuilurt werden, das ist noch röllig dunkel.

Den säum tlichen geisseluagenden Infusorien wurde nach den Vorgange Dujurdu's unt $v$. Siebolds lis in die neueste Zeit sehr allgemein Mund und After abgesprochen umb bei ihnen nu cine enulosmotische Aufnahme:

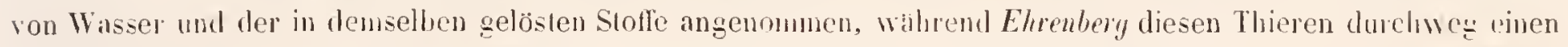
an der Basis Iler Geissehn gelegenen Mund zuschrieb, der zugleich die Stelle des Afters rertrelen sollte. Der Mund wurde zwar von Ehrenberg nirgends deutlich direet beobachtet. aber auf seine Anwesenheit aus der bei vielen nicht grün gefurbten Formen bewirkten Fülterung mil lndigopartikelchen geschlossen. Ich glaube, dass Elrenberg's Ansicht der Wahmeit weit näher liommt, als die entgegenstehende, und anch Cohn ${ }^{2}$ und Lachmamn ${ }^{3}$ haben sich bereits in ihnlicher Weise ausgesprohen. Ich sellst habe bei mehreren. zu versehiedenen Familion gehorigen geissellagenden Infusorien mit grisster Bestimmblheit eine Mundölhung und einige Male auch an ciner vom Mumle verschiedenen Stelle dic Ausschcilung von Excrementen beobachlct. Am deullichsten sah ich tlen Mund an zahılreichen riesigen, lis $\frac{1}{12}=$ langen und $\frac{1}{30}$ "' breiten Exemplaren der Zygoschmis nebulosa Duj., ferner bei Peranena (Trachelius Ehbg., trichophora, Heteronita (Bodo Ehbg.) grandis und Pelalomonas (Cyclidium Duj.) alsscissa $S t .{ }^{4}$; er ist bei den arei ersgenannten Formen eine von dem Insertionspuncte der Geisseln in der Miltellinie der Bauchseite naclı ruckwäts verlaufende, hlatlende liingsspalte, die bei Heleromita fast bis zur Körpermille rejeht, wälırend Pelalomonas an derselben Stelle nur eine hurz elliphisch grubige Mlundölhung bosizt. Im Innerm von Zygoselmis Iraf ich sehr häulig grosse, verschluchte thierische körper, cinmal auch einen sehr dichen und langen Conferven-

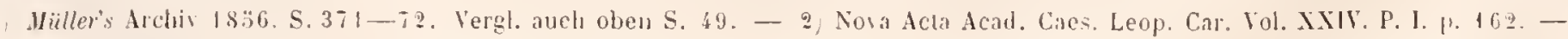
3) Mäller's Arctiv 1836 . S. 367. - 4) Die Gallung Petalomonas griude ich auf Cyclidium alıscissum Duj. Der Körper dieser Gallung isl gepatzerl, hyalın, sehr plattgedrüchl, blaltartio, auf der libckseite mil ein oder zwei Lïngskelen und am rordern Ende mit einer einzigen langen Geissel verselsen. Der Nane Lyclidium kann nicht beibehalten werden, dia er bereils von Ehrenberg für eine ganz andere holotriche Iufusoriengattung ferbraucht ist. 
faden, der einen betrachtlichen Theil des imnern Körperanmes einnahum. Auch Peranema ist seh" gewöhnlich mit fremten Kö̈pern erfillt, die diesem Thier ene schmulzigr gelbbraune Farbe ertheilen; hier sah ich auch am hintem Körperende die Ausscheidung von Excrementen. In Inuern von lleteromita beobachlete ich vielfach verschluckte griine und branne Körnermassen, auch cinige Male eine kleine Naviculacee.

Bei einer achten Monas wahtscheinlich II. guttula) liess sich zwar ller Mund uicht deutlich erkennen, aher im Innern zeigten sich vielfach fremle, zum Theil grü gefüble Körnerhanfen; auch sah ich ofters am hintern Ende sehr klar das Auswerfen von Kothballen. Unter zahllosen Individuen von Polytoma urella fand sich eine geringe Anzahl solcher, welche in der vordern IIatfe mahe vor dem Nucleus eine mehr oder weniger dichte Zusammenläufung von ïberaus feinen, grinen Moleciilen zeigten. Ich möchte auch diese von aussen durch eine sehr enge, an ller Basis der beiden Geisseln gelegene Mundötrung, die ich freilich nicht direct zu constatiren vermochte, eingedrungen sein lassen, da es mir nicht recht einlenchten will, dass Polytoma so sporadisch Chlorophyll entwickeln sollte. Die grimen und braunen geisseltragenden Infusorien sind \%war noch ujeht zur Aufnalıme von Farbstollen zu bewegen gewesen, auch hahen sich in ihrem Innern noch nicht mit völliger Sicherheit ans iler Aussenwelt stammende Körper nachweisen lissen, allein deshall, dirffen wir ilnnen einen Mund noch lieineswegs absprechen. Ielı halje sogar bei Amblyophis viridis mit vollkommener Ueberzengung den Mund erkannt; er liegt hier in der Ausrandung am vordern Ende und zeight sich, wem dasselbe sich gerade gregen den Beobachter hin umbiegt, als eine sehr deutliche, kreisrunde, uach immen zu trichterförmig verengerte Oefinung; sie führt in einen lurzen, engen, etwas geschlangelten, medianen, lichten hanal, welcher in der Gegend des rohthen Augenflecks endight. Dieselbe Organisation ist auch bei Euglena viridis vorhanden, sie lasst sich aber bei diesem Thiere. das unaulhörlich seine gesammte Körperform verindert, weit schwieriger wahrnehmen. Auch bei Cryptomonas ovata sah ich deutlich vou der vordern Ausrandung einen linzen, engen, lichten Kanal sich nach innen erstreclien. Bei den Volvocinen, wo ein Mund und Kanal noch nicht nachweisbar war, zeigt sich das vordere zugespitzte Körperende, von ılem die Geisseln entspringen, stets fablos und augenscheinlich aus einer viel weichern, nachgiebigern Substanz gebildet; ohne Zweifel werden nur durch diese hindurch flissige Stolle anfgenommen und ausgeschieden.

Simmlliche bewimperte Infusorien, mit Ausnahne der bereits betrachteten Opalinen, sind mit einem Munde versehen, dessen Lag̣e und Gestalt sich meist jederzeit leicht ermitteln lasst, zumal wenn ein mehr oder weniger entwickeltes Peristom vorhanden ist. In manchen Fällen i:t jedloch der Mund schwer zu conslatiren, nämlich dann, wenn el fïr gewöhnlich fest geschlossen und wenn keia Schlund vorhanden ist, wie \%. B. hei Amphileptus und Loxophyllum Duj. Bei diesen Thiereu wirl der Mund nur in dem Momente, wo Speisen in denselben eintreten, sichıbar; aber auch wenn man diesen Moment nieht zu belauschen vermag (mir glückte dies z. B. bei sehr zahlreichen Beobachtungen des Loxophyllum Meleagris Duj. noch niemals), kann doch iiber die Anwesenheit eines Mundes kein Zweifel ibrig bleiben, da man olt gentig Individuen antrifft. deren Innenparenchym aus der Aussenwelt stammende feste Körper cinsehliesst. Dre Lage und Form des Mundes muss in soldien, glücklicher Weise nur sehr vereinzelten Fällen ans der Analogie mit den nächst verwandten Formen erschlossen werden.

Der Mund liegt bej allen Infusoricn, deren Körper einen scharf ausgeprägten Gegensatz von Rucken- und Bauchseite zeigt, also z. B. loci allen hyjotrichen Infusorien. stets auf der Biuchseite. Wir werden daher auch bei den ibrigen Infusorien, o ein solcher Gegensatz nicht vorhandon ist, diejenige Körperseite, welche len Mund enthält, als Bauchseite zn bezeichnen haben, und hönnen dennach auch ron einer linken und rechten Scite sprechen. da durch die Bewegung des Thieres der Gegensatz von vorn und hinten gegeben ist. In diesem Sinne besitzt \%. B. Glaucoma scintillans einen platlgedrïchten; Colpoda cucullus dagegen einen zusammengedrückten Körper; letzteres Thicr ist für gewöhnlich ein Scitenschwimmer, sein conveser Rand stellt die walıre Riucliseite, der concave. den Mund enthaltende, die Bauchseite dar. Liegt aber der Mund am vordern liörperende genan in der Lingsaxe. wie z. B. bei den Galtungen Enchelys, Prorodon, Holophrya, Coleps, Licrymaria, Trachelocerca, Didinium, so wirl jede Unterscheidung ron Rucken- und Butuchscite, und von linker und rechter Seite unmoghlich. Solnahl jedoch selbst hei ganz drehrunlem Körper der am vordern Ende gelegene Mlund aus der Längsaxe herausrücki, wie bei stentor und Vorticella, so können wir auch wieder entgegengesetzte Körperseiten unterscheilen, was natürlich die genauere Bestimmung der Lage der einzelnen Körpertheile wesentlich erleichtert. Bei den meisten bewimjerten Infusionsthieren lindet sich ler Mund in der vordern Körperhälfte, und lier wieder viel häufiger in gröosserer oder greringerer Entfernung von dem vordern Ende, als an diesem sclbst; seltener liegt der Mtund in der hintern hörperhälfte, z. B. bei Paramdecium aurelia, Plcuronema chrysalis Duj., Spirostomum ambignum. 


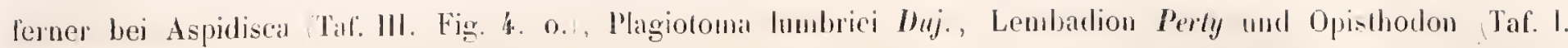
Fig. 26).

Sehr haufig ist der Mund ron einem mehr ouler weniger ausgehildeten Pejistom umgeben. Disselbe besteht in seiner einfachsten Gestalt in einer grruben- oder spaltförnigen Vertiefung der Bauchseite, in deren Grund die Ilundöfhung liegt, z. B. bei Opluryoglena atra und acuminala und Cyrtostomum leucas. Deutlicher trilt das Peristom schon bei Paramaecium aurelia und bursaria hervor; hier erscheint es als eine in der ganzen Breite des vorden Körperendes heginnende und bis hinter die Körpernitte sich erstreckende muldenförmige oder hohlkehlenartige Vertiefung, die sich nach hinten zu stelig verengert und vertieft und ganz hinten, an der tiefsten Stelle die schräg elliptische Mundölfumg enthält. Bei Stentor und Spirostomum wird das Peristom hauphächlich von eines adoralen Zone lingerer und starkerer Wimpern gebildet, die sich wenigstens an ihrem hintern Ende spiralig einrollt und zugleich trichterförmig vertieft; in der Vertiefung licg̨ der runde Mund. Bei Spirostonum ambigumm verläuft die adorale Wimperreihe vom vorden Körperende in gerader Richtung bis weit nach ricliwärts und krummit sich dann auf einem sehr beschranhten Raume nach rechts, vorn und innen. Bei Stentor beschreiben dic adoralen Wimpern um das vorlere, trompetenfömig erweiterte körperende eine selır niedrige, fast in einer Ilorizontalebene gelegene, rechtsgewundene Spirale, indem Anfang und Ende derselben dicht nchen einander liegen. Die Spirale beginnt nämlich etwas rechıs von der Mittellinie der Bauchseite, wendet sich dann in horizontaler Richtung nach rechts und ohen, und wem sie bis zur linken Seite gelangt ist, senkt sie sich wieder auf die Bauchseite ubergehend stetig etwas nach abwàls, um sich dann in der Nähe der Mittellinie nach vorn und immen einzurollen und trichterförmig zu vertiefen. Die ganze von der Wimperspirale umschlossene Körperoberfläche hann als Peristomfeld bezeichnet werden, der trichterfömigr vestiefte Endulueil der Spirale ist eine Art Vorhof zmm Munde. liein Sehlund. Spirostomum besizt hein eigentliches Peristomfeld, sonderm nur den Vorhof.

Noch häufiger wirl das Peristom von einer halbrinnenförmigen oder muldenartigen Vertielung, ja selbst von einer tiefen sackformigen Aushöhlung und von adoralen Wimpern zughleich gebildet. So zieht sich bei der Gattung Plagiotoma (wozu ausser. Pl. Iumbrici Duj. und Pl. concharum Perly auch Bursarja cordilormis Ehby. und meine Burs. blattarum gehören von dem vordern Ende des stark zusammengedrickten Körpers läugs der Bauchkante bis zur Mitte derselben oder noch dariibrer hinaus ein spalförmiger Aussclinill herah, in dem die feinborstigen adoralen Wimpern dicht hinter einander stehen und an dessen sich elwas einwäls kimmenden hinterm Ende die trichterförmige Mundöflnung liegt. Bei den Oxytrichinen und Euplotinen bildet das Peristom einen meist ansehnlichen, fach muschelfömig ausgehöhlten, ron dem Vorderrand des Körpers sich in der linken Hálfte der Bauchseite mehr oder weniger weit nach rückwirts erstreckenden Ausschnitl (Taf. IV. Fig. 7. 1. p. i. Taf. VI. Figy. I. I. p. i.), welcher ohngefahr die Form eines spluirischen Dreiecks lat, dessen Basis von dem Vorderrand (les Körpers gebildet wird und dessen Sjutze nach hinten und innen gerichtet ist. An diesem Peristom sind drei Rander zu unterscheiden, nămlich der Vorderrand 1., welcher mit dem Vorderrand des Körpers zusammenfällt. der Aussenlanıl (P.), welcher von der linken Ecke des Vordcrrandes aus einen sanft gekrümmten Bogen nach der Mittellinie der Rauchseite hin besthreibt, und der Inmenrand (i.), welcher mit dem Aussenmond unter einem spitzen Winhel (ich nenne ilın Peristonwinliel zusammenstösst, den Vorderrand des Peristoms aber gewöhnlich nicht erreicht, so dass dieses vom nach rechts offen ist. Längs des Vordej- und Aussenrandes rom Peristom liuft stets eine conlinuirliche Bogenlinje adoraler Wimpern, welche, wie ein Vergleich mit Stentor leht, ein Segment von einer rechtsgewundenen Spirale darstellt. An dem scharfkantig vorspringenden Innenrand des Peristoms ist wenigstens bej allen Oxyudichinen eine schmale undulirende Membran befestigt und unter dieser versteclit liegt dic lange spaltförmige Mundöffnung (Taf. X. Fịg. I. o. Taf. XII. Fig. 12. o. Taf. XIV. Fig. 2. und 5̈. o.)

Ein ganz ähuliches Peristom fundet sich auch noch hei verschiedenen bursarienarligen lıfusoricn, namentlich bei Condylostoma, Blepharisma, Lembadion und Climacostomun. Bei letzterer Gattung jst Jer Innenrand des Peristoms, der sich bis zur rechten Ecko des Vorderrandes fortsetzl, ohne undulirende Nembran, unt die weitc rumbe Mundölfnung liegt im Peristomwinkel. Sehr eigenthimlich gestaltet ist das Periston von Bursaria truncatella. Dieses Thier besitzt einen ahulichen Peristonausschnitt, wie Climacostomum virens; dieser begranz jedoch licin blos muldenförmig vertieltes Peristomfelıl, sondern er fülırt nach rechts und hinten in eine geräumige sacklörmige lluhle, die sich vom hintern Ende des Ausschnitts oder der Peristommündung an ganz allmahlig trichterförmig rerengert, lis tjef in den hintern Theil des körpers hinabsteigh und hier nach links umbiegend in das Parenchym ansmindel. Der yordere weitere Theil disser Höhle muss wohl als Vorhof. der luntere engere als Schlund gedeulet werden. 
Eine bestimmte Gränze zwischen bejden Abtheilungen ist jedoch nicht vorhanden. Von der linken Ecke des Vorderrandes ziedı sich an der linken Seite des Vorhofes, den Aussenrande des Peristoms parallel, eine breite, quergefurchte. bandfömige Zoue herab, lie sich bis zum lunlen Ende der schlundartigen Fortsetzung des Vorhofes erstreckt; ihrem rechten Raude sint die adoralen Wimpern eingefiight, die also hier grössleutheils imnerliche sind ${ }^{2}$.

Die enuplicitesten furmen des Peristoms kommen bei den peritrichen Infusorien vor, namentlieh bei den Vorticellinen, Ophrydinen, Spirochoninen und Ophryoseolecinen. bei den beiden crstern Familien beslebt das Peristom aus eincr weiten riugfömigen Muindung an den gerad abgestuzten Vorderende des Körpers, dereu vorstehender Rand gewöhnlich wulstförmig verdickt und nach aussen umgeschlagen ist. Aus der Itindung ragt als zweiter Bestandtheil des Peristoms das Wirbetorgan hervor, ein länger oder kinzer gesticlter, muitzen-oder deckelfömiger Fortsitz, der von der innern Wand der Peristomhohle ausgeht und wohl als das nacls aussen umgestüjte Peristonfeld gedentel werden muss. Mas Wirbelorgan kann nach Belieben in das Junere des kürpers zuriickgezogen werden, alsdann ziehi sich die Peristommündung sphincterartig zusammen und sehliessi den imnern Kürperraum

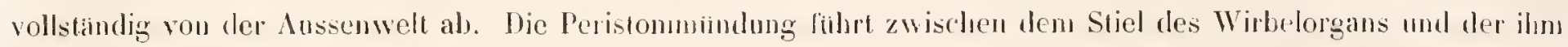
gegenubcrliegenden Körperscite (lie als Bauchseite zu bezeichnen ist, da ihr der Mund zundichst liegl) in einen geraunigen Vorhof ${ }^{2}$, der bei Opercularia und lagenophrys, wo der Stiel des Wirhelorgans lang und dinn ist, eine verticale, den grössten Theil des vurderen Körperrames eimmehmendr Höłle bildet, hei Yorticella, Carchesium und

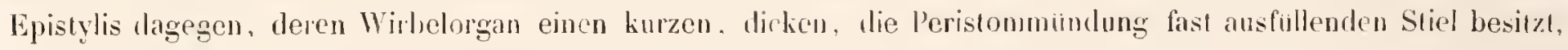
einen fast horizontalen, sich mur wenig nach ahwảrts senkenden, bogenförmig nach links und innen gekrimmten Schlanch darstellt. Am Grunde des Vorhofes liegt erst der eigentliche Mund. Die adoralen Wimpern heschreiben eine die Scheibe des Wrbelorgans stumende und in den Vorhof hinabsteigende linksgewundene Spirale. Diese beginut nämlich (hei Vorticella und Epistylis) rechıs am untern Rand der Schejhe, geht dann nach links un den ganzen Rimd der Scheibe herum und senkt sich, weun sie fast den Anfangspunct wieler erreicht hat, an stiele des Wirbelorgans in den Torlof himab. Die dem untern Theil der Spirale angehörigen Wimpern zeigen sich meist iber den hand der Peristommiindung nach aussen umgeschlagen; hierdurch and durch die innige Innaherung des absteigendeu Theils der Spirale an ihren Anfaugspunct wurde ich in meinen friberen Arbeiten zu der irrigen Ausiclı verleitet, dass dic Scheibe des Wibelorgans von einem geschlossenen Wimperdanz eingefasst werde, und dass auch die Peristomnuimdung Wimpern trage. Luchmam hat diesen Irrhum berichtigt und uberhaupt die Kenntnis: des Emảhrungsapparates der Vorticellinen in mehreren Puncten wesentlich gefördert ${ }^{3}$ ).

Die Ophryoscolecinen besizen elenfalls an vordesn Körpercnde cine weite, innig verschliessbare Peristommändung und aus dieser ragt nur unbetrichllich cin hol, les, weilmumdiges, manschetlenatiges Wirbelorgan bervor, welehes von einer hiutigen, auf der cinen Seite der Läuge nach aufgeschlitzlen Röhre gebildet wird, deren einer Seitenlappen um die Längsaxe spiral nach mnen geroltt ist und von dem andem Seitenlappen flueilweis umbasst wird. Der Vorlerrand und der einc freie Scitenrand des Wirbelorgans ist unt lanģen und diclien griffelförmigen Wimpern besetzl, die zusammen eine sich nach immen hinabzichende Spirale Jeschreiben. Dis Wirbelorgan kann schnell geschlossen und in das lunere des Körpers zuruckgezogren werdeu. - Bei den Spirochoninen trägt das vordere Körperende ein weitmindiges, nicht verschliessbares, trichterförmiges Peristom ${ }^{4}$, welehes aul der einen Seite der liunge nach gespalten ist; der eine der beiden Seitendappen rollı sich um die Längsaxe sjural und trichterförmign bach innen ein und beschreibt melıre nach rechıs aufsteigcnde Ungänge, die an ihsem Grunde durch eine gemeinsame spindel verbunden sind. Der eingerolte Theil entspricht dru Wirbelorgan der verwandten Fumilien; er ist jedoch ganz starr, und hann nicht in das lmere des körpers zuricligezogen werden. Ganz im Grumle der in einander steclienden Trichter, um die Spiudel herum, sitzen die sehı Zarten adoralen Wrimpern; Iler Mund selbst liegt im Grunde des Peristoms hart an der Spindelbasis. - Was Peristom der Tridhodinen ist dem der Vorticellinen verwamdt. Bei llalteria Duj. lindet sich ein terminales, verengertes, hallıingfömiges Peristom, welehes vou sehr langen, gebogenen, griffelförmigen Wimpern cingefasst wird; llie ollene batuchseite des Peristoms führ in einen

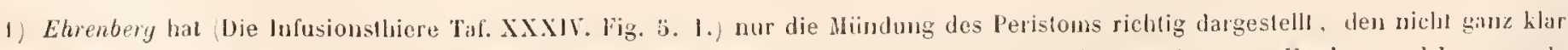
ausgeführen Vorhof und seine schlundartige Forlseczung aber in die linke Körperhälfte verlegl. Auch giebt er am Vorder- und Innenrande

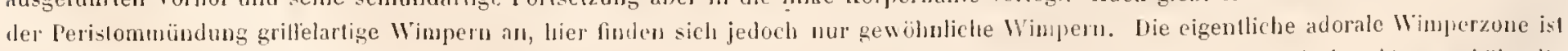

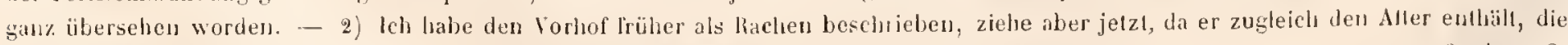
ion Joh. Mäller vorgeschligene und zuerst von Lachmann (Miller's Archis 1856. S. 3 it gebriuchle Benenulus vor. - 3 ) A. a. O. S. 3i6-ij. - 4 Vergl. Slein Die Infusionsthiere Taf V. Fig. I. c. 
nach rechls gehrummlen spaltförmigen Jusschnitt, dessen linlier Rand zartere, nach einwails gewendete adorale Wimpern trigl, die mit den längern vorteren Wimpern zusammen eine continuiliche Spirale hilden.

ller Mund fïlurt bei vielen bewimperten Infusorien olne Vermiltelung eines Schlundes direct in das Körperparenchym. Dies ist z. B. bestimmt bei den Gatungen Colpoda, Cyclidium. Glancoma, Enchelys, Holophrya. Lacrymaria, Trachelocerea. Amphileptus, Loxodes, Loxophyllum, Spirostommm, Stentor und Lembadion der Fall. Bei Enchelys bildet die terminale Mublolfinung eine klaffende, wulstig gerandete Spalte. In dem wulstigen Rande sah ich besonders deutlich bei einer sehr grossen und langgestreckten neuen Art, E. gigas, die sich durch zahlreiche contractile Behälter und durch zahlreiche. kleine, dicht zusammengehäufte Nuclei auszeichnel sehr kurze und feine, dicht neben einander stehente Stabchen eingebettet, die aller Wahrscheinlichkeit nach in die Kategorie der Tastkörperchen gehören. Durch die hetrichtlich erweiterungsfähige Mundöfnung treten oft Nahrungsstoffe, z. B. ganze Vorticellenkörper ein. deren Umfang merlilich grösser ist, als der Halstheil des Thieres l). Haben die Mundränder aher erst die Beule sicher gepackt, die ron dem Thier gewöhnlich gegen einen Wilerstand leistenten Gegenstand gedrangl wirl, so weicht das innere Parenchym aus einander und die Beute gleitet langsam durch den sich stark aufbähenden Hals inmer weiter nach abwärts, ohne irgendwo eine Lücke in Parenchym zu hinterlassen. dessen momentan getrennte Theile sich vielmehr sofort wieler vereinigen. Wo soll nun hier wohl eine besondere verdauende Leibeshöhle liegen? Dieselhen Erscheinungen sind bein Durchgange gröberer Nahrungsmitlel durch den langen und engen Ilals von Lacrymaria und Trachelocerca ${ }^{2}$ ) zu beobachten.

Bei Amphileptus und Loxophyllum ist fur gewöhnlich grar kein Mund wahrnehmbar, dieser tritt erst, wie jch oft bei Amphileptus beobachtete. in dem Momente deutlich hervor, wo ein grösseres Infusionsthier versehlungen wird. Die Amphilepten wickeln sich un ihre Bente anf lie verschierlenste Weise zusanmen, schrauben sich um dieselbe herum und stemmen mun ihren schr beweglichen Hals, ler sich dabei heträchtlich verkürt und verbreitert, gegen dieselbe. Plötzlich zeigl sich damn auf der einen Scite des Halses, parallel seiner convexen Bauchliante. eine lange, am vordern Ende weit klalfende Spalte; in diese wird die Beute in Folge der fort und fort andrangenden Bewegungen des Halses hineingeschoben, das innere Parenchym weicht sichtlich aus einander und der Bissen gleitel bald längs der Mundspalle, die dann auch in ihrem untern Theile klallend wird, nach abwärts, balıl bewegt er sich in schräger Richtung durch das Parenchym nach der entgegengesetzten Körperseile. Von einem Schlunde ist auch nicht die leiseste Andeutung rorhanden, ebensowenig von einem mittlern Raum, der ctwa die verschluckten Nahrungsmittel aufnihme; diese bleihen vielinehr an den verschiedensten Puncten im Parenchym liegen und werten daselbst verlaut. Der Mund schliessı sich, nachlem der Bissen eingedrungen ist, meist sofort wieder vollstamlig. - Bei ter nahe verwandten Gattung Loxodes liegt der Mund an derselben Stelle, wie bei Amphileptus, nämlich auf der rechten Seite dicht neben ter hier concaven Bauchliante des Ilalses; er ist aber eine stets weit oflen stehende, sichelfömige spalte. Ihr innerer liand wird von einem derben, dunkelbraunen Saun eingefasst, welcher sich vom hintern Winkel der Mundspalte aus in schriger Richtung nach hinten und innen in einen noch festern und dunklern stielartigen Streifen forlsetzt, der fast so lang ist, als die Mundspalte. Stiel und Mundspalte zusammen gleichen volliommen einer gewöhnlichen Handsichel3j. Ein eigentlicher Schlund fehlt zuverlassig.

Eine lange, klaffende. spaltförmige Mundöffung ohne Schlund wirh auch hei Lencophrys sanguinea und 1. entozoon angetroflen. Sie erstreclit sich vom vordern Körperende in fast medianer Richtungِ durch das erste Drittel der Banchseite und ist jelerseits von einem schmalen lıäutigen Saume eingefasst; unter dem etwas slärlier entwickelten liuken Randsaume treten krätigere, griflelförmige Wimpen hervor. vermittelst welcher die Nahrungsmittel durch die Mundspalte in das l'arenchym hineingedrücht werden. Bei Glancoma scintillans geschieht dies mittelst der undulirenten häutigen Kilappe, welche von dem rechten Rande der elliptischen Mundspalte ausgeht. Bei den Oxytrichinen, Euplotinen und Aspidiscinen vermochte ich ebenfalls keinen eigentlichen Schlund nachzmweisen. Lachmann nimmt zwar einen solchen an und lasst denselben von dem Peristomwinkel aus in querer Richtung eine

1) Man vergl. Ehrenberg's getreue Jarstellung des Verschlingumsacles von Enchelys farcinen (Die Infusionslhierchen Tal. XXXl. lig. 2/. Von dieser Art scheint mir Lencophrys spathula Ehbg. nichll specifisch verselieden zu sein. - 2) Bej Lacrymaria lindel sich in geringer Entfernung von der terminalen Mundöthung eine ringlömige Einschnürung, aus der längere, uber den Mund liuausragende Wimpern entspringen. Der abgeschü̈rte Eudtheil des Halses bildel ein sehr bewegliches, rüsschartiges Köpfchen. Bei der Gallung Trachelocerca, die

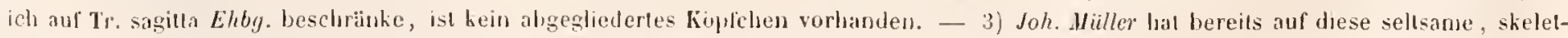
arlige Congränung des Nundes von Loxodes Justrum aufmeısam gemachl (Momatserichle der Berliner Academie von 1856 . S. 390 . Er besclireibt sie als einen mdunklen, ganz detben und festen Lingsstreilen on leicluter Sigmalörmiger Biegung." 
bure Strecke nach rechts verlanfen und imertich bewimpert arin ${ }^{1}$, allein ich hann darin nichls weiter, als das unterste Ende des adonalen Wimperbogens erblicken, ter von den lnnenrambe des Peristoms iberagt wird (vergl. Tall. IV. Fig. 17. mnt Taf. IT. Fig. 1. Dass cin solcher Schlum wenigstens bei den Oxylriehinen nicht existire'u

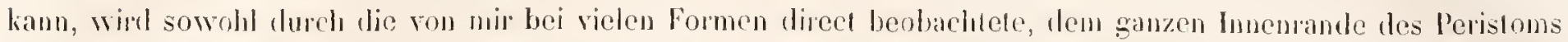
parallel lanfende lange Mundspalte, so wie auch durch die colossalen Nahrungsmiltel, welche die Oxytrichinen zin rerschlingen rermögen /vergl. Thu. XII. Fig. 3.6.7\% bewiosen. Die adoralen Wimpern schleudern die Nahrungs- . stofle ïher das Peristonfeld gegen den lnuenrand des Pcristons, und durch dic an demselben hefestigle undulirende Membran werden sic dann anfgefangen und durch die Mundspalle direet in das Parenchym hineingedriekı.

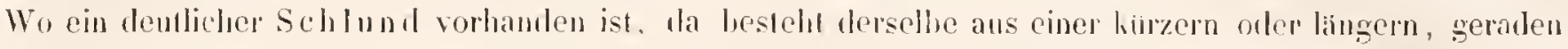

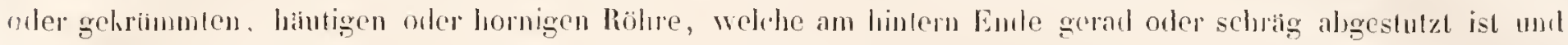
stels oflen in das Parenchym ausmindel. Die innere Oberfliche des Schlumbles ist entwerler glant orler langsgefaltel

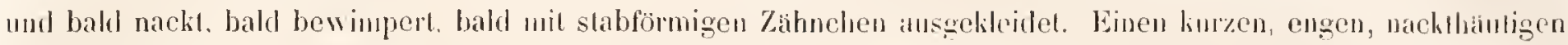
schlund besizen z. B. Blepharisma hateritia, Plagiotona lumbrici, Palamaecium colpoda. Der cbenfalls sehr kurze und enge, hatulige Schlund ron Paramaceim aurelia und bursolit is auf der ganzen imnern Oberliche mit zarten Wimpern bekleidet. Bei Bursaria llava ist ein kurzer, weiler, langsgefalteter und in ter hule mehr oder weniger um die Längsase eingeroller, walzenförmiger Schlund orhanden, an dessen innerer Oberflache lisur\% vor der hinlern Miundung längs der obern Wand rin dreiechiger hin und her schwingender Lappen befestigt ist, auf den

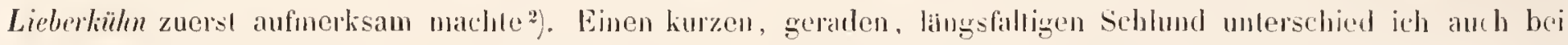
Coleps, doch ist er hiur meist schwer und nur unter gunsligen Umstinten zu heobachlen. Einen langen, längshaltigen, anf der ganzen innern Oberfliche dicht mit zarten Wimpern bekleideten und selır betrichılich erweilerungsfahigen Schlund besilzt Climacostomum virens; er erstreckl sich lier von dem Peristomwinhel ans in querer, elwas aufsteigender Richtung nach rechs und lirümul sich dann in einem weiten Bogen bis zur Jlitle des rechlen Seitenrandes hinah, dem der absteigende Theil fasl parallel haft ${ }^{3}$. Ein ebenfalls sehr langer, quer bogenförmiger und melı orler weniger weil in the hintere Körperhalfte hinabsleigender Schlund ist bej Plagiotoma concharum, cordiformis und blatlarum vorhanden; bei ten beiden letztern liten setzt sich tlic adorale Wimperreihe an der obern Wand des Schlundes bis zu seiner hintern Müntung fort.

Der schlundartigen Fortsetzung des Vorhofes von Bursaria truncatella ist hereits gedacht worden; ih. hinteres Emle ist so eng, dass die grössern thicrischen Körper, welche man so häufig im Parenchym dieses InfusionsHheres antrill. wohl kaum dureh dasselbe hindurdygegangen sein können. Wahrscheinlich ist der Schlund an der untern Scile aufgeschlizt und durch diesen Schlitz gelangen die grössern Nahrungsstolfe in das Parenchym. Einen selur entwickelten häuligen Schlund besitzen anch die Torlicellinen, Ophrydinen, spirochoninen und Trichodinen. Bei den Torticellinen und Ophrydinen geht der Vorhof ohne scharfe Granze in den meist slank gekrummlen und of bis tief in das hintere Körperente hinabreichenden Schlund uber. Einige starke borstenförmige Wimperu. welche die für die Ernahrung nich, brauchbaren Stofle aus dem Vorhof wieder nach aussen schleudern, bezcichuen

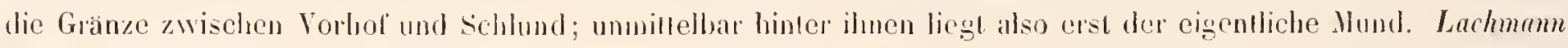
will bei den Vorticellinen das hintere Encle des Schlundes, in den die Nahrungrstolle sich zu einem Bissen ansam.. meh, als einen besondern Abschnilt unter dem Namen Pharynx von dem vordern Theil, den er Oesoprhagus nenn, unferscheiden ${ }^{4}$, ich vermig jedoch keine scharfe Gränze zwischen liesen Endhcil und dem ubrigen Theil des Schlundes aufunfinden; chensowenig konnte ich mich sicher ïlsergengen. dass sich die arloralen Wimpern bis in den sogenanulen Planyx hinat, erstrecken.

Bei Dileptus anser, wo der Mund in einer Ausrandung der Bauclikante an der Basis des Italses liegl und

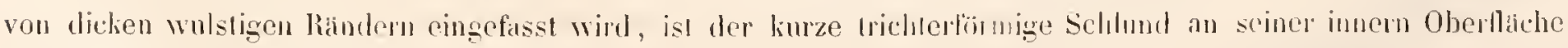

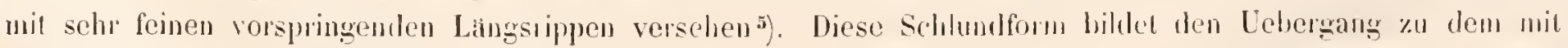

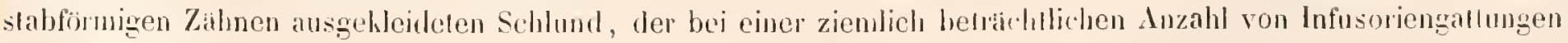

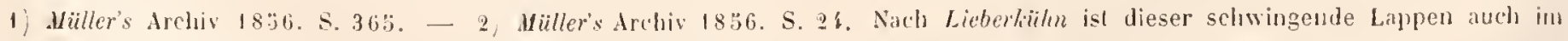
Schlund der nahe verwanden, mir unbekannten Ophryoglena lavicans vorhanden Ebendaselbst S. 22). - 3) Von Ehrerberg's Abbildungen dieses Thieres (Die Infusionshierchen Taf. XXXll. Fig. 1. 1-3.) ist die unter Fig. 3. gegehene die richligste; sie stellt das Thier von der liäckseite mit von unten her durchscheinendem Peristom dar, der Schlund (Jei t.) ist jedoch hier irrig als Samendrüse bezeichnet worden. - 4) Mäler's Archiv 1836.5 .348 und 300 . - 5) Lhenterg hat zwar die Lage des Mundes richtig angegeben (Die Infusionsthierchen Taf. XXXYI. Fig. IY und $V .0^{\prime}$ ), aljer dic genathere Gestalt deaselben und den Sehlund nicht dargeslell. 


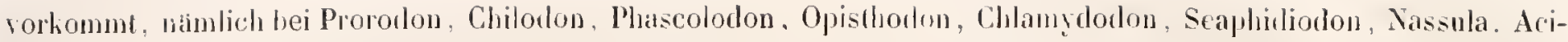
dophorus, Cyrtostonmm und Didinium. Der kurze, gerade und weite Schlund ron Proroulon teres enthall sehr zahlreiche, dicht neben einander stehende, fein borsteuförmige Ziihne, die liaum von blossen Längsleisten verschiçlen sinal und sich nicht isolirt darstellen lassen. In dem längern und engern Schlund von Prorodon niveus sit\%en die schr l,iegsamen horstenförmigen Zỉhne so lose, dass sie schon bei einem missigen Druck auf den Körper vereinzelt oder bindelweis nach anssen, hervortreten oder sich in das innere Parenchyn hinein schieben, wo sie sich dann stark verbiegen und lirimmen, auch sich zopfartig verflechten oder regellos durch einander filzen. Der Schlund von Didinium nasulum gleicht dem ron Prorodon; der Mund dieses Thieres liegt an der Spitze eines rüsscharlgenen, das vordere gerad abgestutzle Körperende krönenden Peristoms, welelıes bald trichter-, bahl nasenförmig erscheint, je nachden der Mund weit offen steht, oder fest geschlossen ist.

Der Zusammenhang, in tem die Zahustabchen mit dem Schlunde stehen, ist am leichlesten bei Chilodon und Nissula zu crkennen, wo dic Zahmsläbclien stäkier entwiclielt sind und weiter von einander entfernt stelıen. Man siehı hier dentlich (vergl. Taf. I. Fig. 6. ph.), dass die Zahnsläbchen partielle, gleich weil von cinander alıstehende, leistenartige Verdichungen der Schlundwandungen dasstellen, die panzeratigr erhartet sind, gleiehsam das Skelel des Schlundes bilden und demselben ein fisehreusenartiges Ansehen erheilen. Dic Zahnstäbchen sind vorn an hreitosı un ihre Spitzen sind melır orler weniger hakenfömig nach innen mmgebogen; naeh hinten zu verschmälem sic sich stetig und verlieren sich zuletz, ganz unmerklich in der Schlundwandung, dic noch weiler nach rickwarts 20 verfolgen ist, als die Zahnslabchen. Die innere Oberliche des Schlundes ist stets wimperlos. Bei

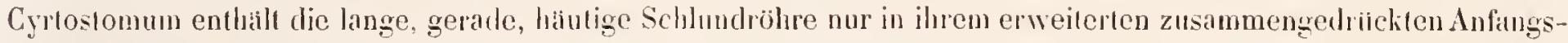
theil zwei einander gegeniberstehende, der linken und reehten Wand angehörige bogenförmige Reihen von kurzen, linealischen, dicht an cinander stossenden Zahnstabchen, dic man an deullichsten erliennt, wenn man gerarle in

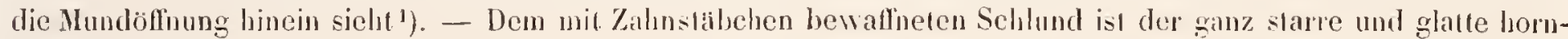
artige Schlund nahe verwandt. Bei ihm sind die Schlundwandungen ihrer ganzen Auslehnung nach gleichmassig verdickt und panzerartig crhibtet; man kann ihn sich als einen fischreusenarligen Schlund rorstellen, dessen Zalunstabchen unter cinander und mit den Schlumbandungen innig verschmolzen sind. Bisher war ein soleher schlund nur bei Liosiphon beliannt, wo er cine birnfömige, vorn und hinten gerad abgestutzte liöhre billet ${ }^{2}$; ich habe ihn ausserdem noch bei den Gattungen Ervilia Taf. Il. Fig. 16. ph.) mnd Troehilia (Tal. II. Fig. 28. ph) angetroffen, wo er eiue gerade, trichterförmige Röhre darslellt.

Noch bedarf der Schlund und der scheimbar ganz abweichende Emahrungsorganismus von Trachelius ovmm einer speciellen Betraclılung. Ehrenberg schrieb diesem Thiere eine selır weite, sachförmige, an ler Basis des Halses gelegene Mundhöhle zu, die in cinen baumförnig verzweigten, an hinten Körperende ausmindenden Darmlianal fulıre, dessen Aeste in runden, sehr ausdelubaren Magenblasen endeten ${ }^{3}$ ). $v$. Siebold dagegen erklarte den angeblichen Darmkanal fur cinen fusrigen, keineswegs hohlen Strang, der das äussersı lockere Körperparenchyn durchziehe und durch seine Verastelungen dem Thier ein grobmaschiges Ansehen ertheile ${ }^{4}$ ). Llicrauf lehrte Cohn, dass der innere Körperraum von Tachclius ovum mit einer wảsserigen Flüssigheit erfuilt sei und dass sich durch dieselhe von dem Rindenparenchym ausgehende, netzförnig mit einander verbundene Parenchymstringe hindurchzögen; mit den Enden dieser innern veristelten Parenchymmasse ständen jerloch keineswegs Magenhlasen in Verbindung, sondern was Ehrenberg dafur gehalten lahe, seien conlactile Hohluaume, die in grosser Anzahl durch das ganze Rindenparenchym zerstreut Jägen 5 . Lieberhüh und Lachmom gaben zwar in dem letztern Punct Colm Rechl, abes den baumförmig verästehen Strang erkärten sie für einen von bosondern Wandungen begranzten mud durch nuit Flissigheit erfullte Liichen von dem übrigen Parenchym getremten Magen, da nur in ihm die verschluckten Nahrmugsstoffe enthalten scien. In dem zmm Magen fiilırenden Schlund wurlen Zahnslibehen beolatchtel $\left.{ }^{6}\right)$. Gegenbam endlich schilderte den angeblichen reristclteu Darmhanal oder Magen als ein die mit wisseriger Fliissigheit erfuilte Leibeshöhle durchzichendes System ron Trabekeln und bemerkte ausdrüclilich, dass die Substanz, ans weleher dic Trabcheln bestchen, von ılcm Rimlenparenchym des körpers nicht verschieden sei. Er unterschied ferner zwei ver-

1) Ehrenberg hat diese Zilunstibchon bereits unterschieden (Die Infusionshlierehen S. 329 und Taf. XXXIY. Fig. VII und lill. o'), ar sagl in der Beschreibung seiner Bursaria vernalis: uder Mund hat einen Kranz von starren kurzen Borsten, die fast Zaihuen gleichen.

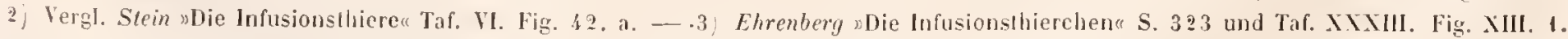

1) v. Sicbold Lehrhuch der vergh. Analomie S. 16. Anmerkung. - - "i) Zeitschrilt lïr wisseuschaftliche Zoologie Band IV. S. 266 -67.

6) Miller's Arehiv 1836. S. 360 und 367 . - 
schiedene Oefinungen, eine vordere enge, welche etwas unterhalb des russelartigen Italses, also an der Stelle liegt.

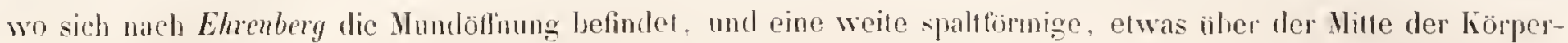
lange gelegrene, welche in cine mit Wimpern ansgekleidete taschenförmige Verticfung fuhlt. Diese hintere Spalte wird von Gegenban für die Mundöfhung gehalten, sie soll in den Hauplstamm des Trabelielsrstems ansminnden und demselben die in ihm zu verdanenden Nahrungsstofle zufuhren. Die vordere Oeffnung fuhnt nach Gegmban zuerst in eine etwas erweiterte, starrwandige, dann trichterformig zugespitzte, häufig langsgefaltete Röhre, welche in eimen guer ausgespannten Trabcliel ibergeht; sie soll durch eine Längsspalte in die Leibeshöhle minden, und auf diesen Wege soll durch die vordere Oeflnung von anssen Wasser anfyenommen und auch wieder ausgeschichen werden $\%$

Meine zahlreichen Beobachtungen des Trachelius orum haben im Wesentlichen zu denselhen Ergebnissen gefuhnt, wie die von Gegenbent, ich kann jedoch scine Dentungen rbensowenigg, wie die von Lieberkühm unl Lachmam gelten lassen. Ich funde nämlich, dass der Körper aus einem consistenten, nicht sehr mähtigen und an verschiedenen Puncten des Umfanges ungleich dicken Rindenparenchum hesteht, in dem zahlreiche rumb. Irohaft contractile Behabter zerstreut liegen. Das kindenparenchym zicht sich nach innen in ganz homogene. selur rerschieden stanke Stringe ans, die sich regellos kreuzen und netzförmig mil cinander anastomosiren. Dieses netzförnige Balkenwerk, dessen lnterstitien von wasseriger Flissiglieit erfullt werden, hat fist bei jedem Indivilumn cine andere Form, es geht ohne irgend eine nachweisbare Grinze in das Rindenparenchym ibber und unterscheidel sich von demselben nur durch grössere Nachgiehigheil und Verschiebbatieit; ich kann darin nur das Innenparenchỵm des Thieres erkennen. Die ron Gegenbaur beschriebene vortere Oclfinung ist der Mund; er liegt ganz analog wie bei der an niblisten verwandten Gattung Dileptus, jedoch nicht unmittelhar an der Basis des Ilalses, sondern etwas

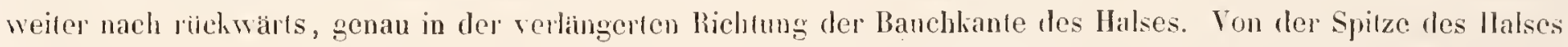
erstreckt sich bis zum Munde eine lineare Zone von feinen Tastlörperehen, wic hei Dilepus. Die enge runde Mundölfnung führt in einen sehr kurzen, aber dickwandigen, fast halblugelförmigen Schlund, cler ganz im Rindenparenclym liegt und innerdich schr fein lingsgestreift ist. An seine breite, gerad abgestntzte Basis schliesst sich stets ein selurgy nach rickwirts und innen verlaufender Strang des lnnenparenchyms an, der mit den iibrigen Strangen des Inneuparenchyms direct oder miltehar zusammenhängl. Durch diesen strang werden die durch den jedenfalls sehr crweiterungsfthigen Hund und Schund cindringenden Nahrungsmittel den ubrigen, nanentlich dem rickwistigen Innenparenchym zugefulıt und in ihn verdaut. Trachelins orum besitzt hiernach weder cinen haumförmig verästelten Darmkanal, noch einen haunfömig verastelten Ilagen; es wire auch in der That seltsam, wenn dieses Thier allein unter allen Infusorien mit einem fiur sich hestehenden, abgeschlossencn Verdaungszapparat versehen sein sollte. Die zweite der von Gegenban beschriebenen Oeffungen liegt fist in der llitte der rechicn Körperscite; sic ist cine langlich elliptische Spalte, die in eine schräge trichterförmige Vertiefung fuhr, in welche hinein sich die gewohnlichen körperwimpern fortsetzen. Eine Oeflungg am Grunde des Trichters konnte ich nicht dentich erliennen, ich zweille jedoch nicht an iluer Gegenwart und nehme an, dass auf diesem Wege das Wasser von aussen aufgenommen wird, welches die Interstitien des Innenparenchyms ausfillt und denselben eine so abweichende Form ertheilt.

Bei den mit eincm offen stehcnden Musd und Schlund versehenen Infusorien wird entweder durch das Spiel der adoralen Wimpern oder, wo diese felılen, der gewöhulichen Körperwimperu unaufhörlich Wasser mit deu in ilmenthaltenen lebenden körpern und anderen festen Partikelchen in den Schlund hinalıgewirhelt. Sind Schlundwimpern vorhanden, so unterstiitzen diese theils die Action der iusscm Wimpern, theils verhalten sie sich antagronislisch. indem sie die hereits in den Schlumb gelangten liörper wieder nach aussen schleudern. Der fort unul fort gegen das untere Ende des Schlumles gerichtete Fibsighcitsstrom treiht häufig, wie man z. B. besonders schön hei Climacostomum virens beohachten kann, das dem abgestuzten Ende des Schındes innig anliegende Parenchym eine lurze Strecke weit ans einander und höhlt es hasenarig aus; die Aushöhlung enthält Wasser und die durch den Schlund hinalgewirbehen festen Körperchen. Zulckz bildet sich ein an der hintern Mundung des Schhndes hägender Troplen oder tichtiger Nahrungshallen, der bis anf den Anhofungspunct ganz rou lunenparenchym umschlossen ist. Pö̈zlich reisst der Nahungsballen vom Schlunde al, und er lyerregt sich nun in der Richtung dos Schlundes noch eine längere oder kïzere Strecke durch das Innenparenchym fort. Zur Ruhe gelangt

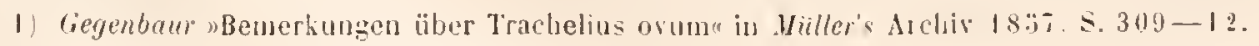




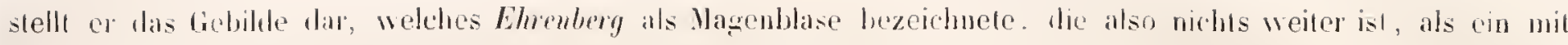
Wasser und in ihm schwehenden festen Körperchen crfuller Hohlumm des hnenparenchyms. Bei nanchen hufusorien, mamentlich bei Plagiotoma lumbrici, cordiformis und blattarum creicht der Nahrungshallen of einen sehr bedeutenden Umbang, heror er sich won dem schlunde ablöst, anch zeigt el sich nichı rmollich blasenförmig, sondern granz unregelmassig eingeluchlet und aufgedunsen.

Auf die Mbstossung des Nilırungshallens rom Schlundende wirkt sicherlich der forlgeselzl ron aussen eindringende Flüssigkeitsstrom mil ein, allein er han nich Hauptursache der Forlbewegung scin. Er allein würde mur bewilken, dass die blasenartige Aushöhlung im Parenchym hinter dem Schlundende immer tiefer und tiefer wiorde und sich nach und nach in eine lianalarlige Liiclie umwandelte. Offenbar drängt auch das lunenparenchỹu von vorn her und ron den Seiten gegen den sich melı" und mehr rom Schlund abgrinzenden Tropfen, und wenn der Schlund nicht ganz velhornt ist. so nehmen dessen Contraclionen gewiss einen sehr wesentlichen Intheil an der Abstossung des Nahrungshallens. Bei Climacostomum virens heobachtete ich schr kiaflige peristaltische Bewegungen des Schlundes. und auch an dem Schlunde der Vorlicellinen sind diese leicht und sicher zu constatiren.

Bei den Vorticellinen und Ophrydiuen wird von dem Nahrungsstrom lieine blasenartige Aushöhlung des Parenchyms an der hinteru Schlumbundung gebildel, sondem hier häulen sich die zu verschluchenden hörperchen in dem Enduheile des schlundes an, wie man am besten chennt, wenn man den Thieren Karmin als Fulter rlarreich. Bei Vorlicella, Carchesium und Epistylis wirl der von den Wimpern des Wirbelorgans cregte Karminstrom ron rechts her zwischen dem Peristomrand und dem Wirbelorgan zum Vorhof getrieben: am Eingange zu demselhen werten die meisten Kamintheilchen wieder üher den Prristomrand nach anssen geschleudert, die eintringenden Theitchen durchaufen den horizontalen Vorhof und den horizontalen Anfangsheil des Schlundes und hiufen sich in dem verticalen, vorn etwas erweiterten, nach hinten zugespitzten, fast spindelförmigen Endheil an. Dies isl der Phargnx von Lachmam. Wenn sich hicr eine grösscre oder geringere Menge ron Karmintheilchen angesammelt hat, zieht sich der Schlund zusammen und das in ihm enthaltene Wasser mit den Karmintheilchen dringt nun turch die sich öfnende hintere Schlundmumlung in tas Parenchyom ein, welches kanalartig aus cinander weich. Bisweilen fullt sich erst der gamze verticale Theil des Schlundes dicht mit Karmin und es vergcht dariber eine geranme Zeil (bis zu $\frac{1}{4}$ Slunde), bevor der Inhalı ausgestossen wirl; gewöhnlich aber erfolgen die Verschluchungsacte iu küzen Zwischentaumen auf einander, nachdem sich mm im hutem Ende des Schlundes eine mässige Anzahl Karmintheilchen angesammelt hat. Im erstem Fall wirl nicht immer die ganze Karminmasse in das Parenchym getriehen, sondern hiufig bleibt die vordere Portion zmrick und sie frill in dem Nomente in den horizontalen Theil des Schlumdes. ja selbst in den Vorhof zurijck, in welchem die hutcre Portion in das Parenchym iibergeht. Diese Thatsache lehu, dass die Austreibung der Nahrungsstofte aus dem Sehlunde durch Contraclionen der Sehlundwandungen bewirlit werlen moss und nicht etwa durch nene Kalıungsufuhr.

Der aus dem Schlund in das Parenchym iberdrende Bissen beschreibt in der hintern Korperhalfte einen längern oder kijrzern Bogen, iudem er sich zuerst von dem Schlundende aus nach abwärts bewegt und dann in der Nihe des hintern Körperendes mach der tem Schlumb gegenuberliegenden Körperscite umbiest und hier gewöhnlich noch eine streche weit in die Höhe steigh. Whirend dieses Verlaules bildet er einen langern oder kiuzem, vorn abgerundelen. hinten zugespizten strang, der bisweilen noch mil dem Schlundende zusammenhängl. wahrend sein vorderes Ende bereits auf der entgegengeschten Seite angelangt ist. In diesen Falle macht der einen contimulichen. hogenförmigen Strang darstellende Bissen ganz den Eiudruck eincs sich an den Schlund anschliessenden Darmkanales. Es währ jedoch aur wenige Momente, so schliesst sich das Parenchym, dessen Continuitat durch den Bissen unterbrochen wurde, von dem Schlundende ans wieder zusanmen, und dadurch werden die himlern Bestandtheile des Bissens an die vorderen herangeschoben. und es bildel sich nun an der Stelle, die das vorder Ende des sich nicht melnr weiter bewegenden Bissens cimnahm, cin runder Ballen, Ehronberg's Magenblase. Dio später machfolgenden Bissen drängen die bereits rorhandenen rumden Nahrungshallen weiter nach der Jlite des Kürpers und nach voru; hierbei sind jeloch auch die Contractionen des Innenparenchyms sehr wesentich thälig.

Bei den Vorticellinen mit horizontalem Vorhofe setzt sich der hintere Theil des Schlundes nur deshalb als

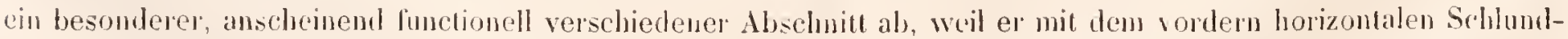

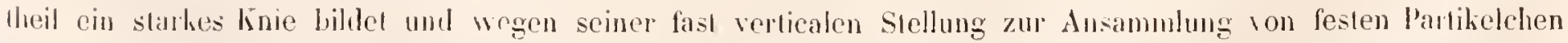

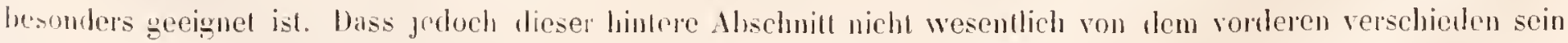
kann, scheinen mir die remandten Gathugen Opercularia und Lagenophrys zu beweisen, bei denen der von der 
einen Seite des weiten rerticalen Vorhofes ahgehende Schlund eine cinfache, abwairts steigende Röhre bildet. Fijltert man Paranaecium aurelia oder bursaria mit Karmin, so werden die in den Sehlund cindringenden Karmintheilchen von den Sehlundwimpern zu cinem kleinen Ballen zusammengewirbelt, der danu in das l'arenchym ansgestossen wird. Ein solcher Ballen im Schlunde hindert nicht, dass fortgesetzt Wasser durch den Schlund, dessen hintere Jibnlung immer offen steht, in das Parenchym getrieben wird und hier das Rohationsphänomen verursacht, welches bereits S. 57 in Betracht gezogen wurde. - Verschluchen die Infusionsthicre grössere Körper, z. 13. ganze Räderthiere, grössere Infusorien, Arcellinen, Naviculaceen, Closterinen, Oscillarien, Confervensticke u. s. w., so ist das mit diesen Körpern eindringente Wasserquantum meist zu unbedeutend, als dass as un diesclben einen basenartigen Ilof bilden könnte, die verschluckten Körper liegen dann fiei im Parenchym, und es sind nielıt einmal scheinbare Magenblasen vorhanden. Die Bildung von runden mit Wasser und Nahrmugsparikeln erfullten Blasenräumen in Parenchym wird natïrlich rorzugsweıse bei den mil emem Schlund rerschenen Infusorien vorkommen, während bei den schlundlosen die Nahrungsstoffe grewöhnlicher frei im Parenchym liegen, namentlich bei soldhen die eine enge, spaltfömige Mundöllumgg besitzen. Die verschluchten Nihrungsstolle werden dureh den unmitel baren Contact mit dem Parenchym verdaut; sie veriudern nach und nach ihre larise und Consistenz und zerfallen in eine grumöse Masse. Waren sie von einer slarren Ilüle begranzl, so werden ihnen nur die leichut böslichen innern Weichtheile entzogen. Die in der Verdaung begriffenen Substimzen werden nach und nach durch das Parenchym fortgeschohen; sie beschreiben meist regellose Bahnen, erhaiten jedoch im Alfgemeinen eine solehe Direction, dass sie der Stelle immer näher rïchen, wo die Ausscheidung der unverdaulichen Massen erfolgn.

Ein After kommt waluschemlich allen mit einem llund verschenen bewimperten Infusionsthicen zu, er hat sich jedoch bei vielen Formen noch nicht direct ermitteln lassen. Die Bestimmung des Ifter's ist deshalh schwierig, weil er in den meisten Fallen keine wirkliche Oetlinug, somderu nur eine beslimmle, sonst durch nichts ansgezeichnete Stelle ist, an der die unverdaulichen Stofle nach aussen hervortreten. Diese Stelle lisst sich nur durch lang anhaltende Beobachtung von solehen Thieren ermilteln, die reichliche Nalurung zu sich genommen haben. Aber anch dann kann man noch leichı getauscht werden; denn zu einer genauen Bestimmung der Auswurfsstelle ist erforderlich, dass das Thier still steht. Viele Infusorien sind jedoch dazu nicht zu bewegren, zwingt man sie aber durch Auflegen eines Deckglaschens oder durch flache Aushreitung des Wassertropfens, in dem sic schwimmen, zum Stilliegen, so durchbrechen die versehlucliten Nahrungsstolle hald an diescr, bahl an jener Stelle das Parenchym, welches sich alsbald wieder schliesst (vergl. z. B. Taf. Vll. Fig. 10). Der Eindruck, den man lierdurch erhält, ist ganz derselbe, wie bei der Ausscheidung vou Excrementen durch die wahtre Afterstelle; das Thier wird dadurch auch nicht in seinem Lebensprozess gestört, sondern es bleibt ganz munter, sobaht man es nur wieder rechtzeitig durclı Zusatz von Wasser aus seiner bedringten Lage bringt. Dergleichen Beobachtungen haben früher zu der irrigen Ansicht gefülıt, dass die Infusorien an jeder bodiehigen Stelle ihrer Körperoberflache die unverdaulichen Stoffe nach anssen betördern könnten. Unter normalen Verhaltuissen geschicht dies immer nur an einer ganz constantun Stelle, diese ist jedoch mit Ausnahme einiger falle lieineswegs scharf unschrieben, sondern das lanenelygm bildet anch hier cin Contiumun unl zeichnet sich nur bis zu einer gewissen Granze durch grössere Nachgiebigkeit und Permeabilitit aus. Sowie die Auswurfsstolle dueh dic Afterstelle hiudurchgegangen smo, schliesst sich das aus einander gedrängle Parenchym sofort wieder innig zusammen. Eine ivirliche, zu jeder Zeit wahrnelumbare Afterötlnung beobachlete jch nur bei Plagiotoma blatlarum und cordiformis und bei den Gattungen Ophyoscolex und Entodinium. Bei den heiden erstern Infusorien liegl sie in einer Ausrandung an hiuleru hörperende und fulurt durch eine kurze schräge kanalartige Lnelie in das Innenparenchyn. Dic ebenfalls am hintern liörperende gelegene, ansehnliche. sumble Afrerölfnung ron Ophryoscolex und Entodinium füht in einen kuzen, längsfaltigen, nchu erweiterungsfaligen, gegen das lmenparenchym scharf begränzten und geral abgestutzten Schlauch, der von eigenen häutigen Wandungen begranzt ist. Dieser Schlauch muss geradezu als ein Afterdarm bezeichnet werden.

Die Afterstelle findel sich in der Regel an hintern Körperende oder toch in geringer Entfemung von demselhen und dam fast immer auf der Bauchseite. Vor dem hintern Körperende lieğ der After mamentlich lann wenu dasselbe zugespitzt oder stark platgedricht ist. Dieser Untersebied hat jedoch keinen selı bedeutenden systematischen Werh, wie rech schlagend die Gattung Paramaecium lehrt; denn bei P. hursaria findet sich die Afterstelle am hintern Körperende, hei P. atuelia in der Batlehkante fist genau in der Mlite zwischen dem Mlunı und der hinterı Körperspitze. Genau am hintern Körperpol liegt die Afterstelle z. B. bei Lnchelys, Holophrya, Coleps. Colpoda, Cyclidium, Glancoma, Loxodes, Trachelius, Nissula, Pleuronema, Blepharisma. Plagiotoma, stean, Orratusinus der hufusimsthiere. 
Bursaria, Climacostomum, Spirostomum, Ialteria. Didinium; nahe vor dem hintern körperende bei Chilodon (Taf. I. Fig. 6. z.), Dileptus, Amphileptus, Loxophyllum, Uroleptus, Lacrymaria. Bei den Oxytrichinen finclet sich die Afterstelle links neben Jer Insertion der Afterwimpern (Taf. VI. Fig. I. z.), bei den Euplotinen und Aspidiscinen dicht hinter den mittlern Afterwimperts.

Bei den Stentoren, Vorticellinen und Ophrydinen ist der After im vordern Körperende angebracht. Bei Stentor beobachtete ich den Austritt von Excrementen immer nur auf der linken Körperseite, licht unter der adoralen Wimperspirale und unnittellar neben dem contractilen Behälter ${ }^{1}$ ). Bei den Vorticellinen und Ophrydinen mindet der After in den Vorlıof ans. Die Gattungen mit horizontalem Vorhof, z. B. Vorticella, Carchesium, Epistylis, Laben den After ganz im Ilintergrunde desselben an seiner obern Wand, dicht iiber der eigentlichen Mundöfnung. Neben den Lfter ist die bereits erwilmte, bis über den Peristomrand hinausragende, starre, gelıogene Borste eingefigt, welche wahrscheinlich bei der Fortleitung der Excrementballen nach aussen thätig ist. Bei den Gattungen mit verticalem Vorhof, z. B. Opercularia und Lagenophys, liegt der After auf dem Boden desselben 2); Lagenophrys besitzt neluen dem After ebenfalls eine lange, starre, fast verticale Borste.

\section{Ton den contractilen Behältern und dem Wasserkanalsystem der lufusionsthiere.}

Ein für die Infusionsthiere characteristisches. wenn gleich noch nicht bei allen nacligerviesenes Organsystem bilden die meist blasenfömigen, an constanten Stellen im l'arenchyul vorkommenden, mit einer klaren wåsserigen Flüssigheit erfuiltten contractilen Behiller, die sich von Zeit zu Zejt plötzlich bis zum völligen Verschwinden zusanmenziehen und ihren Inhalt gänzlich entleeren und dam sich viel lingsamer wieder mil Flïssigkieit erfïllen und zu ihrem frïherm Volmmen zurijclikchren. Diese Behälter sind zwar sehr scharf begranzt, aher es ist bisher noch nicht gelungen, an ihnen eigene, häutige Wandungen nachzuweisen, wir missen sie taher für blosse Aushöłlungen im Parenchym anselıen. Die Flussiglieit, welehe den contractilen Bchälter bei der Diastole desselben füllt; enthält keinerlei körnige Elemente und ist anscheinend reines Wasser; dieses wird ihm aus dem umgebenten Parenchym zugeführ und zwar haufig durch gefässartige Kanảe, welche in deu contractilen Behälter ausuinden. Die während der Systole desselben entweichente Flissiglieit geht theils auf demselben Wege. auf dem sie gekommen jst, wieder in das Parenchym zuriick, theils wird sie durch bestimnt nachzuweisende Oeffungen in die Aussenwelt befördert. Wegen des letztern Unstandes kann ich in den contractilen Behiltern und den mit ihnen communicirenden Kanälen keinen Kreislaufsorganismus erkennen, wofür dieselhen von den meisten neveren Forschern, namentlich mit grosser

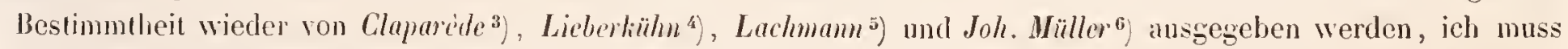
vielmehr durchaus Ehrenberg beistimmen, der von Anfang an die contractilen Behälter der lnfusorien mit den conIractilen Blasen der Ritiler(hiere verglich und wiederlolt gegen die Deutung der contractilen Behälter als herzartige Organe geltend machte, dass dje an ihnen zu beobachtenden Contractionen und Expansionen von Ilerzluewegungen ganz und gar verschieten seien. Die contractile Blase der Riderthiese und die mit ilu in Verbindung stehenden beilen Längskinile haben sich zusammen als ein Wassergefasssystem lerausgestellt, welches Wasser aus der Leibeshöhle aufinimmt und millelst der contractilen Blase nach aussen ejaculirt. Dieselbe Bedeutunğ schreibe ich auch dem contractilen Kanalsystem der Infusionsthiere zu. Diese zuerst ron 0 . Schmidt (vergl. S. 33) begrijndete

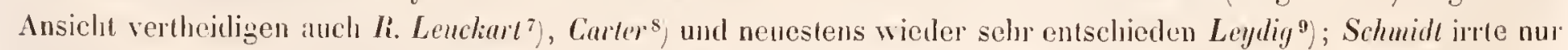
darin, dass er die contractilen Behälter nicht blos Wasser ausscheilen, sontern auch von aussen aufnehmen liess.

Eine der complicirtesten Formen des Wasserkanalsystems, welche in der Infusorienwelt auftreten, ist die sternförmige, sie wude am fruhesten beachtet (rergl. S. I 4) und seither so oft an Parmaecium aurelia studirt; sie findet sich auch nuch hei Bursaria flava und Ophryoglena llavicans und erreicht ilure höchste Entwickelung bei

1) Laehmann giebı Jen After auf der liüekseite des Thieres dicht unter der Wimperspirale an (Miiller's Archiv 1836 . S. 361 und Taf. Xlll. Fig. 8. e). - 2) Vergl. Stein Die Infusionsluiere Taf. II. Fig. X. A' i) - 3) Miller's Archiv 1854. S. 404. - 4) Ehen(aselbsi 18066. S. 26-35. - 3) Ebendaselbst S. 374-79. - 6) Monatsber. der Berliner Acad. Is36. S. 392. - 7) Bergmamn und Lenckart Anatomisch-ph!siol. Cebersicht des Thierreichs S. 184. 214 und 282. - 8) Annuls of natural tisiory 1856. Vol. 18. p. 126. j) Loydig Leluntuch der Ilistiologie 18:37. S. $39 \ddot{3}$. 
Cyrtostonum leucas. Von dieser Form hat Lieberkïhu nach Beobachtungen an den drei zuerst genannten Infusorien eine höchst sorghlallige Schilderung gegeben, die ich, soweit sie Par. aurelia und Burs. flava betrift. durchreg bestitigen muss. Das Wasserlanalsystem liegt ganz und gar im Riulenparenchym, nahe unter der iussern Oberlläche, wie man beim Wảlzen der Thiere um die Längsaxe erkennt; es hesteht entwedler nur aus einem mittlern Cyrt. leucas und öfters auch Burs. fliva) oder aus einem vor und hinter der llitte gelegenen runden, contractilen Behälter, von dessen Peripherie strahlenförmig und der Körperoberfiche parallel scharf begranzte, gefissartige Kanäle auslaufen. Par. aurelia besitzt nur eine geringe Anzahl ron Kanålen, meist 8 - 10 fast ganz gerade; hei Burs. flava finden sich gegen 30 ebenfalls gerade und sehr leine Kantile; eine noch grössere Anzahl besitzt Cyrt. leucas. Bei diesem Thiere sind die Kanaile am längsten und dentlichsten, überall gleichweit und wellenförmiğ hin und her geschlangelt; ich konnte sie bis nahe an das rordere und hintere Körperentle und nach rechts und links bis weit auf die lem contractilen Behälter gegenuberliegende Körperseite hinauf verfolgen; sie gleichen hier auf das Genaueste den Wassergefissen der Strudelwürmer, erscheinen auch bisweilen nach dem Ende zu deullich gegabelt, enthalten aber keine schwingenden Wimperlippchen.

Kehrt Cyrtost. Jencas dem Beobachter die Körperseite zu, in welcher der contractile Behälter liegt, und sieht man gerade auf denselben in dem Momente herab, wo die Wurzeln sammtlicher Kantile in der Horizontalebene liegen und vom Rande des Behälters nach allen Seiten hin ganz gleichartig ausstrahlen, so erbliclit man genan iuber der Vlitte des völlig ausgedehnten Behälters eine zwar enge, aber überaus deutliche, scharf umschriebene, runde Oeflnung in ler äussern Körperwand, welehe volliommen mit der ebenfalls sehr engen Mändung des Wassergefässsystems der Strudelwiimer, nanentlich mit der von Mesostomum übereinstimmt. Sie bleibt waihrend der Systole und Diastole des contractilen Behälters ganz unverändert, und ist auch damn noch deutlich erkennbar, wemn sich der contractile Behalter ganz entleert hat und unsichtbar geworden ist. Dreht sich das Thier so, dass der contractile Behälter am Rande des Körpers erscheint, so sieht man ganz zweifellos, dass die Oeflinung durclı einen sehı hurzen Kanal in den contractilen Behälter fiuht, und dass sich dieser bei der Systole gegen die Oeffnung hin zusammenzieht. O. Schmidl gebihrt das Verdienst, die Mindung des Wassertianalsystems bei Cyrt. leucas entdecht zu haben; ich habe friher seine Angaben selbst in Zweifel gezogen, später aber mich von ilırer Richtigheit unzihlige Nale und an sehr grossen Thieren, bei denen von irgend ciner Tauschung nicht die Rede sein kann, auf das Positirste iiberzeugt ${ }^{1}$ ).

Param. aurelia besilzt an dersellien Stelle, wie Cyrt. leucas, eine äusselst feine und schwer zu beobachtente Ausmuindung des contractilen Behäter's; bei Burs. llava dagegen sah ich statt einer centralen Miindung nur $\ddot{b-7}$ selı feine lichte Puncte über dem contractilen Behälter; es sind dies offenbar verdünnte Stellen der Körperwand, durch welche bei der Systole des behilters Wasser hindurchgepresst wird, womuf sie sich, ähnlich wie die Afterstellen der Infusorien, sofort wieder schliessen. Die Vorginge bei der Systole und Diastole des contractilen Behailters lassen sich an besten bei l'ar. aurelia erkennen, obwohl beide llomente hier schnell auf einander folgen und daher noch am meisten an Herzbewegungen erinnern. Beim Beginn der Systole schwellen die vom contractilen Behälter auslaufenden Kanäle in einiger Eutfernungr von dem Rande desselben plötzlich spindelförmig an, und in dem Maasse, als die Systole fortschreitet, ricken die sich immer mehr ausdehnenden Anschwellungen nach rijckwirts gegen die Stelle hin, die der contractile Behälter einnahu. Ist derselbe ginzlich verschwunden. so erblicht man an seiner Stelle einen Sterı von einander selır genüherten, birnföımigen Strahılen, die nach aussen zu in lange, haarfeine Enten auslaufen. Beim Beginn der Diastole verschwindet zuerst lie Flissigkeit an der Basis der birnförmigen Anschwellungen, und sowie nun der contractile Behälter wieder zu erscheinen anfänğt, ist der Rand desselben mil kegelförmigen Anschwellungen beselzt, die sich in dem Grade rerkïzen, als die Diastole vorschreitet. Hat der Behälter seine grösste Ausdehnung erreicht, so sind die Anschwellungen verschwunden und statt derselben einfache, gleich weite Kanale vorhanden.

Diese Erscheinungen khren unzweideutig. dass bei der Systole Flissiglieit aus dem contractilen Behiilter eine Strecke weit in die peripherischen Kanale hineingetrieben und dass von diesen aus der contractile Belıälter bei der Diastole mit Flussigkeit erfült wird. Wäre das ganze hanalsystem ron besondern lıăutigen Wandungen begränzt und durchaus geschlossen, so missten sich die peripherischen Kanäle während der Systole bis zu den

1) Bereits auf der Naturforscherversanmlung in Wien im Jabre 1856 bestäligte ich Schmid’s Entdeckung (Tageblail Nr. 3 . S. ä̈); ich erkläıle hier auch das system der contractilen Behïler lediglich lür ein excernirendes Wasserkanalsıstem. 
aussersten spitzen hiu erweitern, was Jurehaus nicht der Fall ist. Da der contractile Behatter anch in ofener Communication mit der Aussenwelt steht oder ron derselben doch nur durch sehr verdiinnte Stellen in der Körperwand getrent ist, so muss bei seiner stets sehr energischen und poutzlichen Contraction, die iiberdies sichtlich gegen die aussere Oberfläche gerichtet ist, nothwendigg auch ein Theil seines lnhalts nach aussen entleert werden. Man hat gesagt, lass wenn dies wirklich geschähe, so misste man in dem Momente, wo die Systole des contractilen Behälters erfolgnt, in der nächsten Ungebung desselben an der äussern Küıperoberlläche eine Strömung oder ein Abstossen feiner in Wasser schwimmender Körperchen benerken, wovon aher nichts zn beolachten sei; allein bei den grössten Rälleıtlieren, z. B. hei Hydatina senta, lässt siclı ebenfalls lieine Strömung in der Lmgebung der Kloake nachweisen, wenn sich die contractile Blase zusammenzieht, und doch zweifelt gregenwärtig wohl Niemand daran, dass sie ilren Inhalt durch die Kloake nach aussen ergiesst. Die eigentliche Bedeutung der peripherischen Kanåle wird hiernach darin bestehen, Wasser aus dem Parenchym aufzunchmen und dieses dem contractilen Behajter zuzufuhren; hat sich dieser prall mit Wasser erfillt, so erfolgt ein gewaltsames Zusammendruingen des ungebenden Parenchyms gregen den Bchälter, um das Wasser in die Aussenwelt zu treiben, da jedoch die Oeffnmg nach aussen zu eng ist. so kann nur eine geringe Menge Wasser nach aussen entweichen. das iibrige wird wieder eine Strecke weit in die Kanile zuruickgetricben.

Ein sternförniges, jedoch weniger entwickeltes oder der Beobachtung minder zugängliches Wasserkanalsystem findel sich noch bei einigen audern Infusorien, z. B. bei Ophryoglena atra und acuminala, Glaucoma scintillans, Lembadion hullinum und Paramaccium bursaria. Bei Glaucoma scintillans glaube ich iiber dem contractilen Behälter eine feine Oeffnung erkannt zu haben, bei Ophryogl. acuninata unterschied ich nur mehrere rerdünnte punctförmige Stellen. - Sehr nahe verwand ist das roseltenförmige Wasserkanalsystem; es besteht aus einem runden nahe unter der Oberlläche gelegenen contractilen Behälter, ron dem in Zustande seincr grössten Ausdehnung keinerlei Kanåle abgehen; beim Beginn der Systole erscheinen aber rings um den Rand des Bebälters blasenoder perlartige Vorspringre, die sich gegren das Ende der Systole in eine mehr oder weniger regelmassige Roselte von abgeschlossenen, Iundlichen orler länglichen, ungleich grossen Blasen umwandelu. Diese Form kommt in einfacher Anzahl und ziemlich in der Milte tes kópers gelegen bei Nassula aurea, Acidophorus ornatus. Liosiphon ambiguus, Paramaecium colpoda unt Plagiotoma concharum, in doppelter Anzahl bei Leucophrys entozoon ror. Ueber der vlitte des contractilen Behäliers entdechte ich bei Acid. ornatus und Nass. aurea eine selur deutliche, scharf unschriebene, enge, rumde Oeflunng; auch bei laram. colpoda und Liosiphon unterschied ich mit Bostinmmlieit eine sehr feine centrale Mindung.

Verschielene Infusorien hesitzen ein longgitudinales Wasserkanalsystem; es besteht aus einem gewöhılich nur nach und nacl, zur Erscheinung kommenden Längskanal, der sich entweder an dem einen Ende, oder in der Mitte zu einem contractilen Behaltel erweitert. An leichtesten ist diese Form an Spirostomum ambigumu zu beobachten, da hier der im vordern Köprerende beginnende und bis weit nach rückwärts verlaulende Lảngskanal oft seiner ganzen Ausdehnung nach sichtbar ist: er erweitert sich allmahlig nach rickwarts und geht in einen wciten sackförmigen contractilen Behähter ijher. der einen grossen Theil des hintern Körperraumes ausfijlit ${ }^{1}$ ). Durch cine seichte Ausrantung am gread abgestutzten Hinterende ergiesst derselbe ohne Zweifel seinen luhalt nach aussen; denn es wäre sonst ganz unbegreiflich, wo die grosse Menge Fliissigheit. die wihluend der sehr plötzlichen Systole ans ihm entweicht, bleiben sollte, da sich der Limgskanal bei der Systole nicht merkilich erweitert und sonst keine andern Kanaile erscheinen. Es vergeht anch immer eine sehr gerame Zeit, beror der Behälter sich nur annäherungsweise bis zu seinem fruheren Tolumen wieder fült. Bei Clmacostomum virens liegt der unregelmässig blasenförmiğe contractile Behälter ebenfalls an hinterı Körperende und in denselben mündet entweder nur auf deı linken, oder aul der techten und Jinken Seite cin Lingshanal aus, der aus den vordern Körperende herabsteigt, sich nach hinten zu mehr und mehr erweitert und hie und da schnurförmige Anschwellungen zeigt. Diese Liangshanäle sind nur zeitweise sichtbar, sie zichen sich stets ron der Spitze nach der Basis hin zusammen und ergiessen ihren Inhalı in den contractilen Behălter; die Ausmindung des letztern scheint ganz mit dem seicht ansgerandeten After

1) Lhenberg hat nur den contractilen Behäher und das hintere Ende des Längshanals gesehen Die Infusionshlierchen S. 333 und

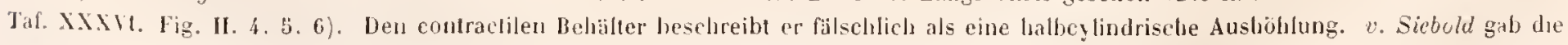
erste richligere Darstellung des Wasserhanalsystems von Spirostommo (Lehrbuch der vergl. Anatomie S. 21 ). 
zusammen zu fallen '). Bei Stentor. wo der After in rordern Kiöperende liegt, findel sich auch der contractile Behălter unmittelbar nebes demselben und der ihm Wasser zuführende Langskanal erstreckt sich von hier aus his in das hintere körperende, das ganze Syslem hat also die ungekehrle Lage im Vergleich zu Spirosinmun ²). Bei Loxophylum meleagris sieht man dichı unter den zahnförmigen Vorspringen der Riickenkante eine Reilıe rundlicher Blaschen, die ron Zeit zu Zeit in einen Langskanal zusammenfliessen, weleher in einiger Entfernung rom luntern Ende liurz ror dem After in einem contraclilen Behaller endigl. Opalina planariarum und uncinata besitzen nur cinen contractilen Lảngskanal ohne abgesonderten Behälter ${ }^{3}$.

Besonders lehreich ist das longitudinale Wasserkanalsystem von Styvlonychia mylilus. Van kann hier leicht verfolgen, wie im rordern körperende znerst in der Gegend der vordersten stirnwimpern und daun auels im Peristomfelde Wassertröpfchen anftreten (Taf. VIII. Fig. I. und 5.g. Taf. Yll. Fig. 4. g.), von denen allubihlig mehrere zu bisquit- und knollenförmiggen Tropfen zusammenlliessen. Nach und nach entsteht ein kurzer, schnurlürmiger Querstrang, der, indem er vou vorn her immer nene Tröpfehen aufnimmi, sich mehr und mehr nach links verlingert und gleichmassig crweitert. Plötzlich fliesst die strangförmige Wassermasse in einem längem orler kürzesn Bogen längs des linken Köpperrandrs ganz langsam nach abwïrts, inden sie mil ihren rorangehenden angeschwollenen Ende sichılich das Parenchỵm aus einander drängt ('laf. VI. Fig. I. 2. 5. g. g. Tal. Vil. Fig. 1. g.); ihr folgen oft schnell nach einander, bald in dejselben Bahn, bald in einer sehr genaberten parallelun lingere oder liurzere Wasserstrảnge, deren im rordern Körperende gewöhnlich mehrere list gleichzeitig iluren Ursprung nehmen (Taf. VI. Fig. 3. g. Taf. VII. Fig. 4. g). Der absteigende Flüssigkeitsstrom mündet stels in den Vorderrand des hinter dem Peristom gelegenen runden, contractilen Behälters (Taf. W. Fig. I. 2. c.) ein, der dadurch so ausgedehnt wird, dass er auf der Riickseite les Thicres meist stark blasenförmig nach anssen vorspringt (Taf. VIl. Fig. 1. c). Bei (ler systole zieht sich der contractile Behälter, der keinerlei Mündung nach aussen besilzt, nach innen zusammen. und es erscheint nun hinter demselben ein Flissigkeitsstrang (Taf. VI. Fig. 2. g' unt Taf. VII. Fig. I. g' ), der bis zul Afterstelle verlänft und dann plötzlich verschwindet. Bisweilen findet die Systole sehon slatt, wenn der von vorn. kommente Flissigkeilsstrom noch nieht vollständıg in den contractilen Behälter aufgenommen ist, damn wird dej erstere wieder eine Streche weit nach rom zuriockgeshat. In der rechten Kïrperbalfte sucht man rewgebens nach einem eiwa ron hinten nach vorn aufsteigenden Flïssigkeilsstrom. Der contractile Behälter wird also fort mnd fort. in Alstitzen von vorn her mit Wasser gefült und treibt dieses bestandig nach hinten bis zum After, durch den 's ohne Zweifel nach aussen entleert wird, da sich eine weitere Verbeitung im Körper absolnt nicht nachweisen hasst. Wir können uns das ganze Sisten auch als eine Längslacune vorstellen, in deren Ilitte der contractile Behailtur liegt. - Achnlich reshält sich wahıscheinlich das Wasserkanalsystem aller anderen Oxytrichinen, da sie den contractilen Behălter an dersellıen Stelle besizen, wie Sty̧onychia my tilus.

Wer die eben geschulderten Verhälunisse selbst beolachtet hat, der wird unmöslich noch dem Geılanhen Raum geben können, dass das Kanalsystem, mil den wir es lier zu thun haben, cin in sich abgeschlossener hreislaulsorganismus sein liönne. Welcher selbstsländige häutige Wandungen besitzt, obghleich selbst J. Mäller, ledıglich auf die Lntersuchung von Paranaecium aurelia gestiizt, dieser Ansicht das Wort redete. Wäre der contractile Behálter die herzarlig emeiterte Stelle eines geschlossenen Gelisssystemes, so misste ep unter allen Verhailunissen rin und denselben Ort einnehmen, ih sah ihn jedoch bei Stylonychia mytihs uicht selten innerhalf der zufuhrenden Wasserbahn mehr oder weniger weit nach rorn geruick (Taf. VIl. Fig. 11. c. Taf. VIII. Fign. 4. c.), wenn in Folge der Entwickelung von Embryonalhugeln an seinem gewöhnlichen Platze liein hinlanglicher Spichanm fiur seine Buwegnugen vorhanden war; ja bei Urostyla grandis sah ich den contractilen Behäter von seiner normalen Stalle linter

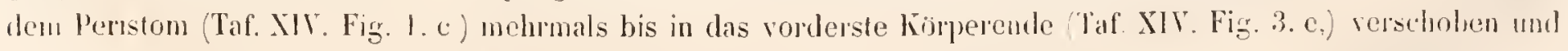
hier zoigte er nun anch bei der Systole ein anderes Yerhalten, indem sich um ihu ein Stern von blasenlömmigen Ausläulern bildele.

1) Ganz ebenso wärde sich nach Lieberkïhn (Mïller's Archiv 1856. S. 33-34, das Wisserhinalsjstem ron Bursaria rorlicellı rerltalten. Solle nicht das von diesem liorscher als Burs. vorticella Ehbg. bestimnte Thier Sjuiroslomum rirens Ehbg. gewesen sein? Licberkïhn erklärt auch S. 33 - 36, dass ihm bei beinem Jufusorium besondere Kanijle bekann gew orlen seien, in denen die Flüssigheil währent der Systole in den Körper zurückströne. - 2) Mit dem contractilen Beluäler von Stentor soll nach Lachmann (Mïller's Arcluiv 1856. S. 376 ) auch noch ein dicht unter der adoralen Wimperspirale vertaufender Ringkanal in Verbindung stelsen. - 3) Vergl. M. Schullze Beitr. zur Naturg. der Turbellarien S. 68-69 und Taf. YH. Fig. 1-5. und 8-9. Schultze vermuthet, dass der Kanal an beiden Enden eine feine Oeffnung nach aussen habe: wihrscheinlich ist jedoch eine solche nur hinten vorhanden. Eine Begrüuzung des Kanals vou eigenen lWindungen, wie ich sie früher anualın, kam ich nicht melar gelten lassen (Vergl. Stein [rie Infusionsthiere S. 178 - 79). 
Auch Licherliühn muss gestehen ${ }^{1}$ ), dass es ihm nichl gelungen sei, nin irgend einem Falle eine llembran der comtractilen Behälter oder der Gefasse zu isoliren." Lachmamn dageggen will aus dem Umslande, dass bei spjrostomum ambigum Kohbhallen den engen Raum zwischen der äussem Körpcrhaut und dem contractilen Behälter passiren, olune in den letzern durchzubrechen, auf eine habugge Begräuzung des contractilen Behälıers und seiner hanalartigen Fortsetzung schliessen ${ }^{2}$ ). Hiergegen muss ich benerken, dass ich melıfach liemde körper innerhalb des Wasserkanalsystemes beobachtet habe. So haf ich einmal in dem Lingskanal von Stentor polymorplums zwei fadenfömige, fulblose Astasiaen, die sich in der Flissigkeil sehr munter auf und nieder beweglen. Bei Siylonychia pustulala sah ich an vielen Exemplaren ejner Localiat ein dichtes Gewimmel von vibrionidenarligen Fiaden im contractilen Behälter (Taf. IX. Fig. ̈. c.), welche bei der Systole desselben mil dem Wasser durch eine kinalarlige Liicke gegen den After lin getrieben wurden, in dessen Nähe sich gewöhnlich ein weiter Blasenraum (v.) mit dicht zusammeugehäuften Fäleu billke.

Bei einer grossen llenge von Infusorien erkennt man nur contractile Behälter in einfacher oder mehrfacher Anzahl, aber durchaus heine zufihrenden Kanale; bei vielen derselben fillt sich der conlactile Behabler walurscheinlich dadurch, dass aus dem umgebenden Parenchym ganz alhühlig Wasser in den Bchäller, der gleichsam eine Cisterne vorstell, hineinsickert. Es vergeht daher auch oft eine geraume Zeit, bevor sich der Behalter zusanmenzicht; dies geschichı aher dann stels sehr plötzlich, wie mil einem einzigen Ruck. Durch einige funfzig kleine, im ganzen Rindenparenchym zersheut liegende contractile Behżler zejchnet sich Trachelius ovum aus; nach verbintenden Kanthen zwischen denselben wird man vergebens suchen. Ich begreife daher nichı, wie diese vielen Bebiller, die sich ganz regellos und unabhängig von cinander contrahiren, zusammengenommen ein Kreislaufssystem darstellen hönen; soll man einige funfzig Herzen in einem Thiere annehmen? Yiel weniger paradox ist doch wohl die Ansicht, dass jeder Behálter ein Sammelpunct von Wasser aus dem Parenchym ist, Welches durch die Ilant nach aussen gesprilzt $n$ ird. Auch bei Dileptus anser fuden sich zahlreiche, bläschenförmige contrachile Behálter, nanentlich langs der Rijckenkante, desgleichen bei Amphilejtus (Trachelius Ehbg.) meleagris und Enchelys gigas. Drei oder mehreme zerstrem liegende contractile Buhalter kommen bei Chilodon, Chlamydodon und Frvilia vor, drei oder vier in der Millellinie der Rüchseite liegende bei Nassula elegans.

lst blos ein contractiler Behälter vorhanden, so ist derselbe meist sehr gertumigr, und er liegt entweder am hintern Körperente dichı neben dem After oder weit nach vorn in der Umgebung des Mundes. Diese Stellen wairden doch schwerlich für ein lıerzarliges Organ gewählt worden sein, sie sind aher die ginsligsten für einen nach aussen Wasser absondernden Behälter. Ganz an das hintere körperende gerïckt zeiğ sich der contractile Behălter z. B. bei Colpoda, Cycliclium, Trichoda, Prorodon, Iolophrya, Enclielys pupa, Coleps, Blepharisma, Urocentrum, Didinium. Liegt der Alter etwas vor dem hintern Köperente, so ist dies auch mit dem contractilen Behthler der Fall, wie wir recht deutlich bei Euploles (Taf. IV. Fig. 12.14. c.) und Aspidisca (Taf. III. Fig. I. 4. c.) sehen hönnen. Während der Systole entleert der Behbiler den grössten Theil seines lnhalts nach aussen und zwar wahrsebeinlich dureh den unmiltelluar neben ilm galegenen After. Rech deutlich beohachtele ich dies bei Plagiotoma cordiformis und blattarum; hier lïufen sich im hintern Körperende lileine und grössere Wassertropfen an, die nach und nach in den an der Bauchliante, kuz vor der Spitze gelegenen contraclilen Behälter aufgenommen werden. Sowie sich dieser zusimmenzieht, ejweitert sich der oben beschrichene Afterkanal merlitich und man sieht durch denselben die Flüssigkeit nach aussen entweichen. Auch bei Blepharisma lateritia sammeln sich im hintern Körperende Wassertropfen an, die allmálılig mit eimander verschumetzen und so einen geriumigen Behilter bilden, der seinen lnhalt durch Höbliche Contraction sichlich durch den After entleert. Nan beobachte ferner nur einige Zeil das Spiel des contractilen Behialters ron Prorodon teres, und man muss die Ueberzeugung gewinnen, dass bej der Systole der grössle Theil seines Inhalts durch den After binausgesprizt wird; der ibrige Theil drängt an verschiedenen Puncten das ungebende innere Parenchym aus cinander und erscheint als cin umregelmissiger Haufen ron Wassertropfen, die spater wieder zusammenlliessen und das erste Material zur Diastole des Behälters liefern.

Bej den Vorlicellinen, Ophrydinen und Spirochoninen findet sich der contractile Behälter im vordem Körpercule, in der Nähe des Mundes, desgleichen auch bei den geisseltragenden lnfusorien, welche contractile Belsailter

1) A. a. O. S. 31. - 2) A. a. 0. S. 378. - 3) Ehrenberg hielt bei diesen Thieren die contractilen Beh:ilter für Organe zur Absonlerung eines Verdaungssaftes (Dje lufusionshhierchen S. 321 und 35:3 und Taf. XXXIII. Fig. 8. Taf. XXxill. Fig. 5). $v$. Siebold machte aber bereits darauf anfmertisam (Lehrb) der vergl. Analomie S. 17 Anuert. und S. 21), dass dies vermeintlichen eigenthümlielıen Organe uichls weiter, als contraclile Bebailter seien. 
besizen. Dass bei den Vorticellinen uer Behaller seinen Inhalt in den Vorlıof ergiesse, ist schon mehrfach ausgesprochen worten; ich schliesse dies daraus, dass bei stark kuglig eontrahirten Vorticellen in den Momente, wo sich der Behălter zusammenzieht, ein merkliches Anwachsen der Flissigheit im Yorhofe zu heobachten ist. Unter den geisseltragenden Infusorien treten die contractilen liehäler am schärfsten bei Polytoma urella I) und Chlamyrlomonas pulvisculus hervor; es tinden sich hier im vordern Ende nahe hinter der Insertion der beiden Geisseln zwei kleine Blischen, die abwedselnd verschwinden und wieder erscheinen. Eines derselben ist immer merklich grösser als das andere; ersteres halte ich für den eiggentliclıen Behälter, der bei der Systole einen Theil seines Inhalts durch den Mund oder die verdinnte stelle an der Basis der Geisseln nach atlssen treibt, wälrent der hest seitwarts ins Parenchym entweicht und hier als das heinere Bbischen erscheint. Achnlich verhalten sich slie contractilen Behälter bei Pandorina, Gonium und Volvox. Bei Cryptomonas ovala und Chilomonas paramaecium benbachtete ich ein einfaches contractiles Blaschen in der comvexeren Seite nahe hinter der vorderen Ausrandung; auch bei Chaetnglena volvocina und hei einer Honas erkannte ich deutlich ein coulmactiles Blischen. Bei lleteromita und Peranema liegt der sehr langsam contractile Behälter dicht neben der Mundspalte. Bei den Peridinzien halsen sich noch keine deutlichen contractilen Behäler auflinden lassen, den Astasiàen und Dinobryinen scheinen sie aher zuzukommen. Ich sah sowohl bei Euglena, als namentlich bei Amblyophis die helle Stelle unter dem rothen Augenlleck, welche Ehrenberg fur ein Ganglion hielt, ihre Contouren ganz langsam verindern; sie zeighte sich bald rundlich und scharf begränzt, bald unreggelmassigg gelappt, bald bisquitformig cingeschniurt. Jerlenfalls ist die belle stelle ein veränderlicher, mit Wasser erfullter Blasenranm $\left.{ }^{2}\right)$; auch bei Dinobryon ist ein soleher im vortern körperende vorlianden $\left.{ }^{3}\right)$.

Unter den bewimperten lnfusorien giebt es nur wenige Formen, bei denen noch keine contractilen Behälter nachzuweisen waren. Es sind dies meistens Opalinen, z. B. Opalina ranarum, lumbrici, armala, branchiarum; diese zeigen zwar gewöhnlich zahlreiche, regellos zerstreute, mit wässeriger Fhissigheit erfullte Blasenräume im Parenelym, aber eine abwechselnde Systole und Diastole ist nicht an denselhen wahrunchmen. Juch bei Loxodes rostrum suchte ich vergeblich nach einem contractilen Behalter; bei diesem Thiere sah ich jetoch zeitweis den ganzen Raum zwischen Mund und After mit grossen, dicht an einander gedrängten, lichıen Blaseuräumen erfullt, welche von sehr matten Contouren begranzt waren $\left.{ }^{4}\right)$. Sollten nicht diese blasenriume, die momentan klarer liervortreten, einem Wasserkanalsystem angehören?

Schliesslich muss ich noch hervolheben, dass bei den in Meere iehenden Infusorien die Syslole tes conIractılen Behälters auffallend langsamer und in längern Zeitintervallen erfolgl, als hei den Sissswasserbewolınern. Die Systole macht hei jenen ganz den Eindruck, als ob ein grösserer Widerstand zu überwinden ware. Ein solelıer Unterschied wurde schwerdich zu heobachten sein. wenn der lnhalt des contractilen Behälters Blut wäre; ist er dagegen Wasser, so begreıft man. dass sich das Salzwasser im Parenchỵm anders verhälı als das süsse Wasser.

\section{i. Von der Fortpflanzung und Entwickelung der Infusionsthiere.}

Die Infusionsthere pflanzen sich auf drejerlei Weise fort, nämlich durch Theilung, durch Knospenbildung und durch innere. dem Mutterhiere mnihnliche sprösslinge. Letzlere gehen stets aus dem Nucleus hervor, dieser muss daher als das eigentliche Fortphanzungsorgan der lnfusionsthiere angesehen werden. Wenn sich die innern sprosslinge in Folge eines vorausgegangenen Befruchtungsidetes entwickeln, so nemen wir sie Embryonen. Die Befruchtung wird durch geschlangelte, fatenfömige Spermatozven rermiltelt. welche ebenfalls aus dem Nucleus ihren Lrsprung nehmen. Ob in allen Fällen zur Erzeugung neuer Individuen aus dem Nucleus eine Befruchtung

1) Hier wurden sie zuerst ron S:2meider (Mieller's Archiv 1854. S. 192 un I Taf. IX. Fig. 1. e.) beschrieben. - 2) Nach Lachmam (Müller's Archiv 1 856 . S. 369) soll die lielte Stelle nicht selbst contractil sein, sondern es würde gerade über oder dicht neben derselten ejn besonderer contractiler Behäller liegen, wovon ich mich jedoch nicht üherzègen honnte. Lachmann beobachtele mil Claparéde auch bei Syncrypta volvox einen confractilen Behalter. - 3) Focke (Physiologische Stullen lleft II. S. 15) erwitunt zuerst einen contractilen Behiblter bei Dinobryon sertularia. - 4) Joh. Mialler meinte othenbar diese Blasenrimue, wenn er in der Beschreibung des Loxodes rostrun anführt, dass dieses Thier auch durch ein netzartiges Ausseben der innern Körperwände kennllich sei, welehes entfernter Weise an die Zeichnung des Vesdaungsorganes in Ehrenberg's Abbildung von Trachelius ovum erinuere. (Monatsber. der Berliner Acnu. 1856. S. 390). 
nothwendig ish. dis lass sich zur Zeit noch nicht iahersehen; Wahrscheinlich liann der Nucleus auch als blosser Kemstock fungricn. Fur die ohne Befruchunner aus dem Nucleus hervorgehenden Sprösslinge behalte ich den von mir frilıer in einem weitern Sinn gebauchten Namen Schwirmsprössling bei.

Die Fortpllanzung durch Theilung ist die häufigste und verbreitetste Vemehrungsweise der Infusorien; sie besteht darin. diss ans einem Thiere duch cine allmälig fortschreitende und immer tiefer cingreifende Einschnujrung des Körpers zwei gleich grosse uder doch nur wenig in der Grösse dillerirende Individuen. die Theilungssprösslinge, gebildet worden, welche genan dieselhe Organisation besitzen, wie das Mutlerlhier. Die Einschmmung des Körpets erfolgt entweler in der Richtung der limgsaxe, odler senkrecht anf dieselbe, oder unter einem spitzen Winliel gegen die Langsaxe: hiernach unterscheilen wir die Längstheilung, die Quertheilung und die diagonale Theilung. Jeder Theilung geht eine Vergrösserung des Körpers in einer auf der Theilungsebene senkrechten Rich-

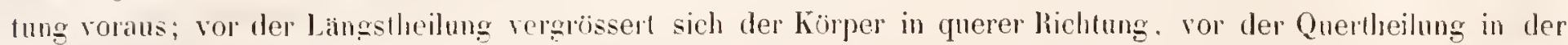
Lingsdimension. Dasselhe gilt auch von dem Nucleus, der stets eine solche Lage annimmt, dass jede der beilen Körperhälften eine nahebei gleiche Portion desselben endi]t. Ist ein doppelter Nucleus vorhanden, wie z. B. bei den meisten Oxyltichinen Taf. II. Fig. I. n. n. so lsekommt die eine Körperbatfte den einen, die andere den zweiten Nucleus; jeder Nucleus zerfält damn bei fortschreitender Theilung in zwei Kerne (vergl. Taf. V]. Fig. 6. In gewissen Fillen verhalt sich jedoch der Nucleus hei der Theilung wesentlich anders; so verschmelzen z. B. bei den Oxytrichinen nicht setten wahrend der Theilung heide Kerne mit einander. Die Theilung scheint dann noch eine andere Bedeulung zu baben, als blos zwei nene, dem Mutterthier gleiche Individuen zu liefern. Hierïler möge man die specielle Darstellung der Theilungsvorgange in der Beschreibung der einzelnen Arten, namentlich bei Stylonychia mytilus vergleichen. Die Theilungrgeht nicht von dem Nucleus aus, wie man häulig angenommen hat; denu sehı oft zeigrt derselhe noch heine Spur ron Veranderung, wibluend an der äussern Oberflache bereits melır oder weniger tief eingreifende Metamorjhosen stallgefunden haben.

Ueber die Theilung lisst sich sonst im Allgemeinen nicht viel sagen, da sje sich ganz und gar nach der specifischen Organisation des sich theilenden Thieres richtet, also fast fü jede Art anf eigenthumbliche Weise erfolgren muss. Nur bei den einfachsten Infusorienformen ist die Theilung haum mehr. als blosse Habbirung des Körpers und des Nocleus. so uamentlich bei viclen Opalinen un demuabhst bei den geisseluagenden Infusorien. Jo complicirter dagegen die Organisation eimes Infusionsthieres ist, un so remiclielter sind aucls die Vorgtinge, welche ber der Theilung stattfinden; denn jede Körperhılfte. welche zu cinen neuen Individuum werten soll. muss so lange umgestaltet werden, bis sie wenigstens in allen wesentlichen Puncten wierler die Organisation des Mutterthieres zeigl; alsdann erfolgt erst die vollständige Abschnirung. In der einen Halfte kann meist ein grosser Theil der vorlandenen Organisation. z. B. das Peristom, Mund und Schlmol, bejbehalten werden. in der andern missen dagegen grade diese Theile neugebildet und die hier hinderliche urspungliche Organisation remichtet werden. Am rerwicheltsten sind die Theilungsvorgäge bei den Oxytrichinen, Euplotinen und Aspidiscinen. Hier wird nicht blos in der einen Körperhalfte der Jund mit seinen complicirten Peristom neu gebildet, Was auch bei den heterotrichen hntusurien geschieht, sondern es wird auch in jeder Köperhälfte ein ganz nenes loconotives Wimpersystem angelugh und atas vorhandene unterdrickt.

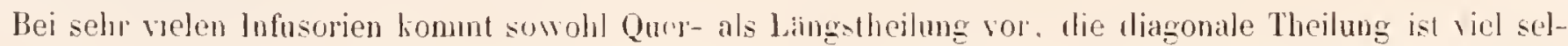
tener; an reinsten tritt diese bei der Gattung hagenophrỵs auf ${ }^{1}$, Die Vorticellinen unt die Ophrgdinen, mit Ausnalume ron Lagenophurs, vermehren sich nur durch Längstheihung, die Ophryoscolecinen und Halteria nur durch QucrWeihug. Durch eine gleichzeitige mehrfache diagonale Theilung zeichnel sich Chorogonim aus. Manche lufusorien remeluren sich in ihrem freien Lehensstadium gar nicht oder doch nur selten durch Theilung. sie thum dies aher, nachdem sie sich kuglig contrahirt orler wenn sie sich mit einer Cỵste umgeben haben. Dies gilt namentlich ron der Gattunz Euglena mul ron Colpoda eucullus. auch von der Gattung Lacrymaria, die ich hiulig im ençstirlen Zustande sich theilen sah. Die Theilungsspröslinge sondern sich nicht immer son einanter, sondern sie hleiben bei manchen fomen an einer Stelle danemd mil einander verbunden; durch fortgresetzle umvollstandige Theilung entstehen alstamn heinere oder grössere beerenformige Familienstöche. Behamnte Beispiele sind die Gattungen Lvella, Polỵloma und Spondỵlomorum. Bei lofusorien. welche eine lliilse bewohnen. Wie Vaginicola. Cothurnia,

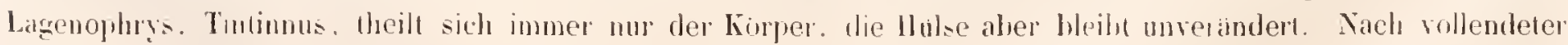


Theilung verlasst der eine Theilungssprössling die IIilse, schweift eine Zeit lang frei unher, setzt sich dann irgendwo wieler fest und scheidel um sich eine neue Hiilse ab. Ist die Miindung einer Hülse für den Austrill eines Theilungssprösslings zu eng, wie z. B. bei Trachelomonas, Lagenella und Cryptomonas lenticularis, so wird sie zuletzt vou den Theilungssprösslingen gesprengt.

Bei den Volvocinen dehnt sich, wie am leichtesten bei Pandorina zn rerfolgen ist, die dem Körper inuig anliegende Gallerthäle mit dem Wachsthum des Korpers und der aus ihm hervorgehenden Theilungsgenerationen aus und so entsteht ein oft sehr umfangreicher, aus vielen Individuen zusammengesetzter Familienstock. Ophrydium versatile hildet dadurch kugel-oder linollenförmige Familienstöcke, dass die durch Längstheilung enıstehenden Theilungssprösslinge an ihrer Basis eine compacte Gallertmasse aussomdern, die in demselluen Harase an Unfang wachst, als die Zahl der sieh üher den ganzen Úmfang der Gallertmasse aushreitenden Individuen zumimmt. Unter den Vorticellinen bilden die Galtungen Carchesium, Zoohamnium, Epristylis und Opercularia baum- oder strauchartige, dichotomisch veristelte Fantienstöcke, die an ten Enden der Zweige die einzelnen Individuen lragren Ein solcher Familienstock geht durch wiederholte Lingstheihng aus cinen einzigen Thier hervor, welches auf einem einfachen, rom hintern Körperende ausgeschiedenen Sticl sitz. Bei der Theilung, die sich nienals auf den Slick urstreckl, zerfält der Körper in zwei voltstindig von einander z̧esmuleıle, nach vorn divergirende Theilungssurösslinge, deren hintere Enden mit der Spize des Slicls in innigem Zusammenhange bleihen. Jeder Theilungssprössling sondert nun aus seiner Basis emen nenen stiel aus, der mit lem ursprunglichen vollig gleichartig ist und ohne Unterbrechung in denselben ubergeht; dadureh verwandelt sich der einfache stiel mit cinem Thierkörper in einen gegabelten Stiel mit zwei Individuen. Frïher oder später wiederholt sich an jedem Individuum derselbe Vorgang, und wir erbalten nun einen doppelt gegabelten Stock, der vier Individuen trägt. Der nichstfolgende Theilungsact liefert einen dreifach gegabelten Stock mit acht Individuen u. s. W. Wachsen die einzehen Theilungsgenerationen ganz gleichmissig fort und wiederholı sich an den zu derseben Ordnung gehorigen lndividuen die Theilung fast gleichzeitig, so entsteht cin doldentraubiger Stock, der die cinzelnen Individuen in nahehei gleicher llöhe trägt; trilt dagegen bei den einen Individuen derselhen Generation die Theilung viel früher ein, als bei den andern, so entsteht ein rispenartig verästelter Stock, an dem die Individuen in selı verschiedenen Höhen silzen. Ersteres ist

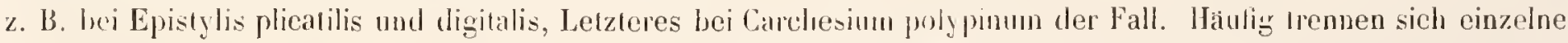
Individuen von ihrem Stocke, nachdem sie vor ihrem hintern Ende einen Wimperkranz entwickelt haben; sie setzen sich dann spiter irgendwo wieder fest, scheiden, wihrend der hintere Wimperkranz eingeht, einen neuen Sticl aus und werden so zum Stammater eines neuen Familienstoclies. Bei der Gattung Vorticella bleibt der Stiel, welehen das Thier ausscheider, hestandig eiufach, da nach erfolgher Liingstheilung der cine Theilungssprössling sofort einen hintem Wimperkanz entwickelt und sich tann vou seinem Gefahrten trennt, der nun die Spitze des Stieles einninmt und diesen nur in der Lingsrichtung weiter entwickelt.

Der Theilung nahe remandt ist die Knospenhildung. Bei dieser Fortpflanzungsweise entwickelt sich

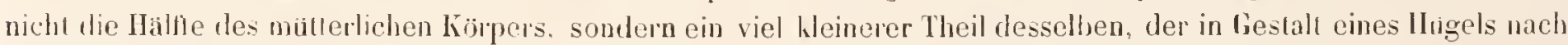
aussen hervorwächst und sich mehr und mehr von dem wïterlichen Körper abschnirt, zu einem neuenlndividuum, dem linospensprösslinğ, dessen Oroanisation ganz und gar durch Neubildung entsteht. Der vollständig entwichelte hospensprössling bleibè bei den Infusorien stets viel kleiner als das Mutterthier, und er löst sich zuletzt immer von demselben ab; daher durch Knospung bei den Infusorieu niemals Fanilienslöcke gebildet werden. Die Knospenbildung ist nur auf wenigre Infusorienfamilien beschränhi, nämlich auf die Vorticellinen, Ophry dinen und Spirochonincu. Bei den heiden ersteren Fanilien hommt die Knospenbildung untergeordnet neben der viel hiufigern Theilung vor '); die Kuospensprösslinge gleichen hier, ahğgsehen ron ihrer Entstehungsweise und ihree Grösse, rolliommen den Theilungssprösslingen, sie entwicheh auch, wie diese, vor ilner Ablösungr einen hintern Wimperhanz. Die Spirochoninen pflanzen sich nur durch Knospenbildung, niemals durch Theihung fort. Nach Ehrenberg ${ }^{2}$, Lachmann ${ }^{3}$, nnd Claparede ${ }^{4}$ soll auch bei der Acinctinengaltung Dendrosoma Knospenbildung vorkommen, ich muss jedoch diesen Angaben widersprechen. Nir sind zwei Arten jener merkwiurdigen Gattung behannt geworden, nämlich Dendrosoma radians Ehbg. und eine nene auf unserem Flusskrebs häufig von mir heobachtete Art, die ich Dendr. astaci nenne;

1) Bei Epistylis aerei, einer neuen auf den Kiemen der Landasseln (Porcellio, Oniscus, Armadiltidium und Ligidium) von mir entdeckten Art, beobachtete ich die Knospenbildung fast noch häufiger als die Theilung. - 2 , Monalsber. der Berliner Acad. ron 1837. S. 152-:33. - 3, Müller's Archiv 1856. S. 384-85. - 4) Annales des scienc. natur. 18:37. 11. Sír. Tome 111 11. 242.

Steı, Grinalsaus der Jufusionsthere 
ich kann jedoch niehts wejer finden, als dass der Körper bej diesen bej(len Arten mehr oder weniger verästelt ist. Jeder Ast ist an Enıle elwas kopfförmig angeschwollen, und diese Anschwellung ist mit zahlrcichen Tentakeln besclzl; durch den gemeinsamen Stamn verlauft ein geschlingelter, stranglörmiger Nucleus, der keineswegs in die einzelnen Aeste einen Zweig lineinschickt, wie Lachmam angicbl. Im Stamm sowohl wie in seinen Verzweigungen liegen kleine contractile Behälter regellos zerstreut. Warum nun ller oft ausserordenllich langgestreckle Stamm ein Mullerlhier und die nicht selten ganz kurzen warzenförmigen Aeste Konospensprösslinge darstellen sollen, die beständig mit dem Mutterhier in Verbindung hleiben, das vermag ich nicht einzusehen. Es fehlt den Aesten jedes Merkmal der Individualitat; sie besizen lieinen besondern Nucleus, wie sonst die Knospensprösslinge, und sic sind aucls nicht im mindesten rom Stamme abgeglicherl. Lelzlerer stellı für sich ebensowenig ein Individumm dar; denn er besilzt gar lieine eigenen Tentakeh.

Die Theilung wird bisweilen der Kuospenbildung dadurch sehr ähulich, dass das Mullerthier in zwei sehr ungleich grosse Theilungsspüösslinge zerfillı. So schnür sich z. B. bei der oft sehr langgesırechten Opalina secans, welche ich häufig im Darmhanal von Saenuris variegala und von Enchytracus vermicularis beobachtele, nur ein sehr hleines Segment des hintersten Körperendes vom übrigen Kürper ab. Dieses Segment gleicht im Verhälniss zı dem langen Vorlerkörjes ciner an demselhen hïngenden Knospe; es erhält jedoch einen seiner Grösse entsprechenden Antheil von dem langen strangfömigen Nucleus des Multerthieres mml characterisirt sich schon dadurch als ein Jlosses Theilungsproulurl. In der Knospe bilulet sich slets ganz unabhängig vou dem muitterlichen Nucleus ein eigener Nucleus aus. Of hat sich der hinospenartige Theilungssprössling von Opalina secans noch nicht vom Ilulterthier getrennt, und es beginnt sich hereits wieder ein neues Segment von dem milterlichen Körper abzuschniiren; von den drei Segुmenten, aus welchen dimn der gesammle Körper bestehl, isl das millelste stels das kleinste, es muss also nach der Ablösung des hintern, äbnlich wie cine Knospe, sich noch eine Zeit lang vergrössern, heror es ebenfalls zur Abschuürung gelangt'). Auch bei zwei Acinelinen (Acinela mystacina und Podoplurya fixa), sowie bei den acinetenarligen Embryonen verschiedener hoherer Infusorien kommt cine Theilnngsweise vor, welche lebhaft an die Knospenbildung erinnert. Nachdem sich nämlich der wimperlose, Tentahelı tragende Körper durch cine ringförmige Einschnürung in ein vorderes und hinteres Segment geschieden hat, von denen cin jedes einen sciner Grösse entsprechenden Theil des vellingerten Nucleus aufninunt, werlen an dem vordern Segment die Tentakeln eingezogen odler doch sehr verkürzt und es entwickelt sich an seiner ganzen Olıerfläche ein dichtes, feines Winperkileid. Nun schnirt sich das vordere Segment immer melır von dem lintern ab; es verlängert und verschmalert sich, wahrend das hintere wimperlose Segment, an dem die Tentakeln ausgestrecki bleiben, wieder die Kugelform annimmt. Der vordere Theilungssprösslinğ der sich demnichst ablöst, gleicht jetzt ganz einem bewimperten, ron einem Acinetenkörper entwickelten Knospensprössling.

Die Theilung und Kunospenbildung können in jedem Lebenssladium eines Infusionsthieres eintrelen; durch Theilung vermchren sich schon dic Embryonen im Mutterleibe. Es gieht nur wenige lnfusionsthiere, bej denen bisher noch keine von jenen beiden Fortpflanzungsweisen nachgewiesen werden honnte. Dahin gebören namentlich alle Acinelinen mit Ausnalme ron Acineta mystacina und Podophrya fixa, und ron selı häng beobachteten bewimperten Infusorien Trichorlina pediculus und mitra und Opalina ranarum.

Bevor wir die von dem $\mathrm{Nucleus}$ ausgehende Fortpflanzungsweise belrachten können, missen wir uns mit dem Vorkommen, der Form und dem feinern Bau dieses Organs bei den verschiedenen Infusionsthieren bekanıt machen. Der Nucleus fehl walıscheinlich heinem einzigen Infusionsthier; er ist bei den meisten in allen Lebensstatien, namentlich nach den Zusatz von Essigsature odes wenn sie abgestorben sind, seh" leicht zu heobachten. Bei manclien Infusoricn, z. B. hei Dileptus anser, ist zu gewissen Zeiten selbst an den grössten Exemplaren heine Spur von einem Nucleus aufzufinden; wahrscheinlich wurde er zuvor ganz und gar zur Erzeugung von Jungen verl)raucht, und er muss nun erst wieder ausgebildet werden. Bei Urostyla grandis entwickelt sich der Nucleus immer erst wăhrend der Theilung, und er geht dann merkwïrdige Mctamorphosen cin, dic wir später betrachten werden. Bei Opalina ranarum suchte ich bisher vergeblich nach einem Nucleus.

Die Form des Nucleus ist nichı blos bei den verschiedenen Infusorienformen selır verschieden, sondern sie erleidet auch bei ein und derselben Art beträchtliche Veränderungen, sobald der Nucleus in Thäligkeit trill. Nur in

1) Die von Frey (Das einfachste thicrische Leben S. 57 und Fig. 20) geschlderte und abgebildete Opaline ist wahrscheinlich mit meiner Opal. secans idenlisclı. Frey hat das hintere Körperende für das vordere genomnen; er beobachlete seine Thiere frei im Wasser, wohin sie wahrscheinlich nur zufälig gerathen waren. Einen Namen hat er denselben nichl gegeben. 
seinem gewöhnlichen, nicht thatigen Zustande zeigt er bei jeder Art eine constante Form. In selır vielen Făllen ist er ein einficher runder oder ovaler Körper, so wahrscheinlich bei allen geisselıragenden Infusorien, ferıer bei Cyclidium, Colpoda, Coleps, Prorodon teres, Glaticoma, Paranaecium, Pleuronema, Nassula, Cyrtostomum, Ophryoglena, Leucophrys entozoon, Blepharisma, Plagiotoma concharum, Chilodon (Taf. I. Fig. 6. 11.), Chlamydodon (Taf. II. Fig. I. n.), Sprirochona, Opercularia berberina und vielen Acinetinen. Breit bandförmig ist der Nucleus bei Bursaria flava und Trachelius ovum. Eine grosse Anzahl von Infusorien besizt einen melır oder weniger langen strangförmiæ̌en Nucleus, der bald ziemlich gerade, bald geschlangelt, bald nieren-, ring- oder hufeisenförmig zusammengelirimnt ist. Ein grader strangförmiger Nucleus fundet sich z. B. bei den Oplıryoscolecinen, bei Opalina lumbrici, armata, secans, ein geschlangelter bei Encliclys pupa, Dendrosoma radians und astaci, Vaginicola crystallina und Ophrylium versalile. Der nieren-, ring- oder hufeisenförmig zusammengelirimmte Nucleus ist besonders den Vorticellinen. Ophrydinen, Euplotinen (Taf. IV. Fig. 13. n.) und Aspidiscinen (Taf. III. Fig. 3. n.) eigen, ferner den Gattungen Trichodina, Urocentrum, Didlinimm und Halteria. Einen lang strangfïmigen, schleifenförmig zusanmengekrümmten Nucleus treffen wir bei Bursaria truncatella, Climacostomum virens, Prorodon nivens, Ilolophrya discolor. Durch einen dendritisch verästelten Nucleus zeichnct sich Acinela Operculariae aus. Bei einigen lnfusorien ist der Nucleus perlschnurlörmigr, er besteht ans hinter einander liegenden kugligen oder ovalen Segmenten, die durch sehr kurze fadenförmige Commissuren mit cinander zusammenhängen; dies ist namentlich bei Stentor coeruleus und polymorplus, bei Spirostonum ambigum, Condylostoma pateus und auch bei Dileptus anser der Fall; bei letzterem Thiere trennen sich jedoch die zahıreichen Glieder des Kerns Jeicht von einand(r ${ }^{\mathbf{~}}$ ). Nicht wenige Infusorien besitzen zwei oder mehrere, gar nicht mit cinander zusanmenhangende, ganz gleich gestaltete Kerne. Zivei ovale Kerne, der eine in der vordern, der andere in der hintern Körperlıălfte gelegen, liommen fast allen Oxytrichinen (Taf. VI. Fiğ. I. n. n.) zu; zwei einander genäherte rundliche Keme finden sich bei Amphileptus fasciola, meleagris, anas, ferner bei Lacrymaria und bej Opisthodon (Taf. I. Fig. 25. n. n.), vier hinter einander liegende ovale Kerne bei Onychodromus grandis (Taf. V. Fig. 2. n. n.). Bei Loxophyllum meleagris beobachtete ich meist 8-10 einander genăherte ovale Kerne, bei Loxodes rostrum 12-20 selır kleine zersireut liegende; noch viel grösser ist die Zahl der Kerne bei Enchelys gigas.

Der Nucleus besteht iberall aus einer dem Parenchym ähnlichen, nur viel dichteren, homogenen, feinliörnigen Substanz, welche naclı aussen von einer lyyalinen, structurlosen, einer Cuticula gleichenden Hülle hegränzt wird. Diese helot sich an isolirten Kernen oft schon nach länerer Einwirkung des Wassers von der Nucleussubstanz ab; viel schneller tritt die Sonderung beim Zusatz von Essigsäure ein. Die Nucleussubstanz ist bei einer und derselben Art bald eine ganz gleichartige, von iberaus feinen Molecülen getriibte Masse, balıl treten in dersellsen, olıne dass der Nuclens seine gewölnhliche Form geändert hat, mehr oder weniger zahılreiche, verschieden grosse, dichtere Kerne vou rundlicher', knollen-oder wurmförmiger Gestalt auf. In recht auffallendem Grade ist dies z. B. hei Paramaccium bursaria und bei Prorodon teres zu beobachten. Hałufig, doch bei weitem nicht immer, umschliesst der Nucleus eine hesondere Ilöhle; so besitzen z. B. sämmtliche Oxytrichinen in der Regel in jedem Nucleus eine querelliptisclıe, spaltförmige Ilölle (verğl. Taf. V. Fig. 2. Taf. VI. Fig. I. Taf. X. Fıg. 1.n.n.). Eine ähnliche Hölıle findel sich im Nucleus der Gattungen Chlanydodon, Ervilia und Trochilia (Taf. II. Fig. 4. 17. 29. n.). Bei Phascolodon (Taf.I. Fig. 1.n.), Chilodon (Taf.I. Fig. VI.n.), Scaphidiodon (Taf. II. Fig. 7. und 9.n.) und bei Spirochona umschliessi der kern eine mehr oder weniger umfangreiche rundliche Hölule, und in dieser liegl ein scharf begä̈nztes, kleines, liernartiges Ciebilde, der Nucleolus

Ein besonderer Nucleolus kommt noch bei einer massigen Anzahl anderer Infusionsthiere vor; bei lliesen liegt er jedoch nicht im Nucleus eingeschlossen, sondern entweder an der iussern Oherfläche desselben in einer seichten Vertiefung oder ganz frei dicht neben tlem Nucleus. Dieser äussere Nucleolus wurde zuerst von $v$. Siebold bei Paramaecium bursaria erkamt (vergl. S. 4.4), ich faut ihn dann bei Prorodon teres auf ${ }^{2}$ ), Lieberkühn bei Bursaria llava und Ophryoglena flavicans ${ }^{3}$; und Cohn bei Nassula elegans $\left.{ }^{4}\right)$. Ich luabe ausserdem noch bei fast allen Oxytrichinen, bei den Ophryoscolecinen, ferner bei Paramaccimm aurelia, Nassula aurea. Lencophrys entozoon, Isotricha intestualis ${ }^{5}$ ) und einigen neuen Infusorienlormen einen äussern Nucleolus heobachtet. In allen diesen Fällen ist derselbe ein kleines rundes, ovales, stabförmiges oder gerstenkornartiges Körperchen, welches aus einer

1. Ehrenberg giebt bei Dileptus anser, wozu auch sein Amphileplus nargaritifer gehöı, irrlhümlich zwei ovale Kerne an (Die Infusionsthierehen S. 355 und Taf. XXXVII. Fig. IV). - 2) Siein Die Infusionshiere S. 243. - 3) Miiller's Archiv 1856. S. $24-25 .-$ 4) Zeilschrift für wissensch. Zoologie 1857. Band IX, S. 144. - 5) Prager Lolos. Mirr 18:39. S. 58. 
homogenen, lirstallhellen. dis lich stath brechenden Sulsstanz und aus einer innigr andiegenden, strueturlosen Hïlle besteht, die wenigstens in mehreren Fällen, z. B. bei Param. bursaria, sich lejeht bein Zusatz von Essigsäure von der innern Substanz abhebt. Einen relativ grossen, dem Nucleus adlıärirenden gerstenkornartigen Nucleolus besitzen Param. Intsaria, Ophryoglena flavicans und Prorodon teres. Mlitten auf dem Nucleus sitzt der selır kleine runde Nucleolus bei Paran. aurelia, Bursaria flava, Nassula aurea und Isotricha intestinalis. Bei den Oxytrichinen liegt der selır kilcine, ovale, einem Felliörnchen gleichende Nucleolus dicht neben dem Nucleus (Taf. V. Fig. I. 2. nl. Taf. V1. Fig. 1. 9. 1. Taf. X. Fig. 5. nl. Prorodon teres hesitzt ausser dem gerstenkornartigen äussern Nucleolus noch einen grossen ovalen Nucleolus im Centrum des Kerns; hieraus darf vielleicht gefolgert werden, dass der innere Nucleolus eine andere Bedeutung hat, als der iussere.

Was nun die Function des Nucleus anbetrift, so konnte daruber schon lägst nicht mehr der geringste Zweifel obwalten, dass derselbe das eigenfliche Fortjllanzungsorgan der Infusorien darstelle. seitdem ron mir iiberzeugend dargethan worten wal, dass sich bei den Acinctinen die Anlagen zu neuen lndividuen aus dem Nucleus entwickeln. Ein noch viel helleres Licht verbreiten alser die in neuester Zeit ron Bulliami an Paramaecium bursaria angestellıen Reobachtungen, sowie meine eigenen davon ganz unabläugig geführten Untersuchungen über die Bedeutung des Nucleus. Es geht aus denselben mit Evidenz hervor, dass bej den Paramaicien und wahrseheinlich bei allen Infusorien, deren Nucleus mit einem ausscrn Nucleolus versehen ist, unter gewissen Umstanten der eigentliche Nucleus als weibliches, der Nucleolus als männliches Geschlechtsorgan fungirt; aus ersterem entwickeln sich die Keime zu den Embryonen, aus letzterem Spermatozoen. Das grosse Verdienst, die ersten auf die geschlechtliche Forffflanzung der Infusorien bezijglichen Thatsachen entdeckt zu halsen, gebiilut aber unstreitig Joh. Mällor, Licberliuhn, Claparede und Lachmam vergl. S. ̈̈2.

Die so eben genannten Forscher beobachteten bei den Stentoren in kiaren Ilohliaumen des Parenchyms, die constant im vordern Körperende in der Nähe des contractilen Behälters lagen, freie, sich schlängelnd hewegende, vibrionenihnliche Fä̈len, welche schnell ibre Bewegungen cinstelten, wenn sie isolirt wurden unt mit Wasser in Beribrung kamen. Letzterer Umstand machte es sehr unwahrscheinlich, dass die Faden von den Stentoren gefressene Vibrionen seien; das Vorkommen ähnlicher, jelloch unbeweglicher Fijden im Nucleus einiger andern Infusorien sehien viehmehr zu der Ansichı zu berechtigen, dass die beweglichen Fäden dej Stentoren im Körper derselben ihren Lrsprung mähmen. J. Mïller hatte bereits im J. 1854 bei Paramaecium aurelia den ganzen Inhalt des vergrösserten Nucleus in einen Bausch ron Locken grekräuselter Fäden formirt gesehen; diese bischeinung zeigte sich aber unter sehr vielen Exemplaren nur seh" selten. Ëmmal ersehien der Nucleus noch viel meh" vergrössert und in zwei Mlassen zerfallen. wovon die eine die gewöhnliche Stelle des lierns einnahm, wahrend die andere sich nach hinlen iber den Schlund ausgebreitet hatte; beide Massen enthielten eine grosse Menge disereter Fäden, welche aber njeht in Locken geordnet und dicht gepackt waren, sondern in verschierlenen Richtungen locher zerstreut lagen. Claparide und Lachmam beobachteten im Nucleus von Chilodon cucullulus kleine, gerade, unluewegliche, nach verseliedenen Richtungen zerstreut liegende stäbchen'\%. Lieberliülun dagegen sah bei einem mit Colpoda ren rerwandien Infusionsthier nicht im Nucleus selbst, sondern in dem Nucleohus fadenförmige Körperehen aultreten. Ohgleich J. Mïller warnte, aus diesen Tlıatsachen vorzeitig weitere Selılussfolgerungen zu ziehen, so hob 'J' doch sellss die Elrenberg'sche Bezeichnung "Samendrise " für den Nucleus wieder so aufallend hervor, dass wohl Jedermann auf den Gedanken kommen musste, die im Vueleus beobachtelen fadenlörmigen Küuper sejen in der Entwichelung legrillene Spermatozoen.

Balbimi, dem die vorstehenden von J. Miller in der Berliner Academie im Juli 1856 vorgetragenen Entdeckungen wolıl nicht ganz unbehannt geblieben waren, wies nun in einer der Pariser Academie im Marz 18308 ubergebenen Abhandlung nach, dass bej l'aramaecium bursaria eine wirliche geschlechtliche Fortpflanzung vorkomme, und dass diese stets durch eine Conjugation zweier Individuen eingeleitet werle, in deren Folge sieh in den Nucleus Eier, in dem Nucleolus alser Spermatozoen entwickelten: der Nucleus sei daher als Eierstock, der Nucleolus als llode zu deuten. Die Conjugation besteht nach Balbiami darin, dass sich zwei Individuen ihrer ganzen Länge nach so an einander legen und mit cinander verwachsen, dass die gleichnamigen Körperenden und die Mundöffnungen neben einander zu liegen kommen. Die conjugirten Individuen stellen denjenigen Zustand dar, welcher bisher als Lingstheilung eines einfachen Thieres anfgelisst wurle. Nach erfolgter Conjugation vergrössert sich 
zun:ichst der Nucleolus jedes Individums zu einer ovalen Kapsel mit längsstreifigem Inlanlt, die dann dureh Quertheilung in zwei oder vier kleinere Kapsehn zerfallt; jele derselthen lesteht aus cinem Bundel feiner Stabehen, welehe von einer gemeinsamen Hiille umschlossen werden. Auch mit dem Nuclens gehen Veränderungen vor, er wird rumler und behommt Einsehnitle, lie immer tiefer greilen und ron ilm eine ofler meluere Portionen alssonlern. Diese, sowie auch öfters der ungetheilte Nucleus enthalten kileine seheibenformige liörperchen unit einem centralen Fleck, welche Balbiami als Eier deutet, während er die aus dem Nucleolus hervorgegangenen Kapseln als Samenhipsehn bezeichnet. Der liefruchtungsact soll darin bestehen, dass die beiden conjuginten Individuen die in ihnen enthaltenen Samenkapseln durch die dicht neben cinander liegenden Ilundiolnungen austauschen. Ist dies geschehen, so trennen sich die Individuen von einander. und es gelangt nun erst in jedem cine der Samenkapsehn zu ihrer völligen Reife. Die reife Samenkapsel hat einen betłächlichen Umfang und umschliesst unzählige spindelförmige Spematozoen, die aus derselhen herausgequetscht hin und her schwankente Bewegungen zeigen. Erst ö-6 Tage nach des Begattung sollen die ersten Keime zu den Embryonen als lileine homogene Kugehn erscheinen. welelse noch keinen Kern und keinen contractilen Behilter besitzen. Aus ihnen gehen endlich flie zuerst von Cohn genauer beschrielsenen vergl. S. 4.3), mit Kem und confactilem Bebilter versehenen acinetenartigen Embryonen hervor.

Ich bin hei Param. bursarja zu ganzähnlichen Resultaten gelangt, wie Bulbiani, den vorliegenten Erscheinungen muss ich jedoch nach einem vergleichenden Studium von Param. aurelia eine wesentlich andere Deutung geben. Als ich von J. Mïller's Vortag iber die Entwickelung ron farlenfömigen Gebilden im Nucleus einiger Infusorien, namentlich von Param. aurelia, Kenntniss erhalten hatte, ging ich solort von Neuem an die Untersuchung der Paramäcien, deren Emlryonen ich in den J. 18530 und 56 wieder vielfuch zu beobachten Gelegenheit gehabt hatte. Ich ïberzeugte mich zurönderst, dass auch bei Parau. aurelia constant eiu besonderer, sebr kleines, runder Nucleolus vorhanden ist, der mitten auf ten ovalen Nucleus in einer seichten Vertiefung sitzt; J. Mirller hatte nach demselhen vergeblich gesucht. Im Januar 1857 fraf ich endlich unter ungeheuren Schadren von P. aurelia cine geringe Anzalıl von Individuen, die genau die von I. Mïllar beschriehenen Erscheinungen zeiglen. Der Nucleus, an dem sich jetzt liein Nucleolus unterscheiden liess, war nämlich beträchtlich vergrössert, so dass er hisweilen zwei Drittel des ganzen Körperraumes einnahm; in seiner ganz lıomogenen Substanz lagen nach allen Richtungen hin zahllose, ganz gretade, sehr feine Stabchen regellos unl locker zerstrent, die sich duch Quctschen des Thieres isoliren liessen und $\frac{1}{150}-\frac{1}{12} 6$ " lang waren. Ein Indivilumm mit einem solehen Nucleus sah ich einmal von Urostyla Weissei gefressen werden vergl. Taf. Xlll. Fig. 3. s.. Mehrmals war der sehr verlangerte Nueleus in zwei Massen gesondert, die jeloch noch durch eine gedrelıte stuangförmige Commissur zusammenhingen. Diese Sonderung dart nicht als eine weilere Entwickelungsstufe des Nuclens auggefasst werden, sondern sie ist lediglich ein Product der krampfhaften Windungen, die das Thier unter dem belastenden Deckglas ausfulirt.

Bei eincr ziemlich beträstlichen Anzahl anderer Individuen bot sich mir im Innern eine ganz neue ijberraschende Erscheinung dar. Sie enthielten gar keinen Nucleus, sontern statt desselluen eine grosse Anzahl blasser rundlicher oder ovaler Körperchen von sehr ungleicher Grösse, die erst nach dem Zusatz von Essigsäure ganz klar hervortraten. Es sondert sich dann an ten grössern cine zarte, krystallhelle Membran von dem ganz homogenen feinkörnigen Inhalt. aus dem meist ein deutlicher liern bervorschimmert. Die grossern kugelförmigen Körper liegen regellos zerstreut zwischen den hleinen, dicht zusammengedringten, ovalen körperchen, welche oft eine sehr unregelmassige Form hahen und wie Bruchsticke eines grössejn Ganzen erscheinen. Sämmuliche runde und ovale Körperchen zusammengenommen nehmen einen grossen Theil des iunern lörperraumes ein, sie sind ohne Zwwoifel aus dem Nucleus hervorgegangen, der sich zuvor beträchtlich vergrösserte und dann durch eine unregelmässige, an verschiedenen Puncten gleichzeitig eintretende Theilung in kleinere und grössere Bruchstiuche zerfiel. An melıeren Individuen war dieser almählige Zerfall des vergrösserten Nucleus mit Bestimmtheit zu erkennen. Die kngelfömigen Körper, welche aus dem Nucleus bervorgehen, sind die Anlagen zu neuen Indiviluen, ich nenne sie aus Grinden, die wir gleich kennen lemen werden, Keimkugeln, nicht Eier.

Als ich diese Thatsachen gefunden hatte, war ich nationich der Meinung, dass die Individuen, welche in dem vergrösserten Nucleus stabfömige Körperchen cuthiclten, Männchen, die mit eiählichen Körperı erfullten dagegen Weibchen seien; ich glaubte, dass der Nucleus bei den einen Indiviluen als Iloden fungire und Spermatozoen erzeuge, bei den andern aber die Rolle eines Eierstocks spiele und in einen Ilaufen Eier zerfalle. Von dieser Ansicht kam ich jedoch bald zurick. Als ich nämlich im Julj 1857 ahermals unter dichten Schaaren von Par. aurelia. 
dieselben Entwichelungszustande antraf, liel es mir auf, dass gleichzeitig sehr viele in der Lingstheilung begriflene Indivighen rorhanden waren. Jeh war nicht wenig ubcroschl, als ich beim Zerquetschen Jerselben dicht neben lem Nucleus jeder Iälfte eine rundliche Kapsel bemerthe, welche sehr zarte, parallel neben cinander liegende Faden enthiell. Die weitere Untersmchung selı vieler in der Langstheilung begrilfener Individuen lelurte, dass die Kapsch nichts weiter als der vergrösserte Nucleolus sei, dessen Inhalt zuerst ein längsstreifiges Ansehen bekommt. und sich dam in parablel neben einander liegende Fasern sondert. Die Kapsel verdingert sich nach und nach zu einen anselublichen nách beiden Enden angeschwollenen Schlauch, der dicht an einander liegende leine Fäden umschliesst und öfters durch Querthelung in zwei gesonderte spindel- oder eiförmige Kapseln zerfïllt. Die in der schlauchförmigen Kapsed enthaltenen Füden sind in der Entwickelung begriffene Spermatozoen, die erst zur Reife gelangen, wenn sich die beiden Theilungspprösslinge von cinander getrennt hahen. Von einem Austansch der schlanchförmigen Samenkapsehn durch die ncben einander lieggenden llundöfhungen der noch zusammenhängenden Theilungssprösslinge kann bei der bedeutenden Grösse der Samenkapseln nicht die Rede sein.

In Gesellschaft der in ter Längstheilung begriflenen Paramacien fanden sich häulig einfache Individuen, die ollenbar die weitcrn Entwickelungszustande der aus der Theilung hervorgegangenen lndividuen darstellen. Sie enthielten einen grossen ovalen Ba\}len von dicht zusammengepacliten, lockenförmig geliäuselten Fäden, weleher in der Regel ummittelbar vor dem gyeiclzeitig vorhandenen Nucleus lag; Ietzterer war natiurlich olıne Nucleolus. Der Ballen war hald noch von eincr besomlern Membran unschlossen, bald nicht; im ersteren Falle waren lie eingeschlossenen Fäden weit zarter, und sie licsen sich beim Quetschen nur unvollslandig isoliren, im letzteren Falle löste sich der Ballen schon bei einem mässigen Druck mit dem Dechiglase in eine zahllose Menge von kurzen, geschlingelten, nach beilen Enden zingespitzten Failen auf, die $\frac{1}{12}{ }^{\prime \prime}$ lang waren und sich unter luin und her schwankenden bewegungen weithin durch das Wasser verbreiteten. Dies sind die reifen Spermatozoen: sie werden im Wasser nur mechanisch furtgetragen, eine automatische Bewegung konnte ich hisher noch nichl an ihnen conslatiren. Der Spermatozocuballen ist nicht selten grösser als der Nucleus selbst, luăufig sind zwei keinere gesonderte Ballen vorhanden, von denen der eine ror, der andere hinter dem Nucleus liegt; zurveilen sah ich drei bis vier Ballen vor den Nucleus.

Endlich l'af ich auch Paranäeien, deren mehr oder weniger vergrösserter Nucleus dicht mit zahllosen reifen geschiangetten Spermatozocn crfullt war, die sich noch leicht aus Jemselben isoliren liessen, aber cbenfalls keine selbstständigen Bewegungen zeigten. Wahrscheinlich war es diese Entwichelungsstufe, welche bereits $J$. Müller beobachtete, möglicher Weise aber auch die zuvor beschriebene, bei welcher nur der eigentliche Nucleus ubersehen wurde. Einige Male sah ich reife Spermatozoen im Nucleus und zugleich noch einen kleinen Ballen ganz gleicher Spermatozoen vor demselben. Gleichzeiligr erschienen nun auch wieder Individuen mil vergrössertem Nucleus und gerad ausgestreckten regellos zerstreut liegenden Spermatozoen in demselben, sawie Individuen, deren Nucleus in Keimkıgeln zerfallen war. Alle diese Thatsichen zusammengenommen lassen gar keine andere Deutung zu, als die, dass die reifen Spermalozoen, deren Entwickelung in dem sich vergrössernden Nucleolus durch alle Stadien bis zu ihrer vollendeten Ausbildung mit der grössten Bestinumtheit zu verfolgen ist, zuletzt in den Nucleus eindringen und demselhen dadurch den Impuls zur Entwickelung von Keimen zu neuen Individuen ertheilen. In dem Uebergang der reifen, frei in Parenchym liegenden Spernatozoen in den Nucleus erlienne ich den eigentlichen Befruchungsact, der also dem von Cohm bei Volvox nachgewiesenen Befruchtungsacte (vergl. S. 37 ganz analogr ist. In Folge der Befruchtung vergrössest sich der Nucleus beträchtlich, die in ihn eingetretenen spermatozoen sterben spitter ab und erscheinen dann nicht mehr als geschlingelte, lockenförnsig an einander geveihte Fäden, sondern als gerad ausgestreckte, reggellos durch einander liegende Stajbchen, welche nach und nach aufgelöst werden. Denn während sie in dem Nucleus der einen Individuen ausserordentlich scharf hervortreten und genau die Grösse der reifen ausserhalb des Nucleus liegenden Spermatozoen besitzen, zeigen sie sich in Nucteus anderer Intividuen nur noch als ginz malle, feinere, liüzere und ungleich lange Strichelchen. Erst wenn in dem vergrisserten Nucleus jede Spur von Spermatozoen verschwunden ist, zerfält derselbe durch eine Art ron Durchfurchung in einen Haufen von Keimkugeln. Da nicht diese befuchtet werden, sondern ter ungetheilte Nucleus, so hönnen die aus letzterem herrorgehenden Kugehn nicht wohl Eier genannl werden; denn für das Ei ist wesentlich, dass Spermatozoen in dasselbe eindringen und es zur weitern Entwickelung anr'yen.

Die eben geschilderten Entwickelungsstufen von Par, anrelia labe ieh im Lanfe ron 1837 und is noch selı hauligg heobachted; ich suchte nach ihnen niemals rergeblich. sobild in einer Infusion, welche reich an Para- 
macien war, in der Längstheilung begriffenc Individuen anfuaten. Zu ganz ablulichen Resultaten gelangte ich in Betrefl des Param. bursaria hereits im Sommer von 183̈7. Auch bei diesem Thiere entwickelt sich während aler Läugshlueilung der gerstenkornarlige Nucleolus jeder Körperhälfte zu einem anselınlichen, an beiden Enden angeschwollenen und mil dicht neben einander liegenten Fiden erfülten Samenschlanch; dieser zerfillt aber constant Jurh Quertheilung in zwei ovale oder eiformige schlauche, welche sich hiulig noch cinmal ter Quere nach theilen, so dass nach beendigter Längshleilung des Mutterthicres jeder Theilungsoprössling einen einfuchen Nucleus, aber zwei oder vier Samenschläuche cnthilt, bisweilen auch drei, einen grösscrn, ungetheilt gebliebenen und zwei kleinere. Ob hlos einer dieser Shläuche zur Reife gelangt, wie Bulbimi behauptet, muss ich unentschieden lassen, la mir von P. bursaria nicht ein so reiches Material zu Gebote stimu, wie von P. aurelia; ich war auch bei P. bursaria noch nicht so glucklich, in alen Nucleus cingedrungene Spermatozoen zu beobacliten. Der Nucleus ist in den mit spermatozoenkapseln versehenen Individıen bald ganz honogen, bald enthath er mehr oder weniger zahıeiche kernarlige Gebilde. Letztere können ınmöglich als Eies gedeutet werlen. Wofür sie Balbiami ansieht; lenn der Nucleus zerfällt nach der Befruchtung immer nur in zwei oder trei hugelfürmige Segmente, und von diesen scheint bestandig das eine als Nucleus fort zu bestelien, wahrend das zweite oder die beiden aulern die Betleutung von Keimkugehn haben und sich zu Embryonen entwichelı.

Es fragt sich schliesslich noch, ob der Ausgangspunct zur geschlechılichen Fortpllanzung der Paramaicien als Läingstheilung, wic iclı angab. oder aber als Conjugation zweicr Individuen, wic Balbimi annimmb, aufzufassen sei. Im letzteren Falle wärle hei den Paramäcien gar lieine Vermelırung durch Lingstheilung, sondern nur Quertheilung vorkommen. Ich habe stets gefunden, dass bei denjenigen Entwickelungsstufen, welche bisher allgemein fiur Längstheilungsstadien gehalten wurden, jede der durch eine vordere und lintere Einschniurung von einander getrennten Hälften auffillend kiirzer, aber verhälınissmässig breiter war, als der Körper der gleichzeitig vorhandenen einfachen Indiviluen. Schon dieser Unstand sprichl mehr für Längstheilungr, als für Conjugation. Ausserdem ist aber der Nucleus in jeder Hälfte viel kleiner, als bei gleichgrossen einfachen Individuen, wie namentlich seh. auffallend bej Par. Intsaria zu beobachten ist; dies lisst sich doch nur durch die Annahme erklären, dass jeder Nucleus aus der Theilung eimes urspringlich einfachen kems lıervorging. Ich muss daher die fragliche Entwickelungsstufe einstweilen noch für einen Acl der Längstheilung (rhlairen, bei dessen Beginn zucrst sowohl der Nucleus. als der Nucleolus des Muttertlieres in zwei Segmente zerfällt; je ein Nucleus- und Nucleolussegment lommt dann in jede ler sich von einander sondernden Köpperhälften zu liegen, worauf die Enlwickelung des Nucleolus zu einem oder mehreren Samenschliuchen erfolgt.

Es scheint eine geraume Zeil zu versehen, bevor sich die Keinkugehn weiter entwickeln; denn ich beobachtete oftmals zahlreiche Pananacien mit Ḱeimkugehn, suchte aber vergeblich nach hndiviluen mit Embryonen. Die Keimhugeh beliommen zuerst einen ansehnlichen, scharf begrinzten, centralen Kern und einen nillu unter der aussern Oberlläche gelegenen contractilon Behïlter. In diesen Zustante nenne ich sie Emb ryonalkugeln. Bei Par. anrelia sah ich ron ten zahlreichen Keimkugeln immer nur cinige wenige, meist zwei oder drei, oft aber anch nur eino sich zu Embrỵonalkugeln entwickeln, wihrend bei l'ar. bursaria jede Keimkugel zu einer Embryonalkugel wird. Par. aurelia enthielt ausser den Embryonalkugeln hald noch ganz iuverinderte heinkupeln, hald hereits wieder einen normalen, oflenbar neı gebilueten Nucleus mil aufsizenden Nucleolus; bei Par. Lursaria traf ich neben den Embryonalkugeln stets eincn besondern Nucleus mit cinem bald anliegenden, hald weit rom Nucleus entfernt liegrenten Nucleolus. Dic Embryonalhugeln rergrössern sich auf Kosten des miitlerlichen Parenchyms; die Stoffe. welche sie sich aneignen. werden wahrscheinlich mittelst kurzer, geknopfter, ron ihrer Oherfläche entspringender Tentakeln anfgenonmen, dic erst hervortelen, wemn man die Embryonalkugeln isolirt hat. Diese Tentakeln gleichen in allen Beziehungen den Tentakeh der Acinetinen. Die Embjyonalkugehn liegen dicht nelien einander und plathen sich durch gegenseiligen Druck mehr oder weniger als. Während sie sich entwickehn, entsteht in ilırer nächsten Ungebung, balı auf der Ruchseite, bahl auf der Bauchseite, bald an einer der Sciten des Mutterthieres eine das Parenchym durehsetzende lianalartige Lijcke, welele an der äussern Oherfliche mit einer elliptischen oder rundlichen Octhung allsmindel. Dies ist dic Gelourtsöffnung.

Die Emlmronallingel verwandelt sich nicht unmittelbar in eincu Embryo, sondern sie producirt melırere Generationen ron Eubryonen; es sondert sich nimulich son der Embryonalliugel durel Quertheilung ein vorderes segment ah, welches etwas hleiner ist, als der Rest terselben. Dieses Segment entwickelt bei fortschreitender Theilung an seiner ganzen Oberlliche ein dichtes zartes Winperhleid und schüut sich collich als der hekante, 
länglich elliptische, acinetenartige Embṛ̨o al, weleher mit zerstreuten, an vordern und hinlern Ende dichter stehenden Tentahehn besetzt ist und im vordem Ende cinen contractilen Behälter, in der Nitte einen querovalen Nucleus enthält. Der Embryo dpangl sich durch die Geburtsotfnung naclı aussen hervor und verłässt bahd, nachdem er frei geworden ist, das Mullerthier, und schwarmt nun gewandt im Wasser umher; die Embryonalhugel dagegen, ron der sich der Embryo alschniute, wichst weiter fort und liefert spater durch abermalige Quertheilung einen neuen Embryo. Zulctzt erlischı die Produclionshraft; und die noch vorhandenen Embryonalkugeln vergrössern sich nieht mehr, sondern gehen unmittelbar in Embryonen ïber.

Nach diesen Ergehnissen werden wir die Paramaicien als Zwitterthiere aufzufissen haben, und wir dürfen wohl weiter schliessen. dass alle Infusorien. deren Nucleus mit eimem gesonderten ciussejn Nucleohs versehen isı, sich zu irgend eincr Zeit ilures Lebens als Hermaphroditen herausstellen werden. Dass bei Nassula elegans die gesclılechtliche Fortphanzung in ahnlicher' Wcise, wie bei den Paramåcien erfolgen werte, daran lassen die wenn auch noeh selı fragmentarischen Beobachtungen von Cohn') kaum zweifeln. Cohn beobachtete Thiere mil ein orler zwei acinctenartigen Embryonalkugehn, die wohl nur zufällig in Folge von Druck mit dem Deckgläschen durch die lange spalıörnige Geburtsöflinng hervortraten; die eigentlielıen Embryonen wcrden ohne Zweifel bewimpert sein. Bei Prorodon teres sah ich mehrmals an einfachen Individuen den Nucleolus beträchtlich vergrössert und seinen Inhalt in ein Bindel von feinen, paraltelen Fiden zerfallen, was sicherlich in der Entwiclielung begriflene Spermalozoen waren. Ausserdem fand ich einige Individuen, welche statt des gewölnhichen Nucleus vier blasse. I'unde Keimkugeln mit mehreren kernarligen Gebilden in ihrem hnern enthielten. Die zahlreichen Thatsachen, welehe ich uher die gesclılechtliche Fortpflanzung der Oxytrichinen, namentlich bei Stylonyehia mytilus und Urostyla grandis, ermittelt habe, werde ich in dem folgenden Theile meiner Schrift bei der Beschreilung der einzelnen Arten vortragen; wir werden sehen, dass sich bei diesen Thieren wahrend der Theilung im Nucleolus ebenfalls Spermatozoen entwickeln, während später aus den Nucleus Keimkugeln hervorgehen, deren weitere Entwiekelung bis zu reifen lewimperten acinetenarligen Embryonen verfolght wurde

Es fragt sieh nun, wie sich diejenigen Infusorien in Bezug auf die vom Nucleus ausgehende Fortphlanzungsweise verhatten, welche keinen besonderı Nueleolus besitzen. Meine Erfahrungen sind in diesem Puncte noch seh" lückenhaft. Bei Stentor blieben alle meine Bcmulungen vergeblich. die zuerst von Echiard und O. Schmilt und neuerlich auch von Claparide und Lachmam² beobachteten Embryonen und die von .J. Mäller beschriebenen spermatozocnartigen Fuden aufzufunden. Dagegen beobachtete ieh im J. I s54 bei Bursilia truncatella sehr häufig das Auftreten von Embryonen, die bisweilen in soleher. Menge vorhanden waren ich schatzte sie auf 200 in einem Thiere), dass das ganze Parenclyym bis nahe an die aussere Oberfläche dieht gedrangt ron ihnen erfullt wurde. IV Embryonen sind oval oder ungekehrt eiförmig, auf Aler ganzen Oherllache bewimpert und am vordern Ende mit einem kleinen saugnapfartigen Vorsprung versehen; in oler llitte des Kürpers liegl ein rundlieher oder länglieher Nucleus und am hintern Ende ein kleiner contractiler Behäter; aus- und einstuilpbare Tentakehn nahm ich nicht wahr. J)as Iutterhier cuthielt ausser den Lmbryonen stets eincn gewöhnlichen strangförmigen Nucleus; Embryonalkugeln waren aber bei keinem einzigen Indiviluum aufzufinden. Einc besondere Geburtsöffuung sehien zu feh]en; wurde ein Dechgläschen auf das Mutterthier gelegt, so durchbrachen dic Embryonen ohne Mühe an den verschiedensten Puncten das l'arenchym und bewegten sich anhaliend und gewandt nach allen Richtungen hin durch das Wasser.

Bei Trachelius orum beobachtete ieh zu versehiedenen Zeiten das Aufteten ron grossen runden. selır lichten kieinkugehn. Die Individnen, welehe keimkugeh enthielten, waren von diclu gedringt liegenden Fettbornchen in Parenchyom sehr dunkel und undurchsichtig, ihr Halsheil war schr verkïrzt oder ganz eingezogen und un Innern des Körjer's liess sich kicine Spur von dem verästelten Trabckelsystem, noch von Nahrungsstoffen wahrnehmen. Meist fund ieh funf zerstrent liegende keimkugeln in einem Individnum, von denen vier fast gleich gross, die fünle merhlich kleiner war; ein Mal sah ich nur eine und ein anderes Mal zwei Keinbugeln. Nie war gleichzeitig der gewöhnliche bandförmige Nucleus torlınden; die Keimkugeln sind also offenbar Theilungsproducte ales Nucleus. Dies lehrlen auch mehrere Individnen, deren Nucleus durch vier guere Einschnilte in fünf, wie Band-

1) Zeitschrift fïr wissensch. Zoologie 1857. Band IX. S. 144-45 und Taf. VII. B. Fig. 1-6. - 2) Annal. des sc. natur. 1857. Tom. VII. p. 233. Claparede und Lachmann erwähen uur bei Gelegenheil der Schilderung ler Fortpllanzungsverhälnisse von Epistylis plicatilis gasz beiliutig, dass sie bei Stentor polymorphus, Paramaecium aurelia, P. bursaria und einer neuen Species P. putrinum, sowie bei Dicyema Mülteri dic Entwickelung von Embryonen beohachtel haben. Die Gatlung Dicy ema dïrfie schwerlich zu den Infusionsthieren gehören (vergl. G. R. Wagner Ueber Dicyema hölliker in Mäller's Archiv 18:37. S. 354-68 mil einem Zusalze ron Claparéde). 
wurmglieder an einander habgende Segmeute abgetheilt war. Die Keimkugeln leuchten aus dem dunkeln Parenchym nur wie helle Flecke hervor, sie lassen sich jedoch leicht isoliren und zeigen nach Behandlung mit Essigsăure eine begranzende zarte Vembran und einen sehr feinkörnigen Inlrah, ausserdem noch ein eigcuthunliches, lappiges, liernartiges Gebilde, welches nicht im Centrum, sondern nalıe an der Oherfache der Keimkugel liegt. - Auch von Prorodon niveus habe jch hảufigg Individuen angetroflen, die nichı den gewölmlichen strangförmigen Nucleus, sondern drei, seltener zwei, gleich grosse, runde Keimkugeln enthielten; sie waren ebenfalls selır blass und im Innern ganz homogen, ohne Kern. - Bei Blepharisma lateritia sah ich mehrmals an der Stelle, wo sonst der ovale Nucleus liegt. vier. sechs odler acht in einer oder zwei Längsreihen nalıe hinter einander gelegene, kleinere honogene Kugehn. die ohne Zweifel aus len Zerlall des Nucleus hervorgegangene Keimkugeln waren.

Von hohem Interesse ist die hei den Vorticellinen vorkommende, vom Nucleus ausgehente Fortpflanzungsweise, dic zuerst von Claparde und Lachmam bei Epistylis plicalilis erkannt wurde (vergl. S. 31 ). Ich labe diese Fortpflanzungsweise, die höchst wahrselıeinlich eine geschlechlliche ist, in den letzten Jahren bei Epistylis crassicollis St., einen der geneiusten Schmarotzer des Fusskrebses, und hei Vorticella nebulifera der Wasserlinsenwurzelu kennen lernen, doch sind meine Untersuchungen noch lieineswegs zu einem lofrierdigenden Abschluss gelangt. Vou Epist. crassicollis beobachtete ich mehrmals peichastige Fanilienstöcke, deren Jndividuen fast sämmtlich eine mássige Auzalı von Keimlugeln, ausserdem abes auch noch einen strangförmigen, auf verschiedene Weise zusammengekiummten Nucleus enthielten. Die Keimkugeln liegen stets im vordersten Ende des Thieres, zwischen dem Peristommande und dem Schlunde und unhijlen gewöhnlich das vordere Ende des Nucleus. Schon bei einer missigen Compression des Thieres leuchten sie als helle, mil einem grossen, dunkeln, centralen Kern versehene Sphaten aus dem Innern horvor; bei einem sehr starken Druche treten sie durch die Peristommundung sammt den Nucleus nach aussen. In einem Thiere finden sich gewöhnlich 4-6, nicht selten auch noch mehr (bis 12) Keimhugehn, die meist sohr ungleich gross sind; sie bestehen aus eincr schr lichten, ganz homogenen Substanz, in der sich Ier opake fcinkömige Kern schr scharf abzcichnet. Die grössten Keimkugehn enthallen oft zwei oder drei Kerne; sie zerfallen spiter durch Theilung in eben so vielc kleinere Keimkugeln, wie jeh direct an mehreren mit zwei Kernen verselıcnen Keimlugeln beohachtete. Die Entwickelung der Keimliugeln aus dem Nucleus des Mutterthieres ist leicht zu verfolgen; es entsteht zuerst in ler homogenen Substanz des Nucleus eine grosse Anzahl lileiner kernartiger Gehilde, dann vergrössern sich in dem cinen Ende des Nucleus ein oder mehrere Kicrne, wälrend gleichzeilig die ungebende Nucleussubstanz betrichtlich anschwillt. Das angeschwollene Stijck schnuirt sich zuletzt von dem ubrigen strangfömig bleihenden Theil des Nucleus al,, und zerfillt später, wenn es mehrere Kerne enthielt, in eben so viele Keiuhugeln, die sich auf hosten lles umgebenden Parcnclıyms weiter vergrüssern. Nachdem sich en rergröscrles stuch rom Nuclens ábgetiennt hat, wederholt sich dieser forgang noch ein-oder melırmal, stets bleibt jedoch noch ein anselnnlicher Rest des Nucleus ibrigg, der als solcher fortbesteht und wieder zu seinem fribern Lmlang heranwaichst.

Obwohl ich die Epistylisstöcke, deren Individuen Keimkugeln entwickelt hatten, sechs Tage lang mit der grössten Aufmerksamkeit verfolgte (ich bewahrte sie isolint in Uhrgläsem auf), so glückte es mir dennoch nicht. irgend cine weitere Veranderung an tlen Keimkugehn wahrzunchmen; die Hutterthiere lösten sich nach und nach von iluren Aesten ab und gingen zuletzl aus Mangel an geeigneter Nahrung zu Grunde. Jedenfalls bedarf es, wie bei Paranaecium aurelia, einer längeren Zeit, luevor sich die keimkugeln zu Embryonalkugehn entwickeln. Anch eine Geburtsölhung liess sich nirgends an den Mutterthieren auffudeu, sie entsteht olme Zweifel erst, wenn sich die Keimkugeh weiter zu entwicheln anfangen. Ich habe jedoch zu einer anderen Zeit einige nicht sehr reichasstige Stöcke von Epist. crassicollis beobachtet, deren Individuen mit einem aussern Hocker rersehen waren, weleher wahrscheinlich dem von Claparede und Lachmam hei Epist. plieatilis beschriehenen Geburtshöcher entspricht. Dieser Höcker sass stets in ver vordern Körperhalfte, meist nahe hinter dem wulstig verdickten Peristomrante. also in dersetben Gegend, wo im Innern rlie Keimlugeln aultreten: er hatle die Gestalt einer conischen oder halbeiförmigen, an der alggestutzlen Spitze mit einer runden Oeffnung versehenen Knospe. Am Grunde dessellsen lag bei einigen Individuen im lnnern des Körpers ein kugelförmiger scharf begränzler Körper von der Grösse einer ansehulichen Keimlingel, den ich jedoch nicht zu isoliren vermochte; er schien einen Kern und einen contractilen behailter zu enthalten, war also wohl eine Embryonalkugel; sonst waren im Innern des Mutterthieres weder Kein- noch Embryonalkugeln vorhanden. Bei andern Individuen zeigte sich der aussere llöcker ausserordentlich kitein und aul seiner ganzen Oberfliche mit hurzen Stachelspitzen besetzt; sic enthielten nicht den eben erwahnten hugelförmigen 
Körper. Ich vermuthe, dass bei diesen Individuen der Höeker in der Rückhildung luegriffen war, und dass sich bei allen zuvor Embryonen entwickelt hatten, welche bereits ausgeschwirmt waren.

Epistylis crassicollis bringt noch eine läohst eigenthümliche Generation acinetenăhnlicher Sprösslinge hervor, die vielleicht die Bedeutung von männlichen Individuen haben. Ich habe diese merliwiadigne Entwickelungsweise zuerst im J. 1853 haulig bei Tharand, später auch gar nicht selten hei Prag beobachtet, dessenungeachtet ist mir noch Vieles daran unklar geblieben. Es entstehen nämlich an der Basis des Epistyliskörpers und zwar dicht neben dem Stiele, auf welchem derselbe sitzt, ein oder zwei, selten drei, sehr kleine, halbkuglige, linospenartige Auswijchse, die sich bald von dem Multerthier abschnüren und dann als fast kugelförmige Knospen erscheinen, welche in ihrem ganz homogenen Parenchym einen centralen runden Kern und dem Anheftungspunct gegeniiber einen lebhaft contractiten Behälter besizen. Diese Knospen, welche nicht selten an sehr vielen Individuen eines und desselben Stockes vorhanden waren, entwickeln sich niemals zu gewöhnlichen Kunospensprösslingen, sondern es weicht bei weiterem Wachsthum der Knospe ihr Parenchym am Scheitel von der begränzenden derhhaubigen Cuticula eine kleine Strecke zuriick und sie gleicht nun einer geschlossenen Kapsel, die bis auf einen schmalen, in Profil halbmondförmig erscheinenden Hohlıaum am Scheitel ton cinem nach vorn elwas abgeplatleten und hies granz scharf begränzlen thierischen Körper ausgefüllt wird. Dieser zerfält nach einiger Zeit llurch guere oder schiefe Theilung in zwei ungleich grosse Segnente, von denen jedes einen besondern Kern und einen besondern contractilen Behälter hesitzt; das ğössere Segment fült den ganzen Hintergrund der liapsel aus, das kleinere liegt in dem vorderen, jetzt betrachllich grösser gewordenen Ilohlraume der Kapsel, hejle Segmente berïhren sich aher so innig, dass sie durch gegensejtigen Druck abgeplattel werden. Bis zu dieser Entwickelungsstufe liann lie Kapse mit dem müllerlichen hörper im Zusanmenhang bleiben, häufig wird sie aber schon ror der Theilung ihres Inhalts von dem weiter wachsenden Mutterthier alsgeschnür und nach rickwaits gedrangt. und sic bleibt nun an eines Seite des Stielendes sitzen. Dassclbe geschieht anch mit den Kapseln, deren Körper bereits in zwei Segmente zerfallen ist.

Der vordere Sprössling verlässt jedenfalls späler die Kapsel; es gliiclite mir jedoeh niemals, diesen Vorganğ direct zu beobachten. Ith traf indess ungemein häufig an den Seiten der Stochäste dicht unter den terminalen Epistylisthicren ganz gleiche Kaspeln, welche am Schcitel mit einer weiten, runden Mundung versehen waren. Die Kapselmembran schlug sich an der Miundung in eine zarhhäulige kurz röhrenförmige Duplieatur nach innen um, und an dieser war ein bald dic Kiupsel fast gan\% ausfiulender, bald frei in ihr schwehenter Körper aufgehingl, der genau nit dem Körper ïhercinslimmte, welehen die von den Epistylisthicren enwwickelten Kapseln einschliessen. Er bestant aus derselben homogenen Substanz, enthielt einen ganz gleichen Kiern und einen eben solchen contractilen Behältes. Von Zeit zu Zeit trieb der Körper an seinem Scheitel einen durch die Kapselmindung weit sich nach aussen erstreckenden, am Ende gehnopften, fudenförmigen Tentakel hervor, der sich genau eben so abwechselnd verhingerte und verkïrzte, wie die Tentakeln der Acinetinen, auch häufig hin und her geschleudert und dann plölzlich wieder in den körper zurickggezogen wurde. Die entwickeltsten Kapseln waren umgeliehırt eiförmiğ, nach der llïndung zu hakartig verengert und nach hinten schnabetförnig zugespitzt. In manchen Kapseln war der Körper genau wie bei den noch an den Epistylisthieren sitzenden geschlossenen kipseln in cin rorderes kleineres und fin hinteres grösseres Segment zerfallen; in diesem Fall trat nie ein Tentakel nach aussen hervor. Eine weitere Entwickelung des vorderen Segmentes kounte ich leider nicht heobachten.

Offenliar sind die eben beschrichenen Kapseln dieselben Gebilde, welehe von Claparide und Lachmam au den Stöcken von Epistylis plicatilis beobachtet und für einen zufälligen, rhizopodenartigen Parasiten des Epistylisslocks ausgegchen wurden, welchen diese Forscher Urnula Epistylidis nennen '). Nach den so eben von mir mutgetheilten Beobachtungen kann es aber wohl kaum noch cinem Zweifel unterliegen, dass die Umula Epistyliclis nicht ein Parasit, sondern mur cine acinetenarlige Sprösslingsform der Epistylishluere sein kann. welche sich ans eigenthümlichen Basalknospen des Epistyliskörpers entwickelı. Ein und derselbe Parasit wiirde sehwerlich, auf zwei versehiedenen, unter ganz andern aussern Verhailtnissen Jehenden Epistylisarlen rorkommen, er wiurde auch geviss nicht so bestandig an den äussersten Enden der stockäsle dicht unter dem Epistylisköper sitzen. sondern ebenso wohl an tieferen stellen des Stockes anzutreflen sein. Nach Claparède und Lachmamm entwickelt sich das

1) Annales des scienc. nat. 1857. Tome VIII. p. 233. 23:3. 238. 242. Claparéde u. Lachmann haben noch keine specielle Beschreibung von ihrer Urnula Epistylidis gegeben; aus den einzehnen zerstreuten Angaben über dieses Geschöpf entuehme ich aber, rlass dasselbe mit den von mir beobachteten acinetenartigen Sprösslingen identisch ist. 
aus der Theilung des Lmulakörpers hervorgehende vordore Seg̣ment anf ganz ähnliche Weise, wie bei Acineta mystacina, zu einem auf ter ganzen Oberflache hewimperten Sprössling. Was ans demselben wird, luaben die genannten Forscher nicht angegeben, sie sprechen aher an einer andern stelle') von gevissen lndiviluen der Urnula Epistylidis, welche in einer lingelförubigen Iushöhlung les Parenchyms lileine, lehlaft bewegte Körperchen enthielten. die sie selbst fir spermatozocnartige Gebilde zu halten geneigl siml. Wenn nun die Uruula nur eine eigenthiiuliche Generation von Epistylisthieren ist, muss mau dann nicht dor Vermuthung Raun geben, dass dieser Generation die Bedeutung von mänlichen Epistglistheren zukomme, wahrend die mit keimbugeln versehenen gewölntichen Epistglisthiere die weiblichen Individuen darstellen? Die Zeit wird lohren, ob meine Vermuthung eine richtige war.

Bei Vorlicella nebulifera hahe ich hisher nur erst einige Male die Entwickelung von ganz ăhnlichen Keimkugeln, wie hei Epistylis crassicollis heohachtet. Die Keimlungeln lagen ebenfalls ganz vorn im Leibe dicht luinter dem l'eristomrande und neben dem vordern Ende des slrangförmigen Nucleus, der keine andere Veranderung erlitten hatte, als dass seine vordere llatfte merlich schmaler geworden war. Gewöhnlich fand ich zwei ouler ulej Keimkugeln ron ungleicher Grösse in einem Thiere; sic bestanden chenfalls aus einer sehr lichten, homogenen Substanz und enthielten einen npaken centralen Kern. Einmal sah ich eine kleine Keimkugel noch mit dem rordern Ende des Nucleus zusammenhängen. während neben demselben eine selı grosse lag, von der sich eben eine kleinere abschniirte.

Ausserdem kommt bei Vorticella nebulifera noch häufig eine ebenfalls rom Nucleus ausgehende Fortptlanzungsweise ror, die wahrseheinlich nur deshalb bisher unbeachtel blieb, weil sie für ein Stadium der Knospenbildung gehalten wurde. Es entwickolt sich nämlich in der hintern Hälfte des Vorticellenhörper's, meist in geringer Entfernung von seinem Insertionspuncte auf dem Stiele ein ansehnlicher, linospenarliger Auswuchs von kegrel- oder eiförmiger Gestalt, der gewöhnlich schıäg nach abwärts gerichtet ist. An seinem freien gerad abgestutzten Ende findet sich ein kurzer ringförmig zusammengeschnirter Absatz. der mil einer rundlichen. an der einen Seite etwas eingeschlitzten Mundung verselıen ist. Aus dem lnnern des knospenförmigen Auswuchses, der sich nie zu einem gewöhnlichen Knospensprössling entwickelt, schimmen eine grosse Anzihl kleiner, ovaler, liernartiger, opaker Körperchen herror, und eben solche Körjerchen finden sich auch im Innern des Vorticellenkörpers an der Stelle des Nucleus; sie zeigen sich hier in emer Weise gruppirt, die der ursprünglichen Form des Nucleus sehr ahnlich ist. Offenbar sind diese liörperchen aus dem Zerfall des Nucleus hervorgegangen, und sie werden dann nach und nach in den knospenförmigen Auswuchs hineingedrängt. In welcher Form sie von hier aus durch die vordere Ifïndung nach aussen hervortreten, habe ich noch nicht ermilteln können; dass aber llurch die Hiundung ein Geburtsact stattfindet, daran kann nicht gezweifelt werten. Denn der knospenförmige Vorsprung wird mit der Zeit airmer an hernartigen Körperchen, el zicht sich immer mehr gegen seine Längsaxe zusammen und an seiner ganzen Oberflache treten ganz kurze Stachelspitzchen hervor. Zuletzt erscheint der frühere knospenartige Vorsprumg als ein enger röhrenfürmiger, nach abwärts hängender Schlauch, der dicht mit kurzen, geralen, aufrecht stehenden Borsten hesetzl ist. Einige Male sab jeh aus der Mündung desselben einen grössern nackten ovalen Körper hervorıgen. der am vordem Ende mit zwei oder drei kurzen, geknopften Tentakeln versehen war und im Innern cinen opaken Kern und ror demselben einen hellen Blasenraum enthielt, der jedoch unveranderlich blieb. Ich vermuthe, lass dies ein abgestorbener, in der Geburtsöffnung stecken gebliebener Embryo war, und jeh möchte daher annelımen, dass auch aus den kleinen ovalen Körpern im Mutterthiere und in dem knospenförmigen Vorsprunge Eumbronen hervorgehen.

Die mir bekannten Embryonen ron Infusorien (die von Paramaccium aurelia und bursaria, von slylonychia mylilus, Urostyla grandis und Bursaria truncatella) sind lem Mutlerthiere völlig unälnlich; sie miissen jedenfalls bedeutende Vetamorphosen durchmachen. um die Gestalt des Hutterthieres zu erbalten. Dil wir iber diese Metamorphosen noch in gäzlicher Unkenntuiss sind, so wäre es ein rergebliches Bemiihen, gegenwartig selion da: Gesetz bestimmen zu wollen, welches dem gesammten Entwickelungsgange eines Infusionsthieres zn Grunde liegt. Balbiani låsst zwar die acinetenartigen Embryonen ron Param. busaria bald nach ihrer Geburt steh direct in junge, dem Mutlerthier glejch organisirte Geschöpfe umwandeln, allein ich habe eine solche Lmwandlung nie beobachten liönnen, obwohl ich Hunderte von Embryonen sehr anhaltend studitte. Dagegen sah ich nicht selten. wie die frei

I) A. a. O. p. 238 
gewordenen Embryonen auf dem Objectglase sich lugelförmig zusammenzogen und ihre Wimpern abwarfen. Sie glichen dann ganz einer ungestielten Podophrya lixa; sie theilten sich auch hald darauf anf die bereits oben beschriehene, den Podophryen und der Acineta mystacina eigene Weise. Wenn in einer Flussiglieit gebahlurembe Paramäcien in grösserer Anzahl auftraten, so beobachtete ich stets an der staubigen Oberlliche der Flüssigkeit in grosser Menge gestielı und ungestielıe Podophryen und die frei umherschweifenden bewimperten Theilungssprösslinge derselben. Letztere zeigten eine selır verschiedene Grösse, sie stimmten aber bis auf das feinste Detail ihrer Organisalion rollkommen mit den Paramacienembryonen uberein. Mehrnals hatte ich gleiclızeilig ein gebahrendes Paramäcium und eine gestielte Podophrya, von ller sich eben ein bewimperter Theilungssprössling ahlöste, im Gesichtsfelde; ich sah dann den eben geborenen Embryo und den frei gewordenen Theilungssprössling sich in zierlichen Schwenkungen um einander bewegen und war nun nicht mehr im Stande anzugeben, welcher von beiden der Embryo und welcher der Theilungssprössling sei. Ich muss daher glauben, dass die Polophryen nur die weiteren Entwickelungsstufen der Paramăcienembryonen darstellen.

Ich homme nun noch einmal auf die Acinetinen wberhaupt zurich, uber die ich meine gegenwartigen Ansichten bercits an Ende des ersten Abschnittes entwickelt habe. Inzwischen ist eine Arbcit ron I'L'delicm erschienen $\mathbf{1}$, in welcher meine urspringhiche Lehre, dass die Acinelinen ledighlich in den Entwickelmugslireis der Vorticellinen gehören, mit grosser Entschiedenheit rertheidligt wird, es werten jedoch dic Acinetinen auf eine ganz andere Weise von den Vorticellinen abgeleitet. D'Udeliem versichert, dass er nicht blos die meisten der von mir beschriebenen Acinetinen und zwar in Gesellschaft derselben Vorticellinen, in der ich sie beobachtete. wicler aufgefunden habe, sondern er habe anch, wemn er eine neue Vorticelline beobachtete, stets auch cine dazn gehörige neue Acinetenform angetrofien. Diese in einer ganz verschiedenen Localitat (bei Brissel) gemachlen Erfahrungen sind gewiss sehr beachtenswerth, und sie sollten wohl dazu auffordem, die Acinetentheorie nicht allzu hastig iber Bord zu werfen. D'Udelem hat bei Epistylis plicatilis ebenfalls jene merkwüdigen Gysten heohachtet, welehe Claparede und Lachmamn von einem parasitischen Ampliteptus ableiten wollten (vergl. S. 50); diese Cysten rühren aber nach dem belgischen Forscher von den Epistylishlieren selbst her. Er sah, wie sich diese auf ihren Stielen zuerst mit einer Cyste umgaben und sich dann in ein frei bewegliches, anf der ganzen Oberfläche wimperndes, opalinenartiges Thier umbildeten, welches sich in der Cyste lehhaft umberdreht, dieselbe zuletzt durchbrichıt und dann frei umherschweift. Diesellye lletamorphose wurde noch bei emer neuen Epistylisart, ferner bei Carchesium polypinum, Zoothanmium arbuscula ${ }^{2}$ ), Vorticella microstoma, V. convallaria und zwei nenen Vorticetlenarten beobachtet. Kann man mun wohl noch glanben, dass, wie Claparede und Lachmam hei Epsslyl. plicatilis heohachtel haben wollen, in all diesen Fallen sich ein Amphileptus auf len Körper des vorticellenartigen Thieres hinaufgefressen und damn um sich eine Cyste ansgeschieden habe? I'Ldeliem läst mu den frei gewordenen opalinenarligen Cystenhewohner sich in eine Acinete verwandeln. Diese Vetamorphose ist jerloch niemals direct verfolgt worden, sondern sie wird nur aus einer Entwichelungsstufe der Acinela mystacina erschlossen, welche noch auf der ganzen Oberlltiche wimperte, zugleich aber schon mit den characteristischen Tentalielu versehen war. Indessen diese Entwichelungsstufe bewcist fur sich allein noch hieineswegs, dass sie aus jenem opalinenartigen starlium hervorgegangen sei, sondern sie kann elsensogut von einem Theilungssprössling der Aci. myslacina lıerühren. der im Begrif ist, sich wieder in die gewöhmliche Acinetenform umzugestalten. D'Ldeliem's Aluleitung der Acinetinen von Vorticellinen ist daher anch nur eine blosse Hypothese.

Die Acinetinen würlen unbestreitbar selbststindige Infusorienfornen sein, wenn sich zeigen liesse, dass die von ihnen entwichelten Schwärmsprösshinge wahre, anf geschlechlichem Wege erzeugte Embryonen seien. Allein so bautig anch bei den Acinetimen die sprosslingsbildung beoluachtet worden ist. so hat sich doch noch nichts wahmehmen lassen, was auf eine dersehen voransgehenle Befruchtong schliessen liesse. Die Enhwichelung der Acinet nsprösslinge weicht auch in mehresen Beziehmgen von der Embryonenbildung ab, weshalb ich glaube. dass der Nuclen: bei den Acinetinen nur als Kemstock. nicht als weibliches Geschlechtsorgan fungirt. Es schnür sich nảmlich von dem Nucleus immer nur ein meist sehr vergrössertes Stuck ab, und ans diesem entwickelt sich

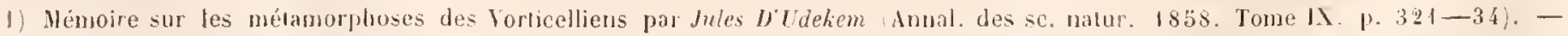
2) Bei einem von mir in der Nordsee auf Carcinus Maenas beobachtelen Zoothamnium habe ich ebenfalls an den Enden der Sıckäste ringe Mble Cysten angetrofien, welche von entem lebhaft rolirenden, ringsum geschlossenen, auf der anzen Ohenlliche wimpernden Thier erfüllt wurden. 
auch in den meisten Fïllen nur ein einziger Sprösslinğ, der sich nicht sclten auf Kosten des mütterlichen Körper's so betrachtlich vergrössert, dass dieser, so wie der Sprösslingr geboren ist, auf cin ausscrordentlich kleines Volumen zusammensinht. Hecht auffullend ist dies bei Acineta aslaci zu beobaehten, wo der Geburtsact ganz den Eindruck einer blossen lläutung macht. Bei Acineta tuberosa und Dendrosoma astaci habe ich nielıt selten mehrere Schwärmsprösslinge in einem Individum sich entwiekeln sehen. Aber auch in diesem Fall sehnüte sich stets nur eine vergrösserte scheihenförmige P'ortion rom Nucleus des Mutterthieses ab, welche mit einem kern und mehreren contractilen Behältern versehen war. Diese Portion zerfiel daun durch ganz regelmässige Theilung in zwei Hailften, welche sich spiter noch ein- oder zweimal theilten. Jodes Segment besitzt seinen besondern Kern und besondere contractile Belälter; zuletzt treten an allen sich abrundenden Segmenten glciehzeitig die iussern Wimpern auf, sie sind num entwickelte Sprösslinge, die bałd sehnell naeh einander aus dem Nutterthiere nach aussen hervorbrechen.

Sehr auffaltend ist, dass die Sprösslinge der verschiedenen Acinetenformen eine so verseliedene Art der Bewimperung zeigen. Bei Aeineta Opercularıe, lighlatat, cothunata und solaris ${ }^{1}$ ) sind die sehr grossen Sprösslinge auf der ganzen Oberfliche dicht und gleichförmig bewimpert. Die Sprössinge ron Aeineta astaci sind nur auf der flacheren Bauchseite und am vordern Ende dicht mit zarten Wimpern bekteilet. Die länglichen, drehrunden Sprösslinge ron Acin. Iuberosa, infusionum. Lemnarum. quadriloba und Cyelopum zeigen den mittlern Thell des Körpers in einer grössern oder geringern Auslehnung mit ringförmigen Eiusehniurungen versehen, und nur dieser quer-

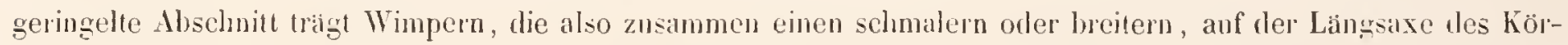
pers senkreeht stehenden Gürtel bilden. Die plallgedrückten, fast schcibenförmigen Sprösslinge von Acineta digitata, Dendrosoma astaci und Dendroeometes paradoxus sind nur am Rande des körpers concentriseh gefurcht und hier allein mit zarten, langhaarigen Wimpern besetzt.

An den Sprösslingen mehrerer Acinetenarten erkannte ich an einer bestimmten Stelle des Körpers einen kleinen mundähnlichen, junden Saugnapf, der zuweilen auf einem ganz kurzen zapfenförmigen Vorsprung sitzı und leicht fül cinen Mlund gehalten werlen kinn; er dient jeloch zum Fixiren des Sprösslings, wenn dieser sich wieder in eine Aeinete umbildet. Die Sprösslinge ron Acineta solarıs und tuberosa besitzen diesen Saugnapf nahe am vordern Körperende, die von Aein. astaci ziemlich in der Nitte der bewimperten Bauehseite. Aueh an dem bewimperten Theilungssprössling von Acin. mystacina und Podophrya fixa ist ein kleines, nabelförmiges Saugnäpfchen vorhanden. - Die ruckschreitende Metamorphose der Acinetensprösslinge erfolght oft schon wenige Minuten naeh der Geburt. Ich beobachtete diese sehr häufig an den grossen, sich nur mit missiger Geschwindigkeit hewegenden Sprösslingen von Aein. solaris. Nachdem die Bewegungen des Sprösslings langsamer geworden sind, bleibt el plötzlich liegen, dic Wimpern hören auf zu schlagen und schrumpfen in wenigen Augenblicken bis zum völligen Versehwinden zusammen. Wahrend sich das vordere Ende mittelst seines Saugnapfes an irgend eincm Gegenstande oder auf tem Objectglase fixirt, treten zuerst am hintern Ende und dann im ganzen Umfange hurze conische Ausstilpungen hervor, die sich bald zu den gewöhnlichen greknopften Tentakeh verlingern. huzwischen hat sich der bisher horizontal liegende liörper am hinteren Ende gehoben, und es währt nicht lange, so nimmt er eine verticale Stellung cin; sein vorderes Ende ist nun das untere oder hintere gevorden und dicses sebeidet naeh und nach durch den Saugnapf die Substanz aus, welche zum Stiel erhïrtet. Auch bei Acin. tuberosa, Operculariae und astaci habe ich die kijekbildung der Schwirmsprösslinge in Acineten verfolgh.

Schliesslich muss ich noch einige Worte über die angebliche Brutbildung sagen, welehe zuerst von mir an encystirten Vorticellen (vergl. S. 4.4) und von Cienkowstit an den Cystenzustanden von Nassula anlbigua (S. 4.S beobaehtet wude. Ich bin jetzt der Ansicht, auf die aucl bereits von Cohu hingedeutet worten ist ${ }^{2}$ ), dass wir es hier gar nicht mit einer Fortphlanzungsweise der hetreflenden Infusorien, sondern mit ciner parasitischen Alge aus der Abtheilung der Saprolegnieen zu thun baben, deren lieime in den Infusorienkörper eindringen und sich naeh der Enç̧stirung desselben auf Kosteu des thierischen Parenchỵms zu schlauehförmigen einzelligen Pflanzen entwickehn. Letztere wachsen, wenn sich in ihrem lnıern Schwärmsporen entwickelt haben, in cinen röhren-

1) Diese neve Acinelenform beobachlete ich in den letzten Jahreu sehr hïufig in Mistpfülzen; sie hat viel Aehnlichkeit mit Podophrya lixa und mag wohl ölters mil ihr verweclselt worden sein. Ihr Körper ist umgelichrt eiförmig und auf der ganzen Oberläiche mit nach allen Richlungen thin ausstrahlenden Tentakeln besetzl, er enlhält einen ovalen Nuclens und gewötulich drei ronlractile Behiitler und wird von einem dünnen, iiberall gnleich hreiten, massiven Stiel getragen. Die Tevtakeln zeigen bei der Verhürzung zickzackförmige Biegungen. 2) Zeitschrift für wissenschaftliche Zoologie 1857 . Band IX. S. I 45 . Anmerkung. 


\section{6}

förnigen, den Infusorienkörper und die Cystenwand durchbohrenden Fortsatz ans, der sich dann an der Spitze offnet und die Sclıwarmsporen heraustreten lasst. Nan hraucht nur die von Pringsheim gegebene Darstellung des im Innern des Copulationskörpers einer Spirogyra sich entwickelnden Pythium entoplyytum ') zu vergleichen. und man wird die iberraschendste Uebereinstimmung mit den von mir an den Vorticellencysten beobachteten Erscheinungen erkennen. Die beweg̨ichen Keime, welche aus dem röhrenförmigen, die Vorticellencyste durchbolırenden Fortsatz hervortreten, sind von mir nenerlich genaner studirt worden. sie hesitzen am rordern Ende eine einzige geisselartige Wimper, lassen aber im Innern weder cinen Kern, noch einen contractilen Behälter erkennen; sie gleichen also in jeder Bezichung den Schwärmsporen von Pythimn entophytum, wie sie Pringsheim abbildet. Auch im Körper anderer encystirter Infusorien, so wie im Innem völlig abgestorhener Individuen ron Acineta Lemnarum sah ich ahnliche geschlossene Schläuche auftreten, wie bei den encystirten Vorticellen; sic wuchsen zuletzt cbenfalls in einen conischen, mach anssen hervortretenden und sich an der Spitze öfuenden Fortsatz aus, durch den ahtuliche Schwirmsporen entleert wurden ${ }^{2}$.

1) Pringshein Jihrbücher für wissenschaftl. Botanik 1857. Band f. S. $288-89$ und Taf. XXI. Fig. 1. - 2) Die von mir in Innern einer Acinela mystacina beobachteten sechs Schliuche (Stcin Die Iufusionsthiere Taf. I. Fig. 20. c. c.) waren höchst wahrscheinlich nichts weiter, als parasitische einzellige Algen, die noch keinen röhrenförmigen Fortsatz getriehen hatten. 


\title{
specieller Theil.
}

\author{
Erstes Buch.
}

\section{Die Ordnung der hyotrichen Infusionsthiere.}

Character: Dic hypotrichen Infusionsthiere sind ausgezeichnet bilaterale Infusionsthiere mil scharf geschiedener Rüchen-umd Banchseite; die convexe Rüclienseite ist stets ganz nacht, die flache abgeplattete Banchseite trägt allein Wimpern. Sowohl der Mund, als auch der After liegen auf der Bauchseite; erstever findet sich immer mehr oder weniger weit vom vordern hürperende entfernt, let:terer in einiger Entfermung vom hintern Kürperende, nie am Ende selbst.

Den Stamm dieser Ordnung bilden diei von Ehreuberg aufgestellte, im Allgemeinen ganz naturgemäss begränzte, jedoch durch keine hinreichend scharfe Charactere von einander geschiedene Familien, nämlich seine Oxytrichina, Euplota und Aspidiscina. Diese Familien stimmen in der Anlage ihrer gesammten Organisation so nahe mit einander überein, dass über ihre Zusammengehörigkeit und ihren unmittellsaren Anschluss an einander nichı der mindeste Zweifel ubrig blciben kann. Sie zeichnen sich vor allen andern Infusorien sogleich durch die eigenthimbliche Entwickelung und Anordnung ihrer Wimpern aus, welche die Form von Borsten, Haken oder Griflum annehmen (vergl. S. 69) und nur auf bestimmte Gegenden der Bauchfliche beschränkt sind. Ein Theil der Wimperm setzt stets einen am linken Seitenrande sich herabziehenden adoralen Bogen zusanımen, die ubrigen Wimpern sind theils in gerade oder schrige Laingsreihen angeordnet. theils gruppenweis zusammengestellt, und lediglich hiernach lassen sich verschiedene Kategorien von Wimpern (vergl. S. 70) unterscheilen. Der Mund wird stets von einem mehr oder weniger entwickelten Peristom umgeben; ein Schlund fehlt, oder es ist doch nur eine schwarhe Indentung dessclisen vorhanden.

Trotzdem, dass die drei in Rede stehenden Familien so hervorstechende Merkmale mit einander gemein haben und dadurch zu einer grössern natiirlichen Gruppe verbunden werden, hat Ehrenberg dennoch den Aspidiscinen eine andere Stelle in scinem Systeme angewiesen, als den Oxytrichinen und Euplotinen. Die beiden letzteren Familien wurden nijmlich wegen ihres auf der Bauchseite vor dem hintern lörperende gelegenen Afters in die Altheilung der Catotreta gestell und lediglich nach der Beschaffenheit ihrer äussern Körperbedeckung von einander unterschieden; die Oxytrichinen sollten die panzerlosen Formen mit borsten-, haken- oder griffelformigen Bcwegungsorganen, die Euplotinen hingegen die gepanzerten Formen umfassen. Die Aspidiscinen erhielten wegen ihres angehlich terminalen Afters ihren Platz unter der. Allotseten; sie wurden als gepanzerte Allotreten bestinnt. Allein der After findet sich hei den Aspidiscinen in Wirlichkeit an derselben Stelle, wie bej den Euplotinen, es scheint daher jefler Grund zur fernern Trennung dieser beiden Familien wegzufallen. zumal da sie sich auch in ihrer ubrigen Organisation schr nahe an cinander schliessen. Die Mighieder beider Familien hesitzen nammlich eine starre, panzerartige Körperbeleckung und nur eine geringe Anzahl starker, griffelfömmiger Bauchwinupern; Randwimpern konmen ihnen nicht zu. Dujardiu hat deshalb auch bereits beide Fanilien in eine zusammengezogen und damit noch einige andere. ungenigend beobachlele Formen verbunden. Er nem diese Familie Plocsconiens; aus den Oxytrichinen Ehrenberg's und der ihnen fremdartigen Gattung Halteria Duj. bildot er seine Familie héroniens. Perly nimmt ehenfalls nur zwei Fimilien an, die Oxytrichinen und die Euplotinen, mit welchen die Aspidiscinen vereinigt sind. Beide Familien werden in scinem Systeme durch die ganz unnatiirliche, die heterogensten Infusorienformen umfassonde Familie der Cobalina von einander getrennt, während Dujardin ganz richtiǧ seine Kéroniens und 


\section{8}

Ploesconiens unmitlellsar auf einander folgen lasst. Claparede und Lachmann sind in ihrer neuesten Arbeit ${ }^{1}$ in der Zusammenziehung noch weiter gegangen; sie vereingen die Oxytrichinen. Euploten und Aspidiscinen Ehrenberg's in die einzige Familie Oxytrichina. Als Grund fur dieses Verfahren wird angeführt, dass einerseits die Trennung der Aspidiscinen ron den Euplotinen lealiglich auf Jer irrigen Toraussetzung eines terminalen Afters bei den ersteren beruhe, und lass andererseits der von Elrewberg zur Unterscheidung der Oxytrichinen und Euplotinen aufgestellte Character nur anf dem Papier klar sei, in der Wirklichkeit aber sich als sehr umbestimmt und unzuverlassig erweise. Beides ist richtig, dennoch glaube ich, dass die drei Ehrenberg'schen Familien aufrecht erhalten werten können, da sich andere ganz scharfe und unzweideutige Merlimale zu ihrer Unterscheidung angeben lassen.

Zunachst bilden die Oxỵtrichinen eine gut alggegranzte Familie, die sich freilich nicht durch einen panzerIosen Körper ron den stets gepanzerten Euplotinen und Aspidiscinen unterscheidet. lch habe selbst bereits (S. 56) darauf hingewiesen, dass zwischen gepanzerten und panzerlosen Infusorien heine scharfe Gränze existire, und dass namentlich bei den Oxytrichinen die äussere Körperbedeckung einen sehr verschiedenen Grad ıler Consistenz zeige. Sämmtliche Oxytrichinen besitzen aber einen sehr ausgezeichneten äussern Character in den zu beiden Seiten lles Körpers sich herabziehenlen, continuirlichen Randwimperreihen, und diesem entsprechen auch noch andere Eigenthimblichkeiten der innern Organisation. namentlich die constante Lage des contractilen Behalters am linken Seitenrante hinter dem Peristom und das fast allgemeine Vorkommen von zwei ovalen Kermen. Bei den stets gepanzerten Euplotinen und Aspidiscinen fimlen sich keine Rantwimperreihen, der contractile Behalter liegt stets in der Nahe des Afters neben den rechten Seitenrande, und der Nucleus ist strangförmig und in der Regel nur in einfacher Zahl vorhanden. Wegen dieser gemeinsamen Merkmale könnte man allerdings die Aspidiscinen und Euplotinen zu einer Familic vereinigen; allein die Aspidiscinen besitzen doch einen wesentlich verschiedenen Hahitus, der durch die ganz andere Form des Peristoms hedingt wird. Es zicht sich nämlich bei ihnen nur am linken Seitemrande eine adorale Wimpereihe herab, welche von einem lamellenartigen Vorsprung der Banchwand ijberdeckt ward; bei den Euplotinen und Oxytrichinen dagegen bildet das Peristom einen mehr oder weniger weiten, offenen Ausschnitt, der nach links vou einem adoralen Wimperbogen beģäinzl wird, welcher sich uber den Vorderrand des Thieres bis zum rechten Seitenrande fortsetzt.

Es existirt nun noch eine vierte Familie von hypotrichen Infusionsthieren, die sich meiner Ansicht nach olne Zwang an die Aspidiscinen anschliesst, obwohl sie zu deu drei ubrigen Familien in einem losern Verwandtschaftsrerhältnisse steht, als das ist, welches diese unter einander verbindet. Die heliannten Reprdisentanten dieser Familie, die ich Chlamydodonta nenue. waren bisher nur ungenügend erforschl, es sind die Gathung Chlamydodon, welche Ehrenbery unter die Euplolinen versetzte, ferner die Gatlunge Chilodon, wclche hisher fir holotrich galt und vou Ehrnberg zu den Trachelinen gestellt wurde, sodann Euplotes monostylus Ehbg.. aus dem Dujardin die Gattung Ervilia bildete, und endlich die nahe verwandte Gallung Trochilia Dnj. Aus den beirlen letzteren Gattungen bildere Injardin die heine Familie der Erviliens, die er mit richtigem Tacte an seine Familie der Ploesconiens anschloss. Zu diesen behannten Formen liommen soch drei neue Gattungen Phascolodon. Opisthodon und Scaphidiodon. Sämmlliche Chlamydorlonten sind nur auf der Bachseite mit gleichartigen. feinharigen Wimpern besetzt, die entweder die ganze Bauchflàche ïberziehen, oder sich nur auf eine mediane oder latcrale Zone beschränken. Der Körper ist eutweler deullich gepanzent oder doch in seinen Unrissen nur unbeleutend veränderliels. Stets ist ein entwickelter trichterförmiger Schlund vorhanden, dessen Wandungen entweder ganz verhornt oder doch zu slabförmigen Zïbnchen verdickt sind.

Uebersicht der vier Fanilien der hypotrichen Infusorien:

A. Hauchfliche ganz oder theilweis mit dichtstehenten, leinbarigen Wimpern besetzl; ein horniger oder fischreusenarliger Schlund.

I. Fam. Chlamydodonla.

[3. Bauchfliche mit hestimmt gruppirten, borsten-, haken-oder grillellöruigen Wimpern beselzl. Schlund undeutlich oder felılend.

1) Ohne lianolwinuserreihen

a) Der von einem Fortsalz der Bauchwand überragte adlorale Wimperbogen reıclı nur bis zum Torderrand.

b) Der freiliegende adorisle Wimperbogen breilel sich über den ganzen Vorderrand aus.

2) Mit kandwimperreilıen.

2. Fam. Asjudiscina.

3. Fann. Euplolina.

4. Fan. Oxylrichino.

1) Etudes sur les Infusoires et les Rhizopodes par Edouard Claparede el Johamnes Lachmann Genève 1858. 1. Livraison p. 135 


\section{Erste Familic. Chlamydodonta. Steix.}

Character: Die Chlumydodonten sind hypotriche Infusorien mil gepanzertem oder doch formbestindigem Körper, dessen Banchseite yanz oder theiheeis mit dicht getringt stehenden, feinhaurigen Wimpern besetst ist; suweilen findet sich am hintern Ende ein beweglicher, fussartiger Griffel. Der stets sehr dentliche gerade, rihren- oder trichterfirmige Schlund ist entweder mit stabfömigen Zaimchen bewu/finet (fischeusenartig) oder seine W'andungen sind panzerartig erhirtet und ganz glatt.

Diese aus 7 liatungen hestehende Familie wurde von mir zuerst in der l'Jager Lotos vom Januar $1859 \mathrm{~S} .3$

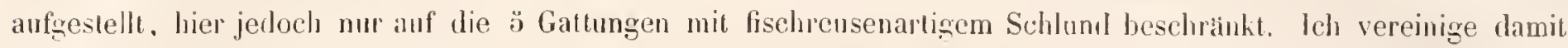
gegenwärtig auch die klene Familie der Erviliens von Dujardin, welelı mir nur den Werth einer Unterfamilie zu haben scheint, obwohl sie in dem bewegliehen Grifel am hintern Körperende und in dem glatten, starren Schlundrohr scharf hervorthetende Kennzeichen besitzt. Die meisten Chlamyrlodonten haben cinen stark plattgedriickien Kö̀per mit ganz planer Bauchseite und massigg gewölbter, uach vorn zu öfters betrachtlich verflachter Rückseite; nur bei ciner Galtung (Phascolodon wirl der Körper fast beutel- oder lirugförmigr, indem sich der Riichen sehr slark wölbt und die Seilen abrunden, wahrend die schmale Bauchflache nach rorn in schräger Richtung gegen die Rijchseite aufsteigt. Das Körperparenchym ist nach aussen entweler zu einem deutlichen Panzer erhärtet (Seaphidiodon, Errilia) oder doch so resistent, dass die Totalform des Körpers keme merklichen Veränderungen erfahren kamu; nur die verflachten landthejle des Körpers sind mehr oder weniger biegsam. Die Bewimperung dehnt sich bald uber die ganze Bauchfliche aus (Phascolodon, Chilorlon, Opisthodon), Jald ist nur ein schmaleres oder breileres rom Vorderrand bis zum Hinterrand sich erstreckendes Mlitelfeld hewimpert (Chlamydodon, Seaphidiodon, Trochilia), bald verliuft nur längs des Vorderrandes und des einen Seitenrandes eine schmale Wimperzone (Ervilia). Der bewimperde Theil der Banchflache ist der Länge nach gestreift, daher die Wimpern in Reihen zu stehen scheinen. Der Schlund liegt in der vordern Körperhälfte und ist gewölınlich hinten nach rechts gerichtet, nur bei Opisthodon lindet er sich in der hintern Körperhłiffe. Die meisten Clılamydodonten besitzen zwei odler mehrere contractile Behälter, dagegen fast immer nur einen Nucleus.

Uebersicht der Gattungen der Culamydorlonten:

1. Interfamilie Chlanyiloulonta s. sir.

Schlund fischreusenförmigr kein beweglicher Griffel am hintern Körperende.

1) Körper fast drehrund, nil schmaler, nach voln schrïg gegen den Riicken aufsteigender Bauchfläche. 1. Phascolodon.

2) Körjer platlgedrückl mit planer Bauchlläche

a) Die ganze Bauchilache bewimpert

a) Mund in der vortern Körperhälfte

ß) Mund in der hintern Körperhiilfte

b. Nur das Hillelfeld der Bauchseite bewimpert

$\alpha$ Das Millelfeld von einem ringförmigen Eindruck umgeben, Körper hinten abgerundel.

B) Das Millelleld olme ringlörmigen Eindruck, Körper hinten zugespitzt.

2. Chilodon.

3. Opisthodon.

4. Chlamydodon.

5. Scaphidiodon.

\section{Interfamilie Erriliina.}

Schlund starr und glall, ein beweglicher Griffel an hintern Köörperende.

1) Wimpern auf einem schmalen seitwärts gekrümnten Miltelfeld der Bauchseıte.

2) Wimpern in einem Ausschnill lïngs des Vorder-und rechleu Seilenrandes.
6. Troclilia
7. Ervilia.

\section{Gattung. Phascoloidon. Steix.}

Taf.' 1. Fig. I-5).

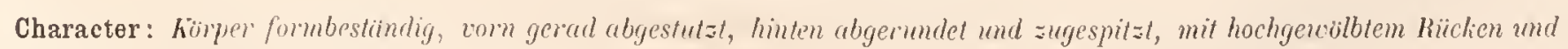
gerundeten Seiten; Bauchllache nach vorn erweitert, gegen die Büchseite aufsteigend und gans bewimpert; ein fischreusenfürmiger schlund in der vordern himperthälle.

Diese neue Galtunğ wurde von mir zuerst ju der Sitzunğ der Böhmisch. Gesell. der Wiss. am 19. Octaber 1857 kurz characterisirt und dann genaner in der Lotos (Januar 1859 S. 2) beschrieben. - Der lirug- odler loutelförmige Köpper gleicht auf den ersten Anblick vollkommen einen Torlicellenkörper; der Rücken und die beiden Seiten sind slark bauchig aufgetrieben, naclı vorn zu schwach halsartig verengert und am erweiterten, aljgestutzten Vorderende mil einel halbringfürmigen, elwas nach aussen ungeschlagenen, peristomartigen Wulst versehen, welche auf der untern Seite Fig. I und 3 ron der Bauchfliche unterbrochen wird. Nach hinten ist der Körper schråg 
abgerundet und anf der Bauchseite in eine kurze schwanzatige Spitze ausgezogen. Die Bauchfliche bildet eine scbiefe, in der hintern Körperhällie nach links gekrimmle und dann sich bis zur Schwanzspize verengernde Ebene; nach vorn steight sie in schrager Richtung gegen die Rüchen- und Seitemwandungen auf, breitet sich halburichterförmig ans und geht in die peristomartige Vorderrandswulst uber. Diese setzt sich unter einem stumpfen Winkel auf ler rechten Seite (Fig. 4) in eine die Bauchflache bis zur Spitze begleitende Seitenwnlst fort; eine wenigher entwickelte, nach binten sich balı verlierende Wulst findet sich auf der linken Seite. Die Bauchfläche ist fein längsgestreift und ihrer ganzen Ausdehnung nach dicht bewimpert (in den Figuren ist die Bewimperung nur theilweis ausgefulurt, am meisten in Fig. 3); die wulstörmige Einfassung der Bauchfläche zeigt rine concentrische Streifung. sic ist ebenfalls mit feinhaarigen Wimpern besetzt, die am Vordernande elwas länger sind. Die Rucken- und Seitenwandungen sind ganz nackt und glall. Die Banchwimpern ragen nach hinten und links über den Körperraud hervor; bei der Riickenansicht des Thieres Fig. 2) sieht man nur die verlingerten Vorderrandswimpern und einen von den vorragenden Bauchwimpern herrübrenden Wimpersaum an linken Körperrande. Die beiden freien abgerundeten Echen des peristomartigen Vorderrandes können einander genähert werden (Fig. 3), bei grössern lndividnen so bedentend. dass fast eine geschlossene rugförmige Mijudung am vordern Ende entsteht; im Uchrigen ist die Körp̣erform unverinderlich. - Der Mund liegt fast in der Mitte des vordern erweiterten Abschnilts der Batuchfidche; der schı̈ăge. trichterfömige Schlund (Fig. 1. 2. ph.) ist der rechten Seite zugehehrt, die borstenförmigen Zahnstilhelıen sind nur im vordern Theil des Schlundes deutlich, nach hinten ist derselbe glatt. Der After findel sich auf der Banchseite nahe vor der schwanzförmigen Zuspitzung; hier sah ich wenigstens lıăulig brăunliche Excremente zusammengehäuft. - Contractile Behälter (Figg. 1. 2. c. c.) sind zwei vorhanden, ein vorderer, nach innen neben dem Schlund gelegener und ein hinterer am linken Seitenrand. - Der ovale, fast die Körpernitte einnelımende Nucleus (Fig. I. 2. 1.) ist mit einer centralcu rundlichen Höhle versehen, die stets einen deutlichen Nuclcolus enthath.

Die Gattung Phascolodon ist eine offenbare Uebergangsform zu den perirrichen Infusorien, weshalb ich auch die Chlanydodonten an die spitze der Iypotrichen Infusorien gestellt habe. Hre Bewegungen sind sehr sehnell und gleichen denen von abgelösten Vorticellenkürpern, von Urocentrum furbo. Trichodina pediculus und andern peritrichen Infusorien; sie bestelıen in maulhörlichen Rotationen un die Längsaxe. Niemals salı ich die Thiere anf der Bauchseite kriechen, auch blieben sie heinen Augenblick stillstehen; ihre Organisation liess sich daher nur ermittehn, nachden sie getöltel worden waren. - Die einzige Art der Gallung leht im siissen Wasser; es isl:

Phascolodon vorticella. Sterx.

Abhandl. der Böhmisch. Geseltsch. der Wissensch. Band X S. 63 umd Lolos Januar 1839 S. ?.

Ich habe diese $\Lambda$ 't im April 1957 in eiucm Bassin des Prager botanischen Gartens, welches ron der Moldau gespeist wird, in zahllosen Exemplaren beobachtel; sonst ist sie mir nirgends vorgehommen. Die Thiere fanden sich an der sehr staubigen Oberfläche des Wassers gleichzeitig mil grossen Mengen ron Chamydomonas pulvisculus und Pandorina morum. Diese beilen Infusorienformen fanden sich auch als die gewöhulichste Nahırung im Innern des sonst ganz farblosen Phascolodonkörpers. Das Thier ham in sehr verschicdenen Grössen vor, Theilungszustände wurden aber nicht bemerkt. Die grössten Individuen waren $\frac{1}{2^{\prime \prime}}$ lang und $\frac{1}{3^{\prime \prime}}$ lreit; die Lảnge ihres Nucleus betrug $\frac{1^{\prime \prime \prime}}{86}$ Die jüngeren Individuen (Fig. 5. a. b.) waren gewöhnlich weit schlanker und nach hinten slarker zugespitzt, von fast kreiselförmiger Gestalı; doch sah ich auch junge Indwiduen Fig. ä. c.), die schon eine selır ähnliche Form hatten, wie die altern. Die jüngern Thiere können leicht nit Halleria (Trichodina Ehbg.) vorax ver-wechselt werden.

2. Gattumg. Chilodou. EHukg.

(Taf. I. Fig. 6-23).

Character: Körper formbestïndig, oval, mit planer, grans bewimperter Banchseite und mässig geurïbtem Räclien, nucle vorn in eine lamellenartige, schief abgerumdete, nach links gehrïmmle Oberlippe erweitert; Mund in der vordern Körperhalfte. sichlumd fischreusenartig.

Die Galtung Chilodon wurde von Ehrenberg in J. 1833 (Abhandl. der Berliner Acad. S. 287) auf Colpoula cuculluhs Mïll. gegrimdet und in die Familie der Trachelinen gestelt, weil Ehrenberg dieses Thier fiir holotrich und panzerlos ansah und den After als terminal bestimmte; unter den Trachelinen sollte sich Chilodon durch eine schiefe, lamellenartige Oberlippe und durch den Zahntpparat im Munde auszeichnen. Zu der urspringlich einzigen Aıt der 
Gattung wurlen im grossen Infusorinwerk noch drei nene Arten hinzugefugt; ron diesen ist jedoch die eine. Ch. uncinatus, nicht wesentlich von Ch. cucullulus verselieién, und die heiden andern, Ch. aureus und ornatus, sind wirklich holotrich und muissen deshall, in die Gattung Nassula gestellt werden. Es bleibt also in der Galtung uur eine Art zurück; diese zeigh nach Aufenthalt und Lebensweise erhebliche Verschiedenheiten in der Grösse und in äussen Körpernmiss. Hre höchste Entwichelung (Fig. (6-8) erreicht sic in langsam fliessenden Gewajssern, an deren Obcrllache sich eine reiche Vegetation von Aggen, besonders von Oscillarien lindet; während sic in Infusionen

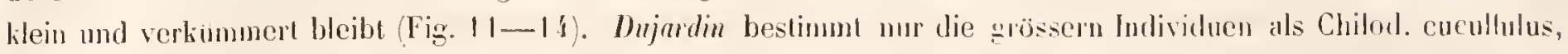
aus den kleineren bildet cr mehrere unhaltbare Arten, aus welchen er scine Gathng Loxodes zusammensetzt. die nicht mit der gleichnanigen Gathung von Ehrenbery identisch ist; fur letztere, die richtig auf Loxodes rostrum beschrankt ist, wird die unberechligte Benenunng Pelecidal eingefublut. Die Gattung Chilodon characterisint Injardiu in Wesentlichen wie Ehenberg, er beschrinkl sie auf Ch. cuculluhs und stellt sie in seine Fanilie der Paraméciens; die Gittung Loxodes dagegen wird in der Familie der Ploesconiens neben Aspidisca eingereiht, sie soll die Kürjerform mit Chilodon gemein hahen, aber von einer panzeraibnlichen Hülle bekleilet und nur an dem lijpenantigen Vorderande bewimpert scin. Perly lolgh. wie gewöhnlich, Mujardin, mur ordnet r' Losodes Muj. hei den Trachelinen ein. während er Chitodon in die neu errichtete Fanilie Decteria bringr, welche alle Formen mu fischreusenartigem Schluml mmfassen soll, magr der Mund auf der Bauchseite oder, wie bei Prorodon, an vordern Ende liegen.

Der Körper von Chilodon ist bald melır oval, bahl mehr eiförmiğ, auf der Bauchseite Fig. 6. 1.3) ganz plan otler selbst etwas concav; auf Jer Rucliseite (rig. 7. 8) setzt sich ein melır oder weniger ausgedehnter, ziemlich stark gewölbter Scheibentheil von den selır niedergedrichten, lamellenartigen Rändern ah. Am starkisten ist der Körper nach vorn abgeplattet und verdinnt, und dieser durchsichtigere Theil bildet eine schief abgerundete, fast beilformige, nach Jinks gekrïmmte lippe, welche bei grössern Individuen in cine schuabelarlige Spitze ausláuft Fig. 7 . 8. I.), wihrend bei kleinern Indiviluen (Fig. 13) statt derselben nur eine abgerundete Eche vorhanden ist. Die Jippe geht ganz altuabhliğ in die Seitenränder des Körpers über, sie ist nichts weiter, als cler stärker entwiclielte Vorderrand. Die Lippe und der ganze vbrige verdunnte Körperrand sind biegsan, sie werden bald aufwärts gebogen Fig. 9. 10. 11), bald beim Kriechen innig an fremde Gegenstände angeschmiegl; die Lippe inshesondere wird zum Tasten gebraucht. Der Scheibentheil des Körpers ist dagegen fast ganz starr; ur scine Wölbung ändert sich mehr oder weniger, indem sie beim Kriechen aus der Mitte mehr nach hiuten rickt (Fig. 7. 8. 10); am wenjgsten ist dies bej keinen Individuen (Fig. II) der Fill, die daber fast gepanzert erscbeiven und, wie Dujardin richtig hervorgehoben lat, sowohl ja ihrer Totalform, wie in der Consistenz ihres Parenchyms lebhaft an Aspidisca erinnern.

Dass Chilodon kein holotriches Infusionshlier ist, wie man bisher allgemein und ich selbst in meiner frülsern Monographie von Chil. cucullulus (Die Infusionsth. S. 126-38) annalum, davon uberzeugt man sich am bestimmlesten, wenn das Thic beim Anf- um Niedergleiten an frenden Gegenstanden dem Beobachter die linke Fig. !); oder die rechte Körperseite Fig. 10. 11 zulieht; man sieht alstann, dass die ganze Rüchseite völlig nackit und sylatt ist. Die Bauchlitiche ist ilırer ganzen Ausdehnung uach dicht mit feimharigen Wimpern besetzl, die am Rande uber die Körpercontouren binausragen. Die vorstehenden Randwimpern, sowie der Unstand, dass bei der hiickenansicht des Thieres die Bauchwimpern durch die durehsichtigen Seịtenrander und die Lippe hindurchseheinen, lıaben zu der irrigen Annalme Veranlassung gegebun, dass auch die Riicliseite bewimpert sei. Gegen den Vorterrand der Lippe hin nelmen die Wimpern mehr odel wenger an Länge zu, Was besonders bei juingern Individuen und zuweilen in auffallendem Grarle der Fall ist, wăhrend der iibrige Theil der Bauchseite sehr kurzhaarige Wimpern träğ. Bei nicht genigend scharler Beobachtung hat es damn den Anschein, als sei auch die ganze Banclıfläche mit Ausnalune der Lippe nacht; hierauf beruht die Gatung Loxodes Duj. Bei ganz jungen Individuen komnte ich hisweilen aller Anstrengung ungeachtet heine Banchwimpern, sonden nur Lippenwimpern unterscheiden.

Auf der Bauchseite ist ein dem gewölbten Scheibentheil der Risckseile nahebei entsprechendes Mittelfeld der Länge nach selı dicht und lein gestreift, der ganze verdinnte Körjorrand zeigt daggegen eine meist stảlier ausgesprochene concentrische Streifung Fig. 6. 11. 13. Diese Streifung bewirkt abermals eine anscheinend reshige Inordnung der Wimpern; die Zahl dieser Strcifen lasst sich nicht mit Sicherheit bestimmen, ist auch selır gleichgiltig, da sie sich olfenhar mit der Grösse der Thiere indert; in keinem Fall aber sind bei grossen Thieren blos 12- 18 Längsrejhen von Wimpern vorhanden, wie Ehrenberg angicbt. - Ganz iubersehen hat man bisher einen feineı bogenförmig gehrummten oller geschlängelten adoralen Wimperstrejfen (Fig. 6. a. 7. 8. 9. i.), welcher ron ler linken, rorspringenden Ecke der Lippe in diagonaler Richtung zum recluten Rand des Mundes rerlinft; el 


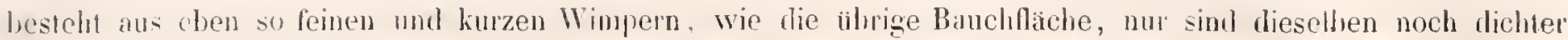
gestell und anders gerichtet'. Bei kleinen Indiviluen gleicht dieser alorale Wimperstreif tauschend einer steifen, gehogenen Borste Fig. 12.13.

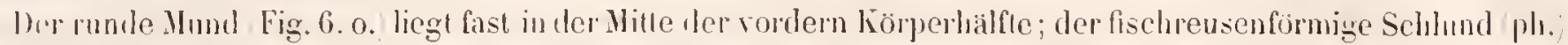
wurde hereits S. 82 geschildert, er ist gewöhnlich schräg nach rechts gerichtel, reicht ctwas iber die Körpermitte hinab und enthäl bei grösseru Individuen 16 Zahnstăbchen. die durch die sich emeiternde Jhndöffung frei nach aussen hervortreten lionnen Fig. 9. 10\%. Der Schlund crscheint in der Ruhe lrichterförmig und ist inmer mehr oder weniger collahirt; er kann sich, wie der Hund, heträchtlich erweitern. wie schon die oft sehr voluminösen verschlucliten Kürper z. B. die grosse Navicula virilis in Fig. 7, heweisen. Boiu Verschlingen grösserer Körper woichen zuerst die nach aussen hervorgetrelenen Zahustahchen aus einander; ist dann der Köper eine Strecke wcit eingedrungen, so neigen sich die Zahnstabchen vorn zusammen, häliehn sich mit ihren cinwärts gelirimmten spitzen an demselben an und schieben ihn so weiter durch den sich nun nach hinten erwciternlen Schlund. Wenn

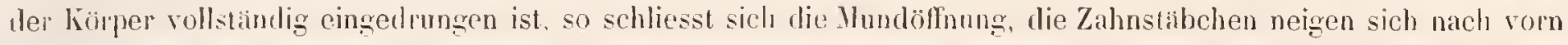
lis zur Berihlung zusammen, und dadurch wird der körper aus lem Schlunde in das Innenparenchym hineingetrieben. Dic Nahrungsstolfe bei den grösscrn hudviduen bestehen sie gewölunlich in Naviculaceen und anderen Bacillarien) erfüllen in der Regel den convexen Scheihentheil des Körpers, den man daher leicht fiur eine besondere rerdaucnde Höhle hallen liönnte. allein nieht selten siehı man auch verschluckle Naviculaceen in der Lippe liegen Fig. 8? und lange Oscillarienfäten, die bis zum Vorterand der Lippe reichen und diese of widematiurlich ansdehnen, von dem Parenchym (ler Lippe eben so gut verdaut werlen, wie von dem centralen Parenchym. - Der After Fig. 6.z.) liegt an Ende des Ilittelfehdes der Bauchseite ror dem Hinterande und etwas uach linlis; da er nicht teminal ist, wie Ehrenberg beobachtet haben wollte, so misste Chilodon selbst in Ehrenberg's System eine andere Stelle, nämlich unter den Catotreten und zwar in der Familie der Colpodca edhalten. In der Nihe des Afters finden sich häulig grosse, mit leeren Naviculaceensclalen crfullte Holılıiume Fig. 7 .

Die Zaht und Lage der contractilen Behälter ist nicht constant. Ehrenberg giebt drei an, run denen zwei links und rechs neben dem Schlund, der dritte weiter nach hinten zu liegen. An kleinern lndiviluen sind allerdings gewöhnlich nur drei contractile Behäter vorhanden, loch ist auch bei ilnen die relative Lage nichu uherall dieselbe vergl. Fig. 13. 14. I:3. 23,. Bei grössern Individuen findet sich eine viel benlentendere Anzálul lileiner, regellos durch das ganze Parenchym zerstreuter contractiler Behiller Fig. 6. c. c. c.), unter denen sich oft zwei grössere und links und rechts nehen dem Schlunde gelegene F. T.c. c.) durch lebhaftere Systole und Diastole auszeichnen, whihrend die k]einern längere Zeit unveränderlich bleiben, dann aber anch plötzlich sich zusammenzichen.

Der Nucleus ist oval, bei grossen Individuen langesestreckt, fast spindelförmig lig. 6. 7. n.), er enthălt hier in seiner ganz lomogenen Substanz eine centrale, runde, blasenförmige Höhlung und in dieser einen rumblen Nucleolus (nl.). Bei kleinern Individuen ist dic centrale Höhlung relatir of vich grösser, so dass die Nucleussubstanz nur eine Art Rindenschicht bildet, welche häufig nach innen unregelmässige zahnfürnige Vorsprünge zeigt Fig. Iö. n. n. 16. 23\% Der Nucleolus war in diesem Falle öfters noch ron einem scheibenföruigen Ilof umgeben Fig. 9. 15. 16). - Statt des gewöhnlichen Nucleus beobachtete ich bei kleinen Individuen in ter hintern Kimpriälfte nicht selten einen anselınlichen. selı: blassen und durchscheinenden scheibenförmigen Körper Fig. 13. li.), (ler erst bei Zusatz ron Essigsture scharfer hervortut und sich als ein ganz homogenes, solides Gebilde answies. Yor ihm lagr ein opakerer, einen gewohnlichen Nucleus ähnlicher, aher vich hleinerer hörper u.'; dieser ist wahrseheinlich ein Rest des ursprüglichen Nucleus und der scheibenfürmige Körpor ein Product lesselhen. Ich rermulhe. Iass der scheibenfömige Kö̈rper das Matcrial zu nenen Individuen liefert, lie ohne Zweifel anf geschlechllichen Wegre entstehen werden, da bereils on Claparide und Lachmam spermatozoenariçe Gebilde im Kern? von Chilodon heobachtet wurlen rem. S. 96).

Quer- und Längstheilung kommen gleich häufig rur. Beim Begimn der Quertheilung wird in ler hintem Köjperbifte ein nerer Schlund angelegr Fig. 12, von dem Anfangs nur die vordersten Spitzen der Zahnstabchen zu unterscheiden sind: der Nucleus bildet zu dieser Zeit einen longindinalen bisguitrörmigen lï̈rper. der in vordern und hintern Ende eine Itöhle mit einem Nucleolus enlhilt. Bald daranf zcrfullt der Nucleus in zrei Hälten. die sich zusammenziehen und alıunden und zum Nuclens jedes Theilungssprösslings werden. Wenn das Mntlep-

1) Auch bei Nassula elegans und $N$. aurea habe ich einen ihnlichen adoralen Wimpersireifen beobachtet. 
thier schon tief eingeschnirt und in seiner hintern Halfte der neue schlund ausgebildet ist (Fig. Iti), erseheint vor demselhen erst der neue adorale Wimperstreif, der von Num :us horizontal nach aussen oder sogar etwas schief nach hinten gerichtet ist. - - Bei der Lingstheilung dehnt sich das Mutterthicr und sein Nucleus zuerst in diagonaler Richtung aus, wobei der Seblund in die linke Körjerhablfte rtickl; in der rechten wird ein neuer Schlund angelegt. Die Theilung schreitet von ter Mitte des Hinterrandes gegen den Vorderand vor und zwar so, dass die Theilungsdrene in schiefer Richtung die Horizontalebene des Körpess schmeidet. Die beiden Hälften decken daher mit ihren an cinander stossenden Ränderm einander (Fig. 14); die rechte Hälfte decht bei der Ansicht der Banchseite mit ihrem

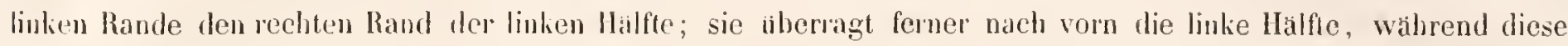
nach hinten über die rechte Hälfte hinausragt. Der muittediche Nucleus wird, weil die Längstheilung von hinten beginnt, selır früh durchgeschüut. Wem die Theilung schon bis iher die llitte des Körpers nach vorn vorgeschritten ist, schuïlt sich auch die Mitte des Vorderandes ein, und bald hängen die heiden Theilungssprösslinge uur noch durch eine liurze, quere Substanzbrücke zusimmen. In diesem Stadiun der Laingstleilung schliagl sich luảufig der eine Theilungsppröstiug nach der entgegengesetzten Seite um (Fig. 15), die beiden Theilungssprösslinge berühren sich nun nit ihren gleichnamigen seitenrändern und der eine kehrt dem Beobachter die Riıctiseite, der andere die Bauchseite zu. Man liann zwei so zusammenhängende Theilungspprösslinge leicht fur zrei durch Conjugation vereingte Individuen ansehen, was sie gewiss nielıt sind.

Die in Infusionen vorkommenden kleinern Thiere gehen zu gewissen Zeiten in einen ruhonden Zustand über, indem sie sich in einen ovalen oder fast nierenlörmigen Körper zusammenziehen und sich mit cuer gallerthäuligen Cyste umgeben, die dem eingeschlossenen Körper meist innieg anliegt (Figg. 17. 18), oft aber anch mehr oder weniger von demselhen absteht und sich daun deutlich ans mehreren concentrischen Schichten zusammengresetzt \%cigt (Fig. 21). Dergteichen Cysten treten theils vereinzelt an der Oberflache von Infusionen auf, theils bithen sie dicht neben einander liegend einen hautartigen Ueberzug an den Wandungen der Gefasse, welche die Infusion enthalten. Ich habe diese Cystenzustinde bereits in meiner friblern Arbeit ausfuhrlich geschildert und meine damaligen Beobachtungen so getleutet, als entwickele sich des Nucleus des encystirten Thieres \%u einem Schwärnsprössling, welcher mit Cyclidium glaucoma Ehbg. identisch sei 1 ). Diese Dentung ist mir nach neneren Unlersuchungen ganz unhaltbar geworden; das Ergebniss derselben ist folgendes. Der in der Cyste eingeschlossene Chilodonkörper erscheint ringsum glatt und winuperlos, in seinem Inncm unterscheidet man die gewöhnlichen zwei oder drei contractilen Behälter (Fig. 17. 2i) und einen miltlern ovalen oder fast nierenförmigen Körlıer, der entweder einem opralien, bomogenen Kem thulich sicht (Fig. 2I). oder sich auf der ganzen Oberfläche mit lebhaft schwingenden Wimpern besetzt zeigt und anscheinend ganz frei in einer besondern Höhle liegt (Fig. 17. I.). Dieser bewimperte Körper wird hăufig innerhall, seiner Höhle hin und her gewalzt. wobej er sieh mehr oder weniger spiralig dreht und windet; er gleicht daher aufs tauschendste einem im Innern des Chilodonkörpers entwiclielten Schwämsprössling, und dafür habe ich ihn eben in meiner frühern Arbeit ausgegeben. Er ist jedoch nichts weiter, als die in eine olıerllachliche, grubenformige Vertiefung eingezogene Lippe des encystirten Thieres, die seltsamer Weise noch lange Zeit nach vollendeter Encystirung überaus lebhaft wimpert und die ehen geschilderten Bewegungen vollfibrt. Was ich für den vergrösscrten Nucleus hielt, aus dem sich ler Schwärmsprösshing entwickehn sollte (Fig. 21), war nur die unbeweglich gewordene, nicht mehr wimpende Lippe. Bei Auwcndung von Essigsaure tritt erst der eigentliche Nucleus (Fig. 18. n.) hervor, welcher viel kleiner ist, als die eingezogene centrale Lippe (1.), der er meistens dicht anliegt; auch wird gewöhnlich nun erst der Schlund sichtbar. Sucht man die Cysten zu sprengen, so tritt meist nur die Lippe durch einen keinen seillichen Riss nach aussen hervor (Fig. 19. I.), und da sich sogleich ihre Wimpern ausspreizen und sie mit dem übrigen Körper nur durch ejue enge Commissur zusannenhängt, so gleicht sie wieder ungenein cinem aus tem Innern hervorgcquetschten Sprössling. Es gelang mir aber auch, den ganzen Chilodonkörper aus seiner Cyste unverletzt heraus zu pressen (rig. 22); el zeigte sich dann als ein nierenformiger, auf der concaven Seite mit ciner nabelartigen Vertiefung verselıcner förper, aus der lie allein wimpernde Lippe I.) wie ein zungenlömiger Zapfen hervorragte. In melıeren Fallen dehnte sich des isolirte Chilodonkörper bald wieder zu seiner gewöhnlichen Form aus, die nur noch etwas bucklig und uncben blieb (Fig. 23); dann fing er an unher zu schwimmen, und es verschwanden nun auch nach und nach die Unebenheiten. - Die encystirten lndividuen erwachen spáter wioder aus jhrem ruhenden Zustand, sie recken sich, so weit dies in len beschränkten Cysten-

1) Stcin bie Infunionsthicre $5.134-38$ und Tilf. III Fig. $60-69$.

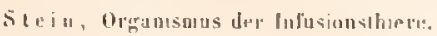




\section{4}

raume möglich isı, aus, wobei die Lippe gewöhnlich die Form eines scharf vom Körper abgeglierlerten, mil ausgespreizten Wimpern hesetzten nierenförmigen Lappens annimmt (Fig. 20), und sie drehen sich nun eine Zeil lang lebhaft im kreise umher; alsdann drängen sie sich durch eine sehr enge Oeffung in der Cystenwand, die wahrscheinlich von den Schlundzahnen gebolırt wird, nach aussen hervor. Der vermeintliche freie Schwärmsprössling. welchen ich bei meinen frïhern Untersuchungen öfters in Cysten mit einem rotirenden Chilodonliörper beobachlete. war höchst wahrscheinhch ein wahres Cycliclium glaucoma, welches nur zufällig von aussen her in vlie Crste eingedrungen war; in einigen Fällen mag ich auch die stark abgeschnirte nicrenförmige Lippe des rotirenden Chilodonkörpers fur einen selbstständigen Sprössling gelıalten haben. Cycliclium glaucoma ist jedenfalls, wie jch aus anderweitigen Unlersuchungen weiss, eine selbstslandige Infusorienform.

Die Galtung Chilodon umlasst nur eine sichere Arı, nämlich:

Chilodon cucullnlus. Eнrвg.

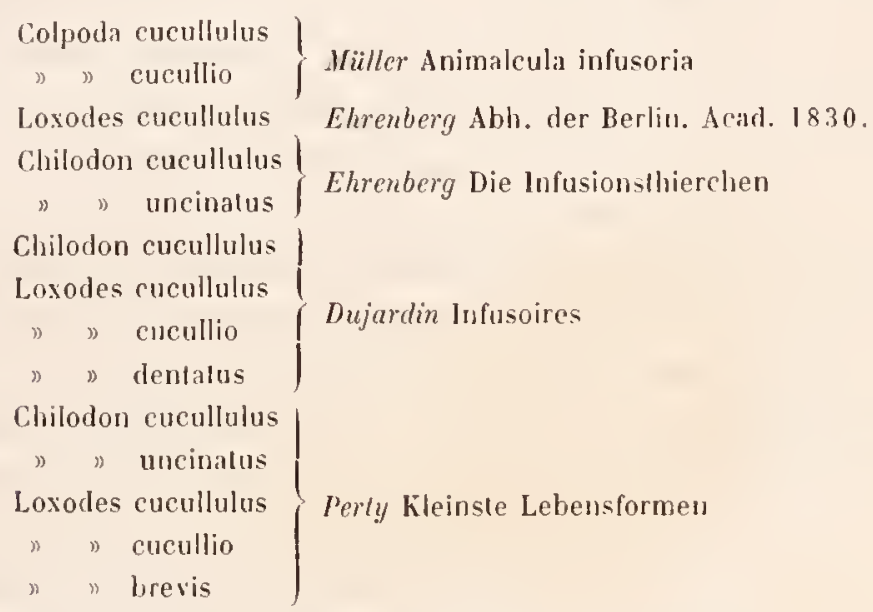

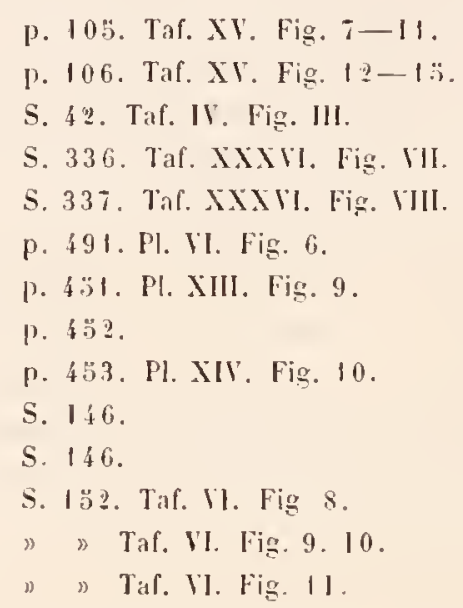

Der Ch. cucullulus gehört zu den gemeinsten und verbreitelsten Infusorienformen, er kommt überall in Infusionen, in Regen- und Mistpfitzen, und in ganz reinen stehenten und fliessenden Gewissern, wie auch im Meereswasser vor. Ehrouberg beobachtete ihn an den norwegischen Küsten, ich traf ihn häufig im Ostseewasser bei Wismar. Die Bewegungen des Thieres sind langsam, gleitend, mit seltener Drehung um lie Längsaxe; an fremden Gegensabulen kriechen sie gewand auf- und abwäıs, indem sie sich mil der Banchfliche innig anschmiegen und die verdunnten, ihre Contouren mannichfach verindernden Ränder aufwarts biegen. - Müller's Colpoda cucullulus ist die kleinere in Infusionen lebende Forn von Chilodon, seine Colp. cucullio dagegen die grösscre, zwischen Wasserphanzen vorkommende, woran die sehr kenntlichen Fig. 12-15 nicht zweifeln lassen; die angeblichen Jungen (Fig. 16) durften wohl eher zu Colpoda cueullus gehören. Die sogenannte Variefă nui verlängerter Lippe (Fig. 17-19) stellt jedenfalls cine ganz andere Infusorienform, vielleicht Loxoplyyllum meleagris Duj. dar. - Ehrenberg nannte Ch. cucullulus bis zum J. I 833 . wo er erst den fischreusenartigen Schlund endeckle, Loxodes cucullulus; eine ganz unwesentliche Varictät der kleinern Form mit etwas stärker ijberhängender Lippe und nit nur 8 Zühnen im Schlunde unterschied er als Ch. uncinalus. Die Form der Lippe ist aber bei Chilodon sehr verånderlich und die Zillıl der Zähne ändert sich mil den Alter. - Dujardin's Loxodes cucullulus berulıl auf der hleinen Form des Clitodon, an der nur die Lippenwimpern unterschieden wurden; sein Loxodes dentatus stellt dieselbe Form mit deullich erkannten Schlundzähnen dar, und scin Loxodes cucullio ist lediglich auf Mäller's Abhildungen gegriindet. Auch Dujardin's Loxotes reficulatus und marinus liönnen recht wohl in den Formenkreis von Chil. cucullulus gehören. - Die Abbildungen, welche Perty ron Loxodes cucullulus, cucullio und brevis liefert, stellen meiner Ansicht nach nur Formenmodificationen von Ch. cucullulus dar, an denen die Bewimperung unvollstăndig, der Schlund gar nicht erkannt wurde. Ich sah genau solche Individuen, wie die ron Perty abgebildelen, boi Anwendung von Essigsäure wurden aber stets auf der ganzen Bauchseite Wimpern und der Zahnapparal im Schlunde sichtbar. Perty's Chilodon depressus dürfte irgend eine junge, ungenuigend beobachtete Nassula gewesen sein. - Die grössten Individuen, welehe ich von Chil. cucullulus beobachtete, waren $\frac{1}{7}^{\prime \prime \prime} \operatorname{ling}$ und elwa hall, so breit; die Lànge jlires Nucleus hetrug $\frac{1}{3}{ }^{\prime \prime}$, die des Schlundes $2^{\prime \prime \prime}$. 
3. (iattung. Opisthodon. ṠTEs.

Taf, I. (ig. $21-26$ )

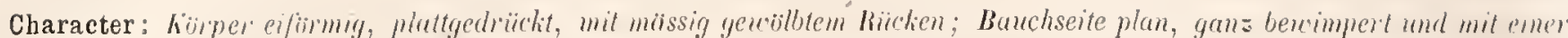
den kimperentomen paralleten Rimne; Schland in der hintem kimperhaifte, fischreasenartig.

Diese neue Galtungr wumle von mir zuerst in ler Prager Lotos (Januar 18599 S. 2) characterisir. - I)

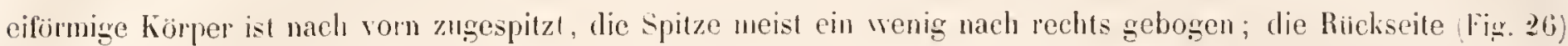
ist ganz glatt und wimperlos, wie ich mich schr bestimm bei ganz langsanen Wendumgen des körpers um die Langsaxe ibberzengte; die jom ganzen Umfange des liandes rorstehenden Wimpern gehören des Bauchscite an. Ein

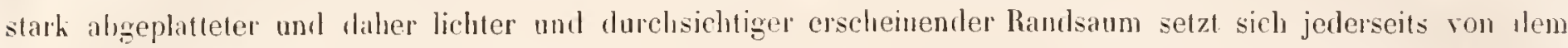
viel dickeren rewöbten Scheibentheil ab und tritl dadurch noch schäfer hervor, dass er auf der Bauchseite Fig. 24.

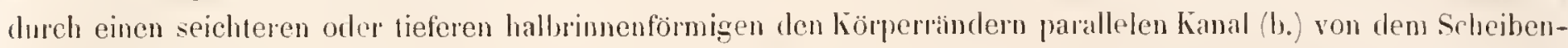
theile gesondert wirl. In der vorleren körperspitze vereinigen sich die bejden scitlichen Kanäle zu einen hurzen, an der spitze nach aussen mindenden, gemeinsamen Kanal (i.), nach hinten zu gehen sie mejst in eine unıegel massige, muldenfömige Vertiefung des Scheibentheils uber, in welcher der Mund liegl. Der Randsaum ist wie eine

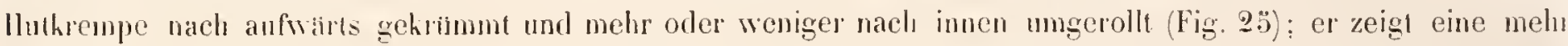
concentrische Streifungr, wähend der Scheibentheil langsgestreift ist. Die ganze Bauchseite, anch die halhrinnenfömige Tertiefung ist dicht mit gleichartigen, feinhaarigen Wimpern besetzt. Im lintern Körperviertel liegt ter schwer wahrnehmbare kurz walzenförnigge Schlund Fig. 24. 26 ph.); scine Zảhnchen sind so zart, dass er nur fein längsgestreift etscheint. - Gewöhnlich ist nur ein ziemlich grosser. runder, contractiler Behälter in der Mitte ıler rechten Körperseite vorhanden (Fig. 26.c.); zuweilen sah ich ihm gegenüber noch zwei hleincre contractile Bchäler

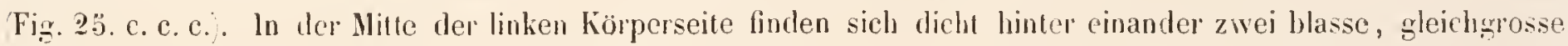
runde, ganz homogene kieme (Fig. 2.j. 26. n. n.).

Dic Gattung umfisst nur eine im sijssen Wasser lebende Art, nänlich:

Opisthodon Niemeccensis. STEIN.

Stein Characteristik neuer Infusoriengatt. Lotos 1859 S. 2.

Ich habe diese seltene Infusorienform im September 1857 in einem Torfstiche bei Niemegk entdeckt, im Ganzen aber nicht mehr als acht, jedoch völlig ïbereinstimmende Exemplare anfgefunden. Die Thiere waren immer nur in Bodensatz anzutreflen; ilıre Bewegungen sind denen ron Chilodon cucullulus ihlnlich, jedoch etwas schneller. auch lieben sie es, längere Zeit mit dem hintern Ende voran zu sehwimmen (Fig. 25). Der mit Ausnahme der liegsamen Rănder fast ganz starre Körper enthielt meist eine grosse Menge graubrauner Fetthïgelchen (Fig. 25), stels war das Parenchym dadurch melır oder wengger getrubt und rothbraun gefarbt. Die grössten Exemplare waren $\frac{1}{12}{ }^{\prime \prime \prime} \operatorname{lang}$ und $\frac{2^{\prime \prime \prime}}{2^{\prime \prime}}$ breil; der Durchmesser des Nucleus betrug $\frac{1}{8}^{\prime \prime \prime}$.

\title{
4. Gattung. Chlamydodon. Emrbg.
}

\author{
(Taf. Il. Fig. $1-6$ ).
}

Character: Korper formbestündig, nierenförmig, mit gexiolbtem, ronn, hinten und seillich abgernendelem Rücken und planer.

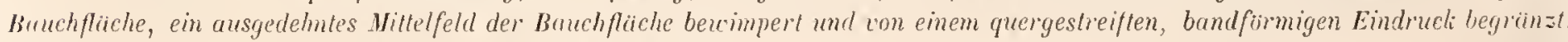
Mund in der vordern hörperhailfte, Schlund fischreusenarlig.

Die Gattung Chlamydodon wurde ron Ehrenbery in den Abhandl. der Berliner Academie rom I. I83:; S. 17.̈ aufgestellt und seiner Fanilie der Euplota einverleibt. Sic sollte einen schildförmigen, den Rücken hedechenlen umd den Körper allseitig iberagenden Panzer besitzen und sich ron den ibrigen Euplotinen durch Mangel an Grilfelı und Haken und durch Besitz von Wimpern und Zähnen im Munde unterscheiden. Ehrenberg bat jedoch die Organisation ron Chlanydodon nicht richtig erhannt, wic ich zuerst in den Abhandl. der Böhmischen Gesellsch. der Wissensch. Band X S. 63 und auch in der Lolos (Januar 1859 S. 3) gezeigt habe. Licberkühn scheint meine Anlfassungsweise zu theilen, denn er hat Chamydodon fur eine am nachsten mit Chilodon verwandte Gattung erhlart ${ }^{\%}$.

Der fast gepanzerte Körper ist njerenförmig. in del vorlern Hälfe etwas breiter, als in der hintern, auf der linken Seite ausgebuchtet, auf der rechten convex. Der ganz glatte und nackte Rücken (Fıg. 2 und $\ddot{3}$, ist zicmlich

1) Vergl. Ctaparéce und Lachmann. Éludes p 136. 
stark gewölbt, anf der Scheibe abgeplattet und nach vorn, hinten und den Seiten gleichförmig abgerundet. Der grösste Theil der Bauchseite (Fig. 1. 4) ist plan, er bildet ein scharf begranztes Mittelfeld. welches von einem seiclıten, den Körpercontouren parallelen, handförmigen Eindruck umschlossen wird, der dadurch ein sehr zierliches Ansehen emảlt, dass seine beiden scharf begrinzten Ränder durch nahe und in gleichen Abstanden auf einander folgende Querlinien verbunden werden, welche an beiden Enden punctförmig vertieft sind. Der von dem bandförmigen Eindruck umschlossene Raun ist fein langsgestreift (Fig. I) und dicht mit feinhaarigen Wimpern bekleidet (Fig. 4). Die Wimpern setzen sich nach vorn in einer der Breite des. Mittelfeldes entsprechenten Ausdehnung über den baudförmigen Eindruck hinaus bis zum Vorderrand des Körpers fort (lig. 1), und diese, auch etwas lingern Wimpern sind allein bei der Rückenansicht. (Fig 2) sichthar. Ehrenberg hat den handförmigen Eindruck nur ungenögend erkannt und für die Gränze des eigentlichen Körpers gehalten, während er den ausserhałb des bandförnigen Eindrucks gelegenen Theil der Bauchseite als cin iberragentes, panzerhäutiges Rückenschild auffasste. Die Streifen des Mittelfeldes der Banchseite versetzte Ehrenberg irrfliimlich auf das vermeintliche Rüchenschild. und die Wimpern, welche als lange Borsten angegeben wurden, beschrinlit er lediglich auf den Rand des körpers.

Der Mund liegt in der Mitte der vordern Körperhälfte und führt nach rechts und hinten in einen walzenförmigen, der ganzen Länge nach mit breiten, linealischen Zahnstibchen ansgehleideten Schlund (Fig. 1. ph). Ich zảhlte stets nur 8, an der Spitze plattenartig erweiterte Zahnstabchen, wahrend Ehrenberg deren 16 angiebt. Die Nahrung besteht hauptsachlich aus Oscillarien, wetche in rundliche, blaugrüne, rosemrothe und rostbraune Ballen (Fig. 2) zerfallen und bei weiterer Auflösung dem ganzen Parenchym eine melır oder weniger intensive orangerothe oder rostgelbe Farbe ertheilen. - Die Zahl und Lage der contractilen Behäler ist nichı constant, ich sah sie am deullichsten auf der Bauchseite (Fig. 1. c. c. c. Fig. 4.); sie lagen hier, 2streut. - Der Nucleus (Fig. 1. n.) ist oval, selır licht, farblos, und meist ganz homogen; zuweilen bemerkte ich in demselben eine querelliptische Höhle (Fig. 4. n.). - Ich beobachtete nur Quertheilung (Fig. 3), die ganz analog wie bei Chilodon beginnt; mit der Einschnirung des Körpers schnïrte sich auch der bandförmige Eindruck bisquitförmig ein. - Die Bewegungen sind denen von Chilodon ähnlich, aber viel schneller.

Die einzige Art der Gattung gehört den Meere an, es ist:

Chlamydodon Mnemosyne. Enrba.

Chlamidodon Mnemosyne Elrenberg Die Julu-ionsth. S. 377. Taf. Xlll. Fig. 8.

Ehrenberg entdeckte diese Art im Ostseewasscl bei Wismar; ich habe sie ebendaselhst in August 1857 in zahdreichen Individuen beohachtet. Nach Werneck soll sie auch mit mehreren andern, von Ehrenberg nur in der Ostsee beobachteten Infusorienformen in den süssen Gewassern bei Salzburg vorkummen 1. - Dje grössten Individnen fand ich $\frac{1}{2}{ }^{\prime \prime \prime}$ lang; die kleineren Individuen (Fig. 6) sind oral und oft in der Nitte auf beiden Seiten etwas verengert, ihı Parenchym ist ganz larblos.

\section{Gattung. Seaphiliodon. S'TEIN. \\ (Taf. II. Fig. 7-15)}

Character: Körper gepunsert, nachenahulich, plutigedrïclit, nuch hinten in eine schnabelurtige spitze ausluufend, vorn mu einem lippenartigen Saum; ein ausgedehntes planes Nittelfeld der Bauchseite dicht bewimpert; Schllunt in der vordern Körperhalfte. fischreusenartig.

Diese neue Gattung wurde von mir in der Sitzung der k. Böhmischen Grsellschaft der Wissenschaften vom 19. Octhr. $183 \%$ hegriudet. - Der ganz stare, seine Form sar nicht s'randernde Körper lat einen fast ungekehrt cifömigen Unriss (Fig. 9. 10), er ist vorn gerad al)̣estutzl unt mit ciner schmalen, dimnhautigen und biegsanen, halhmondförmigen Oberlippe (Fig. 8. 10. I.) rersehen; die rechte Körperseite ist stets langer und starker nach aussen gekrummt, als die linke, welche hiulig fast grerade (Fig. 7. 13) oder nach eimwirts gehogen ist Fig. I4). Der hintere verengerte Theil des Körpers ist nach linlis gekrunmt und läuft in cine rechts und aufwirts gebogene drehrunde schuabelarlige Spitze aus. welche den jügeren Individuen (Fig. IS) fehlt. Die glatte und wimperlose Ruckseite ist schwach gewölbt (Fig. 8), nach vorn etwas nicdergedruckt, die Seiten sind abgerundet, nach hiuten zu an grössem Individuen meist zu einem schmalern oder breiteru flügelartigen Saum abgeplallet $(\mathbf{F}$ g. 7 . 10), in

1) Monatsberichte der Berliner Academie von 1811. S. 10y 
Folge dessen in der hintern Hälfte der Rucliseite zwei gegen die Schwanzspitze convergirende Kiele hervortreten. Das plane oder sogar concave Mittelfelı der Bauchscite bat dic Form cines etwas gekrümmlen gleichschenkligen Dreiccks, dessen Basis von der Oberlippe gebildet wird und lesson abgerundele Spitze vor der schnabelförmigen Schwanzspitze liegt; es ist der Linge nach dicht und fein gestreift Fiğ.9) und ganz mit liurzen, feinhaarigen Wimpern bekleidel (Fig. 14). Dic vordersten, an der Basis der Lippe stehenden Wimpern sind merklich langer und ragen iiher den Vorderrand der Lippe hinans; sie sind allein bei der Riichenansicht (Fig. 7. 10) sichtbar. - Der Mund liegrt in geringer Entfermug vom Vorderrande, am Grunde ciner seichten dreiceligen Vertiefung des Viltelfeldes, er führt nach rechts und hiıten in einen trichterförmižen Schlınd Fig. 7. 9. ph.), der feine borstenföımige Zähnchen enthält. - Stets sind zwei contractile Behłilter in der Nähe des rechten Seitenrandes vorhanden (Fig. 9. 10. c. c.); der eine findet sich rechts neben dem Schlunde, der zweite elwas hinter der hörpermilte. - Der ziemlich in der Körpermitte gelegene Nucleus (Fig. 9. n.) ist oval; er crschcint bald ganz homogen, bald enthált er eine querelliplische Spulle (Fig. 10. n.) oder eine rundliche IIöhle mit einem besondem Nucleolus (Figs. 7. 9. nl.).

Die gewöhnlichste Fortphanzungsweise ist die durch Quertheilung; sie bictet nichs Eigenthimliches dar. Nachdem in der hintern Körperlıălfte ein neuer Schlund angelegt worden ist, schnïr sich der mïlterliche Körper von den Seiten her ein (Fig. 19), der Nucleus zerlällt in zwei cifrimige Segmente (n. $n^{\prime}$ ) und es erscheinen zwischen den zwei urspriuglichen contractilen Behälern (c.c.) zwei nene ( $\left.c^{\prime} . c^{\prime}\right)$. Zuletzl wird das noch gemeinsame Mittelfeld der Bauchseite durch eine Querfurche in ein vorderes und hinteres gesondert. und es wtichst nun langs der Querfurche die Oberlippe fiir den hintern Theilungssprössling lervor (Fig. 11). Nach vollenteler Quertheilung bildet sich erst an Ilem vortern Theilungssprössling die schnabelförmige Schivanzspitze ans. _- Mehrmals sah ich zwei lndividuen mit ihren ungleichnamigen Seitenrändern verbunden (Fig. 1:3, sie kehrten einander ihre Bauchflächen zu und das eine Individuum ragle nach vorn etwas iiber das andere hinaus. Jeclenlalls war dies das letzte Stadium einer ron hunten nach rorn fortschreitenden Längstheilung. - Die Bewegungen sind ziemlich langsam, ganz stetig gleirend und häulig mit Drehungen um die Langsaxe abvechselnd.

Dic einzige Art der Gattung gehört den Meere an, dies ist:

\section{Scaphidiodon navicula, STEix.}

Trichoda navicula Mülter Animalcula infusoria p. 191. Taf. XXVI. Fig. 9-12

Scaphidiodon navicula Stein in den Abhandl. der K. Böhmischen Gesell. der Wissensch. Bant X. S. 63 und Lotos Januar 18 s9. S. 3.

Die Abbildungen, welche $0 . F$. Mäller von seiner Trichoda navicula a. a. O. gegeben hat, namentlich seine Fig. 10 und 11 sind recht wohl mil meiner Darstellung der grössem Formen von Scaph. navicula (Fig. 7. 10) zu vereinigen; auch seine Beschreibung passt aul' Scaphidiodon. Müller komnte natiirlich mil seinen Ifulfsmitteln den fischreusenartigen Schlund und die thrige leinere Organisation nicht erkennen, er unterschied aber sehon die lăngern Wimpern am abgestutzten vordern Ende; iiber den Aufentlalt seines Thieres bemerkt er nur: nin aqua marina passim." - Ich habe diese Infusorienform im August 1857 schr hảufig im Ostsecwasser bei Wismar in Gesellschaft von Chlamydorton Mnemosyme und verschicdenen Euplotinen beobachtet und sie auch lebend mit nach Hause gebracht, wo sie sich noch zwei Wochen lang in dem schon auf der leise in stinkente Fäulniss übergegangenen Seewasser ganz munter erhielt, nachdem fast alle anderen Infusorien, lic lasselbe belcbt hatten, zu Grunte gegangen waren. - Verschluckte feste Körper sah ich nic im Innern der Thiere, ilır Parenchym war stets ganz farblos. Gewöhnlich fand sich auf der linken Seite eine verwaschene, schwärliche, ans sehr feinen dichtgedrängt beisammenlieggenden Pünctchen und Körnchen zusammengesetzle Zone. welche sich vor dem hintern Ende nach rechts wendete unt auf der rechten Seite eine kurzere Strecke weit nach vorn verlief (Fig. 9. 10). — Die grössten Individuen waren $\frac{1}{20} "$ lang und $\frac{1}{4}{ }^{\prime \prime \prime}$ breit.

\section{Gattung. Trochilia. Dusand.}

$$
\text { (Taf. II. Fig. } 28-30) \text {. }
$$

Character: Kirper gepanzert, eiformig, plattgedrïcht mit nach links gelinummtem vordern Ende und einem beueglichen Friffel am hintern Ende; ein schmales, nach rechts gehrümmtes Hittelfeld der Bauchscite dicht bewimpert; Schlund ein glattes, starres Rohr.

Die Gattung Trochilia wurde im J. 184.1 von Dujardin (Infusoires p. 4.̈̈̈) atf ein sehr kileines, nur ungenügend beobachtetes, im Mittelmeer aufgefundenes Infusionstlier gegrindel und in die hleine Familie der Erviliens Duj. 
gestellt. Sie sollte sich durch einen unregelnassig ovalen, vorn verengerten und hies allein hewimperten körper, dnch einen schief gefurchten. gleichsam gedrehıen Panzer und ein bewegliches Stielchen am hintern Ende auszeichnen und keinen deutlichen Mund besitzen. Ich habe nicht blos die von Dujardin entdeckte Form kennen lernen, sondern auch noch eine zweite nahe verwandle Art im siissen Wasser aufgefunden und muss namentlich nach dem genauen Studium der letzleren den von Dujardin aufgestellen Galtungscharaclel berichtigen und erweitern.

Der fast ganz starre eiförmige Körper der Trochilien ist am vordern Ende mehr odes weniger stark nach links umgebogen; die Riickseite (Fig. 28) ist mässig gewölbt und ganz glatt und wimperlos, die beiden Seiten sind abgerundet, die nicht ganz jlane etwas gewölbte Bauchseite (Fig. 29. 30) zeigt ein bindenartiges, vom vordern bis zum hintern Körperende reichendes und sich nach hinten verschmälerndes Vittelfeld, ivelches so stark boszenförmig nach rechts gekriimmt ist, dass hier nur ein sehr schmales, wulstarliges Seitenfeld iibrig bleibt, wahhrend das linke Seitenfeld mehr als die linlie Körperhäffte einnimmt. Das Mittelfeld bildet eine schiefe nach der rechten Seite zu stärker geneigte und hier merklich vertiefte Elene, welche der Lánge nach dicht gestreift (Fig. 29) und mit sehr kurzen, feinhaarigen Wimpern bekleidet ist (Fig. 30). Am vortern Ende des Mittelfeldes stelıen elwas laingere, Jei der Riickenansicht allein sichtbare Wimpern, und nu diese wurden von Dujardin erkannt. Die Rückenflache und die beiden Seitenfelder der Bauchseite kann man zusammengenommen als einen unlen offenen Panzer auffassen; dann stellt das bewimperte Mlitelfeld den unbelecht gebliehenen Theil des Körpers dar. An hintern Ende des Mittelfeldes ist ein steifer, beweglicher Griffel (Fig. 28. a.) eingefügt, der Ilem Thiere wie ein Fuss zum Stiitzen und Fortschieben dient. Er gehıört nicht in clie Kategorie von IIimperı, da er niemals wirhelt, anch sich nicht, wie griffelförmige Wimpern, in Fasern auflös; er entspricht augenscheinlich der schnabeliörmigen Schwanzspitze der Gattung Scaphidiodon, velcher iiberhaupt die Gattung Trochilia am nächsten verwandt ist. - Der glattwandige, starre, röhrigytrichterförmige Schlund Fig. 2s. ph.) liegt auf der linken Seite, er ragt nach vorn und rechts in das Ilittelfeld der Bauchseite hinein. - In der Mitte des Körpers findet sich auf der rechten Seite ein contractiler Behälter (Fig. 28. 29. c.) und ihm gegenuber auf der linken seite des länglich elliptische, mit einer queren, spaltförmigen Höhlung versehene Nucleus (Fig. 28. n.). - Quertheilung wurde hei einer Art beobachtet. - Die Bewegungen sind langsan gleitend. mit häufiger Länğsaxendrehung, auch klettern sie ğern an fremden Gegenständen.

Die Gattung umfasst zwei Arten, eine Meeres- und eine Siisswasserform, nämlıch:

1. Trochilia palustris. Stein. (Taf. II. Fig. $28-30$ ).

Abhandlung. der Böhmischen Gesellsch. der Wissenschaft. Band X. S. 63 und Lohos 18:39. S. 4.

Rüchseite ganz glatt, das vordere gehrümmte Ende schief abgestuzt und bogenförmig ausgerandel.

Ich beolrachtete diese Art im Frïhjalı und September 1857 und in December I 838 in sumptigen Gewässern bei Prag; sie fand sich inmer mur vereinzelt im schlammigen Bodensalz des Wassers. doch wurden von mir nach und nach ziemlich viele Individuen aufgefunden. Der Körper ist farblos und durchsichtig; der Schlusd făllt sogleich auf, wird aber beim Quetschen des Thieres noch weit deutlicher. Nahe vor tlem Munde ist eine stare, iber den Vorderrand hinausragende, biegsame. aber nicht wirbelnde Borste eingelenkt. Die grössten Individuen sind $\frac{1}{6 !}$ lang und $\frac{1}{96}$ breil.

2. Trochilia sigmoides. Dujard.

Dujardin Infusoires p. 4\%. PI. X. Fig. 15. a-d.

Rüchseite mit fïn' bis sechs stumpfen, abgerundeten Längsrippen, dus zugespitzte Vorderende stark hakenförmig nach links gelrüimmt.

Dujardin traf diese Art in grosser Anzahl im Wasser des Mittelmeeres bei Celle und beohachtete auch Quertheilung; ich habe sie m Mai 18.37 in einem Fläschchen mit Seewasser aus dem Hafen von Triest aufgefunten, jedoch nur in wenigen und sehr kteinen Indiviluen. Sie waren nur ${ }_{96}{ }^{\prime \prime \prime}$ lang; gleichwohl erkannte ich an ihnen den hornigen Schlund und das bewimperte Nittelfeld der Bauchseite sehr bestimmt. Da ich uber den Nucleus und den contractilen Behälter im Unklaren blieb, so habe ich keine Abbildung aufgenommen. 


\section{Gattung. lirvilia. Dusard.}

(Taf. II. Fig. 16-27).

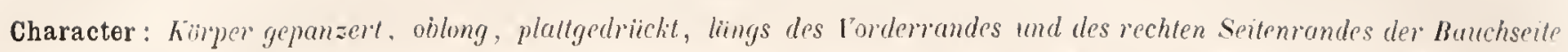
cin bindenartiger. Ausschnitt, dessen Aussemand mit dichtstehenden feimharigen trimpern beselst ist; am hintern Ende des Ansschnittes ein beweglicher Criflel; schlund ein glattes starres Rohr.

Die Gatlung Ervilia wurde von Dujadiu im J. 18 . I auf eine in Viltelmecre beobachtete Infusorienform gegründet, welehe ohne Zweifel mit Ehrenbery's Euplotes monostylus identisch ist. Schon Ehreuberg enliarte die letztere Art fiur cine selu ausgezeichnete Form, die wohl später als eine besondere Gattung abzutrennen sein werde. Die Charactere der Gatlung Ervilia, welche mit der Gattung Trochilia die kleine Familie der Erviliens Duj. bildet, bestehen nach Dujardin (Infusoires p. 4.̈̈̈) in einem ovalen, zusanmengedräckten, von cinem vorn und seitlich geöllneten Panzer bedeckten Körper, der längs dieser Oethung mil Wimpern bekleidet und an hintern Ende mit einem seillichen beweglichen Stiel versehen ist. Einer der wesenlichsten Charactere des Euplotes monostylus. welcher iblser scine naturliche Stellung im System entscheidet, der Schlund, wurde sowohl ron Ehrenberg, wie von Dujactiu ibromehen.

Der stark abgeplattete, schı deulliel gepanzerte Körper der Ervilien hat eine fast ganz flache, nachte Rücksente Fig. 16. 20\%, der linke Seitenrand und der Hinterrand sind dick und germudel, der Vorderrand und der rechte Seitenrand lamellenartig verdünt, selı durchsielıtig und sanft muschelförmig nach alıwärs gekrimmt. Dieser verdiunte Randheil rühl daher, dass der entsprechende Rand der Bauchseite (Fig. 17. 21) rinnenartig ansgehöhlt ist. Der Ausschnitt ist seiner ganzen Ausdehnung nach gleich breit, er nimmt den Vorderrand bis zur linken Ecke dessellsen ein, biegt aul' der rechten Seite unter einem rechten Winkel nach abwarts un und verlauft in gerader Richtung bis zum Hinterrainde, wo er mit einer schwachen Einhuchtung nach imnen endigt; in dieser Einbuchtung ist ein starker beweglicher Griffel Fig. 1\% a.) eingefügt. Der Boden des Ausschnittes, oder was dasselbe ist, die untere Fläche des verdünnten Rantheiles der Rückseite ist in der ganzen aussern Halfte dicht mit feinen langlaarigen Wimpern besetzt, die iber den freien Rand nach aussen hervorragen. Ehrenberg und Dujardin versetzen diese Wimpern an den Innenrand des Ausschnittes, stellen sie mehr borstenförmig dar und lassen sie nur eine einzige Reihe bilden. Der Ausschnitt mit scinen Wimpern entspricht einerseits dem schon sehr stark auf die eine Seite gedıängten Mittelfeld der Trochilien, andererseits dem oft weit nach hinten reichenden Peristom der Euploten. Den erhabenen Theil der Bauchseite will ich als Bauchplatte bezeichnen, sie geht nach links und hinten continuirlich in die Riichenplatte iiber; Rücken- und Bauchplatte bilden zusammen einen zweischaligen, vorn und rechts oflenen Panzer, dessen Rüchenschale dic Banchsehale nach vorn und rechts überragt. Bei der grossen Durchsichtigheit des verdimnten Randtheiles der Riickenplatte sind die freien, scharfkantigen Ränder der Banchplatte, sowie die Randwimpern auch auf der Rückseite des Thieres sichtbar, weshalh Rüchen- und Bauchseite sehr leicht mit einander verwechselt werden können. Eine solche Verwechselung ist Ehrenberg und Dujardin begegnet; denn sie lassen den Ausschnitı der Bauchseite an der linken Körperseite herablaufen.

Der gerade, stare, glattwandige, röhrigg-trichterförmige Schlund (Fig. 16. 17. ph.) mündet neben der rechten Ecke des Vorderrandes der Bauchplatte in den Ausschuitt aus und erstreckt sich in diagonaler Richtung fast his zur Körpermitte. - Contractile Behälter sind wenigstens zwei vorhanden, die dann am Innenrande des Ausschnittes liegen (Fig. 17. c. c.). - Der ovale oder eifürmige Nucleus (Fig. 17. 20. n.) enthält eine quere spaltförmige Höhle und liegt stets auf der linkien Scile; zuweilen zeigt der Nucleus eine der innern Höhle entsprechende aussere Einschnurung (rig. 16.n.). - Von Fortpflanzungsweisen ist bisher nur Quertheilung beobachtet, die häulig vortiommt. Die Bewegungen sind langsan gleitend, hảulig mit Drehung um die Längsaxe Fig. 2? alıechselnd. Beim Beriihren fremder Körper wirl der hintere Griffel zum Nachschieben benutzt.

Von den beiden Arten der Gattung lebt die eine in Meere, die andere im sissen Wasser.

I. Ervilia monostyla. Stein. (Taf. 11. Fig. 16-24).

Euploles monostylus Ehrenberg Die Infusionsllierchen S. 380 . Taf. XLII. Fig. XIV.

Ervilia legumen Dujardin Infosoires p. 455 . PI. X. Fig. 14.

Euplotes monostylus Eichwatd. Zweiter Nachtrag zur Infusorienkunde Russlands S. 127. Taf. IV. Fig. 26.

Ervilia monoslỵla Stein in Abhandl. der Böhmisch. Ges. der Wissenseh. Band X. S. 63 und Lotos 1859. S. 4.

hörper oblong oder längtich rechteckig mit abgerundeten Ecken, Räickseite ganz glatt, meist mit einer Längsfurche am linken Seitenrande.

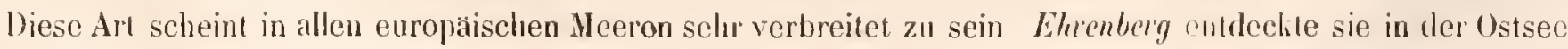


bei Wismar, Mujardin Irof sie im Mlttelmeer. Eichwald in der Ostsee bei Reval; ich labe sie sehr häufig in der Ostsee bei Traveminde und Wismar, in der Nordsee bei Cnxlaven und sparsamer im Ncerwasser aus dem Triester Hafen beobachtel. In dem Meerwasser von Traveminde. welches ich im Januar $183 ̈$ g̈ geschichl erhielt, traf ich die grössten und dicksten Exemplare Fig 16-18), und ich erkannte an ihnen sogleich olne kïnstiche Behandlung den bornigen Schlundtrichter; sie waren durchschnittich $\frac{1}{2^{\prime}}{ }^{\prime \prime}$ lang und $\frac{1}{48}$ "Lreit. die Länge ihres Schlundes betrug $\frac{1}{64}$ ". Der Vorderrand des Körpers setzle sich durch eine seichte Einschniirung von dem linken Seitenrande ab. Die von mir im August 1857 hei Wismar beobachteten Thiere (Fig. 19-21) waren ron mittlerer Grösse und vephảlnissmássig schmaler, sehr dün und durchsichtig, länglich rechleckig mit gleichmassig aligenundeten Ecken; sie zeigten sowolıl auf der Ruckseite Fig. 20) als auch auf der Bauchseite (Fig. 2I) eine Langsfurche neben dem linken Seitenrande. Die hleinen und ganz glatten Triestiner Exemplare (Fig. 23) hatten einen bogenförmigg getirimmten linken Seitenrand, wabrend der rechle Seitenrand ganz gerade war; am vordern Ende lag gewöhnlich links vom Schlunde ein gelhlicher Fleck Fig. 23. x.). Bei Cuxhaven traf ich Ers. monostyla häufig auf Carcinus Maenas, heils zwischen den äussern Kö̀per-

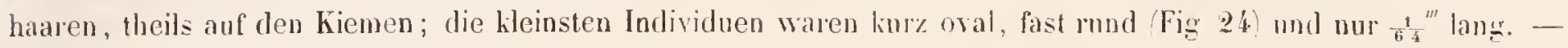
Trotz, der starren Panzerbekleidung isl der Körper doch in seiner Totalitat elwas biegsam; ich sah häifig die gestreckteren Thiere ibre vordere und hintere Körperhälfte unter einem sanflen Bogen ein wenig gegen einander krimmen Fig. 21. 22). - Die Zahı ıler contractilen Behälter ist nicht constant; am häufigsten findel sich ein rorderer und hinterer unter dem rechten Rande der Bauchplatte (Fig. 17.c.c.). dazu hommt oft noch ein dritter, der entweder in derselben Linie, wie die beiden ersten (Fig. 16.c.c.c.), oder im vorilern Ende auf der linken Seile Fig. 20. 21.c.c.c.) liegt. - Die zwei nehen einander liegenden Angenpuncle, welche Eichrald im vordern Körperende entdeckt hahen wollle, existiren nicht, sie sind höchst wahrscheinlich nichts weiter gewesen, als seitliche Bogenstucke vom Rande des Schlnndeinganges, welche namentlich bei gewissen Einstellungen des Mikroscopes wie zwei schwảrzliche Puncte oder kurze Querstriche erscheinen.

Bei der Quertheilung dehnt sich zuvörderst (Fig. 18) mit dem Körper auch der Nucleus (n.) beträchllich in die Lảnge aus, und man sieht dann öfters vor dem vordern und hintem Ende desselben cine querelliphische Höhle. Msdann entsteht in der Mitte des rechten Randes der Banchplatte eine quere, etwas schiefe Einbuchtung, wodurch sich die Banchplatte in eine vordere und hintere zu sondern beginnt. Unter der hintern Ecke der vordern Banchplatte wächst ein never beweglicher Griflel (a') fur den vordern Theilungssprössling hervor, wahlurend unter der vordern Ecke der hintern Bauchplatte ein neuer Schlund ph') lijr den hintern Theilungssprössling angelegt wird. Gleichzeitig entwickelt sich in der Einbuchtung eine quere Wimperzone, welche bald mil der hintern Halfte der Randwimperzone in Verbindung tritt, worauf die miltelste Parthe der Randwimpern schwindet und der Kucleus in eineu vordern und hintern zerfällt. Nachdem so in der vordern und hintern Körperhäffte des Mutterthicres die zur Individualität noch fehlenden Organe neugebildet worden sind, trilt erst die ringlörmige Einschnünng auf Fig. 19). welche die beiden vollstandig entwickelten Theilungssprösslinge von einander sondert.

2. Ervilia fluviatilis, Stexs. (Taf. H. Fig. Q 2:3-27,

hörper nach vorn unt nach hinten verengert, varn schief abgestulat und mit fünf feinen Längskieten auf ter kitickseite.

Ich habe diese kleine zierliche Art im August $18 \%$ bei Tharand in den ganz klaren Gebiroswasser der Weiseritz beobachtet, jedoch nur wenige Exemplare aufgefunden. Der Körper ist fast kummelkornartig. lier linke Seitenrand sehr convex, der rechte ganz gerade, beide stossen nach hinten unter einem spizen Irinkel zusammen. Die Ruckseite (Fig. 2ä) ist stark gewölht und durch die Langsleisten sehr ansgezejchnet; der handausschnitt der Bauchseite (Fig. 26) ist sehr schmal, die Bauchplatte glatı. Nucteus in.), Schlund (ph., und Grifled (a.) verhalten sich wie bei Ervil. monostyla. Contractile Behälter babe ich leider nicht beobachtet. Länge $6^{\prime \prime \prime}{ }^{\prime \prime}$, Breite $\frac{9^{\prime \prime \prime}}{85}$. Ein Individumm trat ich in fast vollendeter Querlheilung (Fig. 27).

\section{Zweite Familie. Aspidiscina. EnrbG.}

Character: Körper gepanzert, schildformig, mit convexer Rïcliseite und planer Bauchseite: der rechte Rond der Bauchselte wulstformig verdicht, lïngs des linken Randes ein weit nach hinlen reichender adoraler 11 imperbogen: wenige ( 7 ) zerstreut stehende griffelformigc Banchwimpern und 5 oder 10-12 griffelformige Afterwimpern. Hund am hintern Ende des adoralen Wimperbogens. Ifter nahe hinter den Afterwimpern.

Die Familie des Aspidiscinen wurde von Ehenberg im J. 1830 (Ahhandl. der Berliner Academ. S. 4.2) aufgestellt; sie umfasste nur lie einzige, gleichzeitig begrindete Gattung Aspidisca und sollte die gepanzerten Magen- 
thiere enthalten, welche einen deutlichen Darmkanal mit doppelter Aindung und nur die Afteröffnung an einem der Enden besitzen. Die Grinde, welehe mich bestimmlen, diese kleine Familie mit einem verbesserten Character aufrecht zu erhalten, sind bereils S. 108 angegeben worten. Die Aspidiscinen sclıliessen sieh in der Bewimperung sehr nalıe an die Euplotinen an, sie zeigen aber auch in der Gusammtforn ihres hörpers eine unverkennbare Verwandtschaft zu den Chlamydodonten, namentlich zu den Galtungen Ervilia, Trochilia und selbst zu Chilodon; sie bilden, wie mir scheint, das watiulichste Bindeglied zwischen jenen beiden Familien. Auch gegenwärtig beschränlit sich die Familie der Aspidiscinen noch immer auf die einzige Gattung Ispidisca; eine Art dieser Galtung (Asp. polystyla) entfernt sich jedoch nicht unerheblich von den tibrigen Arten. sie wird vielleicht später als eine besondere Gattung abgesondert werden.

\section{Gattung Ispidisca. EnrbG.}

(Taf. III. lig. 1-21).

Der Character der Guthung fält nit dem Familiencharucter zusammen.

Die Aspidiscinen sind sammtlich lileine Infusorienformen, deren Untersuchung nit mancherles Sehwierigheiien verknupft ist, weshalb auch ihre Organisation bis in die neueste Zeit dunkel blieh. O. $F$. Müller gah zuerst von zwei Arten, die er zu seiner Gattung Trichoula rechnete, ziemlich kenntliche Abbildungen; auf eine dieser Arten Trich. Iynceus) griundete Ehrenlierg 1830 seine Galtung Aspidisea und er lieferte von derselben im grossen Infusorienwerk eine wenigstens annäliernd richtige Darstellung. Ausserden fugte er noch eine zweite. jedoch 'ganz ungeniigend erforschte Art (Asp. denticulata hinza, von tler es sehr zweifollaft bleibt. ob sie wirklich zur Gattung Aspidisca gehört. Dagegen Leschrieb Ehrenberg eine achte Aspidisea als Euplotes lurrius, und wahrscheinlich sind auch sein Euplotes aculeatus und Lovodes plicatus nur ungenau untersuchte Ispidiscen. Dujardim hat die Kenntniss der Aspidiscen eher verwirt, als gefödert; er find weder den bereits von Ehrenberg bei Asp. Iynceus erkannten adoralen Wimperbogen, noch den Ilund auf und glaubte deshalb Thiere einer andern Gattung vor sich zu haben, welcher er den alten, von Bory in einem andern Sinne gebrauchten Namen Coccudina beilegte. Perly nalım ohne alle Kritik sowohl die Galtung Coccudina Duj., wie auch die Gattung Ispidisca an. Erst Claparede und Lachmamn Iaben die Organisation der Aspiliscen genauer ermittelt, sie erkimnten namentlich deu wichtigen Character, dass der adorale Wimperbogen nicht frei auf der Baucbseite, sondern in einer Spalte zwischen hiicken- und Bauchplatte liege. Diese Forscher haben von drei Arten correcte Darstellungen gegehen, den Nucleus aber nicht erliannt. Ihre Abbildungen lassen die feineren Structurverhältnisse nicht genigend klar hervortreten, was wohl eine Schuld der Litlographie ist.

Der durchsichtige, meist ganz farblose Köper der Aspidiseen gleicht einem unregehmässig ovalen Schilde. dessen Vorder- und rechter Seitenrand einen continuirlichen, stark convexen Bogen bilden, währent der linke Seilenrand fast gerade oder doch nur wenig nach aussen gekrummt ist. Die Scheibe der Rückseite ist gewölbt Fig. If), der linke Seitcurand (Fig. I. '1. d.) lamellenartig verhiunt und zugeschärft, der rechte Seitenrand abgerundet und wulstförmig verdickt; er biltet nach unten zu eine stark vorspringende, die eigentliche Bauchilache betrichtlich uberragende, nach innen zu scharf begranzte, sichelformige Schwiele, die Ramlschwiele Fig. 1.s. 4. s), welche sich gewöhnlich auch über den ganzen Vorderrand fortsetzl. Dic Bauchseite zeigt eine zientich complicirte Configuration; lings des linken Seitenrundes zieht sich ein llacher, zuerst sehr schmaler, binter der Mitte stark bogenlörmig nach innen gebrümuler Ausschnitt herab, dessen innerer, vertiefter Rand mit einer Reihe adorater, feinborsliger Wimpern (Fig. I. p.) besetzl ist, die rorn sehr liurz. hinter der llitte am lingsten sind. Der hinterste Theil der Bauchfliche ist stask niedergedrucht und durch eine quere bogenförmige Kante von dem erhabenern vordem Theil der Bauchliache, den ich Bauchplatte nennen will, gesondert. Die Bauchplatte bildet eine schiefe, gegen die Randsehwiele geneigle Ehene, ihr linker Seitenrand ist in einen frei nach aussen rorspringenden, staren, lamellenarligen Saum (Fig. \{. b. 1 3. b.) ausgedehnt, welcher am meisten nach ruckwills entwickelt ist und mit den Hinterrande der Bauchplalte unter einem reehten Winkel zusammenstüsst. Dieser Randsaum ist bei den meisten Arten durch einen busenartigen Einschnitt vom Vorderrande getrennt, wodurch die Thiere einige Aehnlichlieit mit der Crustaceengattung Lynceus erhalten; der busenartige Einschnitt wird jedoch meist ganz von der Ruekenplatte überwölbt Fi...4. 15). Der Randsaum der Bauchplatte ïlserleckt die adoralen Wimpern, die also in einer liefen, engen, peristomartigen Spalte zwischen der Ricken- und Banchplatte eingeschlossen liegen und sich deshalb leicht der Beobachtung entziehen; nur an busenarligen Einschnitt ragen die vordersten adoralen Wimpern frei hervor (Figr. I. f). 
Auf dem vordern Theil ter Bauchplatte stehen constant sieben griffelförmige Bauchwimpern (Fig. 1. st.); unter ihrem Hinterrande sind fünf (Fïg. 1. a.), nur bei einer Art 10-12 griffelförmige Afterwimpern eingefügt.

Der Mund (Fig. 3. o.) liegt am hintern Ende des adoralen Wimperbogens, nahe vor dem Hinterrand der Bauchplatte, er führt vielleicht in einen ganz kurzen uach innen und vorwärts gekrümmten Schlund. Der After (Fig. 1. 3.z.) wurde bei einer Alt (Asp. lyncaster) auf der rechten Scite, licht linter den Afterwimpern ermittelt. Der einzige contractile Behatter (Fig. I. 4.c.) findet sich in dersell,en Gegend, jedoch vor den Afterwimpern. Der Nucleus (Fig. 2. 4. n.) ist stets strangförmig und hufeisenförmig zusanmengekrummt; er wird erst nach Anwendung von Essigsăure sichtbar. - Quer- und Längstheilung sind gewöhuliche Erscheinungen; die Quertheilung ist dadurch ausgezeichnet, dass stanmtliche Bauch- und Afterwimpern (vergl. Asp. Jynceus) neu gebildet werden. - Die meisten Aspichiscen bewegen sich schnell und anhaltend rudernd und drehen sich dabei häufig im Kreise umher; an fremden Gegenstånden laufen sie geschickt auf und ab, inden sie sowohl die Bauchwimpern, als auch die Afterwimpern wie Füse benutzen.

Mir sind funf sichere Arten bekannt geworden, von denen zwei ausschliesslich im Meere leben, während zwei andere sowohl im salzigen wie im siissen Wasser vorkommen. Die vier ersten Arten sind ächte Aspidiscen. die funfte dürfte wenigstens cine Untergattung reprasentiren.

a) Wit fïf Afterwimpern und einem busenartigen Einschnit vor den Randsaum der Bauchplatte. (Aspidisca s. str.)

1. Aspidisca lyncaster. Steix. (Taf. IIL. Fig. 1-3).

Trichoda lyncaster Mäller Zoolog. Danica Vol. I. p. 9. Taf. IX. Fig. 3.

Körper nach hinten verengert, der Forderrand vor dem busenförmigen Einschnitt in einen Sehnabel ausgezogen, der Randsaum der Bauchplatte hiuten in einen Stachel verlängert.

Ich habe diese grösste und sehr ausgezeichnete Art zuerst im Nai $1853 \mathrm{im}$ Ostscewasser von Stralsund und dann wieder im Januar 1933 im Ostseewasser von Traveminde in zahlieichen Exemplaren beohachtet und dureh deren anhaltendes Studium zuerst eine klare Einsicht in den Organisationstypus der Aspidiscen gewommen. - Der ovale, nach hinten etwas verengerte und stumpf eiförnig zugespitzte Körper zeichnet sich durch den sehr stark hogenförmig gekrümmten Vorderrand aus, der nach links in einen frei vorspringenden, hakenförmig nach hinten gekrümmten, spitzen Schnabel cndet. An der Bildung desselben ninmt die Rücken- und Bauchplatte Antheil, er ist aber von der Bauchplattc durch einen tiefern busenförmigen Einschnitl getrennt, als von der Riickenplatte. Letztere (Fig. 2) ist llach gewölbt und auf der Scheibe mit drei niedrigen Läugskielen verschen, wejehe zuweilen sehr undeutlich sind oder ganz fehlen. Die verhälnissnassig schmale Randschwicle erstrecht sich bis zur Schnabelspitze; der Randsaum der Bauchplatte (Fig. I. bb') ist stark entwickelt und an der hintern Eche in einen nach rückwärls gerichteten, mit der Spitze etwas nach aussen gelirimmten Stachelfortsatz (b') ausgezogen. Von den auffallend dicken und kurzen Bauchwimpern (st.) stehen vier längs des vordern Theiles der Ramdschwiele (s.), die drei andern zienlich in der Mitle der Bauchplatte im Dreieck; die ebenfalls dicken, etwas längern Afterwimpern (a.) sind unter dem Hinterrand der Banchplatte eingefigt. Der contractile Behilter (c.) liegt vor teu beiden rechten Afterwimpern: nahe dahinter, in dem niedergedrüchten Hinterfelde der Bauchseite zwischen der zweiten und der mittelsten Afterwimper suh ich zweimal (bei z.) sehr deutlich den Austritt von Excrementen. Der lange hufeiseuoder ringförmig zusammengekrümmste Nucleus (n.) liegt unter der Bauchplatte und kehrt stels seine freien Enden dem Hinterrande derselben z.u. - Die Bewegungen dieser Art sind weit langsamer, als die der ubrigen Arten. Die meisten Individuen waren $\frac{1}{38}-\frac{1}{3 \pi}{ }^{\prime \prime \prime}$ lang.

Dass die von O.F. Müller im Neerwasser beobachtete Trichoda lyncaster mit meiner Art identisch ist, halte ich für völlig ausgenacht. Seine Abbildungen stellen entschieden eine Aspidisca mit einem hintern Dornfortsatz dar. der Schnabel ist ebenfalls angedentet und noch besonders in der Beschrcibung hervorgehoben. Wenn Müller eine grössere Anzahl von Bauchwimpern angiebt und diese auf einen kugelförmigen, gelenkigen Grundtheil sitzen lässt, so hat dies wenig zu besagen; er konnte mil seinen schwachen Vergrösserungen diese Verhältnisse numöglich genauer ermitteln und musste namentlich über die Zahl der Bauchwimpern um so leichter gelausclıt werden, als diese beständig nach allen Richtungen hin durcls einander schlagen. Ich selbst glaubte Anfangs, dass viel mehr Wimpern vorhanden seien, vorsichlig mit Chromsiure getödtete Thiere gaben aber bald äber die wahren Zahlenverlultuisse Aufschluss. 


\section{Aspidisca lynceus. Ehrig. (Tar. III. Fig. 4-10}

Trichoda Lyuceus Mizller Animal. infusoria p. 225. Taf. XXXII. Fig. 1. 2.

Aspidisca Lynceus Ehrenberg Die Infusionsllicrdien p. 34. Taf. XXXIX. Fig. I

Coccudina crassa Dijardin lnfusoires p. 446 . PI. X. Fig. 2.

Aspidisea Lynceus Clapuride el Lachmann Etudes p. 191. P. VII. Fig. 16.

lörper nach hinten verbreitert und am Ende fast abyeslutzl, ungeschnabelt, Rüchen ganz glall oder mil drei schuvehen Lähgskielen

Diese weit verbreitete, in allen süssen Gewässern selı gemeine Infusorienform lionm auch im Ilecre ror; Ehrenberg heobachtete sie in der Ostsce bei Wismar, und auch ich tral sic ebendasellost im August 1857 lıiufig an. - Der Körper hat fast dic Form eines an den Ecken abgerundeten rechtwinkligen Drejecks, er verengert sich nach rom zu und remreitert sich nach hinten, der linke Seitenrand ist gerade, der rechte massig convex, der Ilinterrand last gerad abgestuzt odler flach bogenförmig abgerundet. Der Rücken ist zienlich gewölbt und bei den Süsswasserformen in der Regel ganz glatt (Fig. 10), bei der Mecresform häufig mit drei niedrigen Längshielen auf der Scheibe. Die breite und dicke Randscluwiele (Fig. f. s.) setzt sich, immer schmaler werdend, iber den Vorderrand fort und verliert sich im Anfange des linken Seitenrandes, obne einen vorspringenden Sclmabel zu lilden. Der Randsaum der. Bauchplatte ragt uicht uber den Rand der Rückenplatte hinaus und bildet mit dem IInterrande eine etwas zngespitzte, fast rechtwinktige Ecke. Von den sieben minder stakken Bauchwimpern stehen vier vorn längs der Randsclıviele, drei in einer fast parallelen Reihe vor der Mitle der Bauchplatte (Fig. 4); die langerm, fast borstenförmigen Afterwimpern nelimen die gewöhuliche Stelle cin. Elwenberg lässt die Bauchwimpern (Hahen) zwisclıen $5-8$ und die Afterwimpern (Griffel) zwischen $5-6$ schwanken, was irrig ist und bereits von Claparide und Lachmam berichtigt wurde. Der Nucleus (n.) verhält sich wic bei der vorigen Art, der contractile Belıảlter (c.) ist dicht an die Randschwiele geriickt. Gewöhnliche Körperlänge $\frac{1}{54}-\frac{1}{4}{ }^{\prime \prime \prime}$.

Die Quertheilung habe ich durch alle Stadien verfolgt. Zuerst dehut sich der Körper des Mutterthieres nur unledeutend in die Länge aus Fig. 5, wahlrend der Nucleus sich verkïrzt und verdickt, ganz in die linke Sceile hineinrückt und hier meist in Form eines dem linken Seitenrande parallel liegenden Krummstabes erscheint (Fig. ̈̈.n.). Die hintere Reihe der Bauchwimpern schwindet, und in dem Raum zwischen den vier vordern Bauchwimpern und den Afterwimpern wachsen eine grosse Anzalıl neuer Wimpern hervor, die Anfangs ungemein zart sind und so lebhaft hin und her schwingen, dass sie zusammen wie ein wogendes Saatfeld erscheinen. Man hann auf diesem Stadium der Querheilung das Iutterthier lejcht fiir cine besondere Infusoriengattung halten. Balıl werden jedoch die neuen Wimpern stärkes und mehr griffelartig, auch gruppiren sie sich in gewisse Reihen, von dencn eine aus funf Wimpern bestehende Querreihe in der Nitte der Bauchplatte und eine ihnliche dicht vor den alten Afterwimpern auffallen. Es sind dies die Afterwimpern für den liüntigen vordern und hintern Theilungssprössling. Jetzt zeigt sich auch ein neucr contratiler Behäter neben der Mitte der Randschwiele (Fjg. ̋̈. c'.). Alsdann dehut sich der Körper hetrachtlicher in die Lange aus (Fig. (i), der Nucleus (n.) streckt sich ebenfalls und wird fist gerade, die neugebildeten Wimpern rijcken weiter aus einander, und.sie irgeben sich nun als zwei vollstindige Bauch- und Afterwimpersysteme, von denen das eine die vordere, das andere die hintere Hálfte der Bauchplatte einnimmt. Letztere bekommt jetzt in der Ilitte ilıres Randsaunes eine Einschnürung und gleiclızeitig zielıt sich auch der mittlere Theil des bisher geraden adoralen Wimperbogens nach einwärts. Bald darauf sehnürt sich zuerst der linke Rand der Rückenplatte und dann auch dic Randschwiele in der Milte nach innen zu ein (Fig. 7), die vordere Hälfte des adoralen Winuperlogens trennt sich ron der hintern, zieht sich stälier nach einwärts und es entsteht an ihrem lintern Ende der Mund fur den vordern Theilungsspössling; der hintere Theilungssprössling behilt den Mlund des Mutlerthieres Erst mit der Tremnng des atloralen Wimperbogens zerfällt der Nucleus in ein vorleres und hinteres sichelförmiges Segrment n. n.). Nun besizt sowohl der vordere, wie der hintere Theilungssprössling wieder alle Organe des Mutterthieres, ausserdem aber noch iberzählige Wimpern; der vordere ist numlich noch immer mit der ursprünglichen vordern Bauchwimpereihe, des hintere mit den ursprüglichen Afterwimpern vessehen. Endlich erfolgh die Alıschnürung ler beiden Theilungssprösslinge (Fig. 8); hierbei verschieben sich dieselben alluählig so gegen einander, dass der hintere Theilungssprössling immer mehr nach rechts rückt. bis zuletzt nur noch scine linke Vorderrandsecke mit der rechten Hinterandsecke des vordern Thcilungssprösshings zusanmenhängt. Gewöhnlich werlen schon vor erfolgler Treunung der beiden Theilungssprösslinge an dem hintern die alten Afterwimpern ganz oder zum Theil ron den neven Afterwimpern verdangt; in unserer Fig. 8, welche durch ein Versehen des Kupferstechers schief gestcllt ist, sicht man noben den funf nenen nur noch zwej der ursyunglichen Afterwimpern. Des 
vordere Theilungssprössting verliert erst, nachdem er frei geworlan ist, die vier vorderen uberzahligen Banchwimperu. Man kann also cinzelne Aspidiscen antreffen, die en/weder uberzälulige Bauchwimpern oder iberzällige Afterwimpern besitzen; dergleichen Formen darf man nicht für besondere Arlen balten. es sind unlangst aus der Quertheilung bervorgegangene Individnen.

Das letzte Stadium der Quertheilung wurde bercis von $O$. F. Müller buobachtet und abgebildel; er glaubte ainen Begaltungsact zweier Individuen vor sich zu hahen und liess dieselben mit ihren Hinterrundern an einander häugen. Hier sollten auclı die Genilalien und im vordern Theil des Körpers ein geliummter Darmschlauch und noch ein anderer Kanal liegen, was natïlich reine Phantasieen sind; höchstens sah Müller den Nucleus. - Die Längstheilung habe ich bisher immer nur in ihrem Endresultat beohachlet, sie seleint anf älnhiche Weise wie bei Chilodon cucullulus zu erfolgen. Der rechte Theilungssprössling überragt stels mit seinem vordern Ende den Jinken (Fig. 9'. und letzterer ragt hinten über den reehten hinaus. Beide Theilungssprösslinge zeigten hereits dic normale Bewimperung, der linke bedeckte bei der Bauchansicht mit seiner rechten Seite die linke Seite des rechlen Theilungssprösslings. mil dem er nur in einem schmalen Längsstreifen vermurlen war. so dass der gesammte, die Peristomspalte enthalende linke Seilenrand des rechten Theilungseprösslings lrei uber dem hiiclien des linken Theilungssprösslings lag.

Da Asp. lynceus auch im Neere hialig angetroffen wird, so vereinige ich olne Bedenlicn danit Dujurlin's Coccudina crassa. welche im Mittelmeer bei Cette beobachtet wurde. Sowolıl die ron Dujardin gegebene Abbildung wic auch seine Beschreibung passen auf die Meeresform von A. lynceus. Tenn in der cinen Figur sechs, in der andern acht Bauchwimpern dargestellt sind, so berulut dies nur auf flichtiger Untersuchung. Die von Dujardiu ebenfalls bei Cetle beobachlete Cocendina polypodi diufte gar keine Aspidisea. sondern cin schlecht beobachteler Euplotes gewesen sein. Seine in der Seine grefundene Cocc. cicada (nfusoires j. 44.7. Pl. XIII. Fig. 1) ist gar nicht zu bestimmen.

3. Aspidisca turrita. Clas. el Lacms. (Taf. III. Fig. 11-14).

Euplotes furvitus Ehrenberg Die Infusionsthierclien S. 380 . Taf. XLII. Fig. XII. Aspidisca turrita Claparéde el Lachmann Études p. 189. PI. VII. Fig. 11-12.

hörper nach hinten verbreitert. um Ende fast abgestutst, ungeschnabelt, mitten auf dem glatter Rüchen tin nach ribchiarts gekrimmter Stachel.

Diese Art stimmt sowohl in dẹ Gesammtform nol Grösse ilıes Körpers, wie auch in der Stellung der Wimpern (Fig. 11) und der Lige und Form des Nuclens n.) und des contractilen Behälters (c. vollkommen mil Aspidisca lyncens überein, in deren Gesellschaft sie auch selur häufig angetrollen wird; sie unterscheidet sich

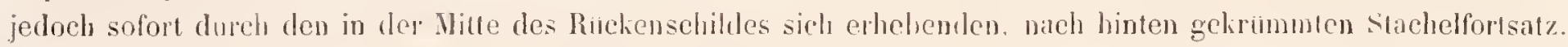
Dieser zeigt aber selbst hei Individuen dersellen Localitat cine selı verschiedene Entwiclielung. Nicht selten ist er nur ein ganz kurzes. fast geraules oder schwach gelimmutes Spizehen Fig. 13. nu. gewöhnlieher aber ein hräftiger, spiz legelförniger, von den seiten her znstmmengetrickter, nach hinten übergebogener Slachel (Fig. 1 g. 14. m.), dep danı of noch ron einem dic granze Vitlellinie des Riickiens einnelımenden Längshiele Fig. 12) getragen wird. Dieser Längskiel ist in der Mitle. da wo der Stachel ron ihm ausgeht, spindelfömig erweitert; er seheint anch anl der Banchseite (Fị. 11) durch, und verursacht an dem sonst abgestutzlen Minterrande des Körpers eine stumpfe Znspilzung. Die grösste Länge erreicht der Ruckenslachel bei den im Heerwasser lebenden Individnen, die von Ehenbry in der Ostsee bei Wismal ebenfalls in Gesellschaft der Asp. lynecus beohachtet wurden. Dass diese lieine besondere Art bilden, lehut eben die bei den Süswasserformen so leicht zu constatirende bedeutende Variation in der Grösse des Richenstachels. Ehrenbery schreilut seinem Euplotes lurrilus, in welehem er selbst schon cine Aspidisca vermuthel, nur fün Bauchwimpern zu; dass in Wahlheil sichen volhanlen sinu, haben bereils Cilaparide und Lachman gelehrt. Die Scheibe ter Richseite ist bei unserer Art läulig sehr hoch gewölbt und seharf ron den Rindern abgesctzt (17ig. 12); letztere krummen sich heim Kletterı an fremden Gegenstïnden elwas

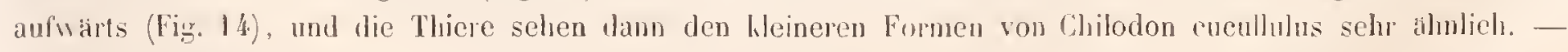
Korperlange bis $\frac{1}{43}$ ".

Der von Ehruberg in Ostseewasser von Kiel beobathlete Euplotes arulealus Die Infusionsho. S. 380. Taf. XLII. Figr. XY kann möglicher Weise eine im milfleren Stadium der Quertheihug begriflene Aspidisca Lurrila gewesen sein. Elwenberg gesteht selbst, dass ilm das betail der Bewimperung unklar gebliehen sei; er eitirt anch Müller's Kerona rastellum Animal. infusor. p. 233. Taf. XXXlli. Fig. 1. 2. welehe ich ebenfills für eine in der Quertheilung begrillene Aspidisca halle. 
4. Aspidisca costata. STEIx. (Taf. III. Fig. $13-17$ ).

(?) Loxodes plicatus Ehrehbrg Die Infusionsth. S, 323 . Taf. XXXIV. Fig. \&

Coceudina costala Dijardin Infusoires p. 146. P. X. Fig. 1.

Coccudina costata Perty Kleinste Lebensform. S. $1 ; 7$.

Aspidisca cieada Claparride et Lachmann Études p. 190. PI. VII. Fig. 13-13.

Körper fast ciförmig, auf der linken Seite eingebuchtet, ungeschnabelt; Rüclien mit sechs stumpfen Längsrippen.

Die Asp. costala ist in süssen Gewässern eben so gemein, wie die beiden vorhergehenden Arten, in deren Gesellschaft sie of angetrollen wird, namentlich erscheint sie läufig in längere Zeit aufbewahıtem Wasser zwischen verfaulten Pflanzenresten. - Der meist etwas trübe, schmutzig grelbliche Körper ist hinten auch verbreitert. aber

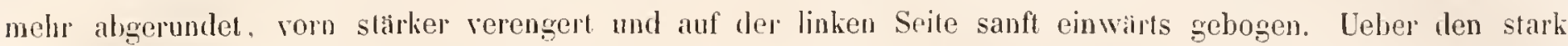
gewölhten Rücken verlaufen fünf liefe gekrimmle Längsfurchen (Fig. I6), die mit sechs stumpfen, abgerundelen Rippen abwechseln. Nicht selten ist eine Furche mehr vorhanden, und man zăhlt dann sieben bis acht Rippen. Die Furchen scheinen auf der Bauchseite (Fig. 15) durch, die Bauchplatte selbst ist aber glatt; ihr Randsaum ïberragt uamentlich mit seiner stank eutwickelten, slumpfwinkligen Ilinterecke (b.) den gegeniberlicgenten Rand der Riickenplatte. Die Randschwiele, die Bauch- und Afterwimpern, der Nueleus (Fig. I6. n.) und der contractile Behălter

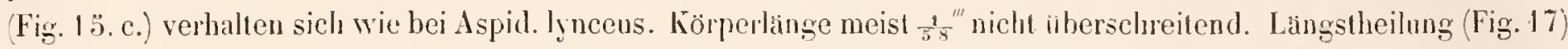
wurde oft beobachtet, die feinern Vorgange bei derselben liessen sich jedoch nicht ermitteln. Die beiden Theilungssprösslinge sind list unter einem rechten Winkel mil cinander verbunden und stark gegen einander verschohen.

Wahrscheinlich gehört Elrenberg's Loxodes plicatus luierher, den Ehreuberg selbst einer Aspidisca ahnlich findet; sicher ist dies jedoch nicht, da nur am hintern Ende sechs schwache Längsleisten vorbanden sein sollen, auch Afterwimpern nicht gesehen wurden. Ehrenberg's Oxytricha cicada (Die Infusionstl. S. 366. Taf. XLI. Fig. IV) liönute nach den Abbildungen allenfalls auf unsere Art bezogen werden, allein Oxyt. cicada besitzt nach der Beschreibung 8-13 gekerbte Längsrippen und einen weichen, zerfliessbaren liörper, was durchaus nicht auf Aspidisea costata passı. Dagegen stellt Dıjardiu's nach einer 900 maligen Vergrösserung gezeichnete Coccudina costata unverkennbar unsere Art dar, obwohl zwei Afterwimperm zu viel und eine Bauchwimper zu wenig angegeben sind; es gelıt dies noch uberzeugender aus der das hintere Ende in Profil darstellenden Abbildung (a. a. O. Fig. 1. b.) hervor, anch passt Dujardin's Beschreilung und seine Angaben über Aufenthalt und Grösse vollkommen. Der Dujardin'sche Speciesname scheint mir daher der allein berechtigte, und irh kann den spätern, von Claparéde und Lachmam gegebenen nicht anmehmen. Der letztere empfiehlt sich ohnehin nichı, da, wenn sich Oxytricha cicada Ehbg. wirklich als eine Aspidisca herausstellen sollte, diese von der Aspid. cicada Clap. et Lachm. specifisch rerschieden sein würde; wir hälten also clanı fur zwei Arten denselhen Namen.

b) Mit 10-12 Afterwimpern und olne busenartigen Einschnitt vor dem Randsaum der Bauchplatte. (Subg. Onyehaspis).

\section{Aspidisca polystyla. STEIx. (Taf. III. Fig. 18-21).}

lch betrachte diese sehr ausgezeichnete neue Form einstweilen als ein Subgenus der Gattung Aspidisca, welches ich mit dem Namen Onychaspis bezeichue. Ste wurke von mil im Mai 1857 im Meerwasser aus dem Hafen von Triest entdeckt und in zahlreichen Exenularen beobachtet. - Der sehr durchsichlige Körper ist rundlich oral, die linke Seile wenig convex, fast gerade, die Rücliseite (Fig. 19) schwach gewölbt und auf der Scheibe mit drei Längskielen versehen. Die Randschwiele setzt sich nicht ïber den Vorderrand fort, welcher lamellenartigg zugeschärft ist. Rücken- und Bauchplatte sind fost bis zur Mlitte des linken Seitenrandes mit einander verwachsen; hier erst beginnt der sogleich stark einwarts gekrummte adorale Wimperbogen, weleher nur ron einem wenig entwickelten, dreieckigen Fortsatz der Banchplatte Fig. 18. b.j überdacht wird. Fon den sielsen dick griffelförmigen Bauchwimpern stehen je drei in zwei queren, einander parallelen Reihen auf dem vordern Theil der Bauchplatte, die siebente steht weit nach rüchwarts nehen der Randschwiele und nahe ror den Afterwimpern. Letztere sind borstenförmig und nicht unmiltelbar unter dem Hiuterande der Bauchplatle, sondern elwas weiter lücliwärts auf dem niedergedrüchten Hinterfelde eingefügl; ich zihtle eben so häufig 10 als II, selten 12 Afterwimpern. Neben der linken Vordereche der Bauchplatte finden sich noch zwei sehr feine borstenförmige Wimpern, die in der liuhe schief nach aussen und hinten gerichtel sind (Fig. 18. 19) und dann lauschend den Eindruck machen, als sei hier ein spaltförmiger Einschuilt vorhanden. - Der Nucleus (Fig. 20. n.) verhţlt sich wie bei den übrigen Aspidiscen, der contractile Behälter (Fig. 19. 20. c.) liegt aber hinter den Afterwimpern, in der Milte des niedergedıuckten Hinter- 
feldes. Länge des Körpers $\frac{1}{4 \frac{1}{4}}$. - Fast vollendete Quertheilung (Fig. 21) beobachtete ich eimmal; der vordere Theilungssprössling zeigte drei überzhhlige Bauchwimpern, die Quertheilung erfolgt daher wohl auf dieselbe Weise, wie bei Aspid. lynceus.

\section{Dritte Familie. Euplotina (Euplota EHrbG.)}

Character: honper gepansert, lur: und gedrungen oxal mit convexem Rüchen und planer Banchseite; im vordern Theile der limken Bauchhälfte ein weiter, offener, sich meist über den ganzen Vorderrand des Kürpers bis zum rechten Seitenrand ausbreitender Peristomansschnitt, dessen Vorder-und Aussemand von adoralen Wimpern eingefasst wird. Slarlic griffelfurmige Vimpern stehen in geringer Zahl and in constanter Ordmung über die Bauchfliche vertheilt. An den Seiten des Bauches findet sich kine contimurliche Randwimperreihe. Mund im hintern Winliel des Peristoms, After vor dem hintern Kürperende.

Die Familie der Euplotinen wurde von Ehrenberg im J. 1830 (Abhandl. der Berliner Acad. S. 4.3) unter dem Namen Euplota aufgestellt. Ich habe mir erlaubt, dem Familiennamen eine andere Endigung zu geben, weil derselbe, namentlich mit deutscher Endigung gebraucht, zweideutig ist und blos auf die Gattung Euplotes bezogen werden lönnte. Anfangs bestand die Familie nur aus dieser Gattung, spiiter liamen dazu noch die Gattungen Discocephalus, Chlamydodon und Himantophorus, und es wurden nun die Euplotinen als gepanzerte Hagenthiere characterisirt, welche einen Ernihrungskanal mit zwei getrennten und ausserhalb der Körperenden gelegenen Miindungen odẹr letztere altein deutlich erkennen lassen. Von jenen vier Gattungen musste ich die Galtung Chlamydodon, deren Organisation Ehrenberg nicht richtig erkannt hatte, zur Familie der Chlamydodonten bringen. Die Gattung Discocephalus beruht auf einer ganz unklar erkannten, von Ehrenbrrg im rothen Neer beobachteten Infusorienform, die sich niemals wird enträthseln lassen, weshally es wohl am zweckmaissigsten ist, die Gattung Discocephalus ganz aus dem System zu streichen. Die Gattung llimantophorus würde, wenn die Darstellung, welehe Ehrenberg ron der einzigen Art (H. charon) gegeben hat, richtig ist, unbedingt zu den Euplotinen gehören. Leider hat kein zuverlassiger neuerer Forscher den Himant. charon wieder auffinden können, von mir ist aber eine neue Oxytrichinengattung (Onychodromus) ent.lecht worden, welche möglicher Weise der Gattung Himantophorus zu Grunde gelegen haben kann. Jedenfalls bedarf die letztere Gattung noch der Bestatigung, bevor wir sie als ein zurerlăssiges Mitglied der Euplotinenfamilie ansehen hömnen. In dieser Familie bleibt also mit Sicherheit nur die allbekamnte Gattung Euplotes ubrig; sie ertalt einen Zuwachs an den beiden zuerst von mir unterschiedenen Gallungen Uronychia und Styloplotes. Mit ersterer Gattung ist die von Claparede und Lachonm aufgestellte Galt. Campylopus identisch; zu letzterer Gattıng gehört allem Anscheine nach der Euplotes excavatus und Schizopus norwegicus dieser Forscher.

Die Euplotinen stinmen in der Anlage ihrer gesammten Organisation sehr nahe mit der folgenden Familie der Oxytrichinen ubercin, sie besitzen aber einen viel kürzern und gedrungenern, ovalen oder rundlichen Körper, der stets entschieden gepanzert und meist mit mehr oder weniger entwickelten Längsippen rerselien ist, die entweder nur auf der Rückseite oder auch auf der Bauchseite vorkommen. Das Peristom bildet gewönlich einen unregelmässig sichel- oder harfenförmigen, muldenartig vertieften Ausschnitt, der sich von der rechten Ecke des Vorderrandes - der Bauchseite über den ganzen Vorderrand ausbreitet und sich dann unter einem rechten oder stumpfen Winkel in der linken Bauchhälfte mehr oder weniger weit nach hinten erstrecht. Den vom Peristom umgürteten vordern Theil der rechten Bauchhälfte, der häufig eigenthumlich gestaltet ist, bezeichne ich als Stirn. Die vorderen längeren und lirafligeren, adoralen Wimpern bilden einen queren, stark gewölbten, der Rijckenfläche zunächst liegenden Bogen, der oft von einem oberlippenartigen Saum überragt wird. Die dem Aussenrand des Peristoms eingefigten adoralen Wimpern liegen der Bauchlläche näher und nehmen ron vorn nach hinten an Länge und Stärke ab. Claparède und Lachmam, welche den Vorderrand des Peristoms als Stim bezeichnen, lassen sowohl bei den Euplotinen. wie anch hei den Oxytrichinen die vordern adoralen Wimpern von der rechten Ecke des Vorderrandes über die Rückseite ilesselben verlaufen und sich erst am Anfange des Aussenrandes nach der Bauchseite hinabwinden. Die vordern adoralen Wimpern werden cirrhes frontaus, die am Aussenrund stehenden aber cirrhes buccaux genannt (vergl. Études p. 169). Ich muss für jetzt bei meiner Auffassung rerharren. Der Innenrand des Peristoms trigt bei den Euplotinen entweder einen starrhautigen Saum oder eine undulirende Membran.

Die locomoliven Wimpern erreichen in dieser Familie ilıre höchste Entwickelung, sie sondern sich in der Regel scharf in Bauch- und Afterwimpern, wozu noch einige vereinzelte oder zu 2 - 3 neben einander stehende Randwimpern kommen. Die Bauchwimpern, deren höchstens 10 vorhanden sind, stehen ïber die rechle Banchhalfte 
vertheilt und zwar die Melızahl anf der Stirn; bei ciner Gattung (Uronychia) fehlen sie bis auf geringe Spuren am finterı Bauchende gànzlich. Dic Afterwimpern, höchstens fïnf an der Zahl, stehen in einer geraden oder gekrümnten Querrcihe hiuter deu Bauchwimpern. Die Randwimpern beschränken sich auf den llinterrand uud linken Seitenrand des Bauches; niemals futlet sich Jings des linken und rechten Seitenrandes eine continuirliche Randwimperreilse, und hierdurch unterscheiden sich die Euplotinen auf den ersten Blick von den Oxytrichinen. - Der coutractile Behtilter liegt in der Regel auf der rechten Seite in der Năhe der Afterwimperı und dicht hinter demsellsen der After. Der Nucleus ist nur bei zwei Gattungen erkannt; bei beiten ist er strangfirmig, bei der einen aber in doppelter Anzahl rorhanden. - Die Qucrtheihng ist die hajufigste Fortpflanzungsweise; während derselben werten in der hintern und vordern Körperhällte zwei neue locomotive Wimpersysteme entwickelt, die das mütterliche nach und nach verdraingen.

Die Bewegungen dor Euplotinen sind ungemein schnell und gewandt und es bedarf eines selır anlaltenden Studiums, bevor man mit den Organisationsverhältnissen derselhen einigermaassen vertraut wird. Die bisher von diesen Thieren gegebenen Darstellungen waren siimutlich so mangelhaft und unvollstandig, dass man nach denselben kaun die gemeinsten Formen wieder zu erkennen im Stande war. Erst Cluparide und Lachmanu hahen den Organisationsplan der Euplotinen richtig erhannt und von verschiedenen Mitgliedern dieser Familie naturgetreue Abbildungen geliefert. Ich bin, unabłıngig von diesen Forschern, zu nahe ubereinstimmenden Resultaten gelangt.

Die Euplotinen gehören vorzugsweise dem Meere an, und sie erscheinen hier oft in ungeheuren Schaaren von Individuen. In len süssen Gewassern kommt nur cine Gattung (Euplotes) vor, die aber auch in Meere reichlich vertreten ist. - Die drei mil bekannten Gattungen unterscheiden sich auf folgende Weise vol! einander:

1) Ohne eigentliche Bauchwimpern, die starken, griffelfömigen After- und Randwinpern sehr genähert und vor dem hintern Ende der Bauclıseite zusammengehäuft

2) Mit Bauch- und Afterwimpern und 4-5 Randwimpern.

a) Bauchfläcbe muldenförmig ausgehölılt, von den š Randwimpern 3 zu einem Büschel vereinigt

I. Uronychia.

b) Bauchflïche mit einem erhabenen Mittelfeld, 4 isolirle Randwimpern

2. Siyloplotes

3. Euplotes.

1. Gattung. Ironychia. Sters.

(Taf. IV. Fig. 1-5).

Character: Körper oval, dick, mit abgerundeten Seiten, vorn abgestutzt und mit einer häutigen Oberlippe versehen; das lintere Körperende schwanzartig verengert und abgerundet und auf der Bauchseite mit zwei gegen einander convergirenden bogenfürmigen Ausschnitten versehen, wetchen die starken griffelförmigen After- wnd Randwimpern eingefügt sind. Eigenttiche Bauchwimpern fehlen.

Diese Gattung unterschied ich hereits im J. 1834. (Die Infusionsth. S. 158) von Euplotes; ich gründete sie auf eine von mir in der Ostsee beobachtete Euplotinenform, in welcher ich die eine der beiden von Dujardiu unter dem Namen Ploesconia scutum zusammengeworfenen Euplotinen erkannle. Da Dujardin's Gattung Ploesconia mit Euplotes Ehbg. synonym ist, so schlug ich vor, der neuen, durch die Beschrankung der locomotiven Wimpern auf das hintere Körperende schon hinlänglich scharf characterisirten Gattung den Namen Ploesconia zu belassen. Später überzeugte ich mich, dass Ploesconia scutım schon ron O.F. Müller als Trichoda transfuga beschrieben worden war, ich zog es nun vor, der Gattung den ueuen Namen Lronychia beizulegen und begründete sie unter demselben in der Sitzung der Böhmischen Gesellschaft der Wissenschaften vom 19. October 1837 mit genaueren Characteren. In J. 1838 haben Claparède und Lachmam aus einer nit Ploesconia scutum nahe verwandten, ja vielleicht identischen Art die neue Gattung Campylopus gebildet, (lie also mit meiner Gatlung Uronyehia zusammenfällt ${ }^{1}$ ).

Der sehr dicke, nur wenig abgeplattete, bisweilen fast drehrunde Körper ist oval, vorn gerad abgestutzt, ror dem hintern Ende etwas eingeschnirt und in einen kurzen, abgerundeten, plattenformigen Schwanz verlängert (Fig. 1), der meist etwas nach rechts geliummt ist (Fig. 4. 5). Die beiden Seiten des Körpers sind aligerundet, die linke stäker ausgebaucht, als die rechte; der Ruchen ist gewöhulich mit Längsrippen versehen (Fig. 4. 3̈), öfters

1) Da die Sitzungsberichte der Böhm. Gesellsch. der Wissensch. von 1857 leider erst mit dem so eben erschienenen X. Band der Ablundlungen ausgegeben wurden, so kann es zweifelıaft erscheinen, ob meinem Gatlungsnamen die Priorität gebührt. Will man jedoch die Prioritatsrïcksichten streng urgiren, so miisste auf den vou nir zuerst vorgeschlargenen Namen Ploesconia zurückgegangen werden. lch lege übrigens auf dic Annabuse meines Gattuısuamens durchaus keinen Werth. 
aber anch ganz glatt (Fig. I). Der obere Rand des abgestutzten Vorderrandes ist schwach buchtig gezähnt, der untere in eine gewölbte, halbmondförmige Oberlippe verlängert, welche die Basis ıler langen und krâftigen vordern adoralen Wimpern bedeckt. Das weite, ticf ausgelıöhlte, fast sackörmige Peristom (Fig. 3. i. I. p.) ist vom linken Seitenande abgerückt und melır nach der Mitte zu gervandert; es besilzt am Innenrande eine bandförmige undulirende Membran (i.), der Aussenrand und namentlich die linkie Vorderecke sind stark nach einwärts gelıogen, so dass die adoralen Wimpern des Aussenrandes (p.) ihre Spitzen nach innen kehren. Das Peristom kann fast ganz geschlossen werden, indem sich Innen- und Aussenrand desselben so nähern, dass nur noch eine enge bogenförmige spalte (Fig. 2. p.) ubbrig bleibt. - Die Bauchseite (Fig. 2. 3) ist nur wenig abgeplattet, mehr gewölbt, als plan. Das schwanzartige Hinterende zeigt zwei seitliche, nach hinten gegen einander convergirente, tiefe bogenförmige Ausschnitte, welche durch einen fast dreiecligen, wulstigen Zwischenrücken von einander getrennt werden; sie bewirken, dass die Seitentheile des Schwanzes, von der Rückseite gesehen, als selr durchsichtige, zugeschärfte, läutige Platten erscheinen. Am Vorderrande des rechten, viel breiteren Ausschnittes sind vier starke griffelförmige, weit iher den Ilinterrand hinausragende Afterwimpern (Fig. 2. a. 5. a.) eingefugt. Enwas weiter nach hinten und auswärts stelsen dicht neben einander in einer schrigen dem Vorkerand des Ausschnitts parallelen Linic drei noch längere und stäkere Griflel (b.) eingefügt, die in die Kategoric ler Randwimpern gehören und am deullichsten ron (ler Rückseite ans (Fig. I. b.) erkannt werden; sie liegen in einer tiefern Eluenc, als die Afterwimpern, und werden vou denselhen zum Theil bedeckt. Sämmthiche Wimpern des rechten Ausschnitts sinł gewöhnlich nach einwärts und links gebogen; mamentlich sind die drei Randwimpern stark hakenförmig gekriimmt; diese schlagen sich auch häufig über den rechten Seitenrand nach der Rïcliseite zu nm (wie b' in Fig. है), wodurch das Ansehen entsteht, als seien sie auf dem Rücken des Schwanzes eingefügt, was ich selbst früher glaubte. In den schmalen linken Aussclınitte stehen vorn und dicht hinter einander zrvei ebenfalls lange und kraftige griffelförmige Randwimpern, die in der Rulıe nach hinten herabhangen und mit deu Spitzen einwảrts gekrümmt sind (Fig. 2. d.). Sảmmtliche After- und Randwimpern sind an ganz frischen, chen erst auf das Otjectglas gebrachten Thicren einfache, zugespitzte Grilfel, sie zerspalten sich aber nach kurzer Zcit ron der Spitze her in feinere orler gröbere Faserı (Fig̣. b. b.), und bald sieht man nur ein dichtes Gewirr von zahllosen Haaren und Borsten, die zum Theil noch am Grunde mit einander zusammenhängen. Uumittelbar vor den Ausschnitten des Schwanzes sitzen auf jorler Seite les Bauches wenigstens noch zwei borstenförmige Wimpern (Fig. 1. 3. f. l., welche wohl als dic einzigen Vertreter der bei den iibrigen Euplotimen vorhandenen Bauchwimpern anzusehen sind; die ganze iibrige Banchlläche ist ohme locomotive Wimpern. - Einen contractilen Behälter konnte ich nichıt auffinden, nach Claparide und Lachmam liegt derselbe in der linken Seite des Schwanzes unmittelbar vor den leiden Randwimpern. Der After und der Nucleus sind noch unbekannt. Mehrmals salı ich zwar in der vordern körperhalfte einen blassen ovalen Körper Fiğ. 2. 4;, ich bliel, jeloch zweifelhaft, ob dies wirklich ein Nucleus war; denn ich vemochte ihn nicht zu isolireu, und innerhalb les dicken, wenig durchsichtigen körpers liess sich seine feinere Structur nicht genügend ermitteln. Es konnte auch ein fremder Körper sein, da die Thiere oft nicht viel kleinere verschluckte Nahrungsstofle euthalten (Fig. 1). Quertheilung wurle beobachtet, jedoch nicht näher studirt.

Die Bewegungen der Thicre sind höchst characteristisch; sie gleiten eine Zeil lang schnell und stetig in gerater linie bald vorwirts, bald rückwärts, wobei nur die vordern adoralen wimpern und hilufig auch die beiden linken Randwimpern und die Bauchborsten in einem geringen Grade thatig sind, wahrend die drei rechten Randivimpern und die Afterwimpern eingekimmt und unbeweglich bleiben. Dann steht das Thier einige Augenblicke still, kaum aber Lat man diesen gunstigen Moment wahrgenommen, um seine Organisation genauer kennen zu lernen, so schmellt es plötzlich mit erstaunlicher Energic und meist seitwärts weit weg aus dem Gesichtsfelte, und man hat nun die grösste Mïhe, den Fliichtling wieder aufznfunden. Dieses gewaltige Fortschnellen des Thieres verursachen die After- und rechteu Randwimpern, die sich in einem Augenbliclie plötzlich grerad ansstrechen und dlann sogleich wieler einwärts lirimmen; mit ilıer allmähligen Zerfaserung wird auch das Sprungrermogen immer schwicher.

Die Gattung Uronychia bewohnt ausschliesslich das Meer. Die Differenzen, welche zwischen meinen Beobachtungen über diese Gattung und denen von Claparide und Lachmam bestelien, weisen anf zrvei rerschiedene Arten hin. Bei den grossen Schwierigheiten, welche sich einer genauen Untersuchung der Uronyehien entgegenstellen, ist es jedoch leicht möglich, dass die vorhandenen Ditlerenzen nur auf Beobachtungsfehlern berulıcn, welche auf der einen orler andern Seite Jegangen sein kömnen. Ich werde zuerst die von mir beobachtete Form unter dem 
Namen Uronych. Iransfuga abhandeln, und dann den Campylopus paradoxus von Claparède und Lachmann damit vergleichen.

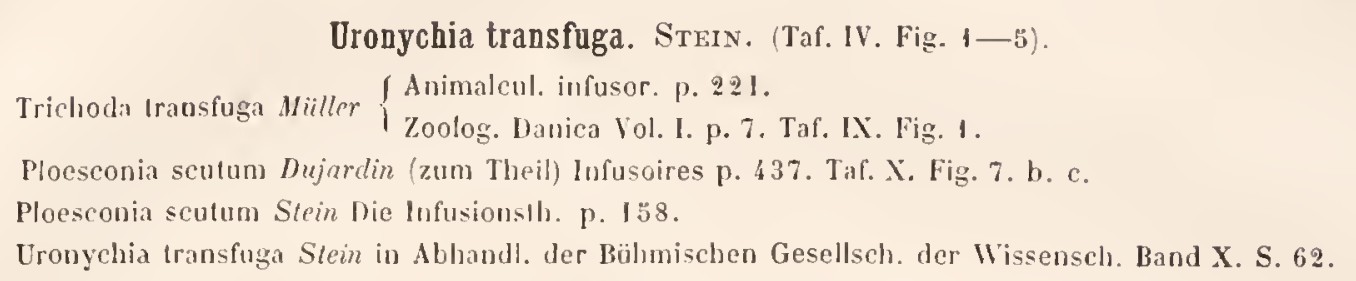

Diese Art wurde von mir zuerst im October $1832 \mathrm{im}$ Ostseewasser von Stralsund in zahlreichen Exemplaren aufgefunden; dann beobachtete ich sie wieder im August 1837 in der Ostsee bei Wismar, jedoch minder lıăufig. Die Stralsunder Exemplare (Fig. 2. 4.5) waren stark alıgeplattet und ziemlich durchsiehtig; ilır Schwanz setzte sich scharf vom Körper ab, war nach hinten etwas erweitert, stark nach rechts gekı iummt (Fig. 5) und oft in der Mlittc des Hinterrandes durch eine seichte Einschnuirung in zwei ungleiche schicfe Lappen getheilt. Ueher den Rücken verliefen stets vier feine Lingsliele in gleichen Abstinden von einander. Sie verlieren sich nach hinten zu und gehen uicht auf den Schwanz ïher, vorn laufen sie in die zahnförmigen Vorspringe der abgestutzten Endfläche aus. Der ausserste Kiel jeder Seite steht nahe an Körperınte. Die Wismarer Exemplare (Fig. 1. 3) hatten einen selır dicken, fast drehrunden Körper und einen weniger entwickelten, nach hinten verengerten Schwanz; der Rücken zeigte keine Spur von Längslielen und das Parenchym war dicht mit groben Fetliörnchen erfült, welche dem Körper eine perlgrauc Farbe ertheilten und ihn sehr undurcbsichtig machten. An den Wismarer Thieren erkannte ich erst die frïher von mir übersehenen Batuhborsten; Afterwimpern zähtte ich bei ihnen bisweilen funf (Fig. 3). Das Periston erstreckle sich bei allen von mir untcrsuchten Uronychien stels nur bis zur Körpermilte. Die meisten Individuen waren $\frac{t^{\prime \prime}}{2^{\prime \prime}}$ lang.

Die Abbildungen, welche O.F. Müller in der Zoolog. Danica von seiner in mehrere Tage lang aufbewahrten Meereswasser beobachteten Trichodla transfuga geliefert hat, stellen ziemlich kenntlich unsere Alt dir. sie stimmen an meisten mit meiner Fig. $\breve{b}$ therein, nur ist der Schwanz verhaltnissnissig zu lang und eckig angegeben, und statt der iber den Schwanz hinausragenden Griffel sincl nur in einer Figur einge feine Wimpern gezeichnet. In des Beschreibung sagt aber Müller ausdrucklich: Subtus e cauda propendent setae quatuor vel plures, curvatae, pediformes. Müller's Beschreibung der Bewegungen seiner Trich. transfuga beseitigl vollends jerlen Zweifel an der Identiat dieser Infusorienlorm mit meiner Urongchia; namentlich bezeichnend sind die Worte: Haud raro correptionc ope setarum posticarum e conspectu et quasi in aerem seu extra gutlam subinde ab una ad alteram guttae plagam aufugil. Der Müller'sche speciesname ist demnach als der älleste allein berechtigl. Miller beobachtete auch zucrst Querheilung, die er fur Begattung hielt; mir ist sic leider nicht vorgetommen. - Dujardin hat unter dem Yamen Ploesconia scutun zwei ganz verschiellene Infusorienformen abgebildet; in der grösscrn Figur 7. a. erkenne ich die folgende Galtung Styloplotes, dic heiden kleinern Figuren 7. b. c., namentlich Fig. 7. b., stellen unverkennbar unsere Uronychia dar; die Gesanmtforn des Körpers, die beiden characteristischen bogenformigen Ausschnitte auf der untern Seite des Schwanzes und die denselhen eingefügten Griffel, so wie auch die vordern adoralen IVimpern sind nahezu richlig angegehen. Die Banchseite erhielt irthumlich an der Stelle des nicht dentlich erkannten Peristons 1-2 Haken. Dujardin's Thiere stammten aus dem Milleheer.

Her Campylopus paradoxus von Chpace und Lachmam Etudes p. I84-88 und Pl. VII. Fig. 8-9). welcher in grosser Menge an den Norwegensehen kiisten lieobachtel wurde, weicht hauptsachlich in folgenden Punclen ron Uronychia lrausfugai ab. Der Rucken ist nur mit drei, aber stark vorspringenden stumpfen Längskielen rerselıen, cinen millem und zwei seillichen, mu an Vorderrand finden sich nur drei zahnförmige Vorsprünge. Die Oberlippe tritt in den Abliddungen nicht kar hervor und wird auch in der Beschreilung nicht erwähnt. Das Peristom la fosse buccalej erstreckt sich viel weiter nach riickwirts; einer undulirenden Ilcmbran am Innenrande desselhen wirt nicht gedacht. Afterwimpern (pieds-rames) sind statt viep hlos drei vorhanden; diese, wie die fumt Randwimpern, werden kiurzer und dicker dargestelt, auch sollen sie an der Spitze luestänlig in ein Büschel ron Fasern zertheilt sein. Dic zwei Gruppen von Randwimpern werden mit Lnrecht pieds dorsanx genannt und zwa blos deshalh, weil sie der Rijckenfliche năher liegen, als der Bauchflache. Diese Bezeichnung muss nothwentig zu ler irrigen Vorstellung fülıen. als ständen diese Wimpern anf der Rücliseite des Thieres, was doch Cluparede und 


\section{0}

Lachmann selbst nicht annehmen. Bauchborsten sind im Ganzen sechs vorhanden, vier ungleiche auf der rechten Seite, zwei glciche anf der linken. - Im Uebrigen stimmt die Organisation von Campylopus paradoxus völlig mit der von Uronych. transfuga iberein, und auch die Bewegungen sind dieselben; sie wurden sehr treffend und anschanlich heschrieben. Quertheilung wurde ebenfalls beobachtet. Claparede und Lachmam erwähnen noch, dass G. Wagner bei Wismar ein mit ihrem Camp. paralloxus nahe verwandtes, aber in mehreren Puncten differirendes Thier beobachtet habe; wahrscheinlich war dies meine Uron. transfuga.

\section{Gattung. Styloplotes. Stein.}

(Taf. III. Fig. 22-29).

Character: Körper linglich elliptisch, dich, mit abgerundeten Seiten, rorn eifürmig zugespitzi mit abgesetzter Oberlippe; das hintere Ende nach rechts gekrümmt und schief abgestutzt; anf der Bauchseite eine mediane, muldenförmige Rimne, in der das Peristom und die griffelformigen 7 Bauch-und 5 Afterwimpern liegen. Ein Büschel von 3 Randuimpern am Ilinterrande und ? Randwimpern auf der linken Seite.

Die Gattung Styloplotes habe ich in der Sitzung der Böhmisch. Gesellsch. der Wissensch. vom 19. October 1857 nach einer in der Ostsee beobachteten Euplotinenform anfgestellt, in welcher ich Ehrenberg's Stylonychia appendiculata erkannte. Claparede und Lachmann haben dasselbe Thier 1858 wahrscheinlich einmal als Euplotes excavutus, und sodann als Schizopus norwegicus beschrieljen.

Der läuglich elliptische, nicht selten fist ovale oder eiförmige Körper ist gewöhnlich nach vorn etwas erweitert (Fig. 23. 24); die beiden Seiten sind bald fast parallel und gerarle (Fig. 20), bald gegen die 1 litte sanlt (rinwarts gekriimmt (Fig. 24), bald schwach nach aussen gebogen. Das vordere Ende hat die Form eines Spitzbogens, dessen rechter Schenkel kürzer ist, als der linke, so dass der rechte Seiteniand weiter nach vorn reicht, als der linke. Das umgekehte Verhältniss findet an hintern Ende statt; dlieses ist mehr oder weniger nach rechts gekrimmt und anf der rechten Seite schusg von vorn und rechts nach linten und links abgestutzt und sanft bogenförmigr ausgeschnitten. Der linke Seilenrand erstreckt sich daher viel weiter nach hinten als der rechte, und der die beiden Rinder verbintlende schiefe concave Bogen wird zum eigentlichen Hinterrande. Der Körper besitzt eine ansehnliche Dicke (Fig. 26), ist aber dennoch ziemlich durchsichtig und gewöhnlich furblos, zuweilen schmutzig gelblich. Der Ruicken (Fig. 2:3) ist stark gewölbt, nacl vorn etwas vertlacht und iiberall ganz glatt; die beiden seiten sind abgerundet. Die plane Banchseite (Fig. 2.2. 24) ist links und rechts von zwei dicken, gerundeten liandwiılsten hegrảnzt, welche eine breite scharf hegranzte, muldenförmige Aushöhlung, die Banchunne, einfassen, ulie sich vom vordern bis zum hintern Körperende crstrecht. Die Banchrinne erweitert sich nach vorn und links und miundet uber len linken Vorderand (Fig. 26) mach aussen; nach hinten zu verengent sie sich etwas, lirumm sich nach rechts und geht am Hinterrande frei nach anssen. Die linke Randwulst ist iberall gleich breit, sie wird vorn von dem Peristom begranzt und endigt an Hinterrande mil einem abgerundeten Vorsprung. Die rechte Randwulst verengert sich nach vorn und setzt sich bis uber die Nitte dos rechten Vorderraurles fort; hier beginnt der arlorale Wimperhogen, welcher noter der eine al)germndet dreieckige Oberlippe (Fig. 22. l.) bildenden Spire des Vorderrantes nach dem linken Rande hinubersetzt, bis zur hintern Ecke dessellien nach abwärts steigt nnd sich danm hogenförmig bis zur Körpermitte nach imnen krümmt. Die hintere grössere Hälfte des adoralen Wimperlogens p.) bildet den Ausscurand des umgekehrt eiförmigen Peristoms (p. i.), welches die linke vordere Hälfte der Bauchrinne einnimmt und vorn keine Fortsetzung nach der rechten Seite hin besitzt, daher cin Stirnrand nicht zu mnterscheilen ist. Die vordern adoralen Wimperu, namentlich die unter der Oberlippe gelegenen, sind lang und griffelförmign, die hintern kurz und feinhtarig. Der Aussenrand des Peristoms wird auch nach hinten von einer scharfen Bogenthie hegränıl; er hildet eine rom Peristomfeld gegen die linke Randwulst aufsteigende, bandfömige, schiefe Ehene. Der erhabene scharfhuntige Innenrand des Peristons Fig. 22. i.) Irigt einen selu dentlichen undulirenden Saun, welcher anscheinend aus sehr feinen gesonderten Wimpern zusimmengeselzt ist.

Der rechten Seite der Bauchrinne sind sieben krâftige, griffelförmigo Bauchwimpern eingefugt. Davon sitzen fül Fig 22.st.) in der Stirngegend und zwar drei nach aussen, lings der Randwust, und zwei etwas tiefer, neben dem Innenrande des Peristoms; die beilen audern Banchwimpern (I.) stelien hinter dem Peristom, nahe vor den Afterwinpern, die sechste nach aussen, die siebente nach innen. Die fünf sehr langen und dicken Afterwimpern (a.)

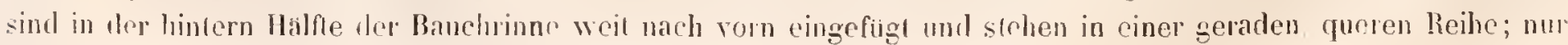


die zweite (ron rechts gezihlt) entspringt etwas weiter richwirts und ragt daher auch mit ihrer Spitze über die iibrigen fast gleich langen hinaus. Die Afterwimpern fiillen fast die ganze Breite der Bauchrinne aus, sind chen so gekriimms, wie diese, mul reichen weit iber den Hinterrand hinaus. Am Ausgange der Bauchrinne, aber nicht mehr auf dieser, sondern ummiltellar am Hintersande sitzt cin nach rechts und hinten gerichteter Schopf von drei dicht neben einander entspringenden knieförmig gebogenen Randwimpern (s.). Diese werten mehr oder weniger von den Afterwimpern verteckt, welche ehenfalls oft stark nach rechts gekrümmt sind. Han übersicht sie erst dann vollstandig mol erkemt klar ihre Insertion, wenn sich die Afterwimpern bei matt wertenden Thieren, die nicht mehr eine genigende Wasscrbedeckung haben, entweder nach vorn umschlagen (Fig. 2̈̈) oder sich nach den Seiten aus einander spreizen (Fig. 24). Dann hiegt sich anch der Randwimperschopf häufg bogenförmig iber die rechte Hintereclie nach vorn um (Fig. 25), und es lösen sich nach und nach alle slärkern Wimpern von der Spitze her in Faserbiischel auf. Ausser dem hintern Randwimperschopf sind noch zwei isolirte griflel- oder borstenförmige Randwimpern (Fig. 22. r. r.) rorhanden, sie stehen vor der Mitte der linken Randwulst nahe hinter einander, an den beiden Enden eines länglich elliptischen Grübchens. Die drei hintern Randwimpern cutsprechen den drei Randwimpern im rechten Bauchausschnitt der Uronychien, whihrend die beiden vordern den im linken Bauchausschnitt ler Uronychien enthaltenen Randwimpern analog sind.

Der contractile Behälter (Fig. 24. 25. c.) liegt imncrhalb) der Bauchrinne hinter den Alterwimpern, nahe an der rechten Randwulst. - Der Nucleus besteht aus zwei kurzen, sanft gebogenen Strängen (Fig. 23. 23. 11. n.); der eine liegt im vordern Körperende, deun linken Vorderrande parallel, der andere inı hintern Ende der linken Randwulst. Beide Kerne treten erst nach ganz allmähliger Einwirlung von verdiunter Essigsăure und auch dann oft nicht binjanglich klar hervor. Bei rascher Einwirkung von Essigsaiure schrumpft der Körjer sofort bis zur Unkenntlichkeit zusammen. - Die Thiere bewegen sich mngemein schnell und stetig, nicht stossweise, noch weniger springend, wie man wohl erwarten sollte; sie stehen keinen Augenblick still und stellen daher die Geduld des Beobachters wahrhaft auf die Probe. Oft sind nur die vordern adoralen Wimpern thătig, gewöhnlich wirken aber auch die Bauch- und liandwimpern mit, wihrend dic Afterwimpern fast unbeweglich ausgestreckt bleiben. Laufen oder kitettern sah ich die Thiere nie.

Quertheilung kommt nicht selten vor; ich babe drei Stadien terselben beobachtet. Im ersten Stadium (Fig. 27) zeigle der milterliche Körper noch scine gewöhnliche Form, nur war er lieträchtlich länger geworden. Die Verlängerung hatte mur den miltlern, zwischen Peristom und Afterwimpern gelegenen Theil des Körpers betroffen; denn die Afterwimpern waren weit weg von dem unverändert gebliebenen Peristom nach hinten gerückt. In dem Zwischenraume zeigte sich auf der linken Seite der Bauchrinne dicht neben der etwas ausgebuchteten Randwulst der Aufang zu einem neucn adoralen Wimperbogen $\left(p^{\prime} \cdot\right)$; er bestand aus eincr schwälı gebogenen Lảngsreilue von ausserst zarten und kumen, noch ganz gleichartigen Wimpern. In der rechten Habte der Bauchrinne war cine grosse Anzahl nener Wimpern entstinden, die die mittertichen Banchwimpern bis auf die drei vordersten verdrảngt hatten; sie bildeten zusammen zwei vollstüdige Bauch- und Afterwimpersysteme fỉr die vordere und lintere Körperhälfte. In der vordern Iälfte standen nämlich neben dem alten Peristom 10 Bauch- und ä Afterwimpern, in der hinterı Ififfte neben der Anlage zum neuen Periston 7 Banch- und ä Afterwimpern; letztere bedeckten die noch vorhandenen Aftewimpern des Muttertheres theilweis. Am Hinterrande war noeh der urspringliche Randwimperbischel vorlanden, der nicht erneuert zu werden scheint. In ter Vitte des Aussenrandes der rechten Randwulst zeigle sich ein neuer, noch schr kurzer Randwimperbuischel $s^{\prime}$.) für den kïnftigen vordern Theilungssprössling, und auf der linhen Randwulst war das ursprimgliche Randwimperpar geschwunden und dafür cin nenes vorderes und hinteres entstanden. - Im zweiten Stadiun der Qucrtheilungr (Fig 2S) sonderte sich hereits die vordere Körperhälfte durch eine quere Einschnirung der beilen Seiten von der hintern. Der adorale Wimperbogen der hintern Halfte halte sich nach aussen gewendet und weiter nach vorn und inmen entwickelt und die hier entstandenen Wimpern waren viel länger und stälker geworden; gleichzeitig halle sich anch der ibrige Theil des Peristoms ausgebildet. Dic miitterlichen Alterwimpern waren geschwunden, in der vordern Hable zeigten sich aber noch die drei überzhlligen Banchwimpern. Der vorlere Randwimperbüschel war dem hintem conform geworden und hatte sich in die seitliche Einschnüıung hineingezogen. Durch beide Kärperbälften verlief längs der linken Seite ein einziger lanğ strangförmiger Nucleus (n. n), der olfenbar durch Versehmelzung der beiden sich vertangernden Keme des Mutterthieres entstanden war. - In letzten Stadium der Quertheilung Fig. 29, zeigten sich heide Theiłungssprösslinge vollstindig entwickelt und fast ganz ron einander gesondert; der hintere war nach liuks gericht und lag unter dem vorderu, mit dessen 
linker Hinterecke seine rechte Vorderecke nur noch lose zusammenhing. Jeder Theilungssprössling enthielt einen einfacheu släangförmigen Nucleus (n. n.).

Unsere Gattung umfasst nur eine ansschliesslich im Neere lebende Art, namlich:

Styloplotes appendiculatus. STElN.

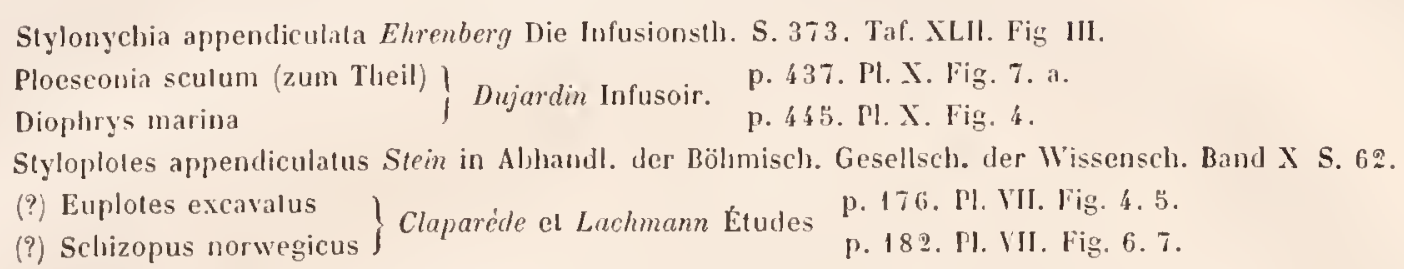

Ich lernte diese Art zuerst im Januar und Februar $1853 \mathrm{im}$ Ostseewasser von Travemunde kennen, in dem sie gleichzeitig mit Ervilia monostyla und Aspidisca !yncaster hảufg vorkam. Im August 1857 heobachtete ich sie in zahllosen Exemplaren sowoh! iu Hafen von Wisıar, wie auch in der Umgebung der lileinen, nördlich von Wismar gelegenen Insel Wallfisch. Die Thiere hielten sich auch in dem ganz faul gewordenen Seewasser, welches ich von der Reise mit nach Hause gebracht hatte, noch Wochen lang ganz frisch und munter, und ich hatte so Gelegenbeit. sie sehr intensiv und mit aller Ruhe zu studiren. lrgend einen erheblichen Bcobachtungsfehler diurfte ich daher schwerlich begangen baben. Die meisten Individuen waren $\frac{1}{3}-\frac{1}{2} \frac{11}{2}$ lang, es kamen alser aucb noch lileinere und heträchtlich grössere bis $\frac{1}{1_{4}^{\prime \prime \prime}}$ lange und last halb so breite Exemplare vor. Letztere euthielten bisweilen zwei viel kürzere, fast ovale kerne.

Ehrenberg's Stylonychia appendiculata ziehe ich ohne Bedenken hierher'; sie kaun keine Stylonychia, sondern uur eine Euplotine sein, da ihr die beiden Randwimperreihen abgehen. Unter den Euplotinen stimmt sie aber am meisten mit Styloplotes ibercin; sie zeigt den fur die letzlere Gattung so characteristisehen bintern Randivimperbüschel, die beiden linken Ranlwimpern und die iber das hintere Körperende hinausragenden Afterwimpern, deren Zahl gewiss irrig auf sechs erhöht wird. Der grosse helle Mund, von dem Ehrenberg spricht, war das ovale ebenfalls für Styloplotes characteristische Peristom; die Bauchwimpern und die Bauchrinne wurden ühersehen. Erwägl man nun noch, dass Ehrenberg seine angebliche Stylonychia bei Wismar fand, wo mein Styloplotes so gemein ist, dass er sich unmöglich einem hier henbachlenden Forscher entziehen konnte, so wird man nicht langer an dep Inlentiła beider Infusorienformen zweifolu können. - Das grössere Thier, welches Dujardin als Ploesconnia seutum abgebildet hat (Fig. 7. a.), stellt augenscheinlich nur ein grosses und breites Individum von styloplotes. dergleichen ich mehrfach beobachtete, von der Riuckseite gesehen dar; denn man erkennt in der Abbildung deutlich die durchscheinende breite Bauchrinne, die in dersélben sitzenden Bauchwimpern, von denen nur eine ubersehen ist, und die heiden linken Randwimpern; sie zeigt ferner den characteristischen schiefen Hinterrand und die iuler denselben hinausragenden gebogenen Afterwimpern. Von den drei hintern Randwimpern wurden un zwei criannt und diese den fünf Aftervinuern angeschlossen. - Dujardin's bei Celte beohachtete Diophrys marina ist weiter nichts, als ein junges Individunm von Styloplotes. Iessen adorale und locomotive Wimpern nur unvollständig erkannt vurden; es lehrt dies sowohl die gesammte Körperform der Diophrys, wie auch die bei ihr sehr klar unterschicdene Rauchrinne.

Der Euploles excavalus und Schizopus norwegicus von Claparede und Lachmam sind sowohl unter einander als auch mit meinem Styloplotes iberaus nabe verwandt. Beide Inlusorienformen hesitzen hei sehr ahnlicher Körperform genau dieselbe Bauchrinne, wie Sıloplotes, was freilich mely ans den Beschreibungen. als aus den nicht recht scharfen Abbildungen jener Forscher ethell. Dem Eupl. excavatus werlun b Bachwinpern pieds-crochets), 5 iber den Ilinterrand hinausragende, ganz wie hei Styloplotes sich verhaltende Alterwimperu (pieds-rames) und 2 am hnenrand der linken Randwulst dich neben den Alemimporn sitzente hamdwimpern (soies) zugeschriehen; er gleicht also meinem Styloplotes bis auf eine lehlende Bauchwinper und den Ilangel der drei hintern liandwimpern, die möglicher Weise uberschen wurden. Nehmen wir aber auch eine ganz richtige lieobachtung an, so würrle doch rer Euplotes excavitus sich immer viel naher an SHytoploles, als an Euploles anschliessen und von letzlerer Gattung getrennt werden mossen. Man wirde danı nur den Galtungricharacter von Styloplutes etwas allgemeiuer zu fassen haben, un E. excavatus dieser Gallung einvelleilsen zu lönnen. - Noch viel grösser ist die Lebereinslimmung zwischen Styloplotes und Schizopus norwegicus. Letzteres Thier soll sieb durch drei nahe am Hiulcrand auf der rechlen Seile des Rijckens in riner hallunondförnigen Vertiefung eingefugte und bestandig an der Spitze zerfaserte Wimpern pieds dursanx) grnerisch von Euplotes mnterscheiden; ausserdem 
werden ihm 7 ganz wie hei Styloplotes angeordnete Bauchwimpern und 7 Afterwimpern zugeschrieben. Von letztern sind die füıf rechlen die entrvickeltsten, sie reichen jedoch noch nicht bis zum llinterrande; die beiden linken, viel kïrzerı und feinern stehen mehr nach vorn und aussen. Nehmen wir an, dass diese nicht zu den Afterwinjpern gehören, soudern in Wirklichkeit auf der linken Randwulst stehen, dann ergiebt sich fuir Schizopus genau dasselbe locomotive Wimpersystem, wie für Styloplotes, und es bleibt mu der Unterschied ubrig, dass bei Schizopus die funf Afterwimpern relativ kürzer sind und dass die drej hintem Randwimpern etwas anders gestaltet und der Rüchseite eingefugl sind. Besteht aber dieser Unterschied wirklich? Ich zweille wenigstens an der dorsalen Einfuigumg der hintern Randwimpern und glaulse, dass Schizopus norvegicus höchstens specifisch von Sıyloplotes appenticulatus verschieden ist. - Euplotes excavalus und Schizopus norwegicus wurlen von Claparède und Lachmann an den Norwegischen Küsten heobachtet; den Nucleus und den undulirenden Saum am Innenrand des Peristoms erkannten diese Forscher nicht; den contractilen Behälter sahen sie innerhalb der rechten landwulst nahe hinter der Insertion der Afterwimpern. Schizopus wurde auch häufig encystirt angetrofien.

\section{Gattumg. Euplotes. Finrig.}

(Taf. IV. Fig. 6-20).

Charactor: Kömer elliptisch oder mullich, plattgedrïklit, mit sugeschïrften Rïndern; auf der planen Bauchseite rechts

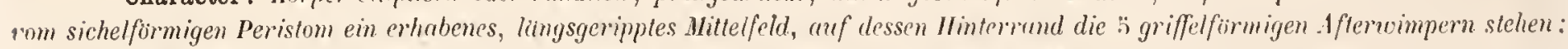
y-10 griffelformige Bauchwimpern und isolinte borsten- bis griflelformige Runduimpern.

Die Gattung Euplotes wurde von Ehrenberg im J. 1830 (Abhandl. Iler Berliner Academie S. 43) auf Trichoda charon von $0 . F$. Müller gegriundet und Anfangs Euploea genaunt; da dieser Name aber bereits für eine Schmetterlingsgattung verhraucht var. so wurde seit 1831 (Abhandl. der lierlin. Acad. S. 118) die jetzt grillige Benennung eingefiuht. Im Allgemeinen war die Gattung naturgemäs begriinzl, nur wengege fremdartige Formen, die zu den Gattungen Aspidisca und Ervilia gehören, hatten sich eingeschlichen. In der Familie der Euplotinen sollte sich Euplotes durch den Besitz von Wimpern, Griffeln und Haken auszeichnen. Dieser Character ist gegenwårtign nicht mehr ausreichend; denn er wïrle auch auf die Gattungen Styloploles uml Lrouychia, ja selhst auf Stylouychia passen. - Dujardin fuihrte stalt des Ehrenherg'schen Gatlungsnamens den von Bory einigen von O. F. Müller sehr unvollkommen alggebildeten Euplotinen ertheilten Namen Ploescomia wiedler ein, was nicht gebilligh werlen kann, da Müller's Formen zweilellıalt sind und Bory gar nichts dazu beigetragen hat, dieselben näher aufukiären.

Der starre, selır durchsichlige und farblose Körper der Euploten gleicht einem ovalen oder rundlichen. Dachen Schilde. Der Rüicken ist in der Mitte mässig gewölbt, nach den beiden Seiten und nach hinten stark verflacht und am Rande lamellenartigg zugeschiıft; ijber den Ricken verlaufen gewöhnlich scharfkantigge Längsrippen, die joduch bei einer und derselben Art balıl stärker, bald schwächer entwickelt sinı, ja selbst ganz fehlen könen. Die Bauchseile ist selır flach; in ihrer linken Halfte liegt das sclımalere oder breitere, oft weit nach hinten reichende Peristom (Fig. 7. j. p. I. Fig. 12. i.p.), welches sich vorn stets unter einen rechten oder stumpfen Winkel nach rechts unbiegt und bis zum rechten Seitentande erstrecht. Das Peristom hat diher ohngefähr eine harfen- oder sichelförmige Gestalt, und an dem rechıs vom Peristom gelegenen Theil der Bauchflàche ist slets eine scharf hegränzte sitirn (Fig. 7. 12. st.) zu untersclieiden, deren Vorderrand bei den verschiedenen Arten versehieden gestaltet ist und brauchbare Artnerkmale darbielet. Die vordern langen und lirafligen adoraten Wimpern stehen entweder dicht am Vorderrande, ouler sie werden von einer deutlichen Oberlippe (Fig. 7. I.) iberragt. Der slark gegen das Peristomfell geneigle breite Aussemrand des Peristoms ist auch nach hinten von einer scharfen Bogenlinie liegranzt. Au Innenrande des Peristons findel sich ein das Peristomfeld uberragender und gegen dasselle slark geneigter Saum (Fig. 7. i.) angeheftel, der entweder ganz sturr oder doch nur wenig biegsam ist. - Rechls von Peristom liegt ein erhabenes, am Anfang des hintern Drittels der Bauchseite endigendes, länglich trapezoidales Hitlelfeld Fị̣. 11. 12. m.). Ls wird von zwei geraden parallelen Seiten und von einem wiukelförmigg gebrochenen Hinterrande begııinzl, der aus zwei ungleich langen, nach linten convergirenden Schenkeln besteht; der rechte Schenkel ist langer und

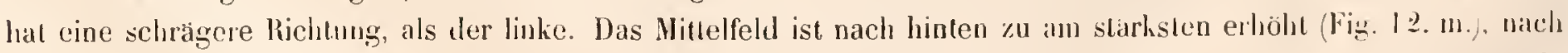
vorn verflacht es sich und geht obne bestimmle Granze in die Stirn uber. Der rechts an das Mitlelleld granzende Theil der Bauchllache ist hohlkehlenartig vertieft, ebenso ist der hinter dem Miltelfeld grelegene Theil der. Bauchnáche stark ausgehöhlt; nach links fält das Mittelfela minder stẹl ab. Vom Hinterande des llittelfeldes aus ver- 


\section{4}

laufen ibler die plane Fläche dessellsen sechs parallele, gleich weit von cinander abstehende Längsrippen, von denen drei starlier entwichelt sind und sich viel weiter nach vorn erstrecken. Die erste, vicrte unil sechste sind die Hauptrippen; die erste und sechste fält mit den beiden Seitenrändern des Mittelfeldes zusammen, die vierte liommt aus der hintern Eclie des Ilinterrandes und theilt dos Mittelfeld in zwei ungleiche llälften, von denen die rechte zwei abgeküzte Rippen enthati, die linke eine.

Von den 9-10 dick gritlelförmigen Bauchwimpern stehen $6-7$ auf der Stirn zusammengehauft, die 3 ibrigen zerstreut. Die langen, über den Hinterrand des Körpers hinausragenden griffelförmigen $\Lambda$ fterwimperm Fig. 12. a.) sind dicht vor dem Hinterrande des Mlttclieldes in je cinem Zwischenraume zwischen zwei Längsrippen eingefüt; sie nehmen von rechts nach links elwas an Limge und Stärke zu. Die 4 vereinzelten Randwimpern ( $r$. r.) stehen fast gleich weit von einander entfernt und zwar zwei melır genahert dicht am Hinterrande der rechten Körperhäffte, zwei etwas entfernter von einander und mehr nach innen längs des linken Seitenrandes. - Der Mund liegt ganz im hintern Winkel des Peristoms, er ist eine kurze enge Spalte, durch welche sich der adorale Wimperbogen noch eine kleine Strecke weit in querer Richtung nach innen fortsetzt (Fig. 14. o. Fig. 17). Claparede und Lachmam schen diese Fortselzung für einen besondern Schlund an; ich vermochte keine Schlundwandungen zu unterscheiden. Die durch den Mund eintretenden Nahrungsstofle beschreiben einen kleinen Kreis in dem benachbarten Parenchym; sie gehen zuerst eine kurze Strecke quer nach rechts und vorn und biegen dann nach links und linten um. - Der contractile Behälter (Fig. 12. 14. c.) liegt unter der rechten hintern Ecke des Nittelfeldes, und unmittelbar dahinter findet sich der After (Fig. 14.z.). - Der Nucleus ist stets langstrangförmig (Fig. 6. 13. n.), keineswegs aber ein ovaler runder scheibenförmiger Körper, wie sowohl Ehrenbery als auch Claparide und Lachmam irrig angeben. Der Körper, welehen diese Forscher fur einen Nucleus gehalten haben, ist ein Product des Nucleus, wahrscheinlich eine Koimkugel (vergl. Euplotes patella und charon); der eigentliche Nucleus trit erst nach Anwendung von Essigsåure deutlich hervor. - Quer- und Längstheilung beobachtete ich bei zwei Arien (vergl. E. patella und charon): die Quertheilung wurde genau ermittelt, die langstheihung ist jedoch noch problematisch. Was bisher dafü gehalten wurde, dürfte wohl eher Conjugation zweier Individuen sein. Wahrseheinlich leitet dieser Vorgang eine geschlechtliche Fortpflanzung ein (vergl. E. charon).

Die Euploten leben theils in süssen Gewässern, theils im Ncere. Die Süsswasserformen werden auch im Meere angetrotlen, letzteres beherbergt aber ausserdem noch eigene Arten. - Von Ehrenberg und Dujardin wurden eine betrichtliche Anzahl von Arten aufgestell, diese beruhen jedoch auf so unzureichenden Beobachtungen, dass man Nühe hat, nur die beiden gemeinsten, in unsern siissen Gewåssern vorkommenden Arten nach don Schilderungen dieser Forscher wieder zu erkennen. Sie hatten noch keine richtige Vorslellung von der Organisation eines Euplotes überhanpt und wussten daher auch nicht, worauf es bei der Unterseheidung der einzelnen Arten ankommt. Höclıst wesentlich sind aber die Zahlen- und Stellungsverhälnisse der locomotiven Winpern. Bei allen genạu gepruften Euploten finden sich nach den übereinstimmenden Untersuchungen von Claparede, Lachmamn und mir :3 After- und 4. Randwimpern und 9-10 Bauchwimpern; da diese constanten Elemente bei den von Elwenberg und Dujardin abgebildeten Arten auch nicht annähernd richtig angegeben sind, so vertieren diese Arten alle Bedeutung, und sic werden his auf zwei, die sich schon nach ilırer Körperform und ihrem Aufenthalte bestimmen lassen, ganz aus dem Infusoriensystem gestrichen werlen müssen. Diese zwej Arten sind Euplotes patella und charon von Ehrenberg; von den sieben übrigen Arien, welche Ehrenberg in grossen lnfusorienwerk zur. Gattung Euplotes bringt, sind nur noch die drei in der Ostsee beobachteten Arten: E. striatus, appendiculatus und truncatus unzweifelhafte Euploten. Itujurdin hat 9 eigene Arten beschrieben, namlich Ploesconia vanuus, scutum, baltcata, cithara, crassa, affinis, subrotunda, radiosa und longircmis; von dicsen steht jedoch nichts weiter mit Sicherheit fest, als dass sie sämmtlich, Ploesconia scutum ausgenommen, wahre Euploten darstellen. - Zı den beiden allein sichern Ehreuberg'schen Euplotesarten kommen nur noch zwei hinlänglich genau sludirte neue Arten. von denen die cine von Lachmam, die andere von mir entdeckt wurde. - Der Euplotes excavatus Clap. Lachm. gehört zur Gattung Styloplotes. Von den vier Arten, welche gegenwithig den Besland der Gattung Euplotes bilden, henne ich folgende drei aus eigener Ansehanung: 
I. Euplotes patella. Emrng. (Taf. IV. Fig. $(6-11)$.

\begin{abstract}
Kerona patella Miiller Animal. infusor. p. 238. Taf. XXXIII. Fig. $1\{-17$.
Euplotes patella Ehrenbery Die Infusionsthierchen S. 378. Taf. XLII. Fig. IX.

Euplotes viridis Ehrenberg Nonatsher. der Berl. Acad. von 1840. s. 200.

Ploesconia palella Dujardin Infusoires p. 435. Pl. VIlI. Fig. 1-4.

Euplotes palella Claparède el Lachmarm Etudes p. 170. PJ. VII. Fig. 1-2.
\end{abstract}

Körper vain gerad abgestutst und mit ciner dreiechigen Obcrlippe verschen; imnerhalb des Peristoms eine besomdere adorale Rinne; der schräg zugespitzte Vorderrand der Stim überragt don rechten Theil des Peristoms; 9 Buuchwimpern; dic beiden rechten Randwimpern verästelt.

Diese sehr ausgezeichnete, leicht kenntliche Art kommt überall häufig in stehenden und langsam fliessenden Gewässern, zwischen Wasserlinsen, Conferven, Callitrichen und andern an der Oberfliche regetirenden Gewaichsen vor; im Sumpf- und Torfwasser ist sie ebenfalls gemein. Claparde und Lachmun heobachteten sie auch im Meere. jedoch in einer elwas abweichenden Form. - Die ‘ussere Körperform ist sehr vertuderlich, was zum Theil vom Aufenthalt bedingt sein mag; sie variirt aber auch bei Individuen derselben Localitait heträchtlich. Die grewöhnlichste Form ist die in Fig. 6. 7 mnl 9 darşestellte; sie hesitzt einen ovalen, hinten eiförmig zugespilzten Körper, der auf der linken Seite vor der Nitte zicmlich stark ausgebaucht und nach vorn nur wenig odej gar nicht verengert ist, so dass die gerad abgestutzte Endfliche eine betrachtliche Breite hat. lhr unterer Rand ist in eine ungleichschenklig dreiechige, auf der rechten Seite stirker entwickelte Oberlippe (Fig. 7. I.) ausgezogen. Die Rüchseite (Fig. 6) ist zienlich stark gewölht und meist mil 7 feinen, glejch weit von einander entfernten, nach der hintern Körperspize convergirenden Längsrippen versehen. Nicht selten sind nur die aussersten Rippen vollstindig ausgebildet, die innern aber nur am hintern Ende angedeutet; zuweilen fehlen die Rippen gänzlich (Fig. 10). - Bei einer zweiten, selınern Form (Fig. II) stellt der Körper ein breites, rundliches, fast rautenförmiges Schild dar; die beiden Seiten sind in der Mitte stark erweitert und in grleichmảssig abgerundete hăutige? und biegsame Flügel ausgeilehnt, das hintere Ende ist schwanzartig verengert und stumpf zugespitzt, und auf dem verengerten. gerart abgestutzten Vorderende ist eine symmetrische, gleichschenklig dreieckige Oherlippe aufgeselzt. Der Riicken ist sehr flach, nur die Scheilse etwas gewölbt; Längsrippen fehlen entweder głinzlich oder es finden sich nur auf uler Scheibe schwache Andentungen, dafir aber erhebt sich in ter Mittellinie der Scheibe ein melı oder weniger entwickelter, alıgerundeter, flügelförmiger Kamm. - Bei einev drillen Form, die ich hesonders in sumpfigen Gewässern beobachtete, ist der Koorper sehr schmal, die beiden Seiten sind fast ganz gerade und einander parallel, und das vordere Ende ist etwas erweitert und wie bei der ersten Form gestaltet. Zwischen diesen drei extrenen Formen kommen alle möglichen Uebergangsstufen vor.

Das weite, fast gleichseitig dreieckige Peristom (Fig. \%. i. p. l.) reicht kaum lois zur Mitte des Körpers hinal, seine rechte rordere Fortsetzung ist eine schmale Rinne, welche von dem schiag aligestutzten, nach vorn und innen zugespitzten Vorderrand der Stirn (st.) ibherdacht wird. Die vordern adoralen Wimpern stehen in einer geraden queren Reihe, welche mit der am Aussenrande des Peristoms Jerabziehenden Wimperreihe fast rechtwinklig zusanmenstösst. Der lnnenrand des Peristoms ist knieförmig gelogen, der an ihm silzende häulige. aber stare Saum (i.) nimmt hauptsächlich die vordere gerade Hălfte des Inneurandes ein und verliert sich allnăhlig nach linten zu. Innerhalb des Peristomfeldes verläuft eine breite, schräge Längsrinne (d.); sie heginnt unter der Spitze der Oberlippe, zieht sich am Innenrande des Peristoms herab, erweitert sich nach hinten und aussen und endigt an P'eristomwinkel. Diese Rinne, welche auf der rechten Seite von dem häutigen Saum des Innenrandes überrag̨ wird, leitet auch von vorn her einen Nahrungsstrom zum Munde; sie bildet eines der aufallendsten Kennzeichen unserer Art. - Die neun Bauchwimpern sind in drei schrage. aus je drei Wimpern gehildete Reihen geordnet. Die beiden ersten (st.) stehen ganz vorn auf ter Stirn, dicht hinter cinander und dem stimande parallel; die drille Reihe ist viel schrager nach hinten gerichtet, ihre vorderste Wimper steht neben dom Innenrande des Peristons, vor der llitte desselben, ihre hinterste rechts neben dem Mittelfeld eingefügle ist den Afterwimpern genihert (Fig. T); nur bei der scheibenförnigen Varicłat (Fig. 11) sint die drei Bauchwimperreihen nahehei parallel. Die sechs rordern Bauchwimpern ragen weit nach rorn und aussen über den Kö̈per hinaus, sie sind immer etwas grösser, als die drei hintern; am stälisten sind die weit über den Hinterrand vorstehenden Afterwimperm entwickelt. Die Randwimpers ( $\mathbf{r r}^{\prime}$ ) variiren betrichtlich in Länge und Dicke, sie sind aber stets mehr griflel- als borstenfümign. die beiden rechten $\left(r^{\prime}\right)$ sind an der Spize constant durch feine Seitenästchen gefiedert.

Der sehr lange strangförmige Nucleus (Fig. 7. n.) liegt auf der linken Seite in rler Nihe des Mittelfeldes, seine beiden Enden sind rechtwinklig nach innen umgehogen: das hintere umfasst den Ilinterrand tes Mittelfelıles. 
Zuweilen zeigle sich kurz vor den beiden Enden eine quere spaltförmige Höhle (Fig. 6. n.). Mehrmals beobachtete ich gleichzeitig an vielen lndividuen einer Localităt in der rechten Körperhälfte nabe an Peristom ein oder zwei sehr helle, blasse, durchsichtige Kugelı (Fig. 10. k. k. Fig. Il.k.); bei Auwesenheit von zwei Kugelı war dic eine in ter Regel beträchtlich kleiner als die andere. Nach Einwirkung von Essigsăure sonderte sich jede Kugel in einc weit abstehende Hülle und in einen ganz homogeneu Inhalt. Die ludividuen, welehe diese Kugeln enthielten, zcigten stets noch einen besondern Nucleus (Fig. 10. 11. 11.), dieser war jedloch viel kürzer und dünner, als bei den gewöhnlichen ludividuen. Jene Kugeln mussten also offenbar Keimkugeln sein, die sieh auf Kosten des Nueleus gebildet hatten; ihre weitere Entwickelung konnte ich leider nicht verfolgen. - Von der Quertheilung balıc ieh nur cin Stadium (Fig. 8) genan uutersucht. In der hintern Körperhailfte zeigle sich links neben einer engen Linł:sspalı der Anfang zu einem nenen adoralen Wimperbogen $\left(p^{\prime}.\right)$; auf der rechten Seite hatte sieh bereits für die vordere und hintere Körperhälfte cin neues System von Bauch- und Afterwimpern und ein zweiter contractiler Behălter entwickelt. Ausserdem war noch das ganze arsprüngliche loconotive Winpersystem vorbanden, nur die mittelste Bauchwimper der dritten Reihe war geschwunden. - Sehr häufig triff man zwei der Länge naeh mit ihren linken Körperseiten innig verwachsene Individuen (Fig. 9), die sieh durch keinen Druek von einander trennen lasseu. Die luken Italften heider Individnen sinı mit ihren Bauchflachen an einauler gefugt und decken einander, so dass Periston auf Peristom liegt und das eine Individuum dem Beobachler die Bauchseite, das andere die Rüekseite zukehrt. Die beiden Kerne (n. n.) kreuzen sich in Form eines $\Upsilon$. Eines der beiden Individnen ist meist etwas grösser, als das andere; jedes besitzt sein vollständiges locomotives Wimpersystem. Diese Verbindung zweier Indiridnen galt bisher für Lảngstheilung, da ich jedoch niemals irgend eine ihr vorausgelsende Entwickelungsstufe auffinden konote, so bis ich genengt, darin viel eher eineu Conjugationsact zu erblicken.

Die Thiere bewegen sich selır schnell und anhaltend, unter beständigem Schwanken, indem sich die linke und rechte Seite abwechselnd heben und senken; sie stehen kaum auf einen Argenlsliek still und sind daher trotz ihrer Grösse weil sehwieriger zu beohachten, als Eupl. charon. Schr häufig ist ihr Parenchym mehı oder weniger dieht mit lebhaft grinen Chlorophyllkörnern erfiultt (Fig. 9-11). Die Nabrungsstoffe und deren Zersetzungsproducte. bilden gewölınlich in der Mitle des Körpers eimen (lunklen, seharf abgegräuzten Fleek (Fig. 6). Die grössteo lndividuen der normalen Form siud $\frac{1^{\prime \prime \prime}}{18}$ lang und durehsehnitılich $\frac{1}{2}-\frac{1}{25}$ breit; die scheibenförmige Varietăt ist fust so breit, als lang. Der Durchnesser der grössten Keinkugeln betảăg $\frac{1}{y^{\prime}}{ }^{\prime \prime}$.

O. F. Mäller's Kerona patella gehört sicher hierher, wie sowohıl ihre sehr kenntlich abgehildete Gesammtform, als auch ilır Aufenthalt beweisen. Müller untersehied hereits die sechs vorderu Bauchwimpern (cornieula) und sämmtliche Afterwimpern (setac), auch giebt er eine innere, scharf hegrảnzte Scheibe mit einem hellern Hof an. was ohne Zweifel eine Keimkugel war, von der sich die begrånzende Membran ahgehoben håte. — Ehrenberg's Ahbildungen sind vielfaclı ungenau und nicht einmal im Unuriss riehtig; die locomotiven Wimpern wurden zwar bis auf die beiden übersehenen veråstelten Randwimpern rollstäudig erkinıt, aber ihre relative Stellung ganz falseh aufgefasst. Die rechte Afterwimper wurde mit der hintersten Bauchwimper verbunden, die achı ubrigen Bauchwimpern in die rechte Vorderecke versetzt, und die beiden viel zu gross dargestellten rechten Rundwimpern einander und den Afterwimpern genähert. Auch das Periston ist ungenuggend dargestellt und ein innerer ovaler Körper. walırscheinlich eine lieimkugel, als Nucleus (Samendruise) aufgefasst. - Ehrenberg's bei Berlin beobachteter Euplotes viridis ist hoehst wahrseheinlich nichts weiter als dic Chlorophyll fübrende Form von E patella; die ron jener Art zegrebene Diagnose (testula ampla oblonga, fronte truncata, denticulo medio olituso, dorso plano, ovulis viridibus) passt wenigstens ganz auf E. patella. - Unter aller Kritik sind die Abbildungen ron Dnjardin; er hat eise betriehtliche Anzalıl locomotiver Wimpern hinzuphantasirt und alle zusammen ganz nach Gutdüuken vertheilt. Ausser dem adoralen Wimperbogen erkannte er keine weitcren Structurverhältnisse. - Erst Claparède und Lachmam haben zwei Darstellungen geliefert, die schr nahe mit meinen Beobaclıtungen übereinstimmen; sie haben namentlich dlic Zahl und Stellung der locomotiven Wimpern vollkonınen richlig bestimmt, auch die mit den Afterwimpern abweelsselnden Rippen des Mittelfeldes unterschieden, die jedoch zu kurz und gleichförmig und bei der scheilsenförmigen Varietät irrig uach links gerichtet angegchen werden. Auch der Bau des Peristoms wurde von ihnen zuerst genaur. ermiltelt, ieh linde es jedoch bei der selseibenförmigen Varietăt verhältnissmässig zu gross umd seinen Inmen- und Vorderrand nieht granz naturgetreu dargestellt. Der Nucleus wird, wie von Ehrenberg. fälschlieh als eiu ovalur Körper angegeben. 
2. Euplotes harpa. Sters. Tar. 11. lig. 12-13)

Körper lang oval, nach vorn crivitert mit gleichförmig abgerundetem Vorderrande; Rücken mit 8 Längsrippen; Stirnrand doppelt ausgebuchtet, dreizähnig; 10 Banchwimpern.

Diese neue, sehr grosse Art wurde von mir im August $185 \%$ in der Ostsce bei Wismar enteckt, wo sie nicht haufig vorkam. - Der langgestreckte, ovale Körper ist nach vorn etwas erweitert, der stark iilıer die Stirn vorgezogene Vorderrand gleichmassig abgerundet, der linke Scitenrand vor der Mitte schwach ausgebauchı, der rechte fast gerade und vorn in eine zahnförmige Spitze greendet. Ueber den måssig gevölbten Rïcken (Fig. I 3 : verlaufen acht gleich weil von einander entfernte, scharflantige Lingsrippen, welche nach hinten convergires, in des. Nabe des Vorderrandes aber alggebrochen endigen. Das Peristom (Fig. 12. i. p.) ist ein langer und lureiter lıarfenähnlicher Ausschnitt, der sich von der rechten Vorderecke des Körpers bis dicht an den Hinterrand des Mittelfeldes erstreckt. Die adoralen Wimpern stehen in ciner continuirlichen Bogenlinie, die vordern, sehr lanģen und liraftigen, fast griffelförmigen so nahe lägss des Vorderrantes, dass sich lieine deulliche Oberlippe absetzt, sondern nur ein schmaler Saum ubrig bleibt, der nach hinten ohne Gränze in den Aussenrand des Peristoms ubergelıt. Der Jnnenıand ist vor der Mitte stark bogenförmiģ ausgeschnitten; sein hinterer längerer Schenkel trägt den stark niedergedrickten, etwas biegsamen, bandförmigen Randsaum (i.). Unter denıselben sitzt eine Reilıe dicht hinter einander stelıender, äusserst zarter und kurzer Wimpern, welche dem Innenrande eingefig und quer nach aussen gerichtet sind. Ich sah diese prăoralen Wimpern, wovon sich bei Eupl. patella keine Spur findet, sebr deutlich langsam auf und nieder schwingen. - Der Stirnrand ist doppelt bogenföımig ausgeschnitten und daher dreizähnigr ; ler :iussere Zahn ist kurz und spitz und auch auf der Riickseite sichtbar, die beiden innern Zälıne sind breite, stumpf zugespitzte Lappen. Das Mittelfeld (m) erstreckt sich weit nach vorn, seine drei Hanptrippen reichen fast bis zun Stirnrand. Von den zelı starken griffelförmigen Bauchwimpern stehen sieben (st.) auf der Stirn und zuvar vier in einer queren Reihe nahe am Stirnrande, drei in einer schrägen, von der rechten Vorderecke gegen den Ausschnitt des lnnenrandes verlanfenden Linie, an je ciner Hauptrippe des Mittelfeldes. Die drei iibrigen Bauchwimpern gruppiren sich im Dreieck un die Mitte des rechlen Seitenrandes; zwei stehen hinter cinander unmittelbar anı Rande, die dritte in ler Mitte zwischen beiden anf dem Mittelfelde, neben der aussern Hanptrippe. Die Afterwimpern (a.) sind selır lange und starke, geschlangelte Griflel, die Randwimpern (r. r.) kurzgrifflig und unveràstelt. - Der Nucleus (Fig. 13. n.) verhält sich wie bei der vorigen Art, desgleichen der contractile Bebälter (c.). - Die Lănge des Körpers betrug $\frac{1}{14}-\frac{1}{12}$

Der vorstehenden Art am nảchsten verwandt ist der von Lachmann an den norwegischen Kuisten entdeckte Euplotes longipes (Claparéde unl Lachmam Études p. 173. Pl. VII. Fig. 3). Er zeigh genau diesellue Stellung der Bauchwimpern, wie mein E. larpa, anch After- und Randwimpern verhalten sich äbnlich, allein der Ricken ist ganz glatt, das Peristom ist eine enge Spalte mit ganz geradem Imnenrande und die adoralen Wimpern sind kurz und gleichartig. Bemerkenswerth ist, dass bei dieser Art die vordern adoralen Wimpern nicht, wie bei den übrigen Euploten, auf die Richseite des Körpers versetzt werden. Lachmamn, von dem die Zcichmung herrührt, scheint hiernach meine Auffassung von der Stellung dieser Wimpern zu theilen. Der E. longipes scheint mir ubbrigens nicht hinlänglich genau untersucht zu sein. da in der Abbjildung weder ein Mittelfeld, noch am Innenrand des Peristoms ein Randsaum angegeben ist, welche Gebilde wohl schwerlich ganz felılen werden. - Dujardin's Eupl. vannus (Infusoires p. 436. Pl. X. Fig. 10) kann möglicher Weise diese Aıt oder Eupl. harpa geweseı sein.

3. Enplotes charon. Enrbg. (Taf. IV. Fig. 14-90).

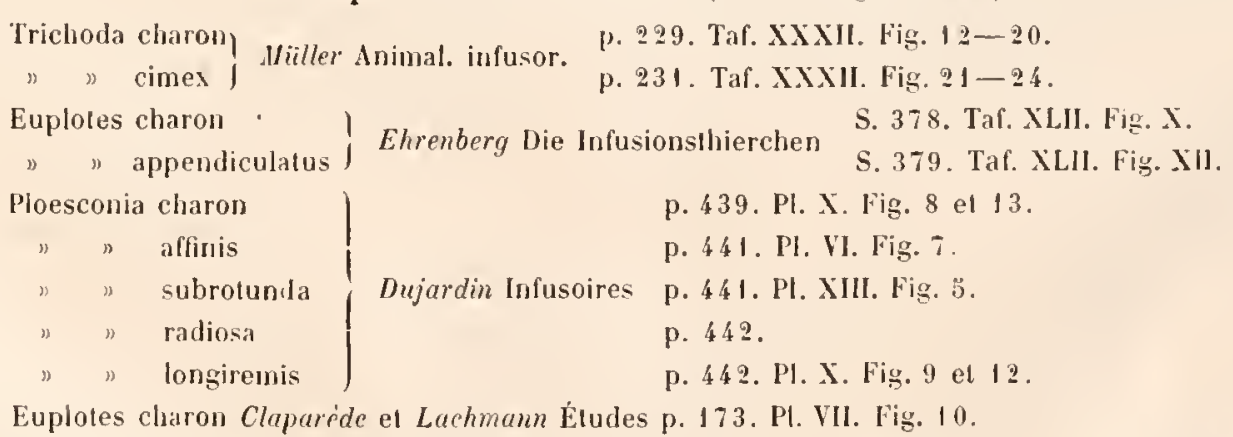

liörper hurz oval, vorn und hinten sehief abgestutzt; nach links bauchig enweitert, Rüeken mil scharflumligen Längsrippen, Stirnrand boyenförmig ausgesclinitten, 10 Bauchwimpern.

Diese Art ist uberall an der staubigen Oberfläche stehender siisser Gewässer und namentlich in fauligen InfuSieru, Organismus der Inlusionshiere. 
sionen selır gemein; noch haufiger und massenhafter tritt sie in längere Zeit auflhewahrtem Meereswasser auf. das oft ganz von diesen Thieren wimmelt. Ich beobachtete sie sowohl im Ostseewasser von Stralsund, Wismar, Travemünde und Eckernförde, wie auch in Mittelmeerwasser von Triest. Je nach dem Aufenthalte variirt das Thier beträchtlich; ich habe nur die am genauesten von mir studirle Süsswasserform abgebildet. - Der Körper ist kurz und breit oval, fast rundlich; der Vorder- und Hinterand sind schicf von vorn und rechts nach links und hinten abgestutzt (Fig. I5) und einander parallel. Der rechte Seitenrand ist nur schwach nach aussen gebogen. der linke in der Mitte (Fig. 15 ) oder noch gewöhnlicher hinter der Mitle (Fig. 14. 17) sehr stark ausgebaucht; er verengert sich nach vorn und geht in einem sanften Bogen, ohne eine Ecke zu bilden. in den Vorderrand über. Der Ruicken (Fig. 15. 16) ist stark gewölbt; er wird bei der Süsswasserform durch eine scharflantige, oft stark geflügelte Längsrippe (Fig. I 5), welche von der linken Ecke des Hinterrandes zu dem gegenüberliegenden Puncle des Vorderrandes verläuf, in zwei unğleich grosse, dachförmig an einander stossende Felder getheilt. Das rechte, grössere Ruickenfeld fällt stark nach dem rechten Seitenrande zu ab; neben demselben èrhebt sich eine scharflantige oder geflügclte Längsrippe, welche stark gegen die Bauchseite geneigt ist und nach aussen über den Seitenrand vorspringt (Fig. 14). Zwischen den beiden Hauptrippen verlaufen noch drei niedrigere, gleich weit von einander abstehende Liangsrippen, welche jedoch zuweilen gänzlich fehlen oder nur sehr undeutlich sind. Das linke kleinere Riickenfeld ist flacher, oft sogar etwas ausgehöhlt, es trägt cinen (Fig. 15) oder zwei (Fig. 14.) feine Längskiele, die of fehlen orler durch zwei Körnchenreihen (Fig. 17) vertreten sind. Auch innerlıalb der finf Rippen des rechten Rückenfeldes zeigh sich häufig eine continurliche Reihe dunkler Körıchen eingeschlossen, die Rippen selbst aber sind stets glattrandig.

Das Peristom reicht stets über die Mitte des Körpers hinaus, oft bis zum Hinterrande des Mittelfeldes, sein Aussenrand ist auffaliend breit, während das Peristomfeld schmal ist. Dic adoralen Winpern setzen einen continuirlichen Bogen zusammen, dessen vordere Hiafte dem Rande so genähert isı, dass sich kaum ein lippenartiger Saum bildet; sie nehınen von vorn bis zur Mltte an Länge zu. Der Innenrand des Peristoms ist hinter der Mitte sehr characteristisch schief nach hinten cingeschnitten; der auf den Einschnitt folgende Randulueil (Fig. 14. i.) ist diinnhäulig und gegen das Peristomfeld geneigt, er vertritt den Randsaum der vorigen Art und scheint ebenfalls eine äusserst zarte, präorale Wimperreihe zu bedecken, die ich mehrmals gesehen zu haben glaube. - Der Stirnrand ist einfach bogenförmig ausgeschnitten; die drei Hauptrippen des schmalen Mlttelfeldes sind ungleich lang, die niltelste reicht meist bis auf dic Stirn, die beiden andern sind abgekürzt, besonders die inuere. - Vom Peristomwinkel verlăuft eine Lingsrippe (Bauchrippe) zur linken Ecke des Hinterrandes, wodurch die Bauchseite ebenfalls in zwei ungleiche Felder getheilt wird, von denen das linke kleinere gegen den Rücken aufsteigt. - Die zehn hakenförınigen Bauchwimpern sind selı thulich gruppirt, wie bei der vorigen Aıt, von den sieben der Stirn angehörigen stehen jedoch stets drei dicht hinter cinander am Innenıunde, und die vereinzelte auf dem Mlitelfelde isı etwas weiter nach vorn gerückt. Die Afterwimpern sind dünne. gerarle Griffel, die Randwimper'n kurze unverłstelte Borsten oder Häkchen; die beiden linken stehen melır nach innen, in der Năhe der hintern Bauchrippe. - Der strangförmige Nuclens Fig. 14.n.) liegt um die Mitte des Körpers fast ringförmig zusammengekrummt.

Die Quertheilung habe ich durch alle Stadien verfolgt. Im ersten Stadium (Fig. 17) zeigt der Körper noch seine gewöhnliche Form und Bewimperung, dicht hinter dem Peristom erblickt man aber eine schiefe, dem Aussenrande des Peristoms fast parallele, tiefe Spalte $\left(\mathbf{p}^{\prime}\right)$, welche die erste Anlage des neu zu bildenden Peristoms darstellt. Gleichzeitig oder etwas später erscheiıen auf dem Mittelfelde und vor demselben mehrere quere schrłge Reihen von sehr feinen, dicht bei cinander stehenden, langsam undulirenden Wimpern (w.), deren Zahl sich jetzt noch nicht genau bestimmen lässt. Jede Wimper macht den Eindsuck eines selı niedrigeı, der Bauchflache angewachsenen, undulirenden Hautstreifens. Dic auf dem Mittelfeld stehende Bauchwimper verschwindet friihzeitig. Im ziveiten Sıalium der Quertheilung (Fig. 18) hat sich der mütterliche Körper hauptsächlich durch Ausdehnung der schmalen zwischen dem ursprünglichen Peristom und dem Hinterrande des Mittelfeldes gelegenen Körperregion beträchtlich in die Länge entwickelt. Gleichzeitig haben sich dic Hauptrippen des Mittelfeldes, namentlich die beiden rechten, weit nach vorn verlängert; auch die hintere Bauchrippe und der Nucleus (n.) sind viel lảnger geworden, und letzterer hat sich dem linken Scitenrande parallel gelagert. Das ursprüngliche Peristom nimmt jetzt die vordere Körperhălfte ein, die frühere schiefe Spalte ist in die hintere Körperhälfte gerückt und hat sich in einen längern und hreitern Längsatusschnitt ( $I^{\prime}$.) verwandelt, dessen Aussenrand mit ciner Reihe zarter Wimpern besetzt ist. Dieser Ausschnitt giebt sich nun deutlich als die Anlage zu einem neuen Peristom zu erkennen; vor denselben sind zwei neue Randwimpern entstanden. Die frijhern zarten Wimpern des Mittelfeldes haben sich zu Häkchen und Griffeln 
entwickelt und so gruppirt, lass sie für die vordere und hintere Körperhalfte je ein neues Systenn von Bauch-und Afterwimpern bilden. Yon den locomotiven Wimpern des Mntterthieres sind noch die vier vorderı, auf der Stirn stehenden und die zwei seitlichen Bauchwimperu, ferner die After- und Randwimpern vorbanden. Neben den neuen Afterwimpern der vordern Halfte hat sich ein zweiter contractiler Behälter (c'.) gebildet; die nenen Afterwimper'u der hintern Halfte sind unmittelbar vor den alten Afterwimpern eingefügt. - Im letzten Stadium der Quertheilung (Fig. 19) hat sich der Körper noch mehr verlïngert und zwischen der vordern und hintern Körperhălfte jst jeclerseits ein tiefer Einschnitt entstanden, ler die nunmehr fast vollstaudig entwickelten Theilungssprösslinge von einander sondert. Dicht vor dem rechten Einschnitte sind die beiden noch felslenden Randwimpern für den vordern Theilungssprössling hervorgewachsen, der jetzt nur noel mit drei ijberzăhligen Bauchwimpern am Stirnrande versehen ist. Am hintern Theilungssprössling ist der grösste Theil des Peristoms entwiekelt und die neuen Afterwimpern haben die alten entweder ganz oder theilweis verdrängt: an der alygebildeten Form waren noch zwei alte Aftelwimpern vorhandes. Auf einem etwas frühern Stadium der Quertheilung stossen die adoralen Wimpern des vordern und hintern Theilungssprösslings oft so innig an einander, dass sie zusammen einen continuirlichen Wimperlıogren biłlen. Kurz vor der völligen Trennung beider Theilungssprösslinge verschieht sich wicder, wie hei Styloplotes, ler vordere nach rechis, der lintere nach links.

In neuester Zeit, als die Tafeln bereits gestochen waren, habe ich auch bei Eupl. cliaron jenen Zustand ïberaus baulig beobachtet, von dem es zweifelhaft bleibt, ob er Laingstheilung oder Conjugation darstellt. Ehreuberg hat denselhen hereits abgebildet (a. a. O. Fig. X. 5) und als Lingstheilung gedentet. Die heiden Individuen waren auf dieselbe Weise an einander gefügt, wie bei Eupl. patella, sie deckten sich aber nur mit ilıren linken Seitenrändern und lagen daher mehr neben als ïber einander. Jedes Individuum enthielt seinen gewöhnlichen strangförmigen Nucleus, welcher stets nalse am linken Seitenrande lag. beicle Nuelei krenzten sich jedoch nicht. sondern waren noch durch einen kleinern oder grössern Zwischenraum von einander getrenut. Nehen jedem Nucleus unterschied ieb in vielen Fällen mit grösster Bestimmtheit zwei kleine, dem Nucleus innig anliegende und etwa um ein Drittel seiner Lánge von einander entfernte, ovale Körperchen, welche ganz den Eindruck machten, wie der Nueleolus der Paramäcien, wenn sich derselbe zu einer Spermatozoenkapsel zu entwickeln beginnt (vergl. S. 98). Ich erkannte an jedem ovalen Körperchen eine diunnhłutige Hülle und einen längsstreifigen Inhalt; die Körperchen sind daher höchst wahrscheinlich nucleolusartige Gehilde, in welchen sich Spermatozoen entwickeln. Dass die in Recle stehende Verbindung zweier Individıen, mag sie nun Länğstheilung oder Conjugation sein. eine gesehleehtliehe Fortp/lanzung zum Ziele hat, schliesse ich auch daraus, dass gleichzeitig in der Fliissigkeit, welche so reich an conjugirten Individueı war, sehr häufig einfache Individuen vorkamen, die in der Nlitte des Körpers eine eben solche helle, lıonsgene Keimkugel enthielten, wie Eupl. patella; meben derselben zeigte sich gewölnlich noch ein kurz strangförmiger Rest des ursprüglichen Nucleus. Statt einer Keimkugel waren zuweilen zwei kleinere vorhanden.

Euplotes charon geht nicht selten in einen rubenden Zustand über, indem sich das Thier kugelförmig zusammenzicht, worauf sich sein Panzer ringsherum vom Parenchym trennt, welches sich mit einer neuen Panzerhïlle ungiebt. Der abgelöste Panzer gestaltet sich zu einer rundlichen, planconvexen Cyste (Fig. 20), welche ringsum geschlossen ist; ihre plane Seite ist ganz glatt, die convexe zeigt sechs bis sieben sehr zierlich quer gefaltete Rippen. welches die fribern Langsrippen des Panzers sind, die in Folge der Verkiurzung zahlreiche. dicht auf eiuander folgende quere Einschuitte bekommen haben. An dem eingeschlossenen Körper untersebied ich nicht selten die adoralen Wimpern und in der Regel sehr deutlich den strangförmigen Nucleus. Ich beobachtete die Cysten in Juli 1855 sehr häufig in einer Mistpfutze bei Tharand in Gesellschaft zahlloser freier Thiere. Mehrmals traf ich auch leere Cysten, welche an dem einen Pole mit einer weiten, unregelmässig zerrissenen Oeflnung versehen waren A. Schncider hat zuerst auf diese merkwiirdigen, durch Hăutung entstehenden Cysten aufmerksam gemacht (Müller's Archiv 1834. S. 20I). Beilaufig sei hier bemerkt, dass ich auch bei Opercularia articulata Hautung des ganzen Thierkörpers beobachtet luabe, olıne dass jedoeh die abgelegte Ilaut als Cyste verwendet wird.

Die Bewegungen von E. charon sind characteristiseh. Die Thiere schwimmen nicht so rasllos und unstal umber, wie E. patella, sondern sie bleiben bald still stehen und ruhen, auf ilure hahenförmig umgebogenen Bauchwimpern gestijtzt, einige Zeit aus, während nur die adoralen Wimpern Nahrung herbeiwirbeln. Danı laufen sie, die Banchwimpern als Fiisse benutzend, eine kurze Strecke vorwärts oder riickwarts und stehen nun wieder still. So wechselt Laufen und Ruhen oft längere Zeit mit einander ab, bis sie daun plölzlich wieder zu schwimmen anfangen. Stossen sie auf grössere fremde Körper. so klettern sie an denselben auf und nieder. Wälırend des Stillstehens der 
Thiere hat man hinlangliche Musse, ihre gesammte Organisation genau zu studiren; man bestinmt dann auch leicht al den hảıfigr zu heobachtenden Austrilt von Excrementen die Lage des Afters (Fig. I4. z.). - Die Meeresform stimmt iu allen wesentlichen Puncten mit der Süsswasserform tiberein, sie ist aber gewöhnlich schlanker und weniger stark nach links ansgebaucht, der Rücken ist gleichförmig gewölbt und abgerundet und die 6-7 Ruckenrippen sind :- leich stark entwickelte, scharfliantige Kiele. Die Bauch- und Afterwimpern sind rerhältnissmảssig längere und hrifligere, mehr geschlangelte Grillel, und manentlich zeichnen sich die Randwinpern durch grössere Länge und Feinheil aus. Wegen dieser Unterschiede hielt ich die Meercsform Anfangs für eine eigene Art, die ich als Eupl. appendiculatus Ehbg. bestimmte (Die Infusionsth. S. 157). Allein die Körperform und die relative Entwickelung der Rippen und locomotiven Wimpern varïrt anch bei der Süsswasserform bedeutend, und man triflt unter gewöhnlichen Individuen derselben oft genug auch solche, die in jeder Beziehung mit der Meeresform übereinstimmen. Dic Süswasserform wird selten über $\frac{1}{2}{ }^{\prime \prime}$ lang, von der Meeresform sah ich oft lndividuen von $\frac{1}{2 \frac{1}{4}}-\frac{1}{2^{2}}{ }^{\prime \prime}$ Länge.

Mïller's Trichoda charon und Tr. cimex ziehe ich ohne jedes Bedenken zu der gegenwärligen Art; die Tr. charon stellt die Meeresform dar, die Tr. cimex, welche von Müller selbst als "Charonti nimis similis " bezeichnet wird, ist die Süsswasserform. Aus den sehr rohen und unvollkommenen Abbildungen allein geht dies ireilich uicht mil Sicherheil hervor, wohl aher aus den damit combiniten Angaben uber das Vorkommen, die Bewegungsweise und die Fortplanzung. - Ehremberg's Abbildungen von Eupl. charon sind in Ganzen characteristisch gehalıen, sie stellen namentlich dic Tolalforn des Körpers und das Peristom ziemlich richtig dar, selbst der characteristische Ausschnilt am Innenrande des Peristoms ist in Fig. X. I scharf hervorgehoben. Die Zahl und Stellung der Bauchwimpern isı jedoch nicht mit der nöthigen schärle beobachtet; es werden nur 7-8 Bauchwimpern in unrichtiges Stellung angegeben, die Rumdwimpern sinł ganz übersehen. Feruer wird der After auf die linke Seite neben die fünfte Afterwinper versetzl und der Nucleus als cin scheibenförmiger Körper dargestellt. -- Der Eupl. appendiculatus Ehbg. ist meiner Ansicht nach nichts weiter, als die Meeresform von E. charon, an der die Randwinpern erkannt, die Bauch- und Afterwimpern aber ungenau beobachtet wurden; kein Euplotes kann, wie Ehrenberg anģiebt, 4 After-und 3 Bauchwimpern besitzen. - Der Eupl. truncatus Ehbg. (Die Infusionsth. S. 379. Taf. XLIl. lig. XIll), welcher die normale Zahl der After- und Randwimpern zeigt, aber nur mit 7 Bauchwimpern versehen sein soll, gehört entweder auch hierher oder wegen des längern und weitern Peristoms und wegen des zahnförmigen Fortsalzes am Vorderrande der Stirn zu E. harpa. - Ganz unzuverlissig ist E. striatus Ehbg. (a. a. O. Fig. XI), schon deshalb, wcil bei ihm das Peristom in dev rechten Körperhälfte liegen soll; Bauchwimperı wurden bei ihm nur 3-4, Afterwimpern $\ddot{3}-6$, und Randwinpern gar nicht unterschieden. Ich vermuthe. dass ebenfalls nur E. charon beohachtet wurde. - Von Dujardin's höchst flichlig untersuchten Plösconien scheinen mir PI. affinis. subrolunda und radiosa wegen ihres Vorkonmens im süssen Wasser unl wegen der Tolalform ihres Körpers und des bogenförmig ausgeschnittenen Stirurandes unbedingt zu E. charon zu gehören, wăbrend seine Pl. charon und longiremis allem Anschein nach auf der Meereslorm unserer Art beruhen. Dujardin's uberall irrige Angaben ibes die locomotiven Wimpern diurfen natülich gar nicht in Betracht gezogen werden. - Lachmam hat zuerst fiir E. charon die Zahl und Stellung der locomotiven Wimperı und die Lage des Afters richtig bestimnt (Müller's Archiv 1856. Taf. XIY. Fig. 10. Noch sorgfaltiger ist alje in den Études von Claparéde gelieferte Ablifdung der Bauchseite llieses Thieres ausgefulurt; es ist jedoch das Mittelfeld nicht deutlich und der Ausschnitl au Innenrand des Peristoms gar nicht mterschieden, auch wirl wieder der Nucleus scheibenförmig angegeben.

\section{Vicrte Familie. Oxytrichina. Enrbg.}

Character: Körper bald gepansert, bald mur formbestïndig, bald metabolisch, meist langgestrecht, mit convexem Rücken und planer Bauchseite. Im vordern Theil der linken Bauchlälfte ein offener, verschieden gestalteter, nach hinten am meisten vertiefter und zugespitzter Peristomausschnitt, dessen Aussenvand von einer adoralen Wimperreihe eingefasst wird, die sich über den Vorderrand des Kürpers bis zum rechten Seitenrande fortsetzt. Die Bunchfläche trägt jederseits eine continuirliche Reihe von Randuimpern und uusserdem noch eine oder mehrere, gerade oder schräge Reihen von griffel-, häkchen- oder borstenformigen Wimpern. Mund am Imenrande des Peristoms, After vor dem hintern hörperende oder nahe an demselben.

Die Familie der Oxytrichinen wurte von Ehrenberg im J. 1830 (Ablandl. der Berliner Academie S. 4.3 mit den vier Gattungen Oxytricha, Kerona, Urostyla und Stỵlonychia begrindel. Hierzu kam in grossen lnfusorienwerke

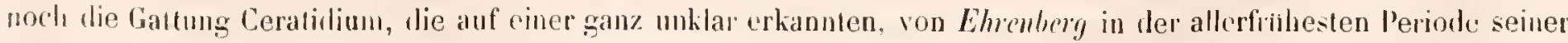


Forschungen mit allzu schwachen Vergrösserungen beohachteten Infusorienform beruht. Da đliese seit Is?0 njeht wieder aufgefunden werden konnte und aus der gegebenen Darstellung nicht eimmal mit sicherheit zu ersehen ist, oh sie wirklich zu den Oxytrichinen und nichı vielmehr zu den Euplofinen gehörl, so diüfte es wohl gerechıferligt sein, die Gattung Ceratidium ganz aufzugeben, zumal da sich der schon von Dujardin ausgesprochene Verdacht nicht unterlricken lasst, dass das fragliche Thier wohl nur ein Bruchstiick von irgend einer Oxytrichine gewesen sein möge. Ehrenberg characterisirt die Oxytrichinen als panzellose Magenthiere, tie einen Darm mit zwei getrennten, nicht an den Körperenden gelegenen Mijndungen oder doch letztere deutlich crkennen lassen und welche nehen wirbehten Wimpern auch nicht wirbehde Borsten, Griffel und Haken führen. Dieser Character muss, abgeselıen von den irrigen Yorstellungen. die er involvirt, wesentlich geăndert werden, da er die Oxyltichinen nicht sicher son den Euplotinen unterscheidet. - Dujardim nahm die Fanilie der Oxytrichinen an und definirte sic nicht besser, wie Ehrenberq, er änderte aber den Faniliennamen, ohne dass irgend ein Grund dazu voulag, in den Kamen Kéroniens um. Die Gattungen Stylonychia und Kerona zog er mit Unrechl in die eine Gattung Kerona zusanmen; eben so verfehlt war es, die auf Trichodiua grandinella Ehbg. gegrumdele Gathung Halteria, welche einem durchaus andern Organisationstypus angehört, mit den Oxylrichinen zn verbinden. Dagegen erliannte Dujardim zuerst richtig, dass die Gattung Uroleptus Ehbg., welche von ilurem Grionder in die Familie der Colporleen gestellt wurle, nach Ausschluss gewisser Arten mil den Oxytrichinen vereingt werden misse. - Perly nahm die Oxylriehinen in dem Unfange, wie Dujardin, nur schloss er die Gathumgr Kerona Ehbg. davon aus und brachte sie lediglich wegen ilurer schmarotzenden Lebensweise in seine wunderliche, Opalinen und bursarienarlige Infusorien umfassende Familie Colualina. Da Perty nach Dujardin's Vorgang stalt des Ehrenberg'schen Gallungsnamens Stylonychia den alten Mr̈ller'schen Namen Kerona wieder herstellen zu müssen glaulse, der doch keineswegs mit slylonychia Ehbog. synonyu ist, so war er genöthigt, für die Gattung Kerona einen neuen Nanen. Alastor, zn schaflen. Dies Verfahıen kann unmöglich gebilligt werten. Die Galtung Uroleptus vereinigte Perly mit Oxytricha. Ferner griundete er auf zwei nicht mit geniigender Schärfe beobachtete Oxylrichinen die beiden neuen Gattungen Stichotricha und Mitophora. Die letztere Gattung, welche auf einem ganz unzureichend untersuchten Thier beruht, muss entschieden zurüchgewiesen werden; die Gathng Stichotricha dagegen glaube ich in einer von mir genauer untersuchten Oxyirichinenform wieder zu erkennen, ich nchme sie mit veränderten Characteren an. - Claparde und Lachmam ziehen die Gattungen Oxytricha, Urostyla und Uroleptus in die eine Gattung Oxytricha zusammen, die Gattunģ Stỵlonychia nehmen sie in dem Sime von Ehrenberg an, die Gatlung Kerona aber, welche sich ihren Nachforschungen entzog, wird unbestimmt gelassen. Dafür wurde cine neue Gathng Stichochacta anfgestell, welche mit Stichotricha Perly wahe verwandt ist. - Ich bin zu dem Resultate gehangt, dass die vier Oxytrichinengattungen Stylonychia, Kerona, Oxytricha und Urostyla, sowie auch die Gattung Uroleptus aufrecht zu erhalten sind; ausserdem errichte ich noch drei neue Gattungen: Onychodromus, Pleurotricha und Psilotricha. Hierzn kommen noch die Gattungen Stichotricha I'erly unt Stichochaela Clap. Lachm., die Fanilie umlasst demnach gegenwirtig 10 Gatlungen, von denen ich nur Stichochacta nicht aus eigener Anschaunng kemne.

Die Oxytrichinen sind fast sämmtlich meh» oder weniger lang gestreckte Thiere, deren meist farhloses und lurchsichtiges Parenchym sehr verschiedene Grade der Consistenz lesilzı. Bei drei Gatıngen ist der Körper eben so deullich gepanzert, wie bei den Euplotinen; hei zwei andern ist er zwar weniger starr und nach gewissen Richtungen ziemlich biegsan, aber in seiner Totalform nicht verdnderlich; bei den ibbrigen ist er nach allen Richtungen mehr oder weniger dehmbar und biegsam, er kann sich meist lang ausrechen und betrichtlich verkürzen. Rückenund Bauchseite sind stets glall und niemals mit Längsrippen versehen. noch gefurcht. - Das Peristom ist ein selı verschieden breiter, gewöhnlich fast dreieckiger oder eiförmiger, mit der Spitze nach rickwarts und innen gerichteter Ausschnit, der lediglich auf den vordern Theil der linken Bauchhälfte beschränkt bleilıt und rorn keinen queren Fortsatz nach der rechten Körperseite aussendet. Er ist muldenförmig ausggehöhlt und nach hinten und innen zu am stăbisten vertieft, nach vorn verflacht er sich mehr oulce weniger und steigt rechts sanft aufwarts. Der Innenrand des Peristoms, welcher stets eine undulirende Membran tright, reicht nicht bis zum Vorderrande, daher das Peristom vorn nach rechts ollen ist. Den Aussenrand des Peristoms bildet eine breite, bandfürmige, gegen das Peristomfelı slark geneigle Zone, deren innerer Seite die adoralen Wimpern eingefugr sind. Diese setzen sich itber den Vorderrand des Korpers wenigstens bis zu dem Puncte fort, wo der verlangerte lnnenrand des Peristoms den Vorderand schneiden würde, noch hïufiger aber erstrecken sie sich noch uber diesen Punct linans bis in die Näle des rechlen Seitenrandes. Die vordern adoralen Wimpern werden meist von einer habmondförmigen Obeılippe iiberragl; hin- 
sichılich ihrer Stellung verhalten sie sich wie bei den Euplotinen. Das Periston reicht höchstens bis zur Mitte des liörpers, nicht selten ist es aber viel kiurzer. Den rechls an das Peristom gränzenden Theil der Bauchseite hezeichne ich als Stirnfehl, den ganzen hinter dem Peristom gelegenen Theil der Banchseite als Bauch im engern Sinn. Das Stimfeld senkl sich vorn nach innen zu und geht ohne Gränze in das Peristomfehl uber; ein vorderer Stirnrand ist nur bei eincr Gattung vorhanden.

Die locomotiven Wimpern sind stets reihig angeordnet; ihre Zahl, Stellung und relative Grösse, die freilich schwierig zu ermitteln sind, bielen die zuverlasssigsten Gattungs- und Artenkennzeichen dar. Constant sind zwei Reihen von borstenförmigen Randwimpern vorhanden, die eine siumt den ganzen rechten Seitenrand, die andere den hinter dem Aussenrande des Peristoms gelegenen Theil des linken Seitenıandes. Beide Reihen gehen gewöhnlich am Hintermande in einander uber, selten lassen sie eine Lücke zwischen sich, in der dann meist drei verlängerte Wimpern (Schwanzwimperm) stehen. Nahe vor dem hintern Ende findet sich meist eine schrage Reihe von 3 - 12 griflel- oder horstenfömigen Afterwimpern, die jedoch gewissen Galtungen gänzlich fehlen. Ausserdem sind ein, zwei oder mehrere, über das Stirnfeld und den Bauch verlaufende gerade oder schrage Längsreihen von Bauchwimpern vorhanden, welche dic meisten Variationen zcigen. Auf dem Stirnfelde sind häufg alle Bauchwimpern oder doch die vordersten und innersten anders gruppirt oder anders gestaltel, als auf dem ubrigen Bauche; wir können diese dann als Slimwimpern unterscheiden. In andern Fällen sind die Bauchwimpern sämutlich gleicharlig und dann entweder griffelförmigg oder horstenförmig. Bei Anwesenheit von mehreren Bauchwimperreihen können die beiden immersten von Griffelı, die äussern von Borsten gebildet werden.

Der Mund ist eine neben dem lunenrande des Peristoms verlanfende Längsppalte; ein Schlund fehlt. Der After liegt entweder links ncben den Afterwimpern oder nahe vor dem hintern Bauchende. - Der contractile Behälter findet sich stets am linlien Seitenrande. meist nahe hinter dem Peristom; er riicht nie in die hintere Körperhälfte. - Der Nucleus ist oval oder rund, meist mil einer queren spallförmigen Hlöhle versehen und fast inmer in doppelter Anzahl vorbanden; nur eine Gattumg besitzt vier Kerne. Neben dem Nucleus findet sich wahrscheinlich äberall ein besonderer, sehr kleiner Nucleolus. - Eime geschlechtliche Fortpflanzung ist bei drei Gattungen beobachtel, jedoch noch keineswegs vollstandig erforscht. - Die gewöhnlichste Vermelırungsweisc ist die Quertheilung; ausserdem kommt aber auch wahre Längstheilung vor.

Die Oxy̨lichinen bewohnen vor»ugsweise die süssen Gewảsser; aus dem Meere sind bisher nur wenige Formen bekannt geworden, die sich sammlich nabe an die Susswasserformen anschliessen.

Uebersicht der Gallungen der Oxytrichinen:

A. Mit griffelförmigen, iı 2, seltener 3-4 medianeu Lingsreilıen stehendeu Bauclıwimpern und mit grilfelförmigen Stirn- und Afterwimperı. Körper gepanzert oder doch formbestindig.

1) ohne seitliche borstenförmige Bauchwimpern. Körper gepanzert.

a) mit 3 Längsreihen von Stirnwimpern und 3-4 Längsreihen von Bawchwimpern

b) mit 8 ringförmig gruppirten Stirnwimpern und 5 in zwei Lïngsreihen slehenden Bauchwimpern

2) mit seillichen borsteuförmigen Bauchwimpern. Kürper formbestindig

1. Onychodromus.

2. Stylongcluia.

3. Peurolricha.

B. Mit borstenförmigen Bauchwimpern. Bei Anwesenheit von zwei Lingsreilıen rou Bauchwimpern sind diese zuweilen fast griflelfürnig; daun ist aber der Körper stels metabolisch.

1) ohne Afterwimpern und meist auch ohne Stiruwimpern. Körper hiuten zugespitzt oder schwanzartig verlängert.

a) mil 6 schrågen, bogenförmigen Reilen kurzborstiger Bauchwinpern. Körper nierenförmig

4. Kerona.

b) mil einer einzigen schrägen Längsreihe kurzborsliger Bauchwimperı. Körper vorn halsarlig verläıgert :3. Sticlıolricha.

c) Init 2 Längsreihen von Bauchwimperu

ai) mit 3 griffelförmigen Stirnwimpern, Bauchwimpern dicht stehend, kurzborstig

bb) ohne Slirnwimpern, Bauchwimpern (und Randwimpern) weit von einander entfernt und sehr langborstig. Körjer gepanzert

6. Uroleptus.

7. Psilotriclıa

2) mit Afterwimperu und Stiruwimpern, Körper hinten meist abgerundet, stels metabolisch.

a) mit 2 medianen Lïgsreihen von Bauchwimpern

b) nit :3 oder melureren längsreiluen ron Batuchwimpern

8. Oxytrichăa.

9. Urastyla. 


\section{3}

\section{Gattung. Onyechodromus. Steis.}

(Taf. V).

Character: Kirper gepanzert, lïnglich elliptisch, fast rechtechig: Peristom von halber hürperbreite, bis zur Nitte der Bauchseite reichend; 3 schräge Längsreihen von griffelfürmigen Wimpern auf dem Stirnfelde und 3-4 whnliche Reihen auf dem Bauche, dahinter 5-6 griflelformige Afterwimpern. Nucleus in vier-oder mehracher An=ahl.

Die Gattung Onychodromus wurde von mir zuerst in der Januarnmmer der Lotos vom J. 1859. S. \{. unterschieden; sie beruht auf einer neuen, sehr grossen Oxytrichinenform, welehe in ihren Habitus viel Aehnlichkeit mit Stylonfehia mytilus besitzt und leicht mit diesem Thiere verwechselt werden kann. Sie unterscheidet sich jedoch sehr scharf und auffallend von der Gattung Stylonychia sowohl durch die viel grössere Anzahl von Stirn- und Bauchwimpern, wie auch durch die ganz verschiedene Stellung derselben; ausserlem entfernt sie sich von allen Oxytrichinen durch die mindestens doppelt so grosse Anzalıl von Kernen.

Das Körperparenchym ist nach aussen fast eben so slark panzerartig verdickt und erhärtet, wie bei den Euplotinen und besitzt eine noch grössere Resistenz, als bei Stylonychia mytilus. Die Form des Körpers variirt nach dem Alter beträchtlich. Bei jüngern Individuen ist derselbe langgezogen elliptisch mit fast parallelen Seitenrändern (Fig. 3. 4) und mehr als noch einmal so lang, als breit. Je alter die Thjere werden, um so mehr entwickelt sich der Körper in die Breite, so dass der Querdurehmesser oft mehr ats zwei Drittel des Langsdurchmessers betrăgt und der Umriss des Körpers abgerundet rechteckig wird. Der rechte Seitenrand ist dann in der Milte melır oder weniger nach aussen und der linke entsprechend nach einwảrls gekrimmt (Fig. 1); seltener sind beide Seitenrander naels einwärts geliümmt (Fig. 2) oder einander fast parallel. Das hintere liörperende ist sowolıl bei ältern, wie auch bei jungern Thieren hăufig gerade oder schief abgestutzt, in der Nitte seicht bogenförmig ausgerandet und an den Echen ahgerundet (Fig. 1. 4.). Das vordere Körperende ist stets auf der linken Seite mehr oder weniger schief abgeshulzt und daher ungleichschenklig dreieckig zugespitzt; der linhe langere Schenkel nimmt namentlich bei altern Thieren den grössten Theil des Vorderrandes ein, er lildet fast allein den Vorderrand des Peristoms. Denn die adoralen Wimpern beginnen nur wenig mach rechts unter der mehr oder weniger scharf als Oberlippe sich absetzenden Spitze des Vorderrandes und begleiten dann den linken Schenkel desselben, dem sie sich immer melır nähern, bis in die Nähe der linken Seiteneclie. Hier biegen sie auf dem sehr breiten, quergestreiften, bandförmigen Aussenrand des Peristoms (Fig. 1.p.) um, der fast genau bis zur Mitte des Körpers oder noch tiefer hinabreicht. Der Innenrant des Peristoms fält beinahe mil der Miltellinic der Bauchseite zusammen, er wendet sich vorn nach rechts gegen den Anfangspunct des adoralen Wimperbogens, bis zu dem er jedoch nicht ganz heranreicht. Das Peristom ist demnach ein sehr breiter, sphärisch dreiechiger Ausschnit, der den grössten Theil der vordern Hălfte der linken Bauchseite eimnimmt. Der Innenrand des Peristoms trägt eine sehr entwickelte. bandförmige undulirende Menbran (Fig. I. i.) und unter derselben noch feinborslige präorale Winspern.

Auf dem vordersten Theil des Stinfeldes, da, wo dassellue in das Peristomfeld übergeht, stehen drei hriftige griffelförmige Wimpen im Dreicek (Fig. I. st.). Ilierauf folgen zwei schiefe, den Innenrand des Stimfelds begleitende und demselhen parallele Lỉngsreihen von etwas kìrzern, meist hakenförnig grekriummen Griffeln isi'). Die rechte Längsreihe beginnt etwas weiter nach vorn, als die linke, daher die Wimpern beider Reihen mit einander alterniren. In jeder Reihe stehen gleich viele, nach hinten an Grösse etwas abnelmende Wimpern; die Zahl derselben ist jedloch nicht conslant, sie nimmt im Algemeinen mit dem Alter zu, variirt aber auch bei gyleich grossen lndividuen nicht unbedeutend. Die geringste Anzahl von Wimpern betriggt fiinf fiir jede Reilıe, sie findet sich bei allen jungern Individuen (Fig. 3); bei den ältesten beobachtete ich sehr gewohnlich acht (Fig. 2), zuweilen neun bis zehu (Fig. I) in jeder keihe. Ausserden trägt das Stimfeld nach aussen und rorn noch constant drei mehr borstenförmige, gerad nach hinten ausgestreckte Wimpern, welehe eine llitte, den beiden innern parallele Lảngsreihe zusanmensetzen. In der verlägerten Richtung derselben stehen weiter nach hinten auf dem Stirnfeld zuweilen noch zwei hakenförmige Griffel dicht neben einander (Fig. I). Die Gesammtzahl der lediglich dem Stinfeld angehörigen Wimpern beträgt hiemach wenigstens 16 (Fig. 3) und höchstens 28 (Fig. 1). Hăuliğ zählte ich auf ılem Stirnfeld im Ganzen 18 oder 22 (Fig. 2) Wimprern, in jeder innern Langsreihe näulich 6 oder 8 und ausserdem noch 3 vordere und 3 äussere. - Die Bauchwimpern (l̈̈g. 1. b. b'. b'.) stehen in der rechten Bauchhälfte zunächst der Mittellinie; sie sind in 3-4. schiefe, ungleich lange, einander und den beiden innern Stirnwimperreihen fast parallele Lảngsreihen geordnet. Die beiden :ussern, rechten Wimperreihen sind an weitesten nach hinten geriicht und erstrecken sich bis zu den Afterwimpern; sic bestelıen aus melır borstenförnigen, gerad nach hinten ausgestreckten Wimpern. 
แu die hinterste Wimper jeder Reihe ist ein hakenförmiger Griffel. In (ler ainssern kürzern Reihe (b.) stehen je nach dem Alter 4-3, in Jer innerm langern (b') 6-9 Wimperm. Weiter nach innen und vorn folgen noch 5 oder 7 hakenförmige, den innern Stirnwimpern gleichende Wimpern $\left(b^{\prime \prime}.\right)$. von denen die vordersten oft noch auf dem Stimfelde stehen; sie bilden gewöhnlich zwei Reihen von je 2 und 3 ader von je 3 und 4 Wimpern, seltener stehen sie in einer Reihe (Fig. 2). Die Gesammtzahl der Banchwimpern beträgt hiernach wenigstens 15 und höchstens 21. - Die Afterwimpern (Fig. 1. a.) sind plattgellriiclite, gerade, fast gleich lange Griffel, welche nalse vor der Mlitte des Hinterrandes eingefügt sind; ihre Zahl luetragt haufiger 6 als $\ddot{3}$; sehr selten beobachtete ich 7 Afterwinipern Fig. 4. Die heiden rechten Afterwimpern sind die stärksten, sie sind am weitesten nach hinten geruckit und zwar die zweite noch mehr, als die erste, und ragen uber den Hinterrand linaus; die drei oder vier linken stelsen in eincr schief nach links aufsteigenden Reihe. - Die beiden Randwimperreihen (Fig. 1. r. r.) gehen am llinterrande nicht in einander ibber, sondern sie bleiben in der llitte desselben durch eine kleine Lücke getrennt, in der drei, die benachbatten Randwimpern kaum iberragende Schwanzwimpern stelıen. Die linke Randwimperreihe wendet sich nach vorn zu nur sehr wenig einwärts.

Die Bauchscite ist ganz plan, die Rückscite mehr oder weniger gewölbt, namentlich sehr stark bei ältern Individuen, deren Seiten dann auch nicht zugeschärft, sondern abgerundet sind. Sehı ausgezeichnet ist die Riickseite dadurch, dass sie auf der linken Scite zwei breite, zusammengedrüchte, an der Spitze erweiterte und abgerundete zapfenförnige Fortsailze (Fig. 4. h. h.) hesitzt, welche schief nach aussen gerichtet sind und eine dunkle körnige Masse einschliessen. Der cine Zapfen liegt dicht hinter dem Peristom nahe am linken Seitentande, den er nicht selten uberragt (Fig. 3. h.), ter zweite Zapfen etwas mehr nach innen dicht vor den linken Afterwimpern. Bei jüngern Thieren sind diese Zapfen constant vorhanden, bei ăltern fehlen sie entweder ganz oder es findet sich nur der hintere vor; ihre Betleutung bliel, mir völlig unbekannt. - Der contractile Behailter (c. liegt auf gleicher llöhe mit dem Peristomwinkel, zwischen diesem und der linken Randwimperreihe; er wirl anf der Riicliseite fast ganz von den voldern Zapfen überagt (Fig. 4. c.). Der After (Fig. 3. z.) findet sich rechts nelsen und etwas vor den Afterwimpern; nahe vor demselben erhebt sich auf der Rickseite der hintere Zapfen. - Die normale Zalil der Kerne betrigt vier; zwei derselben liegen in der vordern Körperhalfte neben oder unter dem lnnenrande des Peristoms, die beiden andern in ıler hintern Körperhälfte links neben der Niltellinie (Figr. 2. n. n. Fiğ. 3. 4). Jeder Nucleus ist oval und mit einer queren spalıörmigen Höhle und mit einem der linken Scite anliegenden Nucleolus Fig. 2. nl.) versehen. Iläufig kommen jedoch, namentlich bei ältern Thieren, fünf' (Fig. I) oder sechs, ja selbst 7-8 Kerne vor, die aus der Quertheilung eines oder mehrerer der ursprünglichen Kerne hervorgehen; die Nucleoli vermeluren sich nicht in gleicher Weise. Die in der Theilung begriffenen Kierne zeigen oft zwei spaltfürnige Höhlen. wie an dem hintersten Kerne in Fig. 1 zu sehen ist.

Die einzige Fortpllanzungsweise, welche ich beobachtete, ist die Quertheilung, sic erfolght nach selır ảhnlichen Gesetzen, wie bei Stylonychia mytilus. Die ersten Stadien der Quertheilung sind mir entgangen; im mittlern Sladium (Fig. 3̈) zeigte sich der sehr verlängerte Körper bereits durch eine scichte Einschnürung der beiden Seilenrander in eine vordere und bintere llälfte gesondert; in der hintern Hälfte war ein vollständiger adoraler Wimperbogen $\left(p^{\prime}\right.$.) unl ein neuer contractiler Bchïlter $\left(c^{\prime}\right.$.) entstanden. Von den urspringlichen locomotiven Wimpern waren in der vordern lläfte nur noch die drei vordersten Stirnwimpern (st.), in der hintern Halfte die Afterwimpern (a.) nebst den heiden letzlen Bauchwimpern, und in beiden Haiften die jetzt weit aus einander geriickten und nicht mehr vollzihligen Randwimpern (r. r. r. r.) vorlanden. Zum Eisatze der letzlern latte sich nelsen der rechten Randwimperreihe nach aussen, neben der linken nach innen eine neue, aus viel feinesn und dichter stehenden Wimpern zusammengesetzte Randwimperreihe ( $r^{\prime}, r^{\prime}, r^{\prime}, r^{\prime}$.) entwickelt. An die Stelle der minterdrickten Stirn- und Bauchwimpern war in jełcr Körperhälfte ein neues System von Stirn-, Bauch- und Afterwimpern getreten. Das vordere System nimmt das ehemalige Stirnfeld ein, die Afterwimpern desselben ( $\mathbf{a}^{\prime}$.) stehen dicht neben dem Peristomwinkel, und die in drei Reihen geordneten Bauchwimpern rechts neben den beiden inuern, aus je 5 Wimpern gebiluleten Stimwimperreihen. Das hintere durch die Afterwimpern (a") begrainzte System zeigt in Bezug auf das noch in der Entwickelung legrifiene Periston eine ganz analoge Lage und Anordnung, wie das vortere System. In jeder Körperhälfte waren vier Kerne, aber nur zwei Nucleoli vorhanden; erstere zeigten zum Theil bereits wieder eine der spaltförmigen Höhle entsprechemle Einschnimung, in ter Richtung dieser Höhle erfolg̨ gewöhnlich die Theilung der Kerne. - In einem spätern, von einem ältern Mutterthier herribrenten Stadiun tlej Quertheilung Fig. (j) hatten sich heide Theilungssurösslinge fast vollstindigg von einander alggeschnirt. uer hintere war mit einem 
entwickelten Peristom versehen, die alten Randwimpern waren ganzlich geschwumlen, die ubrigen loconotiven Wimpern zeigten aber noch dieselbe relative Stellung, wie früher. Die Zahl der Kerne (n. n.) hatte sich in jerlem Theilungssprössling durch nochnalige Theilung auf acht erhöht, in dem hintern lingen die beiden letzten noch mit einander zusammen. - Die Abschnürung der beiden Theilungssprösslinge erfolgt, ohne dass weitere Veranderungen vor sich gehen, wie der Fig. 7 abgehildete, frei umherschwinmend angetroffene hintere Theilungssprössling beweist. Er zeigte noch eine ganz ähnliche Stellung der locomotiven Winpern, wie der hintere Theilungssprössling in Figg. 6 : das mit den miitterlichen Afterwimpern versehene hintere Körperende hatte sich durch eine quere Einschnurung in ein schwanzartiges Anhängsel (s.) verwandelt, welches sammt den davor stehenden zwei mülterlichen Bauchwimpern nach und nach resorbirt wird. Die undulirende Membran (i.) am Innenrande des Peristoms war noch äusserst zart, sie levegte sich beständign unter Bildung zahnförmiger Vorsprünge auf und njeder. Kerne wareu acht vorhanden; ob dieselben später wieder paarweis mit einander verschnelzen, oder ob aus ihnen etwas Anderes wird, weiss ich nicht zu sagen.

Die Bewegungen von Onychodromus sind trotz der vielen Wimpern nur langsam und schwerfälig und im Ganzen denen ron Stylonychia mytilus schı ảhnlich; die Bestimmung der Zahl und Stellung der Wimpern bietet daher keine grossen Schwierigkeiten dar. Die einzige, in sissen Gewässern lebende Art der Gattung ist:

Onjchodromus grandis. STELN.

(?) Himantophorus charon Ehrenberg Die Infusionsth. S. 376. Taf. XLII. Fig. VII. Onychodromus grandis Stein in der Lotos 1859 . S. \&.

Ich entdeckte dieses interessante Infusionsthier in einem sumpfigen Graben des Baumgartens bei Prag ind beobachtete es wihrend des October und November 1857 in zalıllosen Exemplaren; seitdem ist es mir nicht wieder vorgekommen. In seiner Gesellschaft lebten hauptsáchlich Stylonychia mytilus, Oxytricha pellionella, Paramaecium aurelia und Aspidisca lynceus. Das Thier ist ăusserst gefrässig und verschont seine eigene Art nicht; ich traf in seinem Innern nicht selten sehr ansehnliche Individuen seiner Art, die sich zum Theil noch bewegten und den Köıper ganz unregelmässig buckelförmig ausdehnten und verzerrten und hisweilen an irgend einem Puncte wieder nach aussen hervorl,rachen. Andere Individuen hatten Paramaecium aurelia und Arcella vulgaris verschluckt (Fig. 2). Hieraus folgt, dass der Mund eine lange Spalte sein muss; direct liess sich dieselbe nicht beobachten, da sie dicht am Innenrande des Peristons liegt und ron der breiten undulirenden Membran verdeckt wird. Ich sah jedoch häufig grössere in das Peristom gelangte Thiere unter der hintern Hălfte des Innenrandes quer nach rechts in das Parenchyn eindringen. Die unverdaulichen Arcellenschalen verursachen bein Austritt aus den Körper in der Aftergegend eine weite, unregehmässige Oeffnung. Im vordern und hintern Körperende finden sich häufig vereinzelte grosse, von einem liellen Hof umgebene Fettkörner (Fig. 1. 2. f. f.). - Dic grössten Individuen sind $\frac{1}{6}^{\prime \prime \prime}$ lang und $\frac{1}{12}$ " lreit. Ein sehr breites altes Individuam (Fig. 1) hatte bei einer Länge von $\frac{1^{\prime \prime \prime}}{7}$ eine Breite von $\frac{1}{10}{ }^{\prime \prime}$. Die lileinsten Jıdividuen sind liaum $\frac{4^{\prime \prime \prime}}{2}$ lang.

0. grandis mag öfters mit Stylonychia mytilus rerwechselt worden sein. $v$. Siebold schreibt dem letztern Infusionsthier vier Kerne zu (Lehrb. der vergl. Anatom. S. 24); er hönnte also möglicher Weise O. grandis vor sich gehabt haben. - Auch Ehrenberg's zu den Euplotinen gestellter Himantophorns charon, der bei Berlin selten beobachtet wurde, und den Ehrenberg selbst als eine der Stylon. myilus ähnliche Infusorienform bezeichnet, könnte Onych. grandis gewesen sein. Ehremberg giebt freilich bei seinem H. charon keine Randwimpern an, auch schreibt er demselben in Ganzen nu 22-2T gleichartige, iber den ganzen nittern Theil der Bauchseite zerstreut stehende hakenförmige Wimpern zu, ron denen die 4-6 letzten (Afterwimpern) kammartign neben einander sitzen sollen; allein Elrenberg beobachtete nur die Rückseite des Thieres, die er irthimlich fiu die Bauchseite hielt, ev konnte dahej ınmöglich die Zahl und Stellung der locomotiven Wimpern genau eskennen. Die Bauchwimpern entzielıen sich auch hei Onychodromus bis auf wenige hintere sehr häufig ler Wahrnehmung, wenn die Thiere dem Beobachter die Ruckscite zuliehren, indem sie unter dem Rande zurickigczogen bleilsen. Die drusigen Kuoten, welche Ehrenberg längs tles linken Seitenrandes beobachtete, könnten die zapfenförmigen Rückenfortsitze von Onychodromns gewesen sein, deren ich freilich nie mehr als zwei antraf. Die entschiedenste Differenz zwischen Himantophorus und Onychothomus bildet die Lage des contractilen Behilters; dieser soll bei Himantophorus dicht am Hinterrande auf der rechten Seite liegen. Hiernach bleibt allerdings die Beziehung von Himantophorus anf Onychodromus sehr unsicher, ich glaubte jedoch auf dieselbe hinweisen zu muissen, da Ehrenberg seine Untersuchungen selbst für unvollständig Ste:n, Oryanismus der Infusionsthicre. 


\section{6}

erklät hat und kein neuerer Forsclser den Himant, charon wieder auffinden konnte. Perty will ilın zwar in der Schweiz sehr selten angetroffen haben (Zur Kenntn. kleinst. Lebensf. S. I 3\%), wie renig jedorh diese Angabe Verıauen verdient, kann man schon daraus abnehmen, dass Perly seinen vermeintlichen Hinnntophorus mit Euplotes patella vergleicht und ihm eine Läng̣sreilse von Wimpern auf dem Rücken zuschreibt.

\section{Gattming. Stylonychia, EHrbG.}

\section{(Taf. VI-IX).}

Character: Kïrper gepansert, Peristom von halber hörperbreite, bis zur Mitte der Bauchseite reichend; 8 ringformig gruppirte, griffelformige Stirnwimpern, 5 in zuei medianen Längsreihen stehende griffelförmige Bauchwimpern und 5 griffelformige Afterwimpern.

Die Gattung Siglonychia wurde von Ehrenberg im J. 1830 (Abhandl. der Berliner Acad. S. 43) aluf Kerona mytilus und histrio von $O$. F. Müller gegriindet. Die Müller'sche Gattung Kerona beschränkte Ehrenberg auf dessen K. pustulata, da sich jedoch diese Art später als eine ächte Stylonychia herausstellte, so wurde der Gattungsname Kerona wieder vacant und Ehrenberg iubertrug ihn nun auf eine ganz verschiedene, an Sisswasserpolypen schularotzende Oxytrichinenform, die bei Mïller gar nicht in der Gattung Kerona enthalten ist. Dies Verfahren ist gewiss nicht gut zu heissen, sondern es wäre jedenfalls angemessener gewesen, den neuem Namen Stylonychia zu unterdrücken und zu der ältern Müller'schen Benennung Kerona zurückzukehren, statı diese in einem ganz fremden Sinne zn verwenden. Trotzden werden wir Ehrenberg's Nomenclatur beibehalten müssen und nicht dem Beispiele von Dujardin und Perly folgen dürfen, welche Ehrenberg's Stylonychien als Keronen aufführen. Denn Ehrenberg hat zuerst die Gattung Stylonychia genauer bestimmt und ihr weit engere Gränzen angewiesen, als Mïller seiner Gattung Kerona, die z. B. auch Euploten umfasst. Ueberdies wijrde ein Zurïckgehen auf Müller's Nanen auch eine Aenderung des Ehrenberg'schen Gattungsnamens Kerona nothwendig machen, und dadurch wiirde nur weitere Verwirrung entstehen. Nach Ehrenberg soll die Gattung Stylonychia diejenigen Oxytrichinen begreifen, welche neben Wimpern noch Krallen und Griffel hesizen. Diese Definition ist jedoch nicht scharf genug, und sie reicht nicht ans, um die stylonychien sicher von andern Oxytrichinen zu unterscheiden; nach derselben wïrden nicht blos meine Gattungen Onychodromus und I’leurotricha, sondern auch verschiedene Arten der Gattung Oxytricha, ja selbst von Urosty̧a als Stylonychien bestimmt werden liönnen. - Dujardin hat für seine Gattung Kerona, die doclı nicht blos Ehrenberg's Stylonychien, sonderı auch dessen Kerona polyporum umfasst. den von Elwemberg für Stylonychia aufgestellten Gattungscharacter beibchalten und diesen nur durch eine längere Phrase umschrieben. - Nach Claparède (Étules p. 138 und I̋̈4 soll das vorzuiglichste unterscheidende Merkmal der Stỵlonychien von den ubrigen Oxytrichinen darin bestehen, dass bei ersteren die Stirn- und Bauchwimpern nicht in regelmässige Längsreihen geortnet seien, wălırend dies hei den letztern stets der Fall sein soll. Ich kann diesen Unterschied durchaus nicht gelten lassen; es stehen ja nicht blos bei allen Stylonychien die Bauchwimpern in zwei Lingsreihen, sondern es giebt auch in der Gattung Oxytricha mehrere Arten, die in Bezug auf Zahl und Stellungr der Stirn- und Banchwinupern genau mit den Stylonychien iblsereinstimmen.

Die Grundform des Körpers ist die langgezogen elliptische, die jedoch bei den einzehnen Arten verschieden modificirt wird. Das farblose und durchsichtige Parenchym zeichnet sich durch einen ziemlich bedeutenden Grad von Starheit, durch seine geringe Biegsamkeit und durch mangelnde Contractions- und Expansionsfähigkeit aus. Im rerdunstenden Wassertropfen verkïrzl mul verbreitert sich zwar der Körper merklich und fliesst zuletzt plötzlich aus einander, allein dasselhe findet auch bei den Euplotinen, namentlich in ganz älınlicher Weise bei Euplotes charon statt, wie schon von Dujardim hervorgehoben wurde (Infusoires p. 4.29). Iclı nehme daher lieinen Anstand, die Stylonychien in demsellsen Sinne als gepanzerte lnfusorien zu hezeichnen, wie die Euplotinen. Diesen Character hat man bisher unbeachtet gelassen, und doch ist derselbe fur die sichere Unterscheidmng gewisser Oxytricha-Arten von den Stylonychien sehr wesentlich und unenthehrlich. Es rijhrt dies wohl un daher, dass man sich zu sehr auf Ehrenberg's Angabe verliess, dass allen Oxytrichinen ein panzerloser Körper zukomme. - Das Peristom ist ảhnlich geslaltet, wie bei der vorigen Gattung; sein Innenrand fällt nahebei mit der Vittellinie der Bauchseitc zusanmen, seine grösste Breite kommt daher der halben Korperbreite gleich; sein hinteres Lnde liegt clwas vor der Körpermitte. - Die Randwimperreihen bleiben gewöhnlich am Ilinterrande durch eine Liocke getrennt, in der drei sehr rerlangerte Schwanzwimpern stehen; nur hei einer Ant fehlt diese Liiche mul lanit anch dic Schwanzwimpern. Die 
Zahl der griffelförmigen Stirn-, Bauch- und Afterwimpern ist durchweg constant. Die 8 Stirnwimpern sind selır angleich stark und in einen weiten ovalen Ring gruppirt; die 5 Bauchwimpern stelien lings der Mitlellinie in 2 Reihen, und zwar 3 in der rechten und 2 in der linken; die 5 Afterwimpern verhalten sich ähnlich wie hei der vorigen Gattung. Diese Zahlen- und Stellungsverhälnisse der Stirn-, Bauch- und Afterwimpern sind keineswegs fur die Stylonychien alleiu characteristisch, sie kommen auch nicht selten innerhalb der Gattung Oxytricha vor, wo jedoch jene Wimpern viel mehr borsten-als griffelförmig sind. Da dieser Unterschied auch nur relativ ist, so ist es eben nöthiğ, in den Gattungscharacter noch die Beschaffenheil des Köperparenchyms aufzunehunen, welehes bei den Oxytrichen sehr ausdelıbbar ist, bei den Stylonychien dagegen nicht. - Der After liegt links neben den Afterwimpern, der contuctile Behälter nahe am linken Seitenrand auf gleicher Höhe mit dem Peristomwinkel. Der Nucleus ist nur in doppelter Anzahl vorhanden. - Quer- und Längsheilung beobachtete ich bei allen mir bekamuten Arten. Bei der Quertheilung werden an jedem Theilungssprössling stimntliche loconotive Wimpern nen gebildet. Die Lingstheilung erfolgt nach einem doppelten Hodus, einem einfachern und einem complicirteren. Unzweifelhalte Knospenbildung, welche nach Elrenberg vorkommen soll, liess sich nicht constatiren. Dagegen entdeckte ich bei einer Art zahlreiche wichtige Thatsachen in Betreff der geschlechtlichen Fortpflanzung und der Entwvickelıng ron Embryonen.

Die Stylonychien sind die geneinsten Oxyfrichinen und bevölkern oft in grossen Schaaren die siissen Gewhisser; eine der Sisswasserformen ist auch im Veere angetroften worlen. - Ehrenbery hat im grossen Infusorienwerk 6 Arten unterschieden, nämlich St. mỵtilus, pustulata, silurus, appendiculata, histrio und lanceolata. Yon diesen scheint mir St. silurus nicht wesentlich von St. mytilus verschieden zu sein; in der St. appendicntata erkannte ich eine Euplotinenform, meinen Styloplotes appendiculatus (vergl. S. 132); die St. lanceolata endlich repräsentirt eine besondere Oxytrichinengattung (vergl. Pleurotricha). - Dujardin und Perty balsen die Kenntniss der Stylonychien in keiner Weise erweitert. - In den Études von Claparéde und Lachmam werden 4. Arten angefulurt, nämlich die bekannten St. mylilus und pustulata und alusserdem noch zwei neue Arten, St. fissisela und echinata. Von diesen ist die erstere eine achte Stylonychia, letztere dagegen scheint mir zu meiner Gattung Pleurotricha zu gehören. - Ich habe die St. mytilus, pustulata und histrio vielfach beobachtet und mich uberzeugt, dass sie wohl begründete Arten sind, hierzu kommt noch die mir nicht bekannte St. fissiseta Clap. Lachm.; dic Gattung Stylonychia umfasst demnach gegenwaitig 4. Arten.

1. Stylonychia mytilus. EnRBg. (Taf. V'I-VIII).

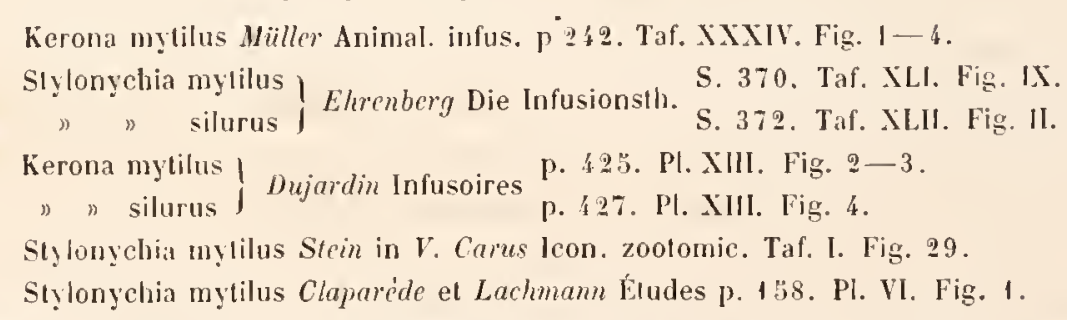

Löper ror der Mitte am breitesten, hinter der Mitte stetig nach hinten su, verengert und vor dem Ende meist $y$ lötslich in cinen

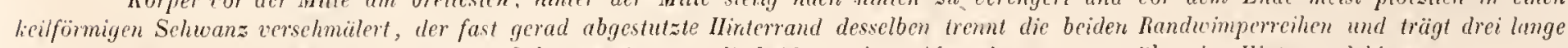
borstenfömige, weit von einander abstehende Schwanswimpern; die beiden reehten Afterwimpern ragen über den Ilinternand hinaus.

Die Styl. mytilusist eine iiberall rerbreitete, in stehenden und fliessenden Gewässern zwischen Wasserlinsen, Callitrichen und Conferven sehr häufig vorkonmende Infusorienform, die sich auch zwischen faulenden Wasserpflanzen noch vortrefllich befindet, ja lier oft ihre grössten Dimensionen erreicht. Sie ist nicht blos die grösste Art der Gatlung, sondern gehört ỉberhaupl zu den grössten Infusionsthieren; man erkennt sie schon mit blossem Auge als weisse, sich stossweise bewegende Puncte. - Der Körper hat in seiner gewöhnlichsten Form (Taf. VI. Fig. I . 2) im Umrisse viel Aehnlichkeit nit einer Miessmuschel, worauf auch der Speciesname hindeutet. Er ist namlich langgezogen elliptisch, etwas mehr als noch cinmal so lang, als breit, nach vorn zu beträchtich erweitert und melı oder weniger nach links umgehogen; der rechte Seitentand ist laher meist nach auswäls gekrümmt, seltener Taf. VIII. Fig. I) fast gerade, und der liuke in der Nitle nach cinwärts gebogen. Von ter Ilitte aus verengert sieh der Körper stetig nach hinten, besonders im letzten Drittel der hintern Haifte plötzlich und hier wieder stalker auf ler linken, als auf der rechten Seite, so dass dieser Theil eine Art keilförmigen Schwanz bildet. lessen schmalerer oder breiterer Hinterrand lald fast gerad abgestutzt und sanft bogenformig germudel. bald stumpf docieckig zugespitzl ist. Das sehr viel breitere vordere Körperende ist ungleichschenklig dreicelig zugespitzt, der rechte etwas nach 


\section{8}

rinwirts gebogene Schenliel des Vorterandes ist kiurzer, als der linke sanfı hogenförmig nach auswärts gekrimmte. Diese normale form des Körpers erleidet jedoch mannichfache Modificationen, von denen die wesentlichsten auf Tat. VIl und VIII dargestellt sind. Iläufig hat der Körper in der Mitte seine grösste Breite, er ist dann entweder nach rorn mässig verengert und anf die gewöhnliche Weise zugespizt, nach hinten aber stark und gleichmässig schwanzartig verengert (Taf. VII. Fig. 9-1 I. Taf. VIII. Fig. 3), oder die vortere Köorperhälfte ist fast iiberall gleich lweit unł stark nach links gebogen, wibrend das schwanzartige Hinterende elwas nach rechts gekrimmt ist; der rechte Seitenrand ist dann sehr stark nach aussen gewöllut, der linke mehr orler weniger eimwärts gebogen (Taf. VII. Fig. 8. 1 2. Taf. VIII. Fig. 4. 3). - Die Ruickseite des Körpers (Taf. VI. Fig. 2) ist måssig gewölbt, die Bauchseite (Fig. I) ganz plan, die Seitenrănder zugeschärft. Beobachtet man das Thier heim Klettern an fiemden Gegenständen im Profil (Taf. VII. Fig. I), so zeigt der Rijcken eine tloppelte Wölbung, eine vordere kïrzere und flachere iber dem Peristom und eine längere und stärkere in dem hinter dem Peristom gelegenen Theil des Körpers; beide Wölbungen sind durch eine saltelartige Einschniirung von einander gesondert. Beim Schwimmen erscheint der Rüclien seiner ganzen Austlehıung nach fast gleichförmig gewölbt, nur auf der rechten Seite immer stärker, als auf der linken; letztere ist namentlich binter dem Peristom mehr oder weniger eingesenkt.

Das Peristom erreicht bei dieser Art die grösste Breite. Der adorale Winperbogen beginnt hakenförmig nach innen gekrimmt neben der Mitte der rechten Seite des Vorlerrandes, er beschreibt dann unter der Spize des Torterrandes einen sehr convexen Bogen nach der Mitte der linken Scite desselben, wodurch sich eine sichellörmige Oberlippe (Fig. 1. l.) absetz, und zielı sich dann von dieser Seite bis zun Anfang des linlien Seitenrandes herab, wo er, wie gewöhnlich, auf den Aussenıand des Peristoms ibthergehı. Letzterer ist eine breite, quergestreifte. landförnige Zone (p.), die mit dem Innenrande des Peristoms nahe vor deı Körpermitte zusammentriffı. Die adoralen Wimpern des Aussenrandes sondern sich båufig in hinter einander liegende Gruppen ab, indem eine gewisse Anzahl von Wimpern sich mit ihren Spitzen gegen einander neigen (Taf. V1. Fig. 5. Taf. VII Fig. 4), die einzelnen Gruppen schlagen dann gemeinschaftlich langsam und abwechselnd aul und nieder und bringen dadurch oft täuschend das Ansehen einer continuirlichen undulirenden Membran hervor. Dieselbe Erscheinung ist anch bei vielen andem Oxytrichinen und bei Euplotinen zu beobachten. Wenn die adoralen Wimpern sich gruppenweis vereinigen, so wirl der Aussenrand tes Peristoms streckenweis frei gelegt und man erhennt nun deutlich, dass derselbe ein auch an seiner hintern Seite scharf begrimztes Band biklet, welches mit dicht auf einander folgenden queren Furchen rersehen ist; diese entsprechen den einzelnen Wimpern und dienen zur Aufnahme derselhen, wenn die Wimpern nicht in Thätghkeit sind. Der lınenrand les Peristoms fällt sehr nahe mit der lungsaxe zusanmen, er wendet sich vorn nach rechts gegen den Anfangspunct des adoralen Wimperbogens, bis zu dem or oft nahe hejan reich; sein hinteres Ende ist ehenfalls nach rechts gebogen. Der Innenrand bildet eine scharfliantige, vorspringende Leiste, unter der eine bandförmige undulirende Membran (i.) angeheftet ist, dic wieder lange, schrảg nach hinten gerichtete, feinhaarige, priorale Wimpern bedechi ; letztere werden erst sichtbar, wenn die undulirende Membran fächerförmign gefaltet und gegen den lnneurand angezogen wird, ich habe sie sebr bestimm von den stärliern schragen Falten der undulirenden Membran unterschieden.

Auf dem Peristonfelde beobachtete jch hiıfig eine quere hogenformige Leiste (Taf. VI. Fig. 1. d. Fig. 3), welehe von der vordern Ecke des Aussenrandes nach dem vordern Theil des Innemandes verlief; vor derselben war das Peristomfeld etwas starker vertieft. Diese Leiste bient in die eigenthiche Mundspalte un, welche sich unter der undulirenden Membran längs des Innenandes his zum Peristomwinkel linabzieht (Taf. VII. Fig. 1. o. 3. o.). Die hintersten adomalen Wimpron setzen sich. wie bej Euplotes, noch eine liurze Strecke unter lem Innenrande les Peristoms hinweg nach rehts mol rorn in das Innere des Körpers hinein fort (Taf. 11. Fig. I), ein eigentlicher Schlund jst jedoch nidht rorhanden. Kleinere Nahrungsstotie werten von der undulirenden Membran his zum Peristomwinkel hinalogedringt und erst hier in die Mundspalte hineingedriicht; hierbei vollfuhrt anch der hinterste Theil des Pcristominuemandes undulireade Bewegungen und daclurch entsteht das Auschen, als schliesse sich an deu Peristomwintiel nach rechts ein ganz küzes trichterförmiger Schlund an. Chaparcide und Lachmmn nehmen auch einen solchen an. Allein voluninösere Nahrungsstoffe, z. B. Paramäcien, Vorticellenkörjer und grosse lndividuen rou Arcella valgaris, werden melı odler weniger weit rom Peristomwinkel enternt in den rordern Theil rer Mundspale hineingedtucki und gehen unter dem mittlern Theil des Peristoninnentandes guer oder schief uach rechts in

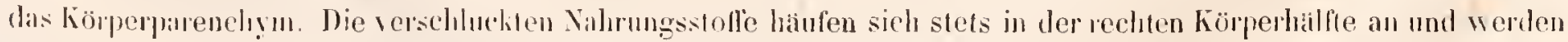

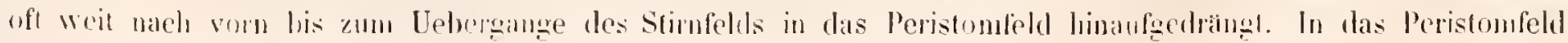


treten nur selten kleinere Nahıungsstofle hinein, daher es viel durchsichtiger bleibt, als der iibrige Körper. In der hintern Körperhảlfte rücken die Nahrungsstoffe allmăhlig schräg nach links und hinten (Taf. VI. Fig. I. 2) rlem hier gelegenen After zu. Die linke Körperhälfte ist mit einer nehr oder weniger dichten Schicht von Fettkörnern erfültt (Fig. 1), und diese Schicht setzt sich nach vorn oft weit in das Peristomfeld luinein fort (Taf. VII. Fig. 8-10j; ausserdem finden sich im vordern und hintern Körperende häufig grosse isolirte von einem hellen Hof umgebene Feltiörner (Taf. VI. Fig. 2. f. f.), von denen bereits S. 68 die Rede war. Das hinterste liörperende bleibt meist von ler Einfügung der Afterwimpern an von körnigen Ablagerungen frei und erseheint daher noch durchsichliger, als das Peristomfeld; doch sieht man nicht selten Iudividuen, welche bis nahe an den Hinterrand nicht blos Fettkörnchen, sondern selhst kiteinere Nahrungsstolle enthalten (Taf. VIl. Fig. 10. 11).

Die 8 Stiruwimpern (Taf. VI. Fig. í. st.) nehmen die vordere Halfte des Stirnfeldes ein; auf dem Uehergange desselben in das Peristonfeld stehen, wie bei Onychodromus, die drei stärksten und längsten im Dreieck, sie sind geschlängelte, gewöhnlich hakenförmig nach vorn umgebogene Griffel. Dann folgen am lnnenrande heral, zwei :ihnliche, elwas schwabchere Griffel, von denen der hintere und kürzere weiter nach rechts gericki ist; sic entsprechen den beiden innern Stirnwimperreilıen von Onychodromus. Die drei übrigen Stirnwimpern stelıen olıngefảı. in einer schriigen, von dem füften Griffel nach der rechten Ecke des Vorlerrandes ggezogenen Linie, sie sind mehr borstenförmig, doch stärker als die Randwimpern, und meist gerad nach hinten und aussen gestreckt; es sind dieselben Wimpern, die bei Onychodromus die dritte Reibe bilden. - Von den fünf griffelförmigen Bauchwimpern (Fig. 1. b. b.) stehen zwei jederseits nehen der Mittellinie dicht hinter dem Peristomwinkel; die dritte liegt nahe hinter Jer vordern rechten und meist ein wenig mehr nach innen, die vierte und fünfle sind weiter nach linten in die Năhe der Afterwimpern gerückt, sie sind grösser als die drei vordern und hakenförmig nach vorn umgebogen, die vierte liegt hinter der linken vordern, die fïnfte hinter der rechten vordern. Die 5 griffelförmigen Stirnwimpern und die ä Bauchwimpern tragen den Körper beim Laufen und Klettern (Taf. VII. Fig. 1). In sehr seltenen Fiallen leobachtele ich sieben Bauchwimpern, alsdann war zwischen dem vordern Paar und der dritten unpaaren Bauchwimper ein dem vordern ganz gleiches Bauchwimperpaar eingeschohen. - Die 5 Afterwimpern (Fig. 1. a.) sind grerade, nach hinten divergirende, fast gleich lange, plattgedruckte Criffel, welche so weit nach vorn eingefuggt sind, dass nur die beilen rechten und starlisten ïber den Hinterrand himaus ragen. Die erste Afterwimper steht dicht hinter der fünften Bauchwimper, die zweite ist weiter nach hinten gerucht, die trei ubrigen stehen einauder genálıert in einer schief nach links aufsteigenden Reihe nahe binter der vierten Bauchwimper. - Die rechle Raudwimperreihe (r) liuft ron der vordern Ecke des Seitenrandes demselben parallel bis zur rechten Ecke des Ilinterrandes; (lie linke Randwimperreihe (r.) dagegen beginnt am Aussenrande des Peristons, weit nach innen linter ler Mitte desselben und läuft von hier aus in schriger Richtung nach hinten und aussen; sie erreicht erst weit nach hinten ihren Seitenrand und zieht sich dann an demselben bis zur linken Hinterrandsecke hinah. Der Hinterrand trägt an jeler Ecke und in der Milte eine langborstige Selıwanzwimper (s.) Zuweilen greift eine Randwimperreihe iuber die Schwanzwimper ihrer Seite hinweg eine kurze Strecke weil auf den Hinterrand iber. Auf die bei allen stärkern locomoliven Wimpern leicht eintretende Zerfaserung ist bereits S. 71 hingewiesen worden.

Der contractile Behialter (c.) liegt an der gewöhnlichen Stelle und zwar zwischen dem linken Seitenrande und seiner Randwimperreihe. Das mit demselben in Verbindung stchende Wasserlianalsystem und sein übriges Verhalten wurde schon S. 89 geschildert. Die Ausscheidung von Excrementen habe ich oft beobachtet; sie erfirlgte stets auf ter linken Seile neben und etwas vor der funften Afterwimper (Fig. I. 2. z.). - Die beiden lierne (n. n.) liegen in Parenchym des Riickens, der vordere rechts neben dem Innenrande des Peristoms, der hintere links neben der Mittellinie, nahe hinter dem vordern Bauchwimperpaar. Jeder Nucleus ist oval und in der Regel mit einer queren, spaltförmigen Höhle versehen, die sich an dem vordem Nucleus gewöhulich etwas vor der Hitte, an dem hintern häufig hinter der Mitte befundet. Auf der linken Seite jedles Nucleus liegt frei abgesondert ein sehr kleiner, rundlicher, eiuem Fetkörnchen gleichender Nucleolus, den man erst deutlich erliennt, wenn man das Thier zerliessen lisst. An dem isolirten Nucleus (Taf. Vl. Fig. 8) treten noch feinere Structurverbaltnisse hervor; dio spalıförmige Höhle zeigt sjels von einer vordern und hintern, halbmondförmigen, lichıteı Wulst eingefasst, die sich scharf yon der opalien, lomogenen Nucleussubstanz absetzt; beim langern Liegen im Wasser oder doch beim Zusalz von Essigsäure hebt sich theilweis eine begrinzende Membran von der Nucleussubstanz ab. Häufig finden sich in der einen Ilälfte des Nucleus zahlreiche, rerschieden grosse, scharf lsegranzte Kerne cingelıettel Tuf. VI. 


\section{0}

Fig. 7. a.), während die andere Hälfte ganz homogen ist. Zuweilen zeigte nur der vordere Nucleus diese Structur, der lintere (Fig. \%. b.) dagegen war honıgen und nicht einmal mit cincr Höhle versehen.

Die Thiere schwimmen schnell und gewandt, sowohl in der Bauch-, als in der Rijekenlage, sie drehen sich, wenn hinlänglich Wasser vorlanden ist, auch nicht selten um die Langsaxe; in dem auf dem Objectglase sich flach ausbreitenden Wassertropfen hleiben sie entweder in der Rücken- oder in der Bauchlage. Bein Schwimmen bewegen sie sich eine Strecke weit mit gleichnaissiger Geschwindigkeit, dann biegen sie plötzlich stossweise, mit beschleunigter Geschwindigkeit hald uach links, bald nach rechts um. Nach einiger Zeit verlangsamen sich die Bewegungen und hald darauf bleibt das Thier stillstehen und wirbelt nur noch mit den adoralen Wimpern nach Nahrung. Von Zeit zu Zeit wechselt das Stillstehen mil einer kurzen stossweisen Bervegung nach vor-oder ruckwärts ab; treffen sie hierbei auf fremde Gegenslande, so lilanmern sie sich miltelst der Stirn- und Bauchwimpern an dieselben an und laufen daran auf und ab. Sind die Thiere einmal ruhig geworden und werden sie nicht gestört, so währt es oft selsr lange, bevor sie wieder zum continuirlichen Schwimmen übergehen. - Die Stylonychien können arg verstimmelt, zerrissen und zerstückelt werlen, dennoch zerfliessen die Fragmente, wenn hinlänglich Wasser vorhanden ist, nicht, sondern sie bewegen sich noch lange Zeit mit den ihnen verbliebenen Wimpern wie selbststandige Thiere. Namentlich werden Fragmente, die den vordern Theil des Peristoms behalten haben, mit ungemeiner Hefligkeit umbergeschlendert. Von O.F. Müller wutlen lergleichen Fragmente als selbstständige Infusorienformen beschrieben. - In längere Zeit aufbewahrtem Wasser, in welchem unsere Art zahlreich vorkommt, sind Cystenzuslänle eine gewöhnliche Erscheinung. Die Cysten (Taf. VIII. Fig. 14) sind kugelförmig, ziemlich dicliwandig, am Rande uneben und mit schiefen, sich krenzenden, bogenförmigen Falten versehen. Der eingeschlossene Körper ist ganz glatt und wimperlos, er zeigt in der Mitte, heim Zusatz von Essigsäure, die beiden dicht an einander stossenden Kerne und an Rande den contractilen Behister, der sich meist noch lebhaft contrahirt unt expandirt. Oft sah ich den Körper innerbalb der Cyste in langsamer Rotation begriffen, besondere Bewegungsorgane liessen sich aber nichı unterseheiden. - Die grössten Thiere erreichen eine Linge von $\frac{1}{7}-\frac{1}{6}$, die bleinsten von mir beobachteten Individuen, welche bereits alle Charactere der Art erkennen liessen, waren nur $\frac{1^{\prime \prime \prime}}{2}$ lang. Der Durchmesser der Cysten beträgt gewöhnlich $\frac{1}{38}-\frac{1}{30}$, seltener his fast $\frac{1}{20}$."

O. F. Müller hat die normale Form bereits recht characteristisch dargestellt, er unterschied schon die Randwimpern, vier Afterwimpern (von der dritten und vierten sah er nur die Spilzen, die fünfte entghing ilım) und zwei der vordersten Stirnwimpern; in seiner Fig. 1 sind sogar die Bauchwimpern fast ganz richlig abgebildet, nur eine ist zu viel angegeben. Das Peristom blieb ihm unklar, doch sind in Fig. 2 die vorderen adoralen Wumpern angedeutet. Auf blossen Fragmenten von Styl. mytilus beruhen, wie schon Ehrenberg hervorgehoben liat, Mïller's Kerona haustrum und haustellum, Himantopus acarus, Judio, sannio und corona und Trichoda fumbriata, delphis, erosa und rostrata. - Ehrenberg's Abbildungen sind zwar im femern Detail weit genauer, sie enthalten aber gerade in den wesentlichsten Characteren die auffallendsten Irrhümer. Ehrenberg unterschied zuerst die beiden Kerne, hestimmte ferner die Lage von Mund, After und contractilem Behälter und stellte auch das characteristische lintere Körperende mit den After- und Schwanzwimpern getreu dar. Das Peristom dagegen wurde ganz verkannt; dic adoralen Wimpern wurden nicht von den Randwimpern unterschieden, sondem mit ihnen zusammen als eine continuirliche Reihe durchaus gleicharliger Wimpern aufgefasst, welche sich in der Mitte der linken Seite bogenförmig nach einwärts krimmt. Noch irriger sind Elrenberg's Angaben uber die Stirn- und Bauchwimpern; statt derselben hat er eine einfache Längshinde von 18 in zwei Reihen stehenden, gleichartigen dicken Haken abgebildel, wăhrend doch im Ganzen nur 13 und ganz anders gruppirte mediane Wimpern vorhanden sind. Wenı bei einem so gemeinen Thiere solehe Fehler begangen werden komnten, dinn werden uns auch Elwewberg's Angaben über die locomoliven Wimpern des nur selten beobachteten Himantophorus charon nicht zuverlåssigg erscheinen können, und mein oben ausgesprochenes Verdach, dass dies Thier ein ungenügend heobachteter Onychodromus grandis gewesen sein werde, diurfte nunmehr begrindeter erscheinen. - Ehrenberg's Stylonychia silurus ist sicherlich nichts weiter als eine jugendliche Form von Styl. mytilus, wie schon ein Yergleich von dessen Abbildungen mit meinen Fig. 7-10 auf Taf. VllI lehren dürfle. - Dujardin's Abbildungen sind höchst oberflächlich und fast in jeder Beziehung unrichtig; die Banch- und Schwanzwimpern, die Kerne und der contractile Behälter wurden ganz weggelassen, die Stirnwimpern falsch dargestellt und die Randwimpern nur theilweis angedeutel und hinten mit den beliebig vermehrten Afterwimpern in eine continuirliche Bogenlinie zusammengestellt. Nur das Peristom wurde von Dujardin besser unterschieden als von Ehrouberg. - Die erste genanere Darstellung des Baues von Styl. mytilus wurde von mir nach älern Zeich- 
nungen $^{1}$ ) im J. 1857 in den Icones zoot. von $\boldsymbol{V}$. Carus veröffentlicht; ich bestimmte zuerst die wahren Zahlen- und Stellungsverhảltnisse der Stirn- und Bauchwimpern, die Form des Peristoms und das Verhalten der Randwimpern zu denselben. Ich erkannte auch zucrst Wimpern am lınenrand des Peristoms, den letzleren liess jch irrthünlich bis zum Vorderrand des Peristoms verlaufen. - Claparede und Lachmam, velche meine fruhere Darstellung nicht erwahnen, sind im Wesentlichen zu denselben Resultaten gelangt, wie ich. Die Stirnwimpern werden alser als gleich grosse Griffel dargesteilt, desgleichen die Afterwimpern; letztere sollen bestandig auf der rechten Seite abgestutzt und hier von der Spitze her zerfasert sein, was ich durchaus nicht bestatigen hann; die beiden rechten Aftewimpern finde ich zu kuz, die drei ïbrigen viel zu breit angegeben. Die undulirende Membran am Innenrand des Peristoms wird als eine blosse Reihe langer und dünner Cirrhen gedeutet, der Hund auf den Peristomsvinkel heschr'ankt und der After auf die rechte Seite vor die Basis der ersten Afterwimpern versetzt. Die Kerne sind zu gross und als ganz homogene Körper gezeichnet; ihre Höhle und der Nucleolus wurden nicht unterschieden. Längs des linken und rechten Seitenrandes soll auf der Rückseite noch eine Reihe kurzer und steifer, nur bei selır giiıstiger Beleuchtung sichtbarer Borsten vorhanden sein, auf die Claparede und Lachmaim erst durch Lieberkühn aufmerksam genacht wurden (Études p. 160). Sollten nicht diese Forscher die beim Beginn der Quertheilung sich neu bildenden, Anfangs äusserst zarten und blassen Randwimperreihen (Taf, VI. Fig. 4. r’. r'.) für Rückenborsten gehalten halsen? Ich habe bei keiıer Stylonychie Riuckenborsten auffuden könuen.

Teber die Fortpflanzung und Eniaickelung von Stylougchia mrtllus.

$$
\text { 1. Querlieilung. }
$$

Sie ist die haufigste Vermehrungsweise und ron mir zu verschiedenen Malen schr genau von ihren fruilıesten Anfüngen bis zu ihrem Abschluss und bis zur völligen Umwandlung des frei gewordenen Theilungssprösslings in ein dem Ilutterthier ganz gleiches Wesen verfolgt worden. Die Quertheilung ist ein sehr complicirter Vorgang; das Gesetz, nach welchem derselbe erfolgt, ist erst von mir entdeckl worden. Ehrenberg liess dic Thiere sich nur einfach quer durchschnüren. - lm ersten Stadium der Quertheilung (Taf. VI. Fig. 3) dehnt sich der mutterliche Körper ansehnlich in die Länge aus; der Zuwachs betrigt oft melır als ein Drittel der bisherigen Länge und zwar findet derselbe hauptsächlich in der ganzen millern, zwischen dem Peristomwinkel und dem vordern Bauchwimperpaar gelegeneu Region des Körpers statt, wie man daran erkennt, dass die Bauclı- und Afterwimpern, ahne ilıre relative Stellung zu ändern, immer weiter nach hinten rücken, bis zuletzl das vordere Bauchwimperpaar den Anfang des zweiten Drittels der hintern Körperhälfte einnimmt. In dem Mlaasse, als sich der Körper verlängert, treten ziemlich gleichzeitig sowohl auf dem Stirnfelde in dem von den fünf hintern Stirnwimpern umschlossenen Raume, wie auch in dem millem Theil des zwischen dem Peristom und den vordern Banchwimperpaar gelegenen Bauchabschniltes sehr auffallende Neuhildungen ein. An diesen beiden Stellen schwinden nämlich die köruigen Ablagerungeu im Parenchym, und es entsteht dadurch ein lichteres, jedoch nicht scharf begränzles Feld, auf dem die ersten Anfange zu neuen Wimpersystemen hervorwachsen. - Auf den vordern Felde erscheinen $5-6$ einandel parallele, wellenformige Längsleisten (w.), welche in etwas schräger Richtung von vorn und rechts nach hinten und links verlaufen. Die innerste Leiste ist die kürzeste, sie beginnt am weilesten nach vorn, dicht vor der vierten Stirnwimper, die zweite entspringt cin wenig weiter nach hinten, ebenso ist jede nach aussen folgende etwas mehr nach ruckwärts geruckt, als die ilır roransgehende innere; die iussersle Leisle liegt in der Richtung der drei borstenfömigen Stirnwimpern. Die Leisten sind Anfangs selı kurz, fast gerade und gleich lang, sie wachsen aber schnell in die Länge und zwar die äusseren am starksten und ausschliesslich nach rïckwärts, die imersten hauptsächlich nach vorwärts; sie bestehen aus einem sehr niedrigen, ihheraus zarten Hautstreifen, der besländig in langsamer undulirender Bewegung begriffen ist und daher wellenfömig gehogen erscheint. Das vordere Ende der innersten Leiste wächst frühzeitig in ein zahnfömiges spitzes Läppchen aus, welches sich in der Richlung der Leiste bald niederlegt, bald wicder aufrichtet und aufrecht stehenıl mit der Spitze hin und her flackert. - Auf dem hintern lichten Felde entwickelt sich zuerst ganz nach links, etwa in der Mitte zwischen der Körperaxe und den linkeu Randwimperı, ein kurzes, fast gerades Länģsband von dicht hinter einander stehenden, sehr zarten queren Wimper'n $\left(p^{\prime}.\right)$, die dem stirker vertieften Innenrande des Bandes eingefügt sind; es ist dies die erste Anlage zu einem

1) Bei dieser Gelegenheil sei bemerhı, dass die Infusorientafel in den Icones zoolomicae bereits zu Anfang des J. 1855 gestochen wurde; als die Icones zoolom. erschienen (1857), hatten sich meine Ansichten üher Bau und Eurwickelung der Infusiouslhiere durcl forlgeselzle Culersuchungen in vielen Puncten wesentlich anders gestaltet. 
neuen adoralen Wimperhogen. Bald darauf erscheinen auf dem mittlern und rechten Theil des lichten Feldes $5-6$ eben solche schrige Laingsleisten (w'.), wie auf dem vordern Felde; die innerste liegt dicht neben dem vordern Theil des Liangbandes umd sie entwickelt ebenfalls frialızeitig ein zahnförmiges Läppchen, die äusserste Leiste liegt in der Richıung der rechten Bauchwimpereihe oder noch etwas dariber hinaus nach rechts.

Nach Verlauf von etwa einer Stunde hatte sich das in Fig. 3 abgebildele Indiviluum zu der in Fig. 4 dargestellten Form entwickelt. Die undulirenten Leisten des vorderen Feldes (Fig. 4. w.) zeigten jelzt eine viel schrägere Richtung, die inneren waren mehr nach vorn und rechts, die ämsseren mehr unch hinten und links geruckl. Die innerste Leiste hatte sich in einen einfachen, längern, noch immer häuligen, zahnförmigen Fortsatz verwandelı, an jeder der folgenden Leisten waren 2-4. ahuliche zahnförmige Lippchen hervorgewachsen, die sich in der kichtung der Leisten beständig bald nach voru, hald nach hinten umbogen, dam wieder aufrichteteu usd mit der spitze flackernd nach links und rechts schlugen, so diss jede Reihe den Eindruck èner einzigen gezáhnelten undulirenden Membıan hervorbrachte. An den innern Leisten waren die schwingenden Läppchen stärker entwickelt, als au den melı nach aussen gelegenen, und die vordersten in jeder Reihe wicder mehr, als die hintern, was der Limpferstecher nicht ganz getreu wiedergegeben hat; an der iussersten Leiste waren noch kaum Andeutungen von Lippehen rorhanden, gleichwohl hatte diese bereits die hinterste borstenförmige Stirnwimper verilrangt. - Auf Ilem hinteren Felde zeigten sich die Längsleisten ( $w^{\prime}$.) in ganz analoger Weise weiter entwickelt. Das friilsere kurze Laingsband war durch Zuwacls nener Wimpern sowohl am vordern, als besonders am hintern Ende in einen langen, vorn stalk knieförmig nach aussen gekrimmten Wimperbogen (j'.) vibergegangen, der sich weit nach linten und innen bis in die Nihle der vierten Bauchwimper erstreckte und vorn bis fast an den Peristomwinkel reichte. Der ganze von diesem Wimperbogen umgïrtele Theil der Bauchfläche erschien jetzt ebenfalls weil lichter, und nehen dem hintern Ende desselben zeigte sich nach links ein newer contractiler Behalter ( $\left.c^{\prime}.\right)$. E Eine andere Neuhildung war zu beiden Seiten des Körpers eingetreten. Die rechte Randwimperreihe (r.) war weiter nach innen geriickt und neben derselben batte sich nach aussen eine neue, aus viel kïirzern, zartern und dichter stehenden Wimpern zusammengesetztc Reilıe $\left(r^{\prime}\right.$ ) gebildet, welche sich von der vordern Seitenecke bis zum Anfang des schwanzardig verengerten Hinterendes erstreckt. Diese Wimprepn hängen anfünglich an ilırem Grunde mit einander zusammen, und noch fruher ist statt derselhen ein einfacher, undulirender Lingsstreifen vorhanden. Letzterer entwichelt zuerst zalınförmige Spitzchen, diese wachsen dann in hurze Borsten ans und trennen sich, immer langer werdend, zuletzt anch an Grunde von einander. Auf der lınken Seite war die Randwimperreihe (r.) weiter nach dussen gedrängt und neben dersellsen zeigte sich nach innen zu eine :ihnliche neue Wimperreihe ( $r^{\prime}$.), wie auf der rechten Seite, sie reichte aber noch nicht bis zum Aussenrand des urspringlichen Peristoms hinauf, entwickelt sich also offenbar von hinten nach vorn. - Die Mitte der heiden Seitenrïinder war mit einer seichten Einschnïrung, der ersten Andeutung zur Sonderung der beiden Körperbảlften verseben.

Die nächstfolgenden Entwickelungsvorgäuge bestehen nun darin, dass auf dem Stirnfelue die trei äussern Leisten immer weiter nach hinten und innen bis in die Nahe des Peristomwinkels ricken, und dass die jetzt an allen Leisten volbandenen zahnförmigen Läppehen ihre verbindende Basis vellieren, schunaler und entsprechend dicker werden, sich mit andern Worten in Griffel oder Borsten verwandeln und weiter und regelloser aus einander rïcken. Dadurch werden sämmtliche Stirnwimpern, mit Ausnahme der drei vordersten, verdrängt. Eine ganz analoge Veranderung geht mit den Leisten des hintern Feldes vor sich und dadurch werilen die drei vordern bauchwimpern des Mutterthieres zum Schwinden gebracht. -- Ein etwas späteres Theilungsstadium ist in Fig. $\ddot{3}$ abgehildel; vom Nuclens muss jedoch lierbei abgeselıen werden. Die beiden Kürpeıbälften haben sich bereits durch eine tiefere Einschnürug ihrer Seiten beträchtlich von cinander gesondert, die hintere Hälfte ist mit einem fast rollstăblig entwichelten Peristom rersehen, nur ist der Innenrand (i.) desselben noch oine sehr schwach ausgeprighte verticale Längsleiste, die eine ausserst zarte, gezähnelte, undulirende Membran trägt. Die theils grillel-, theils borstenförmigen Wimpern, welche sich aus den zahnförmigen Lippchen der ehemaligen Láugsleisten des vordern und hintern lichten Feldes entwickelten, bilden jetzt in jeder Körperhialfte ein vollstindiges System von Stirn-, Bawch- und Afterwimpern (st'. a'. und st". a".), deren stellung nur noch melur oder weniger von aler des entwickelten Thieres abveicht. Die Afterwimpern (a'. und a".) stehen in einer fast verticalen linie hinter einander. dicht nehen und var dem Peristomwinkel, die Stirnwimpern (st'. und st".) zeigen noch die Stellmog der zahnförmigen Läppehen der elsemaligen innern Längsleisten, die Bauchwimpern digegen sind schon zweireihig gcordnet. aber noch nicht scharf von den drei aussem Stirnwimpern geschieden. Zuweilen zahlte ich ein orler zwei Bauchwinpern 
mehr, als die normale Zahıl beträst, diese werden jedoch später fast immer wielcr unterdrickt. Die beiden urspriinglichen Randwimperreihen (r. r. r. r.) hatten sich durch die Einschnirung des Körpers in eine vordere und lintere gesondert, anf der rechten Seite war die hintere Reile vorn nach einwaits grerickt, auf der linken Seite waren die alten Ramhwimpern ganz nach aussen gedrängt und schon theilweis geschwunden; in der vordern Halfte zeigten sich nur noch drei alte kandwimperm. Die nenen Randwimperreilen ( $r^{\prime}, r^{\prime}, r^{\prime}, r^{\prime}$ ) hatten sich weitel entwickelt, die der linken Seite hate sich bis zum Peristom der vordern Kürperhalfte verlingert und war dann durch die Einschnurung dieser Seite in eine vordere, melir ntch aussen gerickte, und in eine hintere, mehr nach innen grerickte zerfallen. Dadurch hatte jede Körperhailfte auf der linken Seite cine neue Randwimperreilıe erhalten, die hereits die characteristische Lage in liezug aul den Aussenrand ihres Peristoms zeigrte. Auf der rechlen Seite hatte die neue Randwimperreilue dieselbe Ver'inderung erfuhren, wie die alte. Von ten abrigen loconotiven Wimpern des Mutterthieres waren nu noch die drei vorlersten Stimwimpern (st.), die beiden hintersten Bauchwimpern (b.). die Afterwimpern (a.) und die Schwanzwimpern (s.) vorhanden.

Die Theilung geht nun rasch ilırem Ende zu. Die beiden jetzt mit den wesentlichsten dussern Organen ausgeriisteten Theiłungssprösslinge schnüren sich innerhalb $\frac{1}{4}$ Stunte fast vollständig von einander ab. Sic bilklen zuletzt zwei umgekehrt eiförmige, nur noch lose und an einer sehr beschrínkten Stelle mit einander zusammenhängende Körper (Fig. 6), von denen der hintere bei der Bauchansicht mil seinem Vordertheile den Hintertheil des vordern bedeckt. Die alten Randwimpern sind jetzt auf der linken Seite gewöhnlich vollståndig geschwunden; auf (ler rechten Seite sieht man nur noch wenige und weit aus einander gerïchte (r.r.). Im Uebrigen haben sich beide Theilungssprösslinge nicht weiter verändert, nur die zwei alten hintern Bauchwimpern sind merklich kleiner geworden, und zwischen denselben und den alten Afterwimpern hat sich eine gerade oder schiefe Furche gebildet, wodurch sich ein besonderes Schwanzsegment (h.) absetzt, welches bald sämmtliche, bald nur die beiden rechten miitleslichen Afterwimpern trigt. Hit dem Auftreten jener Querfurche steht die Entwickelung neuer Schwanzwimpern in Zusammenhang. Diese watısen erst kurz vor dem Abschluss der Theilung in selır kurzer Zeil aus der Rückseite jelles Theilungssprösslings hervor (Taf. VII. Fig. 2). An hintern Theilungssprossling bildet sich auf dem Rücken, der queren Bauchfurche gegenüber, eine quere Kante; an den beilen Eclien und in ler Ilitte derselben wachsen die drei neuen Schwanzwimpern $\left(s^{\prime \prime}\right.$.) hervor, die also von Anfang an dieselbe Stellung haben, wie die alten Selıwanzwimpern (s). Auf dem Riicken des vorderen Theilungssprösslings erscheint eine alunliche, jedoch dem IInterande viel naher gelegene quere Kinte, an der sich in gleicher Weise die neuen schwanzwimpern (s'. entwiclieln.

Nunmehr, zuweilen auch schon etwas früher, trennen sich die beiden Theilungssprösslinge von cinanter'; "s bedarf jedoch noch mehrfacher, eine ziemlich geraume Zeit erfordermter Modificalionen, bevor sie dem Mullerthier vollständig gleich werden. Die frei gewordenen Theilungssprösslinge trifft man liäufig einzeln fur sich in einem Wassertropfen an; wer den gesetzlichen Vorgang der Quertheilung nichı liennt, der wird sie leicht für eine besondere Art, ja selbst fur eine andere Gattung halten. Sie zeichnen sich dadurch aus, dass das Peristoun selır weit nach hinten reicht, dass Stirn-, Bauch- und Afterwimpern das stirnfeld einnehmen und dass gewöhnlich auch noch den Randwimpern parallele Wimpern (die mutterlichen Randwimpern) vorhanden sind. Den vorderen Theilungssprössling erkennt man daran, lass er noch die drei vordersten Stimwimpern des Mutterthieres und ein selı kurzes wimperloses Schwanzsegment hesitzl, vor den auf der Rijckseite drei Schwanzwimpern stehen. Die drei überzahligen Stirnwimpern, das Schwanzsegment und die noch vorhandenen alten liandwimperu gehen nach und nach ein, die Bauch- und Afterwimpern aber rücken von dem Stirnfeld auf den eigentlichen Bauch, der sich mehr und mehr in die Länge entwiclelt. Den hintern Theilungssprössling (Taf. VII. Fig. 3) enliennt man an dem viel grössem Schwanzsegment (h.), welches jetzt mehr oder weniger nach links verschoben ist und an beilen Seiten noch mit Randwimpern und hinten mit den Schwanzwimpern (s.) versehen ist. Ausserdem sitzen vor demselben auf der Rickseite die neuen Schwanzwimpern (s".), wälrend auf der Bauchseite theils auf den Schwanzsegment, theils vor demselben noch die Afterwimpern und die beiden hintersten Bauchwimpern des Multerthieres vorlanden sind. An dem alggebildeten Theilungssprössling fanden sich nur noch vier alte Afterwimpern vor, die erste rechle sass vor dem Schwanzsegmente, die zweite atf demsehen, die heiden iibrigen waren weit nach vorn nehen die beiden restirenden Bauchwimpern gerückt. Ausserdem halten sich auf heiden Seiten die alten Randwimpern r. r. noch in Jeträchtlicher Anzahı erhalten, auch war unter den neuen Bauchwimpern eine uberzbhlige vorhanden. Die weitere, von mir oft beobachtete Enlwickelung des hintern Theilungssprösslings bestelıt darin (Taf. VII. Figr. 4). 


\section{4}

dass das Schwanzsegment zu einem unscheinbaren, warzenförmigen Anhang (h.) zusammenschrumpft, der nur noch Reste der ehemaligen Rand- und Schwanzwimpern erkennen lïsst und ganz nach linkis üloc das hintere Ende des linken Seitenrandes hinausgeschohen lieğ. Dadurch wird die Kante, an welcher bisher das Schwanzsegment sass. zum freien Ilinterrand des Körpers und die hisherigen dorsalen Schwanzwimpern gehen in terminale iber. Die mütterlichen After- und Bauchwimpern sind jetzl ginzlich geschwunden, oder es ist höchstens noch, wie in unserem Fall, eine vereinzelte Afterwimper auf dem warzenförmigen Anhang vorhanden. Von den alten Randwimpern zeigen sich nur noch auf der rechten Seite einzelne spuren (r.). Der eigentliche Bauch hat sich merklich nach hinten ausgedehnt und dadurch sind die nenen Bauch- und Afterwimpern von dem Stirnfelde nach rückwärts gewandert und fast ganz auf den Bauch gerückı. Der Rest des ehemaligen Schwanzsegmentes, der zuletzt nur noch ein eng und lurz gestieltes queres Läppchen bildet, wird nun binnen Kurzem völlig resorbirt, der Bauch noch weiter in dic Linge entwickelt und der Theilungssprössling hat dann ganz die normale Form erreiclıt.

Die Veränderungen, welche der Nucleus während der Quertheilung erleidel, sind nerkwibdiger Weise nicht bei allen Individuen dieselben. In vielen Fällen theilt sich der Nucleus jeder Körperhälfte sammt seinem Nucleolus gleich beim Beginn der Quertheilung, nachdem in der hintern Körperhälfte nur erst ein ganz kurzer adoraler Wimperbogen entwickelt ist, in cinen vordern und bintern. Die beiden Kerne jeder Körperlablfte liegen nahe binter eimander und gleichen ganz den normalen Kernen, nur besitzen sie gewöhılich keine quere Ilölılung; sie bleiben während des ganzen ubrigen Verlaufs der Quertheilung unverändert (Taf. VI. Fig. 6. Taf. VII. Fig. 2), ersı uach der Abschnirung der beilen Theilungssprösslinge rückt der hintere weiter nach rïckitürts in den sich mehr und mehr entwickelnden Hinterleib hinein (Taf. VII. Fig. 3. 4). Zuweilen waren die aus der Quertheilung eines mitterlichen Nucleus liervorgegangenen liciden neuen kerne (Taf. VI. Fig. 10. a. b.) mit einer Querhöhle versehen und ihre einander zugekehrten Segmente bestanden aus einer uberaus lichten Sulsstanz, in der mehrere resistente, dunkelcontourirte, querovale Kernchen eingehettet lagen. - In andern gar nicht selten vorkommenden Fällen dehnt sich der Nucleus jeder Körperhälfte gleich bein Beginn der Quertheilung beträchtlich in die Länge und Breite aus und er verwandelt sich in einen gestrecklen, oblongen oder fast walzenförmigen, ganz homogenen Körper (Taf. VI. Fig. 3. II. n. Fiğ 4. n. n.). Gleichzeitig vergrössert sich auch der Nucleolus, bekommt ein längsstreifiges Ansehen und verwandelt sich in eine kleine ovale Kapsel (nl.), welche der Länge nach dicht mil parallel neben einander liegenden Suabchen erfültt ist. Neben dem einen vergyousserten Nucleus (in Fig. 3 und 4 neben dem vorderen) finden sich fast immer zwei der eben geschilderten Nucleoli, die nur durch Quertheilung aus dem ursprünglich einfachen hervorgegangen sein können. Hăufig verschmelzen die beiden sich verģrössernden Kerne in einen breit walzenförmigen. beiden Körperlıalften gemeinsamen Nucleus (Fig. 5. n.), neben dem sich dann auf der linkicn Seite stets drei vergrösserte, mit słabförmigen Körperchen erfüllı Nucleoli finden. In Fig. 9 ist ein solcher gemeinsamer, noch grösserer Nucleus mit seinen drei Nucleolis aus einem andern, in mittlern Stadium der Quertheilung begriffenen Thier isolirt dargestellt; an demselhen sonderte sich schon durch blosse Einwirkung des Wassers die Nucleusmembran ron der ganz homogenen Nucleussubstanz.

Nach den bei den Paramäcien gemachten Erfahrungen (vergl. S. 97 folg.) kamn es wohl keinem Zweifel unterliegen, dass sich die vergrösserten Nucleoli zu Spermatozoenkapseln entwickeln werden. Aus den in der Quertheilung begriffenen Individuen, welche einen gemeinsamen oder einen vordern und hintern vergrösserten Nucleus und drei vergrösserte längsstreifige Nucleoli enthalten, gehen walırscheinlich Theilungssprösslinge mit einem einzigen Nucleus and einem orler zwei Nucleolis hervor, die wohl eine geschlechtliche Generation darstellen und an denen ein ähınlicher Befruchtungsact eintreten mag, wie hei den Paramäcien. Leider fehlt es mir an directen Beobachtungren, welche diese Vermuthung weiter hegrüinden könnten. Nur eine, vielleicht hierher gehörige Thatsache habe ich noch kemnen lernen, als der Stich der Tafeln bereits rollendet war. Ich traf nämlich mehrmals uniltelgrosse Individuen von Styl. mytilus, welche ganz den normalen glichen, die aber nur einen einzigen, vergrösserten, ovalen Nucleus enthielten. Diescr lag in der Mitte des Körpers, hestand aus ciner sehr lichten und durchsichtigen Substanz und war ringsum ron einem schr breiten unl dunklen Hof dichıt zusammengedrängter Fettliörner umgeben, zivischen denen mehrere lichtere grössere Kïgelchen zerstreut lagen, die sonst den Fettlï̈nerı sehı ähnlich sahen. Einen Nucleolus konnte ich nicht anffinden; dennoch vermuthe ich, dass diese Individuen von jenen Formen der Quertheilung abstammen, bei welchen sich der mijterliche Nucleus nicht theilt, sondern nur vergrössert. 
2. L ängs l he il ung.

Sie tritt viel seltener und immer nur vereinzelt auf. Die in der Längstheilung begriffenen Individuen, welehe ich beobachtete, befanden sich alle fast genau auf derselhen Stufe der Entwickelung und zwar in einem schon ziemlich vorgerïckten Stadiun der Theilung; die ersten Anfänge dieses Actes sind mir nicht zu Gesicht gekomnen. Bei den von mir aufgefundenen Formen (Taf. VII. Fig. 5) hatte sich der miitterliche Körper betrichılich verbreitert und einen fast länglich rechtechigen Umriss angenommen; er war von hinten her bis wenigstens zur Nitte oder noclı etwas daruber hinaus in zwei bereits völlig von einander getrennte IIälften mit parallelen Seitenränderı und abgerundeten Hinterrande getheilt. Die linke Hälfe ragte nach hinten immer mehr oder weniger iber die rechte hinaus; dafür hatte sich die rechte Häfte nach vorn etwas tiber die linke hinausgeschoben. Bei der Bauchansicht lag der freie Thcil der rechten Körperhälfte in einer etwas böheren Ebene, als der der linken, er bedeckte nach vorn zu mit seinem linken Seitenrande den rechten Seitenrand ler linken Körperhälfte. Das mülterliche Peristom war so weit nach links verschoben, dass der Peristomwinkel die Mittellinie der linlien Körperhălfte einnalım, der Innenrand des Peristoms hatte dadurch eine viel schiefere, vorn stärker nach rechls gerichtete Lage erhalten. Der rechten Körperhalfte waren sămmtliche Stirn-, Bauch-, After- und Schwanzwimpern, so wie anch die rechte Randwimperreihe des Muttertheres verhlieben, längs ihrer linken Seite dagegen zeigten sich lauter Neubildungen, nämlich eine neue, bereits vollständige Randwimperreihe, ein nener, noch sehr kleiner contractiler Behilter (e'.) und die Anlage zul einem neuen Peristom $\left(p^{\prime}\right)$. Letzleres wird vom Peristomwinkel aus gehildet; es erscheint nammlich neben dem vordern Ende des linken Seitemandes ein kurzes schräges, nach innen und hinten gerichtetes Band von zarten queren Wimpern, es ist dies der hinterste Theil eines neuen adoralen Wimperbogens, und mit dem hị̂tern Ende desselben stösst rechts eine kurze nach vorn divergirende Lingsleiste. der Anfang zum Innenrand des in der Bildung begriffenen Peristoms, zusammen. Der neue Peristomwinkel und contractile Behälter liegen immer elwas weiter nach vorn. als die entsprechenden Gebilde der linkien Körperbảlfte. Letzlere hat rom Mlutterthier las Peristom, den contractilen Behälter (c.) und die linke Randwimperreihe überkommen. Sie besass ausserdem die normale Zahl der Bauch-, After- und Selwwanzwimpern, aber nur zwei Stirnwimpern am Innenrande des Peristoms, welche chen dieser Stellung wegen der vierten und füften Stimwimper des Mutterthieres entsprechen. Alle diese Wimpern sind neu gebildete Organe; auf welche Weise sie entstehen, bleibt noch zu ermitteln uilsrig. Die rechte Randwimperreihe fehlte entweder noch gänzlich, oder es zeigte sich nur ein Anfang zu derselben an der hintern Seitenecke; sie entwickelt sich also jedenfalls von hinten nach vorn. - Jede Körperhälfte war bereits mit zwei Kernen (u. n. n. n.) versehen, die sich dadurch bilden, dass die beiden Kerne des Mutterthieres hei der Verbreiterung des Körpers cine schiefe diagonale Lage annehmen, sich dann verlängern und in der Mitle durchsehnüren. - Das in der Theilung begriffene Thier nahm häufig noch Nahrung zu sich, naturlich nur miltelst des ursprünglichen Peristoms, daher die Nahrungsstoffe lediglich in die linlie Körperhatffe gelangten. Auch in den ersten Stadien des Quertheilung (Taf. Vl. Fig. 3- 3) treten durelı das vordere Peristom noeh fortwảhrend Nalırungsstoffe in den Körper, dle sich auf der rechten Seite in beiden Körperhälften anhäufen.

Es kommt noch eine andere, aber sehr seltene Forn der Laingstheilung ror, die in umgekehrter Richtung, von vorn nach hinten erfolgt. Ich beobachtete davon nur das eine, auf Taf. Vill. Fig. 6 dargestellte Stadimı. Der mülterliche Körper hatte sich hauptsichlich nach vorn zu sehr stark in die Breite entwickelt und zwar in einer schiefen diagonalen Richtunğ, so dass die linke Körperhälfte nach vorn, die rechte nach hinten verschohen erschien. Das mütlerliche Peristom war, wie bei der gewöhnlichen Längstheilungsform, ganz in die linke Körperhälfte geriickt, von seinen adoralen Wimperbogen hatte sieh aber nach vorn und rechts durch eine verticale Einschnijrung in der Mitte des Vorderrandes ein Segment abgesondert. welches den Anfang zu einem neuen adoralen Wimperbogen für die rechte Körperhälfte bildet. Letztere hatte auch bereits in ihrer llitte und nach links den hintern Theil eines neuen Peristoms $\left(p^{\prime}.\right)$ und neben demselben einen neuen contractilen Behälter $\left(c^{\prime}\right.$.) entwickelt; beide Gelsilde lagen weiter nach hinten, als die entsprechenden der linken Körperhłilfe. Vor dem hintern Körperencle zeiste sich auf der linken Seite ein bogenförmiger Einsehnit, durch welchen für die linkic Körperhälfte ein neuer Hinterrand hergestellt wird, an dem luereits die beirlen äusscren Schwanzwimpern hervorgewachsen waren. Die rechte Körperhălfte hehält den grössten Theil der locomoliven Wimpern des Mutterthieres, nämlich die Stirn-, Bauch-, After- und Schwanzwimpern und die rechte Randwimperreihe, sie hat also später nur noch die linke Randwimperreihe neu zu bilden. Die linke Körperlälfte dagegen übernimmt rom llutterthier nur die linlie Randwimperreihe und muss alle ibrigen locomotiven Wimpern neu anlegen; sie halle in dem dargestellten Fall die fïnf stärkern Stirnwimpern, aber 
erst eine vordere Bauch-, zwei After- und die beiden äusseren Selwanzwimpern entwickelt. Jede Körperhälfte war unit einem doppelten Nucleus versehen; die vier Kerne (n. n n. u.) lagen einander paarweis diagonal gegenüber, das linke Paar war weiter nach vorn gerücht; als das rechte. Die beiden sich rerłingernden Kerne des Mlutterthieres gehen also zuerst aus ihrer verticalen Lage in eine diagonale ijber, danı erfolgt ihre Durchschnürung in der Mitte und es rijckt nun das vordere sergment in die linke, das hintere in die rechte Kürperhälfte. Einmal traf ich ein Individuum, welehes in der vordern Köıperhälfte bereits mit zwei nahe neben einander liegenden Kernen versehen war, wahrend die hintere Körperdálfte noch einen einfuchen, diagonal gelagerten Kern enthielt. - Ein anderes fudividumm, welches ich uber eine Stunde lang beobachtele, um den weitern Fortgang der Theilung zn ernitteln. hot die seltsame Erscheinung dar, dass auf dem hintern Theil jedes Stirnfeldes der beiden küntigen Theilungssprösslinge eine grosse Anzahl dicht gedrängt beisammen stehender, feiner Wimpern hervorwuchs, so dass es den Anschein gewann, als wiirde ein ganz neues System von Stirn-, Bauch- und Afterwimpern für die linke und rechte Körperhillfte angelegt.

3. Fortpflanzung durch Embryonen.

Zı gewissen Zeiten treten im Innenparenchym der mittlem Körperregion bei Individuen des verschiedensten Altej's eine kleinere oder grössere Anzahl von scharf begränzten, grossen, lichten kugeln (Taf. VII. Fig. 7-12. k. und Taf. VIII Fig. I-10. k.) auf, welche mit einem centralen opalien Kern und mil einem peripherischen contractilen Behälter versehen sind. Diese Kugehn sind ohne Zweifel das Resultat einer vorausgegangenen geschlechtlichen Zeugung, deren nihlıerer Hergang jedoch noch zun grössten Theil in Dunkel gehüllt ist; sie gleichen rollkommen den Embryonalkugehn der Paramicien (rergl. S. 99), vermehren sich, wie diese, durch Theilung und liefern auch zuletzt eine Generation lebhaft beweglicher, acinetenartiger Embryonen (Taf. VII. Fig. 12. e. Taf. VIII. Fig. 1. 4. 9.e.), wolche durch cine besondere Geburtsöffnung (Taf. VII. Fig. 1. 4. or.) ausschwärmen. - Ich entdeckte dicse Fortpflanzungsweise bereits in October 1834 in Tharand mol gab dariber die ersten ölfentlichen Mitheilungen im J. 1856 auf der Naturforscherversammlung in Wien (vergl. das Tageblatl Nr. 3. S. 3.3). - Die Entwiclielung von Embryonalkugehn gehört bei Styl. mytilus durchaus nicht zu den seltenen Erscheinumgen, ja sje kommt hier verhailnissmässig weit baufiger vor, als bei den andern Infusorien, welche dieselbe fortpflanzungrweise lıahen erkenuen lassen. Stösst man in einer Flissigkeit auf ein Individuum mit Embryonallugeln, so kann man fast mit Sicherheit darauf rechnen, deren noch mehrere, oft sehr viele anzutreffen. Oft sind diesp jedoch simmmlich nur nit einer oder wenigen Embryonalkugehn verselıen, dann sucht man vergeblich nach reifen Embryonen. Letztere kann man nur dann erwarten, wenı sich Individuen mit zahlreichen Embryonalkugeln zeigen. Behailt man derghleichen Individuen anbaltend im Auge, so wird man stets fruher oder späler eine oder mehrere der kleinsten Embryonalkugelı sich in Eubryonen verwandeln und diese durch die Geburtsöffunng nach aussen treten seben. - Ich habe die Embryonalbildung seit 18304 alljährlich nud in mehreren Fällen an zahllosen Individuen beohachtel, zuerst sah ich sie wieder

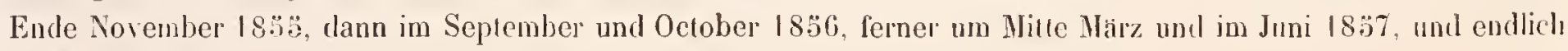
im Mai, Juni und Novemher von 1838 ; sie ist hiernach jedenfalls von der Jahreszeil ganz unabhängig.

Das Vermögen, sich durch Embryonen fortzuphanzen, ist Thieren ron der allerverschiedensten Grösse ejgen. Ich heobachtete zuweilen Embryonalkngeln bei den hleinsten, nur $\frac{t^{\prime \prime}}{2^{4}}$ langen Individuen, am häufigsten Iraf ich sie bei mitlelgrossen Thieren ron $\frac{1}{18}-\frac{1}{10}$ "Länge (Taf. VII. Fig. 7-12 und Taf. VIII. Fig. 7-10/; len grössten Individnen kommt heineswegs vorzugsweise diese Fortpflanzungsweise zu, jch salı sie hier jm Gegentheil verhälnissmässig viel seltener, als bei den miltelgrossen und Kleinen. In ihrer Organisation weichen die mit Embryonalkugeln versehenen Stylonychien nicht wesentlich von den gewöhnlichen Formen ab (in den Abbildungen sind ofters die hintern Stirn- und vordern Banchwimperı, so wie der vordere Theil des linken Bauchwimperreilıe weggelassen worken, um das Detail der Embryonalkugeln nicht undeutlich zu machen), sie bewegen sich auf dieselbe Weise und nelımen auch for'gesetzt Nahrung zu sich, was erst dann aufhört, wenn sich eine grosse Zalıl von Embryonalkugeln entwickelt hat. Die beiden Kerne des Mutterthieres zeigen dagegen eine mehr oder sveniger veränderte Lage. sie sind meist schief oder quer gestellt und oft weit aus einander nach den beiden Enden des Körpers geruckt (Taf. VII. Fig. 9-12. n. n. Taf. VIIl. Fig. 3̈. n. n.); der vordere Nucleus liegt stets vor den Embryonalkugeln, der hintere bald hinter denselben, hald isl er gegen den linken Seitemand ggedrangt odel von den hintersten Embryonalkugeln verdeckt. Auch der contractile Behälter des Mutlerthieres wird, wenn sicł die Embryonalkugeln sehr vermehren, theils mehr nach aussen, theils beträchllich nach vorn geschoben (Tal. VII. Fig. 10.11. c. Taf VIII. 
Fig. 4. с. 9. 10.... Innen besizen die Mutterthicre eine Waflende, ron cinem scharflsantigen Rande eingefasste Geburtsöflnung; sic liegt conslant in ter linken Bauchlıälfte dicht hinter alem Aussenrande des Peristoms und ist bald mehr der Mittellinie des Bauches (Tal. VII. Fign. 9. or. Taf. VIII. Figg. I. 3. or.), bahd mehr dem linken Seilenrande grenähert (Taf. V11. Fig. 12). Gewöhnlich hat sie die Form einer linglich ovalen, nieren- oder sichelfömigen spalte; bei grossen Mutterthieren erreicht sie uicht selten betrachtliche Dimensionen, inden sie sich entwerler nach hinten bis in die Nihe der Afterwimpern verlingert (Taf. VHI. Fig. 3. or.) oder sich beträchlich in die Breite ansdehnt (Taf. VIII. Fig. 4.or.). Die Geburtsöfnung is schon hei Multerthieren vorhanden, welche nur eine einzige Embryonalkugel enthalten (Taf. VII. Fig. 7. or.); sie ist tann aber olt erst eine sehr enge, kurze, dem Aussenrum tes Peristoms parallele Spalte. Hit der Vermehrung ter Embryonallingehn vergrössert sich auch die Geburtsöhrungr mehr oder weniger.

Die Embryonalkugeln liegen stets dicht gedrängt bejsanmen, sie platten sich daher durch gegenseitigen Druck ab und nehmen unregehmassige polyëdrische Formen an; isolirt bilden sie wirkliche Kugeln. Sie bestehen aus einer sehr lichten, homogenen Grundsubstanz (Taf. VIII. Fig. 2), die darch äusserst feine Pünctehen eine blaulich weisse Tribung enhäl; in der Grundsubstanz sind ausserlen vereinzclte Fetliörnchen eingestreut, auch zeigen sich hin und wieder einzelne lichte, natt begrinzte Vacuolen, die erst in Folge von Wassereinwirkung entstaulen zu sein scheinen. Sie durfen nicht mit dem stets sehr scharf begrinzten, wahe an der iussern OberIlache gelegenen contractilen Behalter verwechselt werden, ter sich durch lebhafte Systole und Diastole auszeichnet. Der centrale runde Kern der Embryonalkugel besteht ebenfalls aus einer ganz homogenen, feinkörnigen, aher vicl dichtern und opakem Substanz; er ist gewölnhlich von einem aus feinen Moleciilen zusammengeselzlen ling umgeben. Beim Zusalz von Essigsiure wirl die Embryonalkugel an der Oberfäche uneben und der hern weit dunkler und markirter, es sondert sich jerloch an beiden keine deutliche luegränzende Membran al).

Die Embryonalkugeh vermehren sich leieht und sehmell durch Theilung. In selır vielen Fällen sind sammtliche Embryonalkugeln eines Muttertheres blosse Theilungsproducte einer einzigen primitiven Embryonalkugel. Diese tritt stets in der linken Köruerhälfte dieht hinter dem Peristom auf (Taf. VIl. Fig. 7. k.); unmittelbar iiber ithr liegt in der Bauchwand die mehr oder weniger entwickelte Geburtsölfinung (or). Der lintere, quer gelaggerte Nuclens les Mutterthieres (n.) ist gewöbulich dicht an die Embryonalkugel geruickt. Zuweilen war die primitive Embryonal-

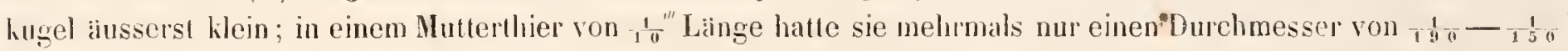
und der hintere Nucleus lag ihr so innig an, dass sie einen knospenartigen Auswuchs desselben zu bildeu schien, was sie jecloch sicherlich nicht isı. Eine Geburtsöfnung liess sich in diesem Fall nicht walurnehmen. Wenn alie primitive Embryonalkugel eine şewisse Grösse erreicht hat, die sich jedoeh nicht näher hestimmen lässt, da sieh in rlieser Bezichung selbst gleich grosse Mutterthere sehı verschieden verhalten, so theill sie sich in zwei llälften, die nun als selbststandige Embryonalkugeln weiler wachsen und oft emen beträblichen Lufang erseichen Tal: VIl. Figg. S. k.), bevor sie sich von Neuem theilen. Die Theilung erfolgrt gewöhnlich an der einen lruilıer, als an der andern, so dass zuerst drej, dann vier Embryonalkugeln entstehen; letztere liegen meist in Form eines geratlen oder schiefen Kreuzes dicht in einander geschoben (Fig. 9. k.). Das in Fig. I0 dargestellte Mutterthier zeigt sechs Enbrỹonalkuggehn, ron denen die zwei mittlern kleinern Pare unlängst aus der Thejlung zweier grössern hervorgegangen sind. In Fiğ I I sehen wir ein Individum mit 9 Embryonallingeln; von diesen befindef sich die hintere linke im Anfing, die vordere linke nahe vor dem Mbscluluss der Theilung. Bei den ersten Generationen ven Embryonalkugeln tritt dic Theilungsfurche entweder genau im Aequator der hugel oder doch in einem ihm sehr mahen Parallelkreise auf, die Kugel dehnt sich dann in der Richtung der Ilauptaxe aus und nimut baht eine Bisquitform an; dasselhe geschieht mit dem Kern und mit den contractilen Behalter, dessen beide Euden sich abwechselud mit Flissigheit fullen und diese dann in das entgegengesetzle Ende entlecren (Fig. II und Tuf. VIll. Fig. ?). Das Resulat der Theihung sint zwei nahebei gleich grosse Emhyonaliugeln. Die spätern Theilungsgenerationen erreichen nicht die Grösse der ätern. sontern sie werden immer kleiner. Die später entstandenen Enbryonallugeln zerfillen bei der Theilung anch nicht in zwej gtciche Häften, sondern es schnurt sich von ihnen nu ein Weines, mehr einer Knospe sleichendes Segment ab (Taf. VIII. Fig. I. li.). Die kileinsten Embryonalkugeln nelımen jmuce den innern Raum des ganzen Haufens ein und liegen nahe an der Bauchwand (Taf. Vul. Fig. 12), wahrend die grössern theils an der Peripherie, theils in einer continuirlichen Schicht unter der Riickenwand liegen. $\Lambda$ us den kilcinsten gehen die Embryonen hervor, während die grösscrn forlfahren, durch ungleiche Theilung neuc kleine Embryonalkugehn zu liefern. 
Die Vermehrung der Emhryonalkugeln erfolgt in verhalunissmissig kurzer Zeit, wie ich direct an einem aut Taf. VIIl. Figg. I dargestellten Indivilum am 29. September 18306 ermittelt habe. Ich behielt dasselbe in einem reinen Wassertropfen, dem ich von Zeit zn Zeit frisches Wasser zusetzle, ununterbrochen von fruh $10 \frac{1}{2}$ Ulı bis Nachmillag ä Uhr unter lem Mikroscope und beobachtete es von Vicrtelstunde zn Viertelstunde. Beim Beginn der Untersuchung zeigte dieses $\frac{1^{\prime \prime \prime}}{7}$ lange Thier eine Geburtsöffumg von $\frac{1}{5} 0^{\prime \prime \prime}$ Lainge und es enthielt dicht hinter lem Peristomwinkel und nach links drei Embryonalkugelı in der in Fig. 2 abgebildeten Gestalt, Grösse und Lage; eine derselhen war in der Theilung begriffen, die heiden andern hatlen einen Durchmesser von $\frac{1}{4}{ }^{\prime \prime}$. Um 11 Uhr war die Theilung vollendet; his 12 Uhr hatte sich eine der leiten andern Embryonalkugeln getheilt, so dass nun fünl vorhanden waren. Um I Uhw zählte ich bereits 8 Kugehn, deren Durchmesser zwischen $\frac{6}{6}-\frac{1}{3}{ }^{\prime \prime \prime}$ schwankte. Um Q Uhr waren 11 Kugeln vorlanden, von denen sich zwei theilten. Um 23 Uhr zeigten sich 13, um 3 Uhr 15 , um 3? Uhr 16 und um \& Lhr 18 Kugeln, von letztern batten die grössern einen Durchmesser von $\frac{1}{76}$, die kleinsten massen $\frac{1}{4} \frac{1}{3}^{\prime \prime}$. Um 4. Uhr wurde bei einer schnellen Wendung des Mutterthieres durch die Gehurtsöfnung, welche jetzt ${ }^{\prime}: "$ lang war, eine kleine mit kurzen geknopften Tentakeln besetzle Embryonalkugel herausgeschlendert, sie verwandelte sich nach ä Minuten in einen reilen Embrygo, der erst langsam zu rotiren anling und bald darauf munter

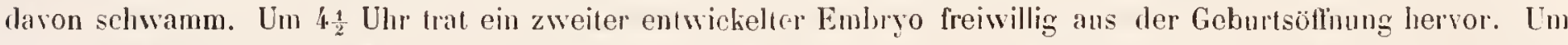
5 Uhr zeigle sich unser Mutterthier auf der in Fig. I dargestellten Entuickelungsstufe. Es waren jelzl siehen grössere, ringförmig gruppirle, peripherische Embryonallugeln vorhanden, von einer derselhen (h.) schnïrte sich wieder ein Segment ab; sie umschlossen cine weite unregelmässige Höhle, in der sich :j reife Embryonen (e.) umhertummelten und ausserdem noch 4 heine Embryonalkugeln zerstreut lagen. - Die Entwickelung zahlreicher Embryonalkugeln aus einer primitiven hat grosse Aehnlichlieit mit der Theilung des befruchteten Dotters bei denjenigen Thieren, wo derselhe einen totalen Furchungsprozess durchmacht, sie unterscheidet sich aber von dem letztern Vorgange schr wesentlich dadurch, dass die Gesammtmasse der Embryonalkugeln, welche sich in einem Mullerthier entwickeln, das Volumen der primitiven Embryonalkngel viele Male übertriff, und dass sảmmtliche Embryonalkugehn nicht zum Aufbau eines cinzigen Embryos verwendet werden, sondern jede für sich einen solchen liefern.

Da die ersten Generationen von Embryonalkugeln hauptsăchlich die linke Banchlıilfte cinnehmen, in der sich gewöhnlich eine reiche Ablagerung von Feltlörnchen findet, so diuften diese wohl das erste Material zur Vergrösserung der Embryonalkugeln hergeben. Dic spätern Generationen wachsen und vermehren sich auf Kosten des mütterlichen Parenchyms, welches in ihrer nächsten Umgebung mehr und mehr resolbirt wird. Hadurch entsteht zuletzl eine oft sehr scharf begränzte, von den Embryonallugeln erfullte Bruthölıle (Taf. VIII. Fig. ̈̈. 6. 7), welche durch die Geburtsoflnung mit der Aussenwelt in oflener Communication steht. Zuweilen beobachtete ich bei ganz kleinen Mutterthieren zwei von einander getrenute. ungleich grosse Bruthöhlen (Fig. 8), von denen die eine dicht. hinler dem weit nach vorn geriicliten vordem Nucleus, die andere dicht vor dem bis zum Schwanz hinabgeschohenen himtern Nucleus lag; die vordere Bruthöhte enthielt in dem abgebildeten Fall 14, die hintere nur 4 Embryonalkugelı. - Die Zahl der Embryonalkugeln, welche sich in einem Hutterthier entwickeln, bevor Embryonen erscheineu, ist sehr verschieden und zum Theil von der Grösse des Nulterthieres ablängiğ. Bei kleinen und millelgrossen Thieren beträgt sie am häufigsten 18-24, bej lileinen zuweilen nur 8-10. Das in Fig. 7 abgebildete Thier enthielt in soiner centralen rundlichen Bruthöhle urspriinglich 8 Embryonalkugeln, zwei hintere grössere und sechs vortere kleinere; von letztern verwandelten sich zuerst 2 in Embryonen, die die Bruthöhle bereits verlassen haben, hierauf entwickelten sich 2 andere zu Embryonen, die sich noch in der Bruthöhle umhertummelı. Bei grossen Mlutterthieren entwickeln sich häufig einige 30 - 4.0 Embryonalkugeln (Fig. ̈. 6), dıe in zwei Schichten iber einander liegen und eine umfängliche länglich elliptische Bruthölle erfüllen, welche sich von der llitte des Peristoms bis zu den Afterwimpern erstrecht und stets dem linken Seitenrande nahler liegt, als dem rechten (Fig. :5); ihren beiden Enden liegen die miitterlichen Kerne (n. n.) gewöhnlich ummittelbar an. - Das in Fig. „̃ dargestelle llutterthier enthielt 4 fast gleich grosse Embryonalkugehn und zwei reife Embryonen. Oefters ist die Bruböhle zum grössten Theil in die linke Körperlálfte lineingeriickt und diese dadurch sehr stark bauchig nach aussen aufgetrielıen (Fig. 6). Eimmal beohachtete ich in der Brulhöhle cines grossen Hutlerthieres einige 50 Enbryonallugeh, welche so innig an einander schliessende l'olyëder bildeten, dass nirgends ein Zwischenraum iblurig blieh; sie glichen vollkommen einem aus reguliren pentagonaten und hexigonalen kernhaltigen Zellen zusammengesetzten Gewehe.

Die Umwandlung der Embryonallingeln in Embryonen geht anf eine sehr einfuche Wrise vor sich. Zuerst 
Ireten an der Peripherie der Embryonalkugel vereinzelte selı hurze, fadenfürmige, in einem Knöp[chen endende Tentakehn horror; dann bomerht man im ganzen Unfange einen sanft wogenden schmalen Hof, der von äusserst kurzen und feinen Wimpern herrilırt. Die Embryonalligel nimmt nun eine gestrecktere Form an, schwankt langsan hin und her und fangt sich an zu drehen; die Wimpen worten inmer deullicher und langer, sie bewegren sich jetzl züngelnd und llackernd, und nach wenigen Minuten ist ein ausgobildeter Embryo vorhanden. der sich nun lebhafter in der Bruhöble umherwălzt und bahl plützlich zur Gcburısöffnung hinausschiesst. - Der reife Embrỵ (Fig. I. 4.6. 9. 10. c.) ist cin kurz walzenförmiger, an beiden Enden abgerundeter, in der Mitte etwas verengerter, ringsum geschlossener Körper von $\frac{1}{25}-\frac{1}{96}$ Linge. Das vordere Ende ist meist ctwas schmaler, als das hinlere, und enthält stels den contractilen Behalter; der runde Kern liegt hinter ler Vlitte des Körpers. Die ganze Oberfläche des Embryos ist mit gleichartigen verhälnissmässig langen, aber iusserst feinhaarigen, abstchenden Wimpern bckleidet; die Tentakeln stehen weitlänftig zerstreut, an beiden Enden aber gebäufter; man sielıt sic sich dcullich verkïrzen und verlängern, meist alıer bleiben sie kürzer, als dic Wimpern. Die Bewegungcn des Embryos sint gewandt und stelig, aher nicht sturmisch, so dass man ihm olne Mhile folgen liann; er beschreilst weite Bogen und dreht sich unaufhörlich um dic Lảngsaxe.

Hăufig fallen zur Geburtsöffnung, wenn diesclbe schr entwichelt ist, noch nicht ganz reife Embryonen und selbst kleinere Embryonalhugreln heraus: ersterc bliben daun einige Mlinuten auf dem Objectglase regungslos liegen. dann fangen sich die Wimpern an zu regen und bald elwacht der Embryo zu energischen Bewcgungen. Die herausgefallenen Embryonalkugeln bekommen einen unebenen wellig höckrigen Rand, und es treten an demselben sofort kurze Tentakeln hervor (Fig. 1 2. a.): später entwickeln sie sich entweder auf die gewöhnliche Weisc zu Embryonen, oder sie lheilen sich von Nouem in zwei ungleich grosse Segmente. Ist die Theilung his zur Bisquilform rorgeschrillen (Fig. 12.b.), so erscheinen an der ganzen Ohcrlläche des lileinern Segmentes kurze Wimpern (in unserer Figur, wie auch bei allen abgebildeten Embryonen sind nur die am Rande stehenden Wimpern angegeben worden); dieses Segment zieht sich dann gegen dic die Nlittelpuncte ljeider Segmente verbindende Axe zusammen, und verlängert sich in demselhen Maasse, zulctzl schniurt es sich als cin entwickelter Emhryo ab (Fig. 12. c.), wahı'end das andere Segment in der Form einer mit Tentakeln versehenen Embryonalkugel zuridibleiht. Dieselbe Erscheinung kann man auch an keinern, durch Zerquetschen eines Nlutterthieres isolipten Embryonalkugehn beobachten. Die aus der Gehurtsöfnung hervortretenden Embryonen verbreiten sich nicht immer sofort in lem ungebenden Wasser, sondern sie saugen sich oft mit dem knopfförmigen Ende ihrer Tentakeln in der Nahe der Geburtsö̈fnung, namentlich auf dem Peristomfelde an (Fig. 9. 10. e.) und werden so längere Zeit von dem Mutterthier mit umhergeschleppl. Ohne Zweifel entziehen sic demselben auch llussige Stoffe. Auch die frei umherschweifenden Embryonen sah ich mehmals sich mit ihren Tentakeln an andere Infusionshliere anheften; sic verhalten sich also ganz wic die Acinetensprösslinge.

Wenn cin Mutterthicr eimmal crst reife Embryonen zu produciren angefangen hat, so rerwandeln sich auch dic ubrigen Embryonalkugeln bald nach einander in Eubryonen; es schwarmon oft mehrere zugleich aus und die Bruthöhle wird immer leerer. Bei einem grösscrn Vulterthier, welches bereits eine Anzahl von Embryonen groboren hatte und noch 16 kleine Embryonalliugeln und 2 reife Embryonen enthielt, verwandelten sich innerhall einer Stunde sămmtliche Embryonalkugeln bis auf eine grösserc, unverandert bleibende in Embryoneu, die bald nach ihrer Ausbildung ausschwämten. Mehrmals traf ich lileine Nutlerthiere mit einer noch ganz scharf begränzten, aber völlig entleerten Bruthöhle. Meisı dehut sich jedoch das Innenparenchym ganz allnählig gegen den Miltelpunet der Brullıöhle in demselhen Maasse aus, als sich diese entleert, so dass dic Bruthölıle auf einen immer kleinern Raum zusammenrickt und zuletzl ganz sehwindel. - In den meisten Fälen werden nicht alie Embryonalkugeln in Embryonen verwandett, sondern es bleiben gewöhnlich eine grrössere oder 2-3 kleinero Embryonalkugeln unverindert zurück. Ilan triff daher sehr hatulig Mutterthicre an, welche eine einzige grosse centrale Embryonalkugel (Fig. 9. k.) enthalten und an denen noch ein oder zwei reifo Embryonen (e. e.) hängen. An dem in Fig. 10 dargestellten ludividuum blieben, nichdem der Jetzte Embryo (e.) ausgeschwärmt war, zwei hleine Embryonalkugeln (k.) zurick, die sich mehrere Slunden später noch ganz unverändert zeigten. Ein grosses im Gebăren begriffenes, mit einer langspaltigen Geburtsöfnung versehenes Hutterthier, wethes einige 30 Embryonalkngeln enthielt und Abends in einem Ułhrgláscheı isolirt wurde, zeigte am andern llorgen nur noch drei, dicht hinter den Perislom gelegene grössere Embryonalkugeln, und scine Geburtsöllnung halte sich his auf einc vorlere kurz ovale Spalte gesclılossen. Höclıs! wahrscheinlich schliesst sich die Gehurtsöflinung. wenigstens in gewissen Fällen, nach und nach vollstandier, und 
die 1-3 restirenden Embrgonalkugeh fungiren dann spater, wenn das Multerlhier den dureh die frubere Geburt crlittenen Substanzverlust wieder erselzt hat. als primitive Embryonalliugeln. Dergleichen Hutterthiere biluten oflenbar die Entwickelungsstufen, von denen unsere ganze bisherige Betrachtung ansging.

Es fragt sich nun, auf welche Weise die allerersten Embryonalkugehn entstehen. Ich hin darüber lange Zeit in Lngewisheit geblicben; erst inn Mlai I S.;8 beobachtete ich mehrere gonse Multerthiere (Taf. VIII. Fig. 3. 4. 6) welche mir jene Frage zn beantworten scheinen. Sie zeichneten sich durch dic auffallende Länge, die unregelmássige Form und die Zusammenselzung ilıer beiden Nuclei (n. n.) aus. In der homogenen Nuclenssubslanz lagen slets hlcine, scharf hegranzle, feste Kerne mit einer centralen Höhle; die grössten derselben hatten einen Durch-

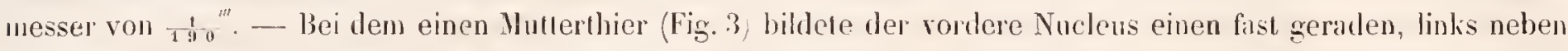
dem Innenrand des Perisloms liegeuden Längsstrang, der hinten zugespitzl und in der Mitte nach links stark höcherfömig anfgetrieben war. Diese angeschwollene Stelle enthielt eine mmeggelmässigg rundliche Höhle. welche cin derselben conformer, scharf begränzter, homogener Kööper ausfullte, der mit cinem ähnlichen kiern versehen " ar, wie sie in aler iibrigen Nuclenssubstanz volkommen. lch halte diesen körper fü eine um einen Kern der Nucleussubstanz gebildele Keimkingel, welche spater rom Nucleus ausgeschieden wird und sich dann zu einer gewöhnlichen Embryonalkugel gestaltet, indem sie einen contractilen Behilter und cinen grössern, ganz homogenen kern bekommt. Der hintere quer vor den Ifterwimpern liegende, ebunfalls strangfürnigre Nucleus war stark knieförmig zusammengeliummt und cnthelt in seinem angeschwollenen lintien Ende ebenfalls eine Höhle mit einer Keimkugel. In der linken körperhailfte des Mutterthieres funden sich ganz vorn eine sehr qurosse Embryonalkugel (k.) und dahinter 14 . leinere, in schiefen Reilıen lose neben cinander liegrende ( $k$ '. , welche nicht viel grösser waren. als die Keinkugel im Nucleus. Sie sind vielleichı sämmtlich unmittelbare Producte der beiden miitterlichen Kerne. können aber auch theilweis durch Theilung einer altern Generation entstanden sein, die ihren Ursprung aus den Vucleus nahm. - Bei einem zweiten Mutterthier (Fig. 4) bildeten die beiłen Kerne n. n.) (quer gelagerte, unregelmissig hin und her gebogene Stränge; der hintere enthielt in der Mitte eine hleine. wohl noch nicht entwickelte Keimkugel. Enbryonallingeln waren Anfangs 13 vorhanden, 5 grosse und 8 kleine, die säumtlich um die sehr weitu, hurz und breit ovale Gehurtsöllinung (or.) ringförmigg gruppirt lagen; zwei ron den heineru Embryonalkugeln verwandelten sich spater in Embryonen (e. e.). Dieses Mutterthier zeichnete sich noch dadurch aus, dass sein contractiler Behilter (c.) in das Peristonfeld geriicht war, und dass sich hinter der Hitte des linken Seitenrandes ein zweiter kleiner contractiler Behabler $e^{\prime}$.) gebihdet halte, der sich ganz unahliangig ron dem rordern zusammenzog und austlehnte. - Bei einem dritten Mutterthice (Fig. 6, hatten sich die beiden kerne (n. n.) ebenfalls strangförmigg verlangert, und in hintern Ende des vordern Nucleus zeigte sich eine kleine, unentwichelte Keimkugel. Enbryonalkugreln waren 32 vorhanden, eine bintere grosse, 3 davor gelegene mittelgrosse und 28 likincre von fast gleicher Grösse; ausserdem beoluachtete ich einen ausschwärmenden Embryo c.). - Ein viertes cben so grosses Mutlerthier enthielt nur 4 kleine, gleich grosse Embryonalkugeln; seine beiden Keme waren langgeshecht elliptisch ; Fig. II und jedel derselben zeigle in der Milte eine fast quadratische Höhle mit einer entwichelten Keimkingel. Beim Zusilz won Essigsiure hob sich ringsum von der Nucleussubstanz eine membranartige Hulle ab.

Einen Nucleolus konnte ich bei den eben geschilderten Hutterthieren mit verlingertem Vucteus durchaus nicht auftinden; auch bei denjenigen Multerthieren, dercu Embrgonaliugehn ledighich 'Theilungsproducte primitiver Embryonalkugeln sind, unterschich ich nur dann und wamn neben dem granz homogenen, keine spalıürmige Querhölıle zeigenden Nucleus einen deutlichen, structurlosen Nucleolus, so z. B. bej den in Fig. I0 abgebildeten Individuun. Das Fehlen des Nucleolus deutet darauf hin, dass derselbe in einem frühern, der ersten Entwiclielung von Limbryonalkugeh vorausgehenden Lehensstadium verbraucht worden sein muss. Da wir nun bei gewissen Formen der (Quertheihung (vergl. S. I:34) den Xuclcohs sich vergrössern und in ihm stabfömige liörperchen auftreten sahen. die völlig mit den ersten Enlwiclielungsstufen der spermatozoen bei den lananacien ïhereinslimmen, so liegt gewiss die Ansicht sehr nahe, diss die aus jenen Formen der Querthrilung herrorgehenden Theilungssprösslinge eine zur geschlechllichen Fortphanzung hestimmte Generation darstellen. deren spatere Entwiclialungsstufe die mit Embryonalkugehı versehenen Ilutterthiere bilden. Bei dieser geschlechtlichen Generation duirfle der Befruchtungsact auf dieselbe Weise erfolgen. wie hei den Paranacien, nänlich dadurch, dass die aus dem Nucleolus hervorgehenden Spermatozoen in den verğösserten. ganz homogen gewordenen Nucleus eindringen und diesen dadurch zur Entwichelung von keinkugelı anregen. Leider kam ich diese Hypolhese durch weiter keine Thatsachen begründen, ats die angefulurten, ich begnige mich deshabl danil, sie nur kurz angedeutet zu haben. Jedenfulls wirl man 
künftighin seine besondere Aufmerksanheit auf diejenigen Formen der Quertheilung zu richten haben, bei welchen sich die beiden Kerne nur vergrössern, ohme sich zu theilen, und oft mit einander verschmelzen und bei welchen sich in Nucleolus Stabchen entwickeh. Es wird namentlich darauf ankommen, die Quertheilung bis zum Alıschluss zu verfolgen und zu ermittelu, wie sich dann die Theilungssprösslinge weiter verhalten.

Vergleichen wir die Organisation der Embryonen mit der der entwickelten Thiere, so finden wir auch nicht die entfernteste Aehnlichkeit zwischen beiden, sie slehen vielmehr in einem totalen Gegensatz zu einander. Kann man nun wohl erwarten, dass sich die Embryonen durch ganz allmăhlige Mletamorphosen zu der ausgebildeten Thierform entwickeln werden? Mir kommt dies höchst unwahıscheinlich vor; viel glaublicher ist es, dass die Eubryonen zunachsı in ein acinetenartiges Lebensstadium abbergehen, da sie völlig mit den Schwảmsprösslingen gewisser Acinetinen ubereinstimmen. - Ich habe heine Zeit und IJhe gescheut, un ibler das weitere Schicksal der Embryonen Aufschluss zu erhalten. Zu dem Ende suchte ich einen eben aus dem Mutterthier aussehwarmenden Limbryo so lange zu verfolgen, bis irgend eine Mletamorphose eintreten wurde. Eine solche Beobachlung ist jedoch hei den rastlosen Bewegungen des Embryos höchst anstrengend und nicht langer als höchstens 2 Stunden amszuhalten. Das Resultat war jedoch immer, dass der Embryo zuletzt an den Rand des Wassertropfens gerieth, lier liegen lulieb und auf die in Fig. 13. a. dargestellte Weise zusammenschrumpfte und faltig wurde. Machte ich ihn dam anch durch Zusatz von Wasser wieder flotl, so trat loch jener Lebelstand bald wieder ein; der mehrfach Insgespiilte Embryo wurde endlich matter, es traten an seiner Oberfläche Sarcodetropfen hervor und er fing an zu zerfliessen. Häufig setzte ich Multerthiere mit reifen Embryonen einzeln in Lhrgläser. welche so weit mit reinem Wasser erfült waren, dass noch eine Beobachtung bei 300maliger Verğösserung möglich war. In den ersten Stunden nachlıer sah ich dann die ausgeschwirmten Embryonen sich munter im Wasser umhertummelı; später fand ich sie alle auf dem Boden des Ulırglases liegend, sie hatten ilıre Wimpern verloren, waren wieder kugelförmig geworden und glichen nun ganz ungestielten Acineteu. Diese ruhenden Embryonen (Fig. 13. b.) zeigen meist nur wenige und nie weit vorgestreckte Tentakeln, die sich nur dann und wann etwas verkiurzen und verlangern; der contractile Behälter dagegen zieht sich in regehmăssigen Intervallen zusammen und dehnt sich wieder aus. Zuveilen sah ich in den ersten Stunden der Beobachtung einzelne ruhende Embryonen sich auf dieselbe Weise theilen. wie die aus Mutterthieren zufthlig herausgeschleuderten oder isolirten Embryonallugeln (Fig. 12. a-c.). Nach Verlauf von 24. Stunden waren die Embryonen in der Regel ahgestorben, ohne dass an ihnen irgend weitere Veränderungen zu heobachten gewesen wären. Sie entwickelten sich jedenfalls nur aus Mangel an Nahrung nicht weiter. Mehrmals mengte ich dem Wasser im Uhrglase einen Tropfen, der zahlreiche andere lebende Infusorien enthielt, bei; es oliclite mir dann aber nicht, die Embryonen wieder anfzufinden.

2. Stylonychia pustulata. Enrbig. (Taf. IX. Fig. 1-16).

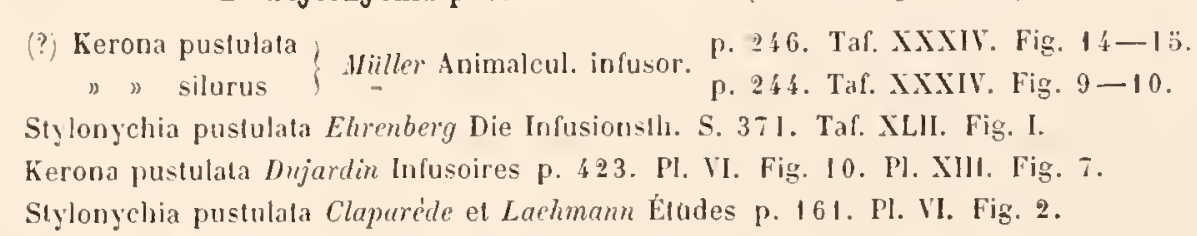

Fürper vor und hinter der Alitte gleich breit, naeh hinten gleichmässig verengert und stumpf eiförmig zugespitzt; die beiden Randwimperreihen sind hinten nur durch einen sehmalen Zwischenruum von einander getrennt, in dem drei borstenförmige, genäherte Sehwanzwimpern stehen; die drei oder vier reehten Afterwimpern ragen iiber den llinterrated hinaus.

Diese der styl. mytilus nahe verwandte, aber von ihr constant verschiedene Art gehört zu den gemeinsten, in allen fatuligen Infusionen, in Mistpfïtzen, sowie in anderen stehenden Gewässem sehr hảufig vorkommenden Infusorienformen. Ehruberg beobachtete sie auch in Meerwasser bei Kopenhagen. - Der Körper ist noch einmal so lang, als breit; die beiden Seitenränder sind hald fast ganz gerade und einander parallel (Fig. 1), oder es ist der rechte Seitenrand doch nur massig convex, der linke gerade oder in der Mitte schwach einwärts gebogen (Fig. 2), niemals zeigt sich die vordere Hälfte stark nach links umgebogen und überhangend, auch ist sie am Uebergange in den Vorderrand nicht breiter, als die hintere Körperhälfte am Uehergange in den Hinterrand. Das vordere Ende ist auf der linken Seite sebr schief und gerarlinig abgestutzt, so dass der linhe Schenkel des Vorderrandes viel länger ist, als der rechte, und die Spitze des Vorderrandes weiter nach rechts gerickt ist, als bei Styl. mytilus. Del Innenrand des Peristoms fallt genau in die Mittellinie des Bauches und ist ganz gerade, nach vorn eher etwas nach links, als nach rechts gerichtet; das Peristom isı daher schmaler, als bei der vorigen Art. Die hintere Körperlıălfte 
verengert sich hinter der Mitte stetig und auf beiden Seiten fast gleichförmig lis zur Spitze; das hintere Ende ist Jaher nicht abgestutzt, wie hei St. mytilus, sonderustumpl eiförmig zugespitzt. Die Stellung der Stirn- und Banchwimpern ist ganz wie bei St. mylilus, die Afterwimpern dagegen sind weiler nach linten eingefiigt, und es ragen wenigstens die drei ersten, gewöhnlich auch noch die vierte melu oder wenger weit tibcr den Hinterrand hinaus. Die beiden Randwimperreihen erstrecken sich bis nahe zur Spitze des Hinterandes, so dass hier nur eine schmale Liicke zwischen ihnen iibrigy bleilst, in der die drei feinborstigen Schwanzwimpern in geringen Abstanden von einander eingefiigl sind. Sie sind relativ kürzer als bei St. myvilus und können leicht iibersehen werlen, da sie oft ron den Afterwimpern bedecht sind oder diese doch die Zwischenrume zwischen ilnen ausfiilien. Der Hinterrand macht daher bei Styl. pustulata den Eindruck, als wire er auch in der Mitte ganz mit Wimpern besetzl; hierdureh mnterscheidet sich dicse Art am auffallendsten von St. mytilus. - Die Kerne (Fig. I.n.n.), der contractile Behälter (c.) und Iler After (z.) verlatten sich wic hei St. mytilus. Der vorlere zufibrende Wasserkanal (Fig. I. 2. g.) ist auch hier leicht zu heohachten, der hintere cntzicht sich gewöhnlich den Nachforschungen, da die linke Köorperhälfte hinter dem Peristom stets mit einer mehr oder weniger breiten und dichten Schicht von Fettkörnchen erfullt ist, die sich auch un den ganzen Hinterrand herumzieht. Der hiuler den Afterwimpern gelegene Theil des Hinterteibes ist laher niemals so glasartig durchsichtig, wie bei Sı, mytilus in der Regel. - Die grössten Individuen werden bis $1^{1}{ }^{\prime \prime \prime}$ lang und $\frac{1}{2}^{\prime \prime \prime}$ breit; am haufigsten sind $\frac{1^{\prime \prime \prime}}{14}$ lange und $\frac{1}{3^{\prime \prime \prime}}$ breite Thiere. Die hleinsten Individuen, welche ich

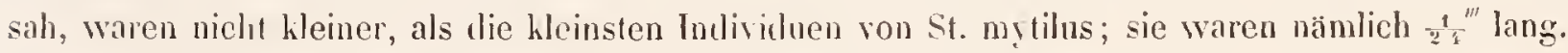

Die Quertheilung erfolgt genau nach densellsen Gesetzen, wie bei der vorigen Art, wie das in Fig. 3 dargestellte Theilungsstadium lelıt. Der mütterliche Körper zeigt noch keine Spur von Einschnürung, in der hintern Korperhalfte ist aler bereits ein neuer contractiler Behäler und ein neuer adoraler Wimperbogen ( $p^{\prime}$.) entwickelt, und nchen demselben ist ein neues System von Stirn-, Bauch- und Afterwimpern herrorgewachsen. Dahinter sieht man noch die beiden letzlen Bauchwimpern und die Afterwimpern des Mutterthieres. Die vordere Körperhälfte hesizt noch die drei urspringlichen vordersten Stirnwimpern, lieraul folgen die neuen Stirn-, Bauch- und Afterwimpern für den kïnftigen vordern Theilungssprossling. Der vordere Nucleus des Mutterthieres ist bereits in zwei zcrfallen, der hintere (n.) hat erst die Bisquitform angenommen. Auf der rechten Seite haben sich nehen den neuen Randwimperm nach innen zu noch die alten Randwimpern theilweis erhalten, auf der linken Seite sind diese granzlich geschwunden.

Die von hinten nach vorn fortschreitende Längstheilung kommt ziemlich häufig ror und ist von mir einmal an schr vielen Individuen einer fauligen Infusion durch verschiedene Stadien bis zum Abschluss verfolgt worden. Das friblıcste Stadium (Fig. 4) stimmte fast genau mit dem bei Styl. mytilus beobachteten iiberein, daher ich zur Erläuterung desselben auf die S. 155 gegebene Beschreibung verweise; in der rechten Körperlualfte war jedoch noch lieine Spur von einem neuen Peristom sichthar. Die Kerne zeiglen ein eigenthumbiches Verhalten; in der Mitte jeder Körperhıilfte lağ nämlich ein sehr langgestrechter bisquitförmiger Nucleus (n. n.) uncl weiter nach hinten, dicht vor den Afterwimpern, fand sich ein ovaler oder runder Körper (m. m.), der ganz das Ansehen eines Nucleus hatte. Auf welche Weise sich diese kernartigen Gebilde aus den mütterhichen Kernen entwickeln, ist mir nicht recht klar geworden, ebensowenig weiss ich mir ihre Function zu deuten. - Iuf einem ctwas spatern Stadium der Langstheiłung (Fig. 5) latte sich in der rechten Körperhäffe der hintere Theil ( $p^{\prime}$.) eines neuen Peristoms entwickelt, und zu den beilen hintern griffelförmigen Stirnwinpern der linken Körperhalfte waren noch die drei äussern borstenförmigen Stimwinupern hinzugekommen. Jede Körperhilfte war noch immer mit cinem bisquitförnigen Nucłeus (n.) und mit einem hintern, kernähnlichen Köper (m.) versehen. Leberaus haufig zeighten sich im Jarenchym beider Körperhälften zahllose vilurionienartige Fàden, die theils glössere Blasenräume cufülten, theils durch das ganze Parenchym zerstreut lagen. Sie wimmelten so lebluaft durch einander, dass die Felliürnchen im Parenchym hin und her gestossen und niclıt selten in eine fast tanzende Bewegung rersetzt wurden. Oftuals geriethen dliese Fäden in den ('ontractilen Behälter (Fig. 5. c.), sie wurden dann bei der Systole desselben gegen deu After zu getricben und lauften sich hier in einem Blasenraum (v.) an, der zuweilen fist die ganze Körperlureite einualım. Später wurden sie wieder auf' der rechten Seite jeder Körperhälfte nach vorn gedringt, uml sie sammclten sich dann l,ald in der Nilte, bald im vordern Ende in kleinern oder grössern Blascntamen an. Dieselbe Erscheinung beohachtete ich eben so häufig an ten gleichzertig vorkommenden, mit nomalen Kemen versehenen einfachen lndividuen; ich kann daher nicht glatuen, dass die vibrionienartigen Fàden. wie man wohl remullien könnte, reife, während der Längsthcilung entwickelte Spermatozoen darstellen, sondern ich halte sie nur fur von aussen aufgenommene wirk- 
liche Vibrionien. Quetscht man die Thiere, welche vibrionienartige Fälen enthalten, so treten letztere ron schleimigen Parenchymresten umhiillt nach aussen hervor, sie bewegen sich alser trotzdem noch lange Zeit lebhaft schlangelnd im Wasser mmher.

Im letzten Stadium der Lảngstheilung (Fig. 6) rickt die Theilungsfurche weiter nach vorn vor, und die beiden Körperhälften verschieben sich immer starker gegen einander, so dass die linke nach hinten weit iber die rechte hinausragt, wahrend diese nach vorn eben so weit die linke ïherragt. In der linken Körperhälfte entwichelt sich nun erst die rechte Randwimperreihe, die friher nur durch einige Wimpern an Hinterrande angedeutet walr, und gleichzeitig wachsen die drei bisher noch fehlenden vordersten Stirnwimpern hervor. In der rechten Körperhälfte rücki die Peristomanlage vom linken Seitenrande weiter nach iunem und gestaltet sich nach und nach zu einem rollständigen Peristom. Der bisherige rudimenläre Innenrand wächst nämlich, nachdem er fast in die Mittellinie geriickt ist, weiter nach rom und erlangt bald seise normale Gestalt und Grösse. Ebenso verlängert sich der rudimentare adorale Wimperbogen immer weiter nach vorn und aussen, bis er zuletzt nit den Vorderrande des elıemaligen mütterlichen Peristoms zusammentrift; er lheilt denselben in zwei fast gleich grosse Segruente, die sich auch ron vorn her durch eine seichte Einschniirung von cinander sondem. Das rechte Segment biltet fortan ten Vorderrand des rechten, das linke den des linken Peristoms. Es selzl sich also das Periston der rechten KörperIalfte nur zum grössern Theil aus neugebilieteu Elementen zusanmen, ausserdem nimm daran auch ein Abschnill des mülterlichen adoralen Wimperbogens Antlieil; das Periston der linken Körperlıäfte dagegen geht ganz und gar aus dem mütterlichen Periston hervor. Nachdem sich so die beiden hörperhälften zu zwei selbstsıundigen, den Ilutterthier völligg gleichen Individuen entwickelt lıaben, Irennen sich die beiden Theilungssprösslinge, die stets nur mit zwei normalen Kernen versehen sind, von einander. - In manchen Fällen scheinen sich beide Körperhälften bereits von einander zu trennen, bevor sie noch vollständig individualisirt sind. Ich traf nämlich zuweilen schmale, sehr ungestium und rashlos umherschwimmende Individuen (Fig. 7), welche ganz und gar einem rechten Theihungssprössling glichen, sie besassen aber nur die vorderm adoralen Wimpern, vom Innen- und Aussenrande des Peristoms war auch nicht die leiseste Spur vorlanden. Die stark vorspringende Ecke an der linken Seite ilires Vorderrandes wies noch auf den friblien Zusammenhang nit einem anderm Individumn hin. Ausserdem fand ich auch ganz :ihnliche Formen, welche bereits das hinterste Ende des adoralen Wimperbogens entwickelı latten, so dass zwischen demselhen und der linken Ecke des Vorderrandes nur noch ein kleiner wimperloser Zwischenraum rorlıanden war. Alle diese isolirten Formen mit unvollständigem Peristom zeichneten sich durch ein sehr lichtes. durchsichtiges Parenchỵm aus.

Es hommt noch eine andere, höchst merkwürlige Art der Langsheilung ror, die ich jedoch nur erst in neuester Zeit einige Male und zwar lediglich in der in Fig. 8 dargestellten Form beoluachtet habe. Der mütterliche Körper hatte sich wie in ersten Stadium der gewöhnlichen Längstheihunģ von luinten her bis zur Ilitte in eine reclıte und linke Hälfte gesondert, das muilterliche Peristom (p.) war in die linlie Körperlaalfte geriielit, und die acht Stirnwimperu hatten ihre Stelle kaum geindert, nur tie beiden hintern griffelformigen waren mil dem Innentande des Peristoms etwas weiter nach links geruckt. Neue Stirnwimpern waren nicht entstanden. Die hintern Endeu der beiden Körperháften und ihre emander zugekehrten Seilenránder verhielten sich hinsichlıch ihrer Bewimperung genau ebenso, wie bei der gewöhnlichen Form der Längstheilung. Dagegen lualte sich an der Stclle der drej vordern Bauchwimperu in jeder Körperhïlfte auf der linken Seite eiu neues Peristom ( $p^{\prime}$. und $p^{\prime \prime}$.) und rechts nehen demselben ein neues vollstintiges System von noch sehr dicht gednangt stehenden, kurz- und feinborstigen Stiru-, Batuch- und Afterwimpern entwickelt. Der miitterliche contractile Belälter war eingegangen; lafur zeigte sich links neben jeulem neuen Peristom ein neuer contrachiler Behälter. Was aus den mutterlichen Kernen geworden war, gelang mir leider nicht zu ernilteln. Bei Stylon. histrio werden wir diese Form der Liangstheilung noch genauer kennen lernen.

Multerthiere mit Embryonalkugeh sind mir niemals vorgekonmen. Dagegen traf ich nicht selten hleine $\frac{1}{2}-\frac{1}{20}{ }^{\prime \prime}$ lange Individuen Fig. I - 13), deren Körperparenchym ausserondenflich dicht mil kleiuern unt grössern Fellkörnchen erfïlt war. Sie erschienen bei durehgehendem Lichte sehr dunkelschwärzlich, bei auffallendem Lichte hreideweiss und enthielten in der Regel einen grossen, ovalen oder rundlichen Kern (Fig. 11. 13. n.), der gewöhnlich in der Mitte des Kö̈pers über und lumer dem Peristomwinkel lag und ans ciner so lichten und durchsichtigen homogenen Substanz bestand, dass man bej der Räckenansicht des Thieres die rordern Bauchwimpern durch den liem hindurch erkennen honute (vergl. Fï. 11. n.). Ausser diesen Kern fanden sich oft noch zwischen den Fell- 


\section{4}

körnchen zerstreut melırere kleinere lichte Kugeln ron verschiedenè Grösse (Fig. 11. m. m. Fig. I3. m.), die bald mehr den gröbern Fethiörnem, balı melı dem Kern älılich sahen. Das in Fig. II dargestellte Individuum war mit sechs lileinen accessorischen Kugeln, das in Fig. 1:3 dargestellte mit zwei grössern versehen. Nicht selten ist der eigentliche licru auffallend klein (Fig. 12. n.), wahrend die accessorischen Kugeln (m.) so gross sind, dass sic sich kaum ron dem Kern unterscheiden; es hat dann den Anschein, als sei ein urspruinglich grösserer kern in mehrere fist gleich grosse Kugeln zerfallen. Ob cin solcher Vorgang wirklich stallfindel, ist mir noch sehr zweifellaft; denn ich traf lndiviluen mit einem sehr kleinen Kern, welche gar keine accessorischen Kugreln enthielten. Wollte man annelınen, dass sich bei diesen Individuen der Kern allmälılig vergrössere und zuletzl in kleinere nahebei gleich grosse Kugeln zerfille, so stehen dieser Annahme doch jene Individuen entgegen, welelıe einen selır grossen Kern und nur ganz kleine, feltkornăhliche accessorische Kugehn enthalten. Ich muss gestchen, dass für mich die eben beschriebenen Entwichelungsslufen noch durchaus răthselhaft sind, und dass ich nicht weiss, in welchen Zusammenhang ich sie unter einander und mit den normalen Individuen von St. pustulata hringen soll. Sic enthielten niemals die geringste Spur von Nahrungsstoffen oder Nahrungsresten. - Wenn der Wassertropfen, in welchem sich ein Individum mit einem grossen centralen Kern befand, so weit verdunstet war, dass das 'Thier nicht mehr schwimmen konnte, sondern auf dem Objectglase liegen blieb, so bildete sich um (len Kern ein heller Hof (Fig. 13. n.), das Parenchym rijchte nach und nach weiter von dem Kerne al,, und das Thier drehte sich nun unausgesetzt in der Horizonlalehene um den unverriclit fest liegenden Keru. Eine ahnliche Beohachtung hat bereits $v$. Siebold (Vergl. Analomie S. 24) gemacht; man hat sie ganz mit Unrecht in Zweifel gezogen.

Die eben geschilderten Formen habe idı cinmal in grosser Anzahl in einer fauligen Infusion angetroffen und zwar in derselben, welche so viele in der Längstheilung begrilfene Stylonychien enthielt. Diese Infusion licferte mir auch ein ziemlich grosses einfaches Individum (Fig. 2), welches sogleich meine Aufmerksamkeit erregte, weil es in seiner Vilte einen grossen, scharf begränzten, sehr dunkehn, schwärzlichen Körper (x.) enthielt, aus dessen Innerem mehrerc lichtere Kugeln, die cine feine Streifung zeigten, hervorschimmerten. Es glüclite mir, diesen Körper durch Zerquetschen der Stylonychie zu isoliren (Fig. 9), und es zeigte sich nun, dass dersellse eine noch lebende, offenbar erst kurz zuvor verschlıchte kleinere Styl. pustulata darslelle, die sich ummittelbar an dic in Fig. $11-13$ ahgebildeten Formen anschloss. Dem ich unterschied deutlich dic rordern adoralen Wimpern, welche noch matt auf- und niederschlugen, und den contractilen Behälter (c.), der sich ebenfalls noch dann und wann langsam zusammenzog und wieder ausdehntc. Anderweitige Wimpern lionnte ich nicht auffinden. Das ganze Körperparenchym war bis in die Nähe des Vorderrandes ausscrordentlich dicht mit groben Fellkörnchen erfullı und zwischen diesen lagen vier fast gleich grosse Kungeln (s. s.) zerstreut, welche ganz und gar ans dicht an einander schliesscnden Stabchen lestanden. In Fig. 10 ist einc isolirte hugel und eine Anzahl durch \%erquetschen ciner andern Kugel frei gewordener Stäbchen mit dazwischen gerathenen Felthörnchen dargestellt. Die Stabchen sind ganz starr, schwach bogenförmig gekrimmt, nach beiden Enden zugespitzt und höchstens i i " lanğ; sie liegen in der Kugel nach rerschiedenen Richtungen bündelweis durch einander. Dass wir es hicr mit Spermatozocuballen zu thun luaben, dürfte wohl kaum zweifehaft sein; ferner liegt die Ansicht sehr nahe, dass das mil diesen Ballen versehene Indiviluum (Fig. 9) eine spatere Entwichclungsslufe der in Fig. 12 abgebildeten Stylonychienform darstellen werde. lch wage jedoch nicht, aus einer noch ganz isolirt dastehenden Bcobachtung, die verschiedene Interpretationen zulässt, jelzt schon weitere Schlussfolgerungen zu ziehen, sondern ich begnüge mich damil, dic einfachen Thatsachen registrirl zu luaben.

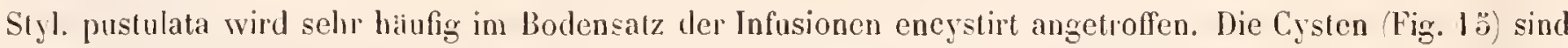
liugelförmig und daran sehr leicht kenutlich, dass ihre Oberfläche stets mit zahlreichen, kräftigen zahnförmigen Stacheln oder loch mit comprimirten warzenfürmigen Höckern besetzt ist. Die Stacheln oder Höcker sind nichı gleichmissig über die Oherfläche vertheilı, sondern in längere und kürzere bogenförmige Reihen geordnet, die sich theils schmeiden, theils cinander parallel laufen. Die Stachch stehen nicht ille vertical, somlem manche haben cine seliefe Richtung; of hängen mehrere benachbarte an ihrem Grunde mit einander zusammen. Die Cysten, deren Durehmesser meist zwischen $\frac{1}{54}-{ }_{3^{\prime}}{ }^{\prime \prime \prime}$ hetright, sind also sehr wesentlich ron denen der Styl. mytilus verschicden. Der eingeschlossene ganz nackte und homogene ǩörper fültt die Cyste vollständig aus, er zcigh stets noch den contractilen Belıalter (c.), und heim Zusalz von Essigsaure werden gewöhnlich anch dic heiden im Centrum des körpers liegenden Kerne sichtıar. In der Encystirung begriffene Thiere Jabe ich nichı selten bcobachlet; sic hallen den Körper kuglig zusammengezogen Fig lis und waren nur noch am Rande mit zerstrcuten, matl auf- und nieder- 
schlagenden Wimperu versehen; sie bewegten sich uichı mehr von der Stelle, sondern lagen entweder ganz still, oder drehten sich doch nur langsam im kíreise umher. Die beiden Kerne (n.) wvaren dicht an einander gerijcht und nahmen gewöhnlich die Nitte des Körpers ein, wăhrend der contractile Behiller (c.) wahe an Rande lağ. Im ganzen Umfange des körpers traten nach und nach hleinere und grössere perlartige Gallertropfen hervor, diese umhultten auch die noch vorlundenen. immer kïrer und undeullicher werdenden Wimpern und flossen schon nach elwa 10 Minuten zu eimer continuirlichen, den nun ganz nackten Körper einschliessenden Schicht zusammen. Die äussere Oberlläche der Schicht war von Anfang an uneben und höckerig; die Höcker traten danu inmer mehr hervor und gestalteten sich zuletzt zu zahnförmigen Fortsitzen. In den noch nicht ganz star gewordenen Cysten befindet sich ler eingeschlossene Körper in beständiger, langsamer Rotation. - In Innern encystirter slylonychien entwickelu sich lıäufig genau dieselıen Schıăuche, wie bei den encystirten Vorticelłen (vergl. S. I03̈), was mich noch meh. in der Ansicht bestärkt, dass dieselben parasitische Algen darstellen. In Fig. 16 selıen wir eine alte Cyste mit gelblich gefirbten Wandungen, deren eingeschlossener Körper vier Schlauche enthält, einen noch unentwickelten, ovalen (d.) und drei birnförmige, in eiuen röhrenförmigen Fortsatz ausgezogene, welcher die Cystenwand durchbohrt hat und frei uber dieselbe hinausragt. Der Schlanch e. ist noch geschlossen, der Schlauch ls. hat sich an deı Spitze geöllnet und seinen luhalt bereits entleert, aus dem vierten Schlauche sind so eben die nierenförmigen Sporen (a.) hervorgequollen, welche iu einen dichten rundlichen Ballen zusammengedrängt sind und lebhaft durch eimander wogen. Die Sporen trennen sich balu nach ihrem Austritte von eimander und zerstreuen sich wach allen Richtungen; sie stimmen rollkommen mit den in den Schlauchen der Vorticellencysten entwickelten iberein.

Von O. F. Mäller's Keronen dürfte wohl Ker. silurus nach den Abbildungen und den Angalıen über das Vorkommen zu utheilen noch am ersteu auf Styl. pustulata Ehbg. zu beziehen sem; es zeigt namentlich die Fig. 9. a. a. O den characteristischen Umriss der St. pustulata. Der Umstand, dass melır griffelförmige Wimpern angegeben werden, als dieser Art zukommen, scheint mir von keinem Belang zu sein, da Müller bei keiner Oxylrichinenform die Stirnund Bauchwimpern richlig erkannt hat. Viel zweifellafter ist es mir, ob Mïller's im Mcerwasser angetroffene Ker. pustulata, wie Ehrewberg annimmt, zu der gegenwiitigen Art gehört; sie scheint mir dafur zu schmal und zu gestreckt zu sein, auch erregt das Vorkommen Bedenken. Müller's Ker. calvilium, die man wohl noch fraglich zu Styl. puslulata gebracht lat, wirde jcl wegen der zwei langen und dicken Afterwimpern viel eher zu Styl. mytilus oder zu Pleurotriclıa laneeulata zielien. - Vou den 26 Abbildungen, dic Ehremberg von unserer Art geliefert hat, sind nur die Fig. 1. 3. 4. und 16 einigermatssen den wirhlichen Organisationsverhaltuissen entsprechent, aber noch keineswegs naturgetreu; die ibrigen Figuren sind ganz ungenave Slizzen ans älterer Zeil, denen Ehronberg selbst keinen sonderlichen Werth beilegt, die daher wohl besser unterdijckt worden wären. Ehrenberg unterschied zuerst die After- und Schwanzwimpern, die beiclen Kerne, den contractilen Behailter, die Nundgegend und den After; die Randwimpern zeichnet er als feine Harcheu, rom Peristom sah er nur die adoralen Wimperu, die als starke, wcitliuftig stehende Griffel aufgefusst wurden. Die Stirn- und Banchwimpern sind als gleichartige dicke Gritfel und nicht in der richligen Stellung dargestellt, ihıe Gesammtzahl ist jerloch fast genau bestimmı, nämlich auf 14 , stalt $1: 3$. Der Unriss đles Körpers ist nicht characteristisch gehalten, die Schwanzwvimpern sind zu wcit aus einander geriicht. auch ist die relative Stellung der eiuzelnen Afterwinpern nichıt die richtige. - Dujardin's Darstellungen sind ungleicl schlechter; in der allein elwas detaillirter ausgefiiluten Fig. 7 der PI. 13 finden sich 11 Stiru- und 8 Bauchwinpern angegeben, und die After- und Schwanzwimpern sind gar nicht von den Randwinpern unterschieden. Von innern Organisationsverhältnissen ist keine Spur angedentet. - Claparede und Lachmam hahen zuerst die Zahl und Stellung der Stirn- und Bauchwimpern ganz richtig bestimmt; iu del Abbildung ist nu aus Verselıen die hinterste aussere Stirmwimper und die rechte Afterwimper weggelassen worden. Der Speciescharacter wurde aber nicht hinlänglich scharf aufgefasst; daher kommt es denn, dass Claparide die Slyl. pustulata gar nicht für eine von styl. mytilus verschielene Alt gelten lassen will, er hehaupter, diss man, von sl. pustulala ausgehend, eine ununterbrochene Reilıe von Formen aufstellen könue, welche ganz allmahlig zu den grössten Individuen der Styl. mytilus iuberfülıten. Dem muss ich jedoch durchaus widersprechen, lenn die Styl. my tilus lisst sich nach abwärts bis zu eben so kleinen, alle Charactere ihrer Art scharf ausgepragt zeigemlen ludividuen verfolgen, wie sie bei Styl pustulata vorkommen. Es giebt allerdings veremzelte Falle. wo man schwankend bleibt, ob inan St. mylitus oder St. pustulata vor sich hat, alleiu wo die eine oder die andere Art in grösserer Individucnanzahı auftritt, da wird man über ilıre Bestimmung niemals in Zweifel sein kömen. Einen schlagenden Beweis liil dio wirkliche specifische Differenz beider Arten liefern die ganz verschiedenen Cxstenzustinde derselben. 
Die S1jlongchia fissiscta von Claparede und Lachmamn (Études p. 163. Pl. V1. Fig. 4), welche bei Berlin in den Torfmooren der Jungfernheide entdecht wurde, schliesst sich in Gestalt und Grösse am nächsten an Styl. pustulata an. Sie zeichnet sich dadureh sehr auffallend aus, dass die Afterwimpern nach der Spize zu selbst wieder mit ausserst feinen und dicht stehenden, wahren Wimpern besetzt sind, und dass die sehr langen Schwanzwimpertu sich an Ende in 3-4 selır feine Zinken theilen. Ein drittes. elsenfalls recht eigenthümliches Kennzeichen besteht darin, dass die drei vordersten Wimpern der rechten Randwimperreilıe die Form und Function der Stimwimpern angenommen laben. so dass anscheinend slatt 8 Stirnwimpern 11 vorhanden sind. Die iilsrigen Randwimpern sind kurz. stark und weiter als bei den andern Arten aus einander geriickt.

\section{Stylonychia histrio. EnRBG. (Taf. IX. Fig. 17-22).}

Kerona histrio Müller Animalcula infusoria p. 23:3. Taf. XXXII. Fig. 3-4.

Stylonychia histrio Ehrenberg Die Infusionsthierchen S. 373. Taf. XLII. Fig. IV.

Körper lïnglich elliptisch, nach vorn und hinten sugespitzl; die Randwimperrcihen gehen hinten in cinander iiber, Schwanzuimpern fehlen: die tferwimpern ragen nicht iiber den Hinterrand hinats.

Diese selur ausgezeichnete, schon an ihren eigenthiimlichen Bewcgungen auf rlen ersten Blick zu erkentuende Art culfernt sich von den iibrigen Arten der Gattung so betrachtlich, dass man sje zu einer eigenen Untergattung erheben liönnte. Sie liomnt überall in klaren fliessenden Gewäissern zwischen Callitrichen, Wasserlinsen und Conferven vor und entwickelt sich oft massenhaft, wenn man diese Pllanzen laingere Zeit stehen làsst. Bej Tharand beobachtete ich sie ungemein haufig in eincm von ganz reinem Quellwasser gespeisten Forellentejche zwischen dichten Rasen von Callitrichen.

Der sclımale, lang gezogene elliptische Körper ist mehr als noch einmal so lang als breit, nach vorn zu ist er gewöhnlich etwas mulu verengert, als nach hinten zu, so dass er an Uebergang in den Vorderıand schrnaler ist, als am Uebergang in den Hinterand (Fig. 17. 19). Der rechte Seilenand ist sehr convex, der linlie geradlinig oder in der Mitle schwach naclı einwärts gebogen. Das lintere Körperende ist breit lanzettformig zugespitzt. das vordere Körperende bildet ein fast gleichschenkliges an der Spitze abgerundetes Drejeck. Der pechte Schenkel des Vorderrandes zeigt vor der Mitte einen bogenförnigen Einschnill, einc entsprechende schwächere Einschniirung findel sich gegenïber am linken Schenkel; hierlurch setzt sich eine fast halbhreisförmige breillappige Oberlippe ab. Die adoralen Wimpern beginnen an dem Einschnit des rechten Schenkels, sie verlaufen nahe unter dem Rande der Oberlippe nach links und ziehen sich dann an dem langen bandförmigen Aussenrand des Peristoms herab. Der Innenrand des Peristoms liegt elwas nach links von der Nittellinie, ist fast ganz gerade und reicht nicht weit nach vorn. - Die Stirn- und Bauchwimpern sind im Wesentlichen eben so gestaltet und gruppirt, wie bei den andern Arten; die drei vordersten, selır hräftigen Stirnwimpern sind jedoch weiter nach links in das Peristomfeltl hineingerückl und stehen an der Basis der Oberlippe (Fig. 18. 19), und die drei vordern Bauchwimpern (Fig. 17) sind merklich schwächer, als die beiden hintern, welche melir neben einander und dicht vor den Afterwimpern sitzen. Letztere sind sehr liraftige, gleich starke, weit nach vorn eingefügte Griflel. deren Spitzen höchstens bis zum Hinterrand reichen, aber nie über denselben hinausragen. Sie sind einander sehr genähert und an ihrer Basis knieförmig gebogen und zwar die beiden rechten nach rechts, die drei linken nach links, ihre Spitzen sind daher in sehr characteristischer Weise zusammengeneigt. Die kurz- und feinborstigen, dicht stehenden Randwimpern erstrecken sich bis zur Hinterleilsspirze, daher kein Raum für Schwanzwimpern übrig bleilı; es ist auch nicht die leiseste Andentung von solchen vorhanden, und diesen Character köınte man zur Begriindung einer eigenen Untcrgattung benutzen. - Die beiden Kerne (Fig. 17. n. n.) und der contractile Behälter (c.) verhalten sich wie bei den andern Arten. Das Parenchym ist gewöhnlich anl' beiden Seiten des Körpers reich an Fetllörnchen. an der Insertionsstelle der Afterwimpern schneiden dieselben aber scharf ab, so dass das dahinter gelegene Körperende, wie bei St. mrtilus, sehı lichı und durchsichtig ist. Dasselbe gilt auch von der Oberlippe und den benachbarten Theil des Peristomfeldes. - Die Thiere sind ausserst unstăt, schwimmen sehr schnell und stehen kaum auf einen Augenblick stille, weshalb ihr Sturlium viele Muhe verursacbt. Will man sie durch Entziehen von Wasser zum Stilliegen bringen, so zerstiickeln sie sich fast unmittellsar darauf, und die Bruchstucke zerstrenen sich im hefligen Wirbel uach allen Richtungen. Das Eigenthunılichste an den Bewegungen der unversehrten 'Thiere isl, (lass, nachdem sie eine Strecke mit gleichmässiger Geschwindigkeit vorwärls geschwommen sind, sie blitzschnell in einem weiten Bogen zuriichfahren. Gleich daranf gehen sie wieder vorwäls, schnellen aler nun gewöhnlich noch friber und heftiger rüchwirts. So wiederbolt sich 
das Vorwärtsgehen und Zurickfahren mehrmals und mit immer grósserer Geschwindigkeit schnell nach einander: dann erst schwimmen sie wieder eine längere Zeit sletig weiter. - Die grössten Individuen erreichen eine Lïnge von $\frac{1}{16}-\frac{1}{14}$.

Dic Quertheilung erfolgt nach denselben Geselzen, wie bei St. mytilus und pustulala; dies crgiebt sich ans dem in Fig. 19 dargestellten Stadium der Quertheilung. Der beträchllich verlängerte mütterliche Körper zeigt noch keine Einschnürung, er besizt noch die drei rordersten Stirnwimpren, die beilen hintern Bauchwimpern und die Afterwimpern; auf dem ursprïnglichen Stirnfeld hat sich ein neues System von Stirn-, Bauch- und Afterwimpern entwickelt, und ein eben solches System zeigt sich rechts neben dem neugebildeten Perislon ( $b^{\prime}$.) in der luintern Körperhälfte. Die beiden mütterlichen Kerne sind in einen homogenen, beiden Körperhălften gemeinsamen, kurzen und breiten, oblongen Nucleus (n.) verschmolzen, dem links zwei verğrösserte Nucleoli (nl. nl.) anliegen, die im Innern eine deutliche Längsfaserunģ erkennen liessen. In andern Fällen sah ich auf derselhen Theilungsstufe in jeder Körperhalfte zwei nahe hinter einander liegende Kerne; auch bildeten ler alte und neve adorale Wimperbogen zusammen öfters ein continuirliches, in der Mitte bogenförnig nach einwärts gekrïmmtes Lảngshand. Die Sonderung der beiden Körperhälften heginnt zuerst auf der rechten Seite, indem hinter der Nitte eine Einschnürung entstehı, die almählig in schiefer Richtung nach innen und rorn eindringt, wahtrend der linke Seitenrand noch immer ein Continum bildet. In Folge dieser Einschnürung krummt sich jede hörperbilfte mil ihrem freien Ende bogenförmigg nach links. - Einge Male beobachıte ich kurze, im Verhältniss zu ihrer Körperłänge ungewöhnlich breite Individuen (Fig. 18), die wahrscheinlich unlängst aus der Qucrheilung hervorgegangen waren. Sic enthielten einen einzigen, sehr lichten homogenen centralen Kern (n.), in dessen Umgebung 3-4. kleine structurlose, ovale, fettkornartige Körperchen (m. n.) zerstreut lagen. Diese Individuen zeichneten sich auch durch eine reichlichere Enlwiclielung von Fettkörnchen im Parenchym aus; sie entsprechen offenbar den bei Styl. mylilus und St. pustulala beobachtelen Individuen (Taf. IX. Fig. 11-13), deren wahre Natur sich noch nicht ergriinden liess.

Lảngstheilung kommt häufig vor, ich suh sie jedoch niemals nach dem bei St. mytilus und pustulata gewöhnlichen Typus erfolgen. Auf den fruhesten Stadien der Lïingstheilung (Fig. 20) war der mütlerliche Körper bereits immer von hinten her bis nahe zur Mitte in eine rechte und linke Hälfte gesondert, die nach hinten weit kiaffend aus einander slanden, so dass der gesammte Körper ein fast gleicluseitiges Dreieck bildete, dessen Spilze die abgerundele Oberlippe krönt, während die Basis tief dreieckig ausgeschnitten ist. Das mutterliche Peristom (p.) war mil dem contraclilen Behïler (c.) in die linke Körperlälfte gerielit, und von den 8 Stirnwimpern hatlen sich dlie 5 hintern anch etwas nach links verschoben. Das hiotere Ende jeder Körperhälfte war mil gleichmässig entwickelıen Afterwimpern versehen, vor denselben unterschied ich immer nu die beiden hintersten Bauchwimpern, die drei vordern schienen zu fehlen. Der innere Rand jeder Körperhälfte zeighte auf ggleicher Höhe mit der Insertionslinie der Afterwimpern eine seichte Einschnürung, nur der hinter derselben gelegene Theil des Randes besass Randwimpern. Etwas spitter wirl hinter der llille jeder Körperhaifle längs des linken Seitemandes ein nenes Peristom angelegl, von dem zuerst ein längerer oder li(irzerer Abschnitt des adoralen Wimperbogens ( $p^{\prime}$. und $p^{\prime \prime}$.) zu unterseheiden ist. In der rechten Körperhálfte trilt derselbe immer etwas früher auf, als in der linken. - Bei einem weiter vorgeruckien Stadium der Längstheilung (Fig. 21) fand ich die beiden neuen Peristome ( $p^{\prime}$. und p".) fast vollständig ausgebildet, und auf den zu ihnen gehörigen Stirnfeldern hatle sich ein neues System von erst borstenförmignen Stirn-, Bauch- und Afterwimpern entwickelt. Der mülerliche contractile Behalter war verschwunden, und dafür war links neben jedem neuen Peristom ein neuer contractiler Behälter ( $c^{\prime}$. und c".) entstanden. Dic drei Peristome, mit denen jetzt das in der Theilung begriffene hudividuum versehen war, hatten nahezu gleiche Grosse. - In einem noch spätern Stadium der Längstheilung (Fig. 22) hatten sich die beiden neuen Peristome (p'. und p", helı:ichtlich vergrössert, sie waren sammt den zu ihnen gehörigen slärker geworlenen locomotiven Wimpern und conlractilen Behältern weiter nach rorn gerijckt und hallen das mullerliche Peristom nebst den fünf alten hintern Stirnwimpern ganzlich verdrängl. Ohne Zweifel wird der vordere, beiden Theilungssprösslingen norh gemeinsame Lappen mit

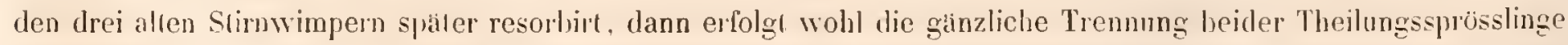
und erst nach derselben endlich die Resorption des mil den alten After- und Bauchwimpem versehenen lintern Körperendes. - Wie sich dic mülterlichen Kerne in Verlanf der Länğstheilung verhalten. habe ich leider nicht erforschen können. Im ersten Stadium der Länģsheilung unterschied ich mehrmals in der Milte jeler Körperhälfie einen blassen homogenen runden Körper (Fig. 20.m.m.). In den spatem Stadien fielen mir ofters ebenfalls in dem mitılern Theil jeder Körperhälfte mehrere regellos verheilte blasse Kugeln Fig. 22.2. m. m., mil einem centralen Kern auf. 
Ich war nicht im slande, sie zu isoliren, mo wage daher nicht zu entscheiden, ob sie Producte der mülterlichen Kerne und nicht vielmehr von aussen aulgenommene fremde Körper waren. In jedem Fafl verdienen die eben peschilderten Theilungszustände, die möglicher Weise ein Conjugationsproduct zweier Individuen sein können, fernerhiu die grijsste Aulmerksamheit; sie düften vielleicht zur geschlechtlichen Fortpflanzung in Bezichung stehen.

O. F. Muller hat von dicser Art bereits eine recht befriedigende Darstellung geliefert und auch ibre so characteristischen Bewequngen rortrellich lueschrieben. Er fasste die Totalform des Körpers ganz richtig auf, unterselied aucl die funf stirkern Stirnwimpern, die hinterste Banchwimper und die fünf Afterwimpern. Die relative Stcllung der letztern hat Müller ganz naturgetreu angegeben, die Rantwinpern aber entgingen ihm, und vom l'eristom sah er nur die vordern adoralen Wimpern. - Ehenberg's Abhildungen sind im Umriss weit weniger characteristisch und anch sonst in den wesentlichsten l'uncten unrichtig; er verwechselte Rücken- und Banchseite, verkannte das Peristom gänzlich und unterschied gar keine Banchwimpern, sondern nur $6-8$ ganz willkiuhrlich gestellte Stirnwimpern und 3-4 Afterwimperı. Dagegen elkannte Ehrenberg zuerst den wichtigen Character, dass sich die Randwimpern bis zur Ilinterleibsspitze erstrecken und dass Schwanzwimpern gänzlich fehlen. Seine Darstellungen der Quer- und Längstheilıng enthalten auch nicht ein einziges richtiges Mloment. - Wer blos nach Ehrenberg's Abbildungen urtheilt, der kann leicht zu dem Glauben verleitet werten, dass Styl. Jistrio gar nicht eine ron Styl. pustulata rerschiedene Art sei. Es haben in ler That auch zuerst Dujardin (Infusoires p. 42 k) und in nenester Zeit sogar der sonst so sorgfaltig prifende Clapaiède (Éludes p. 166) diese Ansicht aufgestellt, sie beweist jedoch nur, dass diese Forscher die Styl. histrio entweder nicht selbst oder doch nur sehr flichtig untersucht haben können.

\section{Gattung, Pleurotricha. STE⿺}

(Taf. X. Fie. $1-i$ ).

Charactex: Kïrper formbesländig, elliptisch-lansettlich, mit s griffelformigen stimuimpern, :5 in zwei medianen Längsreihen stehenden, griffelformigen Baucheimpern und 5 in suei Bündel aus einander geriüchten griffelförmigen A/terwimpern. Ausserdem sind noch =wei oder mehreve Längsreihen ron borsten/örmigen Bauchwimpern worhanden.

Die Gattung wurde von mir in der Prager Lolos Januar 1859 S. 4. mit zwei Arlen begriintel, von denen die eine neu, die andere mit Ehrenberg's Stylonychia lanceolata identisch ist. Hierzu bringe ich noch als dritte Art die stylonychia echinata von Clapurede und Lachmanu. Die Gatlung Pleurotricha ist der Gathung Stylonychia sehr nahe verwandt, sie hat mit iłr die grilfelförmigen Stirn-, Bauch- und Afterwimpern gemein, unterscheidet sich aher von ihr sehr bestimmt dureh die zwischen den Randwimpern und den medianen griffelfürmigen Wimpern wenigstens auf einer Seite noch vorhandenen barstenförmigen Bauchwimpern. Dies Merkmal halte ich schon allein zur Aufstellung einer neuen Gattung für ausreichend, es kommen aber auch noch einige andere Eigenthümlichkeiten hinzu, welche dieselbe vollends rechtfertig(') werden.

Der Korper ist langgezogen elliptisch, melı als noch einmal so lang als breit, nach linten lanzetıörmig zugespitzt und nach vorn stumpf eifömig verengert. Das farblose Parenchym ist an seiner äussern Granze weniger starr und nicht so resistent, als bei stylonychia, ler liörper zerfliesst daher im flach ausgeloreitelen Wassertropfen schneller und leichter; wahrend des Schwimmens behialt er jedoch hestandigr scine Form bei. er kanu sich weder merkich seitwiits biegen, noch sich verkurzen oder verlangern, ich bezeichne ilın daher als formbestandig. Das Peristom reicht uichl bis zur Mitle des Körpers, sein Vorderrand hildet eine halbmondförmige. anf den Vorderrand les Körpers symmetrisch aufgesetzle Oherlippe, der breite bandförmige Aussenrand des Peristoms erscheint hảufig halbrinnenförmig ausgehöhlt (Fig. 2. 4), der Innenrand fält mit der Mittellinie des Köpers zusammen, er erstreckl sich elwas uber die vordern Seitenecken hinıus nach vorn und ist hier stark hakenförnig nach links gekriummt und mit einer schmalen, lebhaft auf- und niederwogenden undulirenden Mlembran (Fig. 1. 3. 4. i.) versehen, deren verschiedene Stellungen und Faltungen am besten aus den Abbildungen zu ersehen sind. Im Peristomfelde hemerkt mau stets eine ansehuliche schiefe Lingsspalte (o.); sie ist dem Inmenrand des Peristums genihert und reichl fast bis zu der hakenförmigen Spitze desselben hinauf, während sie nach biuten gegen den Innenrand convergirl und sich in der Nähe des Peristomwinkels unter der undulirenden Membran verliert. Diese Langsspalte. welche bisweilen auf der linken Seite noch ron einem Zilten Ilautsaum cingefasst schien (Fig. 2. o.), ist ohne Zweifel die Muntöfnung. Ėn Schhunt fehlt; die grossen Körper, welehe die Thiere nicht selten verschluckt haben (man vergleiche z. B. đen grossen. zwei Kerne und cinen hollen Hohlraum enthaltenden kugligen Körper in der rechten Körperbälfte 
von Fıg. 1), würden durch eine etwa nu iu Peristomwinhel gelegeue Mundöfnung und einen sich daran anschlicssenden Schlund gar nicht haben eindringen kömen. Yon der rechten Ecke der Oberlippe verlauft cine mehr oder weniger scharf ausgeprägte. schrage, bogenfümige Falte zum Peristomwinkel, wodurch sich ein eigentliches, auch nach aussen und hinten scharf begràutes Stirnfeld (Figg. I. st.) absetzl, welches in der rechten Körperlualfte eine ganz analoge For'm und Lage hat, wic das Peristomfell in der linken. Das stirnfeld ist nach vorn und innen starli niederg̣edritckt und geht um die hakenförmige Spitze des lunenrandes herum ohne Gränze in das noch mehr verliefte Peristomfeld iiher.

Auf den Stirnfelde stehen fünf starke und drei schwächere grillelförmige Stirnwimpern. Die drei vorderster Stirnwimpern sind die langsten und sthrksten, sie stelıen in einer schriggen Reilıe längs der rechten Seite des Vorderrandes; die vierte griffelfürmige Stimwinuer silzt vor ller Milte des lnnenrandes, die fünfte hinter der Mitte am Aussenrande des Stinfeldes; vor derselben stehen ehenfalls dem Aussenrande des Stirnfeldes eingefügt die drei schwächern, mehr borstenfömigen Stirnwimpern. Hinter dem Peristom folgen zu beiden Seiten der Mittellinie des Bauches in zwei Reihen geordnet füf weit aus einander stelende griffelförmige Bauchwimpern (Fig. 1.4. bhi), von denen die beiden hintersten die entwickeltsten sind. Die füıf griffelförmigen, gleich starken Afterwimpern haben das Eigenthimliche, dass sie in zwei, betrachlich aus einander gerijelite Gruppen getrenni sind. Die heiden rechlen Afterwimpern (Fig. I. 3. 4. a.) sind in der rechten Körperbälfte sehr nahe vor der Hinterleibsspitze eingefügt und zwar dic zweite noch weiter nach hinten, als die erste; sie ragen daher sehp weit iilser den Hinterand hinaus. Die drei linken Afterwimpern (a'.) bilken eine kanmförmige, nach links und hinten gerichtete Gruppe, welche weit nach vorn in dem Zwischenraum zwischen ter letzten und vorletzten Bauchwinper eingefugt ist; sie werden häufig einzelu (Fig. 2) oder zusammen (Fig. 4. a'.) hakenförmig nach vorn und rechts umgeschlagen und können dann leicht für Bauchwimpern gehalten werden. Die langborstigen Randwimpern (Fig. 1. 4.r. r.) erstrecken sich bis zur Hinterleibsspitze und gehen hier, wie bei Stylonychia histrio, olne Zwischenraum in einander über; Schwanzwimpern fehlen gäzlich. Die linlie Randwimperreilıe wendel sich vorn nur wenig nach einwärts. Zivischen den Randwimpern und den griffelfölmigen Bauchwimpern finilen sich entweder nur auf der rechten Seite oder auf beiden Seiten 1-3 den Randwimperreilıen parallele Längsreilıen von horstenförmigen Banchwimpern (Fig. 1.s.s. Fig. 4. s.), die kürzer und feiner sind, als die Randwimpern.

Die beiden ovalen Kerne (Fig. 1. 2. n. n) zeigen dieselbe relative Lage, wie bei Stylonychia, sie besitzen ebenfalls cine selır deulliche quere spaltförmige Höhle, auch liegt ihnen links ein kleiner ovaler Nucleolus (Fig. I.nl.) an. - Der contractile Behälter (Fig. 1. 2. c.) liegt dem linken Seitenrande genähert auf gleicher IIöhe mit den Peristomwinkel. - Der After und dic Vermehrung durch Theilung wurden noch uicht beobachtet; dagegen wurden hei einer Art Embryonallugehn nachgewiesen. - Die Thiere bewegren sich sehr sehnell und anhaltend, aber uichı mit gleichmissiger Geschwindigkeit und nicht lange in derselben Richtung, sondern sie fahren bestandig fast springend und solunell abwechselnd bald nach linhs, bald mach rechts.

Die Arten Ieben ausschliesslich in siissen Gewissern.

1. Pleurotricha grandis. Stèr. (Taf. X. Fig. 1).

Stein Characteristik neuer Iufusoriengatt. Lotos Januar 1839 . S. 4 . abgekiivat ist.

Körper breit eiförmig-lanzettlich, jederseits mit drei seillichen licihen borstenförmiger Bauchwimpern versehen, von denen die innerste

lch habe diese ungemein grosse und sehr ausgezeichnete Art bisher nur bei Tharand beobachtel, wo ich sie im Septenber $18: 4$ in dem Forellenteiche des Hintergehrsdorfer Forstpllanzgartens zwischen Callitrichen entdechte. In ilırer Gesellschaft liam auch die folgende Art, so wie Stylongchia mỵtilus und histrio häufigr vor; sie vermehrte sich in cincm Gefässe nach 8 Tagen, als dle mit eingesetzten Callitrichen zu faulen anfingen, massenhaft, und es erschienen nun erst die grössteu lndivjduen, die nicht setten eine Lỉnge von $\frac{1}{7}^{\prime \prime \prime}$, ja zuweilen sogar von $\frac{1}{5}{ }^{\prime \prime \prime}$ erreichten. Die kleinsten Individuen waren $\frac{1}{11 " \prime \prime}$ lang. - Der Körper ist im Terhiltniss zu seiner Länge viel breiter, als bei der folgenden Art, die grösste Breite liegt hinter der Hitte; der rechte Seitenrand ist convexer, als der liuke, welcher mach vorn zu fast gerade ist mud mit dem Vorderande cine stumpfe Ecke bildet; die beiden Seiten sind abgerundet. Die ö grilfelförmigen Bauchwimperı haben dieselbe Stellung, wie bei Stylongchia mytilus; zuweilen kanen auch hier 7 Baluchwimpern vor. Die seillichen Banchwimpern bilden jederseits zwei vollstandige, von Ausseurand des Stirnfeldes und vom Aussenrand des Peristoms bis in die Nïhe des hintem Kürperendes sich herabzichende Lings- 
reihen s. s.); die vorlersten Wimpern der bejden rechten Reihen sind etwas stäker, als die ubrigen, und gleichen mehr den drei benachbarten schwächern Stirnwimpern. Ausserdem ist jederscils noch eine dritle, innere, nach hinten ahgehiirzte Lïngsreihe von etwas geschlängelten borstenförmigen Bauchwimpern vorhanden, die viel weitläufiger stehen; die rechte Reihe besteht nur aus $6-7$, dic linke aus 3-4 Wimpern. Die drei seitlichen Bauchwimperreihen jeder Seite sim] von eiuander und von der zugehörigen Randwimperreilıe, wie auch von den medianen griffelförmigen Bauchwimpern durch fast gleich weite Zwischenräume getrenot. Durch die grosse Anzahl von Banchwimpern wird unsere Art der Urostyla grandis sehr ăhnlich, sic unterscheidet sich jedoch von letzlerem Thijere sofort durch die sehr dicken medianen Bauch- und Afterwimpern und durch den starren Körper.

2. Pleurotricha lanceolata. Stein. (Taf. X. Fig. 2-4).

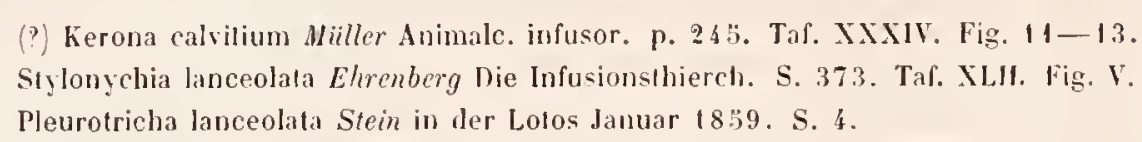

körper langgestreelt lanzettlich, nur auf der rechten Seite mit einer vollständigen und ciner abgekiirsten Längsreihe von borstenförmigen Bauehwimpern versehen.

Ich lernte diese Art zuerst bei Tharand gleichzeitig und in derselben Localität mit der vorigen Art kennen. Im September 1835 beobachtete iclı sie albermals bei Tharand in einem mil grossblitterigen Wasserlinsen überzogenen Fischteiche. Daun traf jch sie erst wieder in September 1857 in dem Puftbach bei Niemegk, wo sie zwischen grossen an der Oberfliche des Wassers schwimmenden Bauschen von Spirogyren und Oscillarien in zahllosen Exenplaren vorliam. Im October desselhen Jihres fand ich sie auch in einem Graben des Baumgartens bei Prag, jedoch nur rereinzelt. - Der Körper ist iber $2 \frac{1}{2}$ mal so lang als breit, gewöhulich schmal umgekehrt eiförmig-lanzettlich, vor der Mitte nămlich am breitesten, vorn zugerundet und nach hiuten lang lanzettförmig zugespitzt (Fig. 3). Das vordere Ende ist häulig etwas nach links ibergebogen (Fig. 2) und der rechte Seitenrand dann schr convex, der linke gerade oder schwach einwarts gekrimmt. Auch fast rein lanzettförmige, hinter ler Nitte etwas erweiterte Formen (Fig. 4) hommen lıaufig vor. - Die Bauchseite ist sehr flach, die Seitenränder sind daher zugeschärft. Das Parenchym enthält nu sehr sparsame feine Körnchen und ist ungewöhnlich blass und hläulichgrau. - Von den 5 griflelförmigen Bauchwimpern (Fig. 4. bl'.) stehen die erste, dritte und vierte in der linken, die zweite und funfte iu der rechten Reihe neben der Nittellinie; die fiufte Bauchwimper ist zuweilen sehr weit nach hinten bis nahe vor die rechte hintere Afterwimper geriickt. In der rechten Körjerhälfte finden sich zwei Reihen borstenförniger Bauchwimpern, eine ăussere vollständige (s.) und eine innere abgckiirzte ( $s^{\prime}$.), welche grewöhnlich nur aus vier Wimpern (Fig. 2. 4) hesteht; lisweilen zăhlte ich sechs (Fig. 3). Die linlie löörperlảlfe hesilzt keine Spur von borstenförmigen Bauchwimperu, wie ich mich sehr bestimmt an vielen, hierauf genau gepriften Exemplaren überzeugt habe. _ Unter den vielen Individuen, welche ich beobachtele, traf ich kein einziges in der Theilung; dagegen kamen mir unter den $\mathrm{im}$ September 18.34 bei Tharand aufgefundenen Individnen hin und wieder Mutterthiere mit mehreren grossen Embryonalkugeln (Fig. 3. k.) vor, die sich in jeder Beziehung wie die von Stylonychia mytilus verhielten. Eine Geburtsöffnung finde ich in den damals aufgenommenen Zeichnungen nicht angegeben, sie wirl aber wohl nicht fehlen, sondern nur von mir unbeachtet geblieben sein. - Die länge des Köpers schwankt zwischen $\frac{1}{12}-\frac{1}{7}^{\prime \prime \prime}$.

O. F. Müller's Kerona calvitium diurfe wohl viel eher zu der gegenwärtigen Art, als zur Stylongchia mytihs gehören; ich schliesse dies theils aus dem Unriss des Körpers und aus den langen Randwimpern, besonders aber aus den beiden ganz hinten eingefügten und weit iber den Körperrand hinausragenden Grilleln, die sich gerade so verhadten, wie die beiden hintersten Afterwimpern von Pleurotr. lanceolata. Müller unterschied ausserdem noch die drei vordersten Stirnwimpern und hinter denselben 3- 3 bewegliche Puncte, welches oflenbar die ubrigen Stirnwimpern waren, die Bauchwimpern blieben ihm unbekannt. - Dass Ehrenberg's bei Berlin zwischen Conferven und Oscillarien aufgefundene Stylonychia lanceolata mit der gegenwartigen Art identisch ist, scheint mir nicht im mindesten zweifelhaft; denn sie besizt genan dieselhe form und Grösse. Ferner beobachtete Elrenberg an ilır fünf starke griffelförmige Stirnwimpern; die drei schwächern lionnten leichl ïhersehen werden. Sorlann giebt er zwar nur vier, aber in einer sehr schrijgen, fast verticalen Reihe stehende Afterwimperu an; geratle so erscheinen die Afterwimpern meiner Pleur. lanceolata, wenn die erste und zweite hinterste Afterwimper, was häufig vorkommt. über cinander liegen und sich decken. Endlich zeigen die Randwimpern am hintern Körperende bei Elmenberg’s 
und meinem Thiere dasselbe Verhalten. In gewalligem Widerspluch mit meiner Annahme steht nur die Angahe von Ehrenberg, dass der Körper seiner Styl. lanceolata mit Lingsteihen von Wimpern besetzt sein soll nnd zwar mit 16- 18 auf der Halbansicht. Diese Angabe ist jedoch schon an und für sich höchst unwahrscheinlich, da wir sonst kein mit griffelförmigen Wimpern ausgeristetes Infusionsthier kennen, welches ausserdem noch anf der ganzen Oberlache wimperte; sie verliert auch dadnrch an Bedeulung, weil sie nur auf einer ältern Beobachtung aus dem Jahre I 832 beruht; als ganz unzuverlässig und irrig muss sie uns aber erscheinen, wenn wir erwagen, dass Ehrenber? auch der Kerona pustulata einen auf der ganzen Oberflache bewimperten Körper zuschreilıt, wälırend doch dieses Thier, wie wir gleich sehen werden, eine ganz nackte Rïckseite mol eine mil nur wenigen schrigen Wimperreihen besetzte Bauchseite besitzt. Ehrenberg sah offenbar die Randwimperreihen und dic ihnen parallelen Bauchwimperreihen von Pleurot. lanceolata und wurde dadurch zo der irrigen Vorstellung verleitet, dass der ganze Kör'jer mit ringsherum gleichmảssig vertheilten Längsreihen von Wimpern hesetzı sei.

Die Stylonychia echinata von Claporede und Lachmom (Éludes p. 16\%. Pl. VI. Fig. 5), welche an verschiedenen Puncten in der Umgebung von Berlin hïufig heobachtet wnrde, ist eine der Pleur. lanceolata nahe verwandte Art, welche nach meiner systematischen Eintheilung den Namen Pleurotricha echinala zu führen haben würle. Sie besitzt jederseits nur eine einzige vollständige Reihe von borstenförmigen Banchwinpern (cirrhes marginaux); die ganz an den Rand geruckten Randwimpern (soies) sind horizontal abstehend, und der contractile Belıălter liegt weit hinter dem Peristom in der Mille am linken Seitenrande.

\section{Gattung. Kerona. Eiriza.}

(Taf. X. Fig. : $;-8$ ).

Character: Körper formbestündig, nierenformig. nach hinten zugesptsl, ohne eigentliche Stirn- und Afterwimpern, mit 6 schrigen bogenformigen Reihen kursborstiger Bauchuimpern, welche sich theils äber die vordere, theils über die hintere kirperhailfte ausbreiten.

Die Gatlung Kerona von Ehrenberg, welche nichts mit O.F. Müller's Gattung Kerona gemein hat (vergl. S. 146), mmfasste in Ehrenberg's ältcrn Arbeiten die spätere Stylonychia pustulata, die Ehrenberg deshalb fur den Reprisentanten einer cigenen Galtung ansah, weil ihm bei diesem Thiere die Afterwimpern (Griffel) entgrangen waren. Als diese später erhannt wurden, und die bisherige Kerona pustulata nun in die Gattung Stylonychia wandern musste, übertrug Ehrenberg den Namen Kerona auf cine von ihm erst in Jahre 1833 aufgefundene, generisch neue Oxytrichinenform, welche auf Armpolypen lebt und bercits im rorigen Jahrhundert mehrach beobachtet worden war. Sic wurle zuerst in den Abhandl. der Berliner Acad. von 183:3 S. I64 und 166 als Kerona polyporum erwähnt, eine Characteristik der Gattnng und die Besclıreibnng und Abbildung der einzigen Art aber erst 1838 jm grossen Infusorienwerk geliefert. Dic Gathung lierona in dem neucrn Sinn ist cine vortreflliche, sehr ausgezeichncte Gattung, deren Organisation jedoch Ehrenberg in sehr weseutlictren Puncten ganzlich verkannt hat. Der von ihm aufgestellte Character, diss sich Kérona von den übrigen Oxytrichinen durch Besitz von Wimpern und Krallen und durch den Mangel an Griffeln unterscheiden solle, ist viel zu unbestimmt und selbst unrichtig, und er drisckt auch nicht cntfernt tas Wesen dieser Galtung aus. Ich hahe zuerst in der Lotos Januar 1859 S. 5 einen völlig veranderten, scharfen und zuverlässigen Gattungscharacter aufgestell, wie el sich mil nach einem sorgfäliģen Studium der Ker. polyporum ergeben hat. Ausser mir scheint kein nenerer Forscher dieses Thier naher untersucht zu haben.

Der Körper ist schon durch- die reine Nierenform, die sonst bei den Oxytrichinen nicht vorlsommt, sehr ausgezeichnet; das vordere Ende isı halbkreisförmigg abgerundet, in der Mille liaum nerklich zugespitzt (Fig. 6), dlas hintere Ende läuft in ein breit ciförmig zugrespitztes Schwänzchen aus. Der rechte Seitenrand ist sehr convex unıl durch eine scichte Einschürung von dem halbkreisförmigen Vorterrand gesondert; der linke Scitemrand zieht sich in der llille des Körpers lief busenförmig nach einwärts, nach vorn zu geht er olıne Absalz in den Vorderrand ïber. Der Rucken (Fig. B. 8) ist missig gewölbt, besonders in der hintern Itälfte, die Bauchspite (Fig. 6. 7) ganz flach und eben. Die Seitemänder sind zugeschäft und lamellenarlig veldunt. sie schmiegen sich beim Kriechen der Unterlige innigy an, wogen sanft wellenfürmig auf und ab und rollen sich auch hăufig etwas nach oben um. Das vordere Körpperende kann ebenfalls aufwärts gebogen und bald mehr gewöllst, balıl mehr verllacht werilen. In Ucbrigen behälı der Körper bei allen seinen Bewegungen fasl ganz noverandert seine Nicrenform bei; sein 
Parenchym stimmt nahe mit dem der Stylonychien überein, doch ist es ctwas weniger stam und sehon in einem geringen Grade dehnbas. -- Das Peristom erstreckt sich his zur Mitte des Körpers hinab; sein hinterer verticfer Theil oder das eigentliche Peristomfeld ist ungemein schmal und im Umriss einem mit der Spitze nach cinwärts gelíimmleu Füllhorn ähnlich. Der Innenrand des Peristoms, der nur bis zur halben Höhe der vordern liörperhălfte hinaufreicht, ist nimlich weit nach linlis gegen den breiten bandförmigen Ausseurand des Peristoms geriickt uma demselben conform gelirimmt; er besizt vielleicht keine eigentliche undulirende Membran. sondern nur feinborslige, von vorn nach lunten an Linge abnchmente príorale Wimpem. Die adoralen Wimpern setzen sich rings um den ganzen Vorderrand bis zur rechten Seilenecke fort, wo sie sich fast ummiltelbar an die Randwimpern anschliessen. Die vordern adoralen Wimpern sind ungewöhnlich lang und die lingsten und stijlisten Wimpern des ganzen Körpers; sie stehen sehr nalıe am Rande eingefiigt und werden nur in der Nitte von einem kaum merklichen Itautsaum üherragt. - Die dichtstehenden, ziculich langborstigen Randwimpern sitzen in einer malıe an Rande herabziehenden, auf der rechten Seile an schărsten ausgepragten Furche; der freie Rantsaum ist sehı diunnhäutig, durchsichlig und biegsam. Beile Randwimperreihen stossen in der Schwanzspilze zusammen, die linke wendel sich gegen das Peristom hin ziemlich stak nach einwäts, - Die Bauchwimperu sondern sich nicht in verschicdene Kategorien, sonderı sind simmtich fast ganz gleicharlige, kurz häkchenformige Borsten, dic vieł kïızer sind, als die Randwimpern. Sie selzen, dicht gedrungt neben einander stehend, sechs schiefe bogenförmige Reihen zusammen, die insgesammt von der Einschntrung zwischen dem Vorderrande und dem rechten Scitenrande ausgehen und theils uber die vordere, lheils ibser die hintere Körperhälfte nach der linken seite hiniber laufen. Die vorderste Reibe, welche aus den kiirzesten Hälichen besteht und daher leicht übersehen werden hann, begleitet die aloralen Wimpern, von welchen sie nur durch einen sehr schmalen Zwischenraum getrennt ist, bis nabe zum Aussenrand des Peristoms. Die zweite und dritte Reihe bilden gewöhnlich (Fig. T) nach vorn und links gekrimmle Bogen, von denen der erste vorn am Innenrande des Peristoms, der zweite etwas ror dem Perislonwinkel endet. Dic vierte, funfte und sechste Reihe bilden nach hinten und rechts gekrummte bogen, sie laufen Anfangs in der rechten Körperhảffe und dem rechten Seitenrand conform gekrinmt nach abwirts und hicgen dann in die linke Körperhilfte hinein um, wo sie in geringer Entfernung ron der Randwimperteihe enden; ihre Wimpern nelımen von vorn nach hinten an Lïnge zu. Die fünf letzlen Wimpern der hintersten Reibe sind in kurze, platlgedrickte Griffel (Fig. 6. 7. a.) umgewandelt, welche den Afterwimpern anderer Oxytrichincn analog sind. Die Eudpuncte der funf hintern Bauchwimperreihen sint durch fast gleich grosse Zwischentiume von cinander getrennt, und eben so gross ist der Zwischenraum, welcher die sriffelförmigen Wimperu der liutersten Reihe von der Schwanzspitze trennt. Vor dem Innemrande des Peristoms bemerkte ich häufig noch cinige vereinzelte lläkchen (Fig. 7), welche sich wohs nur von der zweiten Bauchwimperreihe abgesondert latten. Das Spiel der Banchwimpern gewahut eincu schu lieblichen Anhlick, sie schwingen unauftörtich, theils einzehn fur sich, heils gruppenweis, theils regeimassig alternirend, bald langsam, balı schnell auf und nieder, wobei sie sich sehr stark krallenarlig kriumen, was lebhaft an die Fingerbewegungen beim Klavierspielen erinnert.

Die beiden Kerne (Fig. מ̆-7. n. n.) haben die gewöhnliche Lage in der vordern und hintern Körperhüllte, sie sind kurzoval bis fast rund und besitzen in der Regel (Fig. 5. 7) eine quere spalıformige Höhle; auf der linken Seite liegt ilnen stets ball in der Vlilte, balıl mehr nach vorm ein lunder Nucleulus (Fig. ̈̈. 6. nl.) an. - - Der contractile Behälter (c.) liegt dicht hinter tem Peristom an dem busenförmigen Einschuitt der linken Seite; er Iritt Lei ter Diastole gewölbartig über die Rückseite hervor. Dic Afterstelle bezeichnet in Fig. 5 der Excrementballen z.; den Austritt von Excrementen sah ich nur cinmal dicht hiuter den fünf griffelförmigren laucluwimpern (bei z. in Fig. 6). Ilinter den Periston finden sich am linken Seitenrande herab meist rcichliche Mblagerungen von groben Feltlörnern (Fig. 6). - Quertheilung beobachete ich melımals, aber nur den ersten Anfang zu dersellsen (Fig. 8); leider brachte ich dic Thiere nicht dahin, mir ihre Bauchseite zuzuwenden, wo sicherlich sehr interessante Netamorphosen stattinden werden. Bei der Rïckenansicht unterschied ich nur die Anlage zu dem neuen Peristom ( ${ }^{\prime}$.)

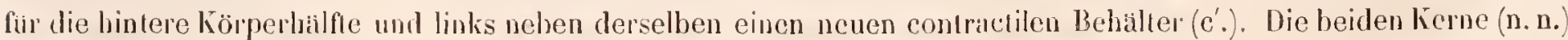
des Multerthieres zeigten sich nur wonigr verlägert und granz homogen; lagegen hatte sıch jeder Nucleolus auffulleml vergrössert und in einen oralspindelformigen Körper rerwantelt, der aus dicht neben einander liegenden Staibchen bestand.

Die einzige Arl der Gattung lebt in sissen Gewassern aul Armpolypen, es isi 
Kerona polyporum. EurbG. (Tir., X. Fig. $\ddot{3}-8$ ).

Cyclidium pediculus Müller Animatcul. infus. p 8\%. Taf. XI. Fig. $15-17$.

Kerona Polyporum Elwenberg Die Infusionslhierch. S. 368. Taf. XLI. Fig. VII

Alastor Polyporum Perly Kleinste Lehensfomen S. $1: 53$.

Diese lichliche Infusorienform wurde schon vou den Mikrographen des vorigen Jahrhunderts, weiche mit so grosser Vorliebe ihre Forschungen den Armpolypen zuwendelen, vielfach beobachtet; man warf sie jedoch meist unter dem Namen Polypenlaus mit einer andern, auf len Arupolypen noch viel labufiger vorkommenden Infusorienform, der Trichodina pediculus Ehbg.. zusammen. Roesel unterschied aber bereits beide Thiere sorgfaltigr; cr stellte in seinen Insectenbelustigungen Banl II. Taf. LXXXıl. Fig. 4. e. e. e. e. die Kier. polyporum und Taf. LXXXVI. bei In. ı. o. p. die Trichod. pediculus kenntlich dar. Müller galb unserer Ait zuerst einen systematischen Namen, Cyclidium pediculus, sein Speciesname häte daher wohl beibehalten werden sollen; Ehrenberg änderte ilun jedoch, weil er in Mïller's allerdings elwas zweideutigen und sehr unvollkommenen Abbildungen die Trichodina pediculus erkenmen wollte. Dass Müller aber unter seinem Cyelid pediculus lie gegentuältige Art meinte, geht sowohl aus seiner Beschreilung, wie aus dem Cilate von Roesel's Abbildungen hervor; die Trichodina pediculus hat Müller als Vorticella stellina und discina beschriehen, er kannte sie freilich nicht als Bewohner der Armpolypen. Ėhenbery verdanken wur die ersten genauern Kenntnisse der Kerona polyporum, aus seinen Untersuchungen ging zuerst klar hervor, dass sie eine Oxytrichinenform sei, er fasste die änssere Form richtigor auf, unterschied die beiden Kerne, den contractilen Behälter, den adoralen Wimperbogen und dic Randwimpern, anch erkannte er schon ziemlich kia den hintern Theil des Peristoms, dessen hnenrand er lïr eine Mumbspalte hielt. In Uebrigen aber war Ehrenbery's Auffassung durchaus irrig. er verwechselte die Rückenseite unit der Banchseite und nahm an, dass der ganze Körper ïberalt bewimpert sei, auf dem Riichen sollten die Wimpern in undeullichen Längsteihen stehen, umbl dıe Bauchfläche sollte vorn 3-4, hinten 5-6 starke griffelförmige Wimpern (Krallen) tragen.

Die Keronen wurden von den ältern Forschern und von Ehrenberg auf Hyulra fusca L. (oligactis Pall.), grisea

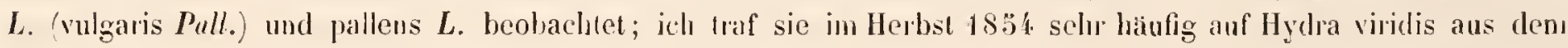
Forellenteiche des Hintergehrselorfer Forspflanzgartens und ich erforschte schon daurals ihre Organisation so weit, als ich sie gegenwaitig kenme. Bei Prag hatte ich alljăhrlich Gelegenheit, mich von der Richtigheil meiner frühern Untersuchungen zu uberzeugen; ich fand die Keronen hier inmer nur auf Hydra fusca umd gunz besonders liäufg anf H. grrisea. Nicht selten kamen mir auch vereinzelte freie Keronen zwischen Wasserlinsen und an der staubigen Oberfliche des Wassers in solchen Localititen vor, welche reich an Armpolypen waren, so namentlich in den liassins des Prager Bolauischen Gartens. - Auf einem Armpolypen finten sich gewöhnlich melırere Keronen, oft s-10, wozu sich häufig noch eine grössere Anzahł von Trichodinen gesellt. Die Keronen schmiegen sich mit ihres Banchseite imnig an die Oberflàche des Polypen an und sitzen theils ganz still, theils laufen sie gewandt dahingleitend an dem Körper und den Fangarmen des Polypen auf und nieder, olne dass eine lebhaftere Action der adoralen und Randwimpern zu benerken wire. Oft verlassen sie freiwillig ihren Wirlı, sie umkreisen dann denselben mit grosser Schnelligkeit in weiten Bogen und zierlichen Schwenkungen und sehen zu, dass sie Nahrungsstofle erbeuten. Zn dem Ende bleiben sie nach einiger Zeit irgendwo stillstehen, wirbehn mit ilıen adoralen Wimpern fremde Körper lierbei und fahren nur daun und wann, ähnlich wie Stylonychia mytilus und pustulata, stossweise hin und hel: Zuletzt machen sie sich plötzlich wieder auf und kehren, abermals weite Kroise beschreibend, zu ihrem Wirthe zurück, der ihnen hauptsächlich nur Wohnung und Obdach, aber gewiss keine ausreichende Nahrungrgewälıt.

Man hat meist angenommen, dass die ḱeronen vou der Körpersubstanz der Polỹen lebten und dass sie bei starker Yermelıung den Untergang dieser Thiere verursachten. Ich kann diese Ansicht uicht theilen, sondern glaube vielmeh", dass das zahlreichere Aufteten von Keronen und Trichodinen auf Polypen nur ein Zeichen ist, dass sich letztere bereits in einem kanklıaften Zustande hefinten und ihrer baldigen Auflösungr entgegengehen. Die Keronen besitzen kein Organ, mit den sie integrirende Bestandtheile les Polypenkörpers abtrennen hönnten, sie werden daher nur den von den Polypen abgesonderten Schleim und zufalliğ albgelöste Körpertheile, wie die so hảufiğ aus dem Parenchym herausgerissenen und an den Fangarmen längen gebliebenen Nesselkapseln und Nesselfülen verzelıren können. Vereinzelte grosse und hlcine Nesselkapseln der Polypen beobachtete ich nicht selten in Innern der Keronen; das in Fig. 5 dargestellte Individuun zeigte vier grosse birnförmige und zivei kleine cylindrische Nesselkapselı. Viel hăufiger enthalten jedoch die keronen ganze thierische und vegetabilische Organismen, wie sie in dem umgebenden Wasser rorkommen, namentlich Bacillarien, Naviculaceen und griune monadenartige Infusorien, ausser- 
dem auch sehr gewöluntich Chlorophỵlliörıer. Nicht selten sah ich die ganze rechte liörperhälfte mit beträchtlich grossen verschluckten Organismen volgcpfropft, woraus folgt, dass der Mund der Keronen eine lange, dem Innenrand des Peristoms fast gleichtommende Spalte sein muss. So hatte das Thier in Fig. 7 ein Euastrum margaritiferum, cinc Euglena viridis und triquetra. Chaetoglena volvocina, eine Bacillarie und noch mehrere andere grosse nicht unit gezeichnete Organismen verschluckl. - Die Länge des Körpers schwankit meist zwischen $\frac{1}{16}-\frac{1}{10}$ ".

\section{Gattung. Stichotricha. Perty.}

(Taf. X. Fig. $9-13)$.

Character: Kürper metabolisch, lanzett-spindelfümig, nach vorn halsartig verlangert; das Peristom lang und schmal

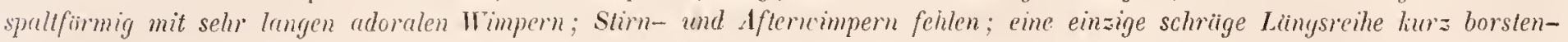
firmiger Bauchwimpern.

Dic Gattung Stichotricha wurde von Perly im J. 1832 auf eine von ihm in der Schweiz entdeclite. aber nicht ausreichend genau erforschte Oxytrichinenform gegrijolet, welche den Namen Stich. secunda erhielt. Die Gattung characterisirte Perly zicmlich düftig folgendermaassen: "Lanzettlich oder bistouriförmig, drehrundlich, nach vorn verlangert, schmal, platt und hier die Mundspalte und auf einer Seite eine Reihe grosser. querstehender Wimpern." Dieser Character passt auf eine von mir hïufig beobacblcte und genauer untersuchte Oxytrichinenform, und la diese auch sonst alle Merlimale zeigt, welche Perly bei seiner Stichotricha secunda ermittelte, so trage jeh liein Bedenken, Perly's Benennugg fur die hicr zu behandelnde Oxytrichinenform in Anwendung zu lıringen.

Das Parenchym ist sehr nachgiebig und dehnbar, der körper kaun sich daber betrảchtlich verlängern und verkiurzen und nach den versehiedensten Richtungen krimmen und winden. Mit den versehicdenen Streckungen und Krümmungen ändert sich die Körperform sehr beteutenl. am reinsten schen wir dieselbe, wenn die Thiere in einem grössern Wasserranme schwimmen und in ibren Bewegungen nicht durch fremde Gegenslände gehenms werden. Msdann erscheint der Körper (Fig. 9. 10. 12) schmal und langgestrecht spindelfömig, f- - ̈ mal so lang als breit, nach linten lanzenförmig zugespitzt und nach vorn in einen langen schmalen llals ansgezogen, der immer mehr oder weniger nach rechts übergebogen ist. Die Rickseite (Fig. 11. 12) und die Bauchseite (Fig. 9. 10). sind llach und gleich stark gewölbt, die Seitenränder abgerundel, der Körper dalıer fast drehrund, nur wenig plattgedirickt. - Das Peristom ist eine lange, schmale, nach hinten sich erweitemule Spalte, welche sich von der Spitze fles Ilalses längs des linken Seitenrantes bis zur Mitte desselben heralıziehı. Der Aussenrand des Peristons fälı mit tem linken Seitenrande des Körpers zusammen, er tright die sehr langborstigen, dicht hinter einander stehenden aloralen Wimpern, welche die lägsten Wimpern des Körpers sind. Sie sind einer nahe am Rande herablaufeuden. nach hinten zu sich mehr und mehr von demselben entfernenden Linie cingefugt, die sich zuletzt liurz hakenförnigg nach innen brïmmt und am Inuenrande des Peristons endel. Letzterer läuft fost der Mlutlinie parallel, nähert sich aber nach vorn tem linken Seitenrande und geht allmahlig in tenselben uber. Bei slichotricha ist demnach in Folge Jer enormen Austehnung des Stirnfeldes nach vorn der Vorterrand des Peristoms anderer Oxytrichiuen zum Aussenrande und der Aussemand zum Hinterrande geworden. Die arloralen Wimpern sind fast gleich lang und gleich stark. nur die hintersten, sich nach innen wendenten nehmen merklich an Grösse ab, und die vordersten sind etwas kräfliger. Sümmlliche atlorale Wimpern nehmen bald eine quere Stellung cin (Fig. 9), bald werden sie in der Horizonfalelsene um ihren Insertionspunel cntweder nach rückwärts niedergelegt (Fig. 11 ), oder nach vorwirts in dis Iöhe gerichtet (Fig. 12). In letztern Fall biegt sich die Spitze des Halses mehr oder weniger bakenförmig nach rechts um, und es spreizen sich dadurch die vordersten Winpern fächerartig aus einander. Oft wogen die adoralen Wimpern schucll hinter einander auf und nieder, sie sondern sich dann in mehrere, theilweis sich krcuzende Gruppen (Fig. 10), imlem eine gewisse Anzahl benachbarter Wimpern sich mit ihren Spitzen an cinander legen. Der Innenrand des Pcristoms trägt an seiner hintern IIälfte einen schmalen, undulirenden llautsaum, unter dem dicht am Peristomvinkel mehrere langborstige präorale Wimpcrn hervorragen (Fig. 9. 10). - Das Verhalten der blos locomotiven Wimpern ist zum Theil selı schwer zu crmitteln, da die Thiere schnell und anhaltend schwimmen und sich alle Augenblicke un die Längsaxe dreben; bringt man sie aher durch Entziehen von Wasser zum Stilllicgen, so verändem sie ganz und gar ihre Form, fles Hals verkijat sich und der Hinterleil) zieht sich ebenfalls zusanmen und nimnt eine breit ovale oder knrz eifömige Gestalt an. Dazu kommt noch, dass sieb die Thiere nun

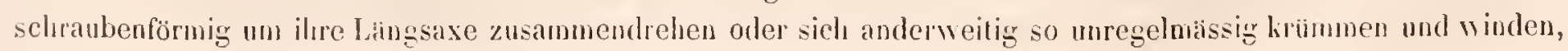


dass Winpern, die dem Rande angehören, nach innen rüchen, wảluend innere sich an den Rand velschiehen. Das: besondere Stirn- und Afterwimpern ginzlich fehlen, davon iiberzengt man sich bald; auch die rechte liandwimperreihe ist leicht zu verfolgen, sie heginnt diclut unter der Spitze des Jalses und erstreckt sich bis zur Ilinterleibsspitze, wo sie mit der linken Randwimperreihe zusammenstösst. Letztere hält etwa luis zur Mitte der hintern Körperhäfte den Rand inne, dam alser wendet sie sich sehrig nach innen und endigt am Jeristomwinkel. Der' vordere Theil der linken Randwimperreibe verschiebr sich bei 〈len schraubenförmigen Drehungen tler hintern Körperhälfte oft so weit nach rechts, dass er wie eine besondere schràge Bauchwimperreilıe erscheint. Lange Zeit wurde ich hierdurch getauscht, so dass ich zwei Bauchwimperreihen annahn; spiter aber gelangte ich zu der Ueberzeugung, dass Joch nur eine einzige vorhanden sei. Diese (Fig. 9. 10.b.) beginnt am rechten Seitenande des Halses, etwa in der Mitte lesselben und verläuft in schragger Richtung nach dem linken Seitenrande der hintern Körperhälfte, den sie zu Anfang des letzten Drittels schneidet. Dic Bauchwimpern stehen dichter hinter einander und sind kürzer, als die Randwimpern, sie krümmen sich, in Aclion, wie die Bauchwimpern von Kerona, hakchenförmig. Anderweitige Wimpern habe ich nicht wahınehmen können, nur zuweilen schien es mir, als waire dicht am Innenrand des Stimfeldes noch eine Reihe sebı liurzer und feiner Häkchen vorlıanden.

Die beiden Kerne (Fig. 10-12. n. n.) liegen nahe hinter einander, der vordere am Grunde des IIalses, der hintere im vordern Theile des Hinterleibes; sie besizen gewöhnlich (Figg. 11. I2) eine quere spaltärmige IIölıle. Der Nucleolus (Fig. II. nl.) zeichnet sich sehr durch seine gestreckte, stabartige Form aus. - Der contractile Behälter ist vom linken Seitenrande weg- und fast in die Mlitte des Körpers geriickt. - An den Bewegungen der Thicre ist besonders characteristisch, dass sie von Zeit zu Zeit plötzlich stossweise weit nach ruichwärts fahren. Hierbei schlägt sich ihr llinterleib oft nach vorn um (Fig. 11), oder er verkiirzt und erweitert sich zu einem eiförmigen, hinten abgerundeten Sack. Die Thiere bleiben daun auf dem Objectglase liegen, drelıen ihren lang und gerad ausgestreckten Hals bald nach links, bald nach rechts schraubenförmig um die Längsaxe zusammen, schieben sich stossweis vor- und rückwärts, kriimmen sich auch um die Queraxe riugförmig zusammen und walzen sich so langsam rotirend um irgenu einen Gegenstand. Nicht selteu schraben sic sich auch um einen Confervenfaden bald vorwärts, bald rickwirts. Wie der Hinterleib, so kann auch der Hals beträchtlich eingezogen und verkiurzl werden; der Körper erscheint dann in der Mitle stark bauchig elweitert und an beiden Enden fast gleichnässig zugespitzt. Das Thier bewohnt zuweilen eine gallentartige, walzenförnige, dickwandige, farl,lose Hülse (Fig. 13. h.), die hinten bahl geschlossen, bald offen und inmer elwas gekrünmu ist. Yon Zeit zu Zeit lritt es bis zur IIälfte aus der Miündung der Hülse hervor, biegt sich dann ijber den liand der Viundung stark bogenförmig mach rechts um und wirbelt nun anhaltend Nahrung herbei. So wie die geringste Gefahr droht, fiblut es plötzlich in den Grund der Hiilse zuriick; nach einiger Zeit schwimmt es wieder vorwärts, streckt aber nur erst vorsichtig die Jalsspitze zur Mündung hinaus und fährt mehrmals wieder zuriick, bevor es sich wieder in der frühern Weise hinauswagt.

Die einzige Art lebt in sumpfigen Gewăssem.

Stichotricha secunda. Perty. (Taf. X. Fig. 9-13).

(?) Trichoda praeceps Miille Animalcula infusor. p. 175. Taf. XXIV. Fig. 23-23.

Slichotricha secunda Perty kleinste Lebensformen S. 153. Taf. VI. Fig. 1 :̈.

lch traf dieses Thier znerst im Herbst 1854 in einem versumpften Quellwasser auf dem Essberge bei Tharand zwischen dichten Rasen von Sphagnum; die Individuen dieser Localität (Figg. 12) hatten eine ansehnliche Grösse und waren meist selır dicht mit Chlorophyglliörjern erfüllt. Die Hijlsen bewohnende Form (Fig. 13) beobachtele ich ebenfalls, aber nur sehr vereinzelt, bei Tharand auf einer sumpfigen Wiese. Bei Niemegk und Prag, wo unsere Art ziemlich häufig, theils in Torfstichen, theils auch in andern stagnirenden Gewdisseru vorliommt, fanden sich immer nur frei umherschweifende Thiere. Einmal traf ich ein Individum in einer leeren auf dem Ruicken liegenden Schale von Arcella aculeata und ein anderes Mal in einer leeren, an dem einen Ende mit einer scharf abgeschnittenen Oeffumg verselıenen Eischale eines grossen Raderthieres; in beiden Fälen verhielten sich die Thiere in den Schalen genau ebenso, wie die Bewohner der Gallerthiilsen, sie traten abwechselnd aus der Mindung der Schale hervor, wirbelten eine Zeit lang nach Nahrung und zogen sich daun wieder zurück. Dieses Spiel verfolgte ich länger als $\frac{1}{2}$ Stunde, ohne dass ich die Thiere 'die Schalen verlassen sah. Ich möchte hieraus schliessen, dass auch die Galler'thïlsen nicht Producte der Thiere sind, von welchen sje bewohnt werden; sie scheinen mir dazı auch zu voluminös zu sein. - Die Körperlange beträgl $\frac{1}{16}-\frac{1}{10}{ }^{\prime \prime \prime}$. 


\section{6}

Mäller's Trichoda praeceps dïrfte wohl hierher gehören, zumal wenn man seine Fig. 24 a. a. 0. beriicksichtigt und die Angahen über die Bewegungen dieser Art vergleicht, die völlig auf Stichot. seeunda passen. Mïller unterschied nur die langen adoralen Wimpern, die in Fig. 23 und 25 an das unrechte Ende versetzt sind. In Perly's Abbildungen sind die in Fig. 1 5. B. dargestellten und die kleinen mit a. a. a. bezeiehneten, naelı rückwärts fahrenden, sogenaunten diastrophischen Individuen leidlich charaeteristiseh gezeichnet. Perly unterschied nur die Randwimpern und die adoralen Wimperu, letztere sind zu kurz angegeben; alles ibrige Detail blieb ihm unklar, jerloeh findet sich das Peristom zum Theil angedeutet.

Die Gattung Stiehoebaela von Claparede und Lachmam (Études p. 122 und Pl. VI. Fig. 6) ist der Gattung Stichotricha sehr nahe verwandt, sie unfasst nur eine einzige, bei Berlin aufgefundene Art, die Stichochaeta eornuta. Dieses Thier lıat ganz die Form einer Stichotricha, deren Hinterleib sich verliurzl und zu einem ovalen Körper erweitert hat. An der Spitze des Halses steht ein langer, spitzer, gerader, nach rechts gerichteter Griffel wie ein Horn; am Grunde des Halses liegt in einer långlichen Grube der Mund, von dem ein Buschel langer Borsten ausgeht, die an die präoralen Wimpern von Stiehotricha erinnern. Die adoralen Wimpern laufen von der Spitze les Halses an einer Kante zum Munde herab, die genau die Lage hat, wie der lnnenrand des Peristoms bej Stichotricha. Dem linlien Rande des Halses sind lange, weitläufig stehende, sehr feine, steife Borsten eingefiigt. Ieh muss gestehen, dass mir diese Angaben etwas verdaehtig vorkommen, denn nach denselben wirde Stichochaeta eine von den übrigen Oxytriehinen ganz abweichende Peristombildung besizen. Die Randwimpern verhalten sich ähnlieh. wie bei Stichotrieba, Banchwimpern sind dagegen drei odler vielleicht sogar vier lieihen vorhanden, die von vorn und reehts nach links und hinten schraig über den Hinterleib verlaufen. Die Bewegungen von Stiehochaeta grleichen denen von Stichotrielıa. Da eine genaue Ermittelung der Organisation von Stichotricha und Stiehoehaeta mit erhehliehen Schwierigkeiten verknüpt ist, und Irrthümer hierbei sehr leicht unterlaufen liönnen, so diurten sich bei einer erneuerten Prifung beider Formen die Differenzen zwischen denselben vielleicht als viel geringer ljerausstellen, als sie naeh den gegenwảrtig vorliegenden Untersuchungen ersclseinen, und es lönnte sich wohl die Nöthigung ergeben, beide in einer Gattung zu vereinigen.

6. Gattung. Iroleptus. Ehrbg.

(Taf. X. Fig. 14-1\%. Taf. Xl. Fig. 1-8).

Character: Korper metabolisch bis formbeständig, schr langgestrecht und schmal, nach hinten su verengert und in einen Schuran- ausgezogen; drei vordere griffelformige Stirnwimpern und swei sehr genaherte mediane Langsreihen borstenfirmiger Bauchwimpern; Afterwimpern fehlen.

Die Gattung Uroleptus wurde von Ehrenberg im J. 1831 (Ahhandl. der Berliner Academ. S. 116) mit \& Arten begriundet, zı denen später noch eine fünfte ham. Sie erhielt ihren Platz unter den Colpodeen zwischen Amphileptus und Ophryoglena, weil Ehrenbery glaubte, dass der Körper der Urolepten auf der ganzen Oberflache gleiehförnig lewinpert sei. Unter den Colpodeen sollte sich Uroleptus hauptsächlich durch den Besitz einer schwanzartigen Schleppe, sowie auch durch den IIangel von Auge, Russel und Zunge auszeichnen. Man braueht nur einen Bliek auf Ehrenberg's Abbildungen zu werfen, um sofort zu erhemen, dass von seinen fün Uroleptusarten nur die drei ersten (U. piscis, musculus und hospes) nach einem ibereinstimmenden Typus gebaut sind und allen Anseheine nach wahre Oxytriehinen darstellen. Von den beiden ubrigen Arten ist U. filum höehst wahrscheinlieh ein mit Spirostomum ambigum sehr nahe verwandes Thier, dessen verengerter Vorderleib für einen Sehwanz gehalten wurle, und U. lamella ein nit dem hintern Ende voranschwimmender Amphileptus (Trachelius Ehbg.), dessen terminaler contraetiler Behälter irrig als Mund aufgefasst wurde. Dujardin hat sich bereits in ảhnlichem Sinne ansgesprochen (Infusoires p. 4.20 Anmerk.). Unter den von mir beobachteten Oxytrichinen glaube ich zwei von Ehrenberg's ächten Urolepten wiederzuerkennen, mänlich den U. piscis, wozı auch Oxytrieha caudata Ehbg. gehöıt, und U. musculus. Beile Arten waren bereits O.F. Müller behannt: der U. piseis ist menestens in den Études von Cluparide und Lrchmam als Oxytricha caudata abgehandelt worden. Ich habe aussurdem noch zwei neue Arten entdeclit, so dass die Gattung gegenwätig vier sicher unterschiedene Arten unfasst, die sammulich eine nahe übereiustimmende Organisation besilzen. Nach den Resultaten meiner Lntersuchungen habe ich bereits in der Lotos lanual I 
Das Parenchym der Urolepten zeigt verschiedene Grade der Consistenz, zum Theil ist es sehr nacligiebig and dehubar, zum Theil ziemlich resistent, aber auch im letztern Fall bleibt der Körper noch immer betráchtlich biegsam. Er ist stels selur langgestrecht und schmal, ibber $3-8$ mal so lang, als breit, im Allgemeinen linealspindelförmig, vorn abgerundet oder abgestutzt, nach hinten zu stark verengent und in einen melır oder weniger langen, meist conischen oder cylindrischen Schwanz ausgezogen. Das Peristom beschïinkt sich auf das vordere Körperende und reicht nie bis zur Körpermitte, es ist meist selı schmal, indem der Innenrand den Aussenrande selır genahert ist. Dic adoralen Wimpern greifen nach rechts um den Vorderund des Körpers herum, der von einer schmalen, symmetrisch angesetzten Oberlippe gesäumt wird. Im Lebrigen verhält sich das Peristom wie bei andern Oxytrichinen. Die beiden lhandwimperreihen erstrecken sich his zur Schwanzspitze, wo sie in einander ubergehen: die rechte beginnt nalıe hinter dem Anfangspunct des adoralen Wimperbogens, die linke, wie gewölunlich, hinter dem Aussenrand des Peristoms. Auf dem Uebergang des Stirnfelds in das Peristomfeld dicht hinter den vordern adoralen Wimpern stehen drei langere und kidifige, griffelăhnliche Wimpern (Taf. XI. Firg 3. 6), die ieh als Stirnwimpern im engern Sinn bezeichne. Die Bauchwimpern bilden zwei einander sehr genäherte, mediane, etwas schicfe Längsreihen, welche rechts neben dem Peristomwinkel vorbei und auf das Stirnfelu ibbergehen, wo sie in der Nahe der drei Stimwimpern endigen. Von Afterwimpern ist lieine Spur vorhanden und lierdurch unterscheidet sich die Gattung Uroleptus am auffallendsten von der nahe verwandten Gattung Oxytrichá. — Die heiden Kerne sind einander genähert und liegen mehr in der Jltte des Körpers, sie zeigen häufig eine quere spaltförmige Ÿöhle und links stets einen rundlichen Nucleolus. Der contraclile Behälter liegt bald linlis neben dem Peristom, bald weiter nach hinten fast in der Hitte des linken Seitenrandes.

Sammtliche Arten leben in stagnirenden süssen Gewissern und laben in ihren Bewegungen das Eigenthümliche, dass sie, wie Stichotricha, von Zeit zu Zeit lueftig nach ruichwärts fahren.

\section{Uroleptus musculus. Ehrig. (Taf. X. Fig. 14-13̈).}

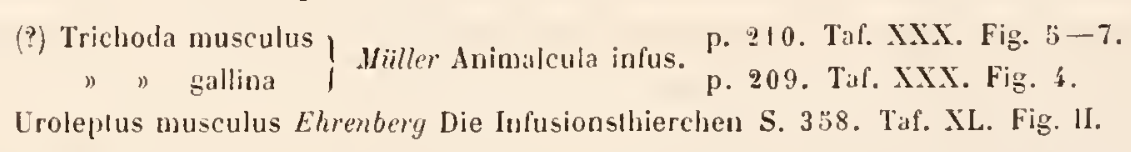

Lürper drchrund, länglich birn/örmig, nach hinten zu bauchig erweitert und plötzlich in einen kurz kegelfömuigen Schuanz verengert.

lch habe diese Aıt erst im Sommer 1858 bei Prag kennen lernen, wo ich sie an einer seichten, dicht mit Callitrichen überwachsenen Stelle des Boticzbaches bei Nusle in vielen Exemplaren antraf. — Der Körper (Fig. I 4 ) ist $3 \mathrm{mal}$ so lang als breit, in seiner vordern halsảhulichen Häfte fist walzenförmig, nach hinten stark bauchig erweitert, dann eiförmig zugerundet und zuletzt plötzlich in einen kurz conisch-lanzetilichen Schwanz verengert, der sich auf der rechten Seite durch eine stärkere Einschnürung und grewöhnlich auch dureh eine seliefe Falte (Fig. 100$)$ von Körper absetzt und inmer etwas nach rechts gehrümmt ist. Das Parenchym ist in der Lỉngsrichtung des Körpers sehr dehubar und contractil, namentlich kann sich der Vorderleih beträchllich zu einem schmalen zugespitzten zungenartigen Fortsatz ausrechen, wobei er sich immer etwas nach links krimmt (den Anfang dieser Ausdehnung zeigt lig. 13). Nichulen er sich mehr oder weniger ausgestreckt hat, wird er plötzlich unter seine gewöhnliche Länge zucliend, ja fast schuellend zusammengezogen. Auch der Schwanz verkiurzt sich namentlich bei den zurichfahrenden Bewegungen des Thieres oft so betrachtlich, dass der Körper hinten einfach zugespitzt erscheint. — Das Peristom nimnt das vordere Körperdrittel ein, es ist schmal und sein Innenrand vorn etwas schurig nach links gerichtet; die atoralen Wimpern zeichnen sich durch ihre bet’łehtliche Länge und Stärle aus. - Die beilen Randwimperreilıen sind nach innen gerüclit, besonders die linke, welehe vom Peristomwinkel ausgelıt, den Bauchwimperreihen selı’ genăhent ist und ihnen parallel lảuft. Die Randwimpern sind daher bei der Rüchenansicht, mit Ausnahme der hintersten, den Schwanz stumenden, nicht wahrnelınbar. Die Baucliwimpern erstreclien sich vom vordern Ende des Stirnfeldes aus, welches öfters nur zwei eigenlliche Stirnwinpern tright, in zwei sanft S-förmig gebogenen Reihen ïber den mittern Theil des Bauches bis zur Schwanzspitze. In der linlien Reihe stehen die Bauchwimpern etwas weitlunfiger, als in der rechten, sie sind auch etwas stäther und, wenn das Thier still steht, gewöhnlich nach rorn umgebogen. Die Bauchwimpern sind eben so lang wie die Randwimpern. - Die heiden Kerne (n.n.) sind rundlich und lomogen, der vordere liegt an Peristomwinliel, der hintere fast in der Mlitte des Körpers. Der contractile Behijlter (c) findet sich etwas vor der Nitte des linlien Seitenrandes. — Die verschluchten Nahrungsstoffe, meist grune monadenartige Infusorien. erfullen die granze hintere Körperlälfte nit Ausnahme des 
sehr lichren, durchsichtigen Schwanzes (Fig. 14). Der After liegt dicht vor der Schwanzwurzel (Fig. 15 bei z.), wo sich aluch oft brảunliche Excremente angehäuft finden. - Die Thiere bewegen sich mit mässiger Geschwindigkeit und bleiben bahl stillstehen. Sie gehen dann abwechselnd cine Strecke vorvärts und fahren gleich wieder in gerader Richlung zuchend nach rüchwailts, ohne sich weit aus dem Gesichtsfelde zu verlieren. - Körperlänge $\frac{1}{18}-\frac{1}{10}$.

Ob Mäller's in Heumfusionen beobachtete Trichorla musculus hierher gehört, wie Ehrenberg annimmt, ist mir sehr zweifelhalt; sie besitzt cinen zu langen und ganz anders angesetzten Schwanz und liönnte wohl eher ein Räderthier gewesen sein. Dagegen scheint mir Mïller's Trichoda gallina die gegenwärlige Art darzustellen, da sic eine sehr :ihnliche Körperform, cinen kurzen Schwanz und lange atorale Wimpern besitzl. — Die von Ehreuberg für scinen U. musculus aufgestelte Arthiagnose ist so scharf, dass ich sie unverindert beibehalten konnte; seine Abbildungen sind in Betreff aller Einzellıeiten der Körperform volliommen zutreffend, er unterschied auch ziemlich genau das Peristom und cinen Theil der adoralen Wimpern und bestimmte den After richtig. Bei so vielen Uebereinstimmungen verliert Ehrenberg's Angube, dass der Körper auf der Halbansicht 9- I1 Lïngsieihen von Wimpern zeige, alle Bedeutung, zumal da wir uns schon oft und namentlich bei Kerona polyporum und Pleurotricha lanceolata ibherzeugt hahen, wie sehr Ehrenberg bei der Bestimmung der Bewimperungsverhältnisse der Oxytrichinen unıl Euplotinen irte. Ehroberg unterschied wahıscheinlich unklar die Bauch- und Randwimperreihen und nahm dann an, dass diese Reilien gleichmässig um den ganzen Körper herum vertheilt seien; er untersuchte auch nur einmal vier Kleine Exemplare und zwar in älterer Zeil (18.31). Ich hege daher nicht den mindesten Zweifel, dass die gegenwirtige Art mit U. musculus Ehlig. identisch ist.

Dic Oxytricha gibba von Claparede und Lachmamn (Études p. 14.4. PI. V. Fig. S) hat viel Achnlichlieit mit gestreckleren Formen von Uroleptus musculus, die den Schwanz sehr verkiirzt oder ganz eingezogen haben, sie soll jedoch im Ganzen sechs Winperreihen auf der Bauchfliche besitzen, eine jederseits hart am Rande und vier mitllere. Letztere zeigen ein sehr almliches Verhalten, wie dic Rand- mnl Bauchwimperreihen von U. musculus zusammengenommen; auch ist Oxyt. giblı mit drei Stirngriffeln rersehen und olıne Afterwimpern, wie U. musculus. Ian liönte daher leicht auf die Vermuthung gerathen, dass U. musculus und O. gibba zu einer und derselben Art gehören, und dass die Differenzen zwischen beiden Formen ledighlich auf Beobachtungsfehlem bernhen. Ich kanı nicht glauben, dass ich bei U. musculus etwa noch am Rande vorhandene Wimpern übersehen haben sollte, da ich dies Thier sehr oft untersucht habe und meine Angaben auch mit den bei den iibrigen Urolepten beobachteten Bewimperungsverhaltnissen im Einklange stehen. Sollten also nicht vielleicht bei $O$. gribba die heiden Randwimperreihen auf einem Irrhum beruhen? Sind wirlich 6 Wimperreihen vorhanden, danı diurften auch wohl die Afterwimpern nicht gainzlich fehlen und die O. gibba wirde in der von mir angenommenen Eintheilung zu einer Urostyla werden.

\section{Uroleptus piscis. Enriba, (Taf. Xl. Fig. 1-3).}

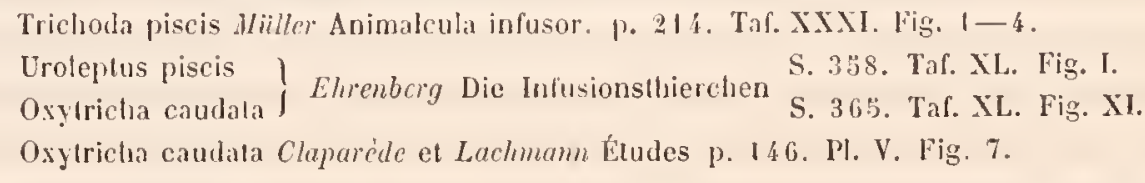

Föryer sehr. contractil, breit lineal-spindelfümig. vorn abgerundel und schwach liopfförmig erweiterl, nach hinten allmählig in cinen strangfürmigon, nachschleppenden Schwanz verengert, mit langborstigen, weit rorragenden, nach hinten an Lä̈ge zunehmenden Randwimpern.

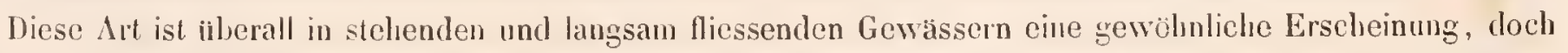

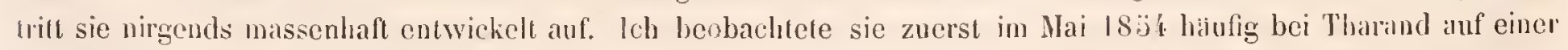
iiberschwemunten Wiese des Badethales und seit 18\%". alljahrlich bei Prag, naneutlich in den Bassins des hotanischen Gartens zwischen Wasserlinsen. Bei Nicmegk traf ich ungemoin grosse Individuen (Fig. 3) an der staubigen Oherflache des Puffbachs zwischen zusammengetriebenen Massen von Conferven und Oscillarien. - Das Parenchym ist so dehubar und contractil, lass sich die Form und die Dimensionen des Körpers sehr beträchtlich verảndern können. Am hiiuligsten zeigen dic Thicre bein ungehenuten Schwimmen die in Fig. I dargestellte Form, und es variirt nu dic Länge des Schwanzes, der sich beim plötzlichen Zuruckfahren meist erheblich verkiirz und danı nicht gleich wieder seine frülıern Dimensionen annimut. Im Allgemeinen ist der gesammte Körper z̈-6 mal, seltener (Fig. 3) \% -S mal so lang, als breit, lineal-spindelförmig, gewölinlich in der Mlitte, nicht selten (Fig. 2) aber auch weiter nach vorn an Ireitesten; der rechte Seitenrand ist stälier nach anssen gekrümmt, als der liuke, 
welcher in der Mitte fist gerade, oder schwach nach einwäıts gebogen isı. Nach vorn verengert sich der Körper mehı oder weniger lıalsartigr (Fig. 3) unıl endigt mit einer schwach liopfförmigen Anschwellung. Nach hinten geht der Körper olıne scharfe Gränze in einen sclmalen, walzenförmigen, am Ende ahgerundeten und meist elwas angeschwollenen Schwanz ïher, der nicht selten den fünften Theil der Körperlänge einnimmt und gew ühnlich mil der Spitze nach rechts gekruimunt ist. Das lnnere des Schwanzes ist mehr orler weniger dicht mit dunkelcontourirten Körnern erfüllt (Fig. 1. 2), die ilı oft so beschweren, dass er von den Thier nur mühsam nachgesehleppt wirl. Die grö̈ssten Individuen (Fig. 3) besitzen einen breil linealisclıen, nach vorn stark balsartig verengerten und am Ende deutlich kopfförmig erweiterten Körper, der nach hinten lanzelförmiğ zugespitzt isı und mil eineu fast geraden, kur" conisch-walzenfömigen Sclıwanz endet. Bei allen normal ausgestreckten Individuen ist dic Riickseite (Fig. 2) mässig gewölbt, lie Bauchseite (Fig. 1. 3) plan. In Folge haufiger zurijclifahrender Bewegungen der Thiere und namentlich im llach ausgebreiteten Wassertropfen verkür'zt sich jedoch der Körper sehr beträchılich, er wird dann drehrund, dicher und regelmässiger spindelförmig, und der Schwanz bildet nur noch einen geralen, oft sehr liurzen, conisch-walzenfömigen Fortsatz. - Das Peristom beschranlit sich auf das vordere Viertel oder Fünftel des Körpers, es ist verhahluissmässig breil, da sein gerader, nur vorn schwach hakenförmig nach linlis gekiümmtes Innenrand in der Mlttellinie des Batuches liegt. Die vordem adoralen Wimpern sind ziemlich lang. - Die starken langborstigen Randwimpern haben die gewöhnliche Stellung in der Nähe des Raudes unl ragen iuber denselben nach aussen hervor; sie werden nach hinten zu merliliclı grösser, so dass der Schwanz von den länsten und Lräftigsten, gewöhulich stał abstehenden Randwimpern eingefasst wird. Die Bauchwimpern sind lïrzer und schwächer, als die Rantwimpern, sie setzen zwei sehr genäherte, fast gerade Längsreilıen zusammen, dic sich am Anfange des Schwanzes verlieren. - Die beiden ovalen Kerne (n. n.) liegen nahe hinter einauder, vor und hinter der Körpermilte, sie besilzen meist eine quere spalı̈̈rmige Ilölıle (Fig. 2. 3). Der contractile Behälter (c.) findel siclı neben dem Peristom am linken Seitenrande, der von ilm hei der Systole blasenformig aufgetrieben wird. Die Bewegungen sind ahnlich, wie bei der vorigen Art; beim Schwimmen schlängelt sich der Körper aber auch oft gewandt nach links und rechıs. - Kööperlinge bis $\frac{1}{4}$."

Miller's Trichoda piscis stellt sicherlich die gegenwärlige Art dar, wie sich sowohl aus der gesamuten Körperform derselben, als auch aus der Abluildung der vordern adoralen Wimpern in Fig. 4. a. a. O. ergicht. Müller unterschied schon den contractilen Behïlter, versetzte ihn aber zu weit nach der Nitle zu, die locomotiven Wimpern entgingen ihm. - Ehrenberg's Uroleptus piscis umfasst meiner Ansicht nach nur die verkürzten, drehrund gewordenen Formen, die ausgestrechten, flachen hat er als Oxytricha caudata beschrieben. Die Abbildungen, welche Ehrenberg von beiden Formen gegehen lual, sind unvollstandig und mangellaf und nur in Betrefl der äussern Gestalt ziemlich gelreu, namentich die von seiner O. caudata. Bei letzlerer Form unterschied Ehrenberg nichts weiter als das Peristom, welches aber auch nicht richtig erkannt wurle, und fijnf Borsten hinten am Schwanze. Bei seinen U. piscis liess er Ilen Körper ringsum mit kurzen Wimperhärchen besetzl sein; die lıei diesem Thiere beobachteten längern Wimpern am Vorderrande des liörpers uud links nelsen der sogenannten Mundspalte lehren jedoch, dlass dasselbe ein l'eristom besitzen mussie, wie es sich nur bei Oxylrichinen und Euplotinen findel; diese Familien schliessen aber nach allen bisherigen Erfahrungen eine tolale Bewimperung des Körpers aus. Ist nun Ehrenberg's U. piscis offenbar nur irrhünlich als ringsum bewimpert bestimut, so fällt auch jeder Grund weg, an ler Identită dieses Thieres mit der gegenwärtigen Art zu zweifeln. Der Unstand, dass Ełhrenberg scinen U. piscis Anfangs selbst in die Galtung Oxytricha stelte (Abhandl. der Berliner Acad. von 1830 §. 4.3), muss uns noch mehr in der Ansicht bestärlien, dass dies Thier eine achte Oxytrichinenform darstellt. - Der von Ehrubery in den leeren Hällen des Frosch- und Schnechenlaichs im kuglig contrahirten Zustande beobachtele U. hospes scheint mir cine lem U. piscis sehu nahe verwandte, vielleicht von ihm gar nicht verschiedene Art zu sein. - Cluparede und Lachmamn luaben von unserer Art die erste, dem gegenwärtigen Standpunct der Wissenschaft angenessene Dar'stellung geliefert, die jelloch von der meinigen in einem selı wesentlichen Puncle abweicht; es soll nämlich ausser den beiden von mir angegebenen Bauchwimperreilıen noch eine dritte, zwischen der linken Bauchwimperreilıe und der linken Randwimperreihe mitten inne gelegene Reilse von Bauchwimpern vorlanden sein. Ich muss diese dritte Banchwimperreilıe entschieden in Abrede stellen. 


\section{0}

3. Uroleptus rattulus. Steis. (Taf. XI. Fig. $4-5)$.

förper sturr, sclmal lineal-spindelförmig, vorn ciförmig sugerundet, nach hinten in cinen langen, pfricmförmigen, zugespitzten Schuanz verenyert, mit hurzborstigen, wenig vorragenden, nach hinten an Lünge abnehmenden Randwimpern.

Ich beohachtete diese Art im September 1857 und im August 1858 ziemlich häufig in Torfstichen bei Niemegk und zwar in durchaus mit einander ibbercinstimmenden Exemplaren. In ihrer Gesellschaft kam niemals Uroleptus piscis vor, mit dem sie am meisten Achnlichkeit hat. Von letzterer Art unterschejdet sie sich sofort durch ihren fast drehrunden, viel schmalern und staren Körper, der keiner merklichen Verlängerung und Verliürzung fähig isı, sich jedoch noch jmmer in weiten Bogen zu hrimmen vermag. Nach vorn ist der Körper stetig verengert und am Ende eiförmig zugerundet, von der Mitte an verengert er sich stetig nach hinten und geht allmälılig in einen langen, drehrunden, an Ende zugespitzten Schwanz iiber. - Das Peristom ist sehr schmal, sein Innenrand geht dem Aussenrande des Perisıoms fast parallel und ist von ihm nur durch einen selı schmalen Zwischenraum getrennt. Die Randwimpern sind liurze, dünne Borsten, die nur wenig über den Rand hervorragen, an Schwanze werden sie bis zur Spize immer kürzer und feiner; durch den kurzhaarigen Schwanz unterscheidet sich U. rattulus sehr auffallend von U. piscis. Die Bauchwimpern sind noch viel hïrzer und feiner, als die Randwimpern, und sehr schwer wahrnehmbar, die beiden Reihen derselben sind einander so genahert, dass sie an manchen Stellen in einander ïbergehen; nach vorn folgen sie nicht den Innenrande des Peristoms, sondern sie verlaufen nach der ausseren Stirnwimper hin, nach hinten erstrecken sie sich nu bis auf die Schwanzwurzel. - Die beilen homogenen Kerne (n. n.) hahen dieselhe Lage, wie bei der vorigen Art, der contractile Behälter (c.) liegt aber constant milten zwischen ihnen am linken Seitenrande, was abermals einen wesentlichen Unterschiel ausmachı. - Das ganze Parenchyn fand jelı stets dicht ron sehr blassen, farblosen Körnchen durchwirlit, zwischen welchen hăufig gröbere Chlorophỵllkörner zerstreut lagen. Bei den zuriekfahrenden Bewggungen hrïmmt sich der Schwanz gewöhnlich hakenförmig nach vorn um (Fig. כ̈). - Körperlänge bis $\frac{1^{\prime \prime \prime}}{5}$.

4. Uroleptus violaceus. Stern. (Taf. XI. Fig. $6-8$ ),

Körper starr, plattgedrücht, lineal-- rechtechig, nach hinten schwach schwanzartig verengert, und am Ende abgestutzt und abgertundet. Randuimpern langborstig, die hintersten am längsten.

Ich traf dicse sowohl durch ihre Gestalt, wie durch constante violette Farbung selı ausgezeichnete Arl. ebenfalls in Torfstichen bei Niemegk sehr verbreitet an; sie licelt sich besonders in dem krümlichen Budensatze des Torlwasser's auf. - Der Körper ist $\ddot{b}-6$ mal so lang als breit, slark abgeplattel, breit linealisch und am rordern Ende gerad abgestutzt mil abgcrundeten Ecken; hinter der Nitte verengerl sich der Körper stctig bis zur Spitze und zwar auf der linken Seite stäther, als auf der rechten, die Verengerung ist jedoch nach Jinten zu so wenig beträchtlich, (lass sich kein deutlicher Schwanz absetzt und der Ilinterleils fast noch hall, so breil bleib, als der Vorderleil,. Das hintere Ende ist ahgestutzt und abgerundet, die Seitcnränder sind ebenfalls abgerundet und der untere Rand des gerad abgestutzten Vorderandes ist in eine quere, sclumale, vorn bogenförmig abgerundete oberlippe ausgezogen. Die Rüchseite (Fig. 8) ist ehen so lhach, wie alie Bauchseite (Fig. 6. 7). Das starre Parenchyn gestallel keine merkliche Verkijrzung und Verlängerung des Körpers; die slärksten Krimunungen, deren der Körper fälį̣ ist, sind aus den in Fig. 7 und 8 abgehideten Individuen zu ersehen. - Das Peristom ist schr kurz, liaum langer, als der Körper breit, sein Innenrand ist dem Ausscnrande stark genahert; die adoralen Wimpern sind verlıăltnissmassig hurz. Die fast eben so langen, steifborstigen Randwimpern aberragen den Rand beträchtlich und schieben sich bei den krummungen des Körpers zum Theil krewzweis durch einander; die luntersten sind die längsten, namentich die an Ende stehenden, die sich auch durch grössere Stärie auszeichnen und nichı selten fast griffelfömig erscheinen. Die Banchwinpern sind sehr kurze, pfiemliche Borsten, die sich hinsichtlich ilırer Stellung ganz. ahulich, wie bei der rorigen Art, verhalten. Dasselbe gilt ron den beiden Kernen n, n.) und ron den contrachilen Behälter (c.). - Das Parenchym fand ich bei allen Individuen dicht von blass blaulichrohlsen Körnchen durchwirht, welche dcm gesamuten Körper eine intensiv violette oder dunkel weinrolhe Farbe crlheilten. Ausserdem zeigte sich im vordern Kö̈perende unter dem vordem erweiterten Theil des Stirnfeldes bestandig ein rundlicher, schwäzlicher Haufen ron selır dichı zusammengedrangten, feinen dunkelcontourirten, farblosen körnchen. Ehen so war das schwanzartige Hinterende bis auf cine langere oder kürzere Dislanz von der Spitze slets dicht mil gröbern, dunkelcontouı irten, farblosen Körnern erfillt. Sonst kamen nur noch vereinzelte Chlorophylliörner zerstreut im Parenchỵm ror: - Die Thiere schwimmen schnell und anhaltend ohne Drehung um die Längsaxe; heim pfeilschnellen Zurürkfilıren bleiben sie gewohnlich ganz gerad gestreckt. - Die Körperlange betrigt $\frac{1}{1}-\frac{1}{4}$. 
7. Gattung. Psilotricha. Sters.

(Taf. XIl. Fig. 21-21).

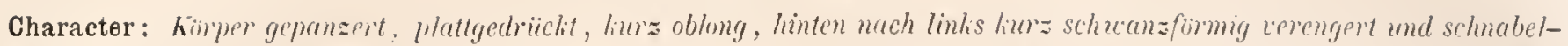
arlig zugespitzt; Stim- und Afterwimpern fehlen, Bauchuimpern in zwei heihen geordnet, mit den landuimpern gleichartig und wie diese überaus langborstig und weillaufing stehend.

Die von mir zuerst in der Lotos Januar 1839 S. ̈̈ unterschiedene Gattung Psitotricha ist auf eine neue Oxytrichinenform gegrindet. welche sich zwar nahe an die Urolepten anschliesst, aber doch auch wieder so viele Eigenthïmlichkeiten darbictet, dass sie nicht mit denselben vereinigl werden hann. - Jer Körper ist ganz starr, steif und glatt und eben so entschieden gepanzert, wie hei den Euplotinen; er ist nicht rötlig noch einmal so lang als breit, liturz und hreit oblong, fast rechteckig, vorn geral abgestutzt, llach bogenförmig zugerundet und in eine symmetrisch angesetzte. halbmondformige Oberlippe ausgezogen. hinten auf der rechten Seite schief abgerundet und nach links in einen kurz und breit lanzellichen, schnabelartig zugespitzten Schvanz verengert. dessen Spitze nach rechts gebogen ist (Fig. 22. 24). Die beiden Seitentimler sind vorn cinander fast paratlel, hiuler der Mitte liegrt aber der rechte stark luieförmigr nach links und hinten un und stösst mit dem linken, hinter der Nitte sanft auswirts gebogenen Seitenrande unter Bildung einer schnabelförmigen Spitze zusammen. Zuweilen ist der Körper hinten nur ungleichseitig, stumpf eiförmig zugespizt und ohne schnabelfömigen Fortsalı. (Fig. 21). Die rechle vordere Seitenecke tritt stark hervor, die linke ist mehr abgerturlet. Der Körper besitzt eine ziemlich beträchtliche Dicke (Fig. 23), die Rickseite (Fig. 24 und die Bauchseite (Fig. 21. 22) sind aber fast granz plan, die Seiten alggerundel. Die Fom des körpers błeibt bei allen Bewegungen ganz unverïndert, nur das vortere und lintere Ende können in einem llachen Bogen gregen einander gekrummt werden, wie Fig. 23 zeigt.

Das Peristom reicht fast bis zur Mitte des körpers, es ist sehr breit, tief ausgehöhlt und ringsum greschlossen. Sein Innenrand liegt uach rechts von der Mittellinie und lauft derselhen bis zur Jöhe der rechten Seitenecke fast parallel, dann hiegt er hakenfömig nach rechts un und endigt an der rechten, etwas einwäts gezogenen Ecke der Oberlippe. Der gerade Theil des Innenrandes trigt cine sehr entwickelte, loreit bandförmige, undulirende Membran (Fig. 23. i.), unter der noeb borstenförmige, präorale Wimpern sitzen. Wegen der starken Verschicbung des Inuenrandes nach rechts hat der Aussenrand des Peristoms eine weit weniger schräge, mehr quere Richtung, als bei andern Oxytrichinen. Die vordern und die obern äussern aloralen Wimpern sind sehr lange kraflige Borsten; an Vorderrande stehen sie so weilliufig, dass hier im Ganzen nur 9-10 Wimpern vorhanden sind. Das schmale, im Verhattniss zum Peristomleld schr ethabene Stirnfeld wirl rorn von einer gerad abgestutzten Endflache begränzt. - Die locomotiven Wimpern beschranken sich auf eine selır geringe, genau bestimmbare Anzahl ganz gleichartiger, sehr langhorstiger, meist wirr sich hreuzender Wimpern, die aber deutlich in vier Längsreihen geordnet und durch weite, gleich grosse Zwischentaume von einander getrennt sind. Die beiden äussern Reiheı, welche den rechten und linken Seitenrand einnelımen, reprasentiren die Randwimpern, die beiden innern die Banchwinpern; eigentliche Stimwimpern so wie Afterwimpern lehlen gänzlich. Die rechte Randwimperreihe besteht aus sieben, ghteichwässig uber den ganzen Rand vertheilten Wimpern, lic linke wird nur von drei, auf die hintere Jialfte des Randes beschränkten Wimpern gebildet. Die rechte Bauchwimpereihe ist der rechten Randwimpereihe genähert und ilur parallel; sie bestelt aus sechs Wimpern, von denen die beiden vordersten auf dem Stirnfelde stehen, wahrend die letzte nahe vor der Schwanzspitze eingefuigt ist. Die linke Bauchwimperreilıe nimmt fast die Mittellinie des Banches ein, sie besteht wieder nur aus drei Wimpern, von denen die rorderste dicht hinter dem Peristomwinkel inserirt ist. - Yon den beiden, kurzovalen homogenen Kernen Fig. 21. n. n.) liegt der vordere links neben dem Innemande des Peristoms, der hintere in der Mitte des Körpers und etwas weiter nach links; einen Nucleolus unterschied ich nicht mit Bestinmtheit. Der contractile Behäter Fig. 22. c.) ninmut die Mitte des linken Seitenrandes cin; er zeigte oft nach vorn und hinten einen kurzen kanalintigen Fortsatz (Fig. 21). Der After (Fig. 2.. z.) wirl durch die nahe vor der Schwanzspitze gelegenen Excrementballen angezeigt.

Die Thiere schwimmen rastlos und sehr schnell in weiten Bogen umher und drehen sich dabei bestindig un die Längsaxe. Jch sah sic weder stillstehen, noch jemals nach rüchwäts fahıen. - Die einzige Art der Gattung is!

Psilotricha acuminata. Steix. (Taf. XII. Fig. 21-24).

Stein Characteristik neuer Iufusor. Lolos Januar 1859. S. 5.

Dieses Thier kam Ende. Iugust und Anfang September 1837 in einem Mistjauchentümpel auf dem Pfarhofe Stein. Organismus der lufusiunathere. 


\section{2}

in Niencgk sehr zahłreich ror. Die meisten Individuen machten sich sogleich durch ihre intensir grune Farbe bemerklich; diese riihrt lediglich ron verschluckten trauligen Monadenstöcken (anscheinend war es Spondytomorum quaternarium) her, die oft den ganzen Körper dicht erfüllten, das Parenchỵm selbst ist völliğ farblos. — Körperlänge $\frac{1}{2 \frac{3}{5}}-\frac{1}{20 "}$.

8. Gattumg. Oxytricha. Ehrug.

Taf. XI. Fig. 9-18. Taf. XII. Fig. 1-20).

Character: Kirpler metubolisch, linglich eifömig oder lïnglich elliptisch, hinten abgerundet, bisueilen stumpf zugespitzt;

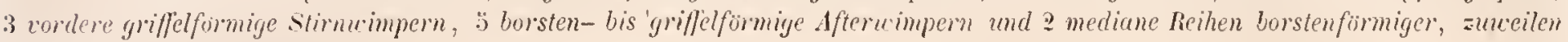
griffelihnlicher Baucheimpern.

Die Gattung Oxytricha wurde von Ehrenberg im J. 1830 Abhandl. der Berliner Acad. S. 43, mit 3 Arten begründet, von denen die allbeliannte 0 . pellionella als der eigentliche Repräsentant der Gattung anzusehen ist, denn die zweite Art, O. piscis, wurde spater in die Gattung Uroleptus versetzt und die dritte, O. pullaster, hat sich noch nicht mit Sicherheit wieder erkennen lassen. Nach Ehrenberg soll sich die Gattung von den ibrigen Oxytrichinen durch den blossen Besitz von Wimpern und Borsten und durch den Mangel von Haken (griffelförmigen Stirn- und Bauchıvimperm) und Griffeln (griffelförmigen Afterwimpern) unterscheiden. Dieser Character ist jedoch gegenwärtig ganz unhaltbar; denn die Oxytrichen besitzen sämmtlich Afterwimpern, und diese sind im Verhältniss zu ihrer Körpergrösse und zur Grösse der übrigen locomotiven Wimpern oft so kräftigg, dass sie mit demselben Rechte als Griffel bezeichnet werden können, wie bei den.Stylonychien. Ebenso sind ron den ibrigen locomotiven Wimpern wenigstens die drei vordersten auf der Stirn stets viel skirker entwickelt und in demselben Sinne Haken, den Ehrenberg mit diesem Ausdruck hei den Stylonychien verbindet. Ehrewberg's Gattungscharacter wiurde ferner nicht hinreichen, um die Oxytrichen von den Gattungen Psilotricha, Uroleptus, Stichotricha und lierona zu unterscheiden. Im girossen Infusorienwerk führt Elrenberg 8 Arten auf, von denen ich nur drei wieder auffinden lionnte, nåmlich O. pellionella, platystoma und caudata; letztere Art erwies sich uns als synonym mit Uroleptus piscis. Die fünf übrigen Arten, O. rubra (aus dem Meere), gibba, pullaster. cicada und lepus werden sich schwerlich je mit voller Sicherheit ermitteln lassen, da bei ihnen die nothwendigsten Bestimmungselemente iberschen wurlen; mit Ausnahme der schon oben S. 120 besprochenen 0 . cicada scheinen sie jedoch sammtich ächte 0syluichen zu sein. - Dujardin defmirt die Gattung wie Ehrenberg, will ihr aber auch die Urolepten zugezahlt wissen; er unterscheidet 8 Arten, nämlich O. pellionella, incrassata, lingua, gibba, ambigua, rubra, caudata und radians, diese sind jedoch sammtlich so unvollständig beobachtet, dass die Wissenschaft daraus nicht den mindesten Nutzen zu ziehen rermag. Die im Mittelmeer aufgefundene O. rubra weicht von der gleichnamigen Ehrenberg'schen Art durch den schwanzartig verlängerten Hinterteib ab, sie dïrfte also wohl zu Uroleptus gehören. Dic ebenfalls im Mittelmeer beobachıte O. gibba wird schwerlich mit der im süssen Wasser lebenden gleichnamigen Art ron Ehrenberg jdentisch scin. Die O. caudata gehört allem Anschein nach zu Uroleptus piscis, wie Uujardin selbst vernuthet. Von den vier angeblich neuen Arten wurden O. incrassata, ambigua und radians im Miltelmeer. O. lingua im süssen Wasser angetroflen. Letztere Art könnte der äussern Form nach eine junge Urostyla grandis gewesen scin, die O. radians hat gar nichts mit der Gattung Oxytricha gemein. - Perty nimmt die Gattung in demsellsen Umfange, wie Dujardin, nur bildet er aus den Urolepten eine besondere Unterabtheilung. Er will fast alle Ehrenberg'schen Oxytrichen und Urolepten in der Schweiz aufgefunden haben, giebt jedoch nicht an, wie es ihm möglich war, dieselben wieder zu crkennen, auch weiss er firr keine Art schärfere Merkmale aufzustellen. Dass Perly weder eine hlare Vorstellung vou den Grinzen der Galtung hatte, noch wusste, worauf es bei der Unterscheilung der Arten ankommt, lehren seine ö neuen Arten: O. ambigua, protensa, gallina, decumana und fusca. Ihre Bewimperungsverhältnisse sind so unvollständig beobachtet, dass sie nicht einmal generisch sicher bestimmt werden künnen. O. fusca gehört olıne Zweifel, O. decumana wahrscheinlich in die Gattung Urostyla, die von der gleichnamigen Dujardin'schen Art ganz verschiedene 0 . ambigua kann ein Uroleptus, aber auch etwas ganz Anderes sein; noch weniger lasst sich iiber die beiden andern Aıten, namentlich nicht uber O. gallina, eine Vermuthung aiussem. Jedenfalls sind dergleichen Arten nur unnitzer Ballast fïr die Wissenschaft, den man am besten über Bord wirft. - Bei Cluparéde und Lachmam ist die Gattung Oxytricha in einem viel weitern Unfange genommen, als bei Ehrenberg; sie begreift alle Oxytrichinen mit Ausnahme der Gattung Stichochaeta Clap. Lachm. und del Gattung Stylonychia im Sinne Elrenberg's. Die Zusammenstellung so heterogener Formen in eine Gatlung kiınu unmöglich gebilligt werden, und es ist 
gar nicht einzusehen, 'warum, wenn eimmal so zusammengezogen werden sollte, nicht auch noch die Gattungen Stylonyehia und Stichochaeta mit Oxytricha reseinigt wurden. Von den 9 Arten, welehe in der Gattung Oxytricha aufgefubrt werten, sind die nicht naher erhuterte 0 . pellionella und die neue 0 . crassa allein aichte $0 x y$ trichen; die O. urostyla, fusea und mullipes gehören in die Gallung Urostyla, dic O. cautlata und vielleichl auch O. gibba vergl. s. 17S) in die Gattung Uroleptus. Was endlich die beiden an den norwegisehen Küisłen entdechlen, höchst merkwürdigen neuen Arten. 0 . auricularis und retructilis betrifl, so enternen sich diese meiner Ansicht nach so erhelslich ron allen ibrigen Oxytrichinen, dass sie wohl unbedingt zu einer neven Galtung erhoben werden müsen.

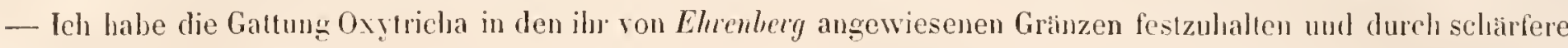
Charactere nen zu begründen versucht. Ausser den beiden Ehrenbery'schen Arten O. pellionella und platrstoma habe ieh noch eine Müller'sche Arl, zu der wahrscheinlich auch die O. crassa Clap. Lachm. gehörl, sowie noch vier neue Arten aufgefuntes.

Die Oxytrichen besitzen einen mässig verlängerten, sich mehr der gestreckten Oxal- und Eiform nähernden, hinten ajgerundeten oder stumpf zugespitzten, aber nie greschwänzten Körper mit stark gewölbtem Rúcken und wenig abgeplatteter, fast gewölbter Bauchseite. Das Parenchym ist stets selır naclıgiebig und dehubar, und dieser Character unterscheidet die Oxytrichen scharf von den Stylonychien, denen sie in der Bewimperung zuweilen sehr áhnlich sind. - Das Peristom ist ziemlich lang und schmal, es nimmt wenigstens ein Driltel der Körperlange ein und reicht meist fast bis zur Vilte des Körpers herab; sein Innenrand ist meist den Aussenrande selır grenähent oder doch wenigstens vorn lakenförmig gegen den Aussenrand umgebogen, der Vorderrand ist nut einer symmetrisch angeselzten Oberlippe versehen. - Die Randwimpern stehen meist nahe am hande, ragen über denselben weit hervor und gehen am hintern Körperende continurlich in einander ijber; nur bei zwei Arten sind sie der Mlttellinie genähert und hinten durch eine breite Lijcke getrennt, wclche von den finf Afterwimperm ausgefiilt wird. Letztere zeigen eine sehı :hhnliche Insertion, wic hei Stylonychia; sie sind bald nur borstenförmig, bald deulich griffelförmig. Auf den vordersten Theil des Stirnfeldes stehen stets drei längere und stärkere, griffelförmige Wimpern, die Stirnwimpern im engern Sinn. Die Bauchwimpern bieten bei den einzehen Arten sehr erhehliehe Verschiedenheiten dar; ihre Zahlen- und Stellungsverhälınisse sind meist ausserordentlich schwer zu ermilteln, da die Oxytrichen sich sehr anhaltend und schnell bewegen und nic ganz still stehen, sondern selbst wenn sie ıuhiger geworden sind, noch heständig langsam auf- und niedergleiten und sich unaufhörlich drehen, krimmen, strecken und verhürzen. Bringt man sie im flach ausgebreiteten Wassertropfen zum Stilliegen, so verkürzen und verbreitern. sie sich dermaassen oder nehmen so verzerrle Formen an, dass vollends keine blare Beobachtung der Banchwimpern möglich ist. So viel ich ermitteln konnte, sind iberall. wenigstens der Anlage nach, zwej mediane Reihen von Bauchwimpern vorhanden, die sich entweder continuirlich und unverändert anf das Stirnfeld fortsetzen oder hier in anderer Gruppirung und theilweis veränderter Form auftreten. Im letztern Fall ist die Bewimperung des Stirnfeldes und Bauches sehr ähnlich oder ganz eben so wie bei den Stylonyehien, und man könnte saimmtliche auf dem Stimfeld stehende Wimpern unter den Namen Stirnwimpern als eine fur sich bestelsende Gruppe zusammenfassen und den eigentlichen Banchwimpern entgegenstellen. Andererseits kann man auch die drei ăussem borstenfömigen Stirnwimpern der Stylonychien als cine Fortsetzung der rechten Bauchwimperreihe und die beiden inneru, hiutern griffelförmigen Stimwimpern als eine Fortsetzung der linken Bauchwimperreihe betrachten. Die Banchwimpern der Oxytrichen sind überwiegend borstenförmig, bei mehreren Arten nabern sie sich aber sehr entsehieden der Griffelform. - Die beilen Kerne und der contractile Behälter velbalten sich ảhnlich wie bei den verwandten Gathungen. - Der Mund wurde bei zwei Alten als eine ansehnliche Langss]alte erkannt, der After zeigte sich bej einer Art hinter den Afterwimpern und nahe ror dem hintern Körperende gelegen.

Unter den mir bekannt gewordenen 7 Arten lindel sich nur eine einzige Meeresform; nach den Beobachumgen von O.F. Mïller, Ehrenberg und Dujardin zu urtheilen, dürfte jedoch das Meerwasser noch eine reiche Ausbeute ron Oxytrichen lieferm. 


\section{4}

1. Oxytricha gibba. Stelx. (Taf. XI. Fig. 9. 10).

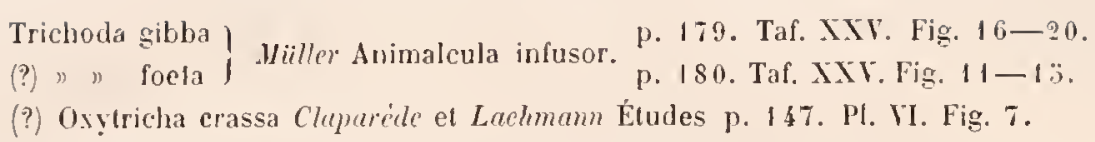

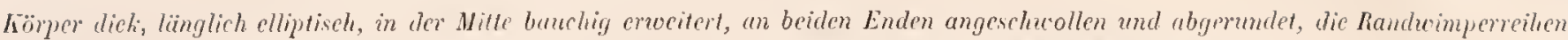

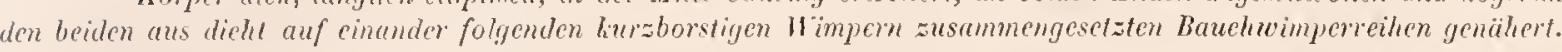

Ich beobachtete diese Art im Januar 1853 hixiufig im Seewasser aus dem Hafen von Traveminde gleichzeitig mit Ervilia monoslyla mul Styloplotes appendiculatns, anch traf ich sie in Maj 1857 nicht selten in einem Fláschchen mit Meerwasser ats dem llafen von Triest. Sie entfernt sich in ller Bewimperung am meisten von den übrigen Oxytrichen und schliesst sich niher an die Urolejten an. - Der Körper (Fig. 10) ist etwa :3 mal so lang als breit, lainglich elliptisch, in der Mitte auf beiclen Seiten mels oder weniger stark bauchig erweitert und zwar auf der rechten Seite mehr nach hinten, auf der linken Seite mehr nach vorn zu; nach beiden Enden hin ist der Körper etwas eingeschniil, die Enden selhst sind gleichmässig angeschwollen und abgerundet. Der Riicken ist stark gewölht und in der Nitte, der bauchigen Erweiterung entsprechend, buchlig aufgetrieben, die Seiten sind abgerundet und nur das Mitte]feld der Bauchseite ist abgeplattet. Beim lebhaften Schwinmen ist der Hinterleib gewöhnlich nacl rechts, der Torlerleib nach links gekrimmt (Fig. 9). - Das Peristom nimmt ein Drittel der Körperläıge ein, sein Innenrand jst nur durch eine sehr schmale spalte vom Aussenrande getrennt und begleitet denselloen bis zum Vorderand. Die adoralen Wimpern setzen sich meist iber den Yorderand hinaus nach rechts und hinten fort. Die

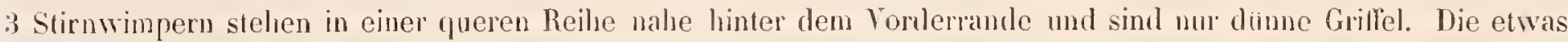
slàkern und längern Afterwimpern sind weit nach hinten eingefïgt, stehen in einer queren boggenförmigen Linje und ragen als ein hald nach rechts, bald nach linlis gehrimmter Schopf meist merklich iiber den Hinterrand hinaus. Die liurzborstigen Randwinperu sind so weil nach innen geríclit, dass sie bei der Rijckenansicht ganz unter dem Banche rerborgen bleiben; sie bilden zwei gromde einander parallele Reiheu, die rechte Reihe erstrechl sich ron Jer äussem Stirnwimper bis zur ersten Afterwimper, die linke ron der funften Alterwimper bis zmm Peristonwinkel, nehen tem sie ein wenigr mach links cndigt. Die beiden den Randwimperreihen parallelen und von jhnen etwas weiter, als von emander abstehenden Bauchwimperreihcu beginnen auf dem vordern Theil tles Stirnfeldes und setzen sich ohne Unterbrechung bis zu den Afterwimperu fort, sie bestehen ans ganz gleichartigen, nit uen Randwimpern nahe ibereinstimmenden, liurzborstigen Wimperm. - Die beiden kierne (u. n.) sind oval und homogen. Der contractile Behiilter 'c. liegt hinter dem Periston und etwas vor der Mlitte des linken Seitenrandes. - Körperlänge bis $\frac{1^{\prime \prime \prime}}{12}$.

Die von $0 . F$. Müller im Meerwasser häufig beohachtete Trichoda gibba, die Ehrenberg mit Unrecht auf seine im siissen Wasser lebende Oxytricha gibba bezieht, stellt meiner Ansicht nach nur die gegenwirtige Art dar. Sie besitzt genau dieselbe Körperform, anch sincl die Randwimpern hei der Rückenansicht nicht sichtbar, Müler unterschied dieselben aher bei der seillichen Ansicht des Thieres a. a. O. Fig. 19. f. sorgfaltig und er hebt ausserdem noch in der Beschreibung hervor: in quicte cilia per totam paginam inferiorem ludentia videbantur, was durchaus auf die Bauchbewimperung unserer Art passt. Die Afterwimpern hat Müllow zwar nicht gezeichnet, er erwähnt aber in der Beschreibung, dass er auch am hintern Ende hervorragende Wimpern gesehen halje. Die Afterwimpern verstecken sich übrigens anch sehr oft mnter den Bauche, indem sich das lintere Körperente weiter nach rijckwairts aussacht und die Bauchfliche sich elwas nach vorn verschiebt. Ich habe daher heinen Anstand genommen, fiir die gegenwärtige Art den Mülle'schen Speciesnamen anzuwenden. Die Trichoda foeta ron Müller scheint von seiner Tr. gibha nicht wesentlich verschieden zu sein und nur auf dunklern, undurchsichtigeren Individuen mit reichlichern körnigen Ablagerungen im Parenchym zu beruhen. - Die an len Bergenschen Küisten beolsachtete Oxytr. crassa ron Claparide und Lachmam is höchst wahrscheinlich nit der gegenwartigen Art identisch, dords weicht die Darstellung dieser Forscher in mehreren Puncten von der meinigen ab. Statt der vier parallelen Wimperreihen uler Banchseite werden funf angegeben, die funfte wirde sich rom Peristomwinkel aus dicht neben der linken Randwimperreihe herabziehen und sich derselben nach hinten sehr nahern. Yon Stirnwimpern ist nicht die Rede, die Afterwimpern werden als viel kiurzere und dummere Borsten dargestellt mol die vordern adoralen Wimporn sollen sich auf Iler rechten Seite nach hinten herabziehen; anch wirde keine Oberlippe vorhanden scin. Meine Thierc waren auch nie so auffallend hoch gewölbt und bucklig, wie das a. a. O. Fig. 7. a. abgebildete; es ware also immerhin möglich, dass die 0 . chassa eine ron meiner 0 . gihha verschiedene Art bildete. 
2. 0xytricha pellionella. EuIzlig. (Taf. XI. Fig. 13-18).

Trichoda pellionella Miiller Animalcula infusor. p. 222. Taf. XXXI. Fig. 21.

Oxytricha pellionella Ehrenberg Die Infusionsthierchen S. 364. Taf. XL. Fig. X.

Oxytricha pellionella Dujardin Infusoires p. 417. M. XI. Fig. 10.

lörper lineal-elliptiseh, in der Milte erweitert, un beiden Euden gleichmässig abgerundet, mit weit über den liörper vorragenden, langborstigen Aftrwimpern, nach eincearts geriichten, grösstentheils unter dem Banch verboryenen lianduimpern und wenigen, vereinzellen, borstenförmigen Bauchuimpern.

Obghleich diese Art iberall in Infusionen und stehenden Gewässern sehr verbreitet ist und zu den allergemeinsten Infusorienformen gehört, so ist doch ihre Organisation l,isher nur unvollstindig erforscht worden. Die geringe Grösse des Thieres, seine grosse Beweğlichkeit, scine vielfachen Formveranderungen und die dichten körnigen Ablagerungen iu Parenchym machen auch seine Beobachtung zu einer ler schwierigsten. Ich bin nach vielen Bemuhungen zu den nachfolgenden Resulaten gelangt. - Der Körper hat bei den entwickeltsten Individuen (Fig. 13. 14) eine sehr thnliche Form, wie bei der vorigen Art, nur ist er verlältnissmässig viel schmaler, 4. mal so lang als breil, in der Milte schwach bauchig erweitert, nach vorm und hinten verengert und liaum merklich eingeschniir, und an heiden Enden stumpf abgerundet. Der Rücken (Fig. 14) ist gleichmässig und ziemlich stark gewölbt, die Bauchllache (Fig. 13) in der Mitte massig ahgeplattet, die Seiten sind alygerundet. Bei jungern Individuen (Fig. 18) ist der Körper einfach lïnglich elliptisch mit schvach convexem rechten Seitenrande und gerarlem oler sanft einwäts gehrimmlem linken Seitenrancle. - Das Peristom stimmt in Form und relativer Grösse fast ganz mit dem der vorigen Art überein, nur verliert sich der Innenand ganz allnählig in der Nihe les Vorderrandes; auch die Stimwimpern verhalten sich ganz ähnlich. Die Randwimpern sind weniger weit nach innen seriicht, tloch liegen sie ebenfalls unter dem Bauche versteckt, nur die hintersten werden hiufig horizontal ansgespreizt und treten dann uber ten hand hervor. Beide landwimperreihen sind fast gerade und einander parallel und lören in einiger Entlernung rom hintem Körperende auf; in der hreilen Lücke zwischen ihren Endpuncten sind die 5 Afterwimpern eingefügt, lie hier gerissermaassen nur die stälker entwickelten Randwimpern lles llinterrandes darstellen. Die Alterwimpern sind sehr langborslig und ragen weit über den Körper hinaus, und hieran erkennt man auf den ersten Blick unsere Art. Die drei rechten Afterwimpern sind lie grössten und von gleicher Länge, die zweite ist jedoch etwas weiter nach rüchwärts eingefugt, als die erste und dritte, und. daher scheinbar länger; die vierte und funfte nehmen beträchtlich an Länge ab. Bej altern Thieren sind die Afterwimpern fadliche Borsten mit hakenlörmig nach links ungebogenen Spitzen. Die den Randwimpern ahnhlichen, kurzborstenfürmigen Bauchwimpern verhalten sich ganz anders, wie bei der rorigen Art, es sind nur sehr wenige vorhanden und diese setzen keine continuirlichen Reihen zusammen. Drei Bauchwimpern stehen auf dem Stirnfeld in einer schragen von der rechten Stirnwimper zum l'eristonwinkel gezogenen Linje; zwei andere sitzen dicht hinter dem Peristomwinkel neben einander und eine dritte gleich dahinter. Ausser diesen sechs zienlich leicht zu beobachtenden Wimpern ist noch ein weit nach hinten gerüclites, nahe vor den Afterwinpern eingefugtes Bauchwimperpar vorhanden, welches mir lange Zeit entging und sehr sehwer wahızunehmen ist, weil es anl' einem sehr dunklen, undurchsichtigen Grunde steht. Die funf, dem eigeutlichen Banch angehörigen Wimpern stehen also in der That in zwei, durch eine weite, mittlere Licke unterbrochenen medianen Lingsreihen und verhalten sich genan wie die fünf Bauchwimpern der sılongychien; die drei Bauchwimpern des stimbehls sehe ich als eine Forlsetzung der rechten Bauchwiuperreihe an. - Die beiden kurzoralen oder rundlichen homogenen Kerne (n. n.) liegen hinter dem Peristom in der linken Körperhälfte ungewölnnlich nahe hinter einander, so dass sie sich zuwcilen herilıren. Einen besondern runden Nucleolus laabe ich an ihnen oft mit grösster Bestmmtheit erkannt (Fig. 14). Der contraclile behäler (c.) liegt zwischen beiden Kernen etwas vor der Mitte des linken Seitemandes, den er bei der Diastole stark blasenartig nach aussen herrortreib. - In vordern und hintern Körperende findet sich fast inmer ein scharf beşanzter, dunkler Haufen von dichıl zusammengedrängten, feinen Felliörnchen, in dessen Centrum ein grosses rundes, von einem hellen Hal mmgebenes Fettioln (f.) wie ein Augre eingebettet liegt. Auch lïngs des linken Seitentandes zieht sich gewöhnlich ein breiter Streilen von lettlörnchen herab. Hin und wieder findet sich auch noch an irgend einem andern l'uncte des Parenchyms ein vereinzeltes grösseres Fettkorn, welehes von feinen Körnchen umgeben ist (Irig. IS). -

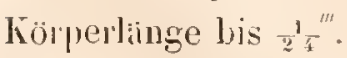

Die Quer- und Lingstheilıng scheint ganz nach denselben Gesetzen wie bei den Stylonychien zu erfolgen; die ersten Studien dieser Yorginge entzogen sich leider meinen Nachforschungen. In dem von mir beobachteten Stadimm der Quertheilung Fig. I:̈. 16 waren aus den beiden Körperbailften des Mutterthiers bereits zwei rull- 


\section{6}

ständig entwickelte Theilungssprösslinge hervorgegangen. Der vordere hing nur noch mittelst seines hintern Endes mit der rechten vordern Ecke des hintern Theilungssprösslings zusammen, er zeigle drei äberzahlige, in Eingehen begriffene Stirnwimpern, die Banchwimpern hatten bereits die gewöhnliche Stellung, nur waren die fünf hinter dem Peristom stehenden einander noch sehr genahert; die Afterwimpern ragten nach rechts iiber den Körper hinaus. Der hintere Theilungssprössling trug am Ende noch den alten Afterwimperschopf, der neu gebildete war viel weiter nach rorn eingefuigt und ragle ebenfalls über den rechten Körperrand hinaus. Die Küze und der dichtere Stand der Randwimpern zeigt an, dass sie nicht die Randwimpern des Mutterthiers sein können, sondern wie die ibrigen locomotiven Wimpern im Verlauf lles Theilungsprozesses neu entstanden sein muissen. Auffallend ist, dass sich in den beiden an einander stossenden Enden der Theilungssprösslinge bereits wieder eine Anhäufung von Fettkörnchen mit einem grössern centralen Kolnn gebildet hat (Figg. I ̈̈). - In dem von mir beobachteten Stadium der Länģstheilung (Fig. 17) hingen beide Theilungssprösslinge in ganz bhnlicher Weise an einander, wie im letzlen Liingstheilungsstadium bei Stylonychia pustulata; jedes Individuum zejgte im vordern und hintern Ende die gewöhnliche Anhänfung ron feinen Körnchen um ein grosses centrales Fettkorn (f. f.). - Die Thicre klettern gern an fremden Gegenstånden, winden sich um dieselben in den mannichfaltigsten Streckungen und Beugungen lıerum und kriimmen ihren Körper hierbei oft so stark ringförmig, dass die beiılen Enden einander berühren.

Mïller's Abbildung giebt die Gesanmtform des 'Thieres hinreichend characteristisch wieder, dem Afterwimperschopf werden aber meh. Wimpern zuertheilt, als er wirtich besilzt. - Ehrenberg's Darstellungen sind im Ganzen recht naturgetreu, aber unvollständig; denn die Stirn-, Rand- und Bauchwimpern wurden gainzlich übersehen. Dagegen erkannte Elwenberg zuerst das Peristom, welches nur zu kurz gezeichnet ist, die beiden Kerne, welche irrthimlich in die rechte Körperhălfte verselzt sint, und den contractilen Behäler. Afterwimpern werden hald 4, bald 5 angegeben. - Dujardin's Abhildung ist ganz verfehlt, sie giebt nicht einmal die aussere Form richtig an.

3. 0xytricha affinis. Stein. (Taf. Xil. Pig. 1-6).

hörper lineal-lanzettlich, nach corn zugespitzt, mit vorragenden, am hintern hörperende zusammenstossenden Randwimpern, sehr kurzborstigen, verstechten Aftcrwimpern und einem langen, schmalen, hinten linieförnig nach cinwärts getirïmmten Peristom.

Diese in sumpfigen Gewassern sehr verbreitete und durchaus nicht seltene Art blieb wahrscheinlich nur deshalb bisher unbeachtet, weil man sie ohne genauere Priifung für Oxytr. pellionella halten mochte, der sie in Form und Grösse sehr ähnlich ist. Ich unterschied sie auch erst seit Anfang März 1857, wo ich sie in Wassel aus dem St. Procop - Thale bei Prag, in welchem abgefallene Baumbläter vermoderten und viele Phryganidenlarven lebten, in grossen Schaaren beobachtete. Spater traf ich sie noch sehr oft in einem sumpfigen Graben des Baumgartens bei Prag, zum Theil gleichzeitig mit der hier seltener vorkommenden Oxyt. pellionella, von der ich sie stels aul' den ersten Blick unterscheiclen konnte. - Der Körper ist $3 \frac{1}{2}-4$ mal so lang wie breit, schmal lanzettlich, nach vorn stetig verengert und stark zugespitzt, mit sehr sclımalem, abgerundetem Vorderrande, der eine sehr hleine abgerundet dreieckige Oberlippe trăgt; das hintere Ende ist mehr oder weniger zugespitzt, der rechte Seitenrand bald convex (Fig. 4. 5), bald in der Mitte geradlinig und etwas einvärts gebogen (Fig. 1. 2). Der linke Seitenrand bildet in der Nitte einen stumpfeckigen Vorsprung, vor demselben ist er geradlinig, hinter demselben nach einwälts gezogen. Der Riicken (Fig. I) ist mässig gewölbt, die Bauchseite (Fig. 2. 4) plan, mil fast zugeschảıften Seiten. -Das Peristom ist eine lange schmale Spalte, die sich hart am linken Seitenrande bis zu dem stumpfeckigen Vorsprunge desselben herabzieht, hier knieförmig nach innen umbiegt und in der Níhe der Mittellinic etwas hinter der Körpermitte endet. Der schmale Vorderrand trägt nur wenige (̋̈-6) adorale Wimpern, die meisten übrigen såumen den geradlinigen Theil des linken Seitenrandes, iiler den sie weit hinausragen, sie sind quergesteltt, gleich lang und einer rom Anfingspunct des linken Seitenrandes an seinel innern Seite herablaufenden Linie eingefügt, die sich nach hinten zu mehr und mehr von demselben entfernt und zuletzt plötzlich in schrager lichtung nach innen umbiegt. Die dem schrägen Theil dieser Linie eingefügten Wimpern nehmen bis zum Peristomwinkel schnell und stetig an Länge ab. Der Innenrand des Peristoms ist fast eben so stark knieförmig gebogen, wie sein Anssenrand. dem er sehr genähert ist; er bildel mit dem schrigen Schenkel des Aussenrandes einen sehr spitzen Peristomwinkel, begleitet denselben eine Strecke und biegt dinn stumpfwinklig nach vorn um, indem er nun fast geuau der Mittellinie parallel bis zur linken Eche des Vorderrandes verlauft. Das Peristom hat hiernach die grösste Achnlichkeit mil dem von Stichotricha secunda, und es bedirfte nur noch eincr geringen Verlingerung der Stirnspitze, um selbst die Körperform unserer Art in die von St. secunda zu verwandeh. Wie sich die Gattung Oxytricha durch O. gibla 


\section{7}

innigg an die Gattung Uroleptus anschliesst, so sehliesst sie sich durch O. affinis ehen so nahe an die Gattungr Stichoticha an.

Die beiden Randwimperreihen reichen bis zur Hinterleibsspitze, wo sie in einander übergehen; die Wimpern der rechten Reihe stelsen nahe an Ramle und ragen weit uber denselben binaus, von den Wimpern der linken Reihe steht nur die hintere Halfte an Rande, die vordere ist nach cinwilts gerichtet und endet an Peristomwinkel. Sammfliche Randwimpern sind langborstig, die hintersten efwas länger. Die 3 wenig entwichelten Stirnwimpern stehen hart am Vorderande in Dreieck. Die Afterwimpern sind b̈ sehr hurze, feine, in einiger Entfernung von der Hinterleibsspitze eingefuggte Borsten (Fig. 2. a. 4. a.), die ganz unter dem Bauch verborgen sitzen und sich um so schwerer wahrnehmen lassen, als das hintere Körperende, so wie auch die linke Bauchlıälfte, gewöhnlich ılichıt mit Fetıörnchen erfült sind. Die erste und fünfte Afterwimper liegen sich oft halienförmig nach vorn um (Fig. ?. 6). sie gleichen dann cinem hintem Bauchwimperpaar. Oefters schien es mir, als sei ausser den 5 Afterwimpern noch ein besonderes, dichı vor ilmen sitzendes Banchwimperpaar rorhanden, wie ich dies in Fig. 4. und $\ddot{3}$ angegelsen habe, zu einer vollen Gewissheit kounte ich jedoch dariher nicht grelangen. Die Zihl und Stellung der Bauchwimpern ist hier eben so schwer, wie bei 0 . pellionella, zu hestimmen. Ausser dem noch elwas problematischen hintern Bauchwimperpaar vermochte ich auf dem IJinterleib durchaus keine andern Bauchwinpern zu unterscheiden, diese schienen sich viehmelı lediglich auf den Vorderleih zu beschrinken. Hier sah ich stets eine schrage Reilıe von $\ddot{j-6}$ Borsten, die sich rom Anfangspunct der rechten Randwimperreihe bis zum Peristomwinkel erstreckte: zuweilen schien es mir, als setzte sich diese Reilse noch weiter nach hinten fort. Weiter nach innen, auf dem Stirnfelde, stehen noch 3-4. efwas stirliere, den Stimwimpern ähnliche, hakenförmige Wimpern; eine isolirte sit: dicht an Innenrand des Peristoms kurz vor der knieförmigren Biegung desselben, die zwei oder drei andern stehen in einer von der iechten Stimwimper nach dem Peristomwinkel grezogeuen Linie, unt zwar die eine niber der Stirnwimper, die eine oler zwei andern näher dem Peristomwinkel (Fig. 2. 4).

Die beiden Kerne (Fig. I. 1. n.) sind langlich oval und homogen, der vordere liegt fast in der vitte des Stimfelds, (ler hintere nahe hinter den Peristomwinkel. Der eontractile Behälter (c.) ist wie hei Stichotricha von dem linken Seitenrande nach innen in die Nahe des Peristomwinkels gerïcht. — Von der Quertheilung beobachtete ieh nur das erste Stadiun (Fig. 5). Der müterliche Körper hatte sich hinter dem Peristom stark nach links ausgebaucht, und auf dieser Ausbauchung zeigte sich die erste Anlage zu einem neuen adoral('n Wimperbogen (p'.). Die Iscilen kerne (n. n.) halten sich verlängert und Bisquitform angenommen, und auf dem Stirnfelde untersehicd ich setur deullich eine von der linken Ecke des Vordenandes schüag nach hinten und rechts verlaufende Reilıe selır zarter Wimpern, welche sich jedenfalls später zu einem neuen System von Stirn- und Banchwimpern fiir den kïnftigen vordern Theilungssprössling gestalten werden. - Lingstheilung sah ich nur nalıe vor dem Abschluss (Fig. 3); der rechte Theilungssprössling iberragte, wie gewöhnlich, mit seinem vordem Ende den linken, dieser hatre sich aber stets so getreht, dass er im Profil erschien, wenn ler rechte dem Beobachter die Riiclien-oder Bauchseite zuhehrte. Die aus der Lingstheilung hervorgehenden Individuen sind of sehr schmal und fast linealiseh (Fig. 6). Die grössten Individuen erreichen eine Länge von $2^{4}{ }_{4}^{4}-\frac{1}{1}{ }^{\prime \prime \prime}$.

\section{Oxytricha ferruginea. Steix. (Taf. xi. Fig. $11-12$ ).}

Körper breit lineal-oblong, vorn plötzlich ungleichschenklig und stumpf zugespitzt, hinten etwas erweitert und abgerundet, mit vorragenden, hinten zusammenstossenden Randwimpern, langere griffelförmigen, unter dem Bauch verborgenen Afterwinjern und wenigen kurz griffelformigen Bauchwimpern.

Die O. ferruginea ist eine schon an ihrer Körperform und der melır oder weniger intensir rostrothen Färbung ilres Parenchyms leicht zu erkennende Art. Ich beobachtete sie im September 1837 sehr hăufig im Pullbach bei Niemegh gleichzeitig mit Uroleptus piscis zwischen Bauschen ron Oscillarien und Conferven, welehe an der staubigen Oberflache des Wassers schwammen. Auch bei Prag habe ich sie seitdem unter gleichen Verhältnissen sehr

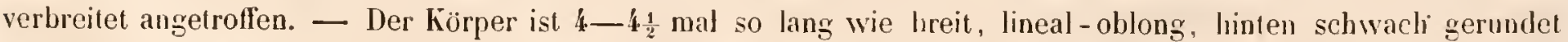
erweitert, mit abgerundetem oder fast abgestutztem IIinterrande; die Seitenränder sind fast ganz gerade und einander parallel oder doeh nur nach der Nitte zu schwach eimwärts gebogen, der linke Seitenrand reicht viel weiter nach vorn, als der rechte, das stumpf eiförnig zugespitzte Vorderende erhält dadurch einen sehr ungleichschenkligen Rand. Die Rüchseite ist flaclı gewölbt, die Batehseite abgeplattet. - Das Peristom nimmt ein Drittel der Körperlänge ein und ist viel breiter, als bei den vorhergehenden Arten. Der mit einer deutlichen undulirenden Membran 


\section{8}

versehene Innenrand fäll last mit der Nittellinie zusammen, ist so lang wie der Aussenrand und vorn gegen denselben hakenförmig umgebogen. Die der Spitze des Vorderandes etwas schief aufgesetzle Oherlippe ist auf der rechten Seite in einen niedrigen Hautstreifen vertingert, welcher nach hinten und innen in der Richtung gegen den Peristomwinkel verlatuft und allmahlig in eine seschte his zum Peristomwinkel reichende Furche ïbergeht. Hierdurel setzl sich ein allscitig begränztes Stirnfeld ab. Die adoralen Wimpern begleiten die Oberlijpe iiber den eigentliclıen Vorderrand hinaus nach rechts und hinten bis zu dem Ende des streifenförmigen Fortsatzes. — Die 3 lraftigen slirnwimpern stelıen mehr aus einander geruickt in einer schrägen, dem rechten Schenkel des Vorderrandes parallelen Linie. Die noch langern und stähern griflelförmigen Aftervimpern sind so weit vor dem Hinterrande eingefügt, dass sie denselben nur mit ihren Spizen erreichen. Die Bauchwimpern sind liurz griffelförmige Ilaken; auf dem eigentlichen Batche stehen deren $\ddot{0}$, in derselben Anordnung, wie bei O. pellionella, nimlich 3 hinter dem Peristomwinkel und 2 dicht vor den Afterwimpern (Fig. 12); ausmahmsweise beobachtele ich bei grossen Individuen noch ein miltleres Par (Fig. 11). Ausserdem finden sich auf dem Stirnfelde noch 2 hinter cinander stehende Bauchwimpern am Innenrande des Peristoms und zwei dergleichen, weiter rijckwirts gerickte, an der schielen zum Peristomwinhel verbufenten Falte. - An den beiden ovalen kernen unterschied ich lıäufig eine spaltfömige llöhle und auch bestimmt einen Nucleolus (Fig. 11. n. n.) Der contractile Behalter (c.) liegt elwas vor der Mlitle des linken Seitentandes. - Der Hinterleib ist meist dicht mit gefressenen Naviculaceen und Bacillarien, wie auch mit vereinzelten Oscillarienfäden erfullt, ihre Zersetzungsproducte ertheilen dem ganzen Parenchym die rostrothe Farbung. Längs des linken Seitenrandes findet sich immer eine reichliche Ablagerung von Fetlkörnchen. — Die Thiere schwinmen missigg schmell; zwischen Conferven bewegen sie sich sehr geschichl schlangelnd, indem sie den körper in weiten Bogen nach linlis und rechts lirimmen, wie dies in eiucm geringen Grade schon bej dem in Fig. I? dar-

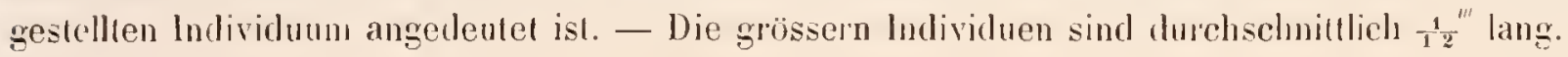

\section{Oxytricha mystacea. Steix. (Taf, xil. Fig. 7-11).}

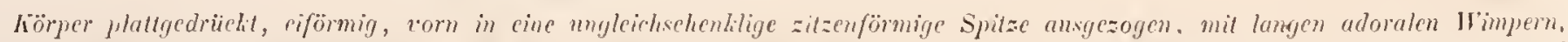
vorragenden, himten zusammenstossenden und verlängerten liandwimpern, diün griffelförmigen, unter dem Bineh verstecliten Afterwimpern und dirhtstehrnden, feinborstigen Banchuimpern.

Ich entdeckte diese An in Juli 1958 in einer Mlistjauchengrube in Tharand, wo sie zwischen Euglena viridis und Chlamydomonas pulvisculus, die die ganze Oberflache der Flissigkeit ariin furbten, ziemlich häug vorkam. Im Augus 1856 traf ich sie wieler in zahlucichen Excmplaren in dem Mlispfulıle anf dem Pfarrhofe in Niemegh, und in neuester Zeit habe ich sie anch bei l'rar in einem Timpel des Canal'schen Gartens, der ebenfalls starlie Zullisse von Mistjauche crhilt, mehrfach anlgefunden. In den beiden letzlern Localitaten war die auflallendste legleitende Infusorienform mein Didinium nasulum. - Der Körper (Fig. 7. 8) ist $2 \frac{1}{2}$ - 3 mal so lang wie lreit, Jinğlich eiförnigr, auf der rechten Seile sehr convex, auf ter linken in der Jlitle sinft nach einwärts gekiummt, nach linten zugerundet und nach rorn in eine alıgerundete, ungleichschenhlige, fast zilzenförmige Spitze ausgezogen. Jhr rechter convexer Schenkel setzl sich vor dem rechten Seitenrande durch eine seichte Einschnirung ab, ihr linker, likingerer, gerallinger Schenkel bildet mit dem linken Seitenrande einen slumpfechigen Yorsprung. Die Rijekscite (Fig. 8) ist lach gewolbt, die Bauchseite (Fig. 7) abgeplattet. Alte Individucu (Fig. 9) sind plumper und breiler, hinten stumpfer abgerundel und vorn in eine hreitere und stumpfere, nicht so scharf abgesetzle Spitze ausgezogen. - Das Peristom reicht l,is nahe zur Mltte des Köpers, sein Innenrand liegt in der Miltellinie oder doch nur wenig naclı links von derselben, er ist so lang wie der Aussenranul und vorn schwach hakenförmig gegen denselben umgebogen. bie Oberlippe ist der Spitze des Vorderrandes etwas selief und mohr nach rechts angeselzt; von ihrer rochten Edhe zeht eine schräge latte nach dem Peristonwinkel, so dass auch hier, wic hei der vorigen Art. ein scharf abgegranzles Stirnfelıl vorhanden ist. Die adoralen Wimpern, namentlich die des Aussenrandes sind ungewöhnlich lang. Im Peristomfelde unterschied ich dicht am lnnenrande, wenn sich dersolhe elwas nach rechts wendete, schr bestimmt eine lange enge Mundspalte Fin. 9. o.). - Die handwimpern stehen nahe am Rande und ragen uber denselhen weit her or, sie nehmen nach hinten melilich an Limge zu und gehen an Ende in einander iiber; die linlie Reihe ist nach vorn nur missig einwärts gezogen. Die Stimmimpern verhalten sich wie bei der rorigen An; die Alterwimpern Fig. 9. a.) stehen in einer schurgen, nach links und rorn anfsteigenden Reihe, sind nehr borsten- als trillelförmig und rejelsen lium bis zum llinterrande. Die feinborstigen, liurzen Banch-

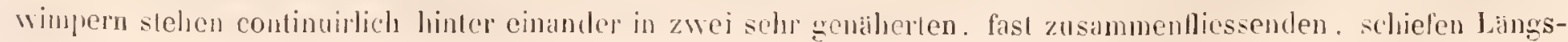


reihen, die sich rom Peristomwinkel bis zur finften Afterwimper erstrecken. Die rechte Reihe setzt sich nach rorn längs der ganzen schragen Falte fort, welche den Aussenrand des Stirnfeldes hildet; an dieser Falte stehen 8-10 Wimpern. Die linke Bauchwimperreihe wird auf dem Stimfeld nur durch zwei an Innenrand stehende dume sriflelfömige Wimpern vertreten, auch die erste hinter dem Peristomwinkel stehende Wimper dieser Reihe ist stäker und mehr griffelförmig. - Die beiden ovalen Kerne zeigten gewöhnlich eine spaltförmige Höhle (Fig. 7. S. n. n.). Der contractile Behálter liegt in der llitte des linken Seitenrandes, der bei der Diastole of blasenfürmig nach aussen gewölbt wird (Fig. 8. c.) - Das Parenchym zeichnet sich durch eine blass bläuliche Färbung aus. Die Thiere hatten meist grosse Quantitaten von Euglenen, auch einzelne Vorticellen rerschluckl (Fig. 9). - Körperlänge $\frac{1}{1^{6}}-\frac{1}{1^{\prime \prime 2}}$.

In allen Localitaten, wo ich 0 . mystacea beohachtete, traf ich häufig eigenthümliche Cystenzustande an, die lıöchst wahrscheinlich ron dicser Art herrihhten. Die Cysten (Fig. 10) waren rund und ron seh" dicken, gallertarligen, concentrisch gestreiften Wandungen (a.) begy'thzt, denen äusserlich feine Molecüle anklebten; sie umschlossen eise halbflissige mit zalulrcichen Felltröpfchen gemischte Iasse, und in dicser lag eine zweite, der äussern conforme, aber riel dünnwandigere, resistentere und glatte Cyste (b.) eingebettet, welche erst den thierischen Körper umschloss. Dieser fültte die Cyste vollständig aus und wäzte sich noch läufig in derselben langsam rotirend umher; er enthielt nahe an der Oberflache den contractilen Behälter und im Centrum die beiden dicht an einander geriichten Kerne. Offenbar hatte sich das Thier zuerst mit der äussern Cyste umgehen, dann innerhalb derselben einen Theil seiner Körperhestandtheile ausgeschieden und zuletzt um sich die zweite Cystenhïlle gebildet. - In der innern Cyste (Fig. 11. b.) hatten sich auf Kosten des eingeschlossenen Körpers öfters mehrere ganz tihnliche parasitische Algenschläuche (c.d.) entwickelt, wie in den einfachen Cysten von Stylonychia pustulata; sie wachsen bei der Reife in einen engen röhrenfömigen Fortsatz (c.) aus, der, beide Cystenwandungen durchbohrend, nuch weit iiber die äussere hinausragl. Ich sah nur geschlossene und hereits entleerte Schläuche.

\section{Oxytricha fallax. Steix. (Taf. XII. Fig. 12-15).}

Förper plattgedrïckt, eiförmig, vorn plötzlich fast gleiehschenklig und stumpf zugespitzt, mit vorragenden, hinten zusammenstossenden und verlängerten fandwimpern, griffelfömigen über den Hinterrand hinausreichenden Afterwimpern und wenigen vereinzelten griffelförmigen Bauchuimpern.

Die O. fallax stimmt in der Bewimperung sehr nahe mit den Stylonychien iberein und ist wahrscheinlich oft fur Styl. pustulata gehalten worden, mit der sie gleiche Grösse hat. Ich beolbachtete sie zuerst im April I85ł. bei Tharand im Badethal an ausgetretenen Stellen der Weiseritz, unterschied sie jedoch damals noch nicht recht sicher von Styl. pustulata. Genauer lente ich sie erst in Prag kemen, wo ich in Marz I85\% eine grosse Anzahl von Individuen zu untersuchen Gelegenheit hatte. Ich traf diese an seichten Stellen des Bachs, welcher alas Procopthal durchfliesst, zwischen vermodernden Bamblättorn und gleichzeitig mil Oxytr. affinis. Auch iu den Gräben des

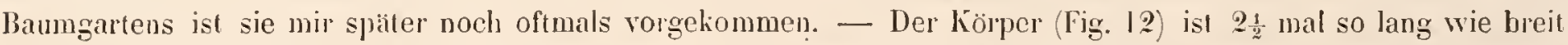
länglich eiförmig, hinten zugerundet, nach vorn allmählig etwas verengert und dann plötzlich fast gleichschenklig dreieclig und stumpf zugespitzt; der rechte Schenkel des Vorderrandes ist nur wenig langer und etwas convexer, als der linke, melır geradlinige. Der Rücken ist sehr flach gewölht, die Bauchseite ganz plan. - Das Peristom rerhält sich fast genau wie bei der vorigen Art, nur ist die Oberlippe auf der Spitze des Vorderrandes symmetrischer aufgesetzt, dic adoralen Wimpern des Aussenrandes sind nicht ungewöhnlich rerlangert und der Innenrand ist rorn noch stärker nach links umgebogen; auch dic lange Mundspalte (o.) ist oft sichthar. Die Stirn- und Randwimpern stimmen ebenfalls mit denen von O. mystacea überein; die den Hinterrand săumenden Wimpern sind noch lingere und liräfligere Borsten. Die Afterwinpern sind lange borstenförmige Griffel, die drei ersten ragen stels lsetrachtlich iber den Hinterrand hinaus, dic zweite ist weiter nach hinten eingefugt, als dic erste, die drei ibrigen stchen in einer schräg nach links aufsteigenden Reilse. Die Bauchwimpern sintl kurze, halienförmige Grillel, fünf derselben stehen auf dem eigentlichen Bauche in ganz ähnliches Grupjirung wie die fünf Bauchwimpern der Stylonychien, die fünf ibrigen sitzen auf dem Stirnfelde, und zwar zwei etwas grössere am Innenrand des Peristoms, und drei melır borstenfömige in einer schragen von der rechten Seitenecke nach dem Peristomwinkel gezogenen Linie. Die acht Wimpern des Stirnfeldes stimmen in ihrer relativen Grösse und Stellung sehr nahe mit den acht Stirnwimpern der Stylonychien überein. - An den beiden ovalen Kernen (n. ı.) unterschied ich stets schon durch das sehr durchsichtige, farblose und körnerarme Parenchym hindurch einen hesondern Yucleolus. Der contractile 


\section{0}

Behälter (c.) liegt in der Nähe des linken Seitenrandes auf gleicher Höhe mit dem Peristomwinkel. - Körperlảilge $\frac{1}{14}-\frac{1}{12}$."

So nahe sich auch unsere Art durch die Bewimperung des Stirnfeldes und des Bauches an die Stylonychien anschliesst, so kann sie doch ummöglich mit denselben vereinigt werten; sie ist eine ächte Oxytricha, wie sowohl die grosse Dehnbarkeit und Contractilitat ihres Parenchyms, als auch ihre noch vicl nähere Verwandtschaft zu der vorigen unl folgenden Art beweist. Gerathen die Thiere zwischen fremde Gegenstände, so zichen sie sich entweder sofort zu einem kurzen, breit eiförmigen Körper zusammen ( $\mathrm{F}$ ig. I3), oder sie recken sich lang aus, winden sich schlängelnd in starken Bogen nach links und rechts (Fig. 14) und suchen siclı so zwischen den fremden Gegenständen hindurch zu zwärgen. Dergleichen Bewegungen vermag heine Slylonychia auszufiihren. Die Thiere schwimmen ungemein schnell und anhaltend, und die grosse Schmiegsamkeit ihres Körpers giebt sich auch hierbei in vielfachen zierlichen Krummungen und Wendungen zu erkennen; sie bleiben niemals eine Zeit lang still stehen, noch fahren sie abwechselnd stossweise hin und her. Schon allein an den Bewegungen unterscheidel man die $O$. fallax ron der steifen Stylonychia pustulata auf den ersten Blick, bei genauerer Beobachtung erkennt man dann auch, dass sie eine andere Körperform, ein anderes Peristom und eine wesentlich verschiedene Bewimperung am Hinterrande des Körpers besitzt. - Mehrmals traf ich die gegenwälige Art in kugelförmigen, diinnwanligen, weichen Cysten eingeschlossen (Fig. 1:3); das Thier hatte sich nicht kugelförmig contrahirt, sondern war ringförmig un die Queraxe zusammengekrünmt und noch mil sämmtlichen Wimpern versehen, es välzte sich nuaufhörlich mit grosser Heftigkeit in der Cyste umher.

In Ehrenberg's aus äterer Zeit herrihrenden Abbildungen der Stylonychia pustulata (Die Infusionsthierehen Taf. XLII. Fig. I. 3-20) ist der ganze Hinterand des Körpers mit langen Borsten besetzt dargestellt; es wäre daher wohl möglich, dass diese Abbildungen wenigstens theilweis auf Beobachtungen ron Oxytr. fallax beruhen. Auch Müller's Kerona lepus (Animalc. infusor. p. 243. Taf. XXXIV. Fig. 5-8) und Ehrenberg's Oxytricha lepus (Dic Infusionsth. S. 367. Taf. XL1. Fiğ. V) könnten, nach der äussern Körpcrform und dem Aufenthalte zu urtheilen, die gegenwärtige Art darstellen, es bleibt dies jedoch nur eine sehr unsichere Vermulhung, da beiden Autoren die Organisation der Banchseite gänzlich verborgen blieb; sie unterschieden nichts weiter als die rordern adoralen Wimpern und die lintern Randwimpern.

7. 0xytricha platystoma. EnRBg. (Tal. XII. Fig. 16-20).

Oxytricha platystoma Ehrenberg Die Infusionsthierch. S. 363. Taf. XLI. Fig. 1. (auf der Tafel als Oxỵtricha eurystoma bezeichnet).

hörper länglich umgehehrt-eiförmig, hochgewölbt. mil ueitem Peristom, langborstigen, corragenden und hinten zusammenstossenden Randwimpern, wenig vorstehenden, diimen griffelförmigen Afterwimpern und wenigen, vereinselten borstenförmigen Bauehwimpern.

Die 0. platystoma, welche in Folge einer Bemerkung ihres Entdeckers mit Unrecht in den Verdacht liam, dass sie eine jugendliche Form von Urostyla grandis sein könne, ist eine sehı ausgezeichnete, von U. grandis ganz verschiedene Infusorienform. Sie gehört zu den seltneren Arten, wo sie alser einmal vorkommt, da tritt sie gewöhnlich in zahlreichen Individuen auf. Ich beobachtete sie zuerst im Mai und Juni 1834 bei Tharand auf einer sumpfigen Wiese des Badethales; dann traf ich sie erst wieder im Mlai 1858 bei Prag in den sumpfigen Graben sowohl des Baumgartens als des Nussler Parkes und zuletzt sammelte ich sie im September desselben Jahres an seichten, verschlanmten Stellen des Boliczbaches bei Wirschowitz. - Der Körper ist 2_2! mal so lang wie breit, schmal umgekelırt eiförmig, vorn breit und stumpf abgerundet, zuweilen fast abgestutzt, nach hinten verengert und stumpf zugespitzt, bald mit abgerundeter (Fig. 17.19), bald mit etwas vorgezogener Spitze (Fig. 16. 18). Der linke Seitenrand ist weniger convex, als der rechte Fig. 19), gewöhnlich fast gerade (Fig. 17); olt sind beide Seitentainder in der Nitte etwas nach einvärts gezogen (Fig. 16). Der Körper besilzt eine beträchtliche Dicke, der Rücken (Fig. 16. 1 7 ) ist stark gewölbt, vorn plötzlich abgestutzt, hinten niedergedrückt, die Bauchseite (Fig. 18. 19) ist plan oder flach gewölbt, die Seiten sind mehr oder weniger alıgerundet. - Das Peristom reicht nicht ganz bis zur Mitle des Körpers und zeichnet sich durch seine Breite und eigenthimliche Form so aus, dass man hieran die Art sogleich erkennt. Der Vorderrand des Peristons wirl von einer breiten, halbmondförmigen, synmetrisch angesetzten Oberlippe und den ihrer Basis eingefugten rordern adoralen Wimpern gebihlet; der Aussenrand erstrecht sich ron der linken Ecke der Oberlippe in einem schrigen Bogen bis zur Mittellinje des Bauches; der Innenrand folgt rom Peristomwinliel aus nur eine kurze Streclic der Mittellinie, dann wendet er sich nach rechts nud krimmt sich allmählig in einem weiten, dem Vorderrande fast palrallelen und von ihm nur durch einen schmalen Zwischenraum getrennten Bogen 
gegen den Aussenrand des l'eristoms. In vielen Fällen stösst das vordere Ende des Innenrandes unnittelbar an den Aussenrand, so dass ein ringsim ahgeschlossenes Peristonfeld entstelit (Fig. 16. 18), welches vorn von einem lakenförmigen Fortsatz des Stirnfeldes ungirtet wird. Das Peristomfeld ist lief ausgehöhlt, namentlich gegen den Imenrand hin, es erscheint daher bei der Rüchenansicht des Thieres Fig. 16) als ein selur lichtes, umgekehrt eiförmiges, mit der Spritze nach innen und hinten gerichtetes Felı. Der Innenrand trăgt eine sehr entwickelte, breit bandförmige undulirende Membran, die bald horizontal liegt (Fig. 19. i.), bald sich vertikal aulrichter und nach rechts umschligigt (Fig. I 8. i.). In letztern Fall sieht man, dass unter ihr am Innenrande noch feinborstige präorale Wimpern sitzen, auch crblickt man dann neben dem Innenrande auf dem Boden des Peristomfeldes die langspaltige Mundöthung $(0)$. In andern, eben so haufigen Fällen setzt sich die Spitze des Innenrandes nicht an den Aussenrand an, sonderu sie rollt sich in geringerer Entfernung ron demselben sehr zicrlich spiralförmig nach linten und innen um; alsdann greif der hakenförmige Fortsatz des Stirnfeldes mit einer dreieckigen, schart begräinzten Erweiterung (Fig. ?.). d.) un die eingerollte Spitze des lnnenrands herum, und das l'eristomfeld erhilt hierdurch die Form eines breiten $\$-$ Zeichens.

Die locomativen Wimpern verhalten sich sehr ahnlich, wie bei der vorigen Art, die dimnen, langborstigen Randwimpern werden jedoch nach hinten zu nicht langer, dic schwächern Stirnwimpern stehen in einer mehr queren Reihe; die Afterwimpern sind sehr dimne, borstenförmige Griffel, von denen nur die beiden ersten elwas über den llinterrand hinatusragen, die drei äbrigen stehen in einer steilen aufsteigenden Reilıe. Die Bauchwinpern stimmen in Zahl und Stellung ganz mit denen der vorigen Art überein. sie sind aber fast rein borstenförmig und den Randwimpern sehr ihnlich. - Die beiden ovalen Kerne zeigten sich bald homogen (Fig. I6. I 8), bald mit einer queren Hölıle (Fìّ. 17.19) und stets mit dem gewöhnlichen Nucleolus versehen. Der contractile Behälter findet sich etwas vor der Mitte des linken Seitenrandes. Die Ausscheidungron Excrementen beobachtete ich einige Male ganz nahe vor dem hintern Ende bei z in Fig. 19. - Das Parenchym ist meist dicht mit scharf begränzlen, farblosen Kugeln erfïllt, die eine schwarze oder bräunliche Körnermasse umschliessen und den Körper sehr undurchsichtig machen (Fig. 17. 19. 20). Wahrscheinlich sind dies lialbverdaute grime monadenartige Infusorien, dergleichen häufig noch ganz unverändert im Körper vorliommen (Fig. 16). Ausserdem finden sich aber durch das ganze Parenchym zerstreut und oft selbst in der Oberlippe (Fig. 18-20) zahlreiche, sehr hleine, grinlichgelbe oder brłunlichgelbe Oellsảschen, welche dem gesammten Körper eine schmutzig gelbbraune Farbe crtheilen. - Der Körper ist wegen sciner Dicke weniger biegsam, als bei den ïbrigen Oxytrichen, aber keineswegs starr. — Längstheilung habe ich nur einmal gesehen, olıne dariber etwas Genaueres ermitteln zu können; sie erfolgte von hinten nach vorn. Quertheilung kam auch nur selten vor; ich habe das erste Stadium derselluen in Fig. 20 abgebildet, obrvohl ich die mediane Bewimperung nicht vollständig erkannte. Wahrscheinlich waren die mütterlichen Bauchwimpern noch sämmlich vorhanden und noch keine neuen locomotiven Wimpern hervorgewachsen. In der hintern Körperhälfte zeigte sich nur crst der $\Lambda$ nfang zu einem neuen adoralen Wimperłogen ( $\mathrm{p}^{\prime}$.) und links neben denselben ein never contractiler Behälter $\left(c^{\prime}.\right)$. Von besonderem Interesse war, dass, wảhrend dic beiden mütterlichen Kerne (n. n.) noch ihre gewölnnliche Form beibehalten hatten, jeder Nucleolus (ul.) sich betrảchtlich vergrössert und aus zarten Liingsfasern zusammengesetzt zeigte. - Die Länge der grössten Individuen belıägt $\frac{1}{1}{ }^{\prime \prime \prime}$.

Ehrenberg hat zwar die O. platystoma ganz kenntlich abgrebildet, aber die feinern Organisationsverhailnisse blieben ihm völlig unbekannt. Er unterschied weder die Stirn-, Bauch- und Afterwimpern, noch die Kerne und den contractilen Behiblter; selbst uber Riichen- und Bauchseite war er nicht im Klaren, denn seine Fig. I stellt nicht, wie angegeben wird, die Bauchseite, sondern die Ruckenscite des Thieres dar. Die Randwimpern liess Ehrenberg gुleichförmig rings um den ganzen Körperrand herumlaufen, und das Peristom sah er als eine für sich hestehende, mil dem Kö̀perrand gar nicht zusammenhängende, von Wimpern umgebene Mundötlinung an.

\section{Gattung. Irostyla. Enriza. \\ (Taf. XIII. XIY).}

Character: Kürper schr metabolisch, langgestreclit, elliptisch, oblong oder cifurmig, vorn und hinten abgerundet; 3 ader

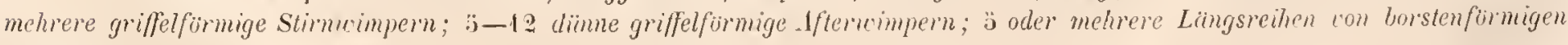
Baucheimpern.

Die Gattung Urostyla wurde von Ehenberg im J. 1830 (Mhandl. der Berliner Acnd. S. \&3) mit zwei, nicht naher characterisirten Arten aufgestellt, die aber schon im folgenden Jahre unter dem Namen U. grandis in eine 
zusammengezogen wurden; diese bildet auch noch im grossen Infusorienwerk den einzigen Repräsentanten der Gattung. Unter den Oxytrichinen sollte sich die Gattung Urostyla durch den Besitz von Griffeln (Afterwimpern) neben Trimpern und durch den Mangel von Haken auszeichnen. Dieser Character ist jedoch unzureichend und unrichtig, denn die Urostylen besitzen auf dem Stirnfeld hakenförmige Griffel. anch ist ihr Körper nicht auf der ganzen Oberläche mit Lỉngsreihen ron Wimpern besetzt, wie Ehrenberg behauptet. Ohne Zweifel hatte dieser Forscher von Haus aus ganz recht gesehen, dass el Anfangs zwei verschiedene Arten annalım. Es existiren wirklich zwei sehr nalı verwande Arten, die ich sehon seit dem J. I $\$ 34$ unterscheide. In der einen, welehe die grösstel Dimensionen erreicht, erkenme ich dic U. grandis des grossen Infusorienwerlis von Ehrenberg, es ist dies dieselbe Art, welche auch ron Colm bereits 18301 als U. grandis bestimmt wurde und üher deren embryouale Fortpflanzung er die ersten Aufschliisse veröfentlicht hat. Auf die zweite Art machte ich zuerst im J. 1857 Ilerrn Staatsrath Dr. Weisse in Sı. Petersburg bei seiner Durchreise rlurch Prag aufmerksam, dem zu Ehren ich sie U. Weissei nannte. Diese Art ist wahrscheinlich mit der ron Claparde und Lathmam beschriebenen Oxytricha Urostyla identisch. Da ich die Gatlung Urostyla aufrecht erhalte, so konnte ich schon deshalb von dem Speciesnamen dieser Forscher nicht Gehrauch machen, und ich zog es um so mehr vor, liei dem von mir ursprünglich gevählten Namen stehen zu bleiben, als es immerhin möglich ist, dass die Oxytricha Urostyla doch noch eine andere Art darstellt. - Zur Gattung Urostyla gehören ferner noch die Oxytricha multipes ron Claparède und Lachmam und die Oxytricha fusca von Perty; die letztere Art scheint mir von L. grandis durchaus nicht rerschieden zu sein. lch labe ausser U. grandis und Teissci noch eine neue Art aufgefunden, die ich U. viridis nenue.

Die Urostylen sind den Oxytrichen sehr nahe verwand, sie stimmen mit denselben in der Beschaffenheit des Körperparenchyms und der Form des Peristoms fast ganz überein, und unterscheiden sich von ihnen wesentlich nur durch die reichere Bewimperung der Bauchseite. Ilierdurch werden die Urostylen zu Uebergangsformen von den hypotrichen zu den heterotrichen Infusionsthieren. - Mu Parenchym ist ausserordentlich dehnbar und contractil und besteht aus einer sehr weichen, elastischen, fadenziehenden und klehrigen Masse; lie äussere Körperform ist daher ungemein verinderlich. - Griffellörmige Stiruwimpern sind nundestens drei vorhanden, bei einer Art sehr viele. Die Zahl der dünnen, melır borsten- als griffelförmigen Afterwimpern betright entweder fünf, oder sieben bis acht, oder zehn bis zwölf. Die Randwimpern gehen, wie bei den meisten Oxytrichen, am Hinterrande in cinander über. Die borstenförmigen Bauchwimpern stehen in parallelen, continuirlichen Längsreihen, teren entweder nur füıf mediane ouler mehrere gleichmässig über die ganze Bauchfläche vertheilte vorhanden sind. — Zwei Arten besizen den normalen doppelten Nucleus, bei der dritten Art ist im gewöhnlichen Zustande gar kein Nucleus vorhanden, sondern es entwichelt sich erst während der Quertheilıng eine grössere Anzahl von Kernen. Iliermit steht höchst wabrscheinlich das bei dieser Art sehır häufige Auftreten von Embryonallugehn im Zusammenhang, die sich zu acinetenartigen Embryonen entwickeln. Längsthcilung wurde nienals beobachtet. — Der contractile Behälter liegt an der gewölınlichen Stelle, der After nalıe vor dem hintern Ende. - Die Thiere schwimmen stetig und mit mảssiger Geschwindigheit.

Sämmtliche bisher beschriebene Arten wurden nur in süssen Gewaissern beohachtet.

1. Urostyla Weissei. Stern. (Taf. XIII. Fig. 1-4).

(?) Oxyłricha Urostyla Claparéte el Lachmann Eludes p. 141. Pl. V. Fig. 2.

Körper schmal und langgestreckt elliptisch, mit 3-5 Stimwimpern, i-8 Afterwimpern und 5 medianen Längsteihen von Bauehwimpern, von denen sieh 3 über das Stimfeld fortsetzen; Nucleus doppelt.

Diese Arl gehört zu den gemeinsten, überall rerbreiteten und oft massenhaft auftretenden lnfusorienformen. Dass sie his anf die neueste Zeit umbeachtet bleiben konnte, riihrt jelenfalls nur daher, dass überhaupt das Studium der Oxytrichinen seit Ehrenberg ïber Gebihr vernachlassigt wurcle; die Schwierigkeiten, welche mit ilner Untersuchung verknipft siml, und die Unmöglichıeit, sie mit den vorhandenen literarischıen Hülfsnittelı sichıer zu bestimmen, mochten davon abschrechen. Ich beobachtete unsere Art bei Niemegk. Tharand und Prag in stehenden und langsam fliessenden, mit Wasserlinsen uherzogenen Gewảssem; besonders häufig trat sie in seichlen, von Erlen beschatteten Gr'tben und Tümpeln auf, wenn dieselben so weil ausgetrocknel waren, đlass die Wasserlinsen unmittelbar auf dem mit dichten Schichten von vermoderoden Baumblattern bedeckten Boden auflagen, so namentlicl alljäılich im hohen Sonmer in den Gräben des Nussler Parkes bei Prag. Ebenso massenhaft entwickelt sie sich zwischen lingere Zeil aufbewahrten Wasserlinsen, wemn diese zu verschrumpfen anfangen und in Fiulniss iibergehen, das 


\section{3}

Wasser eine bräunliche Noderfurbe amnimnt. Damn bevölkert sie sammt grossen Individuen der Stylonychia mylilus oft fast ausschliesslich das Wasser; häufig kommt glcichzeitig auch U. grandis sehr verbreitet vor. Von letzterer Art unterscheidet man die gegenwärtige meist schon sicher ohne oähere Untersuchung bei der blossen Ansicht mit der Loupe an ihren schlankeren, undurchsichtigeren, schwefelgelb bis bräunlichgelb gefàrbten Körper.

Der Körper ist im völlig ausgestreckten Zustande (Fig. 1-3) mehr als 3 mal so lang' wie breil, im Allgemeinen linglich elliptisch, in der Nlitte oder nahe dahinter am breitesten, nach vorn und hinten etwas verengert, an beiden Enden gleichmässig abgerundet oder hinten stunjp eiformigr zugespitzt (Fig. 3). Die Rückseite (Fig. 1) ist stark gewölbt, nach vorn etwas niedergedrückt, die Bauchseite (Fig. 2. 3) plan. Die scitlichen Contouren sind bei der grossen Nachgiebigkeit und Dehubarkeil des Parenchyms sehr verănderlich, doch dürften die in Fig. 1 -3 abgebildeten Individuen wohl die gewöhnlichsten Formen darstellen, welche die Thiere beim ungehemmten Schwinmen in reichlichem Wasser zeigen. Häufig ist der Körper beträchlich verkürzt und wenig mehr als noch einmal so lang; wie hreit, er erscheint danı rein elliptisch oder auch eiförmig und kommt der Gestalt der folgenden Art sehr nalıe, bleibt jedoch immer noch schlanker und ist, wenn eiförmig, vorn und hinten mehr zugespitzt. Das Parenchym besteht aus einer zähen, elastischen, fadenzichenden Substanz, so dass der Körper unter dem Drucke des Deckgläschens nicht zum Zerfliessen zu bringen ist, er weicht dïn plattenförmig aus einander und sondert sich zuletzt in einzchse grössere zusammenhängenbleibende Lappen, ohne dass körnige Bestandtheile des Parenchyms an den Rupturen hervortreten. Hebt man den Druck des Deckgläschens auf, und setzt man neues Wasser hinzu, so stellt sich schnell die frühere Körperform wieder her, und das Thier schwimmt, wenn auch arg verletzt, munter weiler; die getrennten Theile nähem sich einander und wachsen nach und nach wieder zusammen. Im Parenchym finden sich stcts zahlıeiche schr kleine grviulich-orler bräunlichgelbe Ochtröpfchen eingebettet, dic nahe an der Oberflàche des Körpers theils zerstreut, theils in Längsreihen und schmalen Läugsstreifen dicht gedrängt heisammen licgen; sie verursachen die mehr oder weniger intensiv schwefelgelhe oder schmutzig bräunlichgelbe Farbe des Körpers. In Fiğ. I sind die Oeltröpfchenreihen nor an den Seiten und den beiden Enden, in riğ. 4. an der ganzen Oberflache ausgeführ. Die Reihen sind theils continuirlich, theils abgehürzt, theils streckenveis unterhrochen.

Das Peristom nimmt ïber ein Drittel der Körperlänge ein. Der schmale Vorderrand trägl eine etwas schief und meb. nach rechts angeselzte halbmondförmige Oberlippe, die auf der linken Scite des Vorderrandes noch Platz für den Anfang des Peristomaussemmandes lässt; ihre rechte Ecke ist in einen kurzen Streifen ausgezogen, der sich naclı hinten und innen in das Stirnfeld hineinzieht (Fig. 2. 3). Der breit bandförmige und selır deutlich quergestreifte Aussenrand des Peristoms erstreckt sich ron der linken Ecke der Oberlippe in diagonaler Richtung bis zur Mittellinic des Banches. Der lnnenrand hält die Mittellinie ein und biegt vorn auf gleicher Höhe mit den rechten Endpunct der Oberlippe hakenförmig nach links gegen den Aussenraud um, den er jedoch nicht erreicht; er triigt eine schmale undulirende Menbran und präorale Wimpern. Neben dem Innenrande liegt im Peristomfelde die lange, schrige Mundspalte (Fig. 2.o.) — Liangs der rechten Hälfte der Oberlippe stehen in ciner schrägen Reihe drei ziemlich lange und kräftige Stirnwimpern (Fig. 1.2. st. 3); gewöhnlich sind nur diese vorhanclen, nicht selten stelıen aber noch cin oder zwei etwas kleinere Griffel hinter der dritten Stimwimper (Fig. 2); zuweilen ist auch die dritle Stirnwimper nur schwach entwickelt, so dass anscheinend nur zwei, dann desto kriftigere Stirnwimpern vorhanden sind. Die Randwimpern sind lange und hraftige, bald iber den Rand hervortretende, bald grösstentheils unter dem Bauche sich verbergende Borsten; die rechte Reihe beginnt nahe hinter der Oberlippe, die linke ist stark nach cinwärts gerückt und endigt hinter der Mitte des Peristomaussenrandes. Die Afterwimpern (Fig. 2. a.) sitzen ganz unter dem Bauche versteckl, lıöchstens ragen die hintersten ein wenig über den Hinterrand hinaus (Fig. 1); sie stehen in einer steilen, von der Mittellinic aus nach vorn und links aufsteigenden Reilie und sind diunne, aber dic Randwimpern beträchtlich an Länge ubertreffende, nach hinten und links gerichtete Grilfel. In der Regel sind acht Afterwimpern vorhanden; nicht selten zihlte ich aber auch sehr bestimmt nur sieben. Die Bauchwimpern sind etwas kitrzere, dïnnere und dichter hinter einander stchende Borsten, als die Randwimpern, sie sind in fijnf parallele, cinander sehı genäherte Liangsreihen geordnet, welche zusanımen eine breite, ijber den mittleın Theil des Bauches verlaufende und an der Basis der Aftewinpern endende Binde bilden, die rechts und links durch einen hetrachtlichen Zwischenraum von den Randwimpern getrennt ist. Die drej rechten Reihen setzen sich iber das ganze Stirnfeld bis in die Nihe der Stirmwimpern fort, die beiden linken gehen nur bis zum Periston. Die erste, rechte Reihe erstreckt sich von der vordersten Randwimper bis zur ersten, hintersten Afterwimper, sie ist von ter zweiten durch einen ewwas grössem Zwischenraum getrennt, als die vier übrigen gleich weit von einander 


\section{4}

abstehenden. Die zweite und dritte Reihe folgen auf dem Stirnfelde dem Innenrande des Peristoms; die hier stehenden Wimpern sind nicht selten etwas stirker (Fig. 3), namentlich die beiden vordersten und diese erseheinen dann als eine vierte und fünfte Stimwimper (Fig. 2). Die vierte und funfte Reihe beginuen nahe am Peristomwinkel und endigen vor den letzlen linken Afterwimpern.

Die beitlen bellen ovalen Kerne (Fig. 1. 2. n. n.) leuchten stets sehr deullich aus dem dunklern Parenchym hervor, sie besitzen meist eine quere spaltförmige Höhle und liegen gewölmlich in der linken Körperhälfte, bald einander genähert, bald weit aus einander gerückt; ihre Lage ändert sich vielfach mit den verschiedenen Körpercontractionen. Der Nucleolus wurde mir nicht ganz klar, da sich die Kerne bei der zihen Beschaffenheit des Parenchyms nicht vollständig isoliren lassen, doch glaube ich oft einen sehr kleinen Nucleolus gesehen zu haben. - Der contractile Behälter (c.) liegt am linken Seitenrande bald auf gleicher Höhe mit dem Peristomwinkel, bald etrvas weiter nach vorn oder nach hinten; er versehiebt sich ebenfalls mit den Con tractionen des Körpers. Mit ihm steht, wie bei den Stylonychien, ein vorderer zuführender und ein hinterer abfuhrender Wasserkanal (Fig. 4. g. g'.) in Verbindung, die während der Quertheilung am deutlichsten zu beobachten sind. - Die Ausscheidung ron Excrementen sah ich einige Male, sie fand rechts neben der ersten Afterwimper bei z in Fig. 2 statt. - In der rechten Kürperbälfte findet sich stets eine seh breite Zone von dicht zusammengehäuften, zum Theil sehr groben Fetthörnern, welche sich bis zum Anfang des Stimfeldes hinaufzicht, hinten nach rechts umbiegt und auf der rechten Seite sich mehr oder weniger weit mach vorn erstreckt. Nicht selten fliessen beide Läingszonen in der Mitte des Körpers zu einem breiten queren Gürtel zusammen (Fig. I); der Körper erscheint dann bei durchgehendem Lichte fast ganz schwarz. - Die Thiere verschluclien nur selten grosse Körper; das auffallendste Beispiel bietet dis in Fig. 3 abgebildete Individuum dar, welches cin befruchteles Paranaecium aurelia (vergl. S. 97) gefressen hatte. Das in Fig. I dargestellte Thier enthielt zwei grosse contrahirte Vorticellenkörper und weiter nach hinten einen eben so grossen mil Flissigkeit erfillten Hohlraum, dureh welchen hindureh die Bauchwimpern sehr deutlich zu erkennen waren. Sonst sah ich immer nur kleinere gefressene Körper. - Die grössten Individuen sind bis $\frac{1}{7}^{\prime \prime \prime}$ lang.

Quertheilung luabe ich oft beobachtet, ich vermochte jedoch die hierbei mit der Bewimperung vor sich gehenden Metamorphosen nicht zu erforsehen; ich habe daher nur ein mittleres Stadium der Quertheilung von der Ruchseite abgebildet (Fig. 4.). Die hintere Körperhälfte war bereits mit einem ziemlich entwickelten Peristom (p'.) und mit einem neuen contractilen Behälter $\left(\mathbf{e}^{\prime}\right.$.) versehen, und jeder Nucleus hatle sich verdoppelt. Zwischen dem urspringlichen contractilen Behiilter (c.) und dem neu gebildeten bestand eine augenscheiuliche Communication. Der aus dem vordern Körperende von rechts lıer in einem sanften Bogen durch das mitterliche Peristom herabsteigende Wasserkanal (g.) fült zuerst den ursprünglichen contractilen Behälter; bei der Systole desselben entweicht das Wasser nach rückwäits durch den abfiihrenden, inmer nur auf eine kurze Strecke sichtbaren Kanal ( $\left.g^{\prime} \cdot g^{\prime} \cdot\right)$, und bald darauf füllt sich der hintere contractile Behälter. - Die in ler Quertheilung begriffenen Individuen sind immer mehr zusammengezogen und in die Breite ausgedehnt, als die einfachen, und daher oft kiirzer oder doch kaum länger, als diese. Die Sonderung der beilen Körperbälften findet stets in etwas schiefer lichıtung statt; dic rechte Scite wird nämlich weiter nach hinten eingeschnürt, als die linke. Zuletzt haben die beiden Theilungssprösslinge eine eiförmige, nach hinten zugespitzte Gestalt, und sie hängen so zusammen, dass der hintere gegen den vordern nach links verschoben ist. In den meisten Fällen bildeten sich aus jedem mitterlichen Nucleus zwei neue Kerne, mehrmals beobachtete ich aber auch den bei den Stylonychien so oft vorkommenden Fall, dass beide mütterliche Kerne in einen ğössern, beiden Körperhälften gemeinsamen, oblongen Nucleus verschmolzen waren.

Die Oxytricha Urostyla von Claparède und Lachmam weicht von del gegentvärtigen Art, wie ich ihren Bau nach oftmaligen Untersuchungen aufgefasst habe, in mehreren nicht unvesentlichen Puncten ab; die Ditlerenzen könnten jedoch leicht auf Beobachtungsfehlern beruhen. Bei O. Urostyla sind die beiden Randwimperreihen am Ilinterande durch eine breite Liiche von cinander getrennt und in dieser sitzen neben einander, also ganz an Ende des Körpers, die 8 Afterwimpern. Die rechte Randwimperreihe ist nach einwärts geriekt und steht von der ersten Bauchwimperreihe nicht weiter ab, als simmlliche 5 Bauchwimperreihen von einander. Die zweite Bauchwimperreilue ist abgekiirzt und reicht noch nicht bis zur gleichen Hölıe mit dem Perisıomwinliel nach vorn, die dritte und vicrte setzen sich uber das Stirnfeld neben dem Innenrande des Peristoms fort und hiegen auf dem vordersten Theil des Stimfelıles nach links in zwei dem Vorderrande parallele Reihen von elwas släkern Wimpern um. Dic erste und funfte Batuchwimperreihe und die linke Randwimperreihe verhalten sich ganz wie bei unserer Art. 
2. Urostyla grandis. EnnbG. (Taf. Xir. Fig. : -12 und Taf. XIV).

(?) Trichoda patula Miller Animalcula infusoria p. 181. Taf. XXVI. Fig. 3- 3 .

Urostyla grandis Ehrenberg Die Infusionsthierchen S. 369. Taf. XLI. Fig. V111.

Bursaria rorax, Ehrenberg Die Infusionsthierchen S. 327. Taf. XXXV. Tig. I.

Uroslyla grandis Colm in Zeilschrift für wissensch. Zoologie 1851. S. 277. Taf. VIr. Fig. 11-12.

Oxytricha fusca Perly Zur Kenntniss kleinster Lebensformen S. 134. Taf. VI. Fig. 19.

Oxytricha fusca Claparéde et Lachmann Éludes p. 142.

lörper cifürmig oder oblong, mit zahlrcichen Strmwimpern, 10-12 Afterwimpern und vielon ïber die ganze Bauchflïehe vertheillen Buscherimperreihen; kiein Wucleus.

Diese Art gehört zu den grössten und merkwürdigsten Infusorienformen, sie lebt in denselben Localititen. wie die vorige Art, in deren Gesellschaft sic häufig vorkomml. unl mit der sie bei flüchtiger Betrachtung leicht verwechselt werden kann. Ich beobachtete sie zuerst in April I S:5 ungemein zahlreich auf einer sumpfigen Wiese des Badehales bei Tharand und ebendaselbst wieder im November und December desselben Jahres. Bei Prag Iraf ich sic im November $18: 35$ massenhaft im schlammigen Bodensalz eines halb ausgetrockneten Gefisses mit seil liingerer Zeit aufbewahrten und nun ganz verschrumpften und missfarbig gewordenen Wasserlinsen ; später erlhielt ich sie besonders aus den Griben des Nussler Parles, wo sie stets in Gesellschaft der vorigen Art, aber minder hiufigr vorkam. Bei Nienegk fand ich zu verschiedenen Zeiten ausgezeichnet grosse Exemplare an stark mit Schilf bewachsenen Stellen des Puflbaches zwischen schlammigen, an der staubigen Oberllache des Wassers schwimmenden Haufen von Wasserlinsen, Conferven und Oscillarien.

Die Gestalt des Thieres wechselt so ausserordentlich, dass schwer anzugelen ist, welches die eigentliche Form des Köıpers sei. In Allgemeinen ist derselbe viel breiter, dicker und plumper, als bei der vorigen Art, und im mittlem Zustande seincr Ausdchnung bei gnt genährten und ungrehemmt in reichlichem Wasser schwimmenten Individuen (Taf. XIH. Fig. 6) nicht viel melır als noch einnal so lang, wie breit; eiförmig, vorn und hinten stumpf abgerundet und mit der vordern Hälfte mehr oder weniger nach links gekrüumm. Dic Rückseite ist hochgewölbt, hesonders stark nach hinten zu, nach vorn mehr und mehr verflacht, die Bauchseite ist ziemlich plan, nach linten gewölbt und an den Seiten algerundet. Diese Grundgestalt wird sehr gewöhnlich dadurch modilicirt, dass sich der Körper in der Mitte etwas einschnürt und nach hinten sehr stark bauchig oder sackförmig erweitert (Taf. XIV. Fig. 1. 2); sein Hinterrand ist dann gerad abgestutzt, in der Mitte ctwas nach cinvärts gezogen, nicht selten so beträchtlich, dass das hintere Körperende zweilappig wird und in der Mittellinie des Bauches nahe vor dem Ende eine kurze, tiefe, spaltförmige Falte entsteht (Fig. 1). Eine solche Falte wurle wahrscheinlich von Ehrenberg gesehen und als spaltförmiger After beschrieben. In andern Fällen ist der Körper kurz und breit eifürmig (Taf. XIV. Fig. 5), zuweilen so kurz, dass er sich der lïugelform nähert und kaum länger als breit ist. In noch andern Fällen zeigt sich der Körper langgestrecht oblong, nur nach vorn und hinten etwas verengert und an den Enden stumpf abgerundet (Taf. XIV. Fig, 6), oder er ist in der llitle von heilen Seiten her eingeschnïrt und nach vorn und hinten blindsackfümig gerundet erweitert (Taf. XIV. Fig. 4). Thiere, welche längere Zeit gefastet haben, besitzen einen fast ganz drehrunden, langgestreckt walzenförmigen, vorn und hinten fast gleichförmig abgerundeten Körper (Taf. XllI. Fig. 5), der melı als 4 mal so lang, wie breit ist. Dieselbe, nur noch viel schlankere Form kommt auch ıen jugendlichen Individuen zu. - Das Parenchym verhält sich sehr ahnlich, wie bei der vorigen Art, uur ist es eine noch viel weichere und nachgiebigere, wenigrer zahe Masse, die Cohn tretlend mit einer zitternten Gallerte vergleicht. Der Körper geht beim Auflegen eines Deckglases in eine noch viel dïnnere Schicht aus einander, nimmt aber ebenfalls bei neuem Zusalz von Wasser sogleich scine frühere Forn vieder an. Wenn er zerreisst, so biklen sich stels ohne den geringsten Ausfluss ron hörnigem Inhalt und ohne Hervortreten von Sarcodetropfen abgerundete, nachziehende, mit dem Ganzen in Verbindung bleibende Lappen. Nicht selten bekommt der Körper bei starkem Druck mit dem Deckglase in der IItte ein grosses weitliaffendes, von der Bauch- his zur Rïckseile durchgehendes Loch, aber auch dieses schliesst sich bald wieder, wenn das Thier in Freiheit geselzt wird, so klebrig und so geneigt zur Wiedervereinigung ist die Körpersubstanz. In vielen Fällen, namentlich wenn die Thiere in Gesellschaft der vorigen Art leben, enthät das Parenchym dieselben gell,grtinen oder braungelben Oelblisschen, die bei jenel Art beständig vorkommen, sie sind entweder nur in einfachıe, alsgekiirzte Längsreihen geordnet (Taf. XHI. Figr. 10), oder sie bilden noch gewöhnlicher continuirliche breile, aus mehreren dicht neben einander liegenden Reihen znsammengesetzte Längsstreifen, die besonders auf der Rückseite entwickelt sind (Taf. XIV. Fig 4). Anf der Bauchscite treten sie weniger markint hervor (Taf XIII. Fig. 6. 8) oder fehlen 


\section{6}

gänzlich (Fig. 9). Trotz dieser breiten Streifen von Oebblïschen erscheinen die Thiere in der Regel doch wesiger intensiv gell gefirbı, als U. Weissei, da die Oelblasschen ein viel lichteres, wichı durch massenlsaft entıviclielte grohe Fettiörner geschwärztes Parenchym zur Unterlage haben. Eine an der linken Seite herabziehende Fetıörnerzone lıahe ich hei U. gr'andis niemals beobachtet. In sehr vielen Fallen vermisste ich die Oelbläschen gänzlich, so namentlich bei fast allen bei Tharand und Niemegk beobachteten Individuen; diese waren entweder sehr licht und durchsichtig farblos bis bläulichgrau ouler von zahlreichen, durch den ganzen Körper gleichı̈issig vertheilten groben Fettkörnern dunlielgrau bis schwärzlich. Das Auftreten der gelben Oelbliischen hiingt hiernach jedenfalls von der Art der Nahrung ab.

Das Peristom luat fast genau denselben Bau und dieselbe relative Grösse, wie bei ler vorigen Art. Die Oherlippe ist gerad angesetzl und rechts ohıe Fortsatz, sie lässt links am Vorderrande ebenfalls noch Platz für den Anfang des Peristomanssenrandes. Die undulirende Membran am Innenrande des Peristoms (Taf. XIV. Fig. 5. i), ist stälier entwickelt und sehr zart und durchsichtig, so dass man die unter ihr stehenden, feinen, langluorstigen päioralen Wimpern stets deutlich unterscheiden kann; sie erscheint in der Ruhe als ein vorn sehr schmaler, nach hinten sich stetig verbreilernder Hautsaum (Taf. XIV. Fig. ?). Im Peristomfeld fillt stels sofort die lange schräge Mundspalte (Fig. 2. o. 5. o.) auf, da sie zum grössten Theil ganz frei daliegt und nur nach hinten rom Innenrande verdeckt wird. Das Peristomfeld besitzt noch einen sehr ausgezeichneten Character, es ist ntimlich nicht, wie bei allen andern Oxytrichinen, völlig nackt, sondern in einer breiten, am Aussenrande des Peristoms herabziehenden und nach hinten schmaler werdenden Zone dicht mit sehr zarten, undulirenden, angedrückten Wimpern (Taf. XIII. Fig. 6. w. Taf. XIV. Fig. 1. 2. w. 3.) besetzt, welche nach innen und hinten gerichtet sind und eine beständige Strömung gegen die Mundspalte hin erregen. Beim ersten Anblick dieser Peristomfeldwimpern empfängt man den Eindruck, als rieselten zahlreiche feine Strömchen vom Aussenrande des Peristoms schràg gegen die Mlundspalte. Von der rechten Ecke der Oberlippe verlauft in schriiger Richtung nach dem Peristomwinkel eine meist nur schwach markirte Linie, welche ein eigentliches Stirnfeld abgränzl; auf diesem stehen die zahlreichen. kurz griffelformigen, theils geschlängelten, theils hakenförmigen Stirnwimpern (Taf. XlV. Fig. 2. st. 5. st.), welehe einen der wesentlichsten Charactere unserer Art bilden. Sie nehmen von vorn nach hinten an Länge und Starke ab und stehen ziemlich regellos durch einander; nur die vordersten sind deutlich in Querreilien geordnet. Die vorderste Querreihe hesteht aus $\ddot{j-6}$ luakenförmig nach vorn umgebogenen Griffeln (Taf. XIII. Fig. 6. T), die jedoch nie so lang und stark sind, als die drei Stirnwimpern der vorigen Art; dann folgt eine Querreihe ron 4- $\ddot{3}$ ahnlichen Griffeln; die folgenden Stirnwimpern stehen regelloser durch einander. - Die rechte Randwimperreihe beginnt gleich hinter der Oberlippe, die linke hält ihrer ganzen Ausdehung nach den Rand inne und isı vorn laum merklich nach einwärı gerückt. Die Randwimpern sind kräftige, bald ringsum ibler die Seitenrinder und den Hinterrand vorstehende, ball theilweis unter dem Bauch versteckte Borsten. Die Bauchwimpern sind den Randwimpern sehr ähnlich, jedoch ctwas feiner und kürzer, sie setzen zahlreiche, gleichmässig über die ganze Banchfläche vertheilte Längsreihen zusammen, die sich von dem Aussenrande des Stimfeldes und dem des Perisłoms bis zum Hinterrande des Körpers erstrecken (Taf. XIV. Fig. 1. 2. 3̈). Die Bauchwimperreihen sind einander um so mehr genăhert, je weniger sich dic Thiere in die Breite ausgedehnt haben (Taf. XIIl. Fig. 5. Taf. XIV. Fig. 6). Sie sind auf dem trüben Grunde des Körpers nur selıen ihrer ganzen Ausdehnung nach zu ubersehen; an klarsten sah ich ihren Verlauf bei selır blassen, firblosen Individuen und auch bei ganz dunklen an solchen Stellen, wo sich im Parenchym grosse mit Wasser erfïllte llohlräume befanten. - Die sehr dïnnen, fast ganz borstenförmigen Afterwimpern (Taf. Xlll. Fig. 5. 7.8.a.) stehen in einer von der Mitlellinie mehr oler weniger steil nach links und vorn anfsteigenden Reihe, sie sind meist an der Basis etwas knieförmig gebogen (Taf. XIV. Fig. 3) und wie die der vorigen Art nach links und hinten gerichtel, aber merklich kürzer und schwächer; sie lassen sich oft nur mühsam auffunden und hönnen um so leichter übersehen werten, da sie ganz untel dem Bauche versteckt sitzen und ringsum von Bauchwimpern umgehen sind. Ich zählte nie weniger als zehn Afterwinpern, bei grossen Individuen nicht selten selır bestimmt zwölf (Taf. XIV. Fìr. 5̈).

Nach dem gewöhnlichen doppelten Nucleus suchı man bei dieser Art vergehens; ich halıe Hlunderte ron lndividuen aus ten verschiedensten Localiłaten mit der yrössten Sorgfalt untersucht, sie vorsichtig gequnetseht, in eine ganz dünne, durchsichtige Lamelle ausgebreitet und dann noch Essigstiure hinzugesetzl, alleiu es zeigte sich nie die geringste Spur ron einem Gebilde, welches auch nu entfernt an einen Nucleus erinneri luatle. Das constante lehlen desselben wird für die gegenwärtige Art zu einem rortrellichen Kennzeichen, wodureh sie sich selı leicht 
von der vorigen Art unterscheidet, bei der jederzeit ohne alle künstliche Behandlung die beiden Kerne sofort wahırzunehmen sind. Dagegen enthät U. grandis selı bäufig bald nur vereinzelte, bald zahlreiche Embryonalkugelı (Taf. XIII. Fig. 3. k. 6.k. k. und Taf. XIV. Fig. 1-6.k.), die man nicht mit Kesnen verweclsseln darf; wir werden (liese und die aus ilmen hervorgehenden Embryonen gleich niher liennen lernen. - Der contractile Behälter (c.) liegt nahezu auf gleicher Höhe mit dem Peristomwinkel, bald ziemlich in der Nitte zwischen demselben und dem linken Seitenrande, bald dem leıztern näher. Mit dem contractilen Behälter communicirt ein starker zulührender und abführender Wasserkanal, die immer nus streckenweis sichtbar sind. Der zuführende Kanal (Taf. XIII. Fig. 6. g. Taf. XIY. Fig. 1. g.) hommt aus der mittleren Region des Stirnfeldes und gehı in einem sclıragen Bogen dureh das Peristomfeld zum contractilen Behălter; der abführende Kanal (Taf. XlV. Fig. I. g'.) verläuft rom contrachilen Behälter aus in einem :ilunlichen schragen Bogen nach innen und hinten; ich verlolgte den ablliessenden Wasserstrom einige Hlale bis zu einem rechts neben und etwas vol den Afterwimjern gelegenen Puncte. Zuweilen sah ich den contractilen Behälter bei der Systole von stralılenförmig auslaufenden, feinen Kanälen umgeben. - Der After scheint hinter den Afterwimpern dicht vor dem Ende zu liegen; hicr sah jch wenigstens mehrmals leere Bacillarienschalen nach aussen hervortreten. - Die Thiere sind selı gefrissig und verschlingen meist betrichtlich grosse Organismen, namentlich auch laăfig Rảderthiere, die ich nie im lunern ron U. Weissei beobachtete. Die verschluckten Räderthiere waren meist Lepadellen und Squamellen, deren ich bisweilen vier bis funf in einen Thiere antraf; sie wirbelten zum Theil noch sehr lebhaft mit ihrem Räderorgan und schlugen mit ihrem Schwanze heftig hin und her, wodurelı der Körper der Urostyle wunderlich verzerrt wurde, ohne dass er jedoch seine Beute wieder fahren liess. Das in Fig. 6 auf Taf. XllI. dargestellte lndividum enthielt zwei noch sehr lebendige Exemplare von Squamella oblonga, feruer lumten rechts einen todten Coleps hirtus, und links ein todtes Lembadion bullinum Perty und ausserdem noch verschiedene Bacillarien und andere hleine gefressene Körper; mitten zwischen diesen Nahrungsmitteln lagen zwei ganz unversehrte Embryonalkugeln (k.k.). Auch grosse Closterien fand ich nicht selten im Innern unserer Urostylen, einmal sogar bej einem in der Quertheilung begriffenen Thiese (Taf. XIll. Fig. 7) deren zwei.

Im schlammigen Bodensatz der Gefässe, in welchem U. grandis häufig vorkommt, trifft man gewölnnlich auch den encystirten Zustand dieser Alt an. Die grossen kugelförnigen Cysten (Taf. XllI. Fig. 11. 12) sind schon unil blossem Auge als kleine schmutzig gelbe oder gelblı̈iunliche Kügelchen zu erkennen; sie werden von ganz glatten, derbhäutigen, durchsichtigen und farblosen Wanlungen begränzl und umschliessen einen ebeufalls ganz. glatten, dunklen, schmutzig gelbbraunen Körper, der die Cyste ganz ausfüllt (die in Fig. 12 abgebildete ist ein wenigg gequetscht, daher die Cystemwand auf der linken Seite etwas absteht) und an dem keinerlei iussere oder imnere Organe zu unterscheiden sind. In Cenlrum desselben sieht man in ler Regel einen mehr oder weniger ausgedehnten, verwaschenen, dunkler Fleck, der ledigłich aus dichıer zusammengedrängten Feıkörnchen bestelı. wie man beim Zerquetselıen der Cyste erkennt; am Ranıle des Körpers liegt der contractile Behıilter. In manchen Cysten war das Thier noch nicht in eine ruhende, structurlose Kugel ungewandelt, sondern es wailzte sich noch langsam im Kreise umber, und ich unterschied noch sehı deutlich das ganze Peristom (Fig. II). Wenn jelı solche Cỵsten gliicklich sprengte, so zog sich das Thier langsam.durch den Riss hervor, nahm wieder seine gevölınliche Form an, und es wurden nun auch die locomotiven Wimpern sichtbar. - Die Thiere erreichen nicht selıen eine Linge van $\frac{1}{5}$ '" bei einer Breite von $\frac{1}{9}^{\prime \prime \prime}$. Die Cysten haben einen Durchmesser von $\frac{1}{2} \frac{1}{5}-\frac{1^{\prime \prime \prime}}{17}$.

\section{Teber die Fortphanzung und Eutuickelung ron Urostyla grandis.}

Bei U. grandis treten periodisch zwei Fortpflanzungsweisen auf, die im innigsten Zusammenlange mit einander zu stehen scheinen, es ist dies die Quertheilung und die embryonale Fortpflanzung; Längstheilung selıeint gauz ausgeschlossen zu sein. Jene beiden Fortpflanzungsweiseu haben das mit einander gemein, dass sie nichı hin und wieler bei einzelnen Individuen auftreten, sondern lass, wenn man ein Individuum in der Quertheilung oder mit Embryonalkugeln versehen antriff, dann stets noch sehr vicle andere vorkommen, welche dieselbe Fortpllinzungsweise zeigen. Wo die embryonale Fortpflanzung herrscht, da fehlt die Quertheilung und umgehelıri, wo diese waltet, da wird jene nicht gefunden. Deunoch bildet die Queribeilung höchst wahrscheinlich nur die Einleitung zur embryonalen Fortpflanzung; sie kann nicht anf die blosse Vermehrung der Individuen berechnet sein, denn die Theilungssprösslinge sind den Nutterthiere nicht völlig gleich, sondern stellen eine wesentlich andere Generation dar, und diese scheint sich eben später zu den Individuen zu entwickeln, welche mit Embryonalkugeln rersehen sind. 


\section{8}

Die Quertheilung habe ich zu drei verschiedenen Zeiten, nämlich im November 1855 , im Januar 1857 und im Juni und Juli 1858 an sehr vielen Individuen beobachtet und jedesmal dieselben Resultate erhalten. Der äussere Hergang bei der Quertheihung bielet nichts Ungewöhnliches dar; es wird zuerst in der lintern Körperhälfte des weniger verlängerten, als verbreiterten Mutterthieres auf clie gewöhnliche Weise ein neues Peristom (Taf. XIII. Fig. 7. $p^{\prime}$.) und ein neuer contractiler Belıalter ( $c^{\prime}$.) gebildet. Noch ehe das neue Peristom vollstindig entwichelt ist, bekommt der Körper genau in der Mitte eine quere ringförmige Einschnirung (Fig. 8. 10); je tiefer dieselbe eingreift, um so mehr nehmen die beiden Körperhalften zuerst die Eiform, dann die Birnforn an, sie verschieben sich aher nicht merlich gegen emander. Die locomotiven Wimperu scheinen nicht erneuert zu werden, sondern walurscheinlich werden nur an der Stelle, wo das neue Peristom entsteht, die hier vorhandenen Bauchwimpern resorbirt und rechts neben demselben neue Stirnwimpern entwickelt, von denen ich nur mit Mühe einige vordere erkennen konnte, die in deı Abbildungen angegeben sind. An künftigen lintern Theilungssprössling unterschied ich auch immer nur einc einfache Reihe von Afterwimpern (a.), welches offenbar die bleibenden müterlichen waren; der vordere Theilungssprössling zeigte die Stirnwimpern wie heim Nutterthiere, Afterwimpern aber konnte ich an ilm nicht auffuden, sie entsteheu vielleicht erst nach erfolgter Abschnürung. Die Bauchwimpern, die mir nichı genügend klar wurden, habe ich in den Zeichnungen weggelassen. Jedenfalls wird die gesammte Bewimperung der Theilungssprösslinge mit der Zeit wieder genau dieselbe, wie die des Mutterthieres, aber im Immern sind sie wesentlich verschieden, denn sie enthalten Kerme.

Die auffallendste Erscheinung bei der Quertheilung ist also die, dass sich willrend derselben wahre Nucleusgebilde entwickeln, von denen sich, wie wir sahen, bei den gewöhnlichen einfachen Thieren keine Spur findet. Beim Beginn der Quertheilung, wenn in der hintern Körperlıilfte nur ersi ein Theil rom Aussenrande des zu bildenden Peristoms entstanden ist, erscheint nimblich in der vorderı und hintern Körperhälfte langs der Mittellinie ein sehr blasser, lichter, noch sehr weicher, oblonger Strang, der sich von dem umgebenden Parenchym nichı scharf absetzt und erst nach Anwendung von Essigsäure elwas markirter hervortritı. Beide nahe linter einamter gelegene Stränge sind augenseheinlich nichts weiter, als eine melır condensirte Portion des in der Axe gelegenen mütterlichen Körperparenchyms; sie werden nach und nach opaker und sch:irfer begränzt und gleichen dann den verlangerten Kernen anderer in der Quertheilung begriffener Oxytrichinen, namentlich denen von Stylonychia nytilus (Taf. VI. Fig. 3.4.n.n.), nur sind sie weicher, melı brejartig und weniger markirt. Mit fortschreitender Qucrtheilung verlängern und verschmälern sich die beiden Stränge, sie stossen dann oft zusammen und verschmelzen zu einem einzigen, sehr langen, dïnn strangförnigen Nucleus (Taf. XIII. Fig. 7. n. n.), der sich durch die ganze Axe des Mutterthieres in mehr oder weniger geschlängeltem Verlauf hindurchzieht und gewöhnlich ganz homogen erscheint, seltener (wie in Fig. 7) in einer homogenen Grundsubstanz zahllose, dicht gedrängt beisammenliegende sehr bleine längliche Kernchen eingebettet zeigt. Oft sah ich den gemeinsamen strangförmigen Nucleus aus vielen knieföımig bald nach links, bald nach rechts gebogenen, kiirzern und längern Abschnilten zusammengesetzı, die nur noch durch diinne fadenförmige Commissuren zusammenhingen; es ist dies der Anfang zum Zerfall des Nucleus in mebrere getrennte Segmente, aus denen durch fortgesetzte Theilung zuletzt eine grössere oder geringere Anzalıl gleiclı grosser Kerne hervorgehen. In vielen andern Fällen verschmelzen die beiden urspıłinglichen Stränge nichı mit einander, sondern jeder zerfillt für sich durch wiederholte Quertheilung in mehrere hinter einander liegende bisquitfömige orler kurz schunförmige Segmente (Taf. Xlll. Fiğ. 8. n. n. n.), die im Innern an der am stärksten eingeschnürten Stelle eine querovale Höhle besitzen; in der Richtung derselben erfolgt sjaiter eine neue Durchschnürung. llänfig sind die beiden ursprünglichen Stränge nur kurz, dann zerfält jeder derselben, nachdem er zuvor bisquitförmig geworden ist und eine eentrale Höhle erhalten hat, zuerst in zwei kerne, die sich dann ihrerseits wieder verlängeru, bisquitförmig werden und abermals in zwei neue, bald wieder die Bisquitform annehmende Kerne zerfallen, so dass nun in jeder Körperhälfte vier hinter einander liegende bisquitförmige Kerne vorhanden sind. ln andern Fällen verlängert sich jedler ursprimgliche Kern erst betrachtlich und zerfällt dann auf einmal in melırere ungleich lange Segmente, von denen die grössern zwei oder drei ringförmige Einschnurungen und eben so viele entsprechende centrale Höhlungen zeigen. Auf die eine oder die andere Weise gelıen aus den beiden anfiuglichen Strängen nach und nach mehr oder weniger zalılreiche, scharfluegrainzle, ganz homogene, rundliche Kerne liervor, die zum Theil noch paarweis an einander hängen. Wenn sich die beiden Theilungssprösslinge von einander trennen, ist jerler derselben mindestens mil vier grossen bisquitfömigen Kenen (ähnlich denen in Fig. 8) versehen, die sich wahrscheinlich nach erfolgter Trennung weiter vermehren; gewöhnlich ather enthălt jerler Theilungssprössling viel 
mehr, nicht selten 30-50 theils einfache, theils paarweis verbundene Kerne (Ficr. 9. n. 1.), die un so bleiner sind, je grösser jhre Zahl ist.

Fragt man nach der Berlentung dicser Kerue, so hönnen sie wohl kaum eine andere als dic ron Keimkngelu haben, aus denen sich spitier, wenn der Theilungssprössling wieder zur Grösse des Mutlerthieres herangewachsen ist, Embryonalkugeh entwickeln werden. Für diese Ausicht spricht noch eine andere Thatsache, die ich freilich nur cinige Male, aber, wic ich glaube, mit rollkommener Schäife beobachtet habe. Ich salı nảnlich bei kleinen in der Quertheilung begriffenen Individuen von U. grandis, welche einen heiden Körperhälften gemeinsamen, vielfach hin und her geschlingelten, selır dünnen strangförmigen Nucleus enthiclten, links neben demselben 3- 3 hleine ovale Kapselı liegen, welche dicht mit parallelen, geschlingelten, spermatozocnartigen Faden crfullt waren. Sind diese Faden wirklich Spermatozoen, dann unterliegt es lıcinem Zweifel, dass die Querlıcilung nur dic Einleitung zur embryonalen Fortpllanzung bildet, dass im Verlaufe derselben ein Befruchtungsact stattfindet und dass die aus dem Zerfall des Nucleusstranges hervorgehenden Kerne Keimliugeln darstellen. - Erwihnen muss ich noch, dass ich mchrmals bei in der Quertheilung begriffeneu Iudiviluen einen beiden Körperhälften gemeinsamen, länglich ovalen oder eiförmigen Nucleus (Taf. XIII. Fig. 10. n.) beobachtele, der nach hinten in einen stielförurigeu, am Ende gegabelten Fortsatz ausgezogen war und den Eindruck machte, als sei er nach hinten aus einander geflossen; er hestand aus einer selı lichten, fein und dicht wellenförnig gestreiften und gehräuselten Sulstanz, was einigermaassen an die Spermatozocubausche im Leibe der Paramacien (vergl. S. 98) erinnerte. Allein die Streifung gehörte der Nucleussubstanz selbst an, sie rührte uicht von discreten, isolirbaren Fäden her; ilıre Bedeutung is mir völlig duukel geblieben.

Die embryonale Fortpflanzung, welche bereits im J. 1831 von Cohn entdeclit wurde, seittem aber von keinem neuern Forseher beobachtet worden zu sein scheint, hatte ich das Glïck, gleich an den ersten der von nir im April I85\% bei Tharand aufgefundenen Individuen der U. grandis kennen zu lernen; dann beobachtete jelı sie erst wieder in Prag im Juni 1857 an mehreren Exemplaren aus dem Nussler Park und zuletzl im August I85̈8 an sehr zahlreichen Indivjduen in Niemegk. Meme älesten Untersuchungen, welche lediglich die Angaben von Colm bestätigten, brachte ich locreits 1830 auf der Naturforscherversammlung in Virien zur Sprache (vergl. das Tageblatt No. 3. S. 53). - Im Allgemeinen erfolgt die embryonale Fortpllanzung bei U. grandis in sehr älmlicher Weise wie hei Stylonychia mytilus (vergl. S. I56), sie zeigt jedoch auch manches Eigenthümliche. Es treten ebenfalls bei Individuen der rerschiedensten Grösse im Inuenparenchym Embryonalkugeln auf, die sich cine Zeit lang durch Theilung vermehren und zuletzt bewcgliche, acinetenartige Embryonen licforn, welche durch besondere, erst mit den Embryonen sich bildende Geburtskanale aus dem Mutterthier ausschwirmen. Die Mutterthiere grleichen in ihrer gesammten Organisation durchaus den gewöhnlichen Individuen, schweifen wie diese beständiğ unher und nehmen auch noch litufigr Nahrung zu sich; von einem Nucleus oder irgend welchen kernartigen Gebilden honnte ich bei ihnen nie dic leiseste Spur anffinden.

Die Embryonalkugeln (Taf. XIV. Fig. 1 - 3. k. k.) sind meist ganz regellos durch das Parenchym ter hintern Körperhälfte vertheilt und liegren theils völlig isolirt, theils zu kleinern oder grössern Guppen vereinigh lose nehen oder über einander, ohne sich durch gegenseiligen Druck abzuplatten. Sie gleichen den Enbryonalkugeln von Stylonyclia mytilus, sind jedoch ctwas trüber und dunkler grau, was daber ribht, dass in ihrer lıomogenen Grundsubstanz zahlreichere Fetlhörnchen eingebeltet liegen; sie besitzen ebenfalls einen scharf begränzten, runden, centralen Kern, aber gewöhnlich zwei contractile Bchälter, deren relative Lage nicht constant isı. Bald liegen beide contractile Behälter an gegenüberliegenden Puncten rler Peripherie der Embryonalkugel. bald sind sie einander mehr oder weniger genahert; der eine von ihnen ist in der Regel viel kleiner, als der andere, nicht sclten ist wirklich nur ein eimziger vorhanden. Die Zahl und die relative Grösse der in cinem Mutterthier enthaltenen Embryonalkugelu ist ausserordentlich verschieden. Manche Nutterthere besitzen nur eine einzige, bald schr kleine, bald bis $\frac{1}{40}{ }^{\prime \prime \prime}$ im Durchmesser haltende Embryonalkugel, die gewöhnlirh nalıe hinter dem Peristom liegt (Taf. Xlll. Fig. ̈̈.k.); andere zeigen deren zwei (Taf. XIII. Fig. 6.k.k.), die oft sehr ungleich gross sind oder so weil vou einander entfernt liegen, dass sie nicht wohl durch Theilung aus einer und derselben Embryonalkugel hervorgegangen sein kömnen. Diese vereinzelten Embryonalkugeln siud kein unmittelbares Product des Mutterthieres, was ilıre oft selı geriuge Grösse wohl rermuthen lassen könnte, sondern sie stammen sicherlich von einer friblıern Generation ron Embryoualkugeln ab, die sich bis auf eine oller zwei unverwandelt bleibende zu Embryonen eutwickelten. Hat das Mutterthier den durch die fruhere Entwiclielung ron Embryonallugeln erlittenen Substanzverlust durch eine reichlichere Nahrungs- 


\section{0}

aufuahme wieder einigermaassen ersetzt, so fangen die eine oder zwei restirenden Embryonalkugeln sich von Neuem zu rergrössem an und liefern bald dmch schuell sich wiederholende Theilungsacte eine neue Generation von Embryoualkngeln. Man trifft daher sehr häufg Mutterthiere mit 3, 4, 5, 6 und mehreren Embryonalkugeln, von denen oft eine oder' melnese in der 'Theilung begriffen siud. Die Theilung erfolgt in der Regel fast genan im Aequator fler Kugel, so dlass wieder zwei gleich grosse Kugeln entstehen. War ursprüinglich nur eine Embryonalkugel vorhanten und wiederholt sich an jedem Theilungspaare die Theilung ziemlich gleichzeitig, so bleilsen sämmtliche Embryonalkugeln eines Mutterthieres nahebei gleich gross, was nicht selten vorkommt (Taf. XlV. Fig. 3. 4. k. k.). Noch gewöhnlicher aber tritt die Theilung an den einen Embryonalkugeln viel friher ein nnd wiederholt sich schneller als bei den auderen gleichzeilig entstandenen; dann zeigen die in einem Mutterthier vorhandenen Embryoualkugeln eine sehr verschiedene Grösse. So sehen wir in Fig. I auf Taf. XlV ein Indivilumm mit 7 grössern und 8 kleinern Embryonalkugeln; von den grössern sind drei ( $k^{\prime} . k^{\prime} . k^{\prime}$ ) in gleichlälftiger Theilung begriffen, von den kleinern (k.) liegen noch zwei in Folge der Theilung dicht an einander gedrückt. Dieses Multerthier besass keine Geburtskanäle, die rorhandenen Embryonalkugehn latten noch keine Embryonen entwickelt. Aelınliche Multerthiere mit 1 ? 16 Embryonalkugeln und ohne Geburtskanåle sind mir oft vorgekommen.

Nachlcm sich aus den urspriinglich voshandenen Embryonalkugeln durch fortgesetzle gleichhälftige Theilung eine gewisse, nicht naher bestimmbare Anzahl ron gleich oder verschieden grossen Embryonalkugeln auf Kosten des mütterlichen Parenehyms gebildet hahen, tritt die Entwickelung von Embryonen ein. Diese beginnt damit, dass sich ron einer oder mehreren Embryonalkugeln nur ein h]eines Segment abgliedert, welches bald die Form eines knospenartigen Auswuchses annimmt (Taf. XIV. Fig. 3. k'. k'. Fig. 4. k'.); nach und nach gestaltet sich derselbe in einen oralen oder oblongen, bewimperten und Tentakeln tragenden Embryo (Fig. 2. e. e'.) un, der gewölınlich bis zu seiner vollen Ausbildung mit der Embryonalkugel, die ihn erzeugte, in Verbindung bleibt. Sobald sich in einem Mutterthiere reife Embryonen entwickelt haben, treten an demselben auch besondere Geburtskanäle (Fig. 2. 3. or.) auf, welche stets von der Peripherie solcher Embryonalkugeln, die in der Production von Embryonen begrifien sind, ausgehen und das mütterliche Parenchym bis zur aussern Oberfläche durchsetzen. Die Geburtskanäle sind blosse röhrenförmige Aushöhlunģen des Parenchỵms, die zwar scharf begränzt sind, aber durchaus lieine eigenen Wandungen besitzen; ihr Lumen ist gerade so weit, als der reife Embryo brejt ist, so dass dieser nur ler Lảnge nach darin Platz lat, sie sind daher vielleicht lediglich ein Product des sich zuerst entwiekelnden Embryos, der sich allmahhlig durch das mütterliche Parenchym hindurclı einen Weg bahnte, welcher sich für die nachfolgenden Embryonen zu cinen bleibenden Kanale gestaltete. Für diese Ansicht spricht auch die bei den einzelnen Mutterthieren so sehr verschiedene Lage der Geburtskanäle; ihre Mïndungen finden sich an den verschiedensten Puncten der Rückseite und der Körperrinder, auf dem mittlern Theil der Bauchseite sah ich sie nie ausmünden. Ihre Zahl ist ebenfalls nicht constant, doch habe ich nie mehr als vier beobachtet.

Eine der gewöhnlichsten Formen gebärender Nutterthiere zeigt unsere Fig. 3 auf Taf. XIV. Dieses Thier enthält 10 gleich grosse, im mittlern Theil des Hinterleibes zusammengehăufte Embryonalkugeln, von denen die zwei innern $\left(k^{\prime}, k^{\prime}\right.$ ) eine Embryonalknospe getrieben haben. Vou der vordersten rechten Embryonalkugel führt ein queres Geburtskanal (or'.) nach der Nlitte des rechten Seitenrandes, wo er auf der Riickseite ausmündet; ein zwciter querer Geburtskanal (or".) entspringt von der zweiten linken Embryonalkugel nnd mimclet ehenfalls aul der Rückseite linter der Nitte des linken Seitenrandes aus; ein dritter von der hintersten Embryonalkugel abgehender, etwas krummer Gehurtskanal (or"'.) mündet links nehen der Hinterleibsspitze ebenfalls auf dem Rücken aus. Alledrei Kanäle enthalten in ihrem Grunde einen fast vollständig ausgebilueten Embryo, der in den beiden vordern noch mit seiner Embryonalkugel zusammenhängt. Aussertem ist noch ein vierter Geburtskanal vorhanden, von dem nur die mitten auf dem Rïcken gelegene, fast nierenförmige Miindung (or.) zu sehen ist. Eine Anomalie an diesem Mutterthiere war, dlass sein contractiler Behälter nicht an der gewöhnlichen Stelle, sondern ganz nahe am Vorderrande des Körpers bei c lag; bei der Systole desselben bildete sich in seinem Umfange ein Stern von sechs eiförmigen, nach aussen zugespitzten Nehenbehätern, von welchen aus die Flussigkeit gleich nachher wieder gegen den Mittelpunct des Sterns zurückströmte und die Diastole des contraclilen Behälters bewirkte. — Das in Fig. 2 dargestellte Mutterthier, an dem der Deutlichkeit wegen die Afterwimpern weggelassen worden sind, hesitzt im vordern Theil der hintern Körperhälfte 8 grosse $\frac{1}{5}-\frac{1}{48}$ ' im Durchmesser haltende Embryonalkugeln, zwischen denen zwei kleine, nur $\frac{9}{9}{ }^{\prime \prime \prime}$ messende liegen, die wahrscheinlich Segmente zweier grössern sind und sich wohl demnächst in Embryonen verwandelı werden. Von der ersten und zweiten linken grossen Embryonalkugel geht je ein schrig nach vorn und 
links gerichteter Gehurlskanal (or. und or'.) aus, die heide auf der Riickseite des linken Seitenrandes ausmünden; aus dem vordern tritt ehen ein reifer Embryo (e.) hervor, der hintere ist leer. In hintern Theil des Körpers findet sich in der Nilte fermer noch cine Gruppe von drei etwas kleinern Embryonalkugeln; sie umgeben rlen Grund eines last genau in der Körperaxe gelegenen und am Hinterrande ausmindenden Geburtskanales (or".), aus welchem sich eben cin Embryo (e'.) hervorarbeitet, den die rechte Embryonalkugrel erzeugt hat. Die beiden andern haben ebenfalls einen von ihnen noch nicht abgelösten Embryo cntwickelt, die beide in den erweiterten Grund des Geburtskanals hineinragen. Endlich mindet am rechten Seitenrande noch ein vierter, kurzer, querer Geburtskanal (or".) aus, der zu zwei neben einander liegenden kleinen Embryonalkugehn fiihrt, von welchen sich nach dem Gelurtskanal hin je eine noch kugelförmige Embryonalanlage abgesondert hat. - Das in Fig. 4 abgebildete Mutterthicr zeichnet sich durch die Lage der Embryonalkugehn und die ungewöhnliche Form der Geburtskanäle aus. Es enthält 8 gleich grosse Embryonalkugeln, von denen zwei k. k.) ausnahmsweise in der vordern Körperhạlfte ganz vercinzelt liegen; diese sind durch ein gefressenes, bis auf das Skelet verdautes Räderthier (Squamella oblonga) von einander geschieden. Von der vordersten Embryonalkugel geht ein in der Rückenvand gelegener, oben offener, halbrimnenförmiger und nach rechts gekrummter Geburtskanal (or.) bis in die Nihe des Vorderrandes; er ist vorn seicht, nach hinten zu tief ausgelıöhlt und beherbergt hier einen zun Aussehwïmen reifen Embryo (e.). Die sechs iubrigen Embryonalkugeln $\left(k^{\prime}\right.$.) liegen in der hinterı Körperhălfte in einen Ring geordnet; vier derselben haljen nach innen zu eine kuospenförmige Embryonalanlage entwickelt. Für diese 6 Embryonalkugeln ist nur ein geneinschaftlicher, ebenfalls in der Riickenwand gelegener, halbrinnenförmiger Geburtskanal or'.) vorhanden, der iber und zwischen den beiden hintersten rechten Embryonallugehn beginnt und in einem schrägen Bogen nach hinten und rechts rerläuft.

Bei manchen Hulterthieren bilden sich bereits Embry onalanlagen, nachdem sich nur erst wenige Embryonalhugeln entwickelt hahen. So traf ich ein ansehnliches Individnum, welches ohne Gcburtshansile war und nur funf fist gleich grosse Embryonalkugeln enthielt, von denen schon zwei cine Embryonalknospe getriehen hatten. In andern Fállen entwickelt sich eine sehr grosse Anzahl von Embryonalkugeln, bevor Embryonen auftreten. So beobachtete ich zweimal Mutterthiere Taf. XIV. Fig. 5; welche mehr als funfzig Embryonallingeln enthielten; diese esfillten eine unfangreiche, centrale runlliche Höhle (k.), welche sich von der hintern Gegend rles Peristoms bis zu den letzten Afterwimpern erstreckle und nur wenig und gleich weit von den beiden Seitenrandern des Ǩörpers ahstand. Die Embryonallugeln waren, einige wenige lileinere alıgerechnet, $\frac{1}{63}$ gross und lagen so dicht gedraingt neben einander, dass sie sich zu Polyëdern abplatteten; sie selzten eine dorsale und ventrale Schicht zusammen, welche eiren linsenförmigen Zwischenraum umschlossen. In diesem tummelten sich bei dem ahgebildeten Individumm acht reife Embryonen (c. e.j unher, ron denen vier a. b. c. ıl.) plötzlich nach aussen hervorbrachen, als das Thier einmal an den Rand les Wassertropfens gerieth, sich hier auf einige Augenblicke schr stark alpplattele und Wahrscheinlich auf der Rückseite cinen Riss bekam. An dem unverletzten Thiere hatte ich durchaus keine Gehurtskanäle wahrnehmen können, es konnte also noch keine Geburt stattgefunden haben. Höchst wahrscheinlich sind die Embrgonalkugelı solcher Mutterthiere nicht nach und nach durch fortgesetzte Theilung aus Ueberbleilseln von einer frihthern Generation von Eubbyonalkugeln liervorgegangen, sondern sie stellen offenbar die hisher vorausgesetzte primitive Generation selbst dar, welche sich meiner Ansicht nach unmillelbar aus den liernen der zu Mntterthieren herangewachsenen Theilungssprösslinge entwickelt. Welche andere Bedentung hönnten auch wolıl die oft eben so zahlreichen und nur in Theilungssprösslingen vorkommenden Kerne haben, als das erste Material 2.u Embryonalkugeln zu liefern, die ja, so weit wir ihen Ursprung bei andern Infusorien liennen, stets Producte des Nucleus sind? Nicht unerwihnt darf ich lassen, dass ich in Gesellschaft des ehen geschilderten Mutterthieres einen einzelnen Theilungssprössling antraf, der mil einigen 4.0 kleinen Kemen versehen war. Es wird nun darauf ankommen, dergleichen Theilungssprösslinge recht aufmerksam zu verfolgen, um durch directe Beobachtung die Entwickelung ihrer Kerne zu Embryonalkigeln zu constatiren.

Sobald ein Mutterthier zu gebairen angefangen hat, so werden dicjenigen Embryonalkugeln, von welchen sich zuerst Embryonen albschnibten, durch schnell auf einander folgende Production neuer Embryonen bald vollstandig verbraucht. Dadurch rermindert sich nach und nach die Zahl der Embryonallingeln, obgleich noch hin und wieder eine sich durch gleichlsilftige Theilung vermeht, und sie erscheinen immer vereinzelter und regelloser zerstreut. Es können daher die Embryonalkugehn, welche die in Fig. 2-4 dargestellten Individuen besitzen, eben so wohl die Ueberbleibsel ron einer primitiven, weit zahlreichern Generation scin, wie sie andererseits von einer cinzigen, durch fortgesetzte Theilung sich vermehrenden Embryonalkugel abstammen können. An dic Stelle ciner 


\section{2}

ganz in Embryonen aufgegangenen Embryonalkugel treten später eine oder mehrere andere, welche nun in der Production von Embryonen fortahren, bis auch sie verbraucht sind. Zulekt bleiben nur noch einige wenige Embryonalkugeln ibrig, deren näheres Verhalten in melufacher Beziehung von Interesse ist. So traf ich ein Individuum, welches nur noch drei in der Mittellinie des Hinterleibes gelegene, $\frac{1}{5}-\frac{1}{5} \frac{1}{4}$ grosse, isolirte Embryonalkugeln enthielt, ron denen eine jede mit einem Geburtslianal in Verbindung stand. Yon der vordern ging ein Geburtskinal schrïg nach vorn zum linken Seiteurande, von der mittlern fast vertical zur Mitte des Riickens und von der hintern schräg nach hinten zum rechıen Seitenrande; der voldere und hintere Geluutshanal umschlossen einen reifen Embryo. - Ein anderes Hulterthier enthielt drei ehen so grosse, weit aus einander liegende Embryonalkugeln; von zweien ging ein Geburtskanal aus, in welchem cin reifer Embryo sleckte, die dritte und grösste Embryonalkugel war olne Gehurtskanal und noch in der gleichhailfigen Theilung begriffen.

In vielen Fällen gehen endlich auch die letzten Embryonallugeln rollständig in Embryonen auf, indem jede durch fortgesetzte Abgahe neuer Embryonalanlagen immer heiner wirl, bis sie zuletzl nur noch so gross ist, wie eine gewöhnliche Embryonalanlage; dieser liest biluet sich dann direct in einen Embryo um. Wir sehen diese letzlen Entwickelungsverhiltnisse an dem in Fig. 6 dargestellten Nulterthiere; es besitzt noch zwei am linken Seitenrande ausmïndende Geburtskanile. Aus den vordern (or.), an dessen Grund noch eine kleine, $\frac{T^{2}{ }^{m}}{1 m}$ im Durchmesser haltẹde Embryonalkugel hängt, trat während der Beobachtung ein reifer Embryo (é.) hervor, der nur bis zum Peristomfeld schwanm und sich hier mit seinen Tentakelı anheftete. Am Grunde des hintern Geburtskanales (or:') hảngen noch zwei eben so kleine, durch Theilung aus einer grössern herrorgegangene Embryonalkugeln, von denen die vordere demnächst in einen Embryo iibergehen wird. Der letzte kleine Rest der Embryonalkugeln rïicht endlich ganz in den Gehurtskanal hincin und gelangt allmailılig bis zu dessen Hündung, in der er stecken hleibt. und wo er sich erst zu cinem Embryo aushildet, während hinter ihm der Geburtskanal zusammenfält und spurlos rerschwindet. Unser Mutterthier ist bei e. e. mit zwei solchen in den Mindungen zweier ehemaligen Gelurtskanale steckenden, unentwickelten Embryonen versehen, welche keine Wimpern, sondern nur Tentalieln besitzen, die besonters an dem frei aus der Mündung hervorragenden Segmente sichtbar sind; sobald diese Embryonen ausgeschwtirmt sind, schliessen sich die nur noch napförmigen Vertiefungen vollstindig. Aehuliche 1lutterthicre sind mir oft rorgekommen. In ihrer Gesellschaft traf ich auch gar nicht selten andere lndividuen, welche eine oder zwei eben so kleine oder doch nicht viel grössere Embryonalkugeh enthelten, wie das in Fig. 6 abgebildete Thier, sie zeiglen aber keine Spur von einem Geburtskanal oder irgend einer Oeffung nach aussen. Offenbar waren dies Mlutterthiere, die unlängst zu gebären aufgehört hat.len und ihren Embryonalliugelvorrath lis auf einen oder zwei lileine Reste verbraucht hatten; letzlere werden in einer spätern Lebensperiorle sich von Nenem rerglössem und rlie Grundlagen zu der Generation von Emblyonalkugeln liefern, von denen unsere Betrachtung ausging.

Was num den nahliern Hergang hei der Bildung von Embryonen betrifft, so ist dieser am hlarsten zu beobachten, wenn man aus solchen Mutterthieren, die bereits in Gebären begriffen sind, die Embryonalkugeln vorsichtig herauspresst, was sich leicht bewirken lässt, namentlich wenn viele Embryonalkuggeln vorhanden sind. Setzt man dann zu den isolirten Embryonalkugeh hinlianglich Wasser hinzu, so entwickeln sich nicht blos die bereits mit einer Embryonalanlage versehenen ungestört weiter, sondern gewöhnlich wächst auch balı an den andern Embryonalkugeln, an den einen früher, an den andern später, eine Embjyonalanlage hervor. Diese entsteht dadurch, dass sich zuerst an irggend einem Puncte der Oherflache der Embryonalkugel eme sanfte, hỉgellörmige Auftreibung biluet, die leträchtlich schmaler ist, als der Durchmesser der Kugel. Sie setzl sich bald an ilırer Basis rlurch eine ringförmige Einschnürung schärfer von der Embryonalkugel al, und erscheint nun wie eine bruchsackarlige Ausstülpung oder wie ein linospenförmiger Auswuchs derselben (Fig \%. a.). Der Durchmesser der Embryonalkugel, in dessen Richtung sich dieselbe aussackt, wird fortan zu ihıer Hauptaxe; ihr liern dehnt sich ziemlich gleichzeilig mit der Embryonalkugel in der Riclıtung der Iauplaxe gegen die Knospe hin in einen zalfenförmigen Fortsalz aus, der bis in die Vitte der Knospe hineinwaichst und hier mit einer elwas angeschwollenen Sjitze endet. In der ḱnospe erscheinen friiłzeitig ein oder zwei contractile Behiilter, je nachden die Embryonallugel deren einen oder zwei besitzt. Sie scheinen von den contractilen Behillern der Embryonallugel aus gebildel zu werden, denn ich sah öfters zwischen einem contractilen Behibler einer noch ganz jugendlichen kinospe und dem ihr zunächst gelegenen der Embryonalkugel eine gefäsartige Communication. Wenn die knospe zwei contractile Behảlter besitzl, so liegt der eine gewöhnlich in der Hauptaxe nahe unter der Spitze, der andere links oder rechts von der Hauptaxe an der Basis der Kinospe. Nach und nach wächst lie Knospe weiter aus der Embryonalhugel hervor, schürl sich starlier vou 


\section{3}

derselben al und rundet sich mehr und mehr zu einer Kugel ab Fig. 7. b.). Gleichzeilig zjeht sich der Kern zuvschen seinen beiden angeschwollenen Enden zu einem dünnen fadenfömigen Strang zusammen ivergl. Fig. 4. lí. so wie auch die hleinere in Fig. 7 hei c alogebildete Embryonallugel), der lualu ganzlich schwinder, so dass nun sowohl die Embryonalkugel wie auch die hospe mil einem liir sich bestehenden centralen Kern versehen sind (Fig. 7. b.); dic Grösse des beilen kerne verhahl sich zu cinander, wie der Lunfang der Embryonalhugel zu den der Knospe. Noch vor der Theilung des Kerns oder doch grleich nach derselben wachsen an der Oberfliache der Kinospe sehr zarte und dicht stehende Wimpern hervor (Fig. 7. b. c.), die znerst auf dem Scheitel der knospe erscheinen mnd sich dann bald iiber ihre ganze Oberlläche bis zur Basis aushreiten; sie sint Anfangs so kurz und fein, dass man nur am Rande der Knospe einen sanft wogenden Itof bemerht. Je deutlicher die Wimpern hervortreten und je kraftiger sie zu schwingen anfangen, um so melı versetzen sie lie gesammte Eubryonallingel in eine langsame, drehende, abwechselnd nach links und dann wieder nach rechts gerichtelo Bewegung. Die Knospe bildel sich unmehr schnell zu cinem Embryo aus; wähend ihre Wimpern sich noch beträchlich rerlingern und rings herum ausspreizen, zieht sie sich stark gegen die Hauptaxe zusammen und remandelt sich so zuerst in einen länglich ovalen, daun in cinen oblongen oder hurz walzenförmigen Körper (Fig. 7. d.), der jetzl so lehhaft und hraftig wimpert, dass er sich mit der an ilum hängenden Embrgonalliugel von der Stelle bewegt und zicmlich gewandt unsherschwimmt. Endlich schuirt sich der Embryo imuer melı von der Embryonalkugel ab. er fängl an, auf derselben hin und her zu schwamkeu, und reisst sich bald darauf von der nun fast völlig wieder abgerundeten Enbryonalkugel los Fig. 7. e. .

Auf ilie eben beschriebene Weise entwickelten sich die Embryonen nur bei den aus dem Nussler Park stammenden Mutlerthicren. Erst nachdem sie sich von ihren Embryonallugeh getrennt hatten und langere Zeit umhergeschwärmt waren, traten an ihrer Oberflache selır vereinzelte und kurze Tentakeln hervor Fig. a und b, neben Fig. 2), welche den Fmbryonalkugeln und ihren kínospen ginzlich fehlten. - Bei allen andern gebajenden Mutterthieren zeigten sich an den isolirten Embryonalkugeh (Fig. 8. 9) sofort mehr orler weniger zahlreiche, iilser den ganzen oft unehenen, welligen Rand zerstrent stehende, dünne, fadenförmige, mit einem kleinen Knöpfchen endende Tentakeh, die sich ziemlich lebhaft verlangern und verkïzen und auch leicht und beträchtlich ihre Richlung andern. Aus diesen Embryonalkugeln bildet sich der Embryo im Wesentlichen auf dieselbe Weise herror, wie aus den tentaliellosen. An lux Stelle, an welcher sich die Embryonalkugel zur Bildung einer Knospe nach aussen wölbt, worlen die Tentaliehn eingezogen, und anch die Knospe bleibt oft noch ziemlich lange Zcit, nachılem sie schon kuglig geworden ist und ringsum Wimpern bekonmen bat, ohne Tentakehn (Fig. 8. a.). In audern Fällen zeigen sich an der Knospe schon frihzeitig wieder kuze Tentakeln (Fig. 8. b.); spätestens treten dieselben hervor, wenn die Knospe in die Ovalform übergeht, so dass sie dem zur Ablüsuing reifen Embryo (Fig. S. c.) nie fehlen.

Itat sich ron einer Embryonalkugel, mag dieselbe mil Tentakeh versehen sein ouler nicht, ein Embryo abgetrennt, so zeigh sie sich wieder völlig kugelfömig, sie ist aber nalürlich mun um so viel kleiner geworden. als das Volumen des rou ilı producirten Embryos betragt. Den erlitlenen substanzverlust rermag die Eubryonalkugel an ihrer naturlichen Bildungsstalte gewiss theihweis wieder"zu crsctzen, indem sie entweler mil ihrer ganzen Oberflache oder mittelst tentakelförmiger Fortsitze derselben neues Bildungsmaterial aus dem umgebenden Parenchym aufnimm; bei den isolirten, von blossem Wasser umgebenen Embryonalkugehn ist dies aher nicht möglich. Diese treiben sehr bald, nachden sich ein Embryo von ihnen abgelüst hat, eine nene, ihrer nummehrigen Grösse proporlionale Knospe (vergl. Fig. 7. bund c.) und liefern in Allgemeinen einen Embryo, der um so kieiner ausfallt, je mehr sich das Volumen der Embryonalhugel remindent hat. Wenn eine isolirte Embryonalliggel bereits melırere Embryonen nach cinander abgegeben hat, so entwichelt sie nicht selten eine Knospe, die eben so gross ist, wie sie selbst (Fig. 8. d.); sie gleicht in diesem Stadium ganz und gar einer in der gleichlathtigen Theihung begriflenen Embryonalkugel, nur haben beide llatften eine verschiedene Organisation und Bedeulung; die eine ist bewimpert und wirt zum Embryo, die andere ist nackt und besteht als Embryonalkugel fort. Die schr kitein gewordenen Embryonalkugeln (Fig. 9. a.) verwenden stets ihre Hálfte zu einer Enbryonalknospe (c.) und liefern einen kurz ovalen, dicken Embryo (d). Nicht setten zeigt sich an den einen Pole solcher Embryonalkugeln, der zum Scheilel der knospe werden soll, bereits ein Schopf ron sehr kurzen zarten Wimpern (Fi g. 9. b.), beror noch irgend eine Spur von Einschniirung an der Eumbronalkugel vorhanten ist. Die verschielene kntwichelungsweise des Embryos aus der Embryonalkugel tehrt recht deutlich, wie wenig sich eine scharfe Granze zwischen Theilung und knospenbildung ziehen hasst. Mit demselben Rcchte, wie wir bei Urostyla grandis die Entwickelung des Embryos als Kunospung 


\section{4}

auffassten, liönnen wir dieselbe auch als Theilung betrachten, die Anfangs stets ungleichhälftiğ, später gleichbäftig auftritı. - Wem sich isolirte Embryonalkugeln durch fortgesetzte Abgabe von Embryonen bis zu $\frac{1}{y^{\prime \prime}}{ }^{\prime \prime}$ oder löelıstens bis zu $\frac{1}{105}$ "in Durehmesser verkleinert haben, so bleiben sie als einfache Kugeln auf ulem Objectglase liegen (Fig. 10), die mit einer sehr versehiedenon Anzahl von Tentakeh versehen siud, welehe sich noeh energiselı verlängern und verkiurzen und oft beträchtlich beugen. Die in Fig $\$-10$ abgebildeten Embryonallugeln rüluen alle von demselben Nutterthiere her; es enthielt nur grosse Embryonalkugeln, ähnlich den in Fig. 8 bei a und b abgebilteten, wenu dieselben noeb lieine Knospe entwiclsclt haben würden. Nach Verlauf von kaun zwei Stunden hatten diese gुrossen Embryonalliggeln so oft Eubryonen abgegeben, dass nun das Objectglas nur noch mit zahlreichen, so hleinen kugehn, wie die in Fig. 10 dargestellten, bedeckt war; denn auch die alıgelöslen Embryonen nehmen nach liurzer Zeit wieler Kugelform an, verlieren ihre Wimpern und theilen sich, wenn sie dazu noch gross genug sind, auf dieselbe Weise. Wie wir es in Fig. 9 bei c und a sehen.

Die reilen Embryonen stimmen sowohl in ihrer Organisation, wie alueh in ihrem gesammteu ibrigen Verhalten sehr nahe mil denen von Stylonychia mytilus überein, nur sind ihre Wimpern noch langer und die Tentakeln dimner. Sie besitzen cinen ringsum geschlossenen, balı ovalen, bald kurz walzenförmigen und an beiden Enden abgerundeten, in der Nitle etwas verengerten Körper, der bald ganz drehrund, bald ctwas abgeplattet ist, wie der auf der Kante stehende Embryo d neben Fig. ö lehrt. Die ganze Oberlljiche des liörpers ist dicht mit sehr langen, feinharigen, in den Abbildungen nur am Rande des Körpers angegebenen Wimpern besetzt, welche namentlich an lilcinern Embryonen oft so lang oder noch länger sind, als der ganze Körper. Zwischen den Wimpern treten wenigstens immer einzelne Tentakeln, namentlich an vordern Ende, hervor (Fig. a und b neben Fig. ?. unt Fig. 6. é.), hăufig ist der Körper gleiehförmig mil zahlreichen, auf der ganzen Obèfläche zerstreut stehenden Tentakeh lesetzt (Fig. 5. e. e und a-d.). Oft sind die Tenlakeln selı kurz und leicht zu bibersehen; auch wenn sie melu hervorgestrecht sind, erreichen sie doch nie die Länge der Wimpern. In der Mitte des Körpers oder weiter nach hinten liegt der runde onler querovale Kén. Auffallend ist das verschiedene Verbalten der contractilen Behälter. Häufig sind deren zwei vorhanden; der eine und stets ansehnlich grössere liegl dann in der Nuhe des vordern Endes uml ziemlich genau in der Längsaxe, ler andere, ungemein klejue hart am hintern Ende und mehr nach der einen Seıte gerickt Fig. 2. a. .. Fig. 6. e'. Fig. 7. d. e.). In antlern Fälen ist nur ein einziger contratiler Behaitter vorhanden, der dann gewöhmlich in der Mitte des einen Seitenrandes neben dem kem liegt. So verhielten sich alle reifen Embryonen aus dem in Fig. 5 dargestellten Multerthiere (rergl. a. b. c. d.; ; die an den isolinten Embryonalliugeln dieses Mutterthieres siel entwielielnden Embryonen zeigten dagegen fast immer erst einen vortern und hintern contractilen Behălter. Küz ror dem Ablösen des Embryos rollte plötzlich die Flissig̨leit des vordern contractilen behälters, der nun fiur immer verschwand, bis zur llitte der cinen Seite herab (Fig. 8. c.); balıl darauf ergoss sich auch die Flissigkeit aus dem hinlern contractilen Behäller nach derselhen Stelle hin, und fortan zeigte sich mur lier ein grösserer contractiler Behilter. - Die Embryonen schwirmen mit mässiger Gesehwindigheit in weiten Bogen

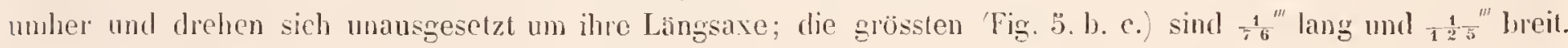
Ihre weitere Entwiclielung liess sich eben so wenig ermilteln, als die der Embryonen von Stylonyehia mytilus. Alles was oben S. 161 ron den letzlern gुesagt wurde, gilt auch ron den Embryonen der Urostyla gramlis.

O. F. Müller's Trichoda patula, welche Ehrenberg gewiss mit Untecht zu seiner Leucophrys patula (Bursaria Iruncatella? vergl. S. 17) ziehı, stellı höchst wahrseheinlieh die Lrostyla grandis dar. Ich schliesse dies cinerseits aus der gesammten Form des Körpers und sciner grossen Dehubarlicit, die aus Müller's Fignr 4 erhellt, andererseits aus der Form des Peristoms, welches Mïller sehr vollständig erliannt und, kleine Versehen ahgerechnet, fast genau so angegeben hat, wie dasselbe bei U. grandis gestaltet ist. Dic Stirn- und Afterwimpern wurden nicht unterschieden, wohl aber dic Randwimpern, die in Fig. 4. als selı feine kurze llärchen abgebildet sind. - Die Ablbildungen, welche Ehrenberg von U. grandis geliefert hat, lassen sehr viel zu wiinsehen iilsig, er fasst das Peristom als eine sehmale, in der Mittellinic des Batuches gelegene, fiir sich bestehende und ringsum mit kraftigen borstenförmigen Wimpern besetzte Lingsspalte auf; die langern Wimpern auf der linken Seite der Spalte sind die aussern adoralen Wimpern, deren Zusammenhang mit ten in Fig. 2 angedeuteten rordern adoralen Wimpern nieht erkannt wurde, die kiuzern Wimpern anf der rechten Seite der Spalte heruhen auf einer irrigen Auffassung ter undulirenden Ilembran, auch mochten wohl die dem Imenrand des Peristoms zunachst stchenden Stimwimpern gesehen werden. 
Den Körper lasst Ehrenberg auf der ganzen Oberlbiche mit dicht stebenden Lingsreihen ron Wimpern besetzl sein, den contractilen Behialter versetzt or in die rechte Kärperhälfte, und Afterwimpern werden nur : 0 - 8 angegeben. Der letztere Unstand, so wic die schlankere Form des Körpers, welche die von Ehrenberg abgebildeten Thiere zeigen, hönnten auf dic Vermuthung fuluren, dass seine U. wrambis nicht die gegrenwintige, sondern dic vorige Art darstelle. Dies ist jedoch nicht möglich, denn die U. Weissei besitzt stets zwei sogleich in die Augen fallende Kerne, die Ehrenberg in lieinem Fall hätte ibbersehen liönnen, wenn er diese Art vor sich gehaht häte; seine U. grandis dagegen besitzl nur eine einzige, in der Mille des Körpers gelegene "hugeldriise ". Diese sogenambe Kugelelise war sichertich kein einfacher Nucleus, sondem eine vereinzete Embryonalhugel, wie in den vou mir in Fis. 3 auf Taf. XIIl abgeliddeten Falle. Dies wird ganz evident durch das von Ehrenberg in Fig. 3 abgebidete Individumm mit zwei uahe hinter cinanter liegenden Kugeldrusen bewesen, welches lediglich wegen der so gewöhnlich vorkommenden Einschnürung der millem Körperregion für cin in der Qucrlleilung begriffenes Thier ansgegeben wirl, was es doch gar nicht sein kiann, da es in der hintern Körperhälfte keine Spur von einem zweiten Peristomund cinem zweiten contractilen Behälter zeigt. Die beiden Kuggeddiasen können mithin nicht, wie Ehrenberg glaubte, Theihngspioducte ciner ursprïnglich eiufachen sein, die sich in Folge der Körpertheilung theilte, sondern sie sind cutstanden, olme dass der Körper in der Theilung begriflen war, und eben deshalb liönnen sie unr zwei Embryonallugehn sein, wie wir

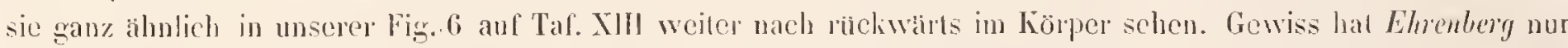
bei einigen der von ihm beobachteten Individuen eine cinfache Kugeldrise geselıen und diese dam als allgemein vorkommend angenommen. - In Ehrenberg's Bursaria vorax, die dieser Forscher selhst als cine ther U. grandis sehr ähnliche Infusorienform bezeichnet, hann ich nur schr lichte, farblose, rerkïrzte und verbreiterte Individuen von U. grandis ertennen. Ich habe oft sehr ahnliche und auch mit Coleps hirtus erfuilte Individuen lseobachtet, dic aber sonst alle Charactere der U. grandis zeigten. Dass Ehrenberg hei seiner Bursaria rorax, trotz der Grösse und Durchsichtigkeit des Thieres, keinen Nucleus unterseheiden liomnte. spricht ebenfalls fuir meine Ansicht. Der angebliche contractile Behaifler am hintern Körperende war ohne Zweifel nur ein zufalliger, mil Wasser erfülter Holılraum, dergleichen bei U. grandis nicht selten rorkommen. - Cohm hat von U. grandis num eine ganz rohe, unausgefuhrte, anscheinend aus llem Gedächtniss und nach Ehrenberg's Abjhlungen entworfene Emrisszeichnungr geliefert, nach der man die Art nicht erliennen wüde; uber dieselbe kann jetoch nicht der mindeste Zweifol bleiben, da er bei ihr die Embryonalkugeln enteleckte und auch schon ohngefïh den Modus erkannte, nach welchen sich aus denselben Embryonen entwickeln. Die Organisation der letztern ist njcht richtig heobachtel, sic werden als hugeln usit centralem contuatilen Behälter und an Rande gelegenem Keru und mit zu dicken und zu weilliuftig stehenden Wimpern dargestelt; die Tentakeln blieben unbeachtet. - Perty's Oxytricha fusca steltt entschieden die gegenwälige Art dar; ich sah hiufig genan ehen so gestaltele und gefiblute Individuen, wic das a. a. 0. Fig. 19. I alggebildete, unterschical aher an denselben stets die Afterwimpern, die Perty nicht auffinden lionnte. Was um so weniger zu besagen hat, als diesem Forscher auch dic ganze iibrige Bewimperung der Bandhseite unbehannt bliels. Die Oxytricha decumana larty, welche nicht abgebildet ist und sich ledighlich durch den Körperumiss, der doch aber bei den Urostylen so sehr verduderlich ist, von Oxyt. fusca unterscheiden soll, wird gewiss auch nichts weiter. als Urost. grandis gewesen sein. - Die Oxytricha protensa Perly dürfte auf jugendlichen Individuen von Urost. grandis beruhen. - Claparede fubrt unter dem Namen Oxytricha lisea Perly eine Art anf, von ter nur mit wenigen Worten angegchen wird, dass sie der Oxytricha Urostyla Clap. Lachm. nahe verwandt sei, abcr grösscre Dimensionen erreiche, lieine Afterwinpern hesize und nit einer grössern Anzahl von Banchwimperreihen rersehen sei, die sich jedoch nicht mil Sicherheil habe bestimmen lassen. Ohne Zweifel war dies unsere Lrostyla grandis, leren Afterwimpern so sehr leicht ïberselen werden können.

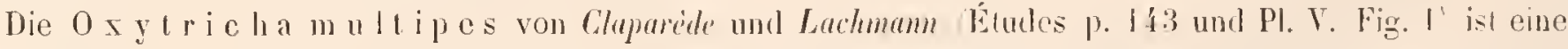
bei Berlin beobachtete Urostyla, welche zwischen U. Weissei und U. grandis mitten inne zu stchen scheint; sie besitzl, wie U. Weissci, \& Afterwimpern und ä parallete gleich weit ron einander abstelsende Bauchwimperreihen, von denen sich die vier rechten über das Stimfeld bis zmm Vorderrande fortselzen. Dic anf Jem stirnfelde stehenden Wimpern dieser vier Reilien sind in hakenfömige Griffel ungewandelt, von denen die erste in jeder Reihe am stäksten entwickett ist. Die Oxytr. multipes besitzt hiernach zahtreiche grviffelförmige Stisnwimpern, wie Urost. grandis. Von letzterer Art unterscheidet sie sich, ausser der geringern Anzahl ron Jfterwimpern und Bauchlwimperreihen, auch durch einen dopjelten Nucleus. 


\section{6}

3. Urostyla viridis. STEIx. (Taf. XIII. Fig. $13-14)$.

hörper Inzellförmig, mit 3 Stirmwimpern, 5 Afterwimpern und vielen über die ganze Banchfä̈he vertheilten Bauehwimperreihen: Nucleas doppelt

Ich beobachtete diese Art im September 1857 und im August 1838 selır häufig in Torfstichen bei Niemegk, und traf sie auch rereinzelt im. Januar 1858 in einem sumpfigen Graben des Banmgatens bei Prag. Sie hat in ter aussern Form viel Aehulichkeit mit Urost. Weissei, welche nie in ihrer Gesellschaft rorkam, ist aber immer viel kleiner und daran leichı kenntlich, dass sie stets von zahllosen, das Parenchym ron rorn bis hinten sehr dicht esfüllenden Chlorophylliöınern lebhaft grïn gefirbt ist. - Der Körper ist platlgedriiclit, mehr als 3 mal so lang, wie breit, langgezogen elliplisch, in der llitte am breitesten, nach rorn und hinten verengert, vorn abgerundel, binten lanzetıförmig zugespilzı. Das vordere Ende ist etwas nach liuks gelirimmt, die Rückseite (Fig. I 4) sehr llach grewölht, die Bauchsejte (Fig. 13) plan und nicht selten längs der Miltellinie llach ausgehöhlt; die Seiten sind ahgerundet. Dis Parenchym ist viel resisteuter, als bei den beiden rorigen Arten, die Körperform daher weit weniger veränderlich. - Das Peristom nimml ein Dritlel der Körperlänge ein und ist ungemein schmal; die Oberlippe ist dem Vorderrande schief und mehr nach rechıs aufgesetzt, der breite bandförmige Aussenrand des Peristoms erstreckt sich ron der linken Ecke ler Oberlippe in schräger Richımg bis zur Mlitellinie, der Innenrand begleitet den Aussenrand, von dem er nur durch eine enge Spalte geschieden ist, bis nahe zum Vorderande, wo er sich allmählig verliert. - Auf dem vordersten Theil des sehr breiten Stirufeldes stehen drei kräflige Stirnwimpern inn Dreieck. Afterwimpen zählte ich mur funf, es sind dinne, borstenförmige Griffel, die in einer steil nach vorn unıl links aufsteigenden Reihe stehen und nicht bis zum Hinterrante reichen. Die Randwimpern verhalten sich wic be: U. grandis, sie mehmen wach hinten an Liinge zu. Die Bauchwimpern sind zalte, wegen der dichten Erfuillung des Körpers mit Chlorophyllkörnern schr schwer wahrnehmbare Borsten, welche in engen parallelen Längsreilıen gleichmässig uber die ganze Bauchflache vertheilt sind. Die der rechten Körperhuilfte angehörigen Reihen setzen sich uber das Stirnfeld his zu den Stirnwimpern fort, ohne dass die hier stehenden Wimpern ihre Form ändern. Stets sind zwei länglich ovale, mit einer queren spaltförmigen IJöhle und mit einem links anliegenden Nucleolus versehene Kerne (n. n.) vorhanden, die hinter dem Peristom in geringer Entfernungr von einander liegen. Der contractile Behälter (c.) findet sich zwischen beiden Kernen in der Mlile des linken Seitenrandes. — Die Línge des Körpers betriagt $\frac{1}{1 \frac{1}{3}}-\frac{1}{12}$ ". 

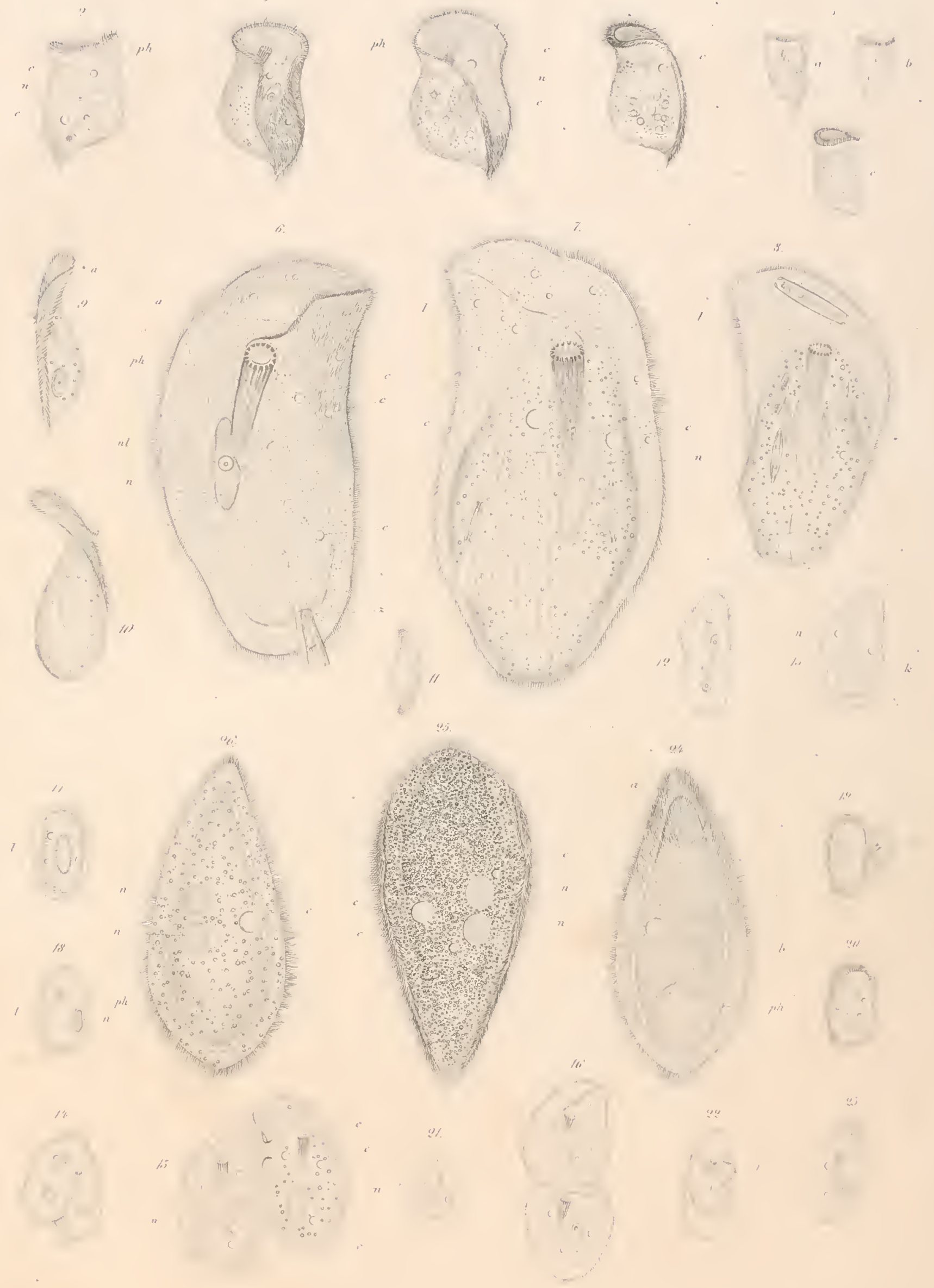



\section{1}
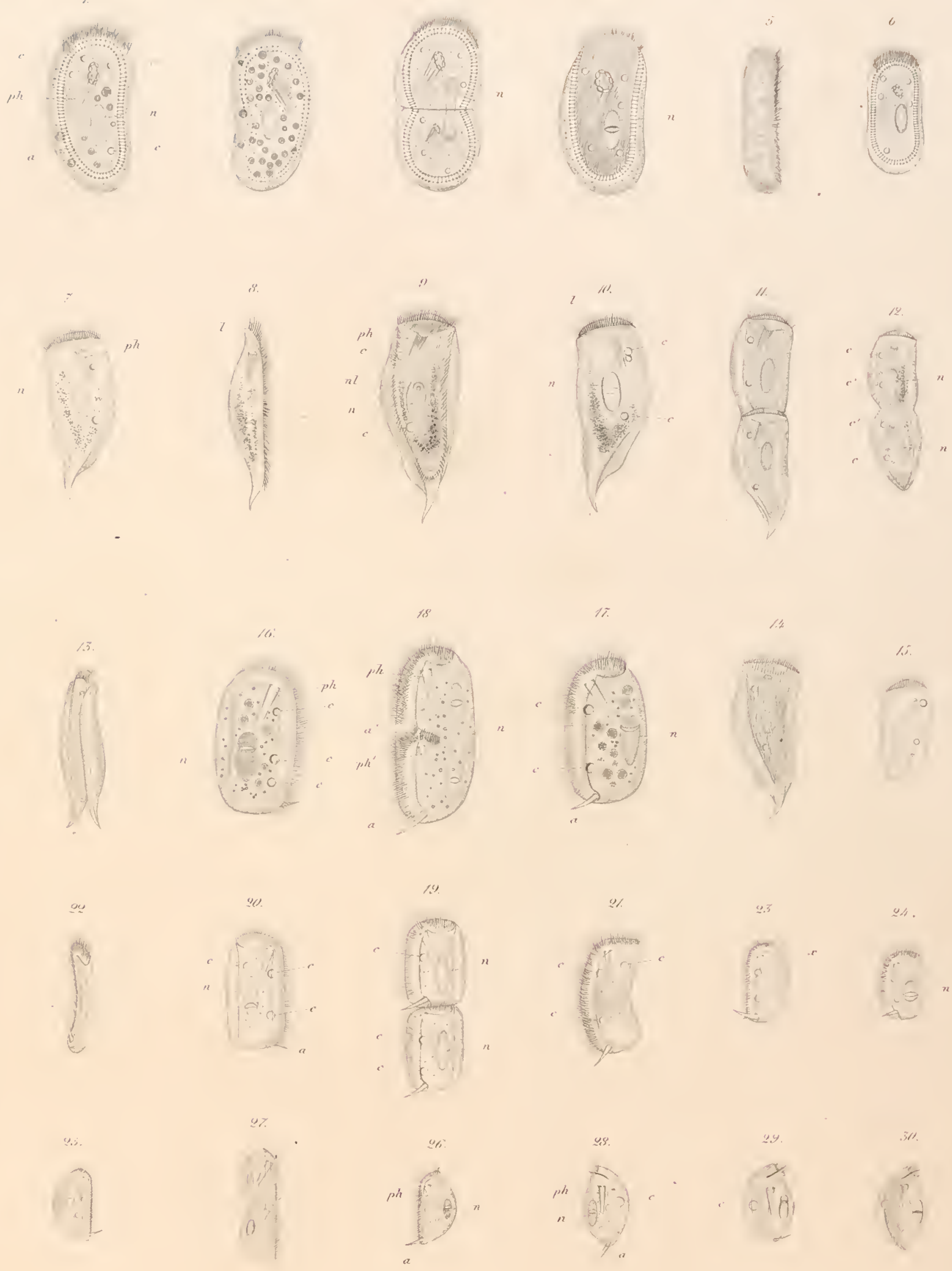


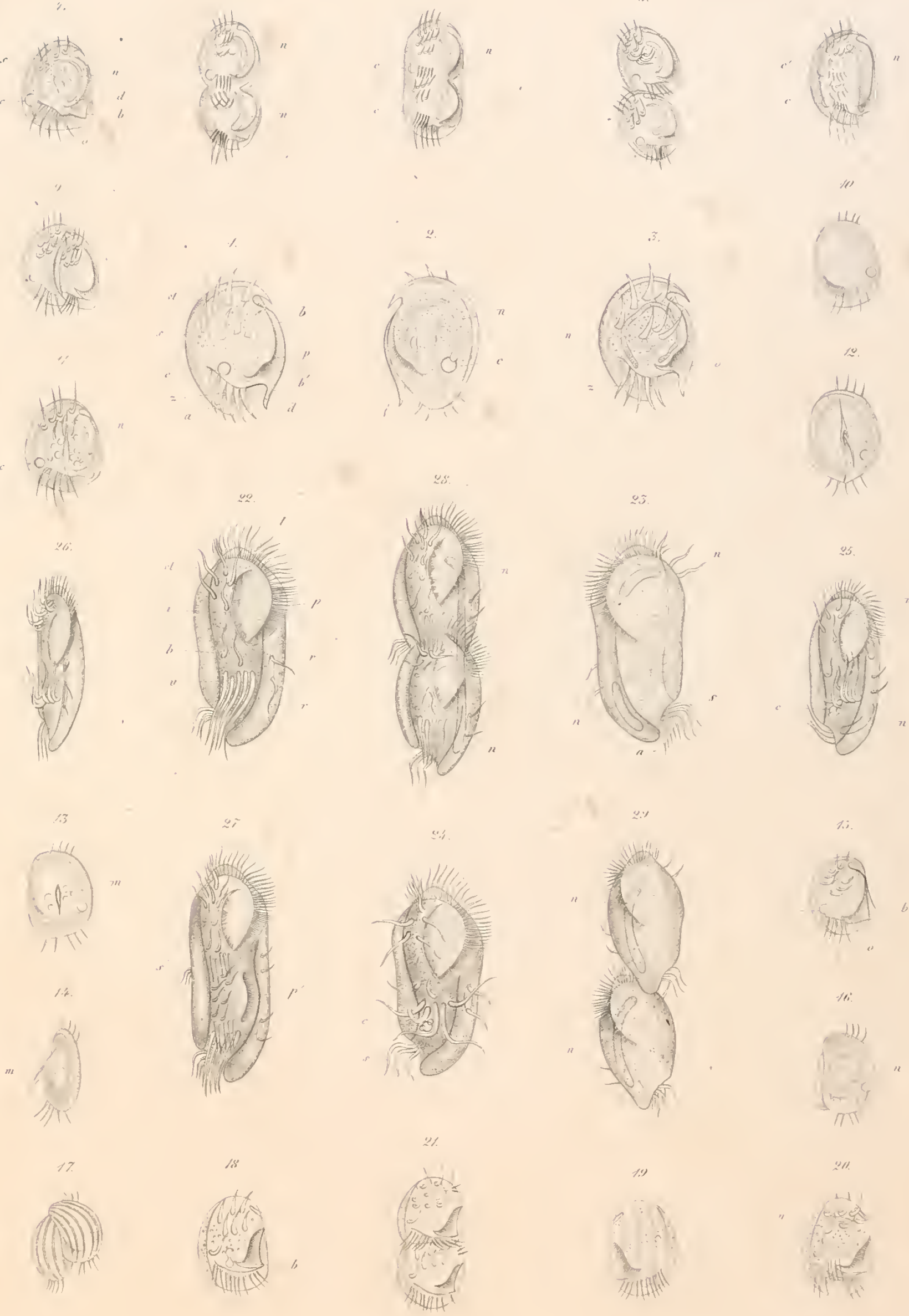

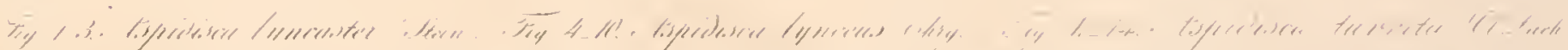

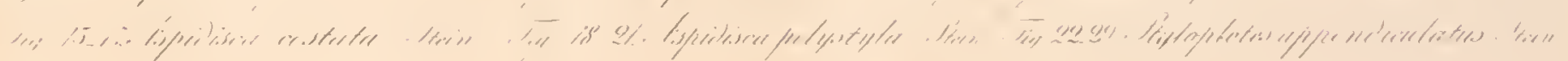




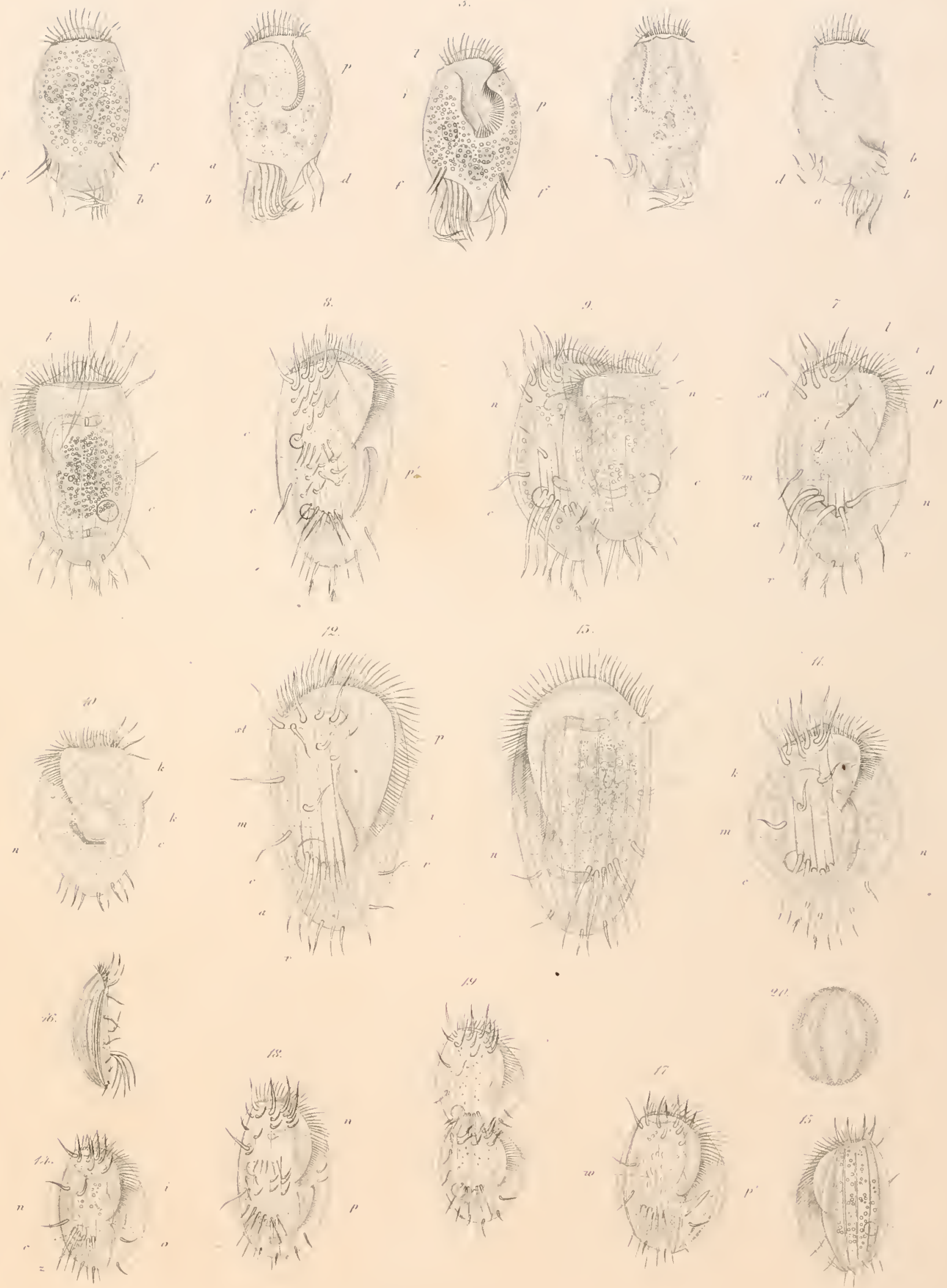



$$
\begin{aligned}
& 808 \\
& 808
\end{aligned}
$$





$$
\begin{aligned}
& 8.80 \\
& 8.88
\end{aligned}
$$




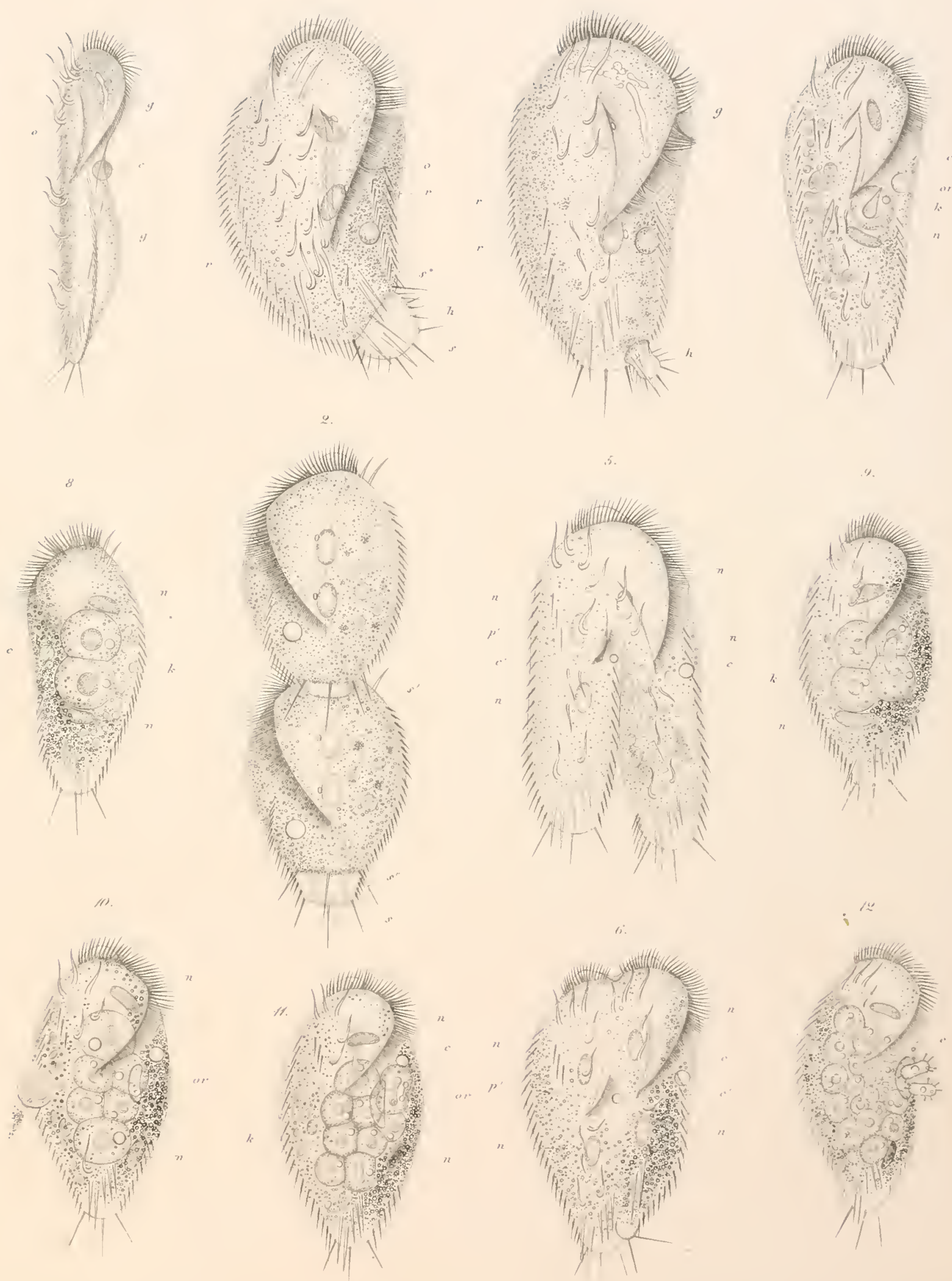



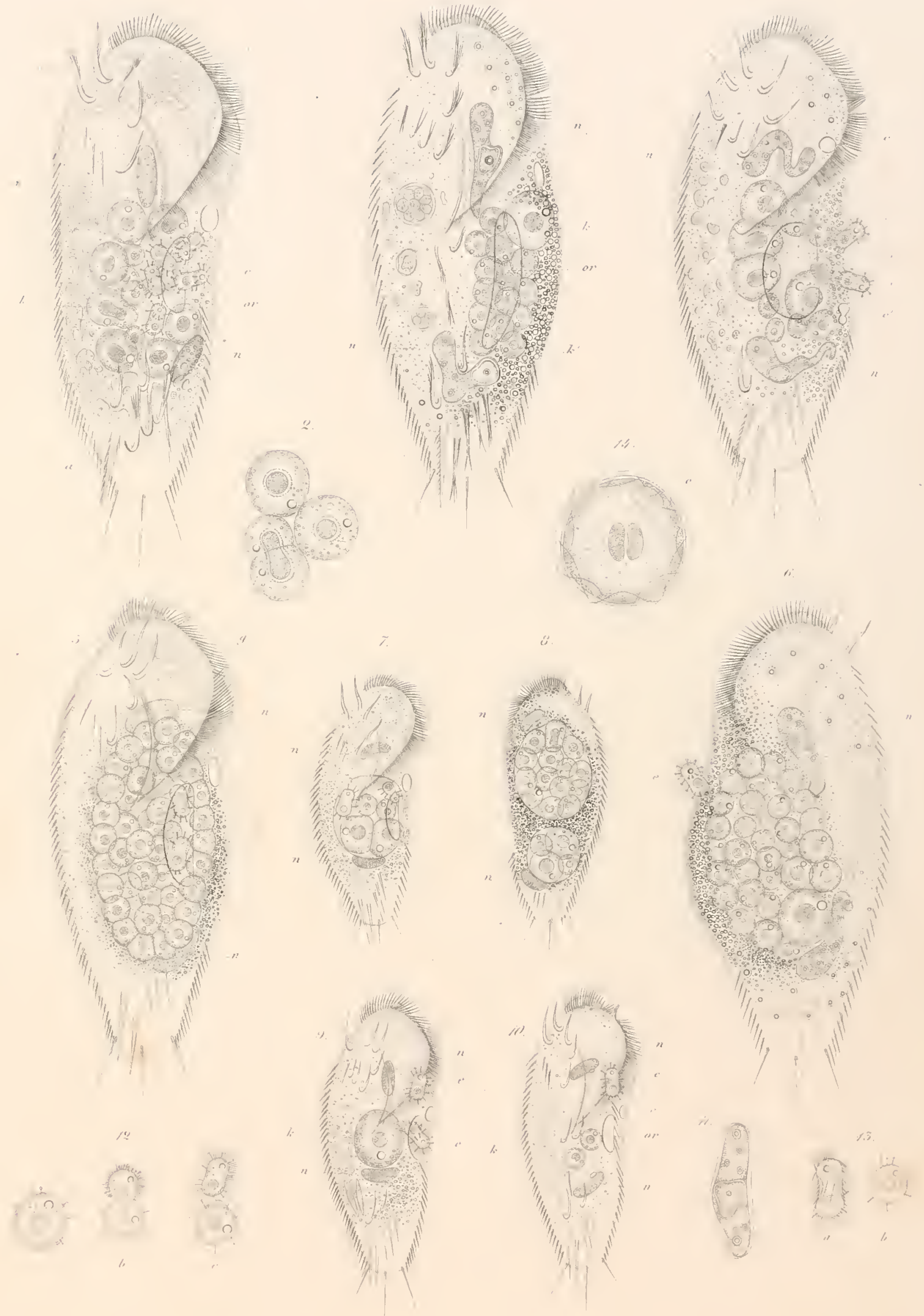




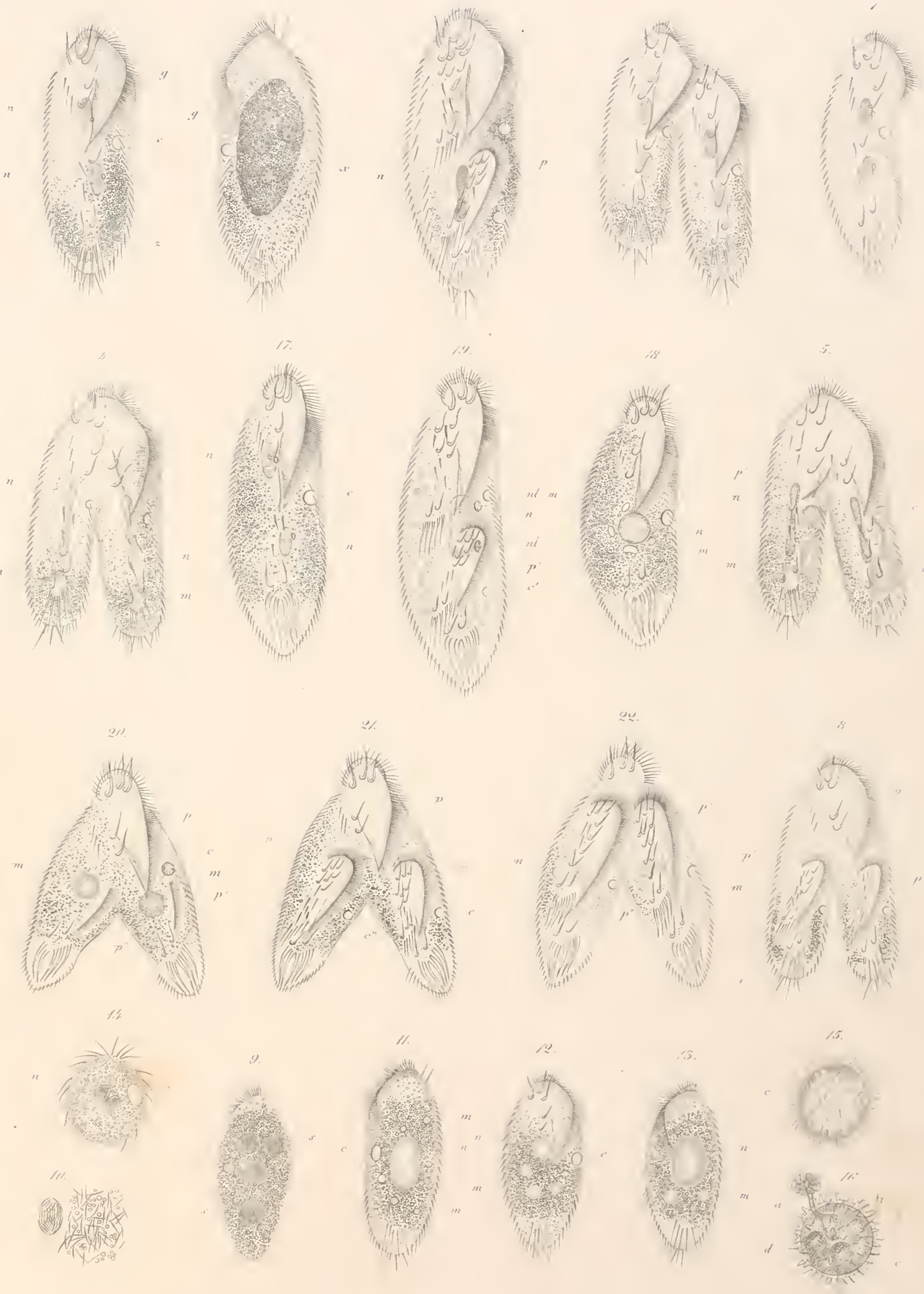


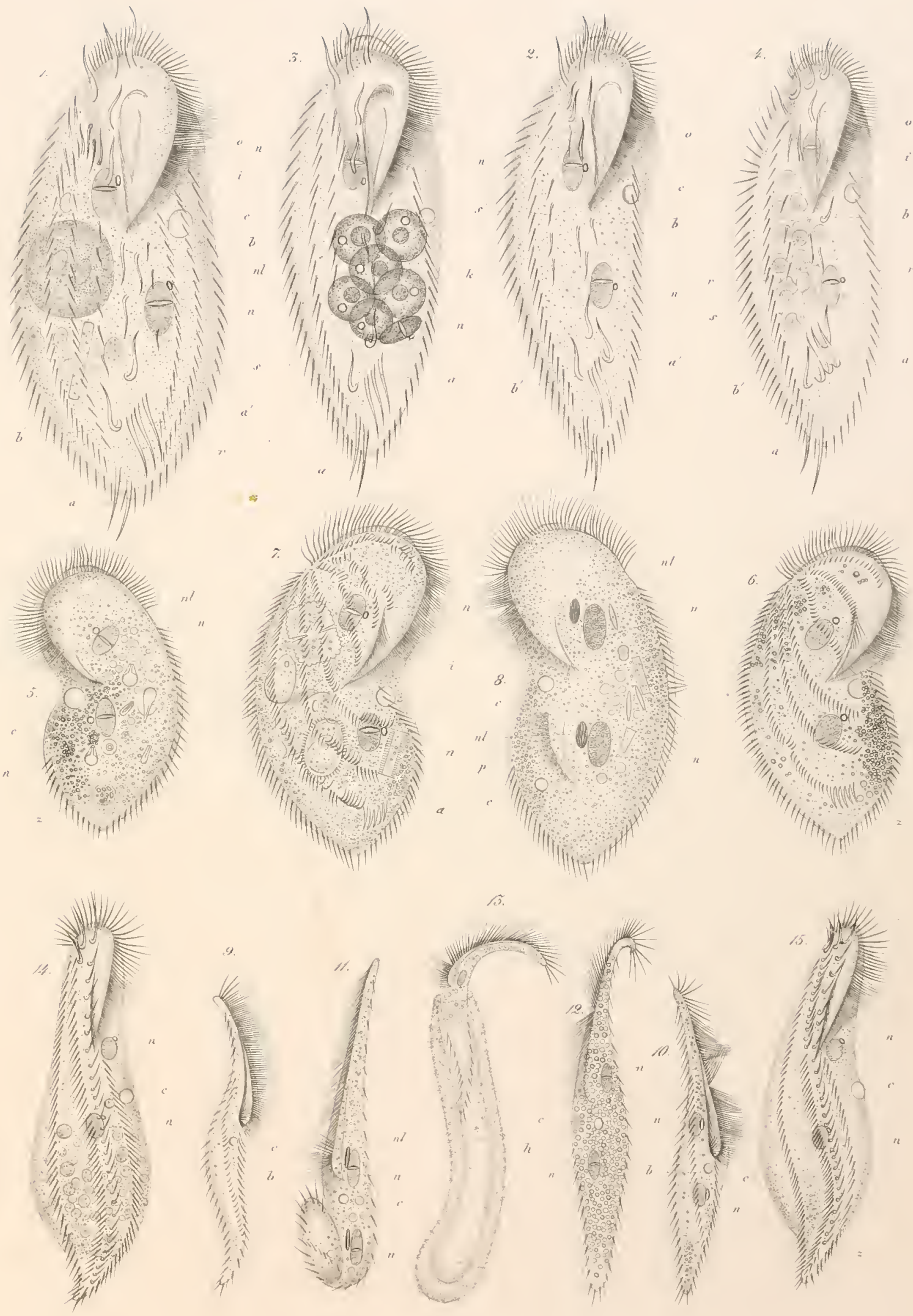

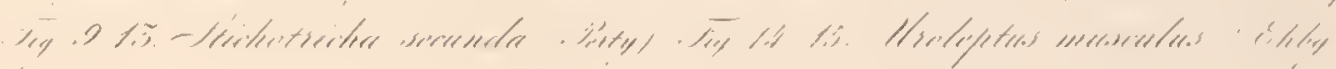





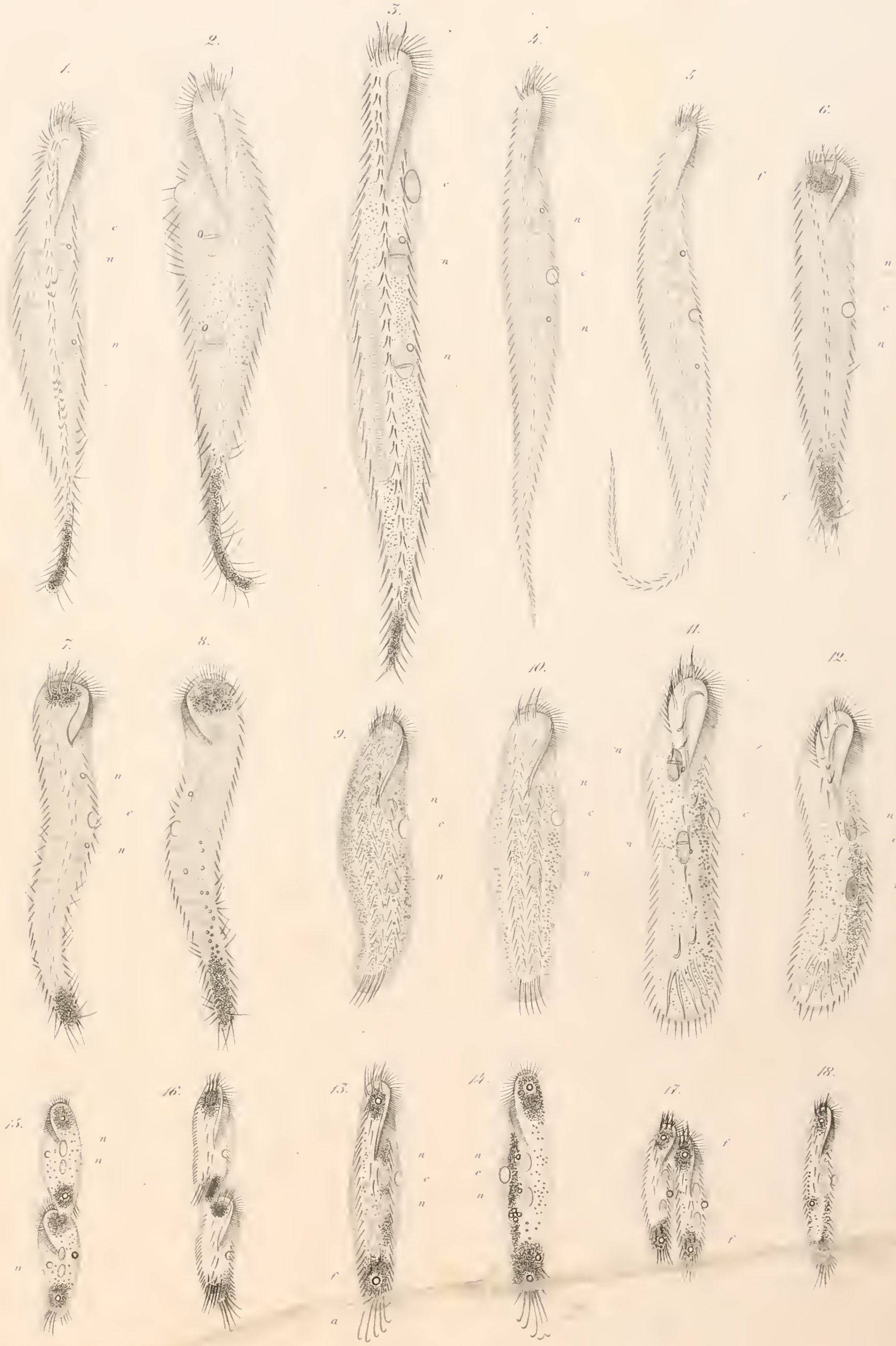




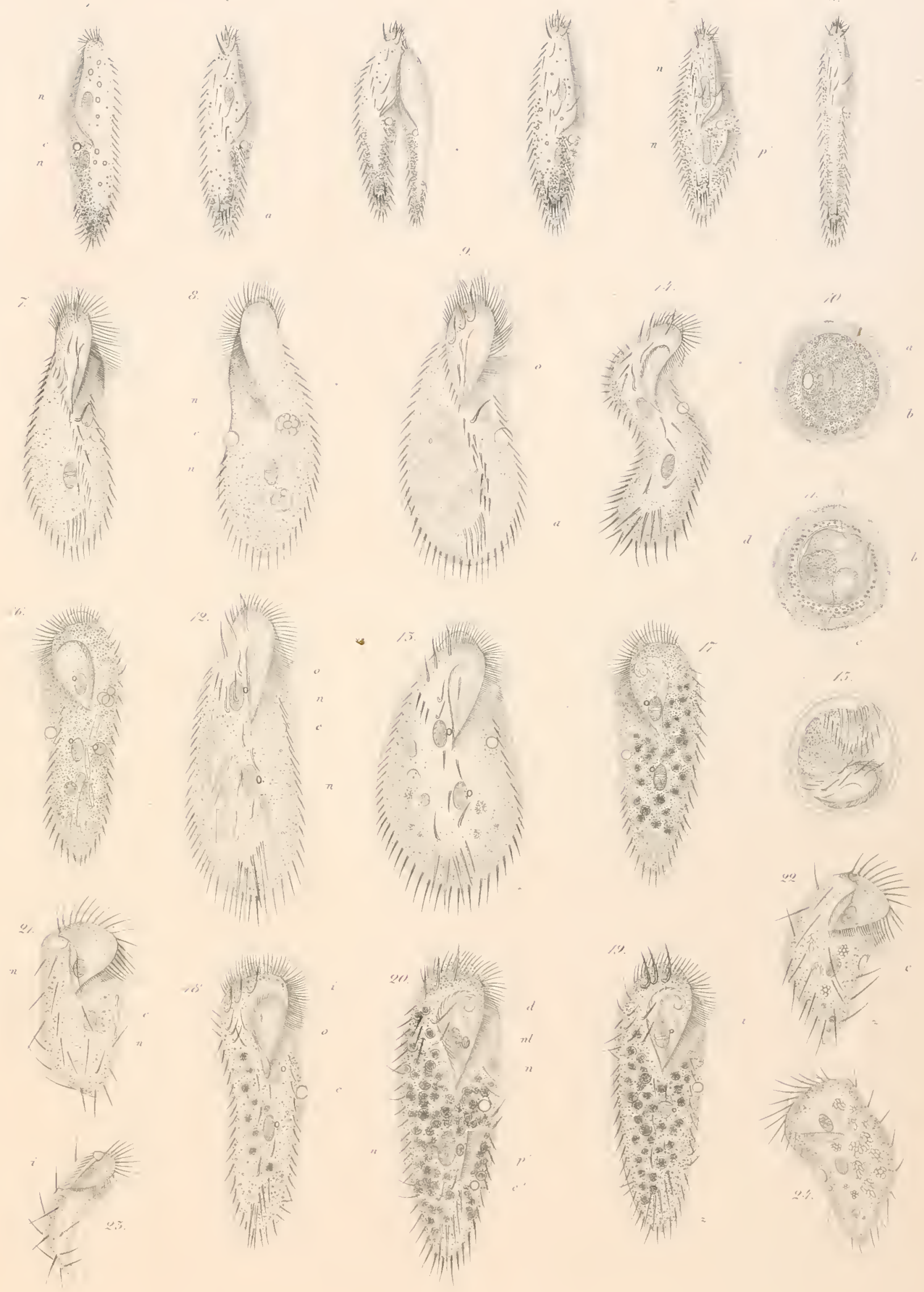


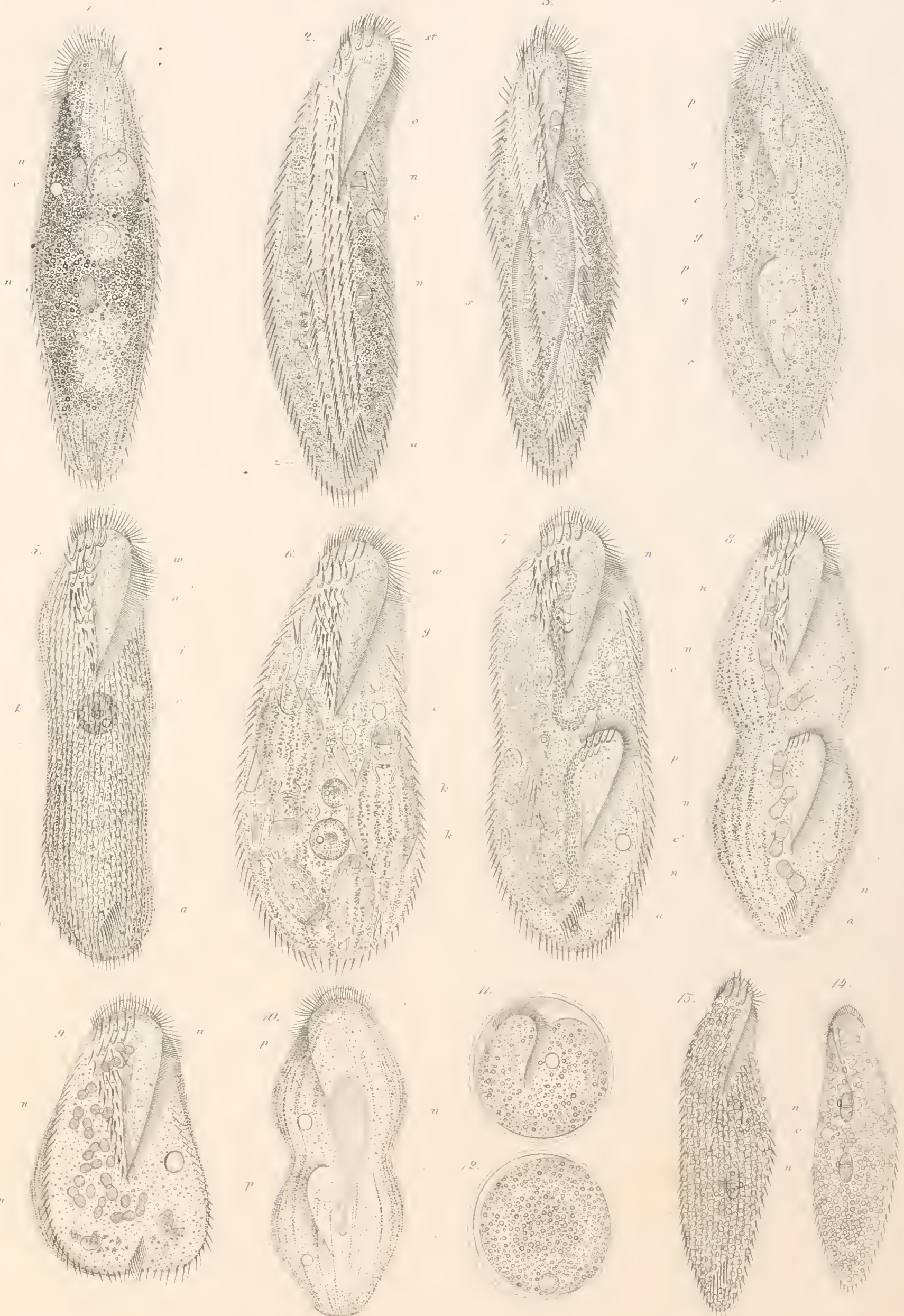


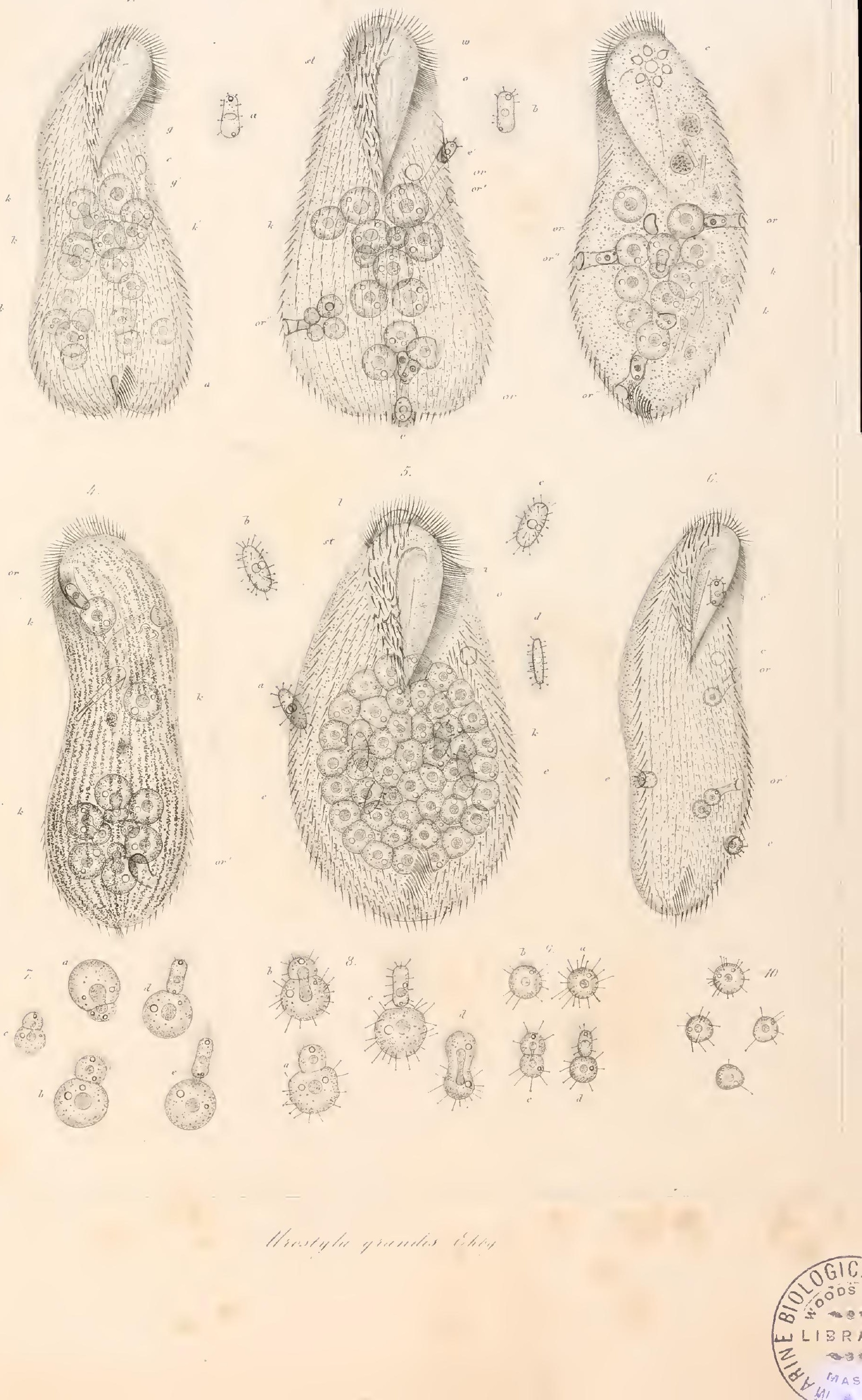




